\title{
Translationsinitiationsfaktoren in Haloferax volcanii
}

\author{
Dissertation \\ zur Erlangung des Doktorgrades \\ der Naturwissenschaften \\ vorgelegt beim Fachbereich Biowissenschaften \\ der Johann Wolfgang Goethe-Universität \\ in Frankfurt am Main \\ von \\ Franziska Verena Schramm \\ aus Ludwigsburg
}

Frankfurt am Main 2021 
Vom Fachbereich Biowissenschaften (15) der Johann Wolfgang Goethe-Universität als Dissertation angenommen.

Dekan: $\quad$ Prof. Dr. Sven Klimpel

Gutachter: Prof. Dr. Jörg Soppa

Prof. Dr. Eckhard Boles 
Für meine Großeltern

The puzzle is never ready!

P. Menth 


\section{Eidesstattliche Erklärung}

Hiermit erkläre ich an Eides Statt, dass ich die vorliegende Arbeit selbständig und nur unter Verwendung der angegebenen Quellen und Hilfsmittel angefertigt habe.

Die entsprechend verwendeten Literaturquellen sind im Literaturverzeichnis vollständig zitiert.

Frankfurt am Main, den 10. Januar 2021

Franziska Verena Schramm 


\section{Zusammenfassung}

In allen drei Domänen des Lebens ist in der Translation die Initiation der geschwindigkeitsbestimmende Schritt. Die Effizienz der Translationsinitiation und ihre unterschiedliche Regulation ist von Translationsinitiationsfaktoren (IFs) abhängig. Bakterien enthalten nur drei IFs, während die Anzahl bei Archaeen (alFs) und Eukaryoten (elFs) deutlich höher ist.

Das Archaeon Haloferax volcanii beispielsweise besitzt 14 Gene, die für alFs bzw. deren Untereinheiten kodieren. Eine Deletionsanalyse ergab, dass fünf alFs essenziell und neun alFs nicht essenziell sind. Um einen Einblick in die Funktions- und Interaktionsbereiche der alFs in $H$. volcanii zu erhalten, wurden die alFs mit einem His-Tag versehen und überexprimiert. Die Überexpression erfolgte in der jeweiligen Deletionsmutante. Für essenzielle alFs fand sie im Wildtyp statt. Durch Affinitätsaufreinigungen wurden die alFs und ihre Bindungspartner isoliert und mittels Massenspektrometrie (MS) identifiziert. Für den Ausschluss unspezifischer Proteine dienten zwei stringente Kontrollen als Referenz, das Reportergen Dihydrofolatreduktase (HVO_1279) mit His-Tag und das Expressionsplasmid ohne Gen.

Die ersten Arbeiten konzentrierten sich auf den heterotrimeren Faktor alF2. Er bindet die Initiator-tRNA und ist damit für die Bildung des Präinitiationskomplexes von zentraler Bedeutung. Der Faktor alF2 besteht aus jeweils einer $\alpha-, \beta$ - und $\gamma$-Untereinheit. In $H$. volcanii existieren zwei Orthologe für alF2 $\beta$. Die Überexpressionen der $\alpha-, \beta 1-, \beta 2-$ und $\gamma$-Untereinheiten führten zur Co-Isolation der jeweils anderen Untereinheiten des alF2 ( $\alpha, \beta 1 / \beta 2, \gamma)$.

Die Strategie der Co-Affinitätsaufreinigung und MS wurde auf alle weiteren annotierten alFs ausgedehnt, um mögliche Funktionen zu identifizieren und ein potenzielles Interaktionsnetzwerk der alFs zu erstellen. Für alle alFs konnte ein unterschiedliches Muster an co-gereinigten Proteinen festgestellt werden. Mitgereinigte Proteine waren alFs, Proteine der Translation, Transkription, Replikation und ribosomale Proteine. Auch RNA-Polymerase-Untereinheiten (RNAPUs) konnten co-isoliert werden. Mit 13 der 14 alFs konnten andere Initiationsfaktoren co-gereinigt werden. Sechs alFs konnten zu Beginn bei keinem weiteren Initiationsfaktor mitgereinigt werden. Einer dieser Faktoren war alF2 $\beta-1$, der jedoch in den Affinitätsaufreinigungen mit nachfolgender FPLC von alF2 $\beta$-2 identifiziert werden konnte. Der Faktor alF1 konnte nur in der stationären Phase von alF2 $\alpha$ mitgereinigt werden.

Die am häufigsten co-gereinigten Proteine waren alF2Bס-1 und alF5B. Für alF2Bס-1 kam dies überraschend, da er bereits als Translationsinitiationsfaktor ausgeschlossen wurde. Mit dem Faktor alF2Bס-1 selbst konnten fünf alFs co-gereinigt werden.

Da mit den alFs auch RNAPUs co-gereinigt werden konnten, wurden sieben RNAPUs ebenfalls mit einem His-Tag versehen und überexprimiert. Auch mit den RNAPUs konnten alFs, sowie weitere Proteine der Translation mitgereinigt werden.

Diese Umstände legen nahe, dass es möglicherweise eine engere Verbindung der Transkription und Translation in $H$. volcanii geben könnte, als bisher angenommen. 


\section{Aus der Arbeit hervorgegangene Veröffentlichung}

Franziska Verena Schramm, Andreas Borst and Jörg Soppa (2021): Characterization of the translation initiation factor interaction network of the halophilic archaeon Haloferax volcanii. Frontiers of Microbiology; in preparation 


\section{Inhaltsverzeichnis}

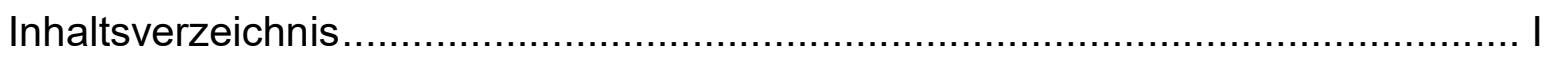

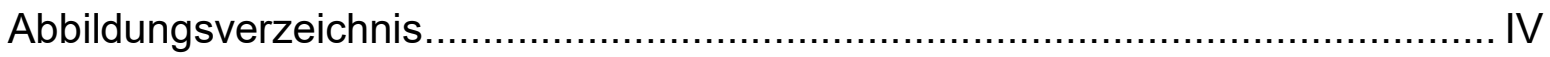

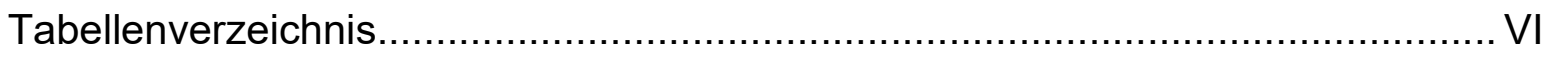

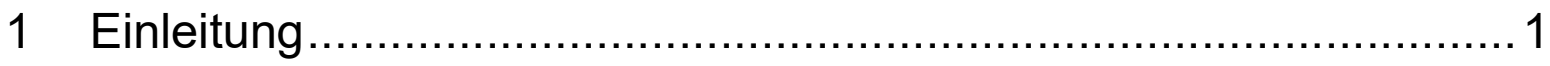

1.1 Diversität in den drei Domänen des Lebens ............................................ 2

1.2 Translation, ein universeller Mechanismus............................................. 4

1.3 Translationsinitiation in den drei Domänen des Lebens ............................ 5

1.3.1 Leaderlose Translationsinitiation................................................................ 6

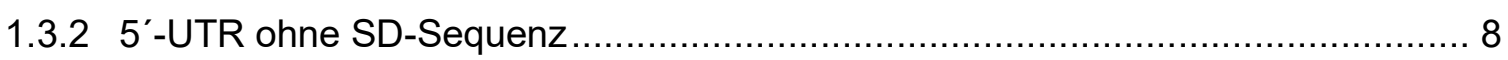

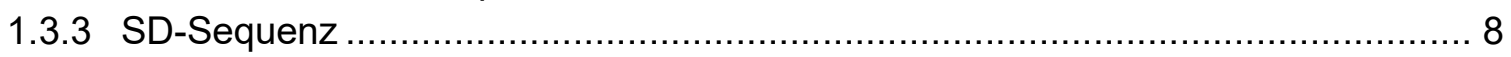

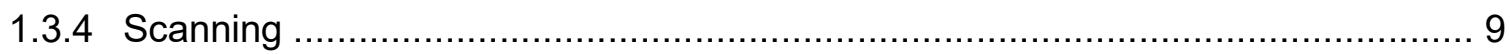

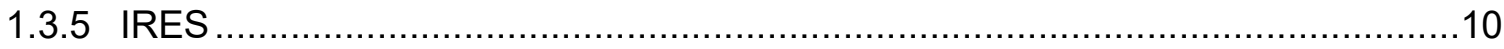

1.4 Translationsinitiationsfaktoren in den drei Domänen des Lebens ...............12

1.4.1 IFs in der Translationsinitiation von Bakterien .................................................12

1.4.2 elFs in der Translationsinitiation von Eukaryonten ...........................................14

1.4.3 alFs in der Translationsinitiation von Archaeen ..............................................17

1.5 Translationsinitiationsfaktoren in $\mathrm{H}$. volcanii ........................................19

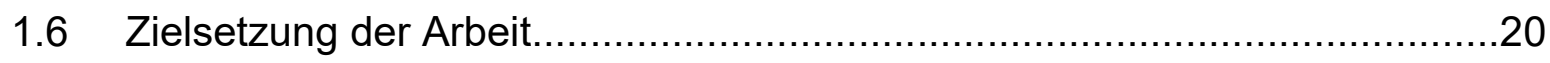

2 Material und Methoden ........................................................... 21

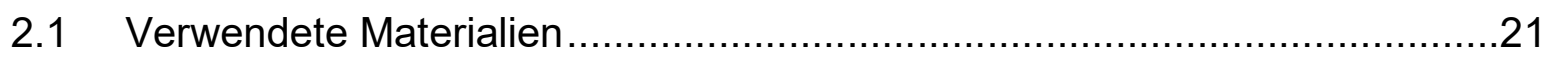

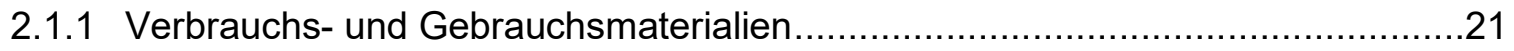

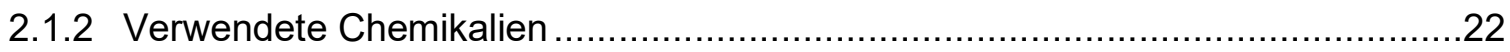

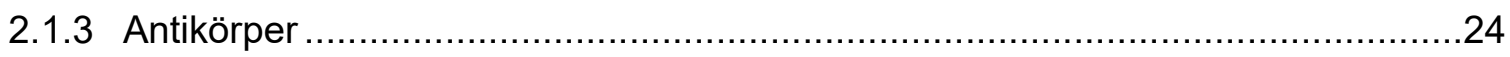

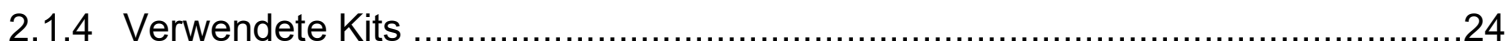

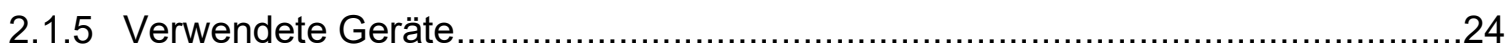

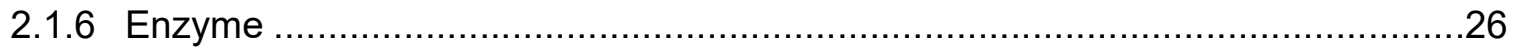

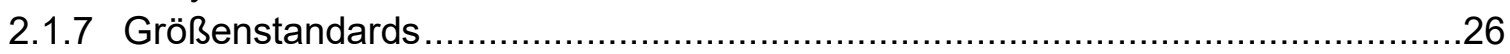

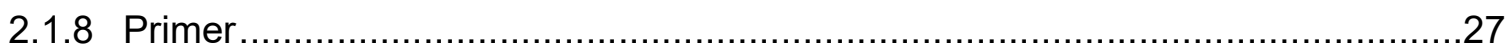

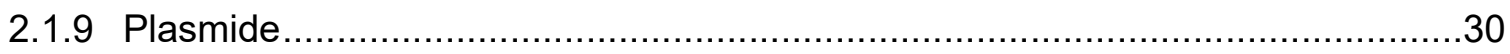

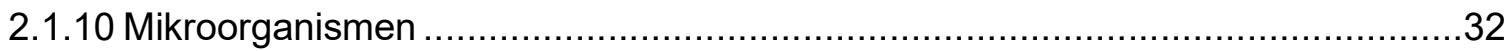

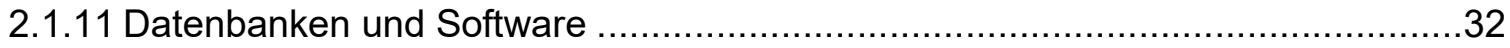

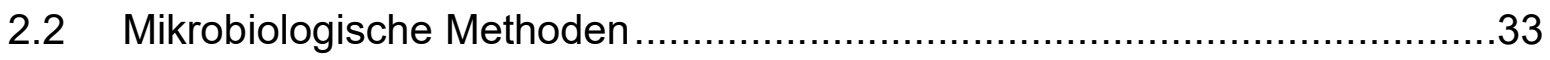

2.2.1 Medien und Zusätze für die Kultivierung von $E$. coli ........................................33

2.2.2 Herstellung von chemisch kompetenten E. coli..............................................33

2.2.3 Transformation von E. coli ...................................................................34

2.2.4 Medien und Zusätze für die Kultivierung von $H$. volcanii .................................34

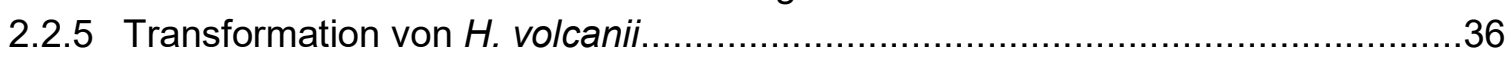

2.2.6 Bestimmung Zelldichte und Zellzahl.........................................................37

2.2.7 Wachstumsversuche in Mikrotiterplatten....................................................... 


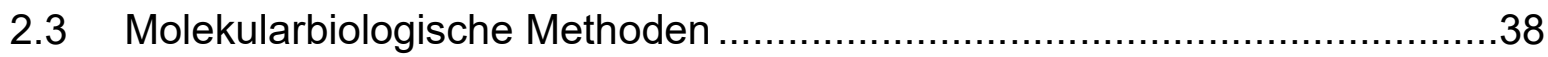

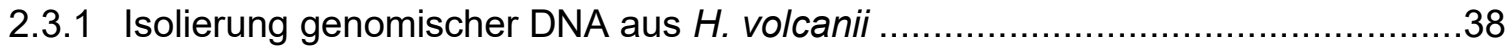

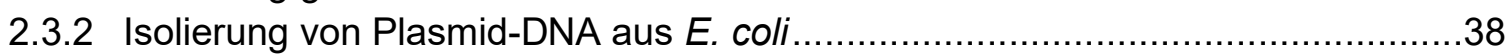

2.3.3 Generierung von in-frame-Deletionsmutanten (Popln-PopOut-Methode) ............38

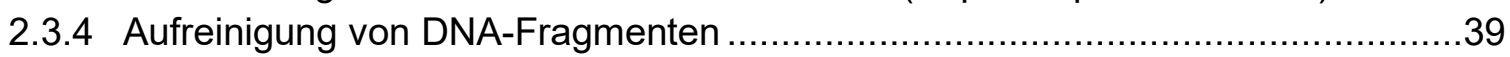

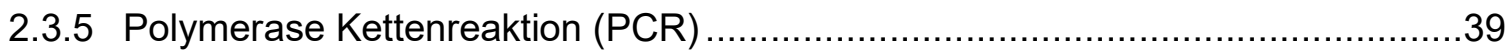

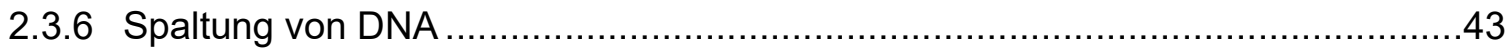

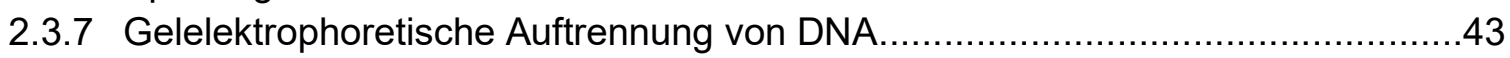

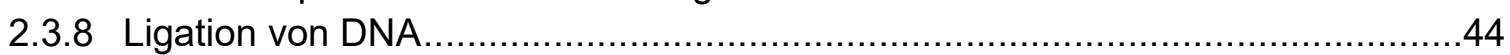

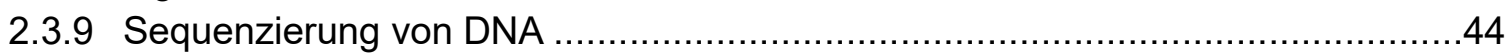

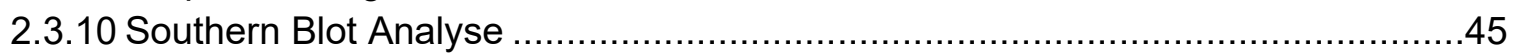

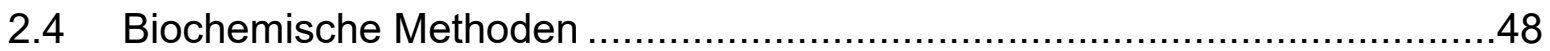

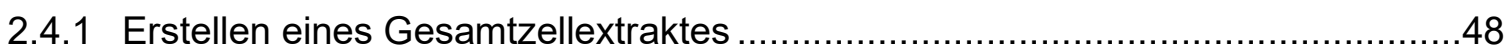

2.4.2 Methanol-Chloroform-Extraktion von Proteinen .........................................48

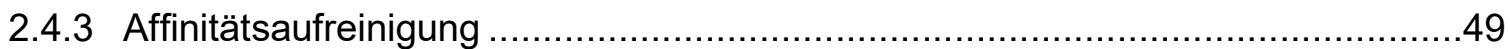

2.4.4 Crosslinking von Proteinen in der Zellkultur .................................................... 51

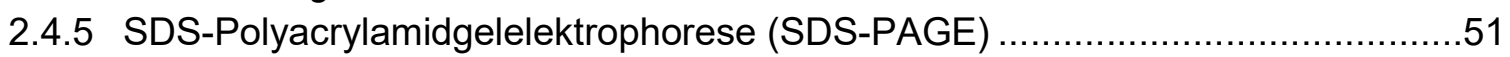

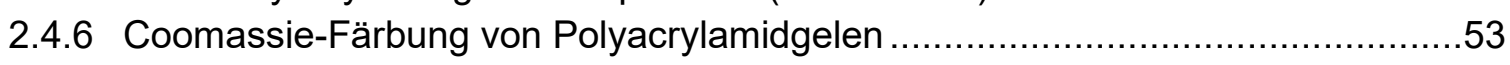

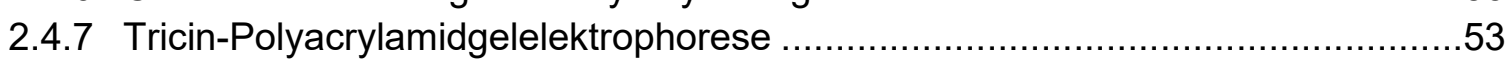

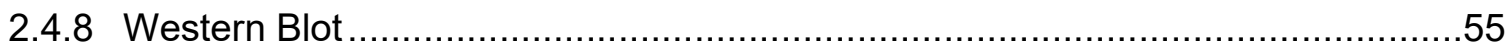

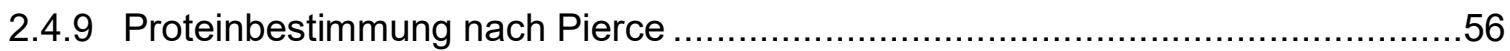

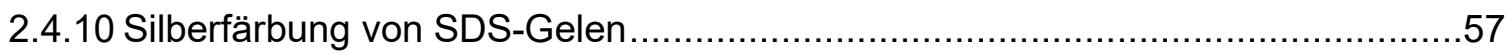

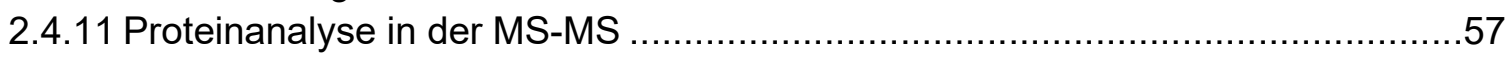

2.4.12 FPLC

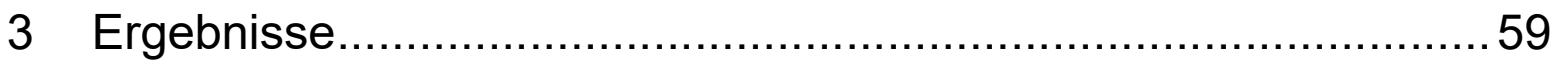

3.1 Überexpression von alFs im Stamm H26 1279 und Deletionsmutanten .....59

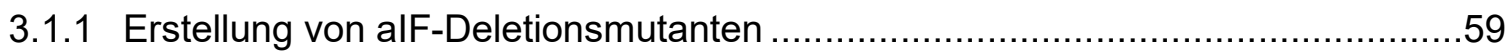

3.1.2 Wahl des Affinitäts-Tags für die Aufreinigung ............................................60

3.1.3 Etablierung der Co-Affinitätsaufreinigung.................................................62

3.1.4 Etablierung der Identifizierung von Proteinen durch Peptide mass fingerprinting 63

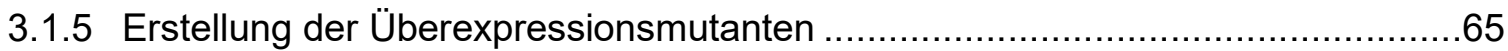

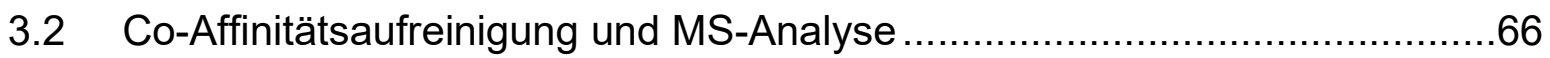

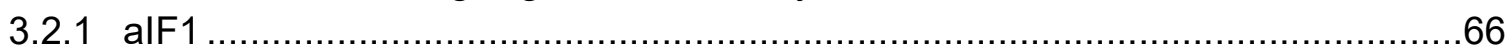

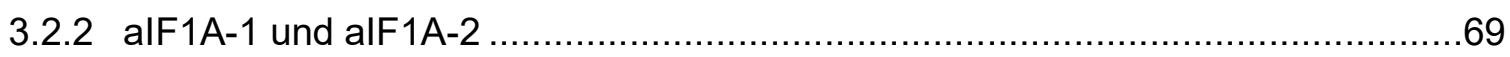

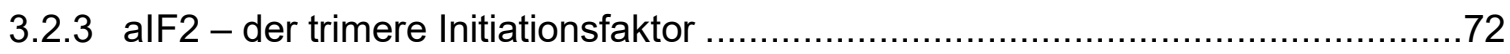

3.2.4 alF2B und seine Untereinheiten........................................................... 100

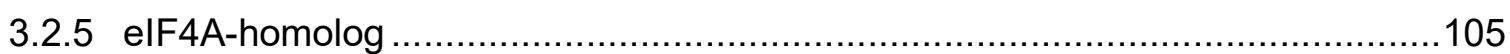

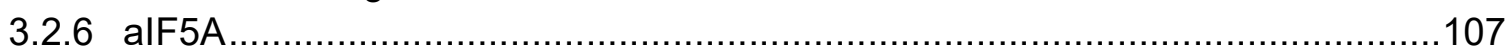

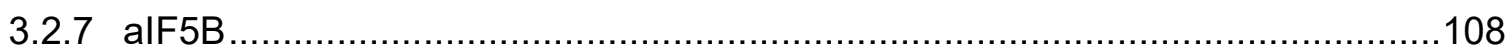

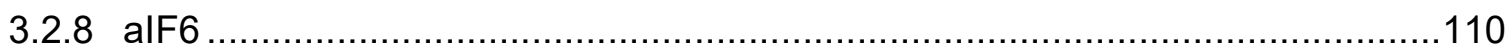

3.3 Interaktionsnetzwerk von alFs-alFs .............................................. 112

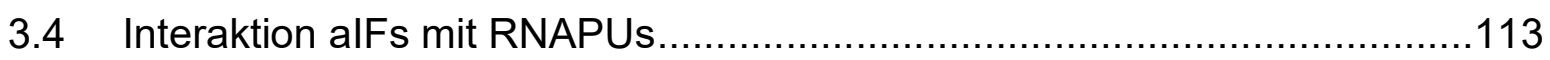

3.5 Untersuchung der Interaktion zwischen RNAPUs und alFs ...................115

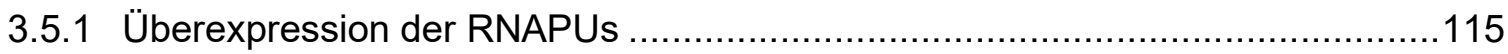

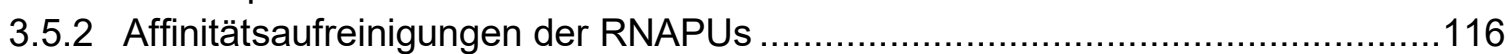

3.5.3 MS-Analyse der RNAPUs .................................................................. 117 
3.5.4 Interaktionen von RNAPUs-RNAPUs.

3.5.5 RNAPUS und Proteine der Translation

3.5.6 Interaktionen zwischen RNAPUs und alFs kombiniert

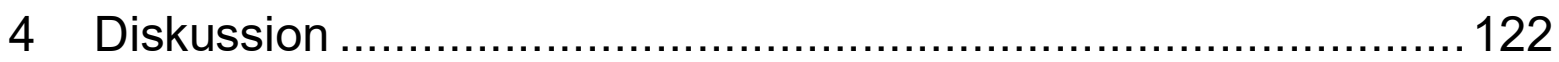

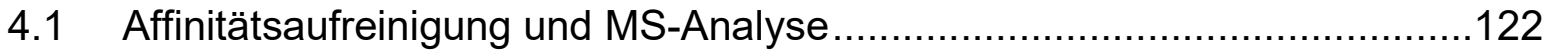

4.2 Auswahl des Tags für die Affinitätsaufreinigung ................................125

4.3 Experimentelles Design zur Identifizierung von Bindungspartnern............125

$4.4 \quad$ Vergleich alF-alF-Interaktionen ...................................................... 126

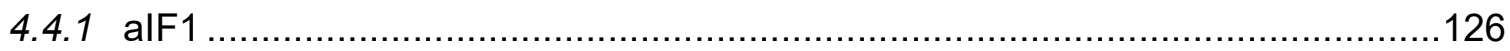

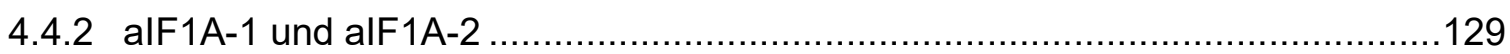

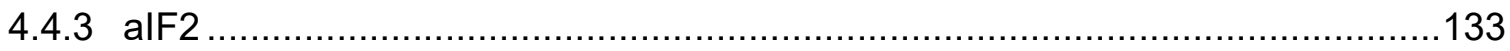

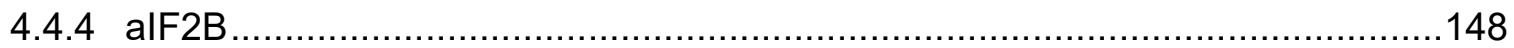

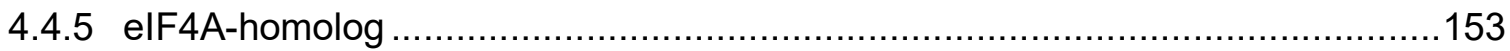

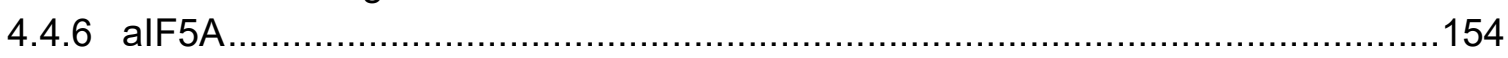

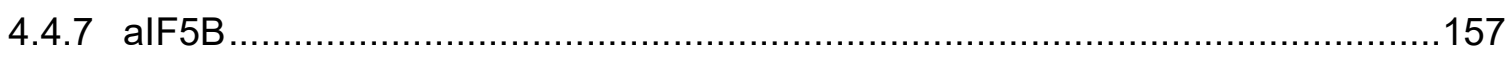

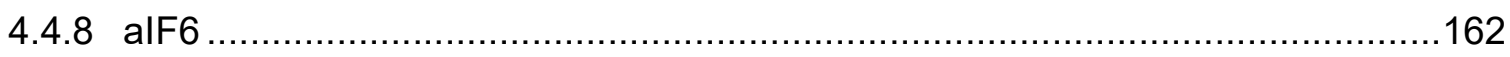

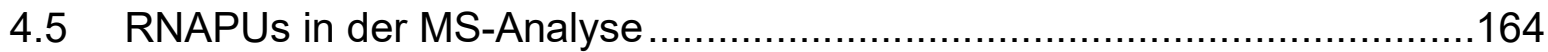

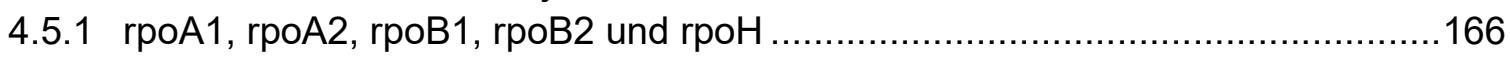

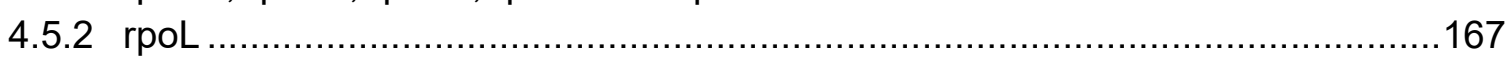

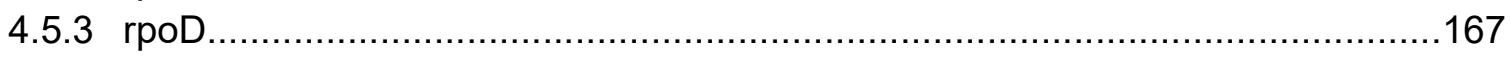

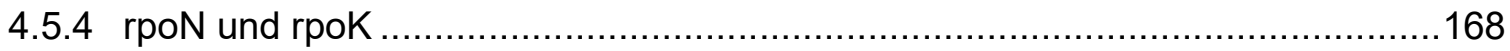

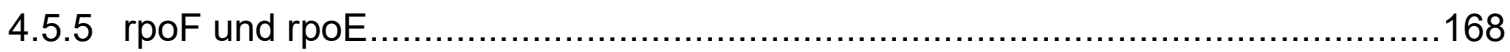

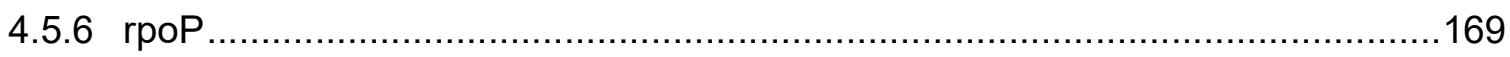

4.6 Vergleich elF-alF und mögliche Funktion in Archaeen .........................170

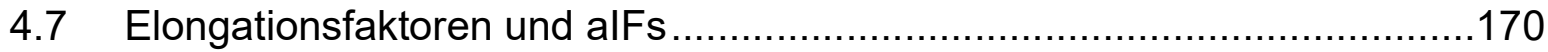

4.8 Kopplung von Transkription und Translation ..................................171

4.9 Kopplung von Translation und Replikation ...................................176

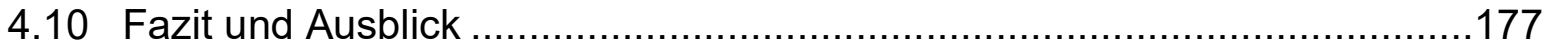

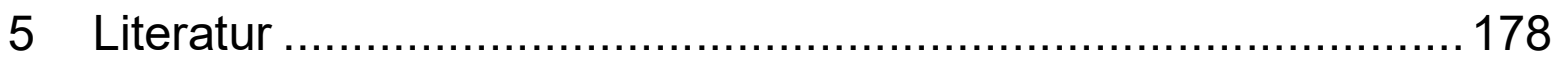

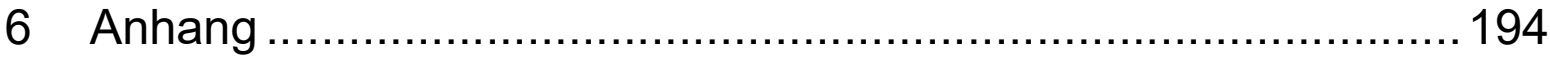

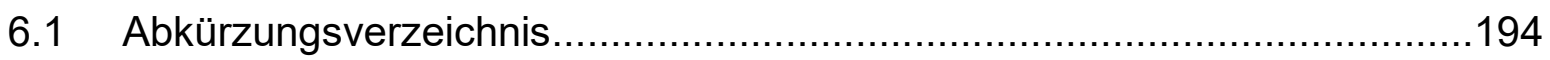

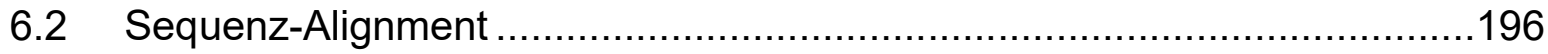

6.3 Zusammenfassung MS-Daten alFs .........................................201

6.4 Zusammenfassung MS-Daten RNAPUs.......................................205 


\section{Abbildungsverzeichnis}

Abbildung 1: Phyla der Archaeen modifiziert (Eme and Doolittle, 2015; Pohlschroder and Schulze, 2019).......... 1

Abbildung 2: Strukturen von RNAPs in den drei Domänen des Lebens modifiziert nach (Jun et al., 2011) ........... 3

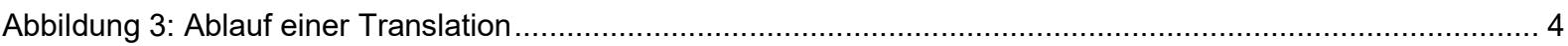

Abbildung 4: Initiationswege der Translation an leaderlosen Transkripten in den drei Domänen des Lebens ........ 6

Abbildung 5: Translationsinitiation an Transkripten mit 5'-UTR ohne SD-Sequenz.......................................... 8

Abbildung 6: Translationsinitiation an Transkripten mit SD-Sequenz ...................................................... 9

Abbildung 7: Translationsinitiation mittels Scanning Mechanismus in Eukaryonten (Shatsky et al., 2010) ............ 9

Abbildung 8: IRES-abhängige Translationsinitiation in Eukaryonten modifiziert nach (Fitzgerald and Semler, 2009;

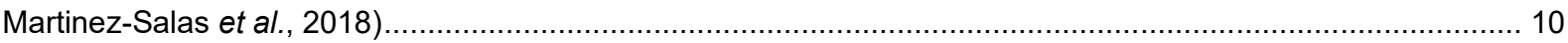

Abbildung 9: Translationsinitiation in Bakterien und die Funktionen der einzelnen IFs .................................. 13

Abbildung 10: Die eukaryontische Translationsinitiation nach (Dever, Kinzy and Pavitt, 2016) ............................ 15

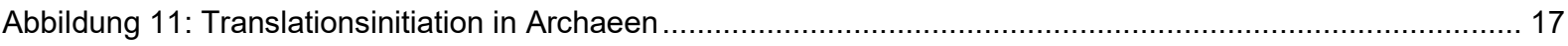

Abbildung 12: Schema für die Generierung von Popln-PopOut-Mutanten (modifiziert nach Allers et al 2004) ..... 39

Abbildung 13: Überprüfung der vorhanden Deletionsmutanten und Generierung neuer Deletionsmutanten ........ 59

Abbildung 14: Testung von CBD, BBP und 6xHis-Tag anhand der DHFR (HVO_1279) .................................61

Abbildung 15: Western Blot mittels Antikörper gegen die DHFR (HVO_1279) ...............................................61

Abbildung 16: Schema für die Affinitätsaufreinigung über einen pull-down-Assay ...........................................62

Abbildung 17: Affinitätsaufreinigung der DHFR aus exponentieller Kultur................................................62

Abbildung 18: Überexpression der DHFR (HVO_1279) und des Leerplasmids (pSD+P) ................................63

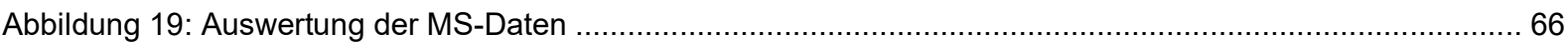

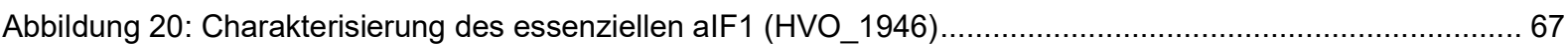

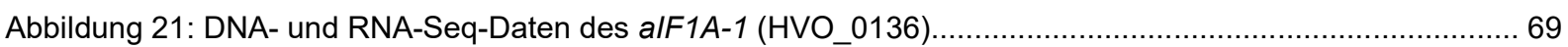

Abbildung 22: Charakterisierung des alF1A-1 (HVO_0136) ohne und mit nativer 3 '-UTR ................................. 70

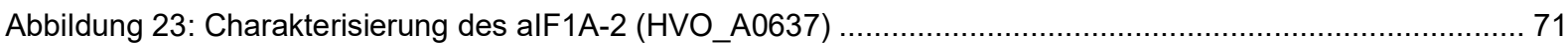

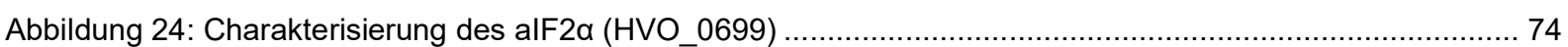

Abbildung 25: FPLC der Elutionsfraktion nach der Affinitätsaufreinigung von alF2a................................... 78

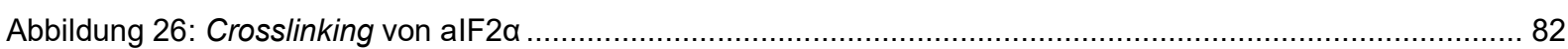

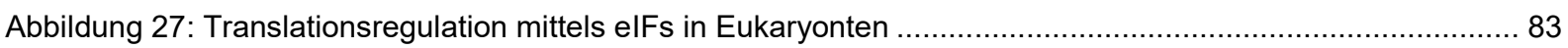

Abbildung 28: Multiple-Sequence-Alignment für die Wahl der Phosphorylierungsstelle in alF2a....................... 84

Abbildung 29: Charakterisierung des alF2a (HVO_0699) mit der Ser46 mutiert zu Ala46 .................................85

Abbildung 30: Charakterisierung des alF2a (HVO_0699) mit der Ser46 mutiert zu Asp46 ................................ 85

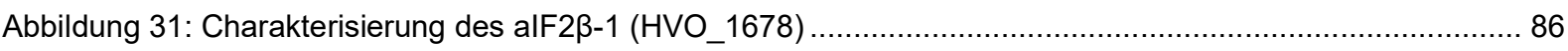

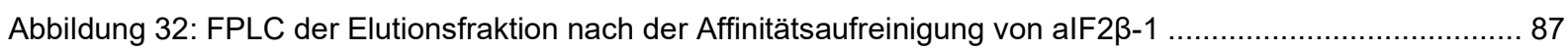

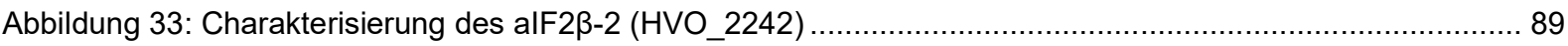

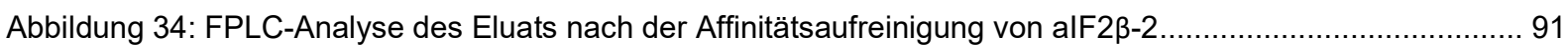

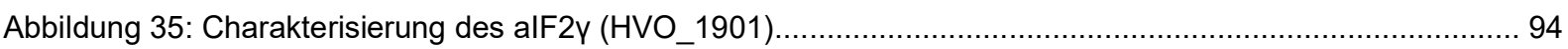

Abbildung 36: FPLC-Analyse des Eluats nach der Affinitätsaufreinigung von alF2 $\gamma$.....................................95

Abbildung 37: Charakterisierung des alF2Ba (HVO_1934) ................................................................... 100

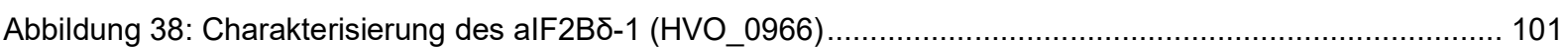

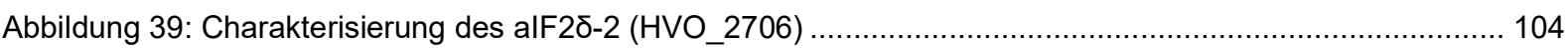

Abbildung 40: Charakterisierung des elF4A-homologes (HVO_1333) .......................................................... 105

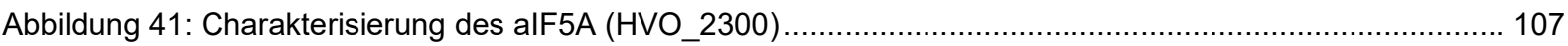

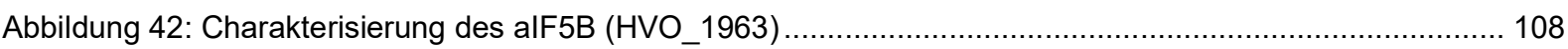

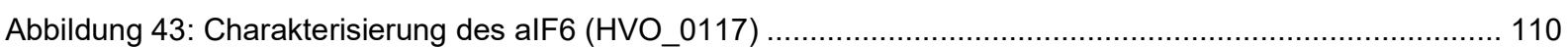


Abbildung 44: Interaktionsnetzwerk der alFs, die weitere alFs mitreinigen konnten .................................... 113

Abbildung 45: Netzwerk der alFs, die RNAPUs mitreinigen konnten ................................................. 114

Abbildung 46: Wachstum der Überexpressionsmutanten von RNAPUs ................................................ 116

Abbildung 47: Affinitätsaufreinigung der überexprimierten RNAPUs .................................................. 116

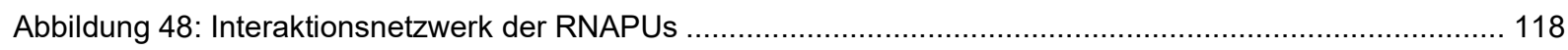

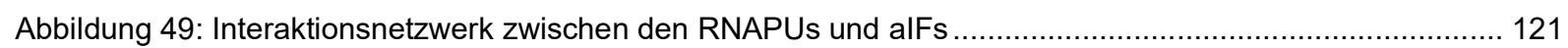

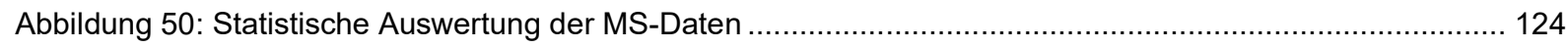

Abbildung 51: Sequenz-Alignment alF1/elF1/SUI1/YciH (modifiziert nach (Gogoi and Kanaujia, 2018))........... 128

Abbildung 52: Sequenz-Alignment IF1/elF1A/alF1A modifiziert (Li and Hoffmann, 2001; Luna et al., 2013)..... 130

Abbildung 53: DNA- und RNA-Seq-Daten des alF1A-2 (HVO_A0637) .................................................. 131

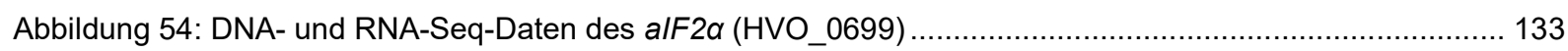

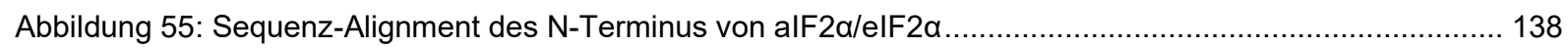

Abbildung 56: Analyse des alF2 $\beta-1$ (HVO_1678) und alF2 $\beta-2$ (HVO_2242) .............................................. 139

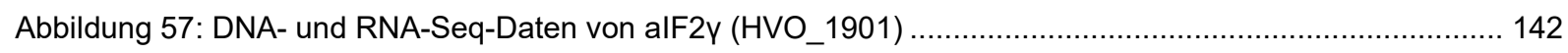

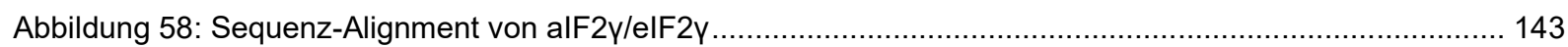

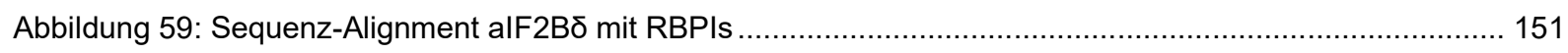

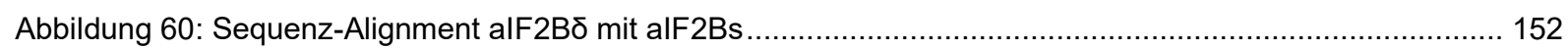

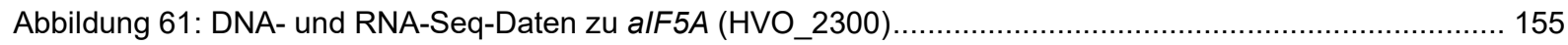

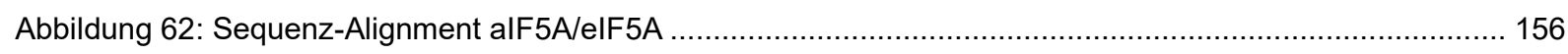

Abbildung 63: Sequenz-Alignment alF5B/elF5B/IF2, modifiziert nach (Roll-Mecak et al., 2000) ....................... 160

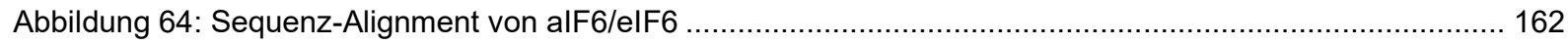

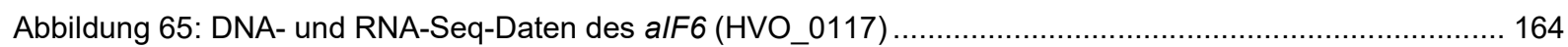

Abbildung 66: Transkriptions-Translations-Expressom modifiziert nach (Kohler et al., 2017) .......................... 172

Abbildung 67: Sequenz-Alignment von alF1A-1 und alF1A-2 im Haloferax-Genus..................................... 196

Abbildung 68: Sequenz-Alignment von alF2 $\beta$-1 (D4GZP2) und alF2 $\beta-2$ (D4GVV8) aus $H$. volcanii ................. 197

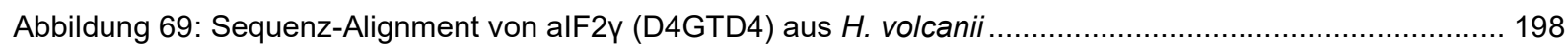

Abbildung 70: Sequenz-Alignment von alF2Ba und Abgleich Nudix-Domäne.............................................. 198

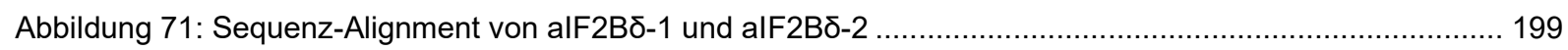

Abbildung 72: Sequenz-Alignment von alF5A aus $H$. volcanii ........................................................... 199

Abbildung 73: Sequenz-Alignment von alF5B aus $H$. volcanii ............................................................ 199

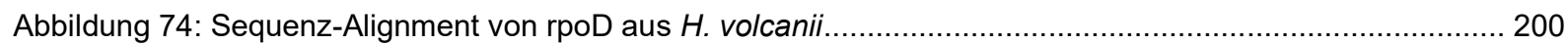




\section{Tabellenverzeichnis}

Tabelle 1: RNAPUs in den drei Domänen des Lebens (Grohmann, Hirtreiter and Werner, 2009) ........................ 3

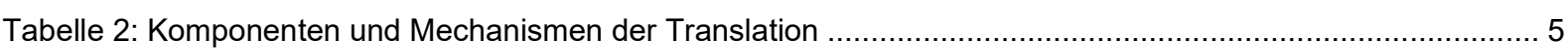

Tabelle 3: Translationsinitiationsfaktoren in den drei Domänen des Lebens nach (Londei, 2005) ...................... 12

Tabelle 4: Eukaryontische Translationsinitiationsfaktoren und deren bisher bekannte Funktionen ...................... 16

Tabelle 5: Translationsinitiationsfaktoren in $H$. volcanii essenziell und nicht essenziell ..................................... 19

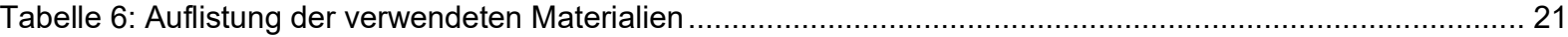

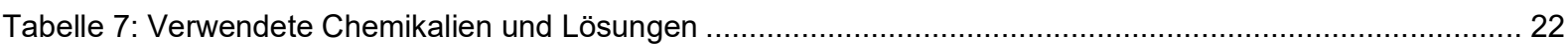

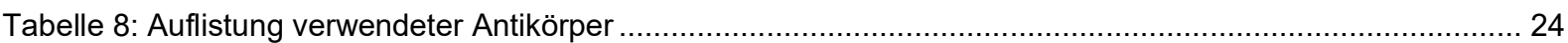

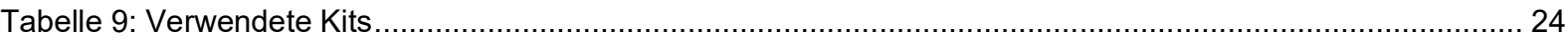

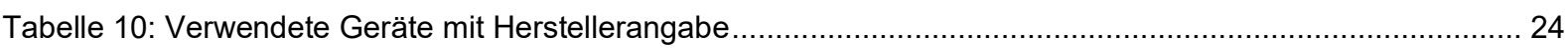

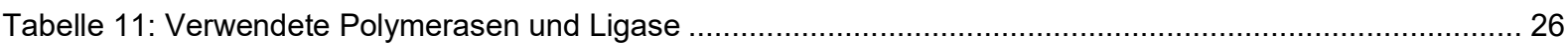

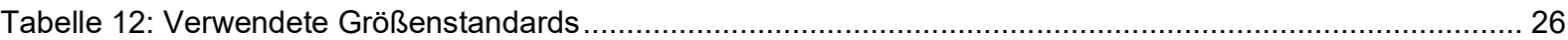

Tabelle 13: Verwendete Primer für die Erstellung der Plasmide............................................................... 27

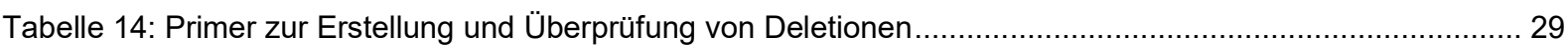

Tabelle 15: Plasmide für die Überexpression und Deletion einzelner Gene ............................................... 30

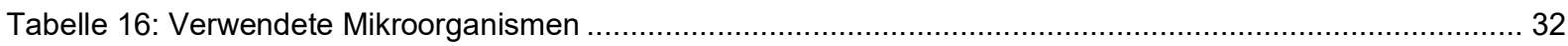

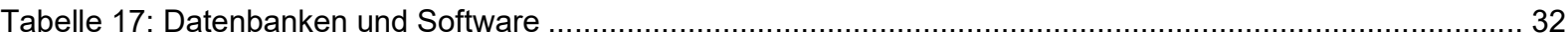

Tabelle 18: Zusammensetzung des $\mathrm{SOB}^{+}-$Mediums für die Kultivierung von E. coli ...................................... 33

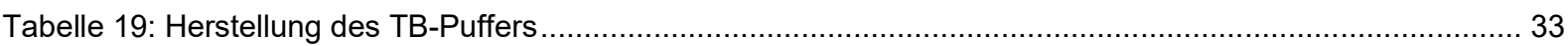

Tabelle 20: Verwendete Selektionsmarker für E. coli bzw. für H. volcanii ..................................................... 34

Tabelle 21: Zusammensetzung Komplexmedium für die Kultivierung von $H$. volcanii ...................................... 35

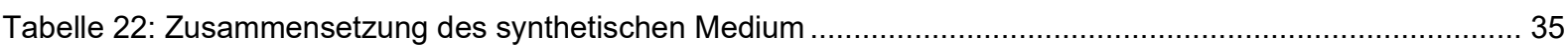

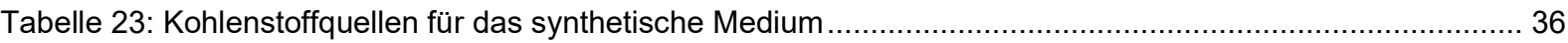

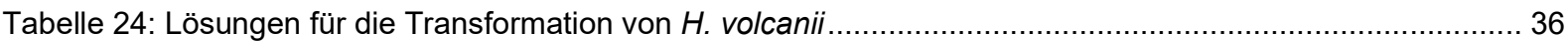

Tabelle 25: Komponenten zur Herstellung des Lysepuffers .............................................................. 38

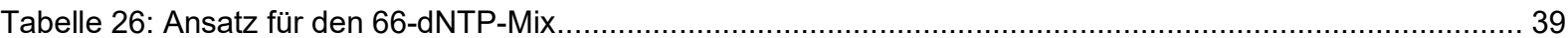

Tabelle 27: PCR-Ansatz zur Erstellung von DNA-Fragmenten für die Klonierungen......................................... 40

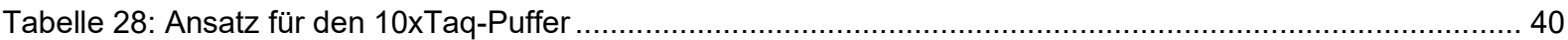

Tabelle 29: PCR-Ansatz für eine Kolonie-PCR mit der laboreigenen Taq-DNA-Polymerase ............................ 41

Tabelle 30: PCR-Ansatz für eine Kolonie-PCR mit der Biozym-Taq ...........................................................4 41

Tabelle 31: Ablauf Fusions-PCR nach Generierung der einzelnen Fragmente ............................................... 41

Tabelle 32: PCR-Ansatz und Programm für die ortsspezifische Mutagenese ............................................ 42

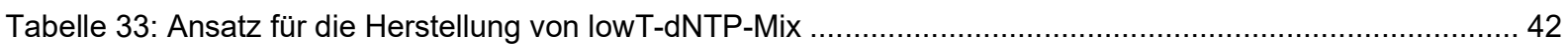

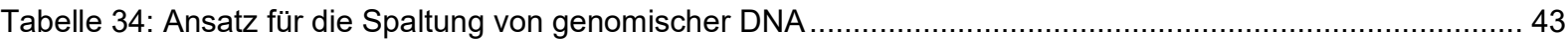

Tabelle 35: Herstellung des TBE-Puffers und des 6xDNA-Probenpuffers ................................................... 43

Tabelle 36: Ligations-Ansatz für DNA-Fragmente mit Überhängen und blunt-end DNA-Fragmente .....................44

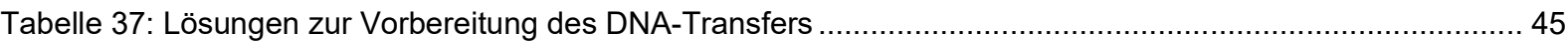

Tabelle 38: Lösungen für die Hybridisierung und Chemilumineszenz ....................................................... 46

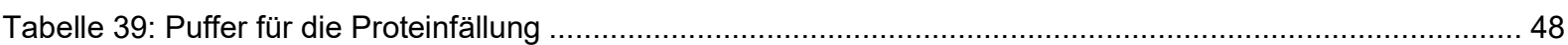

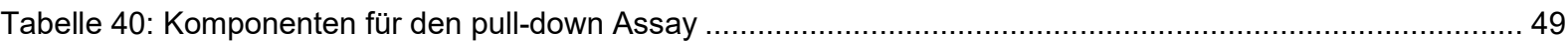

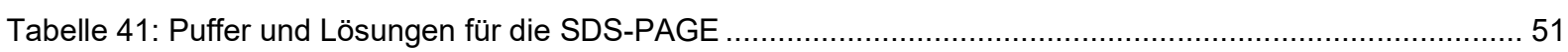

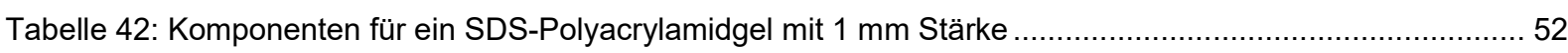

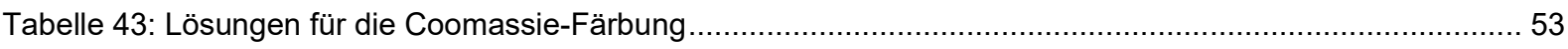

Tabelle 44: Puffer und Lösungen für die Tricin-SDS-PAGE ................................................................. 53

Tabelle 45: Komponenten zur Herstellung eines Tricin-SDS-Polyacrylamidgel ............................................ 54 


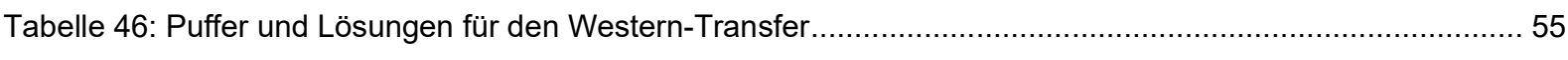

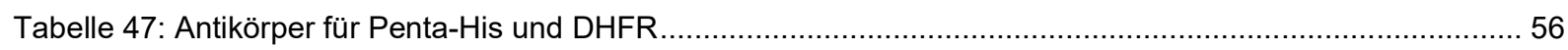

Tabelle 48: Puffer und Lösungen für die Silberfärbung von SDS-Gelen....................................................5 57

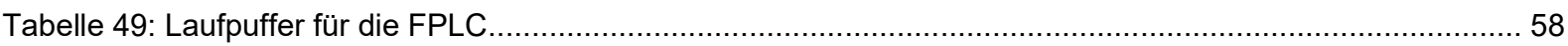

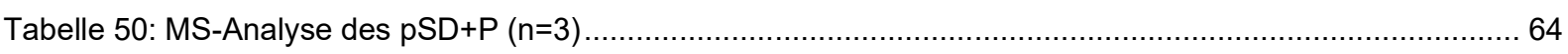

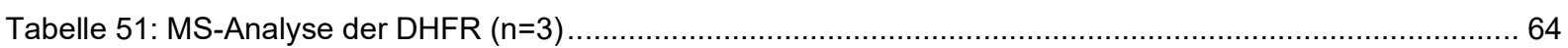

Tabelle 52: Überexpression der einzelnen Initiationsfaktoren in der Deletion oder im Wildtyp..........................65

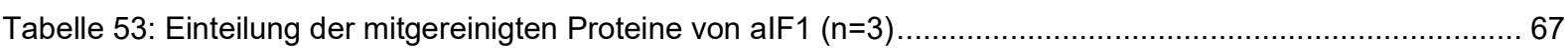

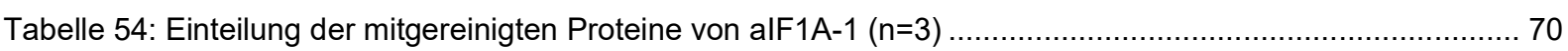

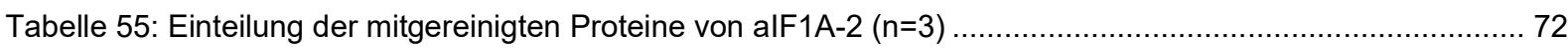

Tabelle 56: Ausschnitt der Diversität des alF2/elF2 in Archaea und Eukarya ............................................. 72

Tabelle 57: Mitgereinigte Proteine von alF2 $\alpha$ aus exponentieller und stationärer Kultur $(n=3) \ldots \ldots \ldots \ldots \ldots \ldots \ldots \ldots . . . . . . . . . . .75$

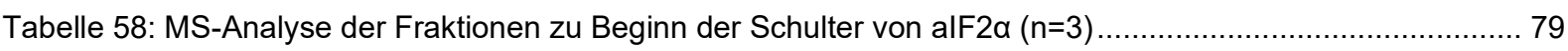

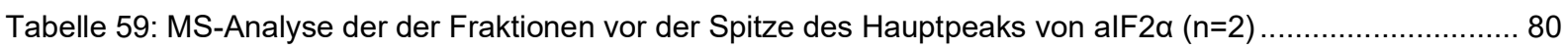

Tabelle 60: MS-Analyse der Fraktionen nach der Spitze des Hauptpeaks von alF2 $\alpha(n=3) \ldots \ldots \ldots \ldots \ldots \ldots \ldots \ldots . . . . . . . . . . . . . . .11$

Tabelle 61: MS-Analyse der Fraktionen zu Beginn der Schulter des Hauptpeaks von alF2 $\beta-1(n=3) \ldots \ldots \ldots \ldots \ldots . . . . . .88$

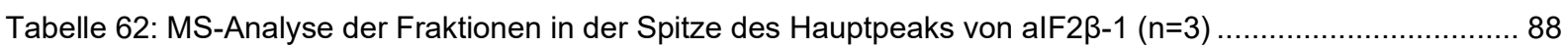

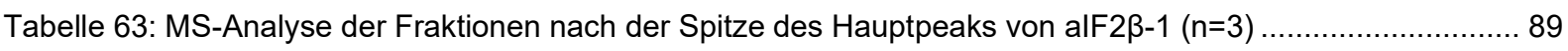

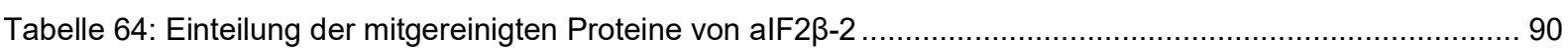

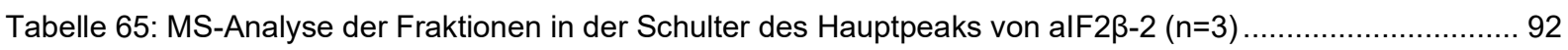

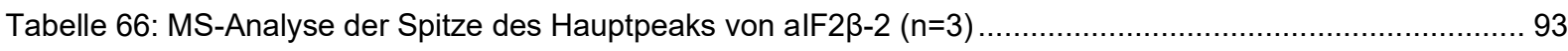

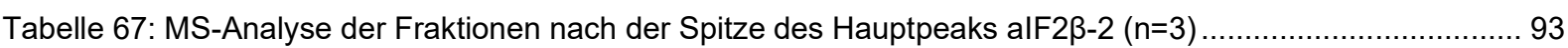

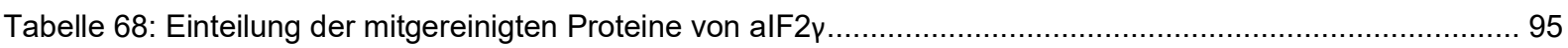

Tabelle 69: MS-Analyse der FPLC-Fraktionen zu Beginn des Hauptpeaks von alF2y $(n=3)$..............................96

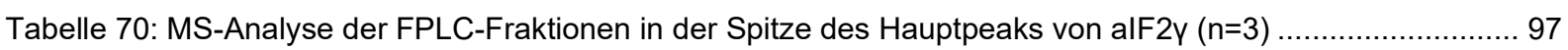

Tabelle 71: MS-Analyse der FPLC-Fraktionen nach der Spitze des Hauptpeaks von alF2 $\gamma(n=3) \ldots \ldots \ldots \ldots \ldots \ldots . . . . . . . . . .99$

Tabelle 72: Einteilung der mitgereinigten Proteine von alF2Ba ....................................................... 101

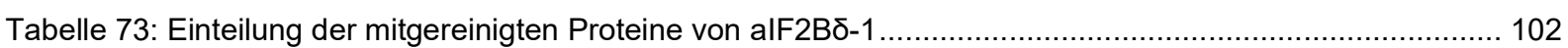

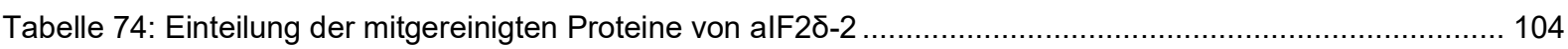

Tabelle 75: Einteilung der mitgereinigten Proteine von elF4A-homolog .................................................. 105

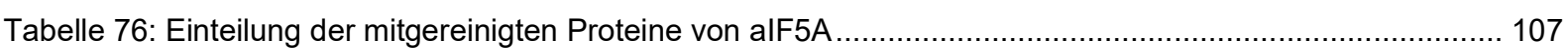

Tabelle 77: Einteilung der mitgereinigten Proteine von alF5B in molekularbiologische Prozesse ..................... 109

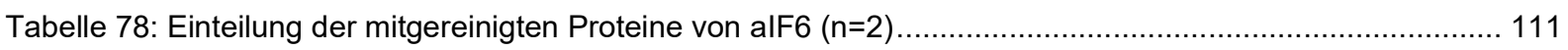

Tabelle 79: Zusammenfassung der MS-Daten für die Interaktion zwischen den alFs ................................. 112

Tabelle 80: Zusammenfassung der MS-Daten für die Interaktion zwischen alFs und RNAPUs...................... 114

Tabelle 81: RNA-Polymerase-Untereinheiten der RNA-Polymerase in H. volcanii....................................... 115

Tabelle 82: Mit den sieben RNAPUs mitgereinigte RNAPUs .............................................................. 117

Tabelle 83: Mit den sieben RNAPUs mitgereinigte Proteine der Translation............................................... 119

Tabelle 84: Mit den 14 alFs und alF-Untereinheiten mitgereinigte RNAPUs ................................................ 120

Tabelle 85: Mit den sieben RNAPUs mitgereinigte alFs und alF-Untereinheiten ......................................... 120

Tabelle 86: Interaktion alF2 mit alFs (Affinitätsaufreinigung-MS) ....................................................... 147

Tabelle 87: Interaktion alF2 mit alFs (Affinitätsaufreinigung-FPLC-MS) .............................................. 147

Tabelle 88: MNT-P, RBPI- und alF2B-like Motive nach (Dev et al., 2009) ................................................ 151

Tabelle 89: Identifikation von rpS2, rpS3, rpS5, rpS10 in den MS-Daten von alFs und RNAPUs ...................... 172

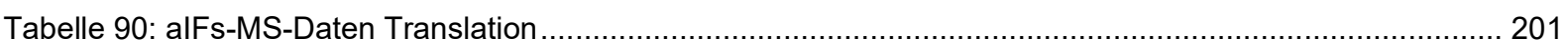

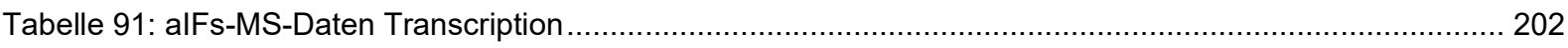

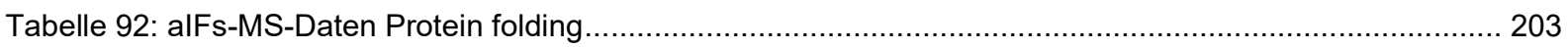




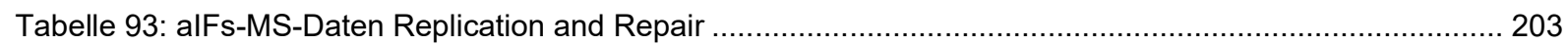

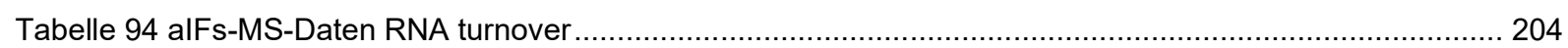

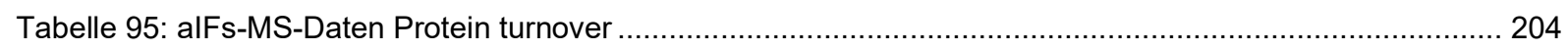

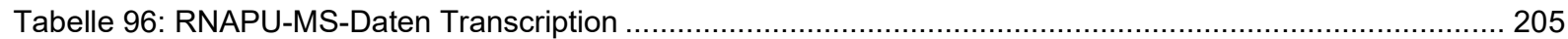

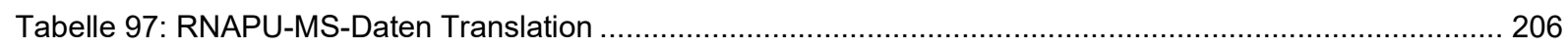

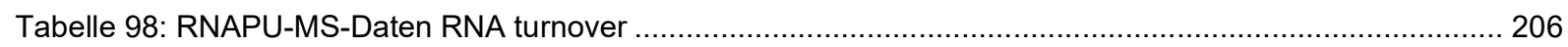

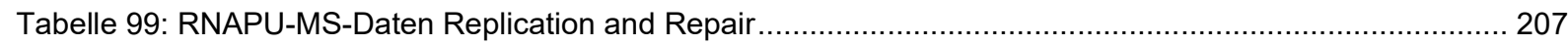

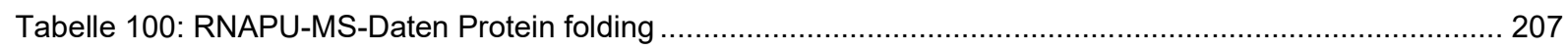

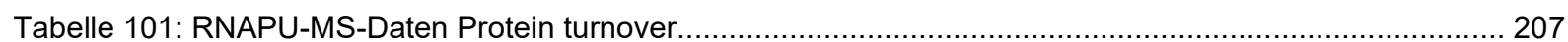




\section{Einleitung}

Das Leben wird in die drei Domänen Bacteria, Eukarya und Archaea eingeteilt (Woese, Kandler and Wheelis, 1990). Sie definieren sich durch die systematische Einteilung aller Lebewesen.

Der in dieser Arbeit verwendete Organismus Haloferax volcanii (H. volcanii) zählt zu den Archaeen (Abbildung 1). Diese Domäne gliedert sich in TACK, Euryarchaeota und DPANN. TACK steht hier für das Thaumarchaeota-Aigarchaeota-Crenarchaeota-Korarchaeota-Superphylum (Guy and Ettema, 2011).

Das Phylum der Euryarchaeota unterteilt sich in weitere Klassen, darunter die Halobacteria, die wiederum die Familie der Halobacteriaceae enthält, zu denen $H$. volcanii zählt (Nunoura et al., 2011).
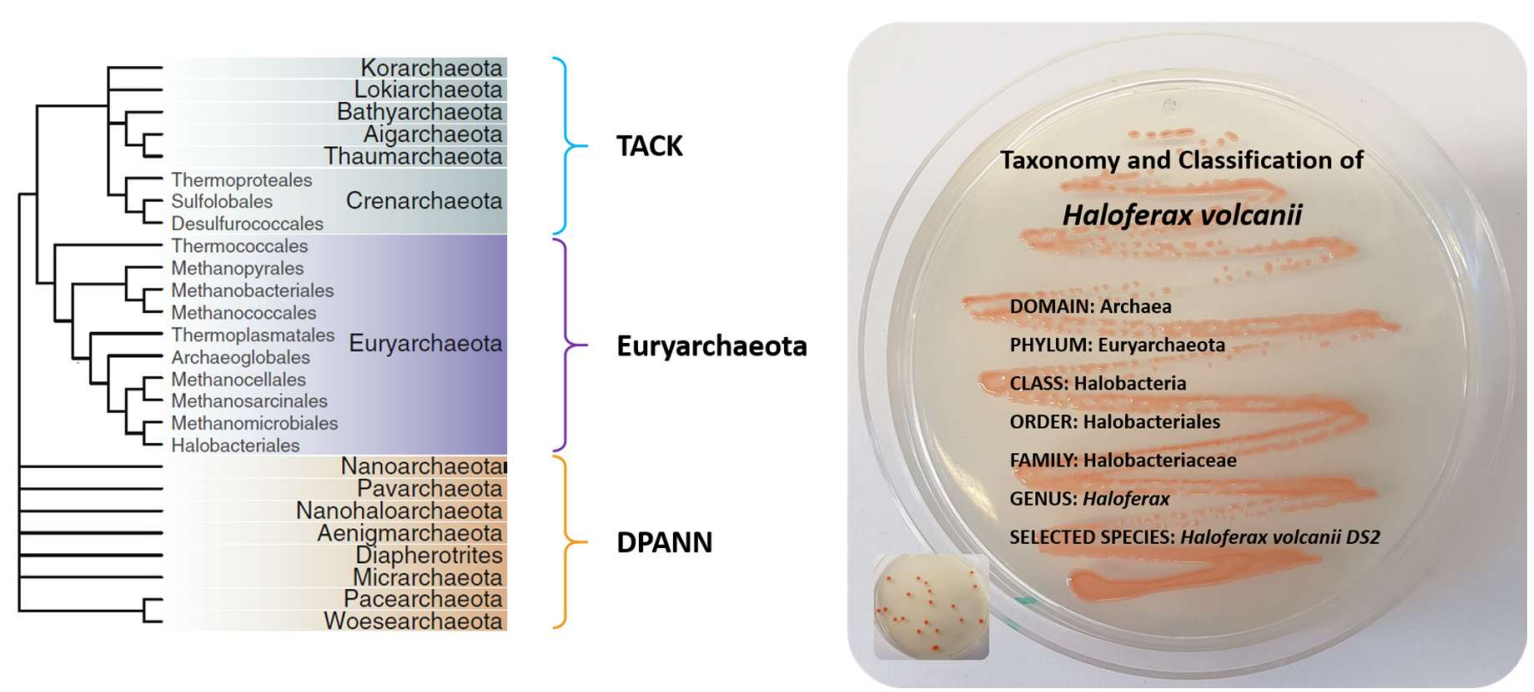

Abbildung 1: Phyla der Archaeen modifiziert (Eme and Doolittle, 2015; Pohlschroder and Schulze, 2019) Einteilung der Archaea in TACK, Euryarchaeota und DPANN. Taxonomie und Klassifizierung des in dieser Arbeit verwendeten Stammes Haloferax volcanii DS2.

H. volcanii wurde 1975 aus dem toten Meer isoliert, ist halophil und fakultativ anaerob (Mullakhanbhai and Larsen, 1975; Jantzer and Zerulla, 2011). Benannt wurde das Archaeon nach Benjamin Elazari Volcani, der erstmals den Beweis für mikrobielles Leben im Toten Meer lieferte (Oren and Ventosa, 1999).

Das Genom von $H$. volcanii besteht aus fünf Replikons: einem Hauptchromosom (2,9 Mb), drei kleineren Chromosomen pHV4 (636 kb), pHV3 (438 kb), pHV1 (85,1 kb) und einem Plasmid pHV2 (6,35 kb). Das Genom wurde 2010 vollständig sequenziert. Es beinhaltet 3996 Gene und sechs Replikationsursprünge. Die codierende genomische DNA von $\mathrm{H}$. volcanii hat einen GC-Gehalt von 65 \% (Hartman et al., 2010). Für optimales Wachstum benötigt das Archaeon eine Salzkonzentration von etwa 2,1 M Natriumchlorid und besitzt eine Konzentrationstoleranz von 0,7-5 M Natriumchlorid. Es gibt zwei Möglichkeiten wie halophile Organismen mit diesem breiten Spektrum an Osmolarität umgehen und sich anpassen. Die eine beinhaltet die Akkumulation von organisch verträglichen gelösten Stoffen (z.B. Glycin, Betain, Ektoin), wie im 
Beispiel von Halomonas. Die andere Möglichkeit wird auch „salt-in“-Strategie genannt, wie z.B. in der Klasse der Halobacteriaceae. Hier geschieht die Anpassung an die salinen Bedingungen durch hohe Kalium-Konzentrationen im Zellinneren (Christian and Waltho, 1962; Bayley, Morton and Lanyi, 1978; Mojica et al., 1997; Santos and da Costa, 2002).

Die Anpassung der Organismen an diesen speziellen Lebensraum wirkt sich bei der salt-in Strategie auf den Aufbau ihrer Proteine aus. Die Aminosäurekomposition beinhaltet einen erhöhten Anteil an sauren Aminosäuren wie Aspartat und Glutamat. Diese Aminosäuren haben hauptsächlich einen Einfluss auf die Löslichkeit der Proteine. Sie erhalten auf der Oberfläche von Proteinen sowohl die Struktur, als auch die biologische Funktion bei hoher lonenstärke. Dies führt auch dazu, dass halophile Proteine einen niedrigen isoelektrischen Punkt besitzen (Jaenicke, 1991; Ortega, Diercks and Millet, 2015; Brininger et al., 2018).

$H$. volcanii kann in Komplexmedium und in synthetischem Medium kultiviert werden. In synthetischem Medium wird eine alternative Kohlenstoffquelle benötigt. Es gibt eine Vielzahl an alternativen Kohlenstoffquellen beispielsweise verschiedene Zucker, Aminosäuren, Glycerin, Acetat oder Pyruvat. Unter optimalen Bedingungen beträgt die Verdopplungszeit von $H$. volcanii etwa drei Stunden. Zusätzlich zum aeroben Wachstum kann $H$. volcanii auch anaerob, unter Verwendung von Nitrat, Trimethylaminoxid (TMAO) oder Dimethylsulfoxid (DMSO) als Elektronenakzeptor kultiviert werden (Soppa, 2011).

Als Modellorganismus in Archaeen eignet sich $H$. volcanii durch die kurze Generationszeit, die einfachen Kultivierungsbedingungen und das umfangreiche und stetig wachsende Repertoire an molekularbiologischen, genetischen und biochemischen Methoden (Allers and Ngo, 2003; MacNeill, 2011; Pohlschroder and Schulze, 2019).

\subsection{Diversität in den drei Domänen des Lebens}

Zu Beginn wurden zwei Domänen des Lebens definiert, da Archaeen aufgrund ihres Zellaufbaus und ihrer Morphologie bis 1977 noch als Bakterien definiert wurden. Mittels 16S- und 18S-rRNA-Analyse konnten Woese und Fox die Archaeen als die dritte Domäne des Lebens etablieren (Woese and Fox, 1977). Evolutionsbedingt gibt es viele Arten, die gleichzeitig zu zwei Domänen gehören. Gemeinsamkeiten bei Bacteria und Archaea betrifft unter anderem ein fehlender Zellkern, Flagellen für die Fortbewegung, das zirkuläre Chromosom und die Organisation ihrer Operons (Kuzminov, 2014; Samson and Bell, 2014).

Auch zwischen Archaeen und Eukaryonten gibt es Gemeinsamkeiten (Pluchon et al., 2013; Adam et al., 2017; Eme et al., 2017). Viele molekularbiologische Prozesse von Archaeen ähneln Prozessen in Eukaryonten. Hinzu kommen viele homologe Proteine. Ein Bereich ist die Replikation, am Beispiel von Orc1 und Cdc6 (Li et al., 2010; MacNeill, 2011). In Eukaryonten bindet der origin recognition complex (ORC), bestehend aus den Proteinen Orc1-6, an die Replikationsursprünge. Daraufhin rekrutieren ORCs viele Proteine zum Replikationsursprung, 
darunter auch Cdc6 (Duncker, Chesnokov and McConkey, 2009). Im Vergleich hierzu besitzen Archaeen, bis auf Methanogene, homologe Gene für Orc1 oder/und Cdc6, mindestens jedoch für eines der beiden Proteine (Barry and Bell, 2006; Samson, Abeyrathne and Bell, 2016; Ludt and Soppa, 2018).

In der Transkription konnten strukturelle und funktionelle Homologien des Transkriptionsapparates zwischen Archaeen und Eukaryonten gezeigt werden. Hierzu zählen die RNA-Polymerase mit ihren Untereinheiten, Transkriptionsfaktoren wie TBP, TFB und E (Qureshi et al., 1995; Richard, Bell and White, 2004; Jun et al., 2011; Pluchon et al., 2013; Gehring, Walker and Santangelo, 2016). Die Tabelle 1 zeigt, dass für Archaeen und Eukaryonten 13 RNAPUs (RNA-Polymerase-Untereinheiten) und für Bakterien 6 RNAPUs bekannt sind (Werner and Weinzierl, 2002; Grohmann, Hirtreiter and Werner, 2009).

Tabelle 1: RNAPUs in den drei Domänen des Lebens (Grohmann, Hirtreiter and Werner, 2009)

\begin{tabular}{|c|c|c|c|}
\hline & Archaea & Eukarya & Bacteria \\
\hline shared in all 3 domains & $A^{\prime}+A^{\prime \prime}$ & rpb1 & $\beta^{\prime}$ \\
\hline & $\mathrm{B}(1+2)$ & rpb2 & $\beta$ \\
\hline & $\mathrm{D}$ & rpb3 & $\alpha \mathrm{l}$ \\
\hline & $\mathrm{K}$ & rpb6 & $\omega$ \\
\hline & L & rpb11 & all \\
\hline \multirow[t]{6}{*}{ archaeal and eukaryotic subunits } & $\mathrm{F}$ & rpb4 & \\
\hline & $\mathrm{H}$ & rpb5 & \\
\hline & $E$ & rpb7 & \\
\hline & G & rpb8 & \\
\hline & $\mathrm{N}$ & rpb10 & \\
\hline & $\mathrm{P}$ & rpb12 & \\
\hline only found in eukaryotes & & rpb9 & \\
\hline found in certain species & rpo13* & Gdown1* & $\delta^{*}$ \\
\hline
\end{tabular}

*these subunits are not orthologues

Fünf Untereinheiten der RNAP sind in allen drei Domänen des Lebens vertreten, die eine Art Krabbenschere formen (Abbildung 2) (Langer et al., 1995; Jun et al., 2011).

Bacteria

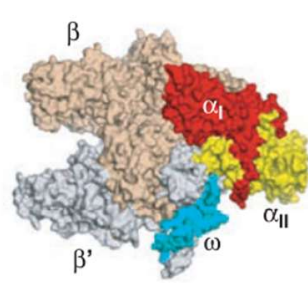

Archaea

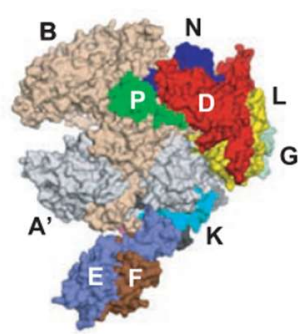

Eukarya

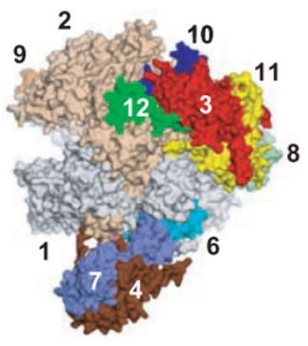

Abbildung 2: Strukturen von RNAPs in den drei Domänen des Lebens modifiziert nach (Jun et al., 2011) In Bakterien (Thermus aquaticus), Archaeen (Sulfolobus solfataricus) und Eukaryonten (Saccharomyces cerevisiae Polymerase II). Orthologe Untereinheiten besitzen denselben Farbcode. 
Diese sind für die Trennung der DNA-Stränge zuständig und bilden den RNAP-Kern. Der Kern beherbergt das katalytische Zentrum in Bakterien an der Schnittstelle der Untereinheiten $\beta / \beta^{\prime}$, in Archaeen an der Schnittstelle von rpoA/B und in Eukaryonten an den Untereinheiten rpb1/2 (Jun et al., 2011; Griesenbeck, Tschochner and Grohmann, 2017).

Trotz der geringen Sequenzidentität zwischen den Untereinheiten gibt es in der Struktur der Kernuntereinheiten einen hohen Grad an Konservierung (Hirata and Murakami, 2009). Sechs weitere Untereinheiten sind nur in Archaeen und Eukaryonten vertreten. Sie bilden eine hervorstehende, stielartige Struktur, die bei bakteriellen RNAPs nicht vorhanden ist. Diese Struktur wird von $\mathrm{E}$ und $\mathrm{F}$ gebildet und ist durch $\mathrm{K}$ an das RNAP-Zentrum gebunden. Dieser Komplex ist an einer Vielzahl von Funktionen beteiligt, unter anderem an der Stabilisierung des Initiationskomplexes und der Bindung des entstehenden RNA-Transkripts. (Hirata and Murakami, 2009; Jun et al., 2011; Griesenbeck, Tschochner and Grohmann, 2017)

\subsection{Translation, ein universeller Mechanismus}

Die Translation findet in allen drei Domänen des Lebens als ein hochkonservierter Prozess statt und gliedert sich in die vier Abschnitte: Initiation, Elongation, Termination und anschließendem Recycling der Ribosomen (Abbildung 3).

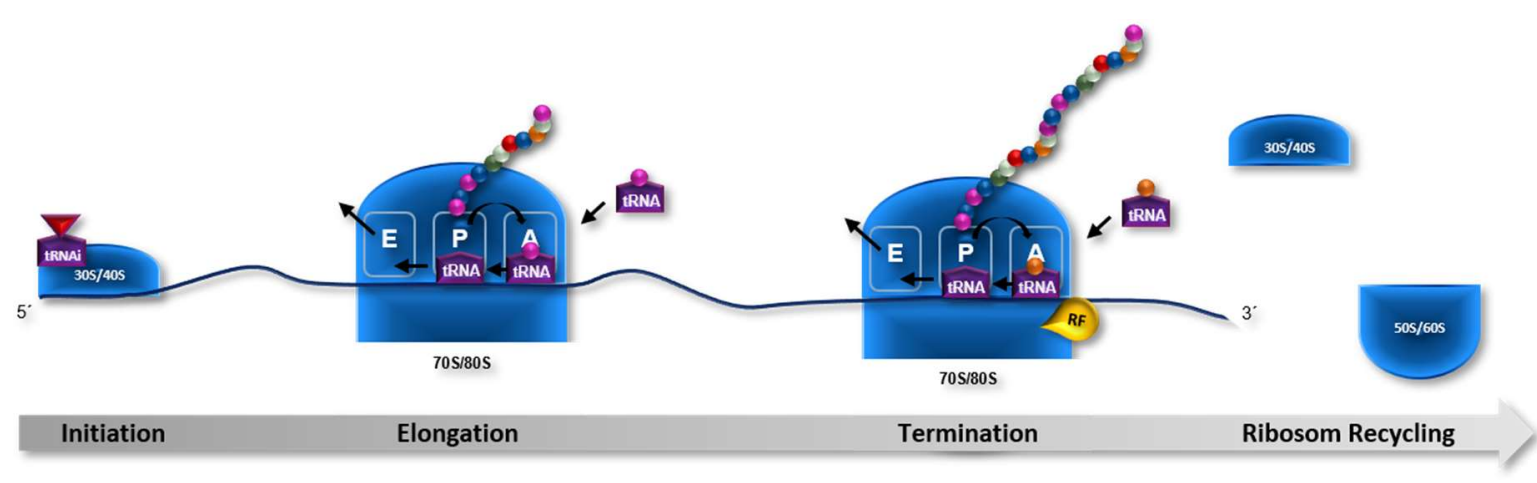

Abbildung 3: Ablauf einer Translation

Die Translation gliedert sich in Initiation, Elongation, Termination und Ribosomen Recycling. Die Initiation beginnt mit der Assemblierung der Start-tRNA und das Ribosomen an die mRNA. Bei der Elongation wird die mRNA abgelesen und die Aminosäuren zu einer wachsenden Peptidkette verknüpft. Bei der Termination wurde das Stopcodon erreicht. Mit Hilfe von Release Faktoren (RF) wird die Polypeptidkette freigesetzt und die Translation geht über zum Ribosomen Recycling, bei dem die ribosomalen Untereinheiten von der mRNA dissoziieren.

Bei der Translation wird die in der Transkription erstellte mRNA benötigt. An diese mRNA bindet während der Initiation das Ribosomen. Die mRNA wird während der Elongation in die Aminosäuresequenz überführt und somit das Protein synthetisiert. Bei Erreichen des Stopcodons wird mit Hilfe von Release-Faktoren die Translation beendet und die Ribosomen recycelt. Bemerkenswert ist hierbei, dass die Initiation der Translation gleichzeitig der limitierende und determinierende Schritt der Translation ist. Diese Komplexität wird von Translationsinitiationsfaktoren und verschiedenen Initiationsmechanismen beeinflusst (Benelli and Londei, 2009). 


\subsection{Translationsinitiation in den drei Domänen des Lebens}

Die Translationsinitiation beschreibt den Start der Translation. Diese beginnt zumeist mit der Verbindung der kleinen ribosomalen Untereinheit mit der mRNA und der Initiator t-RNA. Von besonderer Bedeutung ist die korrekte Positionierung für das Leseraster und die erfolgreiche Decodierung der mRNA. Erst dann stößt die große ribosomale Untereinheit in der Translationsinitiation hinzu, sodass die Elongation der Translation beginnen kann.

Trotz des universellen Mechanismus der Translation, die in allen drei Domänen des Lebens vertreten ist, gibt es Unterschiede bei den Komponenten und Mechanismen, die in Tabelle 2 zusammengefasst sind.

Tabelle 2: Komponenten und Mechanismen der Translation

\begin{tabular}{cccc}
\hline & Bacteria & Eukarya & Archaea \\
\hline mRNA & mono- and polycistronic & monocistronic & mono- and polycistronic \\
Initiator-tRNA & Formylmethionine & Methionine & Methionine \\
Ribosom subunit & $70 \mathrm{~S}(30 \mathrm{~S} / 50 \mathrm{~S})$ & $80 \mathrm{~S}(40 \mathrm{~S} / 60 \mathrm{~S})$ & $70 \mathrm{~S}(30 \mathrm{~S} / 50 \mathrm{~S})$ \\
Ribosom rRNA & $16 \mathrm{~S} ; 23 \mathrm{~S}, 5 \mathrm{~S}$ & $18 \mathrm{~S} ; 28 \mathrm{~S}, 5,8 \mathrm{~S}, 5 \mathrm{~S} ; 23 \mathrm{~S}, 5 \mathrm{~S}$ \\
translation initiation factors & $3-5$ & $>10$ & $>10$ \\
Spatial organization transcrip- & temporally and spatially & temporally and spatially se- & temporally and spatially \\
tion/translation & coupled & parated & coupled \\
initiation mechanisms & leaderless & leaderless & leaderless \\
& $5^{\prime}$-UTR without SD & & $5^{\prime}$-UTR without SD \\
& SD-Sequence & SD-Sequence
\end{tabular}

Diese Unterschiede beginnen bereits bei der Start-tRNA. In Bakterien handelt es sich um formylmethionyl-tRNA (fMet-tRNA), in Archaeen und Eukaryonten hingegen um methionyltRNA (Met-tRNA) (Hussain et al., 2016).

In Eukaryonten besitzt die mRNA eine 5'-Cap und eine Polyadenylierung am 3'-Ende, was bei Bakterien und Eukaryonten nicht der Fall ist (Schmitt et al., 1998). Bei Prokaryonten ist die mRNA mono- oder polycistronisch, in Eukaryonten monocistronisch (Kozak, 2005b).

Eukaryonten haben meist eine kleine $40 \mathrm{~S}$ ribosomale Untereinheit und eine große 60S ribosomale Untereinheit. Archaeen und Bakterien besitzen eine kleine 30S und eine große 50S ribosomale Untereinheit (Pestova et al., 2000; Londei, 2005; Gualerzi and Pon, 2015). Bemerkenswert ist, dass das eukaryontische Ribosom keine evolutionäre Mischung aus archaealer und bakterieller Ribosomenelemente ist. Eukaryonten und Archaeen teilen sich 33 homologe, ribosomale Proteine, die nicht in Bakterien vertreten sind. In verschiedenen Studien konnte gezeigt werden, dass diese ribosomalen Proteine für die Stabilität von Strukturen der rRNA wichtig sind (Wool, Chan and Glück, 1995; Ben-Shem et al., 2010). Jedoch teilen sich alle drei Domänen Homologien in 34 ribosomale Proteinen, darunter 15 Proteine der kleinen ribosomalen Untereinheit und 19 Proteine der großen ribosomalen Untereinheit (Lecompte et al., 
2002; Simonetti et al., 2009; Korobeinikova, Garber and Gongadze, 2012; Armache et al., 2013; Forterre, 2015).

Trotz der Homologien zeigen die ribosomalen Proteine verschiedene Aminosäurereste, die Proteinsegmente formen und nur in Bakterien, Eukaryonten oder Archaeen zu finden sind. Dies führt zu einer hohen Diversität in den Strukturen der universellen ribosomalen Proteinen (Melnikov, Manakongtreecheep and Söll, 2018).

Auch bei den Initiationsmechanismen der Translation gibt es Unterschiede in den drei Domänen des Lebens. In Bakterien ist die Initiation der Translation über die SD-Sequenz, eine 5'-UTR ohne SD-Sequenz, als auch über den leaderlosen Mechanismus möglich. In Eukaryonten geschieht dies über den Scanning-Mechanismus, IRES (internal ribosom entry site) und die leaderlose Translation. In Archaeen ist bisher die leaderlose Translationsinitiation, die Initiation mit 5'UTR ohne SD-Sequenz und die Initiation ohne SD-Sequenz bekannt.

\subsubsection{Leaderlose Translationsinitiation}

In allen drei Domänen des Lebens vertreten und somit der evolutionär älteste Mechanismus, ist der leaderlose Mechanismus der Translationsinitiation (Andreev et al., 2006; Zheng et al., 2011; Gäbel et al., 2013). Bei diesem Mechanismus liegt die mRNA ohne 5'-UTR und ohne Shine-Dalgarno-Sequenz (SD-Sequenz) vor. In Abbildung 4 sind verschiedene Initiationswege für leaderlose mRNA in den drei Domänen des Lebens dargestellt.

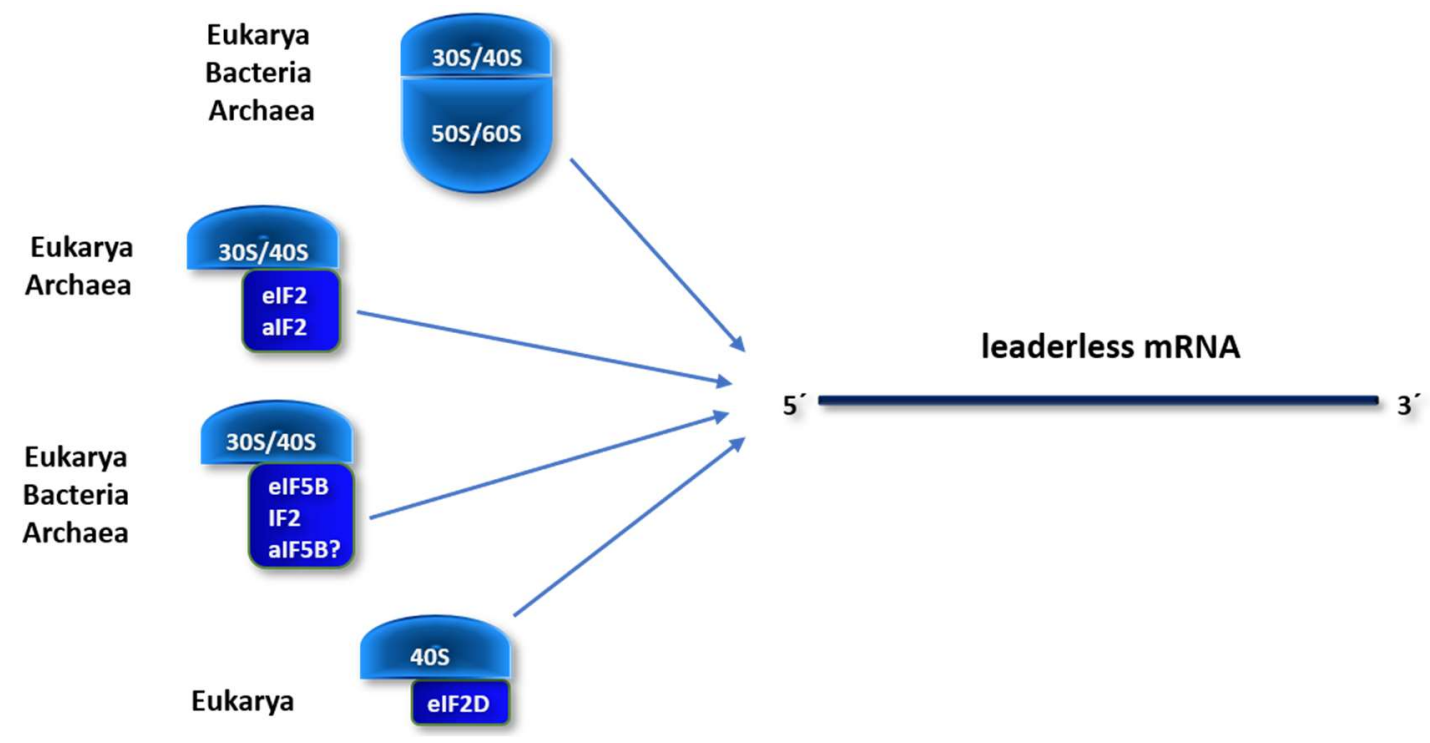

Abbildung 4: Initiationswege der Translation an leaderlosen Transkripten in den drei Domänen des Lebens Hierbei sind das Ribosom und verschiedene Translationsinitiationsfaktoren involviert.

In allen drei Domänen ist die Initiation über ein undissoziiertes Ribosomen möglich (70S bzw. 80S). Des Weiteren wird die leaderlose mRNA sowie eine Initiator-tRNA benötigt (Moll et al., 2002, 2004; O'Donnell and Janssen, 2002). 
In H. volcanii sind $72 \%$ der proteinkodierenden Transkripte leaderlos (Babski et al., 2016). In Sulfolobus solfataricus (S. solfataricus) betrifft dies $69 \%$ aller Transkripte (Wurtzel et al., 2010). Es gibt aber auch Archaeen, bei denen bedeutend weniger Transkripte leaderlos sind. Bei den methanogenen Archaeen ist dies zum Beispiel Methanolobus psychrophilus mit $16 \%$ und Methanosarcina mazei mit 11 \% leaderlosen Transkripten (Jäger et al., 2009). Bei den Thermococcales sind unter anderem in Thermococcus kodakarensis $14 \%$ der Transkripte leaderlos (Jäger et al., 2014).

In S. solfataricus wurde beschrieben, dass die leaderlose Translationsinitiation für monocistronische Gene als auch am Start von Genen polycistronischer mRNA involviert ist (Benelli, Maone and Londei, 2003). Für $H$. volcanii wurde von Hering und Kollegen 2009 gezeigt, dass unter leaderlosen Bedingungen als Startcodon AUG vor GUG und UUG bevorzugt wird (Hering et al., 2009).

In Escherichia coli (E. coli) konnte als Variante der leaderlosen Translation von Grill und Kollegen im Jahr 2000 gezeigt werden, dass bei einer erhöhten IF2-Konzentration, die 30S ribosomale Untereinheit und die leaderlose mRNA effizient um die Translation mit einer mRNA, die eine kanonische Ribosomenbindestelle enthält, konkurrieren kann (Grill et al., 2000; Moll et al., 2002).

Unter anderem wurde bewiesen, dass Translationsinitiationsfaktoren in der leaderlosen Translation eine Rolle spielen: IF3 beeinflusst die Translation über 70S Ribosomen, da es die Dissoziation von 70S Ribosomen unterstützt. Unter anderem inhibiert IF3 die Bindung der $30 \mathrm{~S}$ ribosomalen Untereinheit an die leaderlose mRNA (Tedin et al., 1999; Grill et al., 2001; Moll et al., 2004). IF2 dagegen unterstützt die Assoziation von 30S- und 50S-ribosomalen Untereinheiten. Im Kontrast hierzu stabilisiert IF2 den Präinitiationskomplex mit der 30 S ribosomalen Untereinheit (Moll et al., 2002; O’Donnell and Janssen, 2002; Antoun et al., 2003).

In Eukaryonten sind verschiedene Varianten der leaderlosen Translationsinitiation bekannt (Abbildung 4). Davon hauptsächlich die oben beschriebene Variante, bei der die mRNA und Initiator-tRNA an das 80S Ribosom bindet (Andreev et al., 2006; Akulich et al., 2016).

Die zweite Variante ist mittels elF2D und 48S Ribosomen-Bildung möglich und wurde in Säugetierzellen von Dmitriev und Kollegen 2010 nachgewiesen. Das zuständige Gen ist in allen Eukaryonten vertreten und enthält eine SUI1 Domäne, die auch in elF1 vertreten ist (Dmitriev et al., 2010).

Die dritte Variante ist die elF2-unabhängige Translationsinitiation durch elF5B. Dieser elF2 unabhängige Mechanismus tritt auf, wenn elF2 durch Stressbedingungen phosphoryliert und somit inaktiviert wurde. Mittels elF3 und Initiator-tRNA ist elF5B in der Lage, mit der kleinen ribosomalen Untereinheit den 48S Präinitiationskomplex zu bilden. Unter anderem ist elF5B ein Analog zum bakteriellen IF2 (Pestova et al., 2008; Terenin et al., 2008). 


\subsubsection{5'-UTR ohne SD-Sequenz}

Dieser Translationsinitiationsmechanismus tritt in Archaeen und Bakterien auf. Die Struktur der mRNA beinhaltet dabei eine Verlängerung des 5'-Bereiches, der nicht translatiert wird. Bekannt ist, dass bei diesem Mechanismus eine $5^{\prime}$-UTR verwendet wird, die keine SD-Sequenz beinhaltet (Abbildung 5).

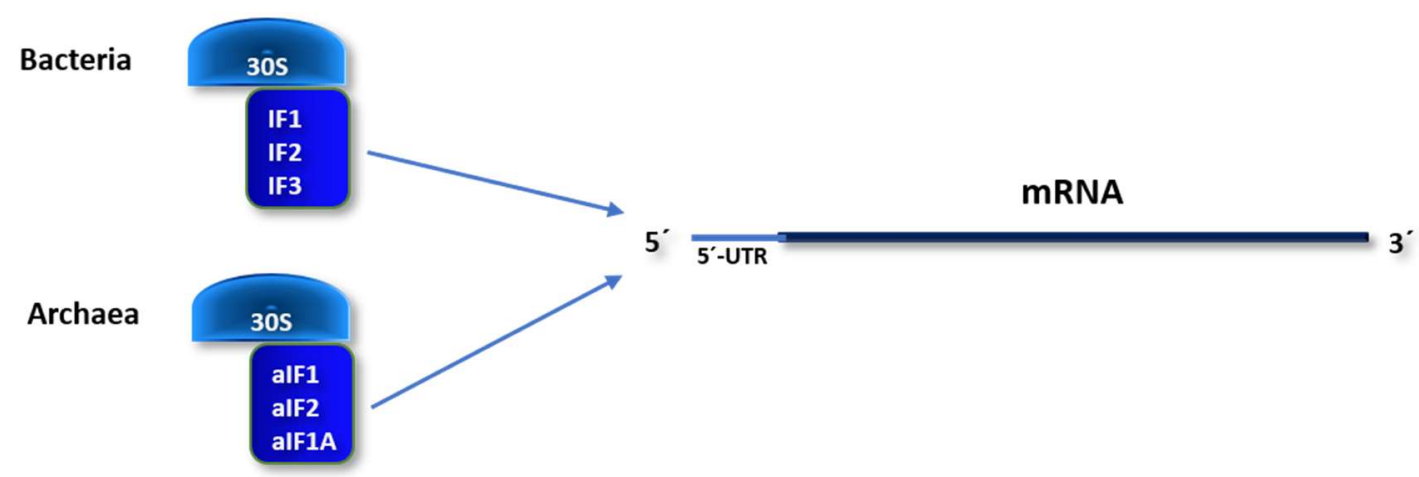

\section{Abbildung 5: Translationsinitiation an Transkripten mit 5'-UTR ohne SD-Sequenz}

Schema für die Initiation an einer mRNA mit 5'-UTR. Dabei werden die kleine ribosomale Untereinheit und Translationsinitiationsfaktoren benötigt.

In $H$. volcanii konnte nachgewiesen werden, dass die meisten Transkripte mit einer $5^{\prime}$-UTR keine SD-Sequenz aufweisen (Brenneis et al., 2007). Damit grenzt sich die Translationsinitiation in diesem Mechanismus von dem bakteriellen SD-abhängigen Mechanismus, als auch vom eukaryotischen Scanning-Mechanismus ab. Hering et al. zeigte 2009 in $H$. volcanii, dass Mutationen die das Scannen inhibieren (z.B. ein AUG vor dem eigentlichen Startcodon, ein Aptamer, oder ein stem-loop) keinen Einfluss auf die Translationsinitiation ausübten (Hering et al., 2009). Im Vergleich zur leaderlosen Translationsinitiation findet in $\mathrm{H}$. volcanii mit gleicher $5^{\prime}$-UTR und unterschiedlichen Startcodons (AUG, GUG, UUG) an allein drei Startcodons eine Translationsinitiation statt (Hering et al., 2009).

\subsubsection{SD-Sequenz}

Die Translationsinitiation an SD-Sequenzen in einer 5'-UTR tritt in Archaeen und Bakterien auf. Die SD-Sequenz ist auf der $5^{\prime}$-UTR vor dem offenen Leserahmen positioniert. Dabei fungiert die SD-Sequenz als Bindestelle der 30 S ribosomalen Untereinheit, die eine anti-SD-Sequenz an der $16 S$ ribosomalen RNA enthält (Abbildung 6). Diese Sequenz ist komplementär zur SD-Sequenz, liegt 4-7 Nukleotide stromaufwärts des Startcodons und ist 4-8 Nukleotide lang (Shine and Dalgarno, 1974; Kozak, 1999; Osada, Saito and Tomita, 1999). 


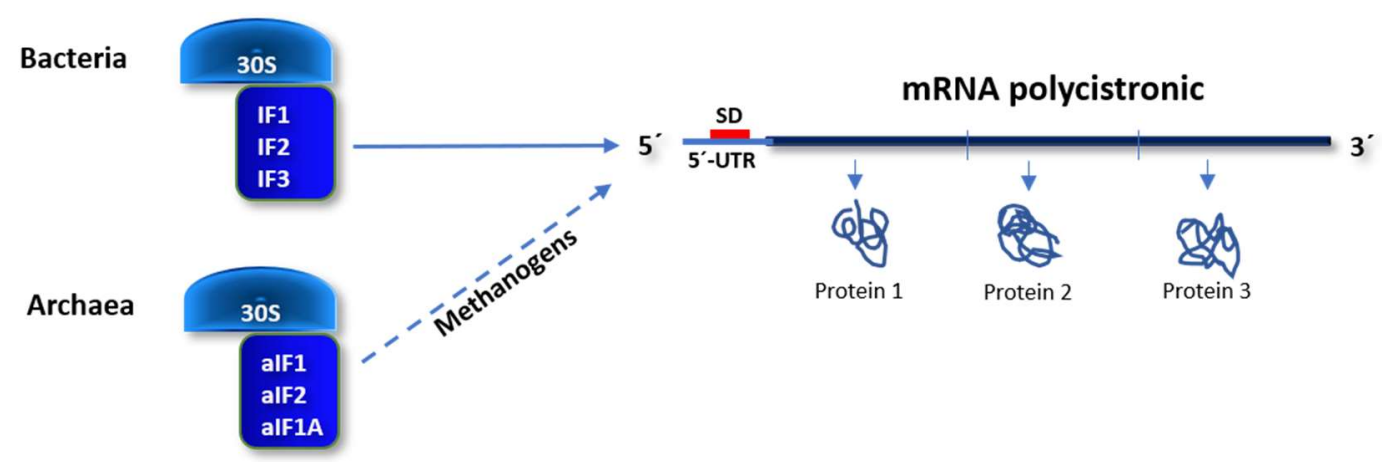

\section{Abbildung 6: Translationsinitiation an Transkripten mit SD-Sequenz}

Schema der Translationsinitiation an Transkripten mit SD-Sequenz im 5'-UTR-Bereich.

In S. solfataricus finden sich SD-Motive hauptsächlich in Operons von polycistronischen mRNAs (Benelli, Maone and Londei, 2003). Eine Genomanalyse ergab, dass SD-Motive (5'GGAGGUGA-3') selten in $\mathrm{H}$. volcanii vorkommen. Ihr Anteil ist im offenen Leserahmen jedoch sehr hoch. Sie liegen teilweise am Ende des offenen Leserahmens, im Abstand von $5 \pm 2 \mathrm{nt}$ zum nächstfolgenden Gen und können so bei der Initiation der Translation des nachfolgenden Gens im Operon beteiligt sein. Dabei handelt es sich um eine Reinitiation (Kramer et al., 2014).

\subsubsection{Scanning}

Die Translationsinitiation mit Hilfe des Scanning-Mechanismus (Abbildung 7) tritt lediglich in Eukaryonten auf.

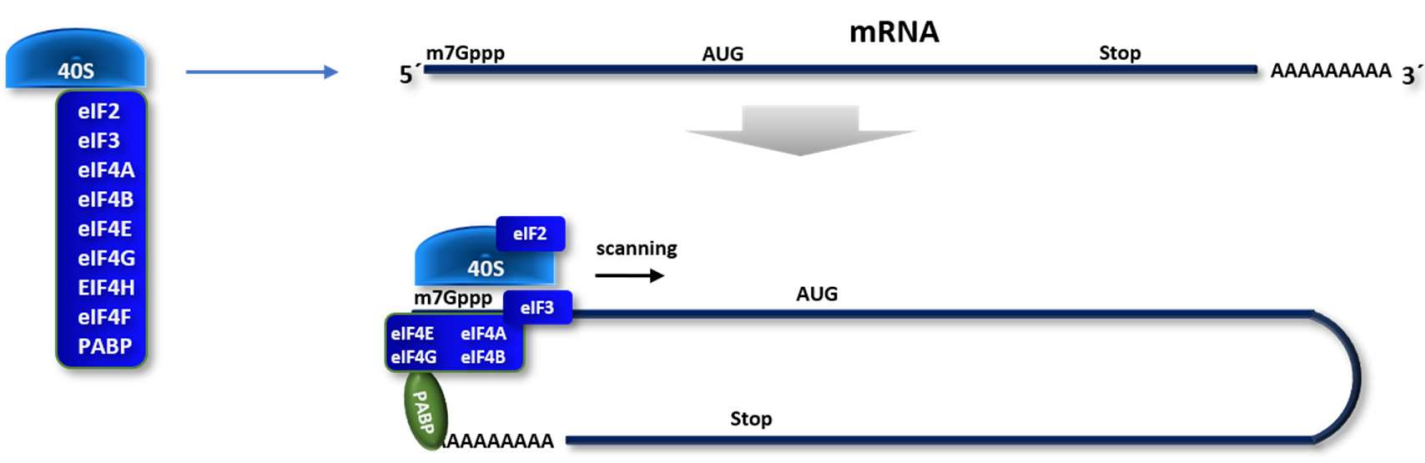

Abbildung 7: Translationsinitiation mittels Scanning Mechanismus in Eukaryonten (Shatsky et al., 2010) Schema der Translationsinitiation und den involvierten Translationsinitiationsfaktoren für den Ringschluss der mRNA und das Scanning.

Dabei bindet die kleine ribosomale Untereinheit Met-tRNA mit Hilfe von Translationsinitiationsfaktoren. Dieser sogenannte 43S-Initiationskomplex bindet an das 5'-Ende der mRNA, die eine $\mathrm{m}^{7} \mathrm{G}-\mathrm{Cap}$ (7-Methylguanylate-Cap) besitzt (Kozak, 1999, 2002). Die $\mathrm{m}^{7} \mathrm{G}-$ Cap besteht aus einem modifizierten Guanin-Nukleotid, dass über eine 5'-5'-Phosphodiesterbindung an das 5 '-Ende der mRNA geknüpft wird. Dies führt zu einer erhöhten Stabilität der mRNA und dient als Ribosom-Bindestelle (Furuichi and Shatkin, 2000; Hinnebusch, 2014; Ramanathan, 
Robb and Chan, 2016). Der Scanning-Mechanismus wird unterstützt durch das Binden des elF4F Komplexes an das 5'-Cap. Er besteht aus den Translationsinitiationsfaktoren elF4E, elF4G und die RNA-Helikase elF4A (Dever, Kinzy and Pavitt, 2016). Sie ermöglichen mit PABP (poly-A-binding protein) einen Ringschluss der mRNA (closed loop). Des Weiteren ermöglicht elF4A das lokale Aufwinden der mRNA und eine einfachere Bindung des 43S Initiationskomplexes. Der $5^{\prime}$-untranslatierte Bereich ( $5^{\prime}$-UTR) wird bis zum Erreichen des komplementären Anticodons zur Met-tRNA gescannt. Wenn dieser erreicht wurde, bindet das Triplet in der P-Site der 43S ribosomalen Untereinheit und bildet den 48S Initiationskomplex, an den die 605 große ribosomale Untereinheit bindet (Hinnebusch, 2011; Korostelev, 2014; Schmitt et al., 2019).

\subsubsection{IRES}

Ein weiterer Translationsinitiationsmechanismus fungiert über interne Ribosomenbindestellen (IRES), die das Ribosomen selbst rekrutieren können und die Translation der mRNA starten. Der Initiationsmechanismus ist unabhängig von der $5^{\prime}$ Cap-Variante (Scanning) und kann dann agieren, wenn dieser inhibiert ist (Jan, 2006). Die IRES liegen meist in der 5'-UTR der mRNA und bilden komplexe Strukturen (Abbildung 8).

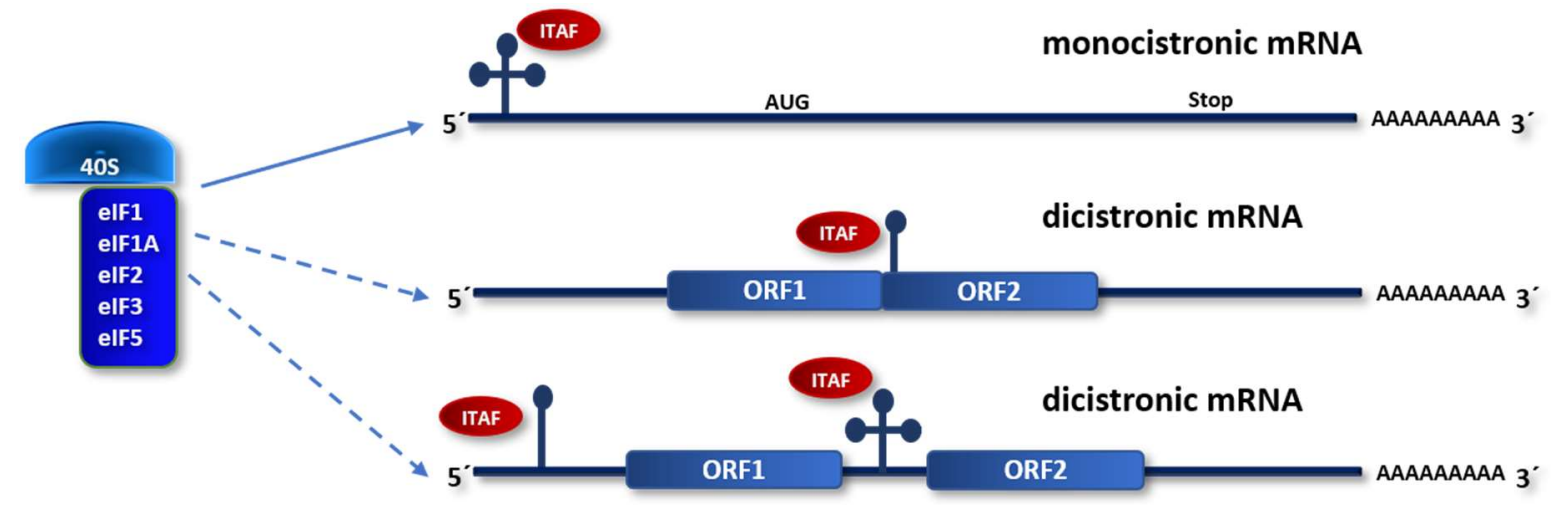

\footnotetext{
Abbildung 8: IRES-abhängige Translationsinitiation in Eukaryonten modifiziert nach (Fitzgerald and Semler, 2009; Martinez-Salas et al., 2018)

IRES bilden komplexe Strukturen und können sowohl an monocistronischer als auch an dicistronischer mRNA auftreten. Hierfür werden IRES-transaktivierende Faktoren (ITAFs) benötigt, die an die mRNA binden.
}

Diese Strukturen ermöglichen durch IRES-transaktivierende Faktoren (ITAFs) einer mRNA, an die $40 S$ ribosomale Untereinheit in der Nähe des AUG-Codons zu binden. Dabei werden viele AUG-Codons, die stromaufwärts auf der 5'-UTR der mRNA liegen, vernachlässigt. Im Jahr 1988 wurde als erstes von Pelletier und Sonenberg die Translationsinitiation von picornaviralen mRNAs beschrieben, die es Ribosomen ermöglicht, die Translation an strukturell komplexen Regionen in der $5^{\prime}$-UTR zu initiieren. 
Diese Strukturen sind in Viren und Eukaryonten zu finden (Pelletier and Sonenberg, 1988; Hellen and Sarnow, 2001; Seino et al., 2005).

Der IRES-Mechanismus und die Aktivität wird bis heute kontrovers diskutiert, da es viele verschiedene Varianten für die Translationsinitiation über IRES-Elemente an zellulären und viralen IRES gibt (Kozak, 2005a; Pestova et al., 2008; Shatsky et al., 2010).

Die Rekrutierung des ribosomalen Komplexes mittels IRES wird unabhängig vom 5'-Cap verwendet und findet hauptsächlich unter Zellstress, wie zum Beispiel bei Nährstoffmangel oder Apoptose statt (Fitzgerald and Semler, 2009). Charakteristisch für IRES-Elemente sind lange, komplex strukturierte RNA-Sequenzen. Es gibt viele verschiedene IRES-Elemente, deren Funktionen noch nicht geklärt sind und die unterschiedliche Methoden für die Translationsinitiation verwenden. Zum Beispiel beim Vertreter der Dicistroviridae, dem Cricket-Lähmungs-Virus (CrPV) wird eine intergenic region (IGR) verwendet, die zwischen zwei ORFs liegt und an eine IRES gekoppelt ist. Diese kann direkt mit dem Ribosom interagieren. Es werden keine elFs benötigt. Bei CrPV werden für IGR-IRES die Elongationsfaktoren eEF1A und eEF2 benötigt. Bei dieser mRNA liegt die funktionale Struktur am Ende der 5 '-UTR. Das erste GCU-Codon ist mit einer tRNA in der A-Site verbunden (Jan and Sarnow, 2002).

Bei anderen IRES werden zumindest eine Teilmenge der elFs sowie der RNA-Bindeproteine für die Translationsinitiation benötigt. Am Beispiel des Hepatitis-C-Virus (HCV) konnte gezeigt werden, dass für den HCV IRES die Translationsinitiationsfaktoren elF2, elF3, elF5 und elF5B benötigt werden (Johnson et al., 2017). Die RNA-Bindeproteine werden auch als IRES-transaktivierende Faktoren (ITAFs) bezeichnet und dienen der Stabilisierung der IRES-Struktur (Jackson, Hellen and Pestova, 2010). Die funktionale Struktur liegt hierbei direkt am Anfang der 5'-UTR. Das Startcodon AUG ist mit einer Initiator-tRNA in der P-Stelle gekoppelt (Gilbert, 2010; Komar, Mazumder and Merrick, 2012; Johnson et al., 2017). 


\subsection{Translationsinitiationsfaktoren in den drei Domänen des Lebens}

In allen drei Domänen des Lebens werden Translationsinitiationsfaktoren benötigt, die eine wichtige Rolle spielen. In Bakterien sind es die drei Initiationsfaktoren IF1, IF2 und IF3. Bei Eukaryonten sind es sehr viel mehr Initiationsfaktoren. Sie besitzen mehr als 14 elFs. Es gibt IFs, die in allen drei Domänen des Lebens vertreten sind. Sie sind universell. Des Weiteren teilen Archaeen homologe bzw. orthologe Gene für IFs mit Eukaryonten, die in Bakterien nicht vertreten sind (Tabelle 3 ).

Tabelle 3: Translationsinitiationsfaktoren in den drei Domänen des Lebens nach (Londei, 2005)

\begin{tabular}{lccc}
\hline & Archaea & Bacterial homologue & Eukaryal homologue \\
\hline universal factors & alF1 & $($ YCiH $)$ & elF1/SUl1 \\
& alF1A & IF1 & elF1A \\
& alF-2/5B & $\mathrm{IF2}$ & elF5B \\
& alF5A & $(\mathrm{EF}-\mathrm{P})$ & elF5A \\
\cline { 2 - 4 } archaeal and eukaryotic & alF2 & & elF2 \\
subunits & alF2B & & elF2B \\
& elF4A-homolog & & elF4A \\
& alF6 & & elF6 \\
domainspecific subunits & & & elF3 \\
& & & elF5 \\
\cline { 2 - 4 } & & $\mathrm{IF} 3$ & \\
\hline
\end{tabular}

In H. volcanii sind zum Beispiel 14 Gene als Translationsinitiationsfaktoren (alFs) und deren Untereinheiten annotiert. Vier Initiationsfaktoren sind universell in allen drei Domänen des Lebens zu finden (Kyrpides and Woese, 1998b). Vier weitere Initiationsfaktoren teilen sich Archaeen und Eukaryonten (Dev et al., 2009; Miluzio et al., 2009; Dmitriev et al., 2011). Alle drei Domänen bilden mit Hilfe der Initiationsfaktoren einen Präinitiationskomplex, der essenziell für den Start der Translation und die Wahl des Startcodons ist (Londei, 2005; Benelli and Londei, 2009; Hasenöhrl et al., 2009; Simonetti et al., 2009).

\subsubsection{IFs in der Translationsinitiation von Bakterien}

Bei der Translationsinitiation in Bakterien bilden die IFs einen Präinitiationskomplex (Hussain et al., 2016). Zu diesem Komplex gehören die kleine ribosomale Untereinheit zusammen mit der mRNA, die Initiationsfaktoren IF1, IF2-GTP, IF3 und formylierte Methionyl-tRNA (fMettRNA) (Simonetti et al., 2009). Die fMet-tRNA tritt dabei in die P-Stelle ein, während die AStelle durch IF1 blockiert wird. IF1 ist eine der wesentlichen Komponenten für die Einleitung der Translation und der Auswahl des Startcodons. Sie bindet in der Nähe der A-Stelle auf der kleinen ribosomalen Untereinheit (Godefroy-Colburn et al., 1975; Moazed et al., 1995; Gualerzi et al., 2001). Unter anderem bildet er für IF2 und IF3 einen Ankerpunkt und verbessert deren Aktivitäten (Hussain et al., 2016). 
In Abbildung 9 wird die Translationsinitiation in Bakterien dargestellt. Darüber hinaus werden die bekannten Funktionen der IFs beschrieben.

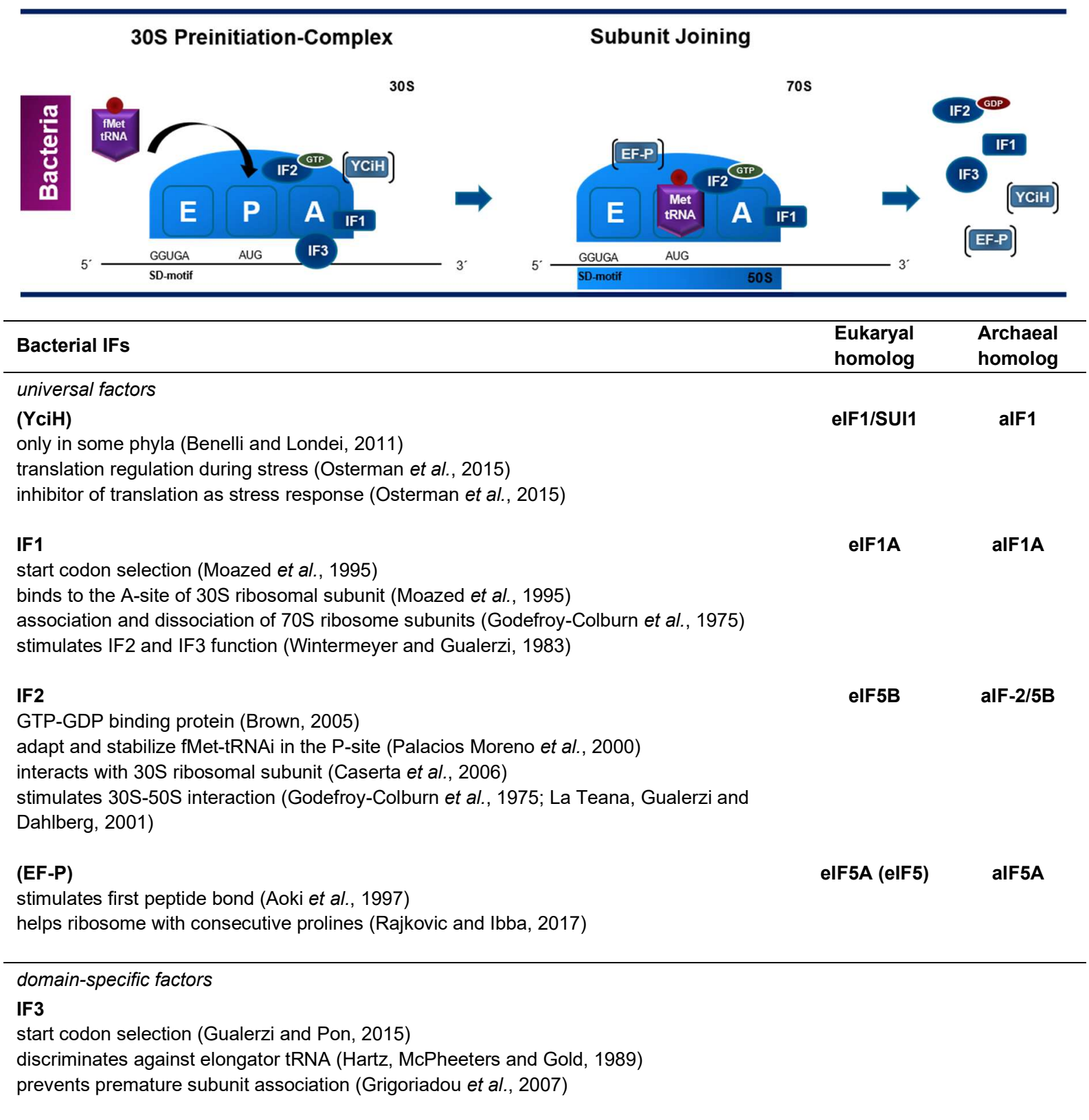

\section{Abbildung 9: Translationsinitiation in Bakterien und die Funktionen der einzelnen IFs}

Ablauf der Translationsinitiation mit den involvierten Initiationsfaktoren in Bakterien. In der Tabelle sind die bekannten Funktionen der IFs beschrieben.

IF2 ist ein GTP-GDP-Bindeprotein (Caserta et al., 2006; Fabbretti et al., 2012). Milon et al. beschrieb 2006 den IF2 als metabolischen Sensor (Milon et al., 2006). Dies geschieht unter Stressbedingungen durch die Konkurrenz zwischen GTP und ppGpp (Guanosin-3',5'-bispyrophosphat). Das ppGpp wird vermehrt unter Stressbedingungen gebildet. GTP und ppGpp agieren als alternative physiologische IF2-Liganden. Der Ligand ppGpp inhibiert dabei die Translation, indem es an die gleiche Nukleotidbindestelle wie GTP bindet (Legault, Jeantet and Gros, 1972; Milon et al., 2006; Steinchen and Bange, 2016). IF2 bindet im Präinitiationskomplex an die kleine ribosomale Untereinheit und ist unter anderem für die richtige Positionierung 
der fMet-tRNAi in der P-Stelle zuständig (Palacios Moreno et al., 2000; Caserta et al., 2006). Anschließend stimuliert IF2 die Interaktion zwischen der 30 S und 50 S ribosomalen Untereinheit (Godefroy-Colburn et al., 1975; La Teana, Gualerzi and Dahlberg, 2001).

Das Homolog von elF1 in Bakterien ist $\mathrm{YciH}$. Es ist nur in manchen Phyla vertreten und reguliert die Translation unter Zellstress (Benelli and Londei, 2011; Osterman et al., 2015).

Die Funktion von EF-P in der Translationsinitiation ist umstritten, da sowohl gezeigt werden konnte, dass er für die Verknüpfung des ersten Peptides zuständig ist, aber auch in manchen Phyla nicht essenziell zu sein scheint (Aoki et al., 1997). Unter anderem wurde 2017 von Rajkovic und Kollegen gezeigt, dass EF-P bei der Synthese von Peptiden mit Polyprolinen wichtig ist, um ein Hängen bleiben des Ribosom zu verhindern (Rajkovic and Ibba, 2017).

In Bakterien wirkt IF3 als Anti-Assoziationsfaktor und verhindert die vorzeitige Bindung der $50 S$ ribosomalen Untereinheit (Dallas and Noller, 2001; Grigoriadou et al., 2007). Ferner ist er an der Auswahl des Startcodons beteiligt und diskriminiert tRNAs, die für die Elongation und nicht für den Start der Translation bestimmt sind (Hartz, McPheeters and Gold, 1989; Gualerzi and Pon, 2015).

Nach Erkennung des Startcodons wird GTP zu GDP, die große ribosomale Untereinheit bindet und die IFs dissoziieren (Gualerzi et al., 2001; Simonetti et al., 2009). Die Elongation der Translation kann beginnen.

\subsection{2 elFs in der Translationsinitiation von Eukaryonten}

In Eukaryonten wird ebenfalls ein Präinitiationskomplex gebildet. elF2 bildet einen ternären Komplex mit GTP und der Methionyl-tRNA (Richter and Lipmann, 1970). Dieser ternäre Komplex bildet mit der 40 S ribosomalen Untereinheit, elF1, elF1A, elF3 und elF5 den sogenannten 43S-Präinitiationskomplex, der an die mRNA bindet (Asano et al., 2000; Olsen et al., 2003). Dabei sind elF1 und elF1A für die offene Konformation der $40 S$ ribosomalen Untereinheit und die Bindung des ternären Komplexes zuständig. Dies ermöglicht der Met-tRNA in die P-Stelle zu gelangen und diese auf die Komplementarität mit dem Anticodon-Triplett zu überprüfen.

Der Initiationsfaktor elF5 agiert als GTPase aktivierendes Protein und stimuliert die Hydrolyse von GTP im ternären Komplex (Saini et al., 2014). Die vorzeitige Hydrolyse wird im scannenden Präinitiationskomplex von elF1 unterbunden. Der Präinitiationskomplex wird anschlieBend durch eIF4E und weitere verwandte eIFs an das 5'-Ende der mRNA rekrutiert.

Das Schema zum allgemeinen Ablauf der Translation in Eukaryonten und die Funktion der einzelnen elFs sind in Abbildung 10 dargestellt.

elF4A agiert hierbei als Helikase und windet die $5^{\prime}$-UTR auf. Von diesen verwandten elFs fungiert elF4G als Brücke zwischen elF4E und dem Poly(A)tail-Bindungsprotein (PABP). Es verbindet so die $3^{\prime}$ - und $5^{\prime}$-Enden der mRNA zu einem closed loop. 


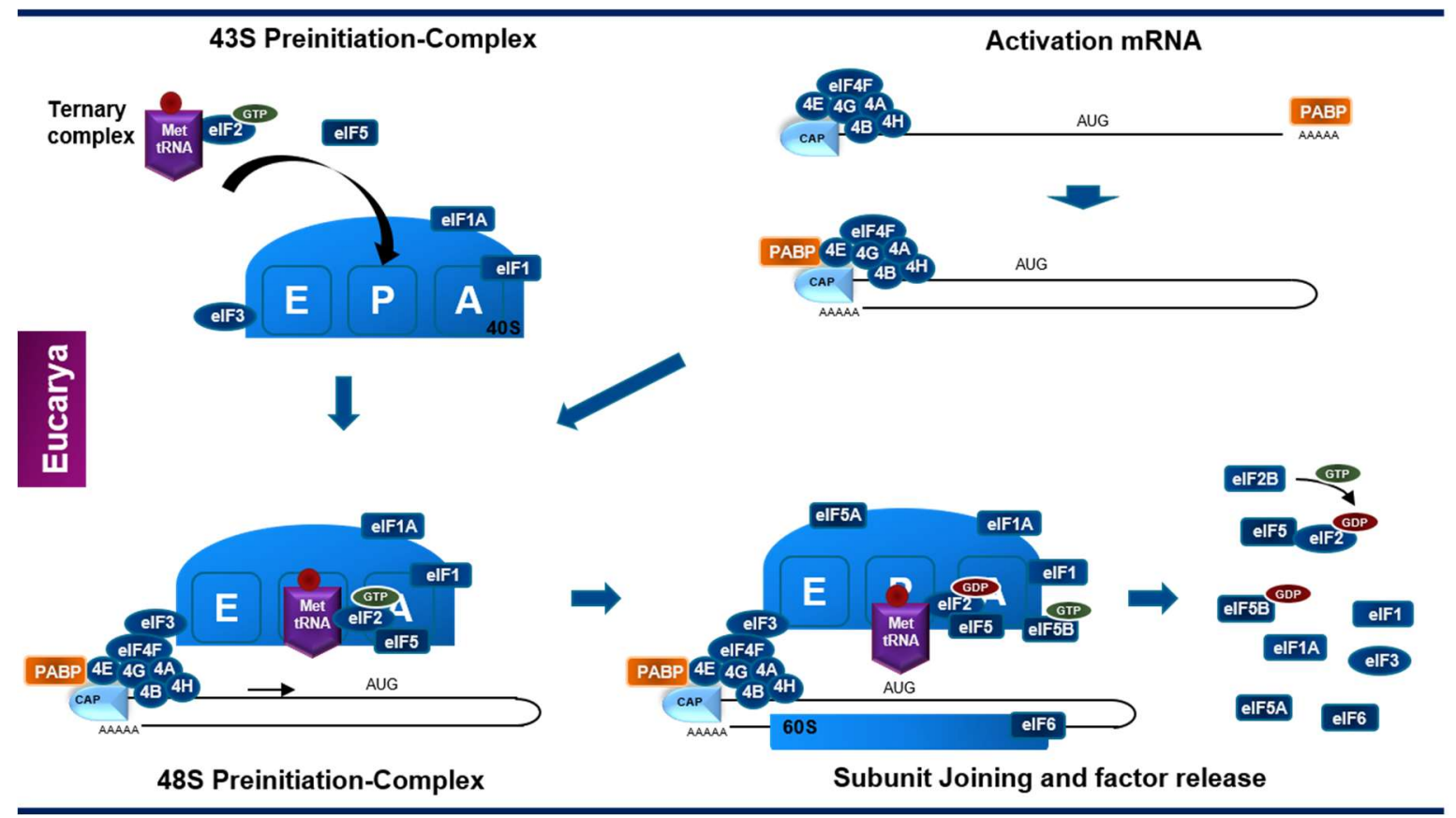

Abbildung 10: Die eukaryontische Translationsinitiation nach (Dever, Kinzy and Pavitt, 2016)

Der 43S-Präinitiationskomplex besteht aus der 40S ribosomalen Untereinheit, EIF1, elF1A, elF3 und dem ternären Komplex, bestehend aus elF2-GTP-Met-tRNAi. Dieser bindet an die aktivierte mRNA und scannt in 3'-Richtung. Bei Erkennen des Startcodons bindet die 60 S ribosomale Untereinheit den Initiationskomplex. Anschließend verlässt der größte Teil der Initiationsfaktoren den Initiationskomplex.

Dieser Komplex bewegt sich dann in 3' Richtung, das sogenannte Ribosomenscanning. Erfolgt die Basenpaarung der Met-tRNA mit dem Initiator-Codon AUG, findet eine Neuordnung der Translationsinitiationsfaktoren im Präinitiationskomplex statt (Luna et al., 2013; Zeman et al., 2019). elF1 wird verdrängt. Das C-terminale Ende von elF1A verändert seine Position von der Nähe zur P-Site, in die Nähe der GTPase aktivierenden Proteindomäne von elF5 (Fekete et al., 2007; Reibarkh et al., 2008).

Diese Neuordnung ermöglicht, dass sich elF1 von der ribosomalen 40S Untereinheit löst und sich eine geschlossene Konformation der 40 S ribosomalen Untereinheit bildet (Lomakin et al., 2003; Cheung et al., 2007). Das elF2-gebundene GTP wird hydrolysiert und resultiert in einer festeren Bindung der Met-tRNA in der P-Site (Nanda et al., 2013). Der Faktor elF6 bindet an die 60S große ribosomale Untereinheit, um so die frühzeitige Bindung der großen Untereinheit an den Präinitiationskomplex zu verhindern. elF6 wird durch die elongation factor-like GTPase, in Saccharomyces cerevisiae (S. cerevisiae) Efl1p dissoziiert. Jetzt kann die 60S ribosomale Untereinheit an den Präinitiationskomplex binden (Graindorge et al., 2005; Gandin et al., 2008; Gartmann et al., 2010). Die Bindung der ribosomalen 60S-Untereinheit wird dann durch die GTPase elF5B erleichtert, die die korrekte Positionierung der Methionyl-tRNA gewährleistet. Die Erkennung der Methionyl-tRNA initiiert die Hydrolyse des gebundenen GTP, gefolgt von der Dissoziation von elF5B. Die Elongation der Translation kann beginnen (Pestova et al., 2000; Benelli and Londei, 2009). In Tabelle 4 werden die bekannten Funktionen der einzelnen elFs näher beschrieben. 
Tabelle 4: Eukaryontische Translationsinitiationsfaktoren und deren bisher bekannte Funktionen

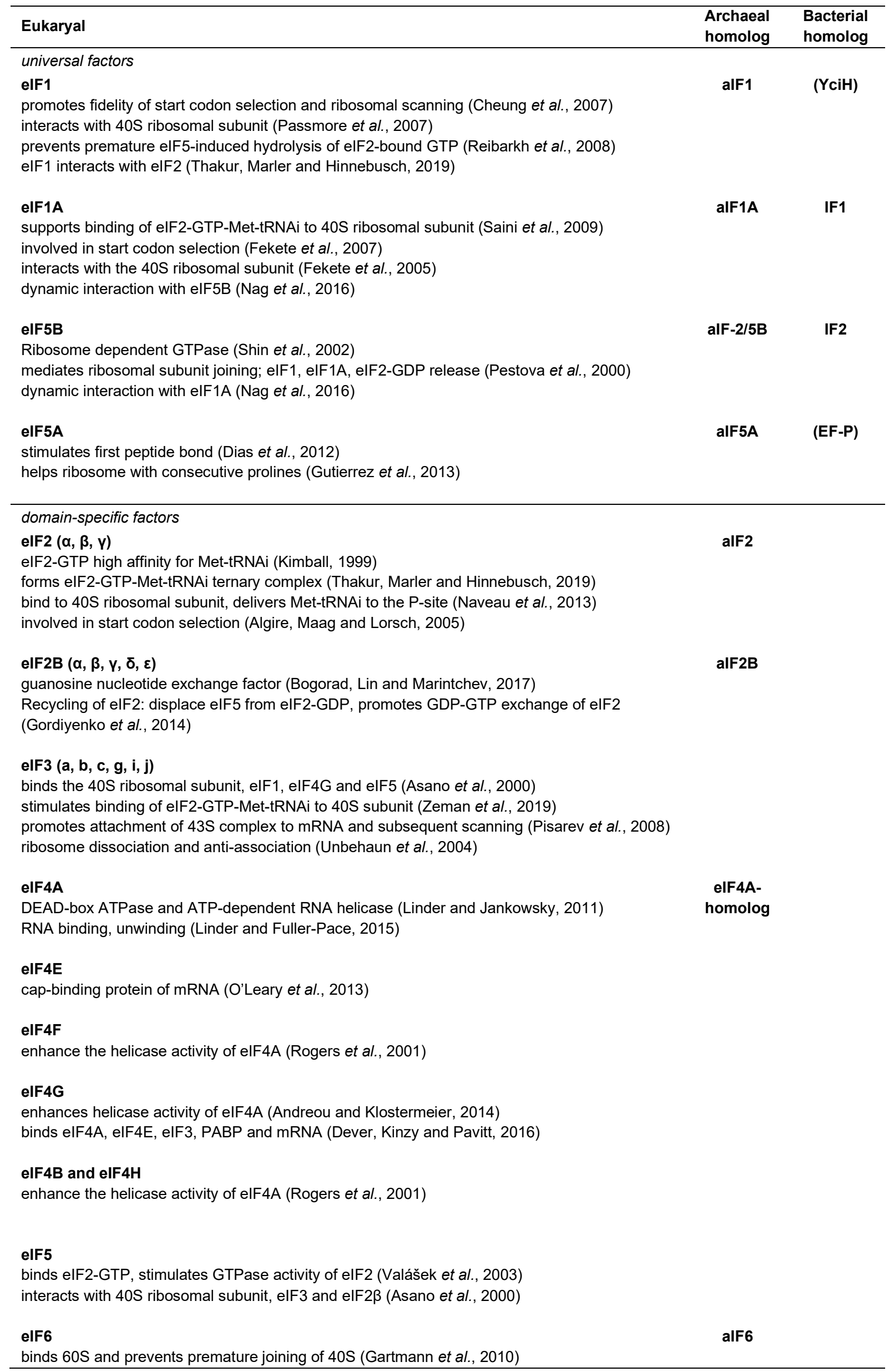




\subsection{3 alFs in der Translationsinitiation von Archaeen}

Im Gegensatz zu Eukaryonten und Bakterien sind in Archaeen die Translationsinitiation und die Funktion der Translationsinitiationsfaktoren bislang noch nicht vollständig aufgeklärt. Ein möglicher Ablauf der Translationsinitiation in Archaeen wird in Abbildung 11 dargestellt.

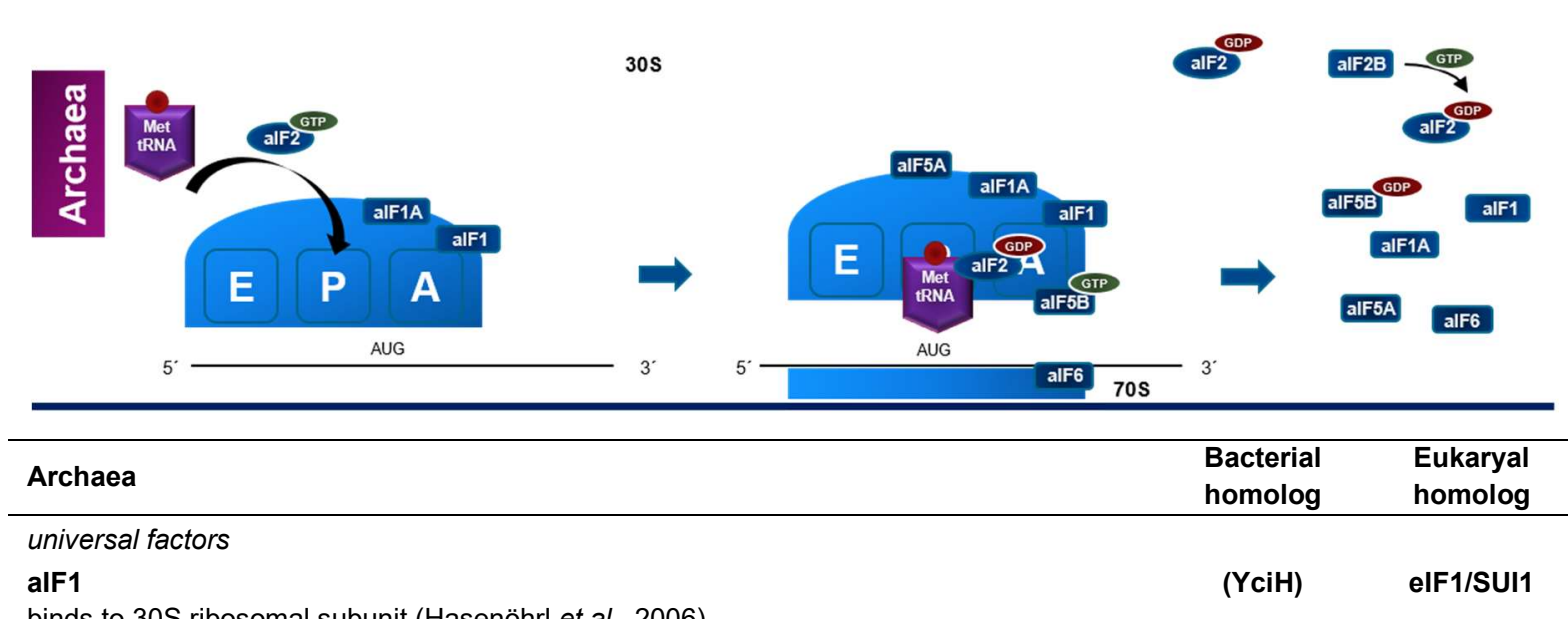

binds to 30 S ribosomal subunit (Hasenöhrl et al., 2006)

stimulates initiation complex formation (Monestier et al., 2018)

Promotes fidelity of start codon selection (Hasenöhrl et al., 2009)

alF1A

IF1

elF1A

binds to the 30 S ribosomal subunit (Hasenöhrl et al., 2009)

stimulates binding of alF2 to 30 S ribosomal subunit (Coureux et al., 2016)

alF5B

IF2

elF5B

Ribosome dependent GTPase (Simonson and Satpati, 2012)

binds Met-tRNAi and adapts Met-tRNAi in ribosomal P site (Guillon et al., 2005)

enhances translation of leaderless and leadered mRNAs (Maone et al., 2007)

alF5A

helps ribosome with consecutive prolines (Bassani et al., 2018)

associates with the ribosome (Bassani et al., 2019)

displays RNase activity (Wagner and Klug, 2007)

domainspecific factors

alF2 ( $\alpha, \beta, y)$

binds to 30 S ribosomal subunit (Schmitt, Naveau and Mechulam, 2010)

mediates Met-tRNAi joining to 30 S ribosomal subunit (Coureux et al., 2016)

binds Met-tRNAi (Stolboushkina et al., 2013)

interacts with alF1 (Coureux et al., 2016)

bind to the $5^{\prime}-\mathrm{P}_{3}$-end of mRNAs (Hasenöhrl et al., 2008; Arkhipova et al., 2015)

alF2B $(\alpha, \beta, \delta)$

elF2B

binds alF2 $\alpha$ (Dev et al., 2009)

interacts with eukaryotic elF2 $\alpha$ and elF2Ba (Dev et al., 2009)

elF4A-homolog

elF4A

ATP-dependent RNA helicase (Gäbel et al., 2013)

alF6

elF6

anti association factor (Groft et al., 2000)

binds to $50 \mathrm{~S}$ ribosomal subunit, keeps subunits dissociated (Benelli et al., 2009)

\section{Abbildung 11: Translationsinitiation in Archaeen}

Möglicher Ablauf der Translationsinitiation in Archaeen mit den beteiligten Translationsinitiationsfaktoren. Die Funktion der einzelnen Translationsinitiationsfaktoren ist in der Tabelle aufgelistet. 
Für die Bindung der Met-tNRAi sind in Archaeen zwei mögliche Wege beschrieben. Bei der ersten Variante bindet alF2, wie bei Bakterien IF2, zuerst an die kleine ribosomale Untereinheit und bindet dann die Met-tRNAi (La Teana et al., 2013). Die zweite Variante verläuft wie bei Eukaryonten, bei der die Met-tRNAi an den GTP gebundenen elF2/alF2 bindet, einen ternären Komplex bildet und dann an die 30 S ribosomale Untereinheit bindet (Schmitt et al., 2012).

Der Präinitiationskomplex besteht in Archaeen aus einer 30 S ribosomalen Untereinheit, den Faktoren alF1, alF1A und alF2-gebundenem GTP mit der Met-tRNAi (Allen and Frank, 2007). Wie in Eukaryonten (elF1) und Bakterien (IF1) beschrieben, verhindert auch alF1 das vorzeitige Binden der großen ribosomalen Untereinheit und beschleunigt so die Bindung der InitiatortRNA und der mRNA an das Ribosomen (Hasenöhrl et al., 2006). alF1A ist unter anderem an der Startcodonwahl und Positionierung der alF2 gebundenen Met-tRNAi zuständig (Coureux et al., 2016). Bei der Codon-Anticodon-Erkennung wird das IF2-gebundene GTP hydrolysiert und alF2 verlässt das Ribosom. Dies geschieht wahrscheinlich zusammen mit alF1 und alF1A. alF5B mit gebundenem GTP stabilisiert die Met-tRNAi in der P-Stelle und fördert die Bindung der $50 S$ ribosomalen Untereinheit (Maone et al., 2007). Für alF2B konnte gezeigt werden, dass er mit alF2, elF2 $\alpha$ und elF2B interagieren kann. Die genaue Funktion in Archaeen ist hingegen noch nicht geklärt (Dev et al., 2009).

alF6 verhindert, wie in Eukaryonten, das frühzeitige Binden der großen ribosomalen Untereinheit an den Präinitiationskomplex (Groft et al., 2000; Benelli et al., 2009). 


\subsection{Translationsinitiationsfaktoren in $H$. volcanii}

In H. volcanii sind 14 Gene für alFs und ihre Untereinheiten annotiert. Katrin Gäbel, die zuvor an diesem Projekt arbeitete, charakterisierte sie durch die Erzeugung von Deletionsmutanten und der Erstellung von bedingten Depletionsmutanten (Gäbel et al., 2013). Neun dieser 14 Gene konnten deletiert werden. Für die anderen fünf Gene gab es keine Möglichkeit Deletionsmutanten zu erzeugen. Daher wurden sie als essenziell eingestuft (Tabelle 5).

Tabelle 5: Translationsinitiationsfaktoren in $\boldsymbol{H}$. volcanii essenziell und nicht essenziell

\begin{tabular}{|c|c|c|c|c|}
\hline Factor & Subunits & Deletion & Depletion & Conclusion \\
\hline \multirow[t]{2}{*}{ alF1A } & alF1A-1 & $\sqrt{ }$ & - & \multirow{2}{*}{$\begin{array}{l}\text { Orthologous genes: essential } \\
\text { (no double-deletion mutant) }\end{array}$} \\
\hline & alF1A-2 & $\sqrt{ }$ & - & \\
\hline \multirow[t]{2}{*}{ alF1 } & alF1 & - & $\sqrt{ }$ & essential \\
\hline & alF1 homolog & $\sqrt{ }$ & - & non-essential \\
\hline \multirow[t]{4}{*}{ alF2 } & $a I F 2 \alpha$ & $\sqrt{ }$ & - & non-essential \\
\hline & alF2 $\beta-1$ & $\sqrt{ }$ & - & \multirow{2}{*}{$\begin{array}{l}\text { Orthologous genes: essential } \\
\text { (no double-deletion mutant) }\end{array}$} \\
\hline & alF2 $\beta-2$ & $\sqrt{ }$ & - & \\
\hline & alF2y & - & $\sqrt{ }$ & essential \\
\hline \multirow[t]{3}{*}{ alF2B } & $a I F 2 B \alpha(a I F 2 / 5 B \alpha)$ & $\sqrt{ }$ & - & non-essential \\
\hline & alF2Bס & $\sqrt{ }$ & - & non-essential \\
\hline & elF4A homolog & $\sqrt{ }$ & - & non-essential \\
\hline alF5A & alF5A & - & $\sqrt{ }$ & essential \\
\hline alF5B & alF5B & - & $\sqrt{ }$ & essential \\
\hline alF6 & alF6 & - & $\sqrt{ }$ & essential \\
\hline
\end{tabular}

In $H$. volcanii sind zwei orthologe Gene für alF1A und alF-2 $\beta$ annotiert. Diese alF-Orthologen sind in der Lage, die Funktion des jeweils anderen Gens in einer Deletionsmutante teilweise zu ersetzen. In beiden Fällen konnte jeweils nur ein Gen deletiert werden. Doppel-Deletionsmutanten konnten nicht erstellt werden. Dies deutet darauf hin, dass auch alF-1A und alF-2 $\beta$ essenziell sind (Gäbel et al., 2013). 


\subsection{Zielsetzung der Arbeit}

Die in H. volcanii annotierten Translationsinitiationsfaktoren und deren Untereinheiten sind Teil eines breiten, wissenschaftlichen Forschungsfeldes. Dies betrifft insbesondere deren Funktion und Zusammenspiel. Bislang konnte anhand von Deletion und konditionaler Depletion festgestellt werden, welche Initiationsfaktoren essenziell sind. Darüber hinaus wurden sie in Wachstumsversuchen phänotypisch charakterisiert.

Ziel dieser Arbeit ist es, die Rolle der Initiationsfaktoren in der Translation von H. volcanii weiter aufzuklären und deren Funktionsbereiche näher einzugrenzen. Hierbei soll die Identifizierung von Proteinen, die spezifisch mit alFs interagieren als Methode dienen. Besonderes Augenmerk liegt hierbei auf den Interaktionen zwischen den einzelnen alFs.

Als geeignetes Verfahren wurde die Überexpression und die native Co-Affinitätsaufreinigung der alFs in $H$. volcanii etabliert. Dies erlaubte mit anschließender MS mögliche Interaktionspartner zu identifizieren und damit korrespondierende Netzwerke zu entwickeln.

Als weiterer Punkt wurde die Charakterisierung des alF2 in $\mathrm{H}$. volcanii weiter vorangetrieben. Es handelt sich hierbei um einen heterotrimeren Initiationsfaktor, der die Initiator-tRNA bindet und damit wesentlich für die Translationsinitiation ist. Trotz gleicher Funktion unterscheiden sich die alF2-Untereinheiten in $\mathrm{H}$. volcanii, die in direktem Kontakt mit der Initiator-tRNA sind, zu den Untereinheiten in Eukaryonten und dem Crenarchaeon Sulfolobus.

Die alF2a-Deletionsmutante zeigte in den vorangegangenen Untersuchungen (Gäbel et al., 2013) unter allen getesteten Wachstumsbedingungen einen Phänotyp. Um die Regulation des alF2 $\alpha$ genauer untersuchen zu können, wurde deshalb ein Aminosäure-Mimikry durchgeführt. 


\section{Material und Methoden}

Die verwendeten Materialien und Methoden sind in diesem Kapitel aufgeführt.

\subsection{Verwendete Materialien}

In diesem Abschnitt sind alle verwendeten Materialien, Geräte, Software, Primer, Plasmide und Organismen aufgelistet.

\subsubsection{Verbrauchs- und Gebrauchsmaterialien}

In der folgenden Tabelle sind die verwendeten Materialien aufgelistet.

Tabelle 6: Auflistung der verwendeten Materialien

\begin{tabular}{|c|c|c|}
\hline Material & Hersteller & Firmensitz \\
\hline Amersham Hyperfilm ${ }^{\mathrm{TM}} \mathrm{MP}$ & GE Healthcare & München (D) \\
\hline Deckgläser 18x18 mm & Knittel Glas & Braunschweig (D) \\
\hline Objektträger & Diagonal & Münster (D) \\
\hline Gel-Blotting-Papier $(0,37$ mm/1,4mm) & Carl Roth & Karlsruhe (D) \\
\hline Mikrotiterplatten 96 well, Flachboden & Sarstedt & Nümbrecht (D) \\
\hline Mikrotiterplatten 96 well, Rundboden & Sarstedt & Nümbrecht (D) \\
\hline Dialyseschlauch MEMBRA-CEL® 3,5 kDa & Serva & Heidelberg (D) \\
\hline Multiply® PCR-Plate 96 well & Sarstedt & Nümbrecht (D) \\
\hline Multiply® Pro Gefäße 0,2 mL & Sarstedt & Nümbrecht (D) \\
\hline Multiply® $\mu$ StripPro 8er Kette & Sarstedt & Nümbrecht (D) \\
\hline Roti $®-N y l o n$ plus, $0,45 \mu \mathrm{m}$ (Southern Blot) & Carl Roth & Karlsruhe (D) \\
\hline Pasteurpipetten & WU & Mainz (D) \\
\hline PCR-Film adhäsive & Thermo Fisher Scientific & Wilmington (USA) \\
\hline Petrischalen & Sarstedt & Nümbrecht (D) \\
\hline Pipettenspitzen $(2,5,20,200$ und $1000 \mu \mathrm{L})$ & Sarstedt & Nümbrecht (D) \\
\hline Glaspipetten (5, 10 und $20 \mathrm{~mL})$ & Brand & Wertheim (D) \\
\hline Reagenzgläser & Assistent & Sondheim/Rhön (D) \\
\hline Reaktionsgefäße $(1,5 ; 2 ; 15$ und 50 mL) & Sarstedt & Nümbrecht (D) \\
\hline Sterilfilter Filtropur $S 0,45 \mu \mathrm{m}$ PAT & Sarstedt & Nümbrecht (D) \\
\hline Spritzen (1, 5 und $20 \mathrm{~mL})$ & B. Braun & Melsungen (D) \\
\hline Dialyseplättchen 13 mm & Merck & Darmstadt (D) \\
\hline Faltenfilter $24 \mathrm{~cm}$ & Machery-Nagel & Düren (D) \\
\hline Küvetten & Sarstedt & Nümbrecht (D) \\
\hline Filtropur BT25 0.2; 250 mL Bottle Top Filter & Sarstedt & Nümbrecht (D) \\
\hline Gel-Blotting-Papier, whatman $® 3 \mathrm{MM}$ & Carl Roth & Karlsruhe (D) \\
\hline Immobilon-P Membran, PVDF 0,45 ㅆm (Western Blot) & Merck Millipore & Billerica (USA) \\
\hline Parafilm & Bemis Flexible Packaging & Neenah (USA) \\
\hline Steristopfen $®$ & Heinz Herenz Medizinalbedarf & Hamburg (D) \\
\hline Handschuhe Nitrile & VWR & Radnor (USA) \\
\hline Handschuhe Nitrile light & VWR & Radnor (USA) \\
\hline Hybridisierungsröhrchen & VWR & Radnor (USA) \\
\hline
\end{tabular}




\subsubsection{Verwendete Chemikalien}

In folgender Tabelle wurden alle verwendeten Chemikalien und Lösungen aufgeführt.

Tabelle 7: Verwendete Chemikalien und Lösungen

\begin{tabular}{|c|c|c|}
\hline Chemikalien und Lösungen & Hersteller & Firmensitz \\
\hline 2-Mercaptoethanol & Merck & Darmstadt (D) \\
\hline 3-(N-Morpholino)-Propansulfonsäure (MOPS) & Merck & Darmstadt (D) \\
\hline $30 \%$ (w/v) N-Lauroylsarcosinat & Applichem & Darmstadt (D) \\
\hline 2-(4-(2-Hydroxyethyl)-1-piperazinyl)-ethansulfonsäure (HEPES) & Carl Roth & Karlsruhe (D) \\
\hline 2'-Deoxythymidin & AppliChem & Darmstadt (D) \\
\hline 2'-Desoxyadenosin-5'-triphosphat (dATP) & Thermo Fisher Scientific & Wilmington (USA) \\
\hline 2‘-Desoxycytidin-5'-triphosphat (dCTP) & Thermo Fisher Scientific & Wilmington (USA) \\
\hline 2'-Desoxyguanosin-5'-triphosphat (dGTP) & Thermo Fisher Scientific & Wilmington (USA) \\
\hline 2'-Desoxythymidin-5‘-triphosphat (dTTP) & Thermo Fisher Scientific & Wilmington (USA) \\
\hline 2-Propanol (Isopropanol) & VWR & Radnor (USA) \\
\hline 5-Fluorotsäure (5'FOA) & Thermo Fisher Scientific & Wilmington (USA) \\
\hline Acrylamid/Bis-acrylamid (30 \%) & Merck & Darmstadt (D) \\
\hline Agarose & Genaxxon & Ulm (D) \\
\hline Ammoniumchlorid & VWR & Radnor (USA) \\
\hline Ammoniumperoxidsulfat (APS) & Carl Roth & Karlsruhe (D) \\
\hline Ampicllin Natriumsalz & AppliChem & Darmstadt (D) \\
\hline Bacto $^{\mathrm{TM}}$-Agar & Becton Dickinson & Franklin Lakes (USA) \\
\hline Bacto $^{\mathrm{TM}}$-Casaminosäuren (CAS) & Becton Dickinson & Franklin Lakes (USA) \\
\hline Bacto $^{\mathrm{TM}}$-Trypton & Becton Dickinson & Franklin Lakes (USA) \\
\hline Bacto $^{\mathrm{TM}}$-Hefeextrakt & Becton Dickinson & Franklin Lakes (USA) \\
\hline Betain & Merck & Darmstadt (D) \\
\hline Blocking-Reagenz & Roche Diagnostics & Rotkreuz (CHE) \\
\hline Ortho-Borsäure & VWR & Radnor (USA) \\
\hline Bromphenolblau & Carl-Roth & Karlsruhe (D) \\
\hline CDP-Star & Roche Diagnostics & Rotkreuz (CHE) \\
\hline Calciumchlorid & VWR & Radnor (USA) \\
\hline Chelating Fast Flow Sepharose & GE Healthcare & München (D) \\
\hline Chloroform & Carl Roth & Karlsruhe (D) \\
\hline Cobalt(II)-Chlorid & Merck & Darmstadt (D) \\
\hline Coomassie ${ }^{\circledR}$ Brilliantblau Blue R-250 & AppliChem & Darmstadt (D) \\
\hline D-Glucose-Monohydrat & Merck & Darmstadt (D) \\
\hline Dextransulfat & VWR & Radnor (USA) \\
\hline Diethylether & VWR & Radnor (USA) \\
\hline Digoxygenin Desoxyuridintriphosphat (Dig-dUTP) & Roche Diagnostics & Rotkreuz (D) \\
\hline Dimethylsulfoxid (DMSO) & Carl Roth & Karlsruhe (D) \\
\hline Eisen(III)-chlorid-Hexahydrat & Carl Roth & Karlsruhe (D) \\
\hline Eisen(II)-sulfat-Heptahydrat & Carl Roth & Karlsruhe (D) \\
\hline Eisessigsäure & VWR & Radnor (USA) \\
\hline Entwickler & Carestream dental & Atlanta (USA) \\
\hline Ethanol absolut & VWR & Radnor (USA) \\
\hline Ethidiumbromidlösung 0,5 \% & Carl Roth & Darmstadt (D) \\
\hline Ethylendiamin-tetraessigsäure Dinatirumsalz Dihydrat $\left(\mathrm{Na}_{2} \mathrm{EDTA}\right)$ & Carl Roth & Karlsruhe (D) \\
\hline Ethylenglykol & Carl Roth & Karlsruhe (D) \\
\hline Fixierer & Eastman Kodak Company & Rochester (USA) \\
\hline Formaldehyd $37 \%$ & Carl Roth & Karlsruhe (D) \\
\hline
\end{tabular}


Material und Methoden

\begin{tabular}{|c|c|c|}
\hline Chemikalien und Lösungen & Hersteller & Firmensitz \\
\hline Glycerin $87 \%$ & VWR & Radnor (USA) \\
\hline Glycin & AMRESCO & Solon (USA) \\
\hline Guanidinthiocyanat & Carl Roth & Karlsruhe (D) \\
\hline Harnstoff & VWR & Radnor (USA) \\
\hline Imidazol & Carl Roth & Karlsruhe (D) \\
\hline Kaliumacetat & VWR & Radnor (USA) \\
\hline Kaliumchlorid & VWR & Radnor (USA) \\
\hline Kaliumhydrogenphosphat & Merck & Darmstadt (D) \\
\hline di-Kaliumhydrogenphopshat Trihydrat & Carl-Roth & Karlsruhe (D) \\
\hline Kaliumhydroxid & Merck & Darmstadt (D) \\
\hline Kresolrot & Merck & Darmstadt (D) \\
\hline Kupfer(II)-chlorid-Dihydrat & Carl Roth & Karlsruhe (D) \\
\hline N-Lauroylsarcosin $30 \%$ & AppliChem & Darmstadt (D) \\
\hline Maleinsäure & Carl-Roth & Karlsruhe (D) \\
\hline Magermilchpulver & VWR & Radnor (USA) \\
\hline Magnesiumchlorid-Hexahydrat & VWR & Radnor (USA) \\
\hline Magnesiumsulfat-Heptahydrat & VWR & Radnor (USA) \\
\hline Mangan(II)-chlorid-Tetrahydrat & Merck & Darmstadt (D) \\
\hline Methanol & VWR & Radnor (USA) \\
\hline Methylenblau & Merck & Darmstadt (D) \\
\hline Molybdänsäure & Merck & Darmstadt (D) \\
\hline Natriumacetat & VWR & Radnor (USA) \\
\hline Natriumchlorid & Carl Roth & Karlsruhe (D) \\
\hline tri-Natriumcitrat-Dihydrat & VWR & Radnor (USA) \\
\hline di-Natriumhydrogenphosphat-Dihydrat & Merck & Darmstadt (D) \\
\hline Natriumhydroxid & VWR & Radnor (USA) \\
\hline Natriumdodecylsulfat (SDS) & Carl Roth & Karlsruhe (D) \\
\hline Natriummolybdat-Dihydrat & Carl Roth & Karlsruhe (D) \\
\hline Nickel(II)-chlorid-Hexahydrat & Merck & Darmstadt (D) \\
\hline Novobiocin Natriumsalz & Merck & Darmstadt (D) \\
\hline Orange G & AppliChem & Darmstadt (D) \\
\hline Pepton & Oxoid & Basingstoke (GBR) \\
\hline Phenylmethansulfonylfluorid (PMSF) & Carl Roth & Karlsruhe (D) \\
\hline Polyethylenglykol 600 & AppliChem & Darmstadt (D) \\
\hline Polyethylenglykol 3350 & Carl Roth & Karlsruhe (D) \\
\hline Polyethylenglykol 8000 & Merck & Darmstadt (D) \\
\hline Rinderserumalbumin (BSA) & Carl Roth & Karlsruhe (D) \\
\hline Salzsäure $25 \%$ & Carl Roth & Karlsruhe (D) \\
\hline TE-gesättigtes Phenol & Carl Roth & Karlsruhe (D) \\
\hline Tetramethylethylendiamin (TEMED) & Carl Roth & Karlsruhe (D) \\
\hline Tinte & Pelikan & Feusisberg (CHE) \\
\hline Tris(hydroxymethyl)aminomethan (Tris) & AppliChem & Darmstadt (D) \\
\hline Triton X100 & Carl Roth & Karlsruhe (D) \\
\hline Tween® 20 & AppliChem & Darmstadt (D) \\
\hline Uracil & AppliChem & Darmstadt (D) \\
\hline Vitaminlösung & Merck & Darmstadt (D) \\
\hline Xylencyanolblau & AppliChem & Darmstadt (D) \\
\hline Zinksulfat-Heptahydrat & Merck & Darmstadt (D) \\
\hline
\end{tabular}




\subsubsection{Antikörper}

In folgender Tabelle sind alle verwendeten Antikörper aufgeführt.

Tabelle 8: Auflistung verwendeter Antikörper

\begin{tabular}{lll}
\hline Antikörper und Fluorophore & Verwendung & Hersteller \\
\hline Anti-Digoxigenin-AP Fab fragments & 2.AK (1:1000) & Roche Diagnostics, Rotkreuz (CHE) \\
Penta-His ${ }^{\text {TM }}$-Antibody BSA-free & 1.AK (1:4000) & QIAGEN GmbH, Hilden (D) \\
Anti-Mouse IgG Peroxidase & $2 . A K(1: 5000)$ & Sigma-Aldrich, Steinheim (D) \\
Anti-GAB-DNFR2 (DHFR-AK aus Kaninchen) & 1.AK (1:4000) & Davids Biotechnologie, Regensburg (D) \\
Anti-Rabbit lgG Peroxidase & $2 . A K(1: 10000)$ & Merck, Darmstadt (D) \\
Anti-Digoxigenin alkalische Phosphatase & $2 . A K(1: 5000)$ & Roche, Mannheim (D) \\
\hline
\end{tabular}

\subsubsection{Verwendete Kits}

In nachfolgender Tabelle sind die verwendeten Kits aufgelistet.

Tabelle 9: Verwendete Kits

\begin{tabular}{lll}
\hline Assay-Kit & Hersteller & Firmensitz \\
\hline E.Z.N.A. Gel Extraction Kit & VWR & Radnor (USA) \\
E.Z.N.A. Cycle Pure Kit & VWR & Radnor (USA) \\
GenElute ${ }^{T M}$ HP Plasmid Midiprep Kit & Sigma Aldrich/Merck & Darmstadt (D) \\
Pierce ${ }^{T M}$ BCA-Assay Kit & Thermo Fisher Scientific & Wilmington (USA) \\
Rotiß-Lumin & Carl Roth & Karlsruhe (D) \\
Amersham ECL Prime Western Blotting Detection Reagent & GE Healthcare & München (D) \\
\hline
\end{tabular}

\subsubsection{Verwendete Geräte}

Die verwendeten Geräte sind in der folgenden Tabelle mit Herstellerangabe aufgeführt.

Tabelle 10: Verwendete Geräte mit Herstellerangabe

\begin{tabular}{lll}
\hline Geräte & Hersteller & Firmensitz \\
\hline Analysewaage TE124S & Sartorius & Göttingen (D) \\
Autoklav FVS/2 & Fedegari & Albuzzano (ITA) \\
Autoklav SANOclav LaM-201 & Maschinenbau Wolf & Bad Überkingen (D) \\
Elektroblottingapparatur Fastblot B43 & Biometra & Göttingen (D) \\
Einkanalpipette discovery comfort 0,01-2,5 $\mu \mathrm{L}$ & $\mathrm{HTL}$ & Warszawa (P) \\
Einkanalpipette discovery comfort 2-20 $\mu \mathrm{L}$ & $\mathrm{HTL}$ & Warszawa (P) \\
Einkanalpipette discovery comfort 20-200 $\mu \mathrm{L}$ & $\mathrm{HTL}$ & Warszawa (P) \\
Einkanalpipette discovery comfort 100-1000 $\mu \mathrm{L}$ & $\mathrm{HTL}$ & Warszawa (P) \\
Heizblock EPT-130-36-1.5 & Liebisch & Bielefeld (D) \\
Heizblock HCL-BT-1302 & $\mathrm{HLC}$ Biotech & Bovenden (D) \\
Heizblock BT3 & Grant Instruments & Royston (GBR) \\
Magnetrührer Combimag RCT & IKA®-Werke & Staufen (D) \\
Magnetrührer Ikamag® RCT & IKA®-Werke & Staufen (D) \\
Magnetrührer RET basic & IKA®-Werke & Staufen (D) \\
Magnetrührer MAG HS 7 & IKA®-Werke & Staufen (D)
\end{tabular}


Material und Methoden

\begin{tabular}{|c|c|c|}
\hline Geräte & Hersteller & Firmensitz \\
\hline Taumelschüttler REAX 3 & Heidolph Instruments & Schwabach (D) \\
\hline Horizontalschüttler G10 Gyratory & New Brunswick & New York (USA) \\
\hline Hybridisierungsofen HB-1000 Hybridizer & UVP LLC & Upland (USA) \\
\hline Hybridiserungsofen Mini Oven MK II & Hybaid & Ashford (GBR) \\
\hline Hybridiserungsofen OV1000 & Analytic Jena & Jena (D) \\
\hline Inkubator kelvitron $\circledast \mathrm{t}$ & Heraeus & Hanau (D) \\
\hline Kühlbrüter T257 & Rubarth Apparate & Laatzen (D) \\
\hline Kühlbrüter T165 & Rubarth Apparate & Laatzen (D) \\
\hline Mikrowelle R-7180 & Sharp & Osaka (JPN) \\
\hline Mikroskop Axiostar Plus & Carl Zeiss & Göttingen (D) \\
\hline Mikrotiterplattenphotometer Spectramax $® 340 \mathrm{PC}$ & Molecular Devices & Sunnyvale (USA) \\
\hline Mikrotiterplattenschüttler Titramax 1000 & Heidolph Instruments & Schwabach (D) \\
\hline Mehrkanalpipette Discovery Comfort 5-50 $\mu \mathrm{L}$ & HTL Lab Solution & Warschau (PL) \\
\hline Mehrkanalpipette Discovery Comfort 20-200 $\mu \mathrm{L}$ & HTL Lab Solution & Warschau (PL) \\
\hline Minitischzentrifuge NG002R & Nippom Genetics Europe & Düren (D) \\
\hline Minitischzentrifuge SD220VAC & Carl Roth & Karlsruhe (D) \\
\hline PAGE-Gelsystem Minigel Twin (010-130) & Biometra & Göttingen (D) \\
\hline Pipettierhilfe pipetus ${ }^{\circledR}$ & Hirschmann & Eberstadt (D) \\
\hline pH-Meter CG 825 & Schott & Mainz (D) \\
\hline Photometer Specord S600 & Analytik Jena & Jena (D) \\
\hline Rollinkubator RSM 7-12V & Ratek Instruments & Boronia (AUS) \\
\hline Schüttelinkubator innova4300 & New Brunswick & New York (USA) \\
\hline Schüttelinkubator SI 20 (K30-300) & Axon Labortechnik & Kaiserslautern (D) \\
\hline Spannungsgeber Power PAC 300 & Bio-Rad & Hercules (USA) \\
\hline Spannungsgeber E835 & Consort Instruments & Tumhout (BEL) \\
\hline Thermocycler GenAmp® PCR-System 2400 & Applied Biosystems & Foster City (USA) \\
\hline Thermocycler GenAmp® PCR-System 2720 & Applied Biosystems & Foster City (USA) \\
\hline Thermocycler GenAmp® PCR-System 9700 & Applied Biosystems & Foster City (USA) \\
\hline Thermocycler Mastercycler gradient & Eppendorf AG & Hamburg (D) \\
\hline Thermocycler Veriti ${ }^{\mathrm{TM}}$ 96-Well Thermal Cycler & Applied Biosystems & Foster City (USA) \\
\hline Tischwaage PM4800 DeltaRange $®$ & Mettler-Toledo & Columbus (USA) \\
\hline Tischwaage PB300 & Mettler-Toledo & Columbus (USA) \\
\hline Tischzentrifuge 5424 & Eppendorf & Hamburg (D) \\
\hline Tischzentrifuge Biofuge 13 & Heraeus & Hanau (D) \\
\hline Röntgenkassette Rotilabo® & Carl Roth & Karlsruhe (D) \\
\hline UV-Stratalinker ${ }^{\mathrm{TM}} 1800$ & Stratagene & La Jolla (USA) \\
\hline UV-Tisch UVT-28 ME & Herolab & Wiesloch (D) \\
\hline UV-Tisch Darkroom Hood RH-5.1 & Herolab & Wiesloch (D) \\
\hline UV-Vis Spektralphotometer Specord S 600 & Analytik Jena & Jena (D) \\
\hline UV-Vis Spektralphotometer Nanodrop 2000c & Thermo Fisher Scientific & Wilmington (USA) \\
\hline Vortexer VF2 & IKA®-Werke & Staufen (D) \\
\hline Wasserbad EM/3 & Julabo Labortechnik & Seelbach (D) \\
\hline Zentrifuge $5810 \mathrm{R}$ & Eppendorf & Hamburg (D) \\
\hline Zentrifuge Sorvall ${ }^{T M}$ RC 6 Plus & Thermo Fisher Scientific & Wilmington (USA) \\
\hline
\end{tabular}




\subsubsection{Enzyme}

Für diese Arbeit wurden verschiedene Enzyme verwendet. Sie sind in der nachfolgenden Tabelle aufgeführt.

Tabelle 11: Verwendete Polymerasen und Ligase

\begin{tabular}{lll}
\hline Enzyme & Hersteller & Firmensitz \\
\hline Phusion high-Fidelity DNA-Polymerase & Thermo Fisher Scientific & Wilmington (USA) \\
Restriktionsenzyme & Thermo Fisher Scientific & Wilmington (USA) \\
T4-DNA-Ligase & New England Biolabs & Ipswich (USA) \\
Taq-DNA-Polymerase & Eigenisolat & \\
Taq-DNA-Polymerase & New England Biolabs & Ipswich (USA) \\
Velocity DNA-Polymerase & Bioline & London (UK) \\
\hline
\end{tabular}

\subsubsection{Größenstandards}

In nachfolgender Tabelle sind die Größenstandards für Agarosegele und SDS-Gele aufgelistet.

Tabelle 12: Verwendete Größenstandards

\begin{tabular}{lll}
\hline Größenstandards & Hersteller & Firmensitz \\
\hline GeneRuler $^{\mathrm{TM}} 100$ bp Plus DNA Ladder (SM0321) & Thermo Fisher Scientific & Wilmington (USA) \\
GeneRuler ${ }^{\mathrm{TM}} 1 \mathrm{~kb}$ DNA Ladder (SM0312) & Thermo Fisher Scientific & Wilmington (USA) \\
GeneRuler ${ }^{\mathrm{TM}} 1 \mathrm{~kb}$ plus DNA Ladder (10787018) & Thermo Fisher Scientific & Wilmington (USA) \\
PageRuler $^{\mathrm{TM}}$ Unstained Low Range Protein Ladder (26632) & Thermo Fisher Scientific & Wilmington (USA) \\
PageRuler $^{\mathrm{TM}}$ Prestained Protein Ladder (26616) & Thermo Fisher Scientific & Wilmington (USA) \\
\hline
\end{tabular}




\subsubsection{Primer}

Die in dieser Arbeit verwendeten Primer wurden von der Firma Merck (Sigma-Aldrich) bezogen und sind in folgender Tabelle aufgelistet. Die lyophilisierten Primer wurden zu einer Stammlösung mit Bidest von $100 \mu \mathrm{M}$ gelöst und für die $20 \mu \mathrm{M}$ Arbeitslösung mit Bidest verdünnt. Die Lagerung der Primer erfolgte bei $-20^{\circ} \mathrm{C}$.

Tabelle 13: Verwendete Primer für die Erstellung der Plasmide

\begin{tabular}{|c|c|}
\hline Name & $5^{\prime}-3^{\prime}$ \\
\hline Oligo-His-Tag_for & CATGGGCCACCACCACCACCACCACGC \\
\hline Oligo-His-Tag_rev & CATGGCGTGGTGGTGGTGGTGGTGGCC \\
\hline Primer-CBD-for & GCATCCATGGCAAATACACCGGTATCAGGCAATTTG \\
\hline Primer-CBD-rev & GCATCCATGGCTACTACACTGCCACCGGGTTCTTTACCC \\
\hline Oligo-BBP-for & CATGGGCGGCCTCGTCGAGGTGATGAAGAACTTCAACGAGATCACTGCTGC \\
\hline Oligo-BBP-rev & CATGGCAGCAGTGATCTCGTTGAAGTTCTTCATCACCTCGACGAGGCCGCC \\
\hline pSD-Seq-dhfr-for & GTGATGGCGGTCACACCC \\
\hline rev-Oligo-psD & TGCGGGCCTCTTCGCTATTACGCC \\
\hline neu-pSD-MB-OH-for & AGATTAGTATTGACAATATCTAGTTGTAATGGCATCCGAA \\
\hline pOHMB-for & ACAGCACGGCCTCGACCGAC \\
\hline $\mathrm{pSD}-\mathrm{MB}-\mathrm{OH}-\mathrm{for}$ & GTTCGACGTGGACGAGCCGG \\
\hline M13-20 for & GTAAAACGACGGCCAGTG \\
\hline T3 rev & AATTAACCCTCACTAAAGGG \\
\hline pSD_empty_for & GCCGACCACGTACTGCACGT \\
\hline HVO 0699 His NheI for & GATGCCCATGGGCCACCACCACCACCACCACGCTAGCGGCATGAAGTACAGCGGATGGCCT \\
\hline HVO_0699_Kpn'̄_rev & CGAATTGGGTACCGTTACTCTTCGTCGCCGCTGC \\
\hline HVO_0136_His_NheI_for & GATGCCCATGGGCCACCACCACCACCACCACGCTAGCGGCATGAGCGACGACGAGAACGAG \\
\hline HVO_0136_Kpn'̄_rev ${ }^{-}$ & CGAATTGGGTACCGCTTACTGGATGTGACCTTCG \\
\hline HVO_1678_His_NheI_for & GATGCCCATGGGCCACCACCACCACCACCACGCTAGCGGCATGGACTACGACGACCAACTG \\
\hline $\mathrm{HVO}_{-}^{-} 1678{ }^{-} \mathrm{Kpn} \overline{\mathrm{I}} \_r e v-$ & CGAATTGGGTACCGTTACAGATCGGGAATCGCTG \\
\hline HVO_2242_His_NheI_for & GATGCCCATGGGCCACCACCACCACCACCACGCTAGCGAGTATCAGACTGCGCTCGACCGA \\
\hline HVO_2242_KpnI__rev & CGAATTGGGTACCTCAGGCGAGTCGCGCGAACGC \\
\hline NheI_HVO_0569_for & CCACCACGCTAGCATGGTACGGAAC \\
\hline KpnI_HVO_0569_rev & CGAATTGGGTACCTCAGACGGCGAA \\
\hline NheI HVO 0359 for & CCACCACGCTAGCATGAGCGACAAA \\
\hline $\mathrm{KpnI}_{-}^{-} \mathrm{HVO}_{-}^{-} 0359_{-}^{-} \mathrm{reV}$ & CGAATTGGGTACCTTATCGCTCGTT \\
\hline NheI_HVO_B0053_for & CCACCACGCTAGCATGGCCTGCGCA \\
\hline KpnI_HVO_B0053_rev & CGAATTGGGTACCTCAGTCCTCGAC \\
\hline NcoIHis_A0637_KpnI_for & GATGCCCATGGGCCACCACCACCACCACCACGCCAGTGAAAATCAAGGGCGTCG \\
\hline NCOIHis_A0637_KpnI_rev & CGAATTGGGTACCTTACTGAATGTGGCCTTCGCGCCGAA \\
\hline NcoIH0136ohne3UTRKpnI_for & GATGCCCATGGGCCACCACCACCACCACCACGCCAGCGACGACGAGAACGAGAG \\
\hline NcoIH0136ohne3UTRKpnI_rev & GAATTGGGTACCTTACTGGATGTGACCTTCGCGG \\
\hline NcoIH0136mit3UTRKpnI for & GATGCCCATGGGCCACCACCACCACCACCACGCCAGCGACGACGAGAACGAGAG \\
\hline NcoIH0136mit3UTRKpnI_rev & GAATTGGGTACCGGCGAGATGAAAAGGGCACAGG \\
\hline NCOI_N_H1677_for & CAGTGATGCCCATGGGCCACCACCACCACCACCACGTTGAAGCGTTCGTC \\
\hline KpnI_-1 $\overline{6} 77 \_r e \bar{v}$ & GAATTGGGTACCCTACTCGAACTGCTTGAGCGTC \\
\hline NCoIH_0359_for & CAGTGATGCCCATGGGCCACCACCACCACCACCACAGCGACAAACCCCAC \\
\hline HVO_0 $\overline{3} 59$ _rev & TTATCGCTCGTTGACTTCGAGCAC \\
\hline NcoI 1677 for & TGATGCCCATGGCAATGGTTGAAGCGTTCG \\
\hline KpnI_C_H1 677 _rev & GAATTGGGTACCTCTTAGTGGTGGTGGTGGTGGTGGCTAGCCTCGAACTGCTTG \\
\hline NCOI_His_0117_for & TGATGCCCATGGGCCACCACCACCACCACCACGCCACTTCGCGCCTCCTT \\
\hline KpnI_-011 $\mathrm{rev}^{-}$ & GAATTGGGTACCTCAGTCGATGTAATCGAG \\
\hline
\end{tabular}




\begin{tabular}{|c|c|}
\hline Name & $5^{\prime}-3^{\prime}$ \\
\hline His_1901_for & GCCACCACCACCACCACCACGCCGTGACGAAAAACCCACAACAACC \\
\hline 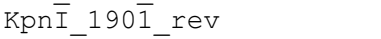 & GAATTGGGTACCTCACTTGAGCGTCCCGAT \\
\hline H1677_template_for & CAAGCCCGCCGACCCCGAGCA \\
\hline H1677_template_rev & CGGCGTCCCCGGATGTCGCGG \\
\hline His_0359_NcoI_new_for & GTGATGCCCATGGGCCACCACCACCACCACCACAGCGACAAACCCCACCA \\
\hline $\mathrm{HVO}_{-}^{-} 0359_{-}^{-} \mathrm{NCOI}_{-}^{-} \mathrm{rev}^{-}$ & TAGGGCGAATTGGGTACCCCATGGTTATCGCTCGTTGACT \\
\hline NdeI_His_1901_for & ACTAGGACCATATGCACCACCACCACCACCACGTGACGAAAAACCCACAA \\
\hline $1901^{-}$Kpn $\bar{I} \_r e v-$ & GGCGAATTGGGTACCTCACTTGAGCGTCCC \\
\hline NcoI_His_1946_KpnI_for & TGATGCCCATGGGCCACCACCACCACCACCACGCTAGCGGCATGTCGGAAGTCTGCTCGA \\
\hline NcoI_His_1946_KpnI_rev & CGAATTGGGTACCGTCACGCGACGTTGAACCCC \\
\hline NCoI_His_1934_KpnI_for & GATGCCCATGGGCCACCACCACCACCACCACGCTAGCGGCATGCCACACGTCGCCACCGT \\
\hline NCOI_His_1934_KpnI_rev & CGAATTGGGTACCGTCAGTCGTCCCACGCCGCC \\
\hline NCoI_His_2706_KpnI_for & GATGCCCATGGGCCACCACCACCACCACCACGCTAGCGGCATGATAGACGAGACCATCGA \\
\hline NCOI_His_2706_KpnI_rev & CGAATTGGGTACCGTCAGAACTCGATGACGCCC \\
\hline NcoI_His_2300_KpnI_for & GATGCCCATGGGCCACCACCACCACCACCACGCTAGCGGCATGGCGAAAGAGCAGAAGCA \\
\hline NcoI_His_2300_KpnI_rev & CGAATTGGGTACCGTTAGACGATCTTTCGCTGG \\
\hline NheI_1963_KpnI_for & ACCACCACGCTAGCGGCATGTCCGACACTGATT \\
\hline NheI_1963_KpnI_rev & CGAATTGGGTACCGCTATTTGCCCCAGAAGGGG \\
\hline NCoI_1333_KpnI_for & GATGCCCATGGGCCACCACCACCACCACCACGCTAGCGGCATGCCAGACGGCGAGGCCGC \\
\hline NCOI_1333_KpnI_rev & CGAATTGGGTACCGTCAGTCCCAGAACGACTGG \\
\hline NheI_1901_KpnI_for & ACCACCACGCTAGCGGCATGGTGACGAAAAACC \\
\hline NheI_1901_KpnI_rev & CGAATTGGGTACCGTCACTTGAGCGTCCCGATA \\
\hline NcoI_His_0966_KpnI_for & GATGCCCATGGGCCACCACCACCACCACCACGCTAGCGGCATGGACGACCGCGTA \\
\hline NcoI_His_0966_KpnI_rev & CGAATTGGGTACCGCTACGGTTCGGCCCGCGGC \\
\hline NCOI_His_2724_KpnI_for & GATGCCCATGGGCCACCACCACCACCACCACGCTAGCGGCATGGAAATCGAAATC \\
\hline NCOI_His_2724_KpnI_rev & CGAATTGGGTACCGTCACTCCACCAGCTGAATC \\
\hline NcoI_His_0350_KpnI_for & GATGCCCATGGGCCACCACCACCACCACCACGCTAGCGGCATGACTGATACCGAC \\
\hline NCOI_His_0350_KpnI_rev & CGAATTGGGTACCGTCAGTCGTCGGACGGTTCG \\
\hline NCOI_His_0349_KpnI_for & GATGCCCATGGGCCACCACCACCACCACCACGCTAGCGGCATGTCAATGCAGACA \\
\hline NCOI_His_0349_KpnI_rev & CGAATTGGGTACCGTCAGTCATCGGATTCGACC \\
\hline NCOI_His_0347_KpnI_for & GATGCCCATGGGCCACCACCACCACCACCACGCTAGCGGCATGAACCGACAAGCG \\
\hline NCOI_His_0347_KpnI_rev & CGAATTGGGTACCGTTAGTCGTCCGCGGGTGCG \\
\hline NCOI_His_0874_KpnI_for & GATGCCCATGGGCCACCACCACCACCACCACGCTAGCGGCATGAGCTCCGTAGAT \\
\hline NCOI_His_0874_KpnI_rev & CGAATTGGGTACCGTTACTTGAAGCGGAACGTT \\
\hline NCOI_H0349_KpnI_for & TGATGCCCATGGGCCACCACCACCACCACCACGGCTCAATGCAGACACCCAAAGAAA \\
\hline NCOI_H0349_KpnI_rev & GAATTGGGTACCGTCAGTCATCGGATTCGACCCCCG \\
\hline NCOI_H1042_KpnI_for & GATGCCCATGGGCCACCACCACCACCACCACGCTAGCGGCGAACTGCGGGTCATCGA \\
\hline NCOI_H1042_KpnI_rev & CGAATTGGGTACCGTTACGCGTCGATACCGGCGCGG \\
\hline SDM_Ser46Ala_mitte_for & CACATCAGCGAGGTCGCCGCCGGATGGATCAAGAACGT \\
\hline SDM_Ser46Ala_mitte_rev & ACGTTCTTGATCCATCCGGCGGCGACCTCGCTGATGTG \\
\hline SDM_Ser46Asp_mitte_for & CACATCAGCGAGGTCGCCGACGGATGGATCAAGAACGT \\
\hline SDM_Ser46Asp_mitte_rev & ACGTTCTTGATCCATCCGTCGGCGACCTCGCTGATGTG \\
\hline NCOI_H0348_KpnI_for & GATGCCCATGGGCCACCACCACCACCACCACGCTAGCGGCGCTCAGGCACAGCGAGA \\
\hline NcOI_H0348_KpnI_rev & CGAATTGGGTACCGTTAGACCGCGTCCTTCAGTTCG \\
\hline NCOI_H2781_KpnI_for & GATGCCCATGGGCCACCACCACCACCACCACGCTAGCGGCGTAAACGACTTCCAGGTCGA \\
\hline NcOI_H2781_KpnI_rev & CGAATTGGGTACCGTTTAAACTTACAGTGCGACCTTCTCTTC \\
\hline NcoI0699MssikpnI for & GATGCCCATGGATGAAGTACAGCGGATGGCCTGACCCCG \\
\hline NcoI0699MssiKpnI rev & CGAATTGGGTACCGTTTAAACTTACTCTTCGTCGCCGCT \\
\hline NcOI_H0346_KpnI_for & GATGCCCATGGGCCACCACCACCACCACCACGCTAGCGGCGTAGACGTAAGCCAACACAA \\
\hline NCOI_H0346_KpnI_rev & CGAATTGGGTACCGTCATTCAATCACCAGTCGGTATACGACT \\
\hline
\end{tabular}


Die Primer der verwendeten Deletionsmutanten und Sonden sind in der nachfolgenden Tabelle aufgelistet.

Tabelle 14: Primer zur Erstellung und Überprüfung von Deletionen

\begin{tabular}{|c|c|}
\hline Name & $5^{\prime}-3^{\prime}$ \\
\hline 0136 Primer 1 for & CCGACGCGCCGCCGACGCTGT \\
\hline $0136^{-}$Primer 2 rev & GCGGAGCTGGTCGGCAAGGTCTCGGCGGCTCTCGTT \\
\hline 0136_Primer 3 for & AGCCGCCGAGACCTTGCCGACCAGCTCCGCCGCGAA \\
\hline 0136_Primer 4 rev & GACGACCTGTCCCTTGTCGTG \\
\hline 0699_Primer 1 for & ACACCAAAACCCACCACAAGGTCGATATCTATG \\
\hline 0699-Primer 2 rev & TTCGCGGTGGTACTCGAGTTCGCCGGGGTCAGGCCA \\
\hline 0699_Primer 3 for & GACCCCGGCGAACTCGAGTACCACCGCGAACGCAGC \\
\hline 0699_Primer 4 rev & GGGTCAGCTCGGCGACGCCC \\
\hline 1678_Primer 1 for & TTCTCGGTTCAGTCGGCTTGCGG \\
\hline 1678_Primer $2 \mathrm{rev}$ & GAGCGCGCCGCACGCCGAGAGCGCGCGGTCCAGTTG \\
\hline $1678^{-}$Primer 3 for & GACCGCGCGCTCTCGGCGTGCGGCGCGCTCTCAGCG \\
\hline 1678_Primer $4 \mathrm{rev}$ & CGGTCGGCCTCGCCGCCGCCG \\
\hline 2242_Primer 1 for & CGTGATTTCGTTCGGCAGCCCG \\
\hline 2242_Primer 2 rev & GAGCGACCCGCTCGTGTTGAGCGCTCGGTCGAGCGC \\
\hline 2242-Primer 3 for & GACCGAGCGCTCAACACGAGCGGGTCGCTCGCGTTC \\
\hline 2242_Primer 4 rev & CGGCTACAAGGCGCTCGACTCC \\
\hline A0637_Primer 1 for & GTCCGCTGTTCTGGGAGACGACGGTAACCG \\
\hline A0637_Primer 2 rev & CCGAAGCTGGTCCGCCATTCGAAGGTTTCGACGCCC \\
\hline A0637_Primer 3 for & CGAAACCTTCGAATGGCGGACCAGCTTCGGCGCGAA \\
\hline A0637_Primer 4 rev & GGGAACCAAGACGGCCGACGACGC \\
\hline 1678_Primer neu 2 rev & TCGTTTTTACAGGTAGTCCATGCGCGGCAGTACG \\
\hline 1678_Primer neu 3 for & GCGCATGGACTACCTGTAAAAACGAACGTCCGGCGG \\
\hline 2242_Primer neu 2 rev & GACCGATTCAGGCCATAGGGGTTCGAGTGTCTGGC \\
\hline 2242_Primer neu 3 for & CGAACCCCTATGGCCTGAATCGGTCGCACGCGTCG \\
\hline A0637_Primer neu 2 rev & TTACTGAATGTGGCCTTCATTTGACGAGGTCATCCACGATTCCCCTACAACAC \\
\hline A0637_Primer neu 3 for & ATGACCTCGTCAAATGAAGGCCACATTCAGTAATCATTTTCTCCGAAAGGAGAG \\
\hline P5 HVO_2242_for & CAGTCGCCCGGCTCAGTTCAG \\
\hline P6 HVO_2242_rev & TATTCGGGCATGATCCGAGCC \\
\hline P5 HVO_1678_for & CATCGCTCCGGTGATTCCTTTC \\
\hline P6 HVO_1678_rev & GAGAAGGTAACCCAAAGCGAGGTCT \\
\hline Primer Sonde A0637_for & ACCCAACGACGAACCGGCGA \\
\hline Primer Sonde A0637_rev & CACGTGCGGTACTTCATGCG \\
\hline Primer Sonde 2242 for & GGACGCGCTCTCGCGGACGC \\
\hline Primer Sonde 2242_rev & CTGCGCGCCGGGCACGAAGA \\
\hline Primer Sonde B0053 for & TGAACATCACCGGAACGACC \\
\hline Primer Sonde B0053_rev & CTCCGAGGTCGTCGAGCAGC \\
\hline Primer Sonde 0569 for & CGTTCGCCCAGCGAGACACC \\
\hline Primer Sonde 0569 _rev & GCCGCGTAGGCGTCGGCCAT \\
\hline Primer Sonde 0359 for & TCAACAAGATGGACGTCGTC \\
\hline Primer Sonde 0359 rev & АCTTCCTCGTGGTGCATCTC \\
\hline P1 HVO_B0053 & GACGCTGGCCGACCGCTATC \\
\hline P2 HVO_B0053 & GGCGTCGTGAAGCGTTCGGAGCGCTTCGAGTTCTGC \\
\hline P3 HVO_B0053 & CTCGAAGCGCTCCGAACGCTTCACGACGCCTTCCC \\
\hline P4 HVO_B0053 & ACGACGCTCCGCCAGACTC \\
\hline P1 HVO0569 & CAGCCGCTCAGTGGATGTGC \\
\hline P2 HVO0570 & GACGGCGAACTCGTCGGCGACGTTCCGTACCATGC \\
\hline P3 HVO0571 & GTACGGAACGTCGCCGACGAGTTCGCCGTCTGAGC \\
\hline P4 HVO0572 & CGCTCCCGGCGATGTACCAC \\
\hline P1 HVO_0359 & GGTTGAGGGAATCCGCAACG \\
\hline P2 HVO_0359 & GCATCGTTATCGCTCGCTCATTGGTGTGGTCACGC \\
\hline P3 $\mathrm{HVO}_{-} 0359$ & ACCACACCAATGAGCGAGCGATAACGATGCAACAGGC \\
\hline P4 HVO-0359 & GTTCCGTCGGGCGATTCTG \\
\hline
\end{tabular}




\begin{tabular}{|c|c|}
\hline Name & $5^{\prime}-3^{\prime}$ \\
\hline 2706_Primer1 & CCCATCTGCGAGGCGGGCCAGC \\
\hline 2706_Primer2 & TCAGAACTCGATGACGGTCTCGTCTATCATACGAGAACGTCGCCGTATCG \\
\hline 2706 Primer3 & ATGATAGACGAGACC GTCATCGAGTTCTGAGCGGGCGGCG \\
\hline 2706_Primer4 & TCGGTTCCTCGTCAGTGACCGCGCC \\
\hline HVO_1333 Primer up1 for & ACGCGGGCGAGTCGCTGCC \\
\hline $\mathrm{HVO}_{-} 1333$ Primer $2 \mathrm{rev}$ & GTCAGTCCCAGAAGCCGTCTGGCATCGCCCGAGGTTACG \\
\hline HVO_1333 Primer 3 for & ATGCCAGACGGCTTCTGGGACTGACGGGGTGGATTCCGGTT \\
\hline $\mathrm{HVO}_{-} 1333$ Primer down4 rev & GTCGCTCGGCTCCGACATCCTCG \\
\hline 1934_Primer1 & CAGCTGCGAGACAGCGCGACGACG \\
\hline $1934^{-}$Primer2 & GTCGTCCCACGCGCGACGTGTGGCATATCGTGACTTACGGC \\
\hline 1934_Primer3 & GCCACACGTCGCGCGTGGGACGACTGAGTCGGGAGTGC \\
\hline 1934_Primer4 & CGGTTTCGGGGCTCCGGTCGAGG \\
\hline Sonde 1333 for & ACСCTTCACCCGCTCTCGAACGGCGTAGC \\
\hline Sonde 1333 rev & GCCGTCTGGCATCGCCCGAGGTTACG \\
\hline Sonde 0966 for & CACGAACGGGGGCGCACCGGTC \\
\hline Sonde $0966 \mathrm{rev}$ & GCGGTCGTCCATGCGAGAACTACGGG \\
\hline Sonde 2706 for & CCCATCTGCGAGGCGGGCCAGC \\
\hline Sonde $2706 \mathrm{rev}$ & ATACGAGAACGTCGCCGTATCG \\
\hline Sonde 1934 for & GCGTGGGACGACTGAGTCGGGAGTGC \\
\hline Sonde 1934 rev & CGGTTTCGGGGCTCCGGTCGAGG \\
\hline
\end{tabular}

\subsubsection{Plasmide}

Die in-silico Planung der Plasmide erfolgte mittels Clone Manager. In nachfolgender Tabelle sind die in dieser Arbeit verwendeten Plasmide aufgelistet.

Tabelle 15: Plasmide für die Überexpression und Deletion einzelner Gene

\begin{tabular}{|c|c|c|}
\hline Konstrukt & Gen & Beschreibung und Quelle \\
\hline pSD1/R1-6 & & $\begin{array}{l}\text { Shuttle-Vektor mit synthetischem, konstitutiven Promotor PrP16, Selektionsgene } \\
\text { für Novobiocin und Ampicillin, Replikationsursprung für E. coli sowie für } H \text {. } \\
\text { volcanii, Gen HVO_1279 mit nativer 3'-UTR (Stefan Danner) }\end{array}$ \\
\hline pWL-CBD-Hq1489 & & $\begin{array}{l}\text { Shuttle-Vektor mit Cellulosebindedomäne aus Clostridium thermocellum (Plavner } \\
\text { and Eichler, 2008) }\end{array}$ \\
\hline pSDBBP1279 & $D H F R$ & $\begin{array}{l}\text { Plasmid mit starkem, konstitutiven Promotor, BBP-Tag und Gen HVO_1279 } \\
\text { (diese Arbeit) }\end{array}$ \\
\hline pSDH1946 & alF1 & $\begin{array}{l}\text { Plasmid mit starkem, konstitutiven Promotor, 6xHis-Tag und Gen HVO_1946 } \\
\text { (diese Arbeit) }\end{array}$ \\
\hline pSDH0136-3‘-UTR & alF1A-1 & $\begin{array}{l}\text { Plasmid mit starkem, konstitutiven Promotor, 6xHis-Tag und Gen HVO_0136 } \\
\text { mit 3'-UTR (diese Arbeit) }\end{array}$ \\
\hline pSDHA0637 & alF1A-2 & $\begin{array}{l}\text { Plasmid mit starkem, konstitutiven Promotor, 6xHis-Tag und Gen HVO_A0637 } \\
\text { (diese Arbeit) }\end{array}$ \\
\hline pSDH0699 & alF2 $\alpha$ & $\begin{array}{l}\text { Plasmid mit starkem, konstitutiven Promotor, 6xHis-Tag und Gen HVO_0699 } \\
\text { (diese Arbeit) }\end{array}$ \\
\hline pSDH1678 & alF $2 \beta-1$ & $\begin{array}{l}\text { Plasmid mit starkem, konstitutiven Promotor, 6xHis-Tag und Gen HVO_1678 } \\
\text { (diese Arbeit) }\end{array}$ \\
\hline pSDH2242 & alF2 $2 \beta-2$ & $\begin{array}{l}\text { Plasmid mit starkem, konstitutiven Promotor, 6xHis-Tag und Gen HVO_2242 } \\
\text { (diese Arbeit) }\end{array}$ \\
\hline pSDH1901 & alF2y & $\begin{array}{l}\text { Plasmid mit starkem, konstitutiven Promotor, 6xHis-Tag und Gen HVO_1901 } \\
\text { (diese Arbeit) }\end{array}$ \\
\hline pSDH0966 & alF2B & $\begin{array}{l}\text { Plasmid mit starkem, konstitutiven Promotor, 6xHis-Tag und Gen HVO_0966 } \\
\text { (diese Arbeit) }\end{array}$ \\
\hline pSDH1934 & alF2B $\alpha(a I F 2 / 5 B \alpha)$ & $\begin{array}{l}\text { Plasmid mit starkem, konstitutiven Promotor, 6xHis-Tag und Gen HVO_1934 } \\
\text { (diese Arbeit) }\end{array}$ \\
\hline
\end{tabular}




\begin{tabular}{|c|c|c|}
\hline pSDH2706 & alF2B $\delta$ & $\begin{array}{l}\text { Plasmid mit starkem, konstitutiven Promotor, 6xHis-Tag und Gen HVO_2706 } \\
\text { (diese Arbeit) }\end{array}$ \\
\hline pSDH1333 & elF4A homolog & $\begin{array}{l}\text { Plasmid mit starkem, konstitutiven Promotor, 6xHis-Tag und Gen HVO_1333 } \\
\text { (diese Arbeit) }\end{array}$ \\
\hline pSDH2300 & alF5A & $\begin{array}{l}\text { Plasmid mit starkem, konstitutiven Promotor, 6xHis-Tag und Gen HVO_2300 } \\
\text { (diese Arbeit) }\end{array}$ \\
\hline pSDH1963 & alF5B & $\begin{array}{l}\text { Plasmid mit starkem, konstitutiven Promotor, 6xHis-Tag und Gen HVO_1963 } \\
\text { (diese Arbeit) }\end{array}$ \\
\hline pSDH0117 & alF6 & $\begin{array}{l}\text { Plasmid mit starkem, konstitutiven Promotor, 6xHis-Tag und Gen HVO_0117 } \\
\text { (diese Arbeit) }\end{array}$ \\
\hline pSDH1677 & Zinkfinger & $\begin{array}{l}\text { Plasmid mit starkem, konstitutiven Promotor, 6xHis-Tag und Gen HVO_1677 } \\
\text { (diese Arbeit) }\end{array}$ \\
\hline pSDH0569 & Rio2 & $\begin{array}{l}\text { Plasmid mit starkem, konstitutiven Promotor, 6xHis-Tag und Gen HVO_0569 } \\
\text { (diese Arbeit) }\end{array}$ \\
\hline pSD-P & $\begin{array}{l}\text { Leerplasmid ohne } \\
\text { Promotor }\end{array}$ & $\begin{array}{l}\text { pSD1/R1-6 ohne Promotor und ohne Gen HVO_1279 mit nativer 3'-UTR } \\
\text { (diese Arbeit) }\end{array}$ \\
\hline $\mathrm{pSD}+\mathrm{P}$ & $\begin{array}{l}\text { Leerplasmid mit Pro- } \\
\text { motor }\end{array}$ & $\begin{array}{l}\text { pSD1/R1-6 ohne Gen HVO_1279 mit nativer 3'-UTR } \\
\text { (diese Arbeit) }\end{array}$ \\
\hline pSDH1279 & DHFR & $\begin{array}{l}\text { Plasmid mit starkem, konstitutiven Promotor, 6xHis-Tag und Gen HVO_1279 } \\
\text { (diese Arbeit) }\end{array}$ \\
\hline pSDH0349 & rроA1 & $\begin{array}{l}\text { Plasmid mit starkem, konstitutiven Promotor, 6xHis-Tag und Gen HVO_0349 } \\
\text { (diese Arbeit) }\end{array}$ \\
\hline pSDH0350 & гроA2 & $\begin{array}{l}\text { Plasmid mit starkem, konstitutiven Promotor, 6xHis-Tag und Gen HVO_0350 } \\
\text { (diese Arbeit) }\end{array}$ \\
\hline pSDH0348 & rpoB1 & $\begin{array}{l}\text { Plasmid mit starkem, konstitutiven Promotor, 6xHis-Tag und Gen HVO_0348 } \\
\text { (diese Arbeit) }\end{array}$ \\
\hline pSDH0347 & rров2 & $\begin{array}{l}\text { Plasmid mit starkem, konstitutiven Promotor, 6xHis-Tag und Gen HVO_0347 } \\
\text { (diese Arbeit) }\end{array}$ \\
\hline pSDH1042 & $r p o L$ & $\begin{array}{l}\text { Plasmid mit starkem, konstitutiven Promotor, 6xHis-Tag und Gen HVO_1042 } \\
\text { (diese Arbeit) }\end{array}$ \\
\hline pSDH2781 & $r p o D$ & $\begin{array}{l}\text { Plasmid mit starkem, konstitutiven Promotor, 6xHis-Tag und Gen HVO_2781 } \\
\text { (diese Arbeit) }\end{array}$ \\
\hline pSDH0346 & rpoH & $\begin{array}{l}\text { Plasmid mit starkem, konstitutiven Promotor, 6xHis-Tag und Gen HVO_0346 } \\
\text { (diese Arbeit) }\end{array}$ \\
\hline pSDH0699Ala46 & 1.SDM alF2a & $\begin{array}{l}\text { Plasmid mit starkem, konstitutiven Promotor, } 6 x \text { His-Tag und Gen HVO_0699, mit } \\
\text { Punktmutation für Aminosäureaustausch an Position } 46 \text { Serin zu Alanin (diese Ar- } \\
\text { beit) }\end{array}$ \\
\hline pSDH0699Asp46 & 2.SDM alF2 $\alpha$ & $\begin{array}{l}\text { Plasmid mit starkem, konstitutiven Promotor, 6xHis-Tag und Gen HVO_0699, mit } \\
\text { Punktmutation für Aminosäureaustausch an Position } 46 \text { Serin zu Asparaginsäure } \\
\text { (diese Arbeit) }\end{array}$ \\
\hline pMH101 & & $\begin{array}{l}\text { Vektor mit Multiple Cloning Site zur Integration von Deletionskassetten mit pyrE- } \\
\text { Gen zur Selektion im H26 und Ampicillin Selektionsgen für E. coli (Hammelmann } \\
\text { and Soppa, 2008) }\end{array}$ \\
\hline pMH101_ $\Delta 1678$ & alF2 $2 \beta-1$ & Plasmid zur Deletion von HVO_1678 (Katrin Gäbel) \\
\hline pMH101_ $\Delta 2242$ & alF2 $\beta-2$ & Plasmid zur Deletion von HVO_2242 (Katrin Gäbel) \\
\hline pMH101__A0637 & alF1-A1 & Plasmid zur Deletion von HVO_A0637 (Katrin Gäbel) \\
\hline
\end{tabular}




\subsubsection{Mikroorganismen}

Alle Klonierungsarbeiten für die Erstellung der Plasmide erfolgten im E. coli Stamm XL1blueMRF‘. Die Konstrukte wurden anschließend sequenziert und mit entsprechendem Selektionsmarker in $H$. volcanii transformiert. Die verwendeten Mikroorganismen sind in der folgenden Tabelle aufgelistet.

Tabelle 16: Verwendete Mikroorganismen

\begin{tabular}{|c|c|c|}
\hline Name & Genotyp & Quelle \\
\hline Escherichia coli: XL1 blue & $\begin{array}{l}\Delta(m c r A) 183 ; \Delta\left(m c r C B^{\prime}-\text { hsdSMR-mrr)173; recA1; endA1; gyrA96; thi- }\right. \\
\text { 1; hsdR17; supE44; relA1 lac [F'proAB+lacZLM15 Tn10 (TetR)] }\end{array}$ & $\begin{array}{l}\text { Stratagene Europe, } \\
\text { Amsterdam (NLD) }\end{array}$ \\
\hline Haloferax volcanii: H26 & $\triangle$ pyrE2 & Allers et al. 2004 \\
\hline $\mathrm{H} 26 \Delta 1279$ & $\Delta p y r E 2 \Delta d h f r$ & Gäbel et al. 2013 \\
\hline $\mathrm{H} 26 \Delta 1279 \Delta 0136$ & $\Delta p y r E 2 \Delta d h f r \Delta 0136$ & Gäbel et al. 2013 \\
\hline $\mathrm{H} 26 \Delta 1279 \Delta 0699$ & $\Delta p y r E 2 \Delta d h f r \Delta 0699$ & Gäbel et al. 2013 \\
\hline $\mathrm{H} 26 \Delta 1279 \Delta 1333$ & $\Delta p y r E 2 \Delta d h f r \Delta 1333$ & Gäbel et al. 2013 \\
\hline $\mathrm{H} 26 \Delta 1279 \Delta 1678$ & $\Delta p y r E 2 \Delta d h f r \Delta 1678$ & diese Arbeit \\
\hline $\mathrm{H} 26 \Delta 1279 \Delta 1934$ & $\Delta p y r E 2 \Delta d h f r \Delta 1934$ & Gäbel et al. 2013 \\
\hline $\mathrm{H} 26 \Delta 1279 \Delta 2242$ & $\Delta p y r E 2 \Delta d h f r \Delta 2242$ & diese Arbeit \\
\hline $\mathrm{H} 26 \Delta 1279 \Delta 2706$ & $\Delta p y r E 2 \Delta d h f r \Delta 2706$ & Gäbel et al. 2013 \\
\hline $\mathrm{H} 26 \Delta 1279 \Delta \mathrm{A} 06347$ & $\Delta p y r E 2 \Delta d h f r \Delta A 0637$ & diese Arbeit \\
\hline $\mathrm{H} 26 \Delta 1677$ & $\Delta p y r E 2 \Delta 1677$ & Vanessa Mijic \\
\hline
\end{tabular}

\subsubsection{Datenbanken und Software}

Die verwendete Software und Datenbanken wurden in der folgenden Tabelle aufgelistet.

\section{Tabelle 17: Datenbanken und Software}

\begin{tabular}{|c|c|}
\hline Name & Entwickler \\
\hline BioEdit 7.2.6.1 & Tom Hall, Ibis Therapeutics, Carlsbad (USA) \\
\hline https://www.clker.com & Rolera LLC, 2270 Route 30, Oswego, IL 60543 (USA) \\
\hline Clone Manager 9 Professional Edition & Scientific \& Educational Software, Denver (USA) \\
\hline Geldoku Software Easy Win 32 & Herolab GmbH, Wiesloch \\
\hline Gimp 2.8 & Spencer Kimball, Peter Mattis und das GIMP-Team \\
\hline HaloLex: https://www.halolex.mpg.de/public/ & $\begin{array}{l}\text { Max-Planck Gesellschaft zur Förderung der Wissenschaften e. V., Mün- } \\
\text { chen }\end{array}$ \\
\hline Jalview 2.11 .0 & $\begin{array}{l}\text { evelopment managed by The Barton Group, University of Dundee, Scot- } \\
\text { land, UK }\end{array}$ \\
\hline http://www.compbio.dundee.ac.uk/jpred4 & (Drozdetskiy et al., 2015) \\
\hline Microsoft Office 2016 & Microsoft Corporation, Redmond (USA) \\
\hline NanoDrop 3.5 .1 & Coleman Technologies Inc., Rockland, USA \\
\hline https://www.bioinformatics.org/sms/index.html & $\begin{array}{l}\text { Stothard, P. } 2000 \text {. The sequence manipulation suite: JavaScript programs } \\
\text { for analyzing and formatting protein and DNA sequences. BioTechniques } \\
28 \text { : } 1102-1104\end{array}$ \\
\hline SnapGene Viewer & GSL Biotech LLC, Chicago (USA) \\
\hline String Database Version 11.0 & $\begin{array}{l}\text { Swiss Institute of Bioinformatics; EMBL Heidelberg; University of Zurich; } \\
\text { Novo Nordisk Foundation CPR }\end{array}$ \\
\hline Softmax $®$ Pro Software & Molecular Devices LLC, San José (USA) \\
\hline WinASPECT & Analytik Jena AG, Jena \\
\hline
\end{tabular}




\subsection{Mikrobiologische Methoden}

Alle sterilen Arbeiten fanden am Bunsenbrenner statt. Generell wurden die verwendeten Medien und Zusätze bei $121^{\circ} \mathrm{C}$ für 25 min autoklaviert. Hitzeempfindliche Lösungen wurden sterilfiltriert.

\subsubsection{Medien und Zusätze für die Kultivierung von E. coli}

Für E. coli erfolgte die Kultivierung aerob in 30-50 mL SOB+-Medium in $100 \mathrm{~mL}$ Erlenmeyerkolben, bei $37^{\circ} \mathrm{C}$ und $220 \mathrm{rpm}$ auf dem Schüttler (Tabelle 18). Als Selektionsmarker diente Ampicillin, welches dem $\mathrm{SOB}^{+}$-Medium direkt vor Verwendung hinzugefügt wurde.

Tabelle 18: Zusammensetzung des $\mathrm{SOB}^{+}-$Mediums für die Kultivierung von $E$. coli

\begin{tabular}{|c|c|c|}
\hline Bezeichnung & Menge & Endkonzentration \\
\hline \multicolumn{3}{|l|}{ SOB $^{+}$-Medium } \\
\hline Trypton & $20 \mathrm{~g}$ & $2 \%(w / v)$ \\
\hline Hefeextrakt & $5 \mathrm{~g}$ & $0,5 \%(w / v)$ \\
\hline $\mathrm{NaCl}$ & $0,6 \mathrm{~g}$ & $10 \mathrm{mM}$ \\
\hline $\mathrm{KCl}$ & $0,187 \mathrm{~g}$ & $2,5 \mathrm{mM}$ \\
\hline \multirow[t]{2}{*}{$1 \mathrm{M} \mathrm{MgCl}_{2} / \mathrm{MgSO}_{4}$ (aus $1 \mathrm{M} \mathrm{Stammlösung,} \mathrm{autoklaviert)}$} & $10 \mathrm{~mL}$ & $10 \mathrm{mM}$ \\
\hline & ad. $1 \mathrm{~L} \mathrm{VE;} \mathrm{autoklavieren}$ & \\
\hline \multirow[t]{2}{*}{ Selektionsmarker: Ampicillin Stammlösung $1 \mathrm{mg} / \mathrm{mL}$} & $1 \mathrm{mg}$ in $1 \mathrm{~mL}$ VE, sterilfiltrieren & $100 \mu \mathrm{g} / \mathrm{mL}$ \\
\hline & ad $1 \mathrm{~mL} \mathrm{H}_{2} \mathrm{O}$-bidest; sterilfiltrieren & \\
\hline
\end{tabular}

Zum Bereiten von $\mathrm{SOB}^{+}$-Festmedien wurde vor dem Autoklavieren 1,2 \% Agar, was $12 \mathrm{~g}$ Agar entspricht, hinzugegeben. Die Agarplatten wurden bei $4{ }^{\circ} \mathrm{C}$ im Kühlraum gelagert, das Flüssigmedium bei Raumtemperatur (RT).

\subsubsection{Herstellung von chemisch kompetenten E. coli}

Chemisch Kompetente E. coli Zellen wurden für die Hitzeschock-Transformation benötigt. Mittels einer Übernacht-Kultur des Stammes XL1-blue wurden $250 \mathrm{~mL} \mathrm{SOB}{ }^{+}$-Medium auf eine $\mathrm{OD}_{600}$ von 0,05 inokuliert. Die Zellen wurden unter Schütteln bei $37^{\circ} \mathrm{C}$ bis zu einer $\mathrm{OD}_{600}$ von 0,6 inkubiert, anschließend für $10 \mathrm{~min}$ auf Eis gestellt und für $10 \mathrm{~min}$ bei $4{ }^{\circ} \mathrm{C}$ und $2.500 \mathrm{xg}$ abzentrifugiert. Der Überstand wurde verworfen und das Zellpellet in $80 \mathrm{~mL}$ eiskaltem TBPuffer (Tabelle 19) suspendiert.

Tabelle 19: Herstellung des TB-Puffers

\begin{tabular}{|c|c|c|}
\hline Bezeichnung & Menge & Endkonzentration \\
\hline \multicolumn{3}{|l|}{ TB-Puffer } \\
\hline MOPS & $0,21 \mathrm{~g}$ & $10 \mathrm{mM}$ \\
\hline $\mathrm{CaCl}_{2} \cdot \mathrm{H}_{2} \mathrm{O}$ & $0,22 \mathrm{~g}$ & $15 \mathrm{mM}$ \\
\hline \multirow[t]{2}{*}{$\mathrm{KCl}$} & $1,86 \mathrm{~g}$ & $250 \mathrm{mM}$ \\
\hline & Ad $90 \mathrm{~mL} \mathrm{H} \mathrm{H}_{2}$-Bidest; $\mathrm{pH}$ 6,8 mit $\mathrm{KOH}$ einstellen & \\
\hline \multirow[t]{2}{*}{$\mathrm{MnCl}_{2} \cdot \mathrm{H}_{2} \mathrm{O}$} & $0,89 \mathrm{~g}$ & $55 \mathrm{mM}$ \\
\hline & Ad $100 \mathrm{~mL} \mathrm{H}{ }_{2} \mathrm{O}$-Bidest; sterilfiltriert; bei $4{ }^{\circ} \mathrm{C}$ gelagert & \\
\hline
\end{tabular}


Nach 10 min Inkubation auf Eis wurde die Zellsuspension erneut für 10 min bei $4{ }^{\circ} \mathrm{C}$ und $2.500 \mathrm{xg}$ abzentrifugiert. Der Überstand wurde verworfen, das Zellpellet in $20 \mathrm{~mL}$ TB-Puffer resuspendiert und 1,4 $\mathrm{mL}$ DMSO durch vorsichtiges Schwenken beigemischt. Nach weiteren $10 \mathrm{~min}$ auf Eis, wurde die Zellsuspension in sterile 1,5 mL Reaktionsgefäße in je $200 \mu \mathrm{L}$ Ansätzen aliquotiert und in flüssigem Stickstoff eingefroren. Die Lagerung der chemisch kompetenten Zellen erfolgte bei $-80^{\circ} \mathrm{C}$.

\subsubsection{Transformation von E. coli}

Für die Transformation von E. coli wurden $100 \mu \mathrm{L}$ chemisch-kompetente Zellen des Stammes XL1 blue verwendet (siehe Kapitel 2.2.2). Sie wurden 30 min auf Eis aufgetaut und mit $10 \mu \mathrm{L}$ Ligationsansatz oder $50 \mathrm{ng}$ Plasmid-DNA gemischt. Es folgte eine Inkubation von $60 \mathrm{sec}$ bei $42{ }^{\circ} \mathrm{C}$ auf dem Heizblock und 2 min auf Eis, bevor 50-100 $\mu \mathrm{L}$ der Zellen auf SOB ${ }^{+}$-Platten, mit Ampicillin und 1,2\% Agar (Tabelle 18), ausplattiert wurden.

\subsubsection{Medien und Zusätze für die Kultivierung von $H$. volcanii}

Die Kultivierung von $H$. volcanii erfolgte in Komplexmedium oder synthetischem Medium aerob, bei $42{ }^{\circ} \mathrm{C}$ und $250 \mathrm{rpm}$ auf dem Schüttler.

In Tabelle 20 sind die verwendeten Selektionsmarker für $E$. coli und $H$. volcanii aufgelistet. Die Stammlösungen wurden bis auf Uracil bei $-20^{\circ} \mathrm{C}$ gelagert.

Tabelle 20: Verwendete Selektionsmarker für $E$. coli bzw. für $H$. volcanii

\begin{tabular}{ccc}
\hline Selektionsmarker & Stammlösung & Endkonzentration \\
\hline Novobiocin & $1 \mathrm{mg} / \mathrm{mL}$ in $\mathrm{H}_{2}$ O-bidest, sterilfiltriert & $0,47 \mu \mathrm{g} / \mathrm{mL}$ \\
Ampicillin & $100 \mathrm{mg} / \mathrm{mL}$ in $\mathrm{H}_{2}$ O-bidest, sterilfiltriert & $100 \mu \mathrm{g} / \mathrm{mL}$ \\
Uracil & $0,1 \mathrm{~g} / \mathrm{mL}$ in DMSO & $50 \mu \mathrm{g} / \mathrm{mL}$ \\
5 -FOA & $150 \mathrm{mg} / \mathrm{mL}$ in DMSO & $150 \mu \mathrm{g} / \mathrm{mL}$ \\
\hline
\end{tabular}

Die benötigten Lösungen und Chemikalien für das Komplexmedium sind in Tabelle 21 aufgeführt. Die Lösungen wurden einzeln hergestellt und autoklaviert. Die Spurensalze und die Eisensulfat-Lösung wurden bei $4{ }^{\circ} \mathrm{C}$ im Kühlschrank gelagert. Nach dem Autoklavieren wurde die Nährstofflösung in die Salzlösung gegeben. Die Spurensalze, Eisensulfat-Lösung und Uracil wurden hinzugefügt.

Als Selektionsmarker für die Stämme mit Überexpressionsplasmid diente Novobiocin, welches direkt vor Verwendung dem Medium hinzugefügt wurde.

Für Festmedien erfolgte die Zugabe von 1,4 \% Agar in die Salzlösung vor dem Autoklavieren, was einer Menge von $14 \mathrm{~g}$ Agar für $1 \mathrm{~L}$ Medium entspricht. Komplexmedium mit unterschiedlichen Salzkonzentrationen wie 0,9 M NaCl und $4 \mathrm{M} \mathrm{NaCl}$, wurde für die Testung unterschiedlicher Wachstumsbedingungen verwendet. Die Salzlösung, die Nährstofflösung und das Uracil wurden bei $4{ }^{\circ} \mathrm{C}$ gelagert. 
Tabelle 21: Zusammensetzung Komplexmedium für die Kultivierung von $\boldsymbol{H}$. volcanii

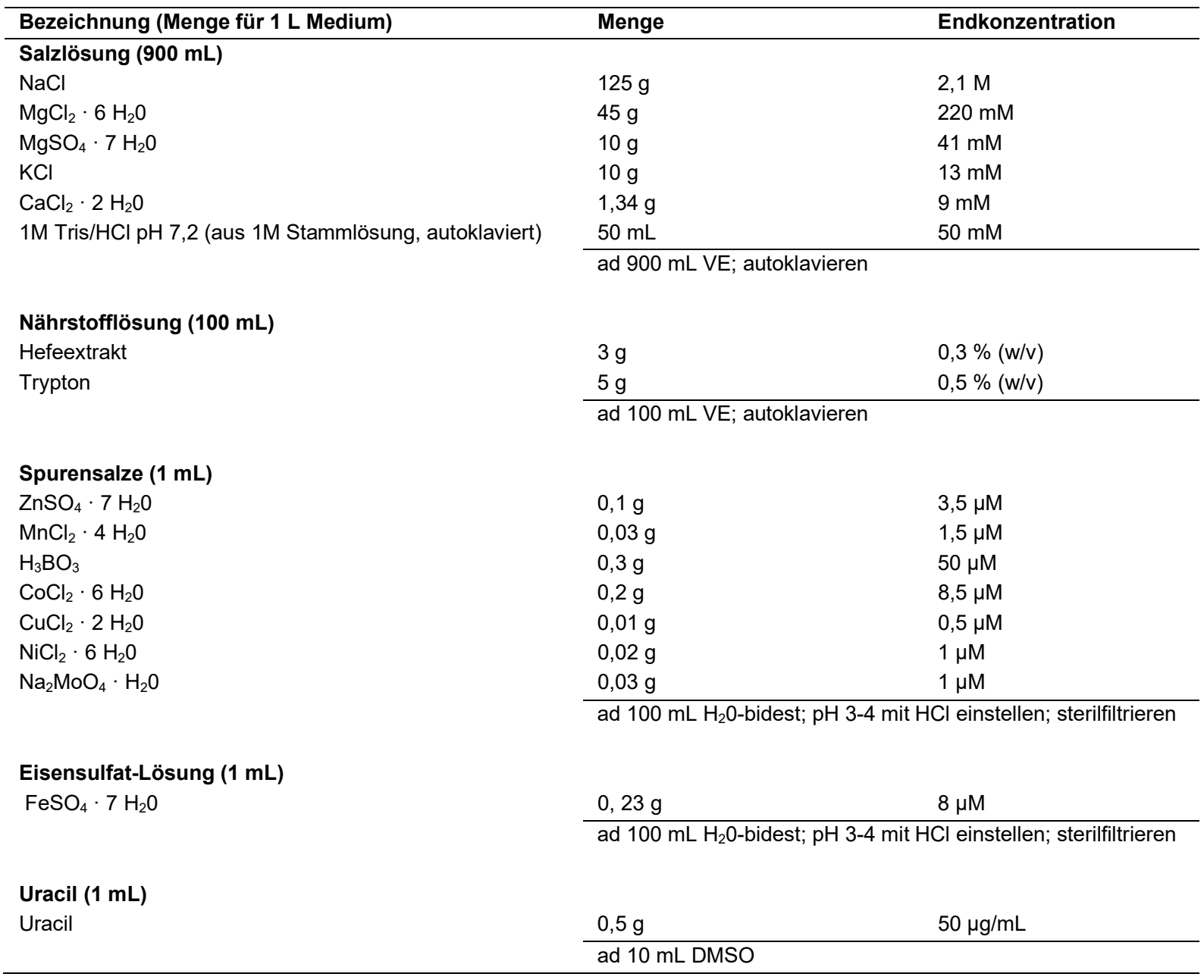

In Tabelle 22 sind die Lösungen zur Herstellung des synthetischen Medium aufgeführt. Zusätzlich wurde eine Kohlenstoffquelle hinzugegeben (Tabelle 23). Synthetisches Medium diente sowohl den Wachstumsversuchen, als auch der Selektion von Popln-Klonen, bei der Erstellung von Deletionsmutanten. Für Stämme mit Deletionsplasmid wurde das synthetische Medium wie in Tabelle 22 hergestellt, jedoch kein Uracil hinzugegeben. Als Kohlenstoffquelle dienten Casaminosäuren (Tabelle 23 ). Anschließend folgte eine weitere Selektion in Komplexmedium mit 5-FOA nach Popout-Klonen.

Tabelle 22: Zusammensetzung des synthetischen Medium

\begin{tabular}{lll}
\hline Bezeichnung & Menge & Endkonzentration \\
\hline Salzlösung & $900 \mathrm{~mL}$ & $1 \mathrm{mM}$ \\
$1 \mathrm{M} \mathrm{K}_{2} \mathrm{HPO}_{4}$ & $1 \mathrm{~mL}$ & $10 \mathrm{mM}$ \\
$1 \mathrm{M} \mathrm{NH}_{4} \mathrm{Cl}$ & $10 \mathrm{~mL}$ & $8 \mu \mathrm{M}$ \\
Spurensalze & $1 \mathrm{~mL}$ & $50 \mu \mathrm{g} / \mathrm{mL}$ \\
Eisensulfat-Lösung & $1 \mathrm{~mL}$ & $50 \mathrm{mM}$ \\
Uracil & $1 \mathrm{~mL}$ & \\
$2 \mathrm{M} \mathrm{MOPS} \mathrm{pH} \mathrm{7,2}$ & $50 \mathrm{~mL}$ & $1 \mathrm{~mL}$ \\
BME-Vitaminlösung & ad 1 L VE & \\
\hline
\end{tabular}


In Tabelle 23 sind weitere Kohlenstoffquellen für das synthetische Medium von $H$. volcanii aufgeführt.

Tabelle 23: Kohlenstoffquellen für das synthetische Medium

\begin{tabular}{lll}
\hline Bezeichnung & Menge & Endkonzentration \\
\hline $20 \%$ Casaminosäuren (sterilfiltriert) & $12,5 \mathrm{~mL}$ & $0,25 \%(\mathrm{w} / \mathrm{v})$ \\
$20 \%$ Glucose (autoklaviert) & $25 \mathrm{~mL}$ & $0,5 \%(\mathrm{w} / \mathrm{v})$ \\
$20 \%$ Saccharose (autoklaviert) & $25 \mathrm{~mL}$ & $0,5 \%(\mathrm{w} / \mathrm{v})$ \\
$800 \mathrm{mM}$ Acetat (sterilfiltriert) & $50 \mathrm{~mL}$ & $40 \mathrm{mM}$ \\
$800 \mathrm{mM}$ Pyruvat (sterilfiltriert) & $25 \mathrm{~mL}$ & $20 \mathrm{mM}$ \\
$86 \%$ Glycerin (autoklaviert) & $1,74 \mathrm{~mL}$ & $20 \mathrm{mM}$ \\
\hline
\end{tabular}

\subsubsection{Transformation von $\boldsymbol{H}$. volcanii}

Für die Transformation von $H$. volcanii wurden $2 \mathrm{~mL}$ einer exponentiellen Kultur für 2 min bei 8000 rpm abzentrifugiert (Puffer und Lösungen siehe Tabelle 24). Der Überstand wurde verworfen und das Pellet vorsichtig in $180 \mu \mathrm{L}$ SBL/EDTA-Lösung resuspendiert. Die DNA-Lösung von 2-5 $\mu$ g Plasmid in 0,8 M NaCl wurde wie folgt hergestellt: $16 \mu \mathrm{L}$ Plasmid und $4 \mu \mathrm{L} 4 \mathrm{M}$ $\mathrm{NaCl}$ wurden gemischt. $20 \mu \mathrm{L}$ dieser DNA-Lösung wurde in die Zellsuspension pipettiert, durch 10-maliges invertieren des Reaktionsgefäßes gemischt und für 5 min bei RT inkubiert. Anschließend wurden $230 \mu \mathrm{L}$ SBL/PEG-Lösung in den Deckel der Reaktionsgefäße pipettiert und diese erneut invertiert, bis keine Schlieren mehr sichtbar waren. Es folgte eine Inkubation von 20 min bei RT. Danach wurden 1,5 mL SVL-Lösung hinzu pipettiert und erneut 10x invertiert. $100 \mu \mathrm{L}$ der Zellsuspension wurden auf entsprechenden Agarplatten mit Selektivmedium ausplattiert und $200 \mu \mathrm{L}$ der Zellsuspension in $30 \mathrm{~mL}$ Flüssigselektivmedium überimpft.

Tabelle 24: Lösungen für die Transformation von $H$. volcanii

\begin{tabular}{|c|c|c|}
\hline Bezeichnung & Menge & Endkonzentration \\
\hline \multicolumn{3}{|c|}{ Sphäroblastenbildungslösung (SBL) } \\
\hline $\mathrm{NaCl}$ & $23,37 \mathrm{~g}$ & $0,8 \mathrm{M}$ \\
\hline $\mathrm{KCl}$ & $1 \mathrm{~g}$ & $27 \mathrm{mM}$ \\
\hline $1 \mathrm{M}$ Tris/HCl, $\mathrm{pH} 8,2$ & $25 \mathrm{~mL}$ & $50 \mathrm{mM}$ \\
\hline \multirow[t]{2}{*}{ Saccharose } & $75 \mathrm{~g}$ & $15 \%(w / v)$ \\
\hline & \multicolumn{2}{|c|}{ Ad $500 \mathrm{~mL} \mathrm{H} \mathrm{H}_{2} \mathrm{O}$-bidest; sterilfiltrieren } \\
\hline \multicolumn{3}{|c|}{ Sphäroblastenverdünnungslösung (SVL) } \\
\hline $\mathrm{NaCl}$ & $100 \mathrm{~g}$ & $3,4 \mathrm{M}$ \\
\hline $\mathrm{MgSO}_{4} \cdot 7 \mathrm{H}_{2} \mathrm{O}$ & $21,6 \mathrm{~g}$ & $175 \mathrm{mM}$ \\
\hline $\mathrm{KCl}$ & $1,25 \mathrm{~g}$ & $34 \mathrm{mM}$ \\
\hline $1 \mathrm{M}$ Tris/HCl pH 7,2 & $25 \mathrm{~mL}$ & $50 \mathrm{mM}$ \\
\hline \multirow[t]{2}{*}{$\mathrm{CaCl}_{2} \cdot 2 \mathrm{H}_{2} \mathrm{O}$} & $0,36 \mathrm{~g}$ & $5 \mathrm{mM}$ \\
\hline & \multicolumn{2}{|c|}{ Ad $500 \mathrm{~mL} \mathrm{H} \mathrm{H}_{2} \mathrm{O}$-bidest; sterilfiltrieren } \\
\hline \multicolumn{3}{|l|}{ SBL/EDTA-Lösung } \\
\hline EDTA & $18,5 \mathrm{~g}$ & $0,5 \mathrm{M}$ \\
\hline \multirow[t]{2}{*}{ SBL } & $100 \mathrm{~mL}$ & \\
\hline & \multicolumn{2}{|c|}{$\mathrm{pH} 8,2$; sterilfiltrieren } \\
\hline \multicolumn{3}{|l|}{ SBL/PEG-Lösung } \\
\hline PEG & $6 \mathrm{~mL}$ & $60 \%(v / v)$ \\
\hline SBL & $4 \mathrm{~mL}$ & $40 \%(v / v)$ \\
\hline
\end{tabular}




\subsubsection{Bestimmung Zelldichte und Zellzahl}

Für die Bestimmung der Zelldichte wurden die Zellen 1:2 in Medium verdünnt und je in Küvetten bei einer optischen Dichte (OD) von $600 \mathrm{~nm}$ am Photometer Specord S 600 gemessen.

Die Zellzahl wurde mittels einer Neubauer-Zählkammer bestimmt. Hierfür wurden die Zellen entsprechend in Basalsalz verdünnt, diagonal 4 Großquadrate (64 Kleinquadrate) ausgezählt und die Zellzahl pro $\mathrm{mL}$ berechnet (F1).

F1) Zellzahl pro $m L=\frac{\text { Zellzahl }}{64} \cdot$ Verdünnung $\cdot 2 \cdot 10^{7}$

\subsubsection{Wachstumsversuche in Mikrotiterplatten}

Zur phänotypischen Charakterisierung der $H$. volcanii Stämme, erfolgten Wachstumsversuche in 96-well Mikrotiterplatten mit Rundboden. Hierfür wurden die Stämme von einer Platte in $30 \mathrm{~mL}$ Komplexmedium 3 Tage bei $42{ }^{\circ} \mathrm{C}$ kultiviert. Dieser Ansatz diente als Inokulum. Anschließend wurde von diesem Inokulum in $30 \mathrm{~mL}$ frisches Medium überimpft und die Zellen am nächsten Tag in der exponentiellen Wachstumsphase geerntet. Zunächst wurde als Verdunstungsbarriere je $200 \mu \mathrm{L}$ sterile, 1M Natriumchloridlösung in die äußeren Vertiefungen der Platten pipettiert. $140 \mu \mathrm{L}$ entsprechendes Medium wurde in die inneren Vertiefungen vorgelegt. Die OD der Zellkulturen wurde bei $600 \mathrm{~nm}$ bestimmt und auf eine OD von 0,75 eingestellt, um eine gewünschte Start-OD von 0,05 in der Mikrotiterplatte zu erreichen (F2).

F2) $O D_{600}$ nm pro Well $=$ Verdünnungsfaktor $\cdot$ gewünschte $\mathrm{OD}=15 \cdot 0,05=0,75$

F3) Erntevolumen $=\frac{\mathrm{OD}_{600 \mathrm{~nm}} \text { pro Well }}{\mathrm{OD}_{600 \mathrm{~nm}} \text { exp.Kultur }} \cdot$ Volumen Basalsalz

Das berechnete Erntevolumen (F3) wurde abgenommen und 5 min bei 13.000 rpm zentrifugiert, in $1 \mathrm{~mL}$ Basalsalz gewaschen und für $5 \mathrm{~min}$ bei $13.000 \mathrm{rpm}$ zentrifugiert. Erneut wurde das Zellpellet in Basalsalz resuspendiert und je $10 \mu \mathrm{L}$ in das vorgelegte Medium pipettiert. Die Inkubation erfolgte bei $1.050 \mathrm{rpm}, 42^{\circ} \mathrm{C}$ und regelmäßigen Bestimmung der optischen Dichte bei $600 \mathrm{~nm}$ bis zur stationären Phase. 


\subsection{Molekularbiologische Methoden}

\subsubsection{Isolierung genomischer DNA aus $\boldsymbol{H}$. volcanii}

Zur Isolierung von genomischer DNA wurden $15 \mathrm{~mL}$ Zellkultur für $15 \mathrm{~min}$ bei $4000 \mathrm{rpm}$ zentrifugiert und das Zellpellet in $300 \mu \mathrm{L}$ Basalsalz resuspendiert. Durch Zugabe von 2,5 mL Lysepuffer (Tabelle 25) wurden die Zellen für 5 min lysiert und anschließend die wässrige Phase mit $5 \mathrm{~mL} 99$ \% Ethanol überschichtet. Mittels einer Glaskapillare mit Häkchen wurde die an der Phasengrenze ausgefallene DNA aufgewickelt. Es folgte zweimaliges Waschen der aufgewickelten DNA in 99 \% Ethanol für 5 min und anschließend zweimaliges Waschen in Diethylether. Die DNA wurde in $1 \mathrm{~mL} \mathrm{H}_{2} \mathrm{O}$-Bidest überführt, bei $60^{\circ} \mathrm{C}$ auf dem Heizblock gelöst und anschließend bei $4{ }^{\circ} \mathrm{C}$ gelagert. Die Konzentration der genomischen DNA wurde am UVVis Spektralphotometer Nanodrop 2000c,mit $\mathrm{H}_{2} \mathrm{O}$-Bidest als Referenz, bestimmt.

Tabelle 25: Komponenten zur Herstellung des Lysepuffers

\begin{tabular}{lll}
\hline Bezeichnung & Menge & Endkonzentration \\
\hline $\mathrm{NaCl}$ & $2,9 \mathrm{~g}$ & $100 \mathrm{mM}$ \\
$1 \mathrm{M} \mathrm{Tris} / \mathrm{HCl} \mathrm{pH} 8,0$ & $50 \mathrm{~mL}$ & $10 \mathrm{mM}$ \\
$\mathrm{EDTA}$ & $0,146 \mathrm{~g}$ & $1 \mathrm{mM}$ \\
$\mathrm{SDS}$ & $0,25 \mathrm{~g}$ & $0,05 \%$ \\
\cline { 2 - 3 } & Ad $500 \mathrm{~mL} \mathrm{VE}$ & \\
\hline
\end{tabular}

\subsubsection{Isolierung von Plasmid-DNA aus $E$. coli}

Plasmid-DNA aus E. coli wurde mittels des GenElute ${ }^{T M}$ HP Plasmid Midiprep Kit (Sigma-Aldrich) nach Herstellerangaben isoliert.

\subsubsection{Generierung von in-frame-Deletionsmutanten (Popln-PopOut-Methode)}

Für die Erstellung von Deletionsmutanten wurde die Popln-PopOut-Methode angewandt. Dieses System hat sich bewährt, um erfolgreich Deletionen in $H$. volcanii zu erstellen (Bitan-Banin et al 2003; Allers et al 2004; Hammelmann und Soppa 2008). Eine in-frame-Deletion entspricht einem Gen, dass durch eine Gen-Version ersetzt wird, bei der ein Teil im Gen entfernt wurde, dessen Nukleotidanzahl durch 3 teilbar ist. Als Deletionsplasmid wurde der pMH101 verwendet. Dieser enthält das für die Uracilbiosynthese essenzielle Gen pyrE2 und keinen Replikationsursprung für $\mathrm{H}$. volcanii. Ein entsprechendes Insert für die Deletion des gewünschten $\mathrm{Ge}-$ nes wurde in diesen Vektor kloniert. Um das Insert zu generieren wurden mittels PCR zwei Fragmente von ca. 500 bp generiert, die einen Teil des 5 '- und 3'-Bereiches, des zu deletierenden Gens flankieren. Diese beiden Fragmente wurden über PCR fusioniert und in den pMH101 kloniert. Der Uracil-auxotrophe Stamm (ApyrE2) H26 wurde mit dem Deletionsplasmid transformiert und auf synthetischem Medium ohne Uracil selektiert. Da das Plasmid kein Replikationsursprung für $H$. volcanii besitzt, musste das Plasmid, durch homologe 
Rekombination in das Genom integriert werden, so dass zwei mögliche PopIn-Varianten entstanden. Die zweite Selektion erfolgte in Komplexmedium mit Uracil und 5-FOA (Abbildung 12). In Kombination mit dem von pyrE2 kodierenden Enzym (Orotate Phosphoribosyltransferase) und 5-FOA entsteht 5-Fluoruracil, das toxisch auf die Zellen wirkt.

Pop in

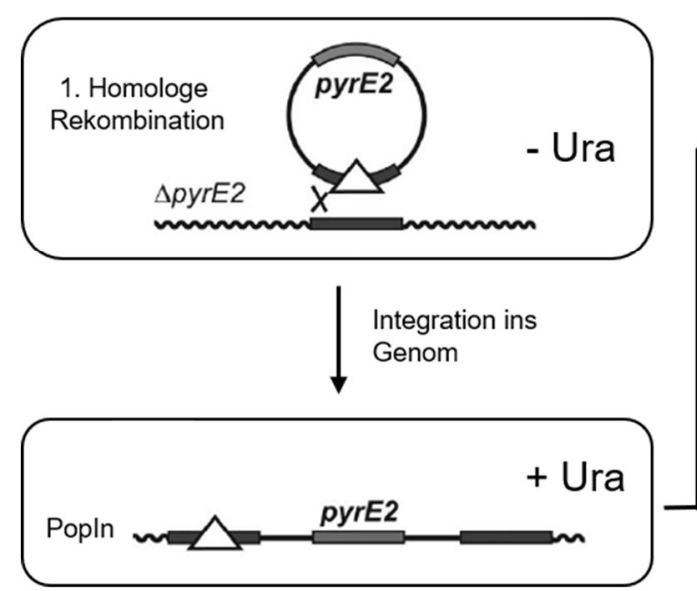

Pop out

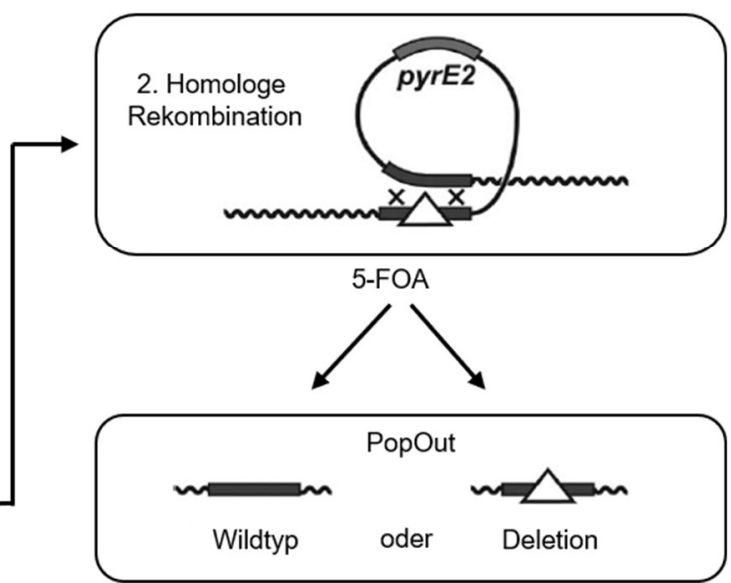

Abbildung 12: Schema für die Generierung von Popln-PopOut-Mutanten (modifiziert nach Allers et al 2004) Erste homologe Rekombination findet in Medium ohne Uracil (-Ura) statt. Es entsteht die Popln-Mutante. Die zweite homologe Rekombination erfolgt mit Uracil und 5-FOA, welche sowohl im Wildtyp als auch in der Deletionsmutante resultieren kann.

\subsubsection{Aufreinigung von DNA-Fragmenten}

Für die Aufreinigung von PCR-Produkten wurde das „E.Z.N.A. Cycle Pure Kit“ nach Anleitung des Herstellers verwendet. Eluiert wurde mit $\mathrm{H}_{2} \mathrm{O}$-Bidest. Zur Extraktion von DNA-Fragmenten aus Agarosegelen wurde das „E.Z.N.A. Gel Extraction Kit“ nach Angaben des Herstellers verwendet. Eluiert wurde ebenfalls mit $\mathrm{H}_{2} \mathrm{O}$-Bidest.

\subsubsection{Polymerase Kettenreaktion (PCR)}

Die PCR wurde für verschiedene Anwendungen in der Klonierung und für die Sondengenerierung verwendet. In den meisten PCR-Ansätzen wurde ein dNTP-Mix mit einem erhöhten Anteil von Guanin und Cytosin verwendet, da die DNA von $H$. volcanii einen erhöhten GC-Gehalt aufweist. In Tabelle 26 ist der Ansatz für die Herstellung des 66-dNTPs-Mix aufgeführt.

Tabelle 26: Ansatz für den 66-dNTP-Mix

\begin{tabular}{lll}
\hline Komponente & Menge & Endkonzentration \\
\hline 66-dNTP-Mix & & \\
$100 \mathrm{mM}$ dATP & $100 \mu \mathrm{L}$ & $1 \mathrm{mM}$ \\
$100 \mathrm{mM}$ dTTP & $100 \mu \mathrm{L}$ & $1 \mathrm{mM}$ \\
$100 \mathrm{mM}$ dGTP & $150 \mu \mathrm{L}$ & $1,5 \mathrm{mM}$ \\
$100 \mathrm{mM} \mathrm{dCTP}$ & $150 \mu \mathrm{L}$ & $1,5 \mathrm{mM}$ \\
\cline { 2 - 3 } & Ad $10 \mathrm{~mL} \mathrm{H} \mathrm{H}_{2} \mathrm{O}-$ Bidest; je $1 \mathrm{~mL}$ Aliquotes bei $-20^{\circ} \mathrm{C}$ lagern \\
\hline
\end{tabular}




\subsubsection{Generierung eines DNA-Fragments für die Klonierung}

In Tabelle 27 ist der PCR-Ansatz für die Generierung eines DNA-Fragments für die Klonierung aufgelistet. Diese PCR erfolgte mittels Velocity.

Tabelle 27: PCR-Ansatz zur Erstellung von DNA-Fragmenten für die Klonierungen

\begin{tabular}{lll}
\hline Komponente & Menge & Endkonzentration \\
\hline $5 X \mathrm{Hi}-$-Fi-Puffer & $10 \mu \mathrm{L}$ & $1 \mathrm{x}$ \\
$1 \mathrm{mM} / 1,5 \mathrm{mM}$ 66-dNTPs-Mix & $12,5 \mu \mathrm{L}$ & $250 \mu \mathrm{M}$ \\
$20 \mu \mathrm{M}$ 1. Oligonukleotid & $1 \mu \mathrm{L}$ & $0,4 \mu \mathrm{M}$ \\
$20 \mu \mathrm{M}$ 2. Oligonukleotid & $1 \mu \mathrm{L}$ & $0,4 \mu \mathrm{M}$ \\
Velocity Polymerase & $0,5 \mu \mathrm{L}$ & $1 \mathrm{U}$ \\
Template & $\mathrm{X} \mu \mathrm{L}$ & $10 \mathrm{ng}$ Plasmid oder 50 ng gen.DNA \\
\cline { 2 - 3 } & $\mathrm{Ad} 50 \mu \mathrm{L} \mathrm{H}_{2} \mathrm{O}-$ Bidest & \\
\hline
\end{tabular}

Die initiale Denaturierung erfolgte bei $98^{\circ} \mathrm{C}$ für $30 \mathrm{sec}$. 40 Zyklen á 3 Schritte folgten mit $98^{\circ} \mathrm{C}$ für $10 \mathrm{sec}, \mathrm{T}_{\mathrm{m}}-5^{\circ} \mathrm{C}$ für $30 \mathrm{sec}$ und $72^{\circ} \mathrm{C}$ für $\mathrm{X}$ min. Die Velocity-Polymerase hat eine Aktivität von $1 \mathrm{~kb}$ pro $15 \mathrm{sec}$. Die abschließende Elongation wurde bei $72^{\circ} \mathrm{C}$ für $1 \mathrm{~min}$ durchgeführt und anschließend der PCR-Ansatz auf $4{ }^{\circ} \mathrm{C}$ heruntergekühlt.

\subsubsection{Kolonie-PCR}

Für die Überprüfung putativ positiver Klone nach einer Transformation wurde eine KoloniePCR durchgeführt. Hierfür wurde ein Klon mit einer sterilen Pipettenspitze von der Ausstrichplatte gepickt, auf die Sicherungsplatte übertragen und anschließend in den PCR-Ansatz getaucht. Zur Durchmischung wurde mehrfach auf und ab pipettiert.

Zur Durchführung von Kolonie-PCRs wurde unter anderem die laboreigene Taq-Polymerase und die Taq-Polymerase von Biozym verwendet.

Für die laboreigene Taq-Polymerase wurde der 10xTaq-Puffer selbst hergestellt (Tabelle 28).

Tabelle 28: Ansatz für den 10xTaq-Puffer

\begin{tabular}{lll}
\hline Komponente & Menge & Endkonzentration \\
\hline 10xTaq-Puffer & & \\
$3 \mathrm{M} \mathrm{KCl}$ & $8,33 \mathrm{~mL}$ & $500 \mathrm{mM}$ \\
$1,5 \mathrm{M} \mathrm{Tris} / \mathrm{HCl} \mathrm{pH} 9,0$ & $3,33 \mathrm{~mL}$ & $100 \mathrm{mM}$ \\
Triton X & $500 \mu \mathrm{L}$ & $1 \%(\mathrm{v} / \mathrm{v})$ \\
\cline { 2 - 3 } & $\mathrm{Ad} 50 \mathrm{~mL} \mathrm{H} \mathrm{H}_{2} \mathrm{O}$-Bidest; $2 \mathrm{~mL}$ Aliquotes bei $-20^{\circ} \mathrm{C}$ lagern \\
\hline
\end{tabular}

Das Pipettierschema sowie der Ablauf des PCR-Programms für die laboreigene Taq-Polymerase sind in Tabelle 29 aufgeführt. Im Schnitt wurde 1 min pro kb als Elongationszeit für die Taq-Polymerase angesetzt. 
Tabelle 29: PCR-Ansatz für eine Kolonie-PCR mit der laboreigenen Taq-DNA-Polymerase

\begin{tabular}{|c|c|c|c|c|c|}
\hline Komponente & Menge & Endkonzentration & & \multicolumn{2}{|c|}{ PCR-Programm } \\
\hline $10 \times 19 y^{-1}$ & $2 \mu L$ & 10 & & & \\
\hline $25 \mathrm{mM} \mathrm{MgCl}{ }_{2}$ & $1,2 \mu \mathrm{L}$ & $1,5 \mathrm{mM}$ & & $96{ }^{\circ} \mathrm{C}$ & $5 \mathrm{~min}$ \\
\hline 1/1,5 mM 66-dNTPs-Mix & $3,2 \mu \mathrm{L}$ & $200 / 300 \mu \mathrm{M}$ & & $96^{\circ} \mathrm{C}$ & $1 \mathrm{~min}$ \\
\hline $20 \mu \mathrm{M}$ 1. Oligonukleotid & $0,5 \mu \mathrm{L}$ & $0,5 \mu \mathrm{M}$ & 30 Zyklen & $\mathrm{X}^{\circ} \mathrm{C}$ & $30 \mathrm{sec}$ \\
\hline $20 \mu \mathrm{M}$ 2. Oligonukleotid & $0,5 \mu \mathrm{L}$ & $0,5 \mu \mathrm{M}$ & & $72{ }^{\circ} \mathrm{C}$ & $1 \mathrm{~min} / \mathrm{kb}$ \\
\hline Taq-DNA-Polymerase & $0,2 \mu \mathrm{L}$ & & & $4{ }^{\circ} \mathrm{C}$ & $\infty$ \\
\hline Wasser & \multicolumn{2}{|c|}{ Ad $20 \mu \mathrm{L} \mathrm{H}{ }_{2} \mathrm{O}$-Bidest } & & & \\
\hline Template & \multicolumn{2}{|l|}{1 Klon } & & & \\
\hline
\end{tabular}

Für die Biozym-Taq war vom Hersteller eine Elongationszeit von $15 \mathrm{sec}$ pro kb angegeben.

In Tabelle 30 ist das Pipettierschema sowie der Ablauf des PCR-Programmes für die Biozym-Taq dargestellt. Zusätzlich wurde bei dieser Polymerase DMSO verwendet.

Tabelle 30: PCR-Ansatz für eine Kolonie-PCR mit der Biozym-Taq

\begin{tabular}{|c|c|c|c|c|c|}
\hline Komponente & Menge & Endkonzentration & & \multicolumn{2}{|c|}{ PCR-Programm } \\
\hline sxlaq-Reaktıonsputter & $2 \mu \mathrm{L}$ & $1 \mathrm{x}$ & & & \\
\hline 1/1,5 mM 66-dNTPs-Mix & $0,2 \mu \mathrm{L}$ & $12,5 / 19 \mu \mathrm{M}$ & & $98^{\circ} \mathrm{C}$ & $1 \mathrm{~min}$ \\
\hline $20 \mu \mathrm{M}$ 1. Oligonukleotid & $0,8 \mu \mathrm{L}$ & $0,8 \mu \mathrm{M}$ & & $96^{\circ} \mathrm{C}$ & $30 \mathrm{sec}$ \\
\hline $20 \mu \mathrm{M}$ 2. Oligonukleotid & $0,8 \mu \mathrm{L}$ & $0,8 \mu \mathrm{M}$ & 30 Zyklen & $\mathrm{X}^{\circ} \mathrm{C}$ & $30 \mathrm{sec}$ \\
\hline Taq-DNA-Polymerase & $0,1 \mu \mathrm{L}$ & $0,5 \cup$ & & $72^{\circ} \mathrm{C}$ & $15 \mathrm{sec} / \mathrm{kb}$ \\
\hline DMSO & $0,6 \mu \mathrm{L}$ & $3 \%(v / v)$ & & \multirow[t]{3}{*}{$4{ }^{\circ} \mathrm{C}$} & $\infty$ \\
\hline Wasser & \multicolumn{2}{|c|}{ Ad $20 \mu \mathrm{L} \mathrm{H} \mathrm{H}_{2} \mathrm{O}$-Bidest } & & & \\
\hline Template & 1 Klon & & & & \\
\hline
\end{tabular}

\subsubsection{Fusions-PCR}

Für die Verbindung von zwei PCR-Fragmenten ohne Ligation wurde die Fusions-PCR verwendet. Die hier verwendeten Primer wurden bereits mit einem komplementären Überhang von 15 bp geplant. Zunächst wurden die beiden einzelnen Fragmente in einer PCR generiert (siehe Kapitel 2.3.5.1) und über das „E.Z.N.A-Cycle-Pure Kit“ aufgereinigt (Kapitel 2.1.4). Je 150 ng beider Fragmente wurden in einen neuen PCR-Ansatz eingesetzt, die Annealing-Temperatur des überlappenden Bereichs um $5{ }^{\circ} \mathrm{C}$ niedriger angesetzt und die Dauer des Annealings auf 1 min verlängert. Die Zugabe der Oligonukleotide (Fragment $15^{\prime}$-Oligonukleotid; Fragment 2 $3^{\prime}$-Oligonukleotid) erfolgte erst nach 5 Zyklen mit einer weiteren Amplifikation von 30 Zyklen (Tabelle 31).

Tabelle 31: Ablauf Fusions-PCR nach Generierung der einzelnen Fragmente

\begin{tabular}{|c|c|c|c|c|c|}
\hline \multicolumn{3}{|c|}{ PCR-Programm A ohne Oligonukleotide } & \multicolumn{3}{|c|}{ PCR-Programm B mit Oligonukleotiden } \\
\hline \multirow{4}{*}{5 Zyklen } & $98^{\circ} \mathrm{C}$ & $10 \mathrm{sec}$ & & $98^{\circ} \mathrm{C}$ & $10 \mathrm{sec}$ \\
\hline & $96^{\circ} \mathrm{C}$ & $30 \mathrm{sec}$ & & $96^{\circ} \mathrm{C}$ & $30 \mathrm{sec}$ \\
\hline & $\mathrm{Tm}-5^{\circ} \mathrm{C}$ & $1 \mathrm{~min}$ & 30 Zyklen & $\mathrm{Tm}-5{ }^{\circ} \mathrm{C}$ & $1 \mathrm{~min}$ \\
\hline & $72{ }^{\circ} \mathrm{C}$ & $15 \mathrm{sec} / \mathrm{kb}$ & & $72{ }^{\circ} \mathrm{C}$ & $15 \mathrm{sec} / \mathrm{kb}$ \\
\hline \multicolumn{3}{|c|}{$\begin{array}{c}\text { Zugabe von je } 1 \mu \mathrm{L} \text { Oligonukleotide und } \\
\text { Start PCR-Programm B }\end{array}$} & & $4{ }^{\circ} \mathrm{C}$ & $\infty$ \\
\hline
\end{tabular}




\subsubsection{Site-Directed-Mutagenesis-PCR}

Für die Erzeugung einer ortsspezifischen Mutagenese z.B. einer Punktmutation wurde die Site-Directed-Mutagenesis-PCR verwendet. Hierfür wurde zuerst das zu verändernde Gen in den pSK+ kloniert. Zwei Oligonukleotide wurden so geplant, dass die Mutation von jeweils 15 Basen stromaufwärts und stromabwärts flankiert wurden. Für die ortsspezifische Mutagenese wurde die Phusion-Polymerase verwendet. Der PCR-Ansatz und der Ablauf des PCRProgrammes sind in Tabelle 32 aufgeführt. Die Elongationszeit wurde auf die Größe des Plasmides angepasst. Anschließend wurden $2 \mu \mathrm{L}$ des Restriktionsenzymes Dpnl und $2 \mu \mathrm{L}$ 10xTango Puffer zum PCR-Ansatz gegeben und über Nacht bei $37^{\circ} \mathrm{C}$ inkubiert. Sie zerstört das methylierte Template, sodass das Amplifikat übrigbleibt. Der Verdau wurde für 10 min bei $90{ }^{\circ} \mathrm{C}$ abgestoppt, auf $4{ }^{\circ} \mathrm{C}$ gekühlt und direkt $2,5 \mu \mathrm{L}$ des PCR-Ansatzes und somit das Plasmid in E. coli transformiert (Kapitel 2.2.3).

Tabelle 32: PCR-Ansatz und Programm für die ortsspezifische Mutagenese

\begin{tabular}{|c|c|c|c|c|c|}
\hline Komponente & Menge & Endkonzentration & & \multicolumn{2}{|c|}{ PCR-Programm } \\
\hline 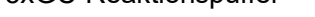 & ris & & & & \\
\hline 1/1,5 mM 66-dNTPs-Mix & $8 \mu \mathrm{L}$ & $160 \mu \mathrm{M}$ & & $98^{\circ} \mathrm{C}$ & $1 \mathrm{~min}$ \\
\hline $20 \mu \mathrm{M}$ 1. Oligonukleotid & $0,6 \mu \mathrm{L}$ & $0,24 \mu \mathrm{M}$ & & $98^{\circ} \mathrm{C}$ & $30 \mathrm{sec}$ \\
\hline $20 \mu \mathrm{M}$ 2. Oligonukleotid & $0,6 \mu \mathrm{L}$ & $0,24 \mu \mathrm{M}$ & 18 Zyklen & $\mathrm{Tm}-5^{\circ} \mathrm{C}$ & $1 \mathrm{~min}$ \\
\hline Phusion-Polymerase & $0,3 \mu \mathrm{L}$ & $0,5 \cup$ & & $72{ }^{\circ} \mathrm{C}$ & $15-30 \mathrm{sec} / \mathrm{kb}$ \\
\hline DMSO & $1,5 \mu \mathrm{L}$ & $3 \%(v / v)$ & & $4^{\circ} \mathrm{C}$ & $\infty$ \\
\hline Template & $X \mu L$ & 50 ng Plasmid & & & \\
\hline Wasser & \multicolumn{2}{|c|}{ Ad $50 \mu \mathrm{L} \mathrm{H}{ }_{2} \mathrm{O}$-Bidest } & & & \\
\hline
\end{tabular}

\subsubsection{Sonden-PCR}

Für die Southern-Blot-Analyse wurden Digoxygenin-markierte Sonden hergestellt. Hierfür wurde die laboreigene Taq-Polymerase (Tabelle 29) in einem $100 \mu \mathrm{L}$ Ansatz verwendet. Jedoch wurde der in Tabelle 33 beschriebene lowT-dNTP-Mix anstatt des 66-dNTP-Mix eingesetzt. Der PCR-Ansatz wurde auf je $50 \mu \mathrm{L}$ in zwei 0,2 mL Reaktionsgefäße aufgeteilt. In ein PCR-Ansatz wurde zusätzlich 0,5 $\mu \mathrm{L}$ Dig-UTP hinzugefügt. Der Einbau von Dig-UTP in das Amplifikat führt zu einem langsameren Laufverhalten des Fragments bei der gelelektrophoretischen Auftrennung. Der zweite PCR-Ansatz diente als Kontrolle. Da die Taq-DNA-Polymerase mehr Zeit für den Einbau von Dig-UTP benötigt, wurde die Elongationszeit verdoppelt. Die Anzahl der Zyklen wurde auf 40 hochgesetzt.

Tabelle 33: Ansatz für die Herstellung von lowT-dNTP-Mix

\begin{tabular}{lll}
\hline Komponente & Menge & Endkonzentration \\
\hline lowT-dNTP-Mix & & $1 \mathrm{mM}$ \\
$100 \mathrm{mM}$ dATP & $100 \mu \mathrm{L}$ & $0,2 \mathrm{mM}$ \\
$100 \mathrm{mM} \mathrm{dTTP}$ & $20 \mu \mathrm{L}$ & $1,5 \mathrm{mM}$ \\
$100 \mathrm{mM} \mathrm{dGTP}$ & $150 \mu \mathrm{L}$ & $1,5 \mathrm{mM}$ \\
$100 \mathrm{mM} \mathrm{dCTP}$ & $150 \mu \mathrm{L}$ & $\mathrm{Ad} 10 \mathrm{~mL} \mathrm{H} \mathrm{O}_{2}$-Bidest; je $1 \mathrm{~mL}$ Aliquotes bei $-20^{\circ} \mathrm{C}$ lagern \\
\cline { 2 - 3 }
\end{tabular}




\subsubsection{Spaltung von DNA}

Für die Spaltung von Plasmiden und DNA-Fragmenten wurden sowohl Restriktionsenzyme als auch Fast-Digest-Restriktionsenzyme nach Anleitung des Herstellers (Thermo Fisher Scientific) verwendet. Der Ansatz für die Spaltung von genomischer DNA wich von der Anleitung des Herstellers ab (Tabelle 34). Die Inkubation und Inaktivierung erfolgte für alle Restriktionsansätze nach Herstellerangaben.

Tabelle 34: Ansatz für die Spaltung von genomischer DNA

\begin{tabular}{ll}
\hline Komponente & Menge \\
\hline 10x Puffer & $3 \mu \mathrm{L}$ \\
Restriktionsenzym & $1,5 \mu \mathrm{L}$ \\
Gen. DNA & $3 \mu \mathrm{g}$ \\
\cline { 2 - 2 } & $\mathrm{ad} 30 \mathrm{~L} \mathrm{H}_{2} \mathrm{O}-$ Bidest \\
\hline
\end{tabular}

\subsubsection{Gelelektrophoretische Auftrennung von DNA}

Um DNA elektrophoretisch aufzutrennen wurden Agarosegele mit einer Konzentration von 0,7 $\%-1,8 \%$ verwendet. TBE-Puffer wurde sowohl als Laufpuffer, als auch für die Herstellung der Agarosegele verwendet. Hierfür wurde die entsprechende Menge an Agarose eingewogen und mit TBE-Puffer aufgefüllt. Nach dem Aufkochen in der Mikrowelle für 2 × 1,5 min wurde die Agarosegel-Lösung auf einem Magnetrührer auf $65^{\circ} \mathrm{C}$ herunter gekühlt und anschließend in einen Gelschlitten gegossen. Anschließend wurde das Agarosegel in eine Laufkammer mit TBE-Puffer gelegt. Vor dem Auftragen der Proben wurde diese mit 6x Probenpuffer 1:6 versetzt (5 $\mu \mathrm{L}$ Probe mit $1 \mu \mathrm{L}$ 6x Probenpuffer). Die Laufhöhe der mit Probenpuffer versetzen Proben bei einem 1 \% Agarosegel betrug für Xylencyanolblau 4000 bp, Kresolrot 1500 bp, Bromphenolblau 400 bp und Orange G 50 bp. Der entsprechende Größenstandard wurde mit je $5 \mu \mathrm{L}$ aufgetragen (Tabelle 35$)$.

Tabelle 35: Herstellung des TBE-Puffers und des 6xDNA-Probenpuffers

\begin{tabular}{|c|c|c|}
\hline Komponente & Menge & Endkonzentration \\
\hline \multicolumn{3}{|c|}{ 10xTBE-Puffer (Tris-Borat-EDTA) } \\
\hline Tris & $107,82 \mathrm{~g}$ & $0,89 \mathrm{M}$ \\
\hline Borsäure & $55,03 \mathrm{~g}$ & $0,89 \mathrm{M}$ \\
\hline \multirow[t]{3}{*}{$\mathrm{Na}_{2}$-EDTA } & $7,45 \mathrm{~g}$ & $0,02 \mathrm{M}$ \\
\hline & \multicolumn{2}{|c|}{ Ad $1 \mathrm{~L} \mathrm{H}_{2} \mathrm{O}$-Bidest } \\
\hline & \multicolumn{2}{|c|}{ Zur Verwendung 10xTBE-Puffer 1:10 in VE verdünnt } \\
\hline \multicolumn{3}{|c|}{ 6x DNA-Probenpuffer } \\
\hline $87 \%$ Glycerol & $3,3 \mathrm{~mL}$ & $28,7 \%(v / v)$ \\
\hline Bromphenolblau & $0,025 \mathrm{~g}$ & $3,7 \mathrm{mM}$ \\
\hline Xylencyanolblau & $0,025 \mathrm{~g}$ & $4,6 \mathrm{mM}$ \\
\hline Orange G & $0,025 \mathrm{~g}$ & $5,5 \mathrm{mM}$ \\
\hline \multirow[t]{2}{*}{ Kresolrot } & $0,025 \mathrm{~g}$ & $6,2 \mathrm{mM}$ \\
\hline & \multicolumn{2}{|c|}{ Ad $10 \mathrm{~mL} \mathrm{H}{ }_{2} \mathrm{O}$-Bidest; je $1 \mathrm{~mL}$ Aliquotes bei $-20^{\circ} \mathrm{C}$ lagern } \\
\hline
\end{tabular}


Die elektrophoretische Auftrennung erfolgte für große Gele bei 100-160 V, für mittlere und kleine Gele bei 80-120 V. Zur Analyse wurden die Agarosegele anschließend für 10-15 min in ein Ethidiumbromidbad $(2 \mu \mathrm{g} / \mathrm{mL}$ ) gelegt und mittels UV-Licht visualisiert (Easy Win 32 Software).

\subsubsection{Ligation von DNA}

Zur Ligation von DNA wurde die T4 DNA Ligase von Thermo Fisher Scientific und New England Biolabs verwendet. Zur Ligation eines Inserts in ein Plasmid wurde ein Verhältnis von 3:1 und 10:1 verwendet. Generell wurden 50 ng des geschnittenen Plasmids in die Ligation eingesetzt. In F4 ist die Formel für die Berechnung der benötigten Insert-Menge für ein Verhältnis von 1:1 dargestellt. Entsprechend für 3:1 und 10:1 wurde die 3-fache bzw. die 10-fache Menge des Inserts in den Ligations-Ansatz eingesetzt.

$$
\text { F4) Verhältnis 1:1 Insert }[n g]=\frac{\text { Menge Plasmid }[n g] \cdot \text { Länge Insert }[b p]}{\text { Länge Plasmid }[b p]}
$$

In folgender Tabelle ist ein Ansatz für die Ligation mit Überhängen, sowie ein Ansatz für die blunt-end Ligation dargestellt.

Tabelle 36: Ligations-Ansatz für DNA-Fragmente mit Überhängen und blunt-end DNA-Fragmente

\begin{tabular}{|c|c|c|}
\hline Komponente & Ligation mit Überhang & blunt-end Ligation \\
\hline 10x T4 DNA Ligase-Puffer & $2 \mu \mathrm{L}$ & $2 \mu \mathrm{L}$ \\
\hline 50 ng Plasmid & $\mathrm{X} \mu \mathrm{L}$ & $\mathrm{X} \mu \mathrm{L}$ \\
\hline Insert Verhältnis 3:1/10:1 & $X \mu L$ & $\mathrm{X} \mu \mathrm{L}$ \\
\hline T4 DNA Ligase & $1 \mu \mathrm{L}$ & $2 \mu \mathrm{L}$ \\
\hline \multirow[t]{2}{*}{ Optional Restriktionsenzym } & - & $(1 \mu \mathrm{L})$ \\
\hline & Ad $20 \mu \mathrm{L} \mathrm{H} \mathrm{H}_{2} \mathrm{O}$-Bidest & Ad $20 \mu \mathrm{L} \mathrm{H} \mathrm{H}_{2} \mathrm{O}$-Bidest \\
\hline
\end{tabular}

Zur Optimierung der blunt-end Ligation konnte Restriktionsenzym hinzugegeben werden. Die Ligation erfolgte für 10-90 min bei RT oder als Gradient auf Eis über Nacht bei $37^{\circ} \mathrm{C}$. Durch das Schmelzen des Eises wurde die Temperatur Schritt für Schritt erhöht. Die Hitzeinaktivierung der Ligation erfolgte bei $75^{\circ} \mathrm{C}$ für 10 min im Heizblock. Anschließend wurden $10 \mu \mathrm{L}$ des Ligations-Ansatzes für die Transformation von E. coli eingesetzt.

\subsubsection{Sequenzierung von DNA}

Die Sequenzierung Plasmid-DNA sowie von PCR-Produkten erfolgte durch GATC Biotech AG, die Proben wurden nach Firmenangaben vorbereitet. 


\subsubsection{Southern Blot Analyse}

Die Southern Blot Analyse erfolgte, um bereits vorhandene und neu erstellte $H$. volcanii Deletionsmutanten zu überprüfen. Als Kontrolle wurde genomische DNA aus dem Wildtypstamm mitgeführt. Hierfür wurde wie in Kapitel 2.3.1 genomische DNA isoliert und wie in Kapitel 2.3.6 beschrieben wurden, $3 \mu \mathrm{g}$ der genomischen DNA verdaut. Die Restriktionsansätze wurden nach Herstellerangaben hitzeinaktiviert, mit 6x Probenpuffer versetzt und auf ein mittleres 1$1,5 \%$ Agarosegel aufgetragen. Zusätzlich wurden $5 \mu \mathrm{L}$ entsprechender Größenstandard aufgetragen und die Proben bei 80-120 V für 2-5 h elektrophoretisch aufgetrennt.

Nachfolgend wurde das Gel 10 min im Ethidiumbromidbad $(2 \mu \mathrm{g} / \mathrm{mL})$ inkubiert und die Dokumentation mittels UV-Lichttisch durchgeführt (Easy Win 32 Software). Anschließend folgten Bäder: für 10 min in SB1-Lösung, 20 min in SB2-Lösung und 30 min in der SB3-Lösung, jeweils auf dem Wipp-Schüttler. Diese Schritte dienten zuerst der partiellen Depurinierung der DNA mittels SB1-Lösung, zur Denaturierung in der SB2-Lösung und zur Neutralisierung in der SB3Lösung (Tabelle 37). Abschließend wurde das Agarosegel für 10 min in 20x SSC-Puffer äquilibriert, bevor der Blot aufgebaut wurde.

Tabelle 37: Lösungen zur Vorbereitung des DNA-Transfers

\begin{tabular}{|c|c|c|}
\hline Komponente & Menge & Endkonzentration \\
\hline \multicolumn{3}{|l|}{ SB1-Lösung } \\
\hline VE & $900 \mathrm{~mL}$ & \\
\hline \multirow[t]{2}{*}{$25 \% \mathrm{HCl}$} & $32,5 \mathrm{~mL}$ & $0,25 \mathrm{M}$ \\
\hline & ad $1 \mathrm{~L} \mathrm{VE}$ & \\
\hline \multicolumn{3}{|l|}{ SB2-Lösung } \\
\hline $\mathrm{NaCl}$ & $87,6 \mathrm{~g}$ & $1,5 \mathrm{M}$ \\
\hline \multirow[t]{2}{*}{$\mathrm{NaOH}$} & $20 \mathrm{~g}$ & $0,5 \mathrm{M}$ \\
\hline & ad 1 L VE & \\
\hline \multicolumn{3}{|l|}{ SB3-Lösung } \\
\hline $\mathrm{NaCl}$ & $87,6 \mathrm{~g}$ & $1,5 \mathrm{M}$ \\
\hline \multirow[t]{2}{*}{ Tris } & $60,57 \mathrm{~g}$ & $0,5 \mathrm{M}$ \\
\hline & \multicolumn{2}{|c|}{ ad $1 \mathrm{~L} \mathrm{VE;} \mathrm{pH} 8$ wurde mit $\mathrm{HCl}$ eingestellt } \\
\hline \multicolumn{3}{|l|}{ 20x SSC-Puffer } \\
\hline $\mathrm{NaCl}$ & $175,3 \mathrm{~g}$ & $3 \mathrm{M}$ \\
\hline \multirow[t]{2}{*}{ tri-Natriumcitrat $\cdot 2 \mathrm{H}_{2} \mathrm{O}$} & $88,2 \mathrm{~g}$ & $0,3 \mathrm{M}$ \\
\hline & ad 1 L VE; & \\
\hline
\end{tabular}

\subsubsection{Transfer der DNA}

Für den Aufbau des Blots wurden 20 Blatt eines 1,4 mm dicken Blottingpapiers gestapelt. Darauf wurden 3 Blatt, 0,37 mm dickes Blottingpapier, in 20x SSC-Puffer äquilibriert und auf den Stapel gelegt. Die positiv-geladene Nylonmembran wurde für 10 min in $\mathrm{H}_{2} \mathrm{O}$-Bidest vorgequollen und ebenfalls in 20x SSC-Puffer äquilibriert, bevor sie auf den Stapel des Blottingpapiers gelegt wurde. Es folgte das Agarosegel, das luftblasenfrei auf die Nylonmembran gelegt und mit einem Glasröhrchen gewalzt wurde. 3 weitere Blätter, in 20x SSC-Puffer äquilibriertes $0,37 \mathrm{~mm}$ dickes Blottingpapier, wurden auf das Agarosegel gelegt. Abschließend folgte eine 
Pufferbrücke aus 0,37 mm dickem Blottingpapier, die rechts und links des Blottingstapels in ein 20x SSC-Puffer-Reservoir eintauchte. Zur Fixierung der Pufferbrücke wurde der Gelschlitten abschließend auf den Blottingstapel gelegt und mit einer $500 \mathrm{~mL}$ Schottflasche beschwert. Das Blotten erfolgte über Nacht, jedoch mindestens für 20 h. Anschließend erfolgte der Abbau des Blottes bis zum Agarosegel: die Taschen wurden mit einem Bleistift auf die Membran durchgezeichnet und am UV-Lichttisch das Gel, als auch die Membran dokumentiert. Die Membran wurde dann im Stratalinker bei 120 mJ UV-quervernetzt und bei RT getrocknet oder direkt mittels Sonde hybridisiert.

\subsubsection{Hybridisierung der Membran mittels Sonde und Nachweisreaktion}

Die Membran wurde in ein Hybridisierungsröhrchen überführt und mit $10 \mathrm{~mL}$ Hybridisierungspuffer für $1 \mathrm{~h}$ bei $55^{\circ} \mathrm{C}$ im Hybridisierungsofen unter langsamen Drehen vorhybridisiert. Gleichzeitig wurde die in Kapitel 2.3.5.5 hergestellte Sonde $5 \mathrm{~min}$ bei $95{ }^{\circ} \mathrm{C}$ denaturiert und in $10 \mathrm{~mL}$ Hybridisierungspuffer überführt. Die verwendeten Lösungen sind in Tabelle 38 aufgelistet.

Tabelle 38: Lösungen für die Hybridisierung und Chemilumineszenz

\begin{tabular}{|c|c|c|}
\hline Komponente & Menge & Endkonzentration \\
\hline \multicolumn{3}{|l|}{ 100x Denhardt-Lösung } \\
\hline Rinderserumalbumin & $10 \mathrm{~g}$ & $2 \%(w / v)$ \\
\hline Ficoll 400 & $10 \mathrm{~g}$ & $2 \%(w / v)$ \\
\hline \multirow[t]{2}{*}{ Polyvinylpyrolidon } & $10 \mathrm{~g}$ & $2 \%(w / v)$ \\
\hline & \multicolumn{2}{|c|}{ ad $500 \mathrm{~mL}$ VE, Filtration durch Faltenfilter, bei $-20^{\circ} \mathrm{C}$ gelagert } \\
\hline \multicolumn{3}{|l|}{ Hybridisierungspuffer } \\
\hline 20x SSC-Puffer & $250 \mathrm{~mL}$ & $5 x$ \\
\hline 100x Denhardt-Lösung & $30 \mathrm{~mL}$ & $3 x$ \\
\hline SDS & $5 \mathrm{~g}$ & $0,5 \%(w / v)$ \\
\hline $30 \%(w / v) \mathrm{N}$-Lauroylsarcosin & $6,7 \mathrm{~mL}$ & $0,2 \%(v / v)$ \\
\hline \multirow[t]{2}{*}{ Dextransulfat } & $50 \mathrm{~g}$ & $5 \%(w / v)$ \\
\hline & \multicolumn{2}{|c|}{ ad $500 \mathrm{~mL}$ VE, autoklaviert; anschließend $500 \mathrm{~mL}$ Formamid (50 \% (v/v)) hinzugefügt } \\
\hline \multicolumn{3}{|l|}{ Maleinsäurepuffer } \\
\hline Maleinsäure & $11,6 \mathrm{~g}$ & $100 \mathrm{mM}$ \\
\hline \multirow[t]{2}{*}{$\mathrm{NaCl}$} & $8,77 \mathrm{~g}$ & $150 \mathrm{mM}$ \\
\hline & \multicolumn{2}{|c|}{ ad $1 \mathrm{~L} \mathrm{H}_{2} \mathrm{O}$-Bidest; $\mathrm{pH}$ 7,5 eingestellt; autoklaviert } \\
\hline \multicolumn{3}{|l|}{ Blocking-Lösung } \\
\hline \multirow[t]{2}{*}{ Blocking-Reagenz } & $10 \mathrm{~g}$ & $1 \%(w / v)$ \\
\hline & \multicolumn{2}{|c|}{ ad $1 \mathrm{~L}$ Maleinsäurepuffer; autoklaviert; gelagert bei $4{ }^{\circ} \mathrm{C}$} \\
\hline \multicolumn{3}{|l|}{ Waschpuffer } \\
\hline \multirow[t]{2}{*}{ Tween 20} & $900 \mu \mathrm{L}$ & $0,3 \%(v / v)$ \\
\hline & \multicolumn{2}{|c|}{ ad $300 \mathrm{~mL}$ Maleinsäurepuffer } \\
\hline \multicolumn{3}{|l|}{ Detektionspuffer } \\
\hline $\mathrm{MgCl}_{2}$ & $4,77 \mathrm{~g}$ & $50 \mathrm{mM}$ \\
\hline $\mathrm{NaCl}$ & $5,84 \mathrm{~g}$ & $100 \mathrm{mM}$ \\
\hline \multirow[t]{2}{*}{ Tris } & $12,11 \mathrm{~g}$ & $100 \mathrm{mM}$ \\
\hline & \multicolumn{2}{|c|}{ ad $1 \mathrm{~L} \mathrm{H}_{2} \mathrm{O}$-Bidest; $\mathrm{pH}$ auf 9,5 eingestellt } \\
\hline
\end{tabular}


Der Puffer der Vorhybridisierung wurde verworfen und die vorbereitete Sonde im Hybridisierungspuffer hinzugegeben. Die Membran wurde bei $55^{\circ} \mathrm{C}$, unter langsamen Drehen über Nacht hybridisiert. Die Sonde in Hybridisierungspuffer wurde mehrfach verwendet und jeweils vor Gebrauch bei $95{ }^{\circ} \mathrm{C}$ im Heizblock $10 \mathrm{~min}$ denaturiert. Gelagert wurde sie bei $-20{ }^{\circ} \mathrm{C}$. Nach der Hybridisierung wurde die Membran unter schnellem Drehen $2 \times 5$ min in $50 \mathrm{~mL}$ 2x SSC-Puffer mit 0,5\% (w/v) SDS bei $55^{\circ} \mathrm{C}$ gewaschen. Die nächsten Waschschritte folgten für $2 \times 15 \mathrm{~min}$ bei $55^{\circ} \mathrm{C}$ in $50 \mathrm{~mL} 1 \times$ SSC-Puffer mit $0,5 \%(w / v)$ SDS.

Die Membran wurde kurz in Waschpuffer geschwenkt und anschließend für 30 min in $25 \mathrm{~mL}$ Blocking-Lösung unter langsamen Drehen bei RT inkubiert. Als nächster Schritt folgte $1 \mu \mathrm{L}$ Anti-Digoxigenin-Antikörper in $25 \mathrm{~mL}$ Blocking-Lösung für $30 \mathrm{~min}$ bei RT unter langsamen Drehen. 2-maliges Waschen in $100 \mathrm{~mL}$ Waschpuffer für 5 min unter schnellem Drehen folgte. Die Membran wurde in $20 \mathrm{~mL}$ Detektionspuffer 5 min unter langsamen Drehen inkubiert. Abschließend wurde die Membran für 5 min mit $10 \mu \mathrm{L}$ CDP-Star in $15 \mathrm{~mL}$ Detektionspuffer inkubiert und in eine Röntgenkassette gelegt. Die Detektion erfolgte in der Dunkelkammer mittels Röntgenfilmen (GE Healthcare), die je nach Sonde für $15 \mathrm{sec}$ bis $2 \mathrm{~h}$ aufgelegt wurden. Die exponierten Filme wurden 2 min in Entwicklerlösung geschwenkt, durch ein Wasserbad geführt und für 2 min in Fixierlösung gelegt. Zuletzt wurde der Röntgenfilm unter Wasser abgespült und getrocknet. 


\subsection{Biochemische Methoden}

\subsubsection{Erstellen eines Gesamtzellextraktes}

Beim Erstellen des Gesamtzellextraktes zur Untersuchung mittels Western Blot wurden 2x 1,5 mL exponentielle Zellen von $H$. volcanii bei 13.000 rpm für 2 min bei RT pelletiert. Der Überstand wurde verworfen und die Zellen bei $-20^{\circ} \mathrm{C}$ für $24 \mathrm{~h}$ eingefroren. Anschließend wurde das Pellet aufgetaut und in $50 \mu \mathrm{L} 1 \times$ Probenpuffer gelöst, für 10 min bei $95^{\circ} \mathrm{C}$ auf dem Heizblock erhitzt und kurz auf Eis gestellt. Nach einer erneuten Zentrifugation von 13.000 rpm für $30 \mathrm{sec}$ bei RT wurde der Überstand abgenommen und auf ein vorbereitet SDS-Gel (12\% Acrylamid) mittels einer Hamiltonspritze geladen.

\subsubsection{Methanol-Chloroform-Extraktion von Proteinen}

Die Zellernte und Proteinfällung wurde nach Wessel und Flügge mittels Methanol und Chloroform durchgeführt. Die verwendeten Puffer sind in Tabelle 39 aufgelistet. Hierfür wurden 15 $\mathrm{mL}$ Zellen in exponentiellem Wachstum bei RT, 4000 rpm für 15 min geerntet. Der Überstand wurde verworfen, das Zellpellet in $1 \mathrm{~mL}$ MCE-Lysepuffer resuspendiert und 30 min bei RT inkubiert. $4 \mathrm{~mL}$ Methanol, $1 \mathrm{~mL}$ Chloroform und $3 \mathrm{~mL} \mathrm{H} \mathrm{H}_{2} \mathrm{O}$-Bidest wurden hinzugegeben und zwischen jeder Zugabe gevortext.

Tabelle 39: Puffer für die Proteinfällung

\begin{tabular}{llc}
\hline Komponente & Menge & Endkonzentration \\
\hline MCE-Lysepuffer & $10 \mu \mathrm{L}$ & \\
DNase (1mg/mL) & $10 \mu \mathrm{L}$ \\
\cline { 2 - 2 } Proteinase-Inhibitor-Mix & ad $1 \mathrm{~mL} \mathrm{H} \mathrm{H}_{2} \mathrm{O}-$ Bidest; immer frisch angesetzt \\
& & \\
$\begin{array}{l}\text { Rücklösungspuffer } \\
\text { Tris }\end{array}$ & $3,03 \mathrm{~g}$ & $25 \mathrm{mM}$ \\
\cline { 2 - 2 } & ad $1 \mathrm{~L} \mathrm{H} \mathrm{H}_{2} \mathrm{O}-$ Bidest; $\mathrm{pH} \mathrm{7,2} \mathrm{mit} \mathrm{HCl}$ eingestellt; immer frisch angesetzt \\
\hline
\end{tabular}

Es folgte eine Zentrifugation bei $4000 \mathrm{rpm}$ für $15 \mathrm{~min}$ bei RT. Die obere Phase wurde vorsichtig abgenommen und verworfen. $3 \mathrm{~mL}$ Methanol wurden hinzugegeben, gevortext und $5 \mathrm{~min}$ bei 4000 rpm zentrifugiert. Der Überstand wurde verworfen und das Proteinpräzipitat für einige Minuten an der Luft getrocknet. 200-400 $\mu$ L Rücklösungspuffer wurden hinzugegeben und die Proteine durch Erwärmen auf $65^{\circ} \mathrm{C}$ gelöst. 


\subsubsection{Affinitätsaufreinigung}

Die Affinitätsaufreinigung erfolgte in Form einem pull-down-Assays, bei der das Zelllysat einer $H$. volcanii Kultur auf nickelbeladene Chelat-Sepharose-Beads gegeben wurde. Die ChelatSepharose-Beads wurden mehrfach in Waschpuffer gewaschen und letztendlich die Proteine mit Elutionspuffer eluiert. Die verwendeten Puffer und Lösungen sind in Tabelle 40 aufgelistet.

Tabelle 40: Komponenten für den pull-down Assay

\begin{tabular}{|c|c|c|}
\hline Komponente & Menge & Endkonzentration \\
\hline \multicolumn{3}{|l|}{ NiCl-Lösung } \\
\hline \multirow[t]{2}{*}{$\mathrm{NiCl}_{2}$} & $12,96 \mathrm{~g}$ & $0,2 \mathrm{M}$ \\
\hline & ad $500 \mathrm{~mL} \mathrm{H} \mathrm{H}_{2} \mathrm{O}$-Bidest & \\
\hline \multicolumn{3}{|l|}{$20 \%$-ig Ethanol } \\
\hline $99 \%$ reinst Ethanol & $20,2 \mathrm{~mL}$ & $20 \%(v / v)$ \\
\hline $\mathrm{H}_{2} \mathrm{O}$-Bidest & $79,8 \mathrm{~mL}$ & \\
\hline \multicolumn{3}{|l|}{ PMSF-Lösung } \\
\hline \multirow[t]{2}{*}{ PMSF } & $0,174 \mathrm{~g}$ & $200 \mathrm{mM}$ \\
\hline & ad $5 \mathrm{~mL} 99 \%$-ig Ethanol; in je $1 \mathrm{~mL}$ Aliquotes be & $4^{\circ} \mathrm{C}$ dunkel lagern \\
\hline \multicolumn{3}{|l|}{ Grundlagenpuffer } \\
\hline $\mathrm{NaCl}$ & $187,5 \mathrm{~g}$ & $2,1 \mathrm{M}$ \\
\hline \multirow[t]{2}{*}{ HEPES } & $7,2 \mathrm{~g}$ & $20 \mathrm{mM}$ \\
\hline & ad 1,5 $\mathrm{L} \mathrm{H}_{2} \mathrm{O}$-Bidest & \\
\hline \multicolumn{3}{|l|}{ Bindepuffer } \\
\hline \multirow[t]{2}{*}{ Imidazol } & $0,68 \mathrm{~g}$ & $20 \mathrm{mM}$ \\
\hline & ad $500 \mathrm{~mL}$ Grundlagenpuffer; gelagert bei $4{ }^{\circ} \mathrm{C}$ & \\
\hline \multicolumn{3}{|l|}{ His-Waschpuffer } \\
\hline \multirow[t]{2}{*}{ Imidazol } & $1,02 \mathrm{~g}$ & $30 \mathrm{mM}$ \\
\hline & ad $500 \mathrm{~mL}$ Grundlagenpuffer & \\
\hline \multicolumn{3}{|l|}{ Elutionspuffer } \\
\hline \multirow[t]{2}{*}{ Imidazol } & $2,38 \mathrm{~g}$ & $700 \mathrm{mM}$ \\
\hline & ad $50 \mathrm{~mL}$ Grundlagenpuffer & \\
\hline \multicolumn{3}{|l|}{ Dialysepuffer } \\
\hline \multirow[t]{2}{*}{ Tris } & $3,03 \mathrm{~g}$ & $25 \mathrm{mM}$ \\
\hline & ad $1 \mathrm{~L} \mathrm{H}_{2} \mathrm{O}$-Bidest; $\mathrm{pH} 7,2$ mit $\mathrm{HCl}$ eingestellt; imr & ner frisch angesetzt \\
\hline
\end{tabular}

\subsubsection{Die Zellernte}

Für die Affinitätsaufreinigung wurden $400 \mathrm{~mL}$ exponentielle Kultur von $H$. volcanii bei $4700 \mathrm{rpm}$ für 30 min bei $4{ }^{\circ} \mathrm{C}$ pelletiert. Das Pellet wurde in $4 \mathrm{~mL}$ eiskaltem Bindepuffer suspendiert, in $2 \mathrm{~mL}$ Reaktionsgefäße überführt und auf Eis gestellt. Der Aufschluss der Zellen erfolgte auf Eiswasser mittels Ultraschalltauchsonde für $3 \times 30 \mathrm{sec}$, Tastgrad 50 (duty cycle), Leistungsregelung 3 (output control). Das Zelllysat wurde für $30 \mathrm{~min}$, mit $13.000 \mathrm{rpm}$ bei $4{ }^{\circ} \mathrm{C}$ zentrifugiert und auf Eis gestellt. Zur Kontrolle der Aufreinigung für das spätere SDS-Polyacrylamidgel wurden $30 \mu \mathrm{L}$ des Zelllysates in ein $2 \mathrm{~mL}$ Reaktionsgefäß überführt und auf Eis gestellt. 


\subsubsection{Beladung der Nickel-Chelat-Sepharose-Beads (NCS)}

$500 \mu \mathrm{L} 50$ \%-ige NCS-Beads wurden in ein $2 \mathrm{~mL}$ Reaktionsgefäß überführt und mit $1 \mathrm{~mL} \mathrm{H}_{2} \mathrm{O}$ Bidest durch vortexen gewaschen, für $30 \mathrm{sec}$ bei RT mit 13.000 rpm abzentrifugiert.

Der Überstand wurde verworfen und die NCS-Beads mit $1 \mathrm{~mL} \mathrm{0,2} \mathrm{M} \mathrm{NiCl-Lösung} \mathrm{beladen.}$ Die Mischung wurde am Rotor für 5 min inkubiert und $30 \mathrm{sec}$ bei RT und 13.000 rpm abzentrifugiert. Dieser Schritt wurde nochmals wiederholt. Anschließend wurden die NCS-Beads 2x mit $\mathrm{H}_{2} \mathrm{O}$-Bidest gewaschen, am Rotor für 2 min inkubiert und für $30 \mathrm{sec}$ bei RT mit 13.000 rpm abzentrifugiert. Für die Lagerung wurden die NCS-Beads 2x in $500 \mu \mathrm{L} 20 \%$ Ethanol gewaschen und bei $4{ }^{\circ} \mathrm{C}$ gelagert. Für sofortige Verwendung erfolgte 2-maliges Waschen in $500 \mu \mathrm{L}$ Bindepuffer, 2 min Inkubation am Rotor und die Zentrifugation bei 13.000 rpm für $30 \mathrm{sec}$ bei RT. Anschließend wurde die Mischung in $500 \mu \mathrm{L}$ frischen Bindepuffer gegeben, gevortext und mit einer an der Spitze abgeschnittenen $1000 \mu \mathrm{L}$ Pipettenspitze je $250 \mu \mathrm{L}$ dieser Mischung auf vier $2 \mathrm{~mL}$ Reaktionsgefäße verteilt. Jeweils eines dieser Aliquotes wurde für eine Aufreinigung verwendet.

\subsubsection{Der Pull-down Assay}

$250 \mu \mathrm{L}$ der vorbereiteten bzw. beladenen NCS-Beads wurden nochmals bei $13.000 \mathrm{rpm}$ für 30 sec bei RT abzentrifugiert und der Überstand verworfen. Anschließend wurde direkt $1,6 \mathrm{~mL}$ Zelllysat auf die beladenen NCS-Beads pipettiert und am Rotor für 1 min bei RT unter Drehen inkubiert. Nach einer Zentrifugation von 13.000 rpm, $30 \mathrm{sec}$ bei RT wurde der Überstand abgenommen und die NCS-Beads erneut mit Zelllysat beladen. Diese Schritte wiederholten sich, bis das komplette Zelllysat aufgetragen wurde.

Die NCS-Beads wurden in 1,6 mL His-Waschpuffer gewaschen, am Rotor für $30 \mathrm{sec}$ bei RT inkubiert und mit 13.000 rpm für $30 \mathrm{sec}$ bei RT abzentrifugiert. Dieser Waschschritt wurde viermal wiederholt.

Für die Elution wurden $100 \mu \mathrm{L}$ Elutionspuffer zu den NCS-Beads gegeben und für $1 \mathrm{~min}$ am Rotor bei RT inkubiert. Nach einer Zentrifugation bei RT, mit 13.000 rpm für $30 \mathrm{sec}$ wurde der komplette Überstand in ein 1,5 mL Reaktionsgefäß pipettiert. Der Elutionsschritt wurde für die zweite Elutionsfraktion nochmals wiederholt.

\subsubsection{Dialyse der Proben}

Je $35 \mu \mathrm{L}$ der Eluate wurden für je 30 min über Dialyseplättchen in Petrischalen dialysiert. Dieser Schritt wurde wiederholt, bis die kompletten Eluate dialysiert waren. 


\subsubsection{Crosslinking von Proteinen in der Zellkultur}

Das Crosslinking von Proteinen in der Zellkultur erfolgte mittels Formaldehyd nach modifizierter Anleitung von Hoffman 2015 (Hoffman et al., 2015).

Hierfür wurde $1 \mathrm{~L}$ exponentielle $H$. volcanii Kultur bei $4{ }^{\circ} \mathrm{C}$ für 30 min bei $4700 \mathrm{rpm}$ pelletiert, anschließend in $20 \mathrm{~mL}$ Basalsalz resuspendiert und in je $10 \mathrm{~mL}$ in ein $15 \mathrm{~mL}$ Zentrifugenröhrchen überführt. Die beiden Zellsuspensionen wurde bei $4{ }^{\circ} \mathrm{C}$, mit $4000 \mathrm{rpm}$ für $10 \mathrm{~min}$ abzentrifugiert. Der Überstand wurde abgenommen, das Volumen mit Basalsalz auf je $5 \mathrm{~mL}$ aufgefüllt und die Pellets gleichzeitig resuspendiert. Anschließend wurden je $54 \mu \mathrm{L} 37$ \%-iges Formaldehyd hinzu pipettiert und beide Ansätze am Rotor bei RT für 10 min inkubiert. Das Crosslinking wurde mit je $420 \mu \mathrm{L} 3 \mathrm{M}$ Glycin gestoppt (0,25 M Endkonzentration) und die Zellsuspension nochmals 15 min am Rotor bei RT inkubiert. Die Zellsuspensionen wurden mit $4000 \mathrm{rpm}$ für $10 \mathrm{~min}$ bei $4{ }^{\circ} \mathrm{C}$ abzentrifugiert und in $10 \mathrm{~mL}$ Basalsalz resuspendiert. Nach 2 min waschen am Rotor bei RT wurden die Ansätze erneut für 10 min mit $4000 \mathrm{rpm}$ bei $4{ }^{\circ} \mathrm{C}$ zentrifugiert und die beiden Pellets anschließend in je 4,5 mL Bindepuffer suspendiert. Es folgte die Zugabe der PMSF-Lösung (Tabelle 40). Die Zellsuspension wurde in 1,8 mL Aliquotes in $2 \mathrm{~mL}$ Reaktionsgefäße für den Zellaufschluss pipettiert und auf Eis gestellt. Der Zellaufschluss erfolgte wie bereits beschrieben mittels Ultraschallsonde (siehe Kapitel 2.4.3.1). Anschließend erfolgte die Affinitätsaufreinigung wie in Kapitel 2.4.3.3 beschrieben.

\subsubsection{SDS-Polyacrylamidgelelektrophorese (SDS-PAGE)}

Die Auftrennung von Proteinen erfolgte mittels Natriumdodecylsulfat-Polyacrylamid-Gelelektrophorese. Es wurden 8 \%-ige, 12 \%-ige und $15 \%$-ige Polyacrylamidgele mit einer Stärke von $1 \mathrm{~mm}$ verwendet. In Tabelle 41 sind die verwendeten Puffer und Lösungen aufgeführt.

Tabelle 41: Puffer und Lösungen für die SDS-PAGE

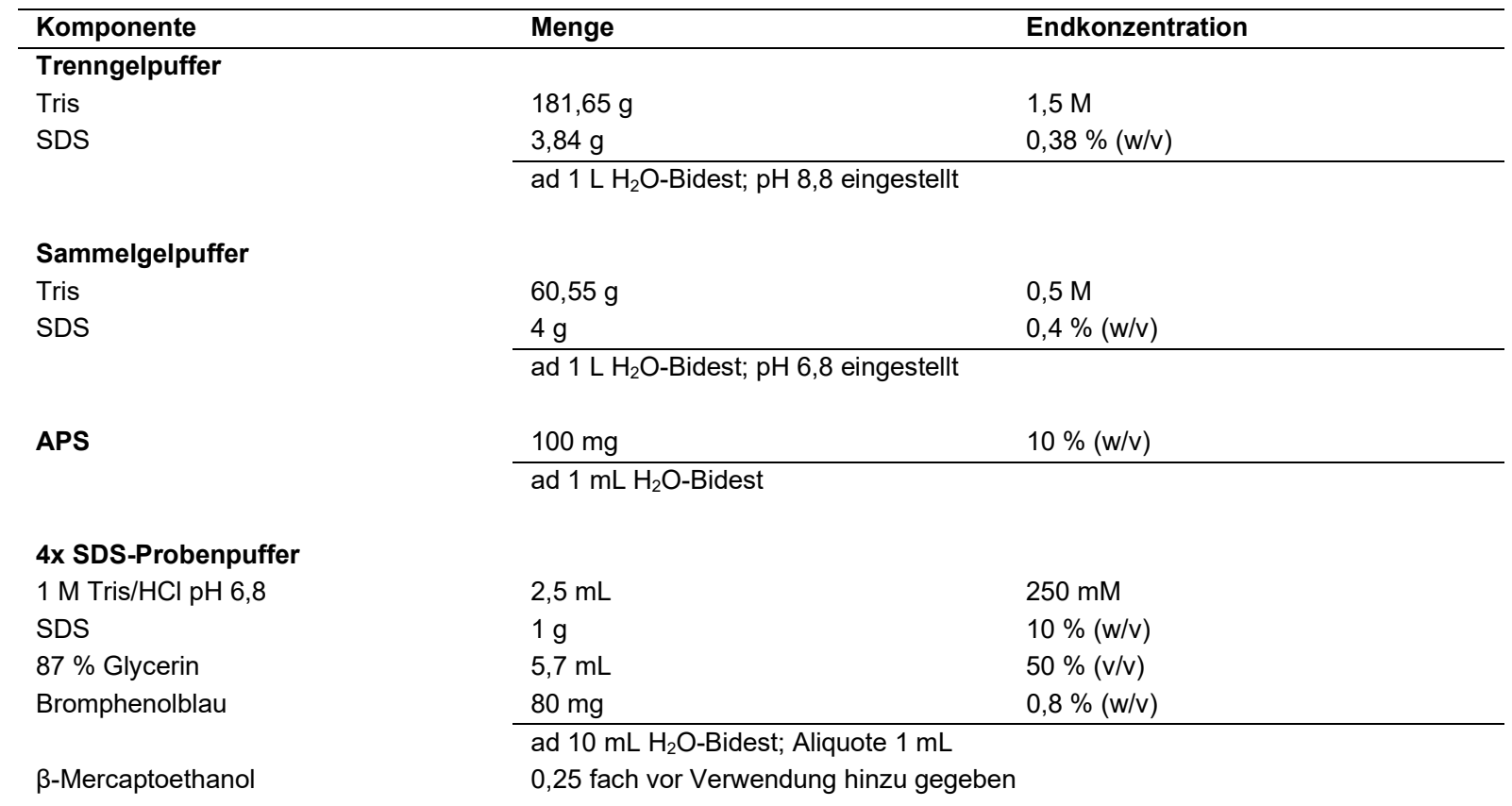


10x SDS-Laufpuffer

Tris

Glycin

SDS
$30,3 \mathrm{~g}$

$144 \mathrm{~g}$

$10 \mathrm{~g}$

\subsubsection{Herstellung der SDS-Polyacrylamidgele}

Zuerst wurde das Trenngel wie in Tabelle 42 beschrieben angesetzt, direkt $5 \mathrm{~mL}$ (etwa 4/5 der Laufstrecke) mittels einer Glaspipette in die Gelgießvorrichtung pipettiert und mit $200 \mu \mathrm{L}$ Isopropanol überschichtet. Nach der Polymerisation des Trenngels wurde das Isopropanol auf ein Papiertuch abgegossen. Anschließend wurde das Sammelgel wie in Tabelle 42 zusammen pipettiert, auf das Trenngel gegossen und der Kamm für die Taschen hineingesteckt. Nach der Polymerisation wurdes das SDS-Gel in mit $\mathrm{H}_{2} \mathrm{O}$-Bidest getränkte Tücher gewickelt und bei $4{ }^{\circ} \mathrm{C}$ über Nacht im Kühlschrank gelagert.

Tabelle 42: Komponenten für ein SDS-Polyacrylamidgel mit $1 \mathrm{~mm}$ Stärke

\begin{tabular}{|c|c|c|c|}
\hline Komponente & & & \\
\hline Trenngel & $12 \%$ & $8 \%$ & $15 \%$ \\
\hline $\mathrm{H}_{2} \mathrm{O}$-Bidest & $2,2 \mathrm{~mL}$ & $3,1 \mathrm{~mL}$ & $1,5 \mathrm{~mL}$ \\
\hline Trenngelpuffer & $1,8 \mathrm{~mL}$ & $1,8 \mathrm{~mL}$ & $1,8 \mathrm{~mL}$ \\
\hline $30 \%$ Acrylamid & $2,7 \mathrm{~mL}$ & 1,8 & $3,4 \mathrm{~mL}$ \\
\hline $10 \%$ APS & $100 \mu \mathrm{L}$ & $100 \mu \mathrm{L}$ & $100 \mu \mathrm{L}$ \\
\hline TEMED & $10 \mu \mathrm{L}$ & $10 \mu \mathrm{L}$ & $10 \mu \mathrm{L}$ \\
\hline gesamt & $6,81 \mathrm{~mL}$ & $6,81 \mathrm{~mL}$ & $6,81 \mathrm{~mL}$ \\
\hline \multicolumn{4}{|l|}{ Sammelgel } \\
\hline $\mathrm{H}_{2} \mathrm{O}$ Bidest & $1,8 \mathrm{~mL}$ & & \\
\hline Sammelgelpuffer & $0,8 \mathrm{~mL}$ & & \\
\hline $30 \%$ Acrylamid & $0,5 \mathrm{~mL}$ & & \\
\hline $10 \%$ APS & $50 \mu \mathrm{L}$ & & \\
\hline TEMED & $5 \mu \mathrm{L}$ & & \\
\hline gesamt & $3,155 \mathrm{~mL}$ & & \\
\hline
\end{tabular}

\subsubsection{Beladen der Gele}

Zum Beladen der Gele wurde der 4x Probenpuffer wie in Tabelle 41 beschrieben mit $\beta$-Mercaptoethanol versetzt und $5 \mu \mathrm{L}$ Probenpuffer zu je $15 \mu \mathrm{L}$ Probe hinzugegeben. Im Heizblock wurden die Proben bei $95^{\circ} \mathrm{C}$ für 10 min erhitzt, $25 \mathrm{sec}$ auf Eis abgekühlt und für $30 \mathrm{sec}$ bei RT mit 13.000 rpm zentrifugiert. Nach dem Auftragen der Proben wurde die SDS-PAGE mit $100 \mathrm{~V}$ durchgeführt, bis die blaue Farbbande des Probenpuffers den unteren Gelrand erreicht hatte. 


\subsubsection{Coomassie-Färbung von Polyacrylamidgelen}

In Tabelle 43 sind die Lösungen für die Coomassie-Färbung aufgelistet. Die Gele wurden von den Glasplatten gelöst und in $20 \mathrm{~mL}$ Coomassie-Färbelösung gelegt. Danach wurden sie für $20 \mathrm{sec}$ bei 300 Watt in der Mikrowelle erhitzt und 2 min auf dem Wippschüttler zum Schwenken gestellt. Dieser Schritt wurde dreimal wiederholt.

Anschließend wurde das Gel in Entfärbe-Lösung für $20 \mathrm{sec}$ bei 300 Watt in der Mikrowelle erhitzt, 5 min auf dem Wippschüttler geschwenkt und die gebrauchte Entfärbe-Lösung verworfen. Dieser Entfärbeschritt wurde nochmals wiederholt und das Gel mit frischer Entfärbe-Lösung und zusätzlichem Schwämmchen über Nacht vollständig entfärbt. Für die Dokumentation wurde das Gel in eine Plastikfolie gelegt und eingescannt.

Tabelle 43: Lösungen für die Coomassie-Färbung

\begin{tabular}{lll}
\hline Komponente & Menge & Endkonzentration \\
\hline Coomassie-Färbelösung & & \\
$\mathrm{H}_{2} \mathrm{O}-$ Bidest & $454 \mathrm{~mL}$ & \\
Coomassie Blue R-250 & $0,5 \mathrm{~g}$ & $0,05 \%(\mathrm{w} / \mathrm{v})$ \\
Methanol & $545 \mathrm{~mL}$ & $55 \%(\mathrm{v} / \mathrm{v})$ \\
Eisessig & $92 \mathrm{~mL}$ & $9,2 \%(\mathrm{v} / \mathrm{v})$ \\
& & \\
Entfärbe-Lösung & & \\
$\mathrm{H}_{2} \mathrm{O}-$ Bidest & $1,4 \mathrm{~L}$ & \\
Methanol & $500 \mathrm{~mL}$ & $25 \%(\mathrm{w} / \mathrm{v})$ \\
Eisessig & $100 \mathrm{~mL}$ & $5 \%(\mathrm{w} / \mathrm{v})$ \\
\hline
\end{tabular}

\subsubsection{Tricin-Polyacrylamidgelelektrophorese}

Diese SDS-Page wurde für die gelelektrophoretische Auftrennung von kleinen Proteinen mit einer Molekülmasse von 1-10 kDa verwendet (Jiang et al., 2016).

Die verwendeten Puffer und Lösungen sind in Tabelle 44 dargestellt. Der 10x Kathoden- und 10x Anodenpuffer wurde 1:10 in VE-Wasser verdünnt und bei $4{ }^{\circ} \mathrm{C}$ gelagert.

Tabelle 44: Puffer und Lösungen für die Tricin-SDS-PAGE

\begin{tabular}{lll}
\hline Komponente & Menge & Endkonzentration \\
\hline 10x Tricin-Anodenpuffer & & \\
Tris & $121,14 \mathrm{~g}$ & $1 \mathrm{M}$ \\
$7,7 \mathrm{M} \mathrm{HCl}$ & $29,7 \mathrm{~mL}$ & $0,225 \mathrm{M}$ \\
\cline { 2 - 3 } & ad $1 \mathrm{~L} \mathrm{VE-Wasser;} \mathrm{pH} \mathrm{8,9}$ & \\
& & \\
10x Tricin-Kathodenpuffer & $121,14 \mathrm{~g}$ & $1 \mathrm{M}$ \\
Tris & $179,2 \mathrm{~g}$ & $1 \mathrm{M}$ \\
Tricin & $10 \mathrm{~g}$ & $1 \%(\mathrm{w} / \mathrm{v})$ \\
SDS & ad $1 \mathrm{~L} \mathrm{VE-Wasser;} \mathrm{pH} 8,2$ & \\
& & \\
AB-3-Lösung & & $48 \%(\mathrm{w} / \mathrm{v})$ \\
Acrylamid & $48 \mathrm{~g}$ & $1,5 \%(\mathrm{w} / \mathrm{v})$ \\
Bisacrylamid & $1,5 \mathrm{~g}$ &
\end{tabular}




\begin{tabular}{|c|c|c|}
\hline 3x Tricin-Gelpuffer & & \\
\hline Tris & $181,7 \mathrm{~g}$ & $3 \mathrm{M}$ \\
\hline SDS & $1,5 \mathrm{~g}$ & $0,3 \%(w / v)$ \\
\hline & ad $500 \mathrm{n}$ & \\
\hline 4x Tricin-Probenpuffe & & \\
\hline SDS & $1,2 \mathrm{~g}$ & $12 \%(w / v)$ \\
\hline $87 \%$ Glycerin & $3,24 \mathrm{~mL}$ & $30 \%$ \\
\hline Coomassie blue R250 & $50 \mathrm{mg}$ & $0,05 \%(w / v)$ \\
\hline Tris & $0,18 \mathrm{~g}$ & $150 \mathrm{mM}$ \\
\hline & ad $10 \mathrm{~mL}$ & \\
\hline$\beta$-Mercaptoethanol & 0,25 fach & \\
\hline
\end{tabular}

Zur Herstellung des Tricin-SDS-Gels wurden die Komponenten für das Trenngel gemischt (Tabelle 45), direkt in die Gel-Gießapparatur gegossen und mit $200 \mu \mathrm{L}$ Isopropanol überschichtet. Nach der Polymerisation des Trenngels wurde das Isopropanol abgekippt. Die Komponenten für das Sammelgel wurden gemischt, auf das Trenngel gegossen und der Kamm für die Taschen hineingesteckt. Nach dem Erstarren des Sammelgels wurde das Gel in mit $\mathrm{H}_{2} \mathrm{O}-$ Bidest getränkte Papiertücher gewickelt und im Kühlschrank bei $4{ }^{\circ} \mathrm{C}$ über Nacht gelagert.

Tabelle 45: Komponenten zur Herstellung eines Tricin-SDS-Polyacrylamidgel

\begin{tabular}{lll}
\hline Komponente & Trenngel (16\% T, 3 \% C) & Sammelgel (4 \%) \\
\hline $\mathrm{H}_{2} \mathrm{O}-$-Bidest & $1,9 \mathrm{~mL}$ & $4 \mathrm{~mL}$ \\
$3 x$ Tricin-Gelpuffer & $2,5 \mathrm{~mL}$ & $1,5 \mathrm{~mL}$ \\
$\mathrm{AB}-3$-Lösung & $2,5 \mathrm{~mL}$ & $0,5 \mathrm{~mL}$ \\
$87 \%$ Glycerin & $0,6 \mathrm{~mL}$ & - \\
$10 \%$ APS & $45 \mu \mathrm{L}$ & $45 \mu \mathrm{L}$ \\
TEMED & $8 \mu \mathrm{L}$ & $7,5 \mu \mathrm{L}$ \\
gesamt & $7,55 \mathrm{~mL}$ & $6,05 \mathrm{~mL}$ \\
\hline
\end{tabular}

\subsubsection{Beladen der Gele}

Zur Probenvorbereitung wurde der 4x Tricin-Probenpuffer wie in Tabelle 44 mit $\beta$-Mercaptoethanol versetzt. Zu drei Teilen Probe wurde ein Teil Probenpuffer hinzu pipettiert und im Heizblock bei $95^{\circ} \mathrm{C}$ für 10 min erhitzt. Anschließend wurden die Proben $20 \mathrm{sec}$ auf Eis gestellt und für $30 \mathrm{sec}$ mit 13.000 rpm bei RT zentrifugiert. Es folgte das Auftragen der Proben und des entsprechenden Marker (Tabelle 12) auf das Gel. Die elektrophoretische Auftrennung erfolgte in drei Stufen. Begonnen wurde mit $40 \mathrm{~V}$, bis die Proben ins Sammelgel eingelaufen waren. Danach wurde auf $3 \mathrm{~W}$ für 1,5 h umgestellt. Anschließend wurde auf $5 \mathrm{~W}$ erhöht und bei Erreichen der blauen Pufferbande des unteren Gelrandes (ca. 1,5 h) wurde die Elektrophorese gestoppt. 


\subsubsection{Western Blot}

Für einen Western Blot wurde zuvor eine SDS-PAGE, die in Kapitel 2.4.5 beschrieben wurde, durchgeführt. Anschließend wurde das Sammelgel des SDS-Gels vom Trenngel entfernt und das Trenngel in den Transferpuffer für den Western Blot gelegt.

\subsubsection{Transfer der Proteine}

Der Transfer der Proteine erfolgte mittels Elektroblotting-Apparatur der Firma Biometra (Fastblot B43 Blotting Apparatur). Die verwendeten Puffer und Lösungen sind in Tabelle 46 dargestellt.

Tabelle 46: Puffer und Lösungen für den Western-Transfer

\begin{tabular}{|c|c|c|}
\hline Komponente & Menge & Endkonzentration \\
\hline \multicolumn{3}{|l|}{ Transferpuffer } \\
\hline Glycin & $11,3 \mathrm{~g}$ & $150 \mathrm{mM}$ \\
\hline $15 \%$ Methanol & $100 \mathrm{~mL}$ & $15 \%(v / v)$ \\
\hline \multirow[t]{2}{*}{ Tris } & $3 \mathrm{~g}$ & $25 \mathrm{mM}$ \\
\hline & \multicolumn{2}{|c|}{ ad 1L $\mathrm{H}_{2} \mathrm{O}-\mathrm{Bidest} ; \mathrm{pH} 8,5$ mit $\mathrm{HCl}$ eingestellt } \\
\hline \multicolumn{3}{|l|}{ Tintenfärbelösung } \\
\hline Tween 20 & $0,5 \mathrm{~mL}$ & $0,05 \%(v / v)$ \\
\hline Essigsäure & $10 \mathrm{~mL}$ & $1 \%(v / v)$ \\
\hline \multirow[t]{2}{*}{ Tinte } & $1 \mathrm{~mL}$ & $0,1 \%(v / v)$ \\
\hline & ad 1L 1x PBS & \\
\hline \multicolumn{3}{|l|}{ 10x PBS } \\
\hline $\mathrm{NaCl}$ & $80 \mathrm{~g}$ & $1,38 \mathrm{M}$ \\
\hline $\mathrm{KCl}$ & $2 \mathrm{~g}$ & $26 \mu \mathrm{M}$ \\
\hline $\mathrm{Na}_{2} \mathrm{HPO}_{4}$ & $11,5 \mathrm{~g}$ & $81 \mu \mathrm{M}$ \\
\hline \multirow[t]{2}{*}{$\mathrm{KH}_{2} \mathrm{PO}_{4}$} & $2 \mathrm{~g}$ & $15 \mu \mathrm{M}$ \\
\hline & ad 1L $\mathrm{H}_{2} \mathrm{O}$-Bidest; $\mathrm{pH} 7,4$ & \\
\hline \multicolumn{3}{|l|}{ 1x PBS } \\
\hline \multirow[t]{2}{*}{ 10x PBS } & $100 \mathrm{~mL}$ & \\
\hline & ad $1 \mathrm{~L} \mathrm{H}_{2} \mathrm{O}$-Bidest & \\
\hline \multicolumn{3}{|l|}{ 1x PBST } \\
\hline 10xPBS & $100 \mathrm{~mL}$ & \\
\hline \multirow[t]{2}{*}{ Tween 20} & $1 \mathrm{~mL}$ & $0,1 \%(v / v)$ \\
\hline & ad $1 \mathrm{~L} \mathrm{H}_{2} \mathrm{O}$-Bidest & \\
\hline \multicolumn{3}{|l|}{ Blocking-Lösung } \\
\hline \multirow[t]{2}{*}{ Magermilchpulver } & $5 \mathrm{~g}$ & \\
\hline & ad $100 \mathrm{~mL} 1 \times$ PBS & \\
\hline
\end{tabular}

10 Blätter 0,37 mm dickes Blottingpapier und eine Blottingmembran (Polyvinylidendifluorid: PVDF-Membran) wurden auf $6 \times 9 \mathrm{~cm}$ zugeschnitten. Das Blottingpapier wurde $10 \mathrm{~min}$ in Transferpuffer äquilibriert und 5 Blätter auf die Platte der Elektroblotting-Apparatur gelegt. Die Blottingmembran wurde für $10 \mathrm{~min}$ in $\mathrm{H}_{2} \mathrm{O}$-Bidest vorgequollen, für $10 \mathrm{~min}$ in Transferpuffer äquilibriert und auf den Blottingpapierstapel gelegt. Das zuvor in Transferpuffer äquilibrierte SDS-Gel wurde luftblasenfrei auf die Membran gelegt, weitere 5 Blätter des äquilibrierten Blottingpapiers folgten. Die Luftblasen wurden mittels Glasröhrchen heraus gewalzt und das Gel 
für $1,5 \mathrm{~h}$ bei $4 \mathrm{~mA} / \mathrm{cm}^{2}$ geblottet. Das Gel wurde wie in Kapitel 2.4.6 beschrieben in Coomassie gefärbt.

Zur Kontrolle wurde die Membran in Tintenfärbelösung 15 min gefärbt, das Bandenmuster dokumentiert und anschließend 10 min in $\mathrm{H}_{2} \mathrm{O}$-Bidest entfärbt. Die Membran wurde dann in Blocking-Lösung gelegt und über Nacht bei $4{ }^{\circ} \mathrm{C}$ unter Schwenken inkubiert.

\subsubsection{Immundetektion und Nachweisreaktion}

Der Western Blot wurde sowohl für die DHFR als auch für Proteine mit His-Tag durchgeführt. In Tabelle 47 sind die Antikörper und deren Verdünnung für die Immundetektion aufgeführt. Die über Nacht geblockte Membran wurde kurz in 1x PBS gespült und für 1,5 h bei RT in 15 $\mathrm{mL}$ Erstantikörperlösung inkubiert. Nach dreimaligem Waschen mit je $30 \mathrm{~mL}$ 1x PBST für 10 min wurde die Membran für 1,5 h bei RT in $15 \mathrm{~mL}$ Zweitantikörper inkubiert. Die Membran wurde erneut dreimal in $30 \mathrm{~mL}$ 1x PBST gewaschen.

Für die Nachweisreaktion wurde Roti® Lumin nach Angaben des Herstellers verwendet. Die Detektion erfolgte in der Dunkelkammer mittels Röntgenfilmen (GE Healthcare), die für $15 \mathrm{sec}$ bis $2 \mathrm{~h}$ aufgelegt wurden. Die exponierten Filme wurden $2 \mathrm{~min}$ in Entwicklerlösung geschwenkt, durch ein Wasserbad geführt und für 2 min in Fixierlösung gelegt. Zuletzt wurde der Röntgenfilm unter Wasser abgespült und getrocknet.

Tabelle 47: Antikörper für Penta-His und DHFR

\begin{tabular}{|c|c|c|}
\hline Antikörper & Konzentration & Puffer \\
\hline \multicolumn{3}{|l|}{ Nachweis Penta-His } \\
\hline $\begin{array}{l}\text { 1. AK Penta-His }{ }^{\mathrm{TM}} \text {-Antibody BSA-free } \\
\text { (QIAGEN GmbH, Hilden) }\end{array}$ & $1: 4000$ & Blocking-Lösung mit 0,1 \% (v/v) Tween 20 \\
\hline $\begin{array}{l}\text { 2. AK Anti-Mouse IgG Peroxidase } \\
\text { (Sigma-Aldrich, Steinheim) }\end{array}$ & $1: 5000$ & Blocking-Lösung \\
\hline \multicolumn{3}{|l|}{ Nachweis DHFR } \\
\hline $\begin{array}{l}\text { 1. AK Anti-GAB-DNF2, DHFR-AK } \\
\text { (Davids Biotechnologie, Regensburg) }\end{array}$ & $1: 4000$ & Blocking-Lösung mit 0,1 \% (v/v) Tween 20 \\
\hline $\begin{array}{l}\text { 2. AK Anti-Rabbit IgG Peroxidase } \\
\text { (Sigma-Aldrich, Steinheim) }\end{array}$ & $1: 10000$ & Blocking-Lösung \\
\hline
\end{tabular}

\subsubsection{Proteinbestimmung nach Pierce}

Der Bicinchoninsäure-Test erfolgte mittels Pierce ${ }^{\mathrm{TM}}$ BCA Protein Assay Kit der Firma Thermo Fisher Scientific. Hierfür wurde eine BSA-Reihe (0-2 mg/mL BSA) für die spätere Berechnung der Konzentration in Doppelbestimmung in eine 96 well-Mikrotiterplatte mit flachem Boden pipettiert. $10 \mu \mathrm{L}$ Proteinproben in Doppelbestimmung wurden in einer Verdünnung von 1:2, sowie 1:5 vorgelegt und anschließend mit je $200 \mu \mathrm{L}$ BCA-Reaktionslösung versetzt. Nach 20$25 \mathrm{~min}$ bei $37^{\circ} \mathrm{C}$ wurde die Platte bei einer OD von $562 \mathrm{~nm}$ gemessen. 


\subsubsection{Silberfärbung von SDS-Gelen}

Die Silberfärbung nach Blum wurde für die Visualisierung von Proteinen und Nukleinsäuren in SDS-Gelen verwendet (Blum H., Beier H., 1987). Die verwendeten Puffer und Lösungen für die Silberfärbung sind in Tabelle 48 aufgeführt.

Das SDS-Gel wurde hierfür 15 min in Fixierlösung und anschließend für 30 min in Sensitivierungslösung gelegt. Es folgte dreimaliges Waschen für je 5 min in $\mathrm{H}_{2} \mathrm{O}$-Bidest und 20 min Inkubation in Silbernitratlösung. Anschließend wurde das Gel für 5-10 min in Entwicklerlösung gelegt und die Färbereaktion mittels Stopplösung abgestoppt. Im Anschluss wurde das Gel 3x 5 min in $\mathrm{H}_{2} \mathrm{O}$-Bidest gewaschen und mittels Scanner dokumentiert.

Tabelle 48: Puffer und Lösungen für die Silberfärbung von SDS-Gelen

\begin{tabular}{|c|c|c|}
\hline Komponente & Menge & Endkonzentration \\
\hline \multicolumn{3}{|l|}{ Fixierlösung } \\
\hline Ethanol & $400 \mathrm{~mL}$ & $40 \%(v / v)$ \\
\hline \multirow[t]{2}{*}{ Eisessig } & $100 \mathrm{~mL}$ & $10 \%(v / v)$ \\
\hline & ad $1 \mathrm{~L} \mathrm{H}_{2} \mathrm{O}$-Bidest & \\
\hline \multicolumn{3}{|l|}{$\mathrm{Na}_{2} \mathrm{~S}_{2} \mathrm{O}_{3}$-Lösung } \\
\hline \multirow[t]{2}{*}{ Natriumthiosulfat } & $5 \mathrm{~g}$ & $5 \%(w / v)$ \\
\hline & ad $100 \mathrm{~mL} \mathrm{H} \mathrm{H}_{2} \mathrm{O}$-Bidest & \\
\hline \multicolumn{3}{|l|}{ Sensitivierungslösung } \\
\hline Ethanol & $30 \mathrm{~mL}$ & $6 \%(v / v)$ \\
\hline $\mathrm{Na}_{2} \mathrm{~S}_{2} \mathrm{O}_{3}$-Lösung & $20 \mathrm{~mL}$ & \\
\hline \multirow[t]{2}{*}{ Natriumacetat } & $34 \mathrm{~g}$ & $1,2 \mathrm{M}$ \\
\hline & ad $500 \mathrm{~mL} \mathrm{H} \mathrm{H}_{2} \mathrm{O}$-Bidest & \\
\hline \multicolumn{3}{|l|}{ Silbernitratlösung } \\
\hline \multirow{2}{*}{$\mathrm{AgNO}_{3}$} & $1,25 \mathrm{~g}$ & $0,25 \%(w / v)$ \\
\hline & ad $500 \mathrm{~mL} \mathrm{H} \mathrm{H}_{2} \mathrm{O}$-Bidest & \\
\hline \multicolumn{3}{|l|}{ Entwicklerlösung } \\
\hline Natriumcarbonat & $12,5 \mathrm{~g}$ & $2,5 \%(w / v)$ \\
\hline $\mathrm{Na}_{2} \mathrm{~S}_{2} \mathrm{O}_{3}$-Lösung & $10 \mu \mathrm{L}$ & \\
\hline \multirow[t]{2}{*}{$37 \%$ Formaldehydlösung } & $200 \mu \mathrm{L}$ & \\
\hline & ad $500 \mathrm{~mL} \mathrm{H} \mathrm{H}_{2} \mathrm{O}$-Bidest & \\
\hline \multicolumn{3}{|l|}{ Stopplösung } \\
\hline \multirow[t]{2}{*}{$\mathrm{Na}_{2}$-EDTA $\cdot 2 \mathrm{H}_{2} \mathrm{O}$} & $7,3 \mathrm{~g}$ & \\
\hline & ad $250 \mathrm{~mL} \mathrm{H} \mathrm{H}_{2} \mathrm{O}$-Bidest & \\
\hline
\end{tabular}

\subsubsection{Proteinanalyse in der MS-MS}

Für die Analyse von Polyacrylamidgelfragmenten und Proteinen in Lösung wurden die Proben an der Philipps Universität in Marburg mittels MS-MS analysiert.

Jeweils $75 \mu \mathrm{L}$ des ersten oder zweiten Eluats wurden nach Dialyse und Bestimmung der Proteinkonzentration mittels Proteinbestimmung nach Pierce (Kapitel 2.4.9) auf Eis verschickt. Banden aus Polyacrylamidgelen wurden ausgeschnitten und ebenfalls auf Eis verschickt.

Die aus Marburg erhaltenen MS-Daten in Excel-Form enthielt Gruppierungen zu Peptiden und eventuellen Modifikationen. Für statistische Auswertungen wurden diese, sowie deren 
Untergruppen entfernt. Anschließend wurden alle als Kontamination identifizierten Proteine entfernt. Darunter fallen humane Verunreinigungen wie Keratin oder, das für den Verdau der Proteine verwendete Enzym, Trypsin. Danach wurde die Excel-Tabelle nach Unique Peptides sortiert und alle Proteine mit einem Wert von unter 2 Unique Peptides entfernt. Die daraus resultierende Excel-Tabelle wurde mit den MS-Daten der DHFR und des Leerplasmids abgeglichen und die Proteine, die in den Kontrollen vorhanden waren, ebenfalls abgezogen. Zur einfacheren Auswertung der Daten wurden die ausgewerteten Tabellen mit Hilfe der Accession-Nummern mit den HVO-Nummern für die Orientierung erweitert. Für die weitere Auswertung wurden dann drei unabhängige Proben zusammengefasst und die Proteine, die als Triplikate identifiziert werden konnten, als co-gereinigte Proteine gewertet (https://www.uni-marburg.de/de/fb15/fachbereich/infrastruktur/servicelabors/massenspektrometrie-und-elementaranalytik/bioanalytik/hinweise-zur-dateninterpretation).

\subsubsection{FPLC}

Die fast protein liquid chromatography (FPLC) wurde für die analytische Gelfiltration nach der Affinitätsaufreinigung verwendet. Mittels FPLC sollte ein möglicher Komplex, der in der Affinitätsaufreinigung eluiert wurde, sichtbar gemacht werden. Die FPLC erfolgte mit den Eluaten der drei Untereinheiten von alF2: alF2 $\alpha, \beta-1, \beta-2$ und $\gamma$. Hierfür wurde in der Aufreinigung das doppelte Volumen an Zellsuspension eingesetzt. $200 \mu \mathrm{L}$ des zweiten Eluates wurde direkt nach der Aufreinigung für die FPLC verwendet. Die analytische Gelfiltration erfolgte auf einer Superose ${ }^{\circledR}$ 6HR 10/30 Säule (Amersham Pharmacia Biotech; Säulenvolumen 24 mL, Ausschlusslimit $4{ }^{*} 10_{7} \mathrm{Mr}$ ). Die Fraktionierung erfolgte in je $500 \mu \mathrm{L}$ Volumen bei einer Flussrate von $0,3 \mathrm{~mL} / \mathrm{min}$. Die Zusammensetzung des FPLC-Laufpuffers ist in der nachfolgenden Tabelle aufgeführt. Ein Teil der Fraktionen wurden anschließend dialysiert, auf ein SDS-Gel aufgetragen und in der MS-MS analysiert.

Tabelle 49: Laufpuffer für die FPLC

\begin{tabular}{lll}
\hline Komponente & Menge & Endkonzentration \\
\hline Laufpuffer & $125 \mathrm{~g}$ & $2,1 \mathrm{M}$ \\
$\mathrm{NaCl}$ & $4,77 \mathrm{~g}$ & $20 \mathrm{mM}$ \\
\cline { 2 - 3 } $\mathrm{HEPES}$ & $\mathrm{ad} 1 \mathrm{~L} \mathrm{H}_{2} \mathrm{O}-\mathrm{Bidest} ; \mathrm{pH} 7,2$ & \\
\end{tabular}




\section{Ergebnisse}

Translationsinitiationsfaktoren sind in allen drei Domänen des Lebens essenziell für die Translation. Bislang konnte für $H$. volcanii gezeigt werden, dass fünf der $14 \mathrm{im}$ Genom annotierten alFs und deren Untereinheiten sind. Die anderen neun alFs konnten deletiert werden. Sie wurden daher als nicht essenziell eingestuft. Zur Untersuchung und vertiefenden Charakterisierung der Translationsinitiationsfaktoren wurden alle in $H$. volcanii bekannten alFs überexprimiert, affinitätsgereinigt und mittels MS-MS analysiert.

\section{1 Überexpression von alFs im Stamm H26 1279 und Deletionsmutanten}

Zu Beginn der Arbeit erfolgte die Überprüfung von vorhandenen Deletionsmutanten über den Southern Blot. Wenn keine Deletion mehr nachgewiesen werden konnte, wurden die Mutanten im Stamm H26 1279 neu erstellt. Dieser Stamm wurde zudem als Wildtyp für diese Arbeit verwendet. Des Weiteren folgte die Wahl des Affinitäts-Tags für die Affinitätsaufreinigung mit Hilfe des Reportergens DHFR.

\subsubsection{Erstellung von alF-Deletionsmutanten}

Ein Teil der Deletionsmutanten wurden bereits von Katrin Gäbel erstellt (Gäbel et al., 2013). Die vorhandenen Mutanten wurden mittels Southern Blot überprüft. Für die Überprüfung wurden die Mutanten in $30 \mathrm{~mL}$ Komplexmedium angezogen und für die Isolation der genomischen DNA in der exponentiellen Wachstumsphase geerntet. Die genomische DNA wurde dann mit einem geeigneten Enzym verdaut und auf ein Agarosegel aufgetragen. Für die Deletionsmutante von alF2 $\alpha$ wurde genomische DNA mit Mval verdaut. Der Southern Blot wurde mit der Sonde aus den Oligonukleotiden P3 und P4 für alF2 $\alpha$ (siehe auch Kapitel 2.3.10) durchgeführt (Abbildung 13A).

A

12

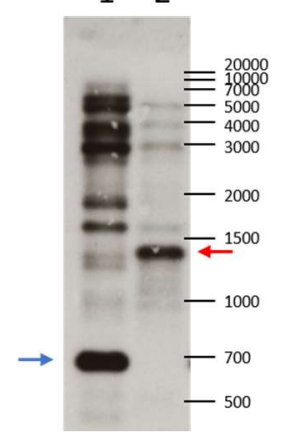

B

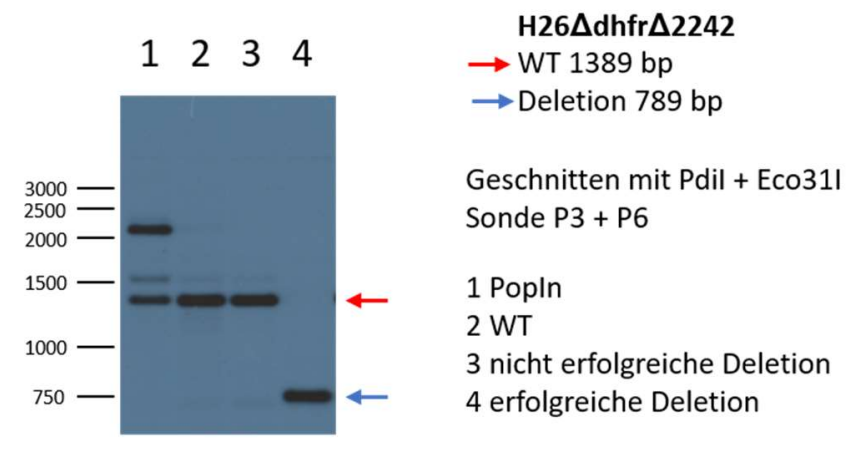

Abbildung 13: Überprüfung der vorhanden Deletionsmutanten und Generierung neuer Deletionsmutanten A. Southern Blot als Nachweis für die vorhandene alF2a-Deletionsmutante (blauer Pfeil, Bande Deletion) im Ver-

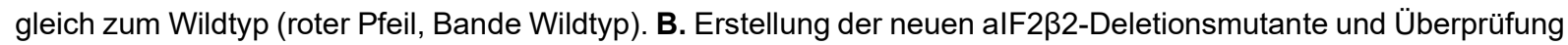
anhand eines Southern Blots. Aufgetragen wurden die Popln-Mutante, der Wildtyp (roter Pfeil, Bande Wildtyp), die negative Deletionsmutante und die positive/erfolgreiche Deletionsmutante (blauer Pfeil, Bande Deletion). 
Die Deletion von alF1A-2, alF2 $\beta 1$ und alF2 $\beta 2$ konnte in den vorhandenen Deletionsmutanten im Southern Blot nicht bestätigt werden. Daher wurden neue Deletionsmutanten erstellt. Dies erfolgte mit der Popln-PopOut-Methode im Stamm H26 1279 , die in Kapitel 2.3.3 beschrieben wurde (Abbildung 12). Dieser Stamm wurde bereits für die vorhandenen Deletionsmutanten verwendet. Auf dem Locus HVO_1279 codiert das Gen hdrA für die Dihydrofolatreduktase (HVO_1279), das als Reportergen in H. volcanii verwendet wird.

Die Selektion auf Popln- und PopOut-Medium erfolgte wie in Kapitel 2.3.3 beschrieben. Zur Kontrolle der Deletionsstämme wurde ein Southern Blot durchgeführt (Kapitel 2.3.10).

In Abbildung 13B sind der Southern Blot der Deletion von alF2 $\beta 2$ mit Popln, WT, sowie der erfolgreichen Deletion abgebildet. Mit den Enzymen Pdil und Eco31I wurde die genomische DNA verdaut. Die Sonde wurde mittels Oligonukleotid P3 und P6 für alF2 22 amplifiziert.

Auch alF1A-2 und alF2 $\beta 1$ konnten mittels in-frame-Deletion erfolgreich deletierten werden (Daten nicht gezeigt).

In Anlehnung an (Gäbel et al., 2013) wurden die Deletionsmutanten anhand ihres Wachstums unter verschiedenen Bedingungen getestet und mit den vorhandenen Daten verglichen (Daten nicht gezeigt).

\subsubsection{Wahl des Affinitäts-Tags für die Aufreinigung}

Für die optimale Aufreinigung der Initiationsfaktoren wurden drei verschiedene Tags anhand des Reportergens DHFR getestet. Diese umfassten die Zellulosebindedomäne (CBD), Streptavidin (BBP) und ein Polyhistidin-Tag (6xHis). Sowohl der 6xHis- als auch der BBP-Tag wurde mittels Fusion von jeweils zwei Oligonukleotiden hergestellt. Die DNA-Sequenz für die CBD wurde aus dem Plasmid pWL-CBD-Hq1489 amplifiziert. Das Plasmid wurde von der Arbeitsgruppe um Prof. Dr. Jerry Eichler (Ben-Gurion University of the Negev, Israel) zur Verfügung gestellt. Die Zellulosebindedomäne stammte aus Clostridium thermocellum (Morag et al., 1995). Die Tags wurden jeweils $\mathrm{N}$-terminal an die DHFR in den pSD1R16 kloniert und in H26 1279 transformiert. Mittels Methanol-Chloroform-Extraktion (Kapitel 2.4.2) wurden die Proteine aus je zwei exponentiellen Zellkulturen extrahiert, dialysiert und jeweils $75 \mu \mathrm{g}$ auf ein SDS-Gel aufgetragen (Kapitel 2.4.5).

Nach der elektrophoretischen Auftrennung wurden die SDS-Gele mittels Coomassie gefärbt (Abbildung 14).

Als Positivkontrolle diente der Deletionsstamm H26 1279 mit dem Gen der DHFR im pSD1R16 ohne jeweiligen Affinitäts-Tag. Bei der Positivkontrolle und der Variante mit 6xHisTag wurde im Vergleich zum Deletionsstamm eine zusätzliche Bande nachgewiesen. 


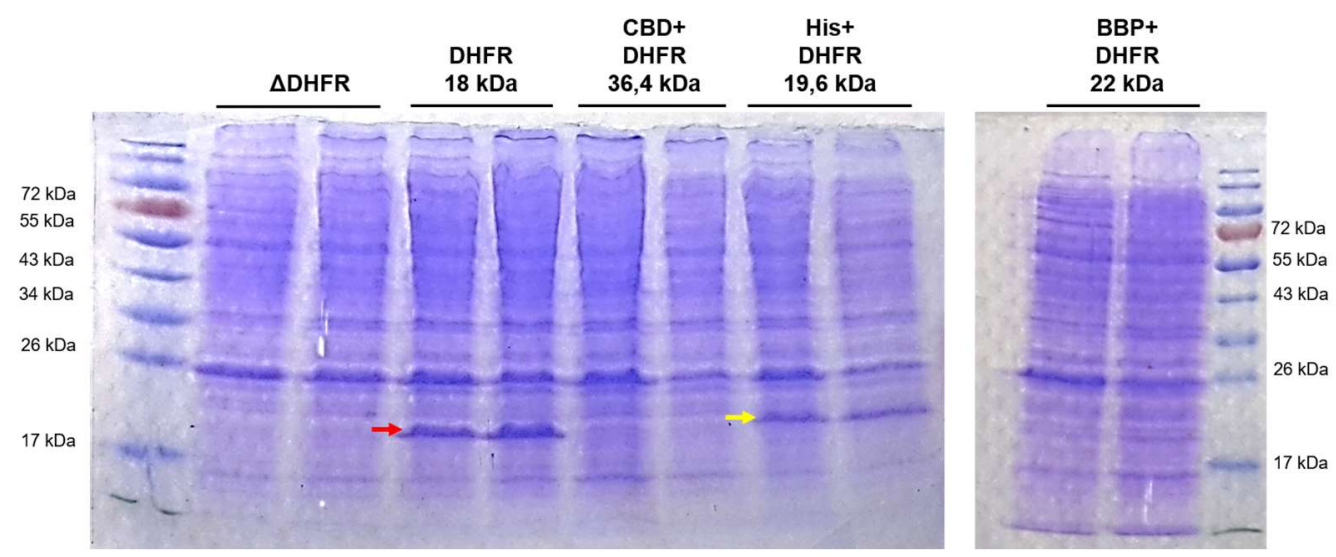

Abbildung 14: Testung von CBD, BBP und 6xHis-Tag anhand der DHFR (HVO_1279)

Auf einem $12 \%$ SDS-Polyacrylamidgel wurden je $75 \mu \mathrm{g}$ Proteinextrakt aufgetragen, elektrophoretisch aufgetrennt und mittels Coomassie gefärbt. Aus den Proteinextrakten konnte eine Bande entsprechender Größe für die Überexpression der DHFR ohne Tag (roter Pfeil) sowie für die Variante mit 6xHis-Tag (gelber Pfeil) nachgewiesen werden. Für den Tag mit der CBD und den Tag mit der BBP konnte keine Bande mit entsprechender Größe detektiert werden.

Zur weiteren Untersuchung wurde ein Western Blot mit einem Antikörper gegen die DHFR durchgeführt (Abbildung 15).

Im Western blot wurde die DHFR für die Positivkontrolle und 6xHis-DHFR nachgewiesen. Auch bei der DHFR mit dem BBP-Tag konnte die DHFR nachgewiesen werden, wenn auch in einer geringeren Menge. Für die Kombination DHFR mit dem CBD-Tag konnte kein Protein mit entsprechender Größe mittels Western Blot detektiert werden. Da sich der 6xHis-Tag als der am effizienteste der drei Protein-Tags erwies, wurde er für alle Aufreinigungen in dieser Arbeit verwendet.

A

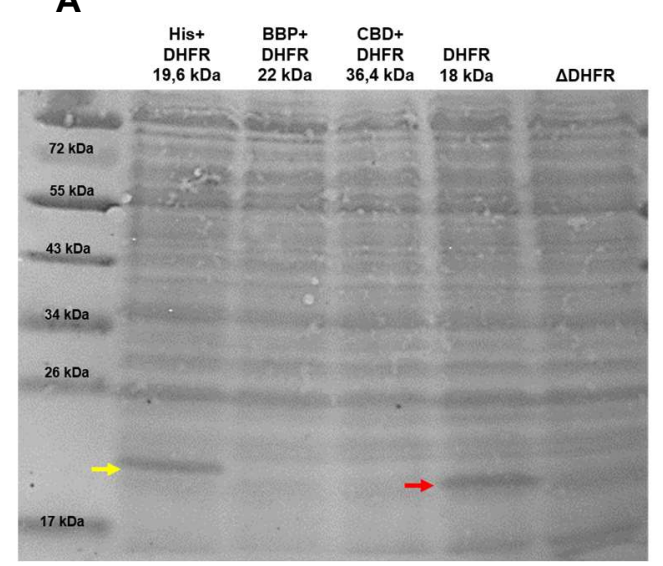

B

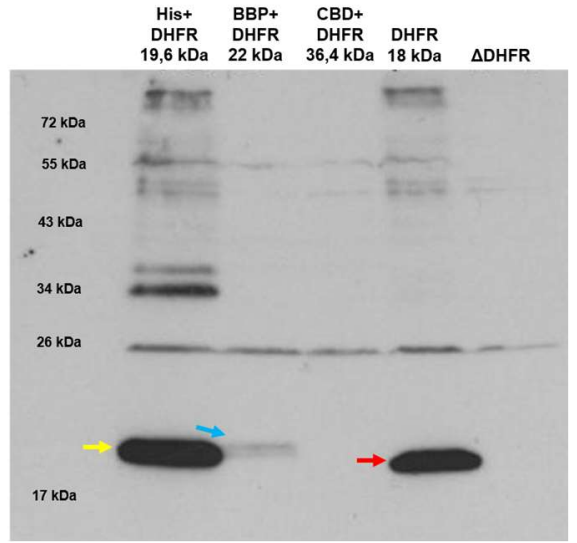

Abbildung 15: Western Blot mittels Antikörper gegen die DHFR (HVO_1279)

A. Bereits auf der geblotteten Membran konnte die His-getaggte DHFR (gelber Pfeil), als auch die nicht-getaggte Variante (roter Pfeil) visualisiert werden. B. Sowohl für His-DHFR (gelber Pfeil), als auch für BBP-DHFR (blauer Pfeil) konnten im Western Blot die Fusionsproteine nachgewiesen werden. Als Kontrolle diente die DHFR (roter Pfeil) ohne Tag. 


\title{
3.1.3 Etablierung der Co-Affinitätsaufreinigung
}

Da die Überexpression mit N-terminalem 6xHis-Tag erfolgreich war, wurde die Aufreinigung über Sepharose-Beads in einem pull-down-Assay etabliert (Abbildung 16).

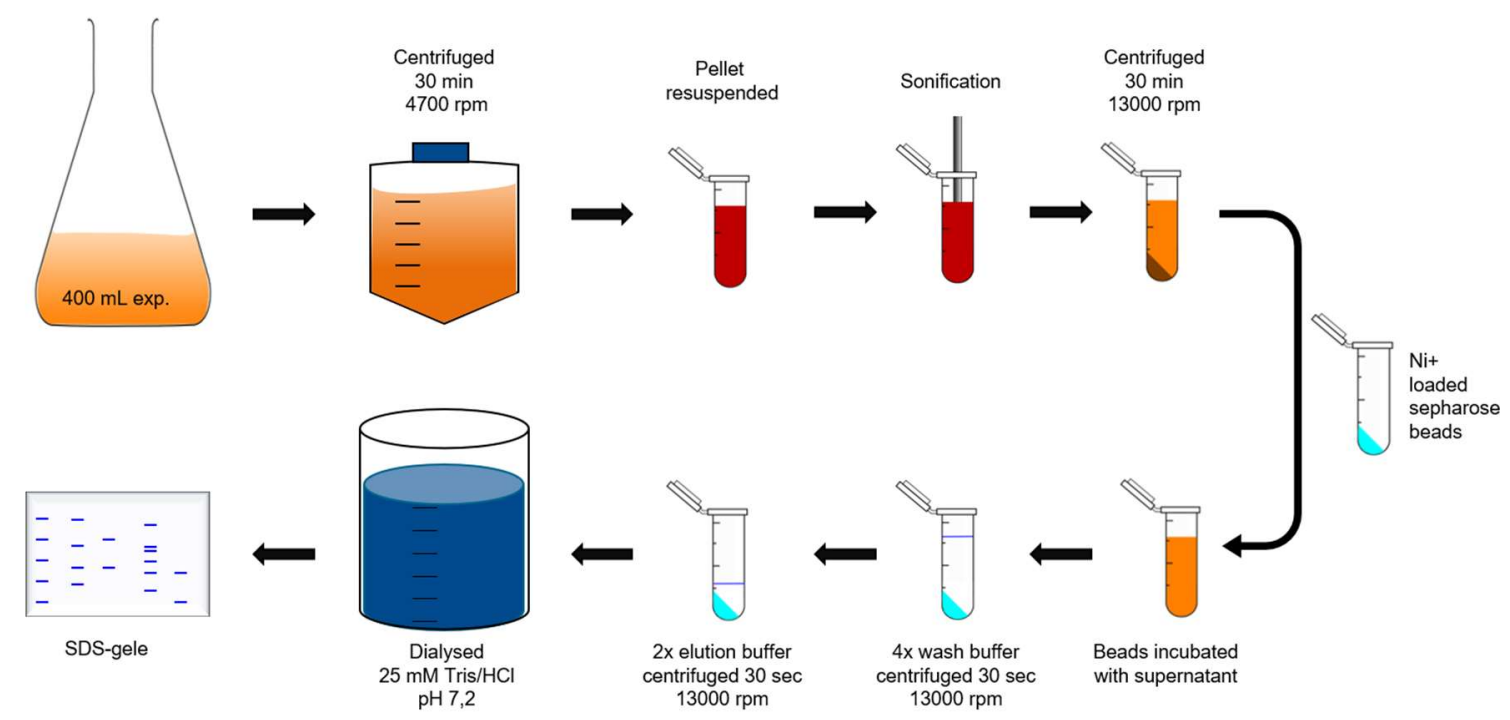

Abbildung 16: Schema für die Affinitätsaufreinigung über einen pull-down-Assay

Die Zellen wurden geerntet und abzentrifugiert. Das Pellet wurde in Bindepuffer resuspendiert, mittels Ultraschallsonde aufgeschlossen und die Zelltrümmer pelletiert. Der Überstand wurde auf Nickel-beladene Sepharose-Beads pipettiert. Anschließend folgten vier Waschschritte sowie zwei Elutionsschritte. Da die Aufreinigungen nativ stattfanden, wurden die Eluate dialysiert.

Hierfür wurden $400 \mathrm{~mL}$ Zellkultur im exponentiellen Wachstumsstadium, wie in Kapitel 2.4.3 beschrieben, geerntet und abzentrifugiert. Da die Aufreinigungen unter nativen Bedingungen stattfanden, wurden die gesammelten Proben gegen $25 \mathrm{mM}$ Tris/ $\mathrm{HCl} \mathrm{pH} \mathrm{7,2} \mathrm{dialysiert} \mathrm{und} \mathrm{auf}$ ein SDS-Gel aufgetragen. Nach der elektrophoretischen Auftrennung wurden die SDS-Gele mittels Coomassie gefärbt. In Abbildung 17 ist die erfolgreiche Affinitätsaufreinigung der DHFR (20 kDa) dargestellt.

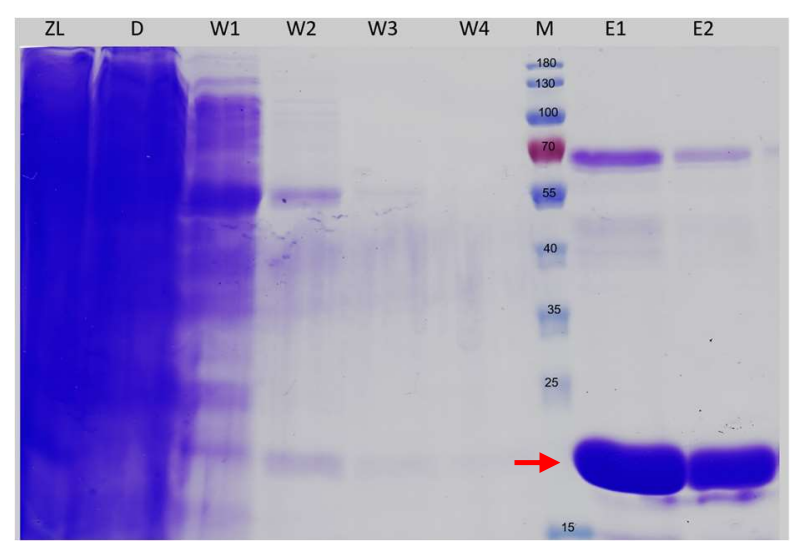

\begin{abstract}
Abbildung 17: Affinitätsaufreinigung der DHFR aus exponentieller Kultur

Die verschiedenen Teilschritte der Affinitätsaufreinigung wurden gesammelt und gegen $0,25 \mathrm{mM}$ Tris/ $\mathrm{HCl} \mathrm{pH} \mathrm{7,2} \mathrm{dialysiert.} \mathrm{Auf} \mathrm{einem} 12 \%$ SDS-Gel wurde von links nach rechts das Zelllysat (ZL), der Durchlauf (D), die Waschschritte (W1-W4) und die Elutionsfraktionen (E1-E2) aufgetragen. Nach der elektrophoretischen Auftrennung wurde das SDSGel mit Coomassie gefärbt. Die DHFR liegt bei 20 kDa (roter Pfeil).
\end{abstract}

Die Probe des Zelllysats (ZL) wurde direkt vor dem Auftragen des Zelllysats auf die Sepharose-Beads abgenommen. Der Durchlauf (D) beschreibt das Zelllysat nach dem es von den beladenen Sepharose-Beads wieder abgenommen wurde. Die vier Waschschritte (W1-W4), und die Elutionsfraktionen (E1-E2) wurden jeweils nach dem Waschen bzw. der Elution 
abgenommen. Bei der Affinitätsaufreinigung konnte ein hoher Reinigungseffekt erzielt werden. Neben der DHFR konnten nur wenige zusätzliche Banden auf dem Gel nachgewiesen werden.

Für die weitere Charakterisierung wurden Wachstumsversuche in Komplexmedium durchgeführt. Um die Auswirkungen des Novobiocin und der Überexpression besser einschätzen zu können wurde als Kontrolle in der Deletionsmutante ein Leerplasmid (pSD+P) mitgeführt. Dieses repräsentiert den pSD1R16 jedoch ohne funktionales Gen. In Abbildung 18A sind im Vergleich der Stamm H26 1279 mit pSD+P und die Überexpression der DHFR im Stamm H26 1279 dargestellt. Wobei letztere im Vergleich ein besseres Wachstumsverhalten zeigte.

Die erfolgreiche Aufreinigung der His-getaggten DHFR mit einer Größe von 19,6 kDa ist in Abbildung 18B gezeigt. Sowohl die Überexpressionsmutante der DHFR (H26 1279 mit pSDH1279) als auch die Deletionsmutante mit dem Leerplasmid (H26 1279 mit pSDH1279) wurden in der MS analysiert (siehe nächstes Kapitel).

A

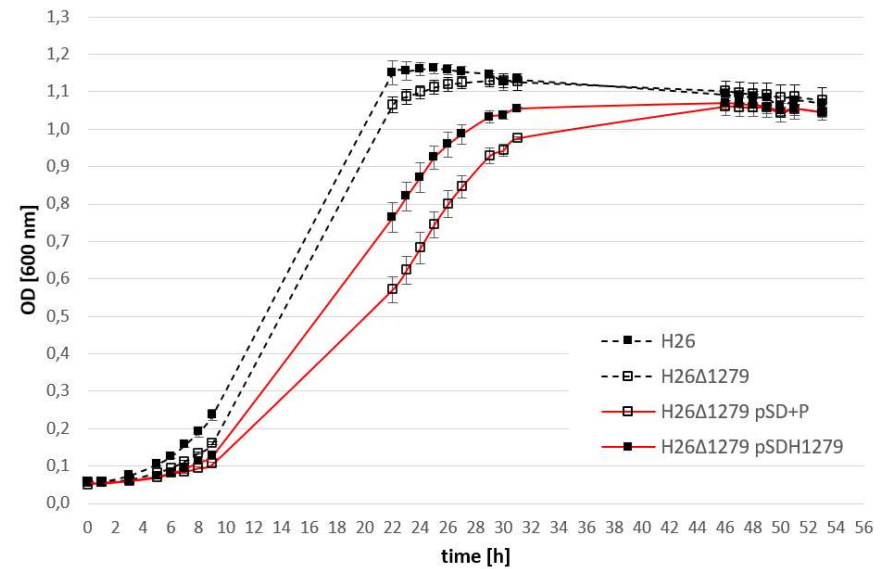

B

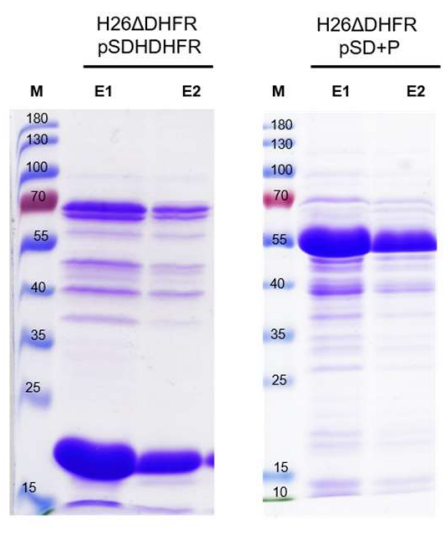

Abbildung 18: Überexpression der DHFR (HVO_1279) und des Leerplasmids (pSD+P)

A. Die Überexpressionsmutante wurde unter optimalen Bedingungen bei $42{ }^{\circ} \mathrm{C}$ in Komplexmedium mit dem Wildtyp und der Deletionsmutante verglichen. Als weitere Kontrolle diente das Leerplasmid im Deletionsstamm. B. Eluat eins und zwei der 6xHis-DHFR (pSDH1279) und der Kontrolle des Leerplasmids pSD+P im Deletionsstamm $\mathrm{H} 26 \Delta 1279$ aus der Affinitätsaufreinigung. Nach der Dialyse auf ein $12 \%$ SDS-Polyacrylamidgel aufgetragen und anschließend Coomassie gefärbt.

\subsubsection{Etablierung der Identifizierung von Proteinen durch Peptide mass fingerprinting}

Für die Überprüfung der erfolgreichen Aufreinigung und den Ausschluss von unspezifischen, gebundenen Proteinen wurden die Überexpressionsmutante der 6xHis-DHFR und des Leerplasmides in $\mathrm{H} 26 \Delta 1279$ herangezogen. Beide dienten in ihrer Funktion als Negativkontrollen für die weiteren Analysen. Mit der 6xHis-DHFR wurden spezifische Proteine, die durch die Überexpression hoch reguliert wurden und an das Säulenmaterial binden, ausgeschlossen. Um spezifisch bindende Proteine, die selbst Polyhistidine enthalten und die an das Säulenmaterial binden, ausschließen zu können, wurde sowohl die 6xHis-DHFR, als auch der pSD+P verwendet. Der pSD+P diente auch zusätzlich als Kontrolle für die Wachstumsversuche und die Antibiotikaresistenz. Dieses Leerplasmid entspricht dem Überexpressionsplasmid pSD1R16 mit der Ausnahme, dass es kein zu überexprimierendes Gen enthält. 
Zur MS-Analyse wurden die Proben versendet. Die Ergebnisse der Analyse wurden in Form einer Excel-Tabelle mit allen Hits erhalten. Zur Auswertung wurde sich an den peptide-spectrum-matches (PSM) orientiert und nur Peptide mit mindestens zwei und mehr Unique Peptides für die Auswertung verwendet. Des Weiteren wurden die als Kontamination identifizierten Proteine aus der Liste entfernt.

Für das in H26 1279 pSD+P ergaben sich nach der Auswertung der Daten, sieben identifizierte Proteine (Tabelle 50), darunter auch cdc48d (AAA-type ATPase core domain protein bzw. ArNOG05511 family protein, HVO_1907).

Tabelle 50: MS-Analyse des pSD+P ( $n=3)$

\begin{tabular}{llll}
\hline Gene ID & Accession & Description & MW [kDa] \\
\hline HVO_0359 & D4GZY6 & Elongation factor 1-alpha & 45,7 \\
HVO_0454 & D4GRZ5 & Alanine dehydrogenase & 35,6 \\
HVO_1577 & L9VF61 & TR & 19,4 \\
HVO_1907 & D4GTE0 & ArNOG05511 family protein & 53,4 \\
HVO_2384 & L9V766 & Uncharacterized protein & 42,5 \\
HVO_2663 & D4GV33 & Putative oxidoreductase (Aldo-keto reductase family protein) & 32,5 \\
HVO_2783 & L9V7N1 & 30S rpS4 & 20,1 \\
\hline
\end{tabular}

Für die Überexpression der DHFR ergaben sich nach der Auswertung 30 identifizierte Proteine, die in allen drei Aufreinigungen in der MS-Analyse identifiziert wurden (Tabelle 51).

Tabelle 51: MS-Analyse der DHFR $(n=3)$

\begin{tabular}{|c|c|c|c|}
\hline Gene ID & Accession & Description & MW [kDa] \\
\hline HVO_1279 & L9UT07 & Dihydrofolate reductase & 18 \\
\hline HVO_0019 & D4GYL4 & Putative S-adenosylmethionine-dependent methyltransferase & 25,6 \\
\hline HVO_0133 & 030561 & Thermosome subunit 1 & 58,9 \\
\hline HVO_0359 & D4GZY6 & Elongation factor 1-alpha & 45,7 \\
\hline HVO_0536 & D4GS68 & Ferritin & 19,9 \\
\hline HVO_0831 & D4GUG7 & YgfD family GTPase & 39,6 \\
\hline HVO_1572 & D4GZ01 & DNA gyrase subunit B & 71,2 \\
\hline HVO_1575 & D4GZO4 & Arginase & 31 \\
\hline HVO_1576 & L9VEX5 & UDP-glucose 4-epimerase & 33,9 \\
\hline HVO_1758 & L9VDG7 & Thioredoxin reductase & 36,3 \\
\hline HVO_1871 & D4GSX4 & Heme-binding protein $\mathrm{HemQ}$ & 56,1 \\
\hline HVO_1907 & D4GTE0 & AAA-type ATPase core domain protein & 53,4 \\
\hline HVO_1950 & D4GTH9 & Uncharacterized protein & 18,6 \\
\hline HVO_2040 & D4GU54 & GalE family epimerase/dehydratase & 33,8 \\
\hline HVO_2297 & D4GWG0 & Deoxyhypusine synthase & 38,6 \\
\hline HVO_2381 & D4GWM9 & UPF0272 protein HVO_2381 & 52,3 \\
\hline HVO_2514 & L9V6R5 & ArsR family TR & 24,1 \\
\hline HVO_2536 & D4GTW8 & TIGR00300 family protein & 44,8 \\
\hline HVO_2542 & L9V7W8 & $50 \mathrm{~S} \mathrm{rpL15}$ & 17,8 \\
\hline HVO_2645 & D4GUY1 & Molybdopterin adenylyltransferase & 20,7 \\
\hline HVO_2663 & D4GV33 & Putative oxidoreductase (Aldo-keto reductase family protein) & 32,5 \\
\hline HVO_2979 & L9UI09 & Cobalamin synthesis protein/P47K & 46,8 \\
\hline HVO_A0388 & L9V129 & Transcriptional regulator, AsnC family protein & 20,1 \\
\hline HVO_A0418 & D4GQE6 & HTH domain protein & 17,9 \\
\hline HVO_A0487 & D4GRF0 & Cobyrinate a,c-diamide synthase & 46,9 \\
\hline HVO_B0053 & D4GP55 & DUF3209 family protein & 13,9 \\
\hline HVO_B0054 & D4GP56 & Sirohydrochlorin cobaltochelatase & 44,1 \\
\hline HVO_B0071 & O34179 & Dehydrogenase & 41,4 \\
\hline HVO_B0115 & L9VKB0 & Fumarylacetoacetate hydrolase domain containing $2 \mathrm{~A}$ & 30,3 \\
\hline HVO_B0151 & D4GPF2 & Putative nickel-responsive regulator & 16,1 \\
\hline
\end{tabular}


Darunter waren vor allem Proteine, die in ihrer Aminosäuresequenz Poly-Histidin aufwiesen, wie z.B. HemQ (pitA, HVO_1871) und cdc48d. Die Co-Reinigung der beiden Proteine wurde bereits im Jahr 2010 von Allers und 2012 von Stroud beschrieben (Allers et al., 2010; Stroud, Liddell and Allers, 2012).

Es wurden in den MS-Daten viele Proteine des Zentralstoffwechsels und des Zellstoffwechsel identifiziert. Sie werden in dieser Arbeit nicht diskutiert, da nicht klar ist, ob sie die Translation beeinflussen. Sie konnten damit in dieser Arbeit nicht definiert werden. Ein Beispiel hierfür ist die Moonlight Enolase, die im Zentralstoffwechsel und dem DNA-Turnover beteiligt ist (Jia, Cheong and Zhang, 2013; Jeffery, 2016).

Die ausgewerteten MS-Daten der DHFR und des Leerplasmids wurden als Grundlage für den Ausschluss mitgereinigter Proteine verwendet und als Kontrolle von allen weiteren MSDaten abgezogen.

\subsubsection{Erstellung der Überexpressionsmutanten}

Für die essenziell eingestuften Initiationsfaktoren alF1, alF2y, alF5A, alF5B und alF6 fand die Überexpression im Stamm H26 $\Delta$ dhfr statt. Deshalb wurde er als Wildtyp bezeichnet. Für die nicht essenziell eingestuften alFs, mit Ausnahme von alF2B $\delta$-1, erfolgte die Überexpression in der entsprechenden Deletionsmutante. Dieser Faktor wurde auch im Wildtyp überexprimiert.

In Tabelle 52 sind die Initiationsfaktoren und deren Untereinheiten mit Genname, verwendetem Stamm für die Überexpression, die Protein-ID (Accession) von UniProt sowie das Molekulargewicht aufgelistet. Alle 14 annotierten Faktoren wurden mit einem N-terminalen His-Tag in das Plasmid pSD1R16 kloniert, das den konstitutiven fdx-Promotor enthält. Alle Überexpressionsmutanten wurden jeweils in dreifach-Bestimmung in der exponentiellen Wachstumsphase aufgereinigt.

Tabelle 52: Überexpression der einzelnen Initiationsfaktoren in der Deletion oder im Wildtyp

\begin{tabular}{|c|c|c|c|c|}
\hline Gene & Gene ID & Strain & Accession & MW [kDa] \\
\hline$d h f r$ & HVO_1279 & $\mathrm{H} 26 \Delta 1279$ & L9UT07 & 18,0 \\
\hline alF1 & HVO_1946 & $\mathrm{H} 26 \Delta 1279$ & D4GTH5 & 11,0 \\
\hline alF1A-1 & HVO_0136 & $\mathrm{H} 26 \Delta 1279 \Delta 0136$ & D4GZ79 & 11,5 \\
\hline alF1A-2 & HVO_A0637 & $\mathrm{H} 26 \Delta 1279 \Delta \mathrm{A} 0637$ & D4GRU5 & 11,2 \\
\hline alF2 $\alpha$ & HVO_0699 & $\mathrm{H} 26 \Delta 1279 \Delta 0699$ & D4GT46 & 29,5 \\
\hline alF2 $2 \beta-1$ & HVO_1678 & $\mathrm{H} 26 \Delta 1279 \Delta 1678$ & D4GZP2 & 15,0 \\
\hline alF2 $\beta-2$ & HVO_2242 & $\mathrm{H} 26 \Delta 1279 \Delta 2242$ & D4GVV8 & 22,2 \\
\hline alF2y & HVO_1901 & $\mathrm{H} 26 \Delta 1279$ & D4GTD4 & 44,0 \\
\hline alF2Ba & HVO_1934 & $\mathrm{H} 26 \Delta 1279 \Delta 1934$ & D4GTG3 & 43,2 \\
\hline alF2Bס-1 & HVO_0966 & $\mathrm{H} 26 \Delta 1279$ & L9USK7 & 35,0 \\
\hline alF2B $2-2$ & HVO_2706 & $\mathrm{H} 26 \Delta 1279 \Delta 2706$ & D4GW08 & 30,8 \\
\hline elF4A-homolog & HVO_1333 & $\mathrm{H} 26 \Delta 1279 \Delta 1333$ & D4GXK1 & 104,5 \\
\hline alF5A & HVO_2300 & $\mathrm{H} 26 \Delta 1279$ & D4GWG6 & 14,2 \\
\hline alF5B & HVO_1963 & $\mathrm{H} 26 \Delta 1279$ & D4GTJ2 & 65,4 \\
\hline alF6 & HVO_0117 & $\mathrm{H} 26 \Delta 1279$ & D4GYW3 & 23,0 \\
\hline
\end{tabular}




\subsection{Co-Affinitätsaufreinigung und MS-Analyse}

Mittels 6 xHis-DHFR wurde die Affinitätsaufreinigung und die MS-Analyse für $H$. volcanii in dieser Arbeit etabliert. Die Methode wurde dann für die Untersuchung der Translationsinitiationsfaktoren übernommen. Die Faktoren wurden in dreifach-Bestimmung affinitätsgereinigt, die Elutionsfraktionen zur MS-Analyse geschickt und die erhaltenen Daten, wie in Abbildung 19 beschrieben, ausgewertet. Entsprechend dieses Schemas wurde für alle MS-Daten des Netzwerks vorgegangen.

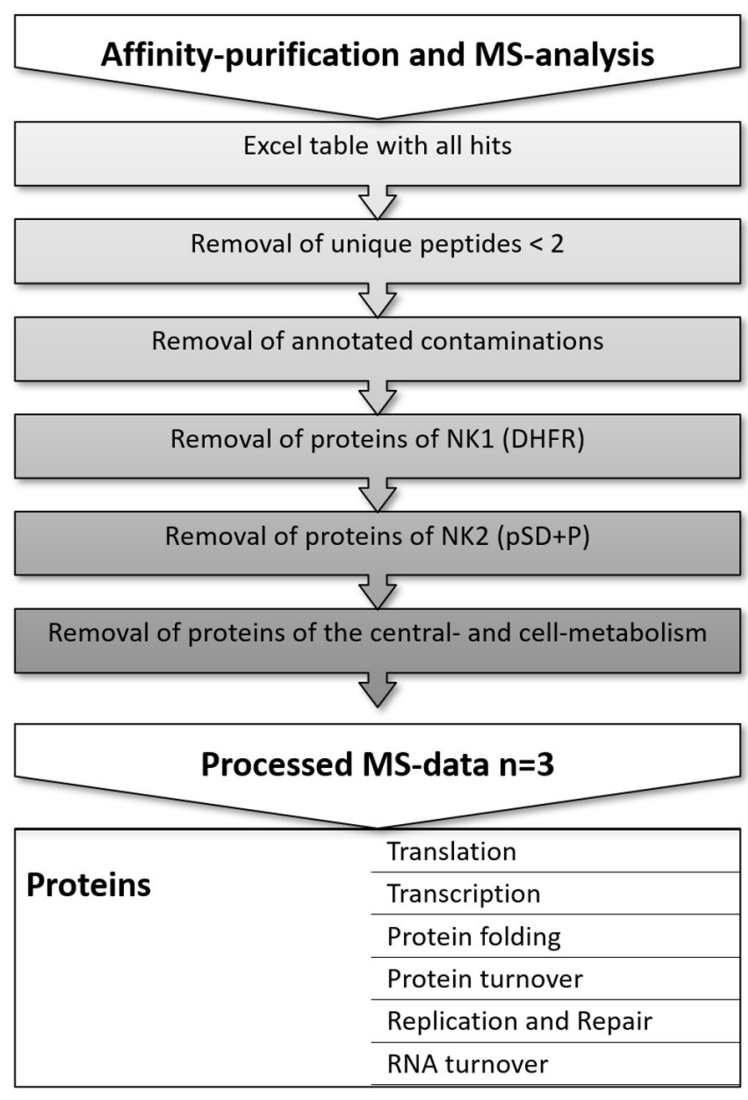

Abbildung 19: Auswertung der MS-Daten

Vorgehensweise für alle MS-Daten zur Erstellung der Netzwerke.

Die nach der Auswertung übrig gebliebenen Proteine konnten der Translation, Transkription, Proteinfaltung, dem RNA- und Protein-Turnover sowie der DNA-Replikation und -Reparatur zugeordnet werden.

\subsection{1 alF1}

Der Translationsinitiationsfaktor alF1 ist ein essenzieller Initiationsfaktor, der in allen drei Domänen des Lebens vertreten ist (Hasenöhrl et al., 2009). In H. volcanii liegt er auf dem Hauptchromosom mit Locus HVO_1946. Das Gen umfasst $294 \mathrm{nt}$ und das Protein ist ca. 11 kDa schwer. Der Faktor alF1 wird auch als „protein translation factor SUI1 homolog“ bezeichnet.

Da alF1 in $H$. volcanii als essenziell eingestuft wurde (Gäbel et al., 2013), erfolgte die Überexpression im Wildtyp H26 1279 mit dem Plasmid pSDH1946. Die Wachstumsversuche bei 
$42{ }^{\circ} \mathrm{C}$ in Komplexmedium zeigten ein sehr viel schlechteres Wachstum der Überexpressionsmutante im Vergleich zur Kontrolle H26 1279 mit dem Leerplasmid (Abbildung 20A).

A

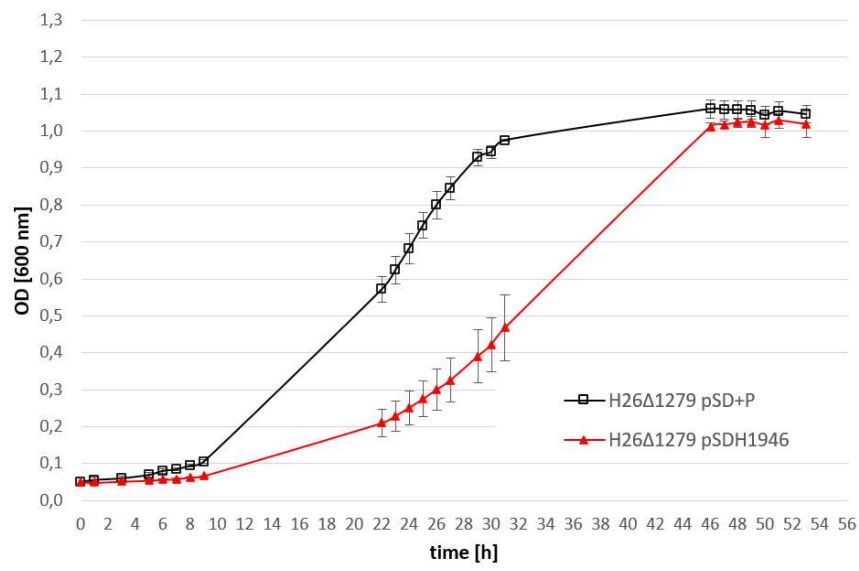

B

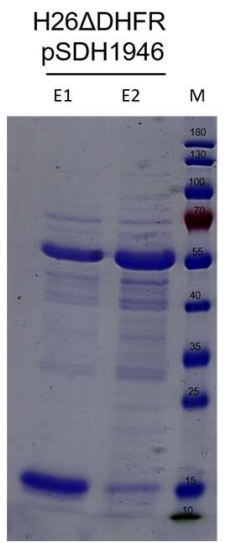

Abbildung 20: Charakterisierung des essenziellen alF1 (HVO_1946)

A. Vergleich des Wachstums der Überexpression von alF1 in H26 1279 mit pSDH1946 mit der Kontrolle (H26 $1279 \mathrm{pSD}+\mathrm{P})$ unter optimalen Wachstumsbedingungen bei $42{ }^{\circ} \mathrm{C}$ in Komplexmedium. B. Affinitätsaufreinigung von alF1 auf einem 12 \% SDS-Gel, Coomassie-gefärbt mit Eluat 1-2. alF1 befindet sich bei $11 \mathrm{kDa}$.

Der Faktor alF1 wurde dreimal mittels pull-down-Assay aufgereinigt, die Proben dialysiert und auf einem SDS-Polyacrylamid mittels Coomassie-Färbung visualisiert (Abbildung 20B). Bereits auf dem Gel konnten in den Elutionsfraktionen viele mitgereinigte Proteine nachgewiesen werden. Die Elutionsfraktionen wurden anschließend zur MS-Analyse geschickt und die erhaltenen Daten wie im Kapitel zuvor beschrieben aufbereitet (Tabelle 53).

Mit dem alF1 konnten drei weitere alFs mitgereinigt werden: alF1A-2, alF2Bס-1 und alF5B. Des Weiteren konnten sieben ribosomale Proteine der 305 Untereinheit und zehn ribosomale Proteine der 50S Untereinheit zugeordnet werden. Unerwarteterweise konnten sechs Untereinheiten der RNA-Polymerase, sowie 20 Transkriptionsregulatoren und drei Translationselongationsfaktoren identifiziert werden.

Tabelle 53: Einteilung der mitgereinigten Proteine von alF1 $(n=3)$

\begin{tabular}{|c|c|c|c|c|}
\hline Group & Specification & Description & Genloci & Accession \\
\hline \multirow[t]{15}{*}{ Translation } & alFs & alF1 & HVO_1946 & D4GTH5 \\
\hline & & alF1A-2 & HVO_A0637 & D4GRU5 \\
\hline & & alF2Bס-1 & HVO_0966 & L9USK7 \\
\hline & & alF5B & HVO_1963 & D4GTJ2 \\
\hline & aEFs & aEF1a & HVO_2413 & L9V6J4 \\
\hline & & aEF1a-like protein & HVO_2575 & L9V605 \\
\hline & & $\mathrm{aEF2}$ & HVO_0356 & L9UK07 \\
\hline & $30 \mathrm{~S} \mathrm{rpS}$ & $30 S$ rpS3 & HVO_2558 & D4GTZO \\
\hline & & $30 S$ rpS4e & HVO_2552 & L9V7Y2 \\
\hline & & $30 \mathrm{~S}$ rpS7 & HVO_0354 & L9UJR0 \\
\hline & & $30 S$ rpS10 & HVO_0360 & L9ULL7 \\
\hline & & $30 S$ rpS13 & HVO_2784 & L9V5M6 \\
\hline & & $30 S$ rpS19P & HVO_2560 & L9V659 \\
\hline & & $30 \mathrm{~S}$ rpS24e & HVO_1896 & D4GTC9 \\
\hline & $50 \mathrm{~S} \mathrm{rpL}$ & $50 S$ rpL1 & HVO_2757 & P41199 \\
\hline
\end{tabular}


Ergebnisse

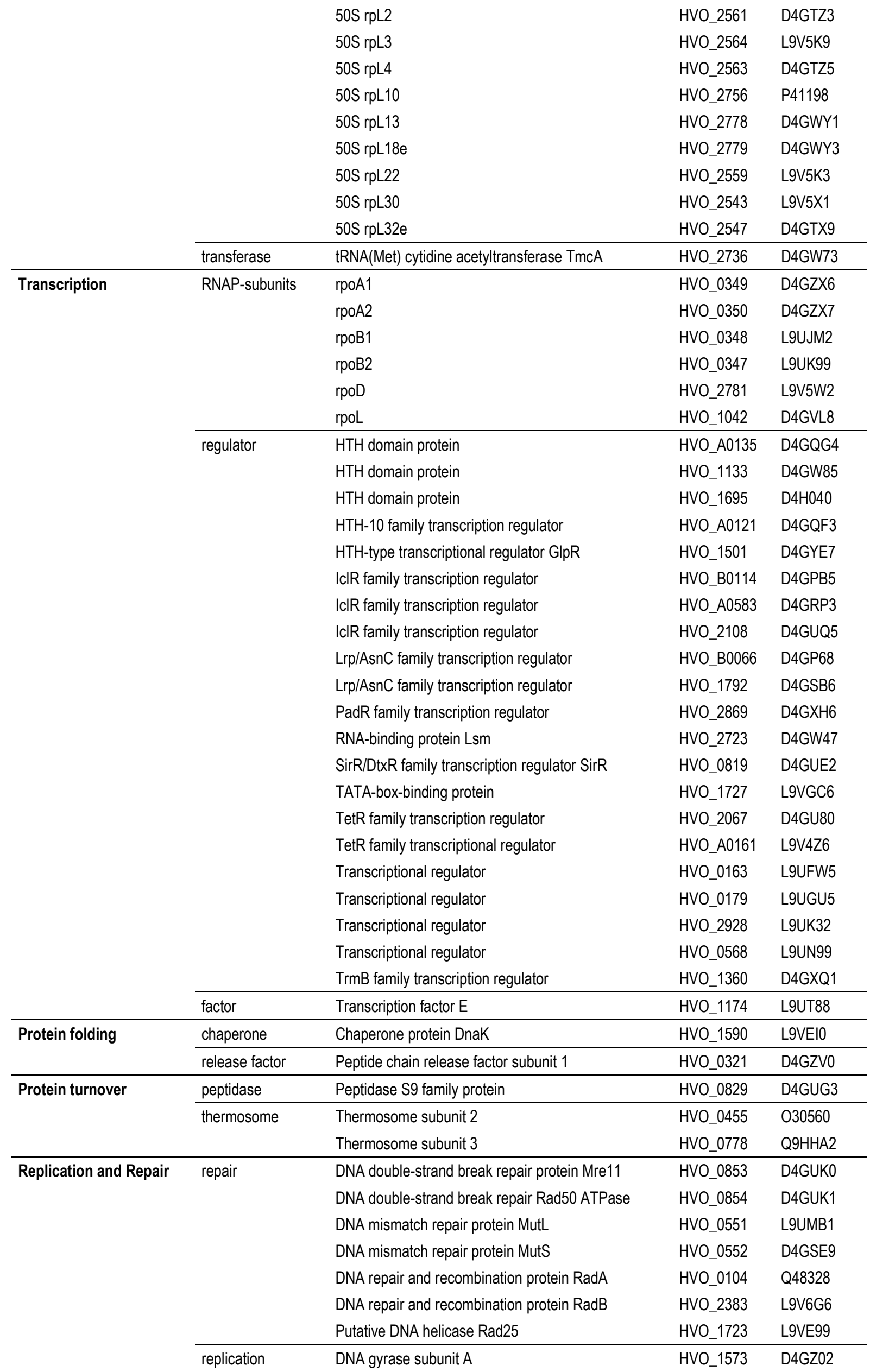




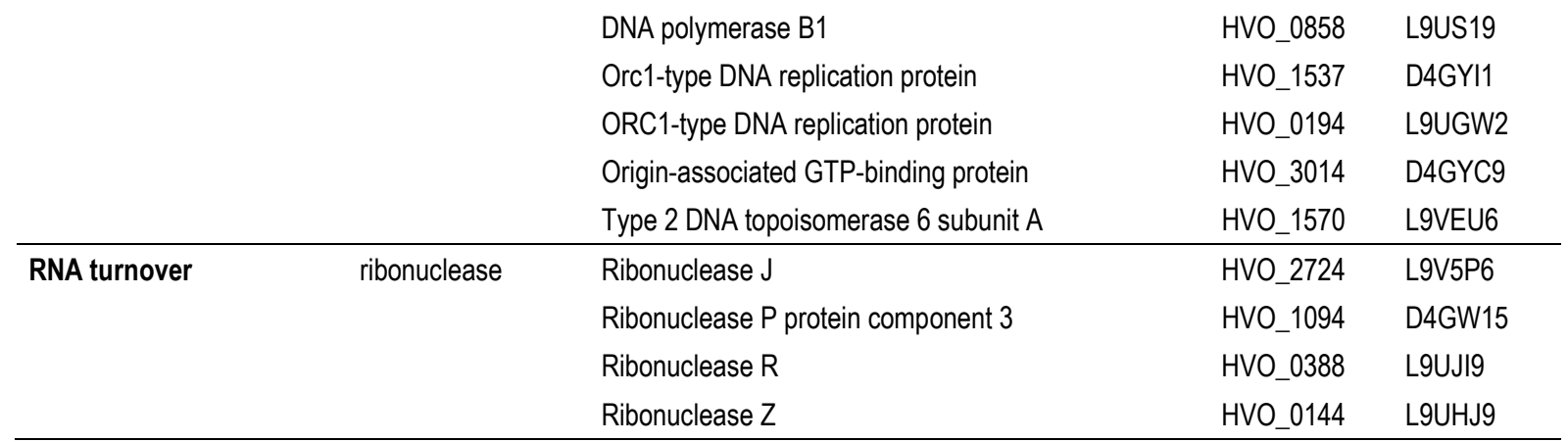

\subsection{2 alF1A-1 und alF1A-2}

Der Translationsinitiationsfaktor alF1A ist in allen drei Domänen des Lebens vertreten und umfasst in $H$. volcanii zwei orthologe Gene: alF1A-1 (HVO_0136) und alF1A-2 (HVO_A0637). Diese konnten unabhängig voneinander einzeln deletiert werden, allerdings nicht gleichzeitig. Sie wurden daher gemeinsam als essenzielle Translationsinitiationsfaktoren eingestuft (Gäbel et al., 2013).

\subsubsection{1 alF1A-1}

Das Gen des Faktor alF1A-1 (HVO_0136) ist 291 nt lang und das Molekulargewicht des Proteins beträgt $11,5 \mathrm{kDa}$. Da alF1A-1 deletiert werden konnte, fand die Überexpression in H26 $1279 \Delta 0136$ statt. Das Protein alF1A-1 konnte zu Beginn nicht im Western Blot nach der Proteinextraktion nachgewiesen werden (Daten nicht gezeigt).

Nach Überprüfung des Gens in den DNA- und RNA-Seq-Daten deutete alles auf eine mögliche 3'-UTR downstream bzw. ein verlängertes Transkript des alF1A-1 hin. Die DNA- und RNA-Seq-Daten in Abbildung 21 zeigen alF1A-1 (HVO_0136) bzw. tif1A1, das Nachbargen rio1 auf dem Hauptchromosom. In blau sind die Gene, das Transkriptionslevel in rot und der Transkriptionsstart in grün dargestellt. Anhand des Transkriptionslevels wurde eine $3^{\prime}$-UTR von 83 nt festgelegt, welche mit dem Gen alF1A-1 für die Klonierung mitamplifiziert und für die Erstellung des Konstruktes pSDH0136-3'-UTR verwendet wurde.

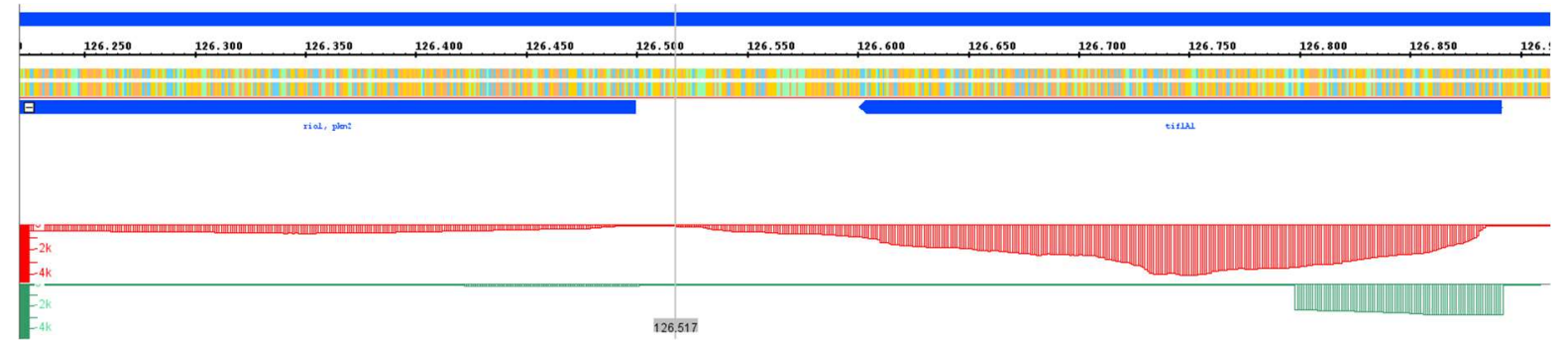

Abbildung 21: DNA- und RNA-Seq-Daten des alF1A-1 (HVO_0136)

alF1A-1 bzw. tif1A1 und das Nachbargen rio1 in blau, das Transkriptionslevel in rot und der Transkriptionsstart in grün auf dem Hauptchromosom. Anhand des Transkriptionslevel wurde eine 3'-UTR von 83 Nukleotiden mit dem Gen alF1A-1 für die Klonierung verwendet. 
Die Überexpression des Gens mit der 3'-UTR wurde im Deletionsstamm H26 $1279 \Delta 0136$ mit dem Plasmid pSDH0136-3'-UTR durchgeführt. Es wurden Wachstumskurven unter optimalen Bedingungen bei $42{ }^{\circ} \mathrm{C}$ in Komplexmedium erstellt (Abbildung 22A).

Der Deletionsstamm wuchs im Vergleich schlechter als der Wildtyp H26 $\Delta 1279$. Die Deletionsmutante mit der Überexpression des alF1A-1 mit 3'-UTR wuchs im Vergleich besser als die Deletionsmutante mit dem Leerplasmid.

A

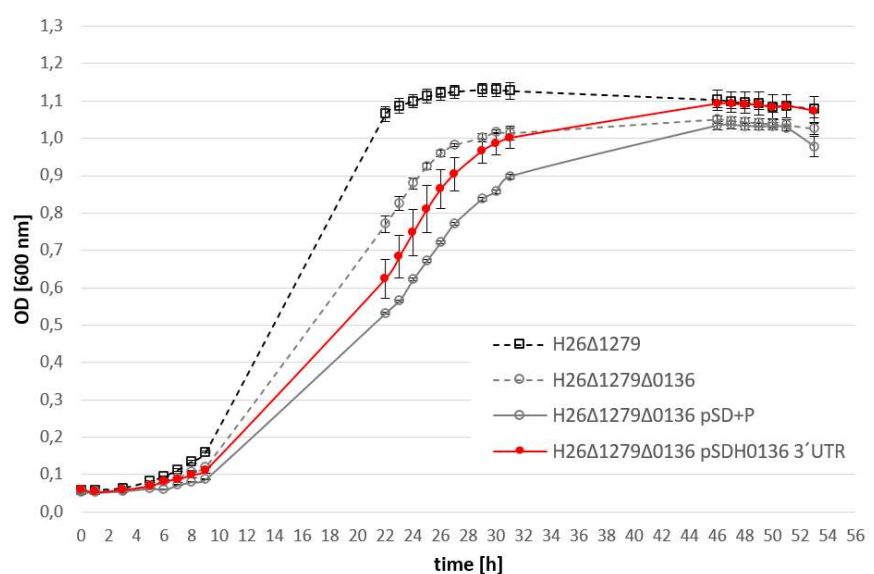

B

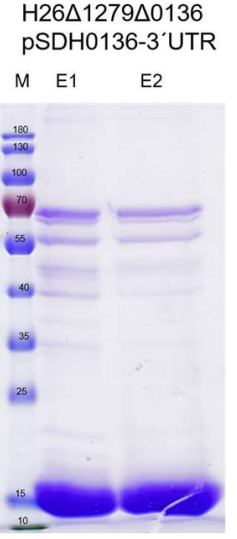

Abbildung 22: Charakterisierung des alF1A-1 (HVO_0136) ohne und mit nativer $3^{\prime}$-UTR

A. Im Vergleich das Wachstum der Überexpression von alF1A-1 mit 3'-UTR (pSDH0136-3'-UTR) mit der Kontrolle H26 $1279 \Delta 0136$ mit pSD+P, der Deletionsmutante (H26 $1279 \Delta 0136)$ und dem Wildtyp (H26 1279$)$. B. Die beiden Elutionsfraktionen der Affinitätsaufreinigung auf einem $12 \%$ SDS-Polyacrylamidgel Coomassie-gefärbt. Bei $11,5 \mathrm{kDa}$ ist alF1A-1 zu sehen.

Durch das verlängerte Gen bzw. die 3'-UTR konnte alF1A-1 überproduziert werden (Abbildung 22B). Dies spricht für eine große Bedeutung der 3'-UTR.

Die Elutionsfraktionen von drei Affinitätsaufreinigungen wurden zur Identifizierung der Proteine zur MS-Analyse geschickt. Nach der bereits beschriebenen Auswertung konnten mit alF1A-1 Proteine der Translation, Transkription, Replikation und Repair sowie dem DNA- und RNA-turnover co-gereinigt werden.

Zur Translation gehörten unter anderem die zwei Translationsinitiationsfaktoren alF2B $\delta-1$ und alF5B. Ferner konnten ein $30 \mathrm{~S}$ ribosomales Protein, vier $40 \mathrm{~S}$ ribosomale Proteine, eine RNA-Polymerase-Untereinheit, zwei Translationselongationsfaktoren und fünf Transkriptionsregulatoren mitgereinigt werden (Tabelle 54 ).

Tabelle 54: Einteilung der mitgereinigten Proteine von alF1A-1 $(n=3)$

\begin{tabular}{lllll}
\hline Group & Specification & Description & Genloci & Accession \\
\hline Translation & alFs & alF1A-1 & HVO_0136 & D4GZ79 \\
& alF2Bס-1 & HVO_0966 & L9USK7 \\
& alF5B & HVO_1963 & D4GTJ2 \\
\cline { 2 - 5 } & aEFs & aEF1a & HVO_2413 & L9V6J4 \\
& aEF2 & HVO_0356 & L9UK07 \\
\hline 30S rpS & 30S rpS19P & HVO_2560 & L9V659 \\
\hline 50S rpL & 50S rpL2 & HVO_2561 & D4GTZ3
\end{tabular}




\begin{tabular}{lllll} 
& & 50S rpL24 & HVO_2553 & L9V5Y5 \\
& & 50S rpL30 & HVO_2543 & L9V5X1 \\
\hline Transcription & RNAP-subunits & rpoA1 & HVO_0349 & D4GZX6 \\
\cline { 2 - 5 } & regulator & AsnC family transcriptional regulator & HVO_2029 & L9VBJ7 \\
& & HTH domain protein & HVO_1133 & D4GW85 \\
& & HTH domain protein & HVO_1695 & D4H040 \\
& & IcIR family transcription regulator & HVO_2108 & D4GUQ5 \\
& & Transcriptional regulator & HVO_2928 & L9UK32 \\
\hline Replication and Repair & repair & DNA repair and recombination protein RadB & HVO_2383 & L9V6G6 \\
\hline RNA turnover & ribonuclease & Ribonuclease J & HVO_2724 & L9V5P6 \\
\hline Protein turnover & thermosome & Thermosome subunit 2 & HVO_0455 & O30560 \\
\hline
\end{tabular}

\subsubsection{2 alF1A-2}

Bei alF1A-2 hat das Gen (HVO_A0637) eine Länge von 285 nt und das Protein ist 11,2 kDa schwer. Da das Gen deletiert werden konnte, wurde die Überexpression im Deletionsstamm H26 1279 $\Delta$ A0637 mit dem Plasmid pSDHA0637 durchgeführt.

In den Wachstumsversuchen verhielt sich die Deletionsmutante von alF1A-2 unter optimalen Bedingungen bei $42{ }^{\circ} \mathrm{C}$ in Komplexmedium wie der Wildtyp. Die Deletionsmutante mit Leerplasmid und die Deletionsmutante mit Überexpression verhielten sich im Wachstum zu Beginn ähnlich, jedoch zeigte die Überexpression in der spätexponentiellen Phase ab $24 \mathrm{~h}$ ein besseres Wachstum (Abbildung 23A). Da alF1A-2 sich aufgrund seiner Größe auf einem 12 \% SDSPolyacrylamigel nicht visualisieren ließ, wurde zusätzlich ein Tricin-Gel erstellt (Abbildung 23BC). Auf beiden Gelvarianten ließen sich mehrere mitgereinigte Proteine nachweisen. Jeweils von drei Aufreinigungen wurden die Elutionsfraktionen für die Identifizierung der Proteine zur MS geschickt.

A

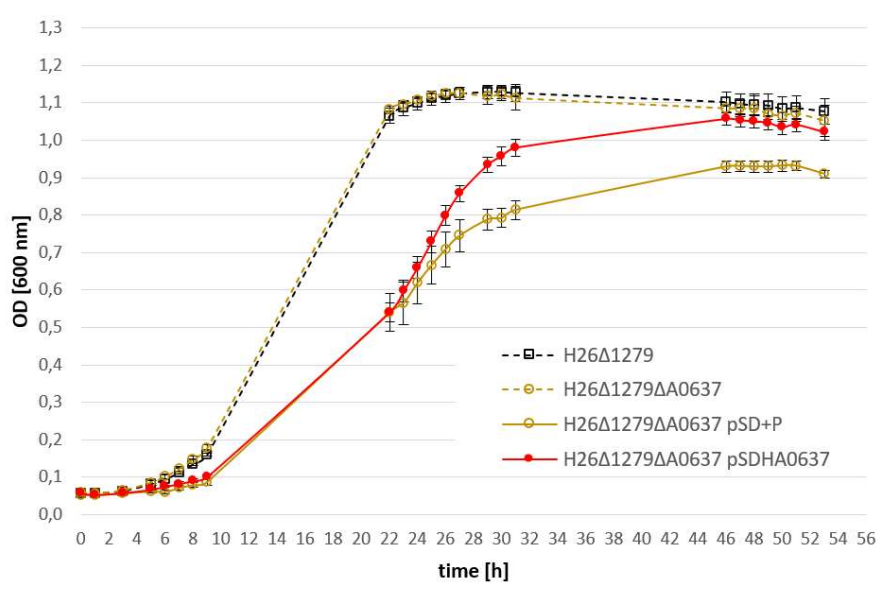

B

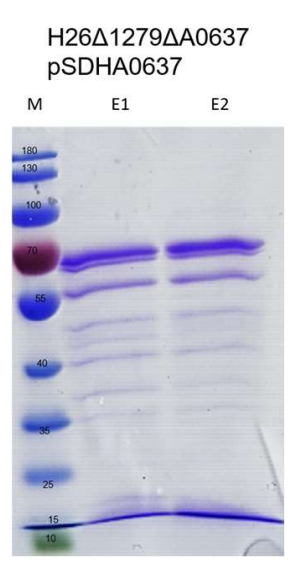

\section{C}

$\mathrm{H} 26 \triangle 1279 \triangle \mathrm{A} 0637$ pSDHA0637

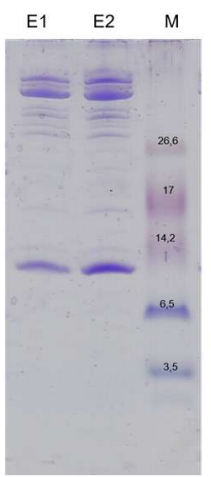

Abbildung 23: Charakterisierung des alF1A-2 (HVO_A0637)

A. Wachstumsversuch bei $42^{\circ} \mathrm{C}$ in Komplexmedium. Die Deletionsmutante $(H 26 \Delta 1279 \Delta 0637)$ wuchs wie der Wildtyp (H26 1279). Im Vergleich dazu wuchs die Überexpressionsmutante (pSDHA0637) ab der spätexponentiellen Phase besser als die Kontrolle mit dem Leerplasmid ( $\triangle$ A0637 pSD+P). B.-C. Die Elutionsschritte (E1, E2) der Überexpression von alF1A-2 (11,2 kDa) nach der Affinitätsaufreinigung auf einem $12 \%$ SDS-Polyacrylamidgel (B) und einem Tricin-Gel (C), jeweils Coomassie-gefärbt. 
Nach der Aufbereitung der Daten konnten neun Proteine zugeordnet werden. Darunter zwei weitere alFs, alF2Bס-1 und alF5B, wie bereits bei alF1A-1. Des Weiteren wurde ein Translationselongationsfaktor sowie vier Transkriptionsregulatoren mitgereinigt (Tabelle 55).

Tabelle 55: Einteilung der mitgereinigten Proteine von alF1A-2 ( $n=3)$

\begin{tabular}{lllll}
\hline Group & Specification & Description & Genloci & Accession \\
\hline Translation & alFs & alF1A-2 & HVO_A0637 & D4GRU5 \\
& & alF2Bס-1 & HVO_0966 & L9USK7 \\
& & alF5B & HVO_1963 & D4GTJ2 \\
\cline { 2 - 5 } & aEFs & aEF1a & HVO_2413 & L9V6J4 \\
\hline Transcription & regulator & IcIR family transcription regulator & HVO_2108 & D4GUQ5 \\
& & Lrp/AsnC family transcription regulator & HVO_1792 & D4GSB6 \\
& & Transcriptional regulator & HVO_0163 & L9UFW5 \\
& & Transcriptional regulator & HVO_2928 & L9UK32 \\
\hline RNA turnover & ribonuclease & Ribonuclease Z & HVO_0144 & L9UHJ9 \\
\hline
\end{tabular}

\subsection{3 alF2 - der trimere Initiationsfaktor}

alF2 ist ein Faktor, der in der Domäne der Archaeen und Eukaryoten als elF2 vertreten ist. Er besteht aus drei Untereinheiten: einer $\alpha-, \beta$ - und einer $\gamma$-Untereinheit. Das gilt auch für $H$. volcanii. Allerdings kommt hinzu, dass für die $\beta$-Untereinheit zwei orthologe Gene vorhanden sind. Diese sind das Gen HVO_1678, das für alF2 $\beta$-1 codiert und HVO_2242, das für alF2 $\beta$ 2 codiert. Die beiden Untereinheiten können sich teilweise in ihrer Funktion ersetzen. In $H$. volcanii wurden sie als essenziell eingestuft, da sie zwar einzeln aber nicht gleichzeitig deletiert werden konnten (Gäbel et al., 2013). Dies ist ein signifikanter Unterschied in der Gruppe der Archaeen, da viele Archaeen nur ein Gen besitzen, das für die $\beta$-Untereinheit codiert. Hinzu kommt, dass alF2 $\beta-2$ in S. solfataricus nicht essenziell ist (Tabelle 56 ).

Tabelle 56: Ausschnitt der Diversität des alF2/elF2 in Archaea und Eukarya

\begin{tabular}{|c|c|c|c|}
\hline TIF & \multicolumn{2}{|c|}{ Archaea } & \multirow{2}{*}{$\begin{array}{c}\text { Eukarya } \\
\text { Yeast } \\
\text { (Saccharomyces cerevisiae) }\end{array}$} \\
\hline alF2/elF2 & $\begin{array}{c}\text { Crenarchaeota } \\
\text { (Sulfolobus solfataricus) }\end{array}$ & $\begin{array}{c}\text { Euryarchaeota } \\
\text { (Haloferax volcanii) }\end{array}$ & \\
\hline$\alpha$ & essential & non- essential & essential \\
\hline$\beta$ & non-essential & essential & essential \\
\hline Y & essential & essential & essential \\
\hline
\end{tabular}

In Eukaryonten sind alle drei Untereinheiten essenziell. Wie für Eukaryonten als auch für Archaeen beschrieben, ist auch in H. volcanii alF2y (HVO_1901) ein essenzieller Faktor.

Der Faktor alF2 $\alpha /$ elF2 $\alpha$ ist in Eukaryonten und Archaeen essenziell. In $H$. volcanii jedoch konnte die Untereinheit alF2 $\alpha$ (HVO_0699) deletiert werden. Damit unterscheidet sich die $\alpha-$ Untereinheit in $\mathrm{H}$. volcanii innerhalb der Archaeen und den Eukaryonten. Die Deletionsmutante wies aber unter allen getesteten Kultivierungsbedingungen einen Phänotyp in Form eines 
starken Wachstumsdefizits auf. (Schmitt, Blanquet and Mechulam, 2002; Pedullà et al., 2005; Yatime et al., 2007; Gäbel et al., 2013).

\subsubsection{1 alF2 $\underline{\text { al }}$}

Das Gen des alF2 $\alpha$ in $H$. volcanii ist 801 nt lang. Das resultierende Protein ist 29,5 kDa schwer. $\mathrm{Da}$ alF2 $\alpha$ als nicht essenziell eingestuft wurde, fand die Überexpression in der Deletionsmutante H26 $1279 \Delta 0699$ mit dem Plasmid pSDH0699 statt. Bei Wachstumsuntersuchungen unter optimalen Bedingungen wuchs die Deletionsmutante des alF2 $\alpha$ sehr viel schlechter als der Wildtyp. Im Vergleich hierzu, wuchs die Überexpression im Deletionsstamm ähnlich zur Deletionsmutante mit Leerplasmid, jedoch zeigte sie ein besseres spätexponentielles Wachstum als die Kontrolle mit Leerplasmid (Abbildung 24A).

Um diese Beobachtung weiter zu untersuchen, wurden die Aufreinigungen des alF2 $\alpha$ nicht nur im exponentiellen, sondern auch in der stationären Phase untersucht (Abbildung 24BC). Die Elutionsfraktionen der beiden unterschiedlichen Wachstumsphasen des alF2 $\alpha$, zeigten beide die Überexpression des alF2 $\alpha$ und Proteine, die in beiden Wachstumsphasen erschienen. Im Vergleich dazu konnten bei der stationären Phase sehr viel mehr Proteine mitgereinigt werden als in der exponentiellen Phase. Hier konnten auch mehr Proteine visualisiert werden, die größer als $70 \mathrm{kDa}$ sind.

Von je drei Affinitätsaufreinigungen von alF2a-exp und alF2 $\alpha$-stat wurde jeweils die zweite Elutionsfraktion auf einem gemeinsamen $12 \%$ SDS-Polyacrylamidgel aufgetragen (Abbildung 24D). Aus diesem Gel wurden einzelne Banden ausgeschnitten, die nur für alF2astat erschienen (Bande 1, 2), in beiden Ansätzen auftauchten (Bande 4, 5) und eine Bande, die nur bei alF2 $\alpha$-exp präsent war (Bande 3). Die ausgeschnittenen Banden wurden in der MS analysiert und anschließend Anhand des PSM-Wertes und der Abundanz ausgewertet. Ferner wurden die Elutionsfraktionen der Affinitätsaufreinigungen in der MS analysiert.

Für die Bande 1 konnte ein ABC-type transport system periplasmic substrate-binding protein (HVO_0062) identifiziert werden. Anders als es auf dem SDS-Gel schien, konnte in den analysierten Elutionsfraktionen für alF2 $\alpha$-exp und alF2 $\alpha$-stat das Protein nachgewiesen werden.

Für die Bande 2 konnten alF2 $\alpha$ mit dem höchsten PSM-Wert identifiziert werden. Mit der höchsten Abundanz konnte jedoch ein Beta-lactamase domain protein (HVO_0874) nachgewiesen werden. Auch hier konnte das Protein für beide Ansätze in den Elutionsfraktionen nachgewiesen werden.

Für Bande 3 konnte überraschenderweise alF2 $\beta-2$ (HVO_2242) nachgewiesen werden, die ebenfalls in beiden Ansätzen in den Elutionsfraktionen nachgewiesen werden konnte.

Für die beiden Banden 4-5 konnte sowohl alF2 $\alpha$ als auch die Molydopterin adenylyltransferase (HVO_2645) nachgewiesen werden, was vermutlich an der Überladung des Gels lag. Auch in den Elutionsfraktionen beider Ansätze konnte das Protein nachgewiesen werden. 
A

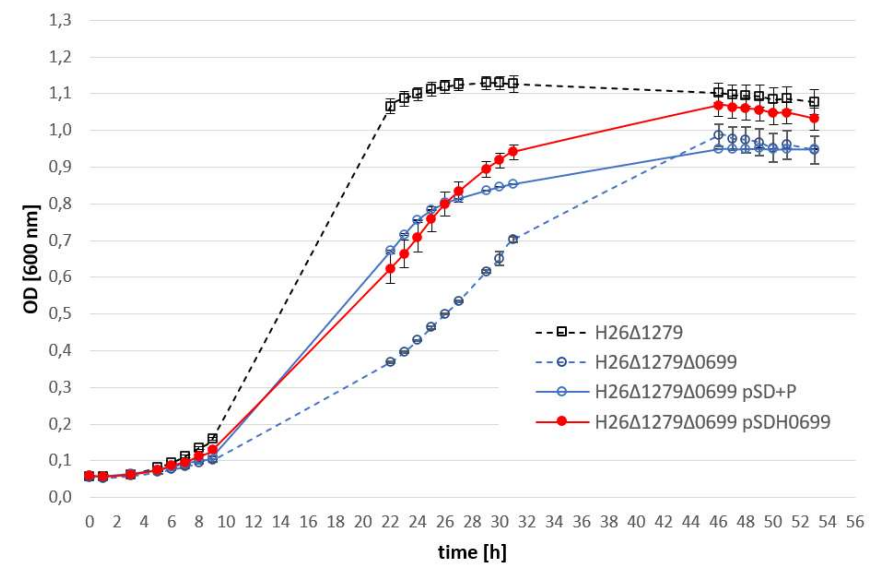

B

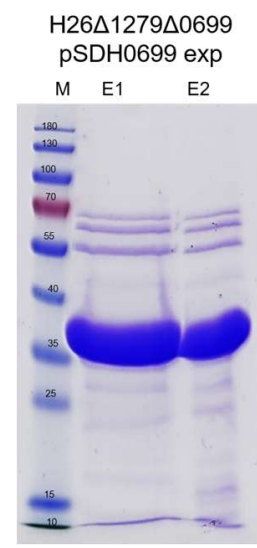

C

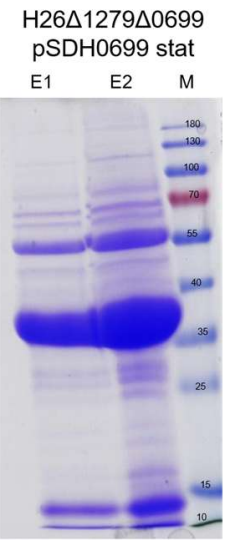

D
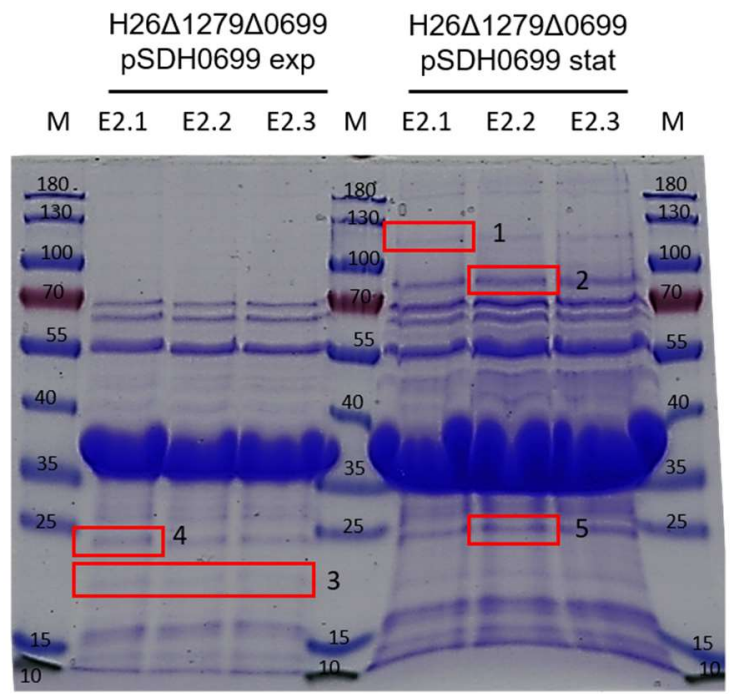

Abbildung 24: Charakterisierung des alF2 $\alpha$ (HVO_0699)

A. Die Wachstumsversuche bei $42{ }^{\circ} \mathrm{C}$ in Komplexmedium zeigen einen starken Phänotyp für die Deletionsmutante von alF2 $\alpha(H 26 \Delta 1279 \Delta 0699)$. Der Deletionsstamm mit der Überexpression (pSDH0699) von alF2 $\alpha$ wuchs ähnlich wie der Deletionsstamm mit Leerplasmid (pSD+P). Die Überexpression zeigte jedoch im spätexponentiellen Bereich ein besseres Wachstum. B.-C. Die Aufreinigung der Überexpression von alF2 $\alpha$ unter exponentiellem (B) und stationärem (C) Wachstum mit den mitgereinigten Proteinen auf dem SDSGel nach der Coomassie-Färbung, zeigten ein unterschiedliches Bandenmuster. D. Vergleich der Elution 2 der Affinitätsaufreinigungen von alF2 $\alpha$-exp und alF2 $\alpha$ stat.. In der Tabelle sind die, in der MS identifizierten Proteine für die einzelnen ausgeschnittenen Gelbanden aufgelistet. Berücksichtigt wurden die Proteine mit dem größten PSM-Wert und der größten Abundanz.

\begin{tabular}{|c|c|c|c|c|c|c|c|}
\hline Cut & Description & & Accession & Genloci & MW [kDa] & PSM & Abundance \\
\hline 1. & $\begin{array}{l}\text { ABC-type transport system peripl. } \\
\text { substrate-binding protein }\end{array}$ & stat & D4GYQ7 & HVO_0062 & 67,3 & Highest & Highest \\
\hline 2. & $\begin{array}{l}\text { alF2a } \\
\text { Beta-lactamase domain protein }\end{array}$ & stat & $\begin{array}{l}\text { D4GT46 } \\
\text { D4GUM1 }\end{array}$ & $\begin{array}{l}\text { HVO_0699 } \\
\text { HVO_0874 }\end{array}$ & $\begin{array}{l}29,5 \\
71,9\end{array}$ & $\begin{array}{l}\text { Highest } \\
2 .\end{array}$ & $\begin{array}{c}2 . \\
\text { Highest }\end{array}$ \\
\hline 3. & alF2 $\beta-2$ & $\exp$ & L9VAS4 & HVO_2242 & 22,2 & Highest & Highest \\
\hline 4. & $\begin{array}{l}\text { Molybdopterin adenylyttransferase } \\
\text { alF2a }\end{array}$ & both & $\begin{array}{l}\text { D4GUY1 } \\
\text { D4GT46 }\end{array}$ & $\begin{array}{l}\text { HVO_2645 } \\
\text { HVO_0699 }\end{array}$ & $\begin{array}{l}20,7 \\
29,5\end{array}$ & $\begin{array}{l}\text { Highest } \\
2 .\end{array}$ & $\begin{array}{l}\text { Highest } \\
2 .\end{array}$ \\
\hline 5. & $\begin{array}{l}\text { alF2a } \\
\text { Molybdopterin adenylyltransferase }\end{array}$ & both & $\begin{array}{l}\text { D4GT46 } \\
\text { D4GUY1 }\end{array}$ & $\begin{array}{l}\text { HVO_0699 } \\
\text { HVO_2645 }\end{array}$ & $\begin{array}{l}29,5 \\
20,7\end{array}$ & $\begin{array}{l}\text { Highest } \\
2 .\end{array}$ & $\begin{array}{l}\text { Highest } \\
2 .\end{array}$ \\
\hline
\end{tabular}

Dieses Protein wurde allerdings auch bei der Kontrolle der $6 x-H i s-D H F R$ co-gereinigt (Tabelle 51) und deshalb als unspezifisches Protein ausgeschlossen.

In Tabelle 57 sind für alF2 $\alpha$-exp und alF2 $\alpha$-stat die ausgewerteten MS-Daten für die Elutionsfraktionen aufgelistet. Die nur in der exponentiellen Phase identifizierten Proteine sind dunkelgrau hinterlegt. Die nur in der stationären Phase identifizierten Proteine sind hellgrau hinterlegt. 
Mit alF2 $\alpha$ konnten die beiden anderen Untereinheiten alF2 $\beta-2$ und alF2 $\gamma$ des alF2 mitgereinigt werden, jedoch nicht die Untereinheit alF2 $\beta-1$. Des Weiteren konnte alF2B $\delta-1$ und alF5B nachgewiesen werden.

Bei den stationären Kulturen konnten, wie es sich in Abbildung 24C mit der CoomassieFärbung auf dem SDS-Gel schon zeigte, mehr Proteine mitgereinigt werden.

Auch in der stationären Phase konnten mit alF2 $\alpha$ die Untereinheiten alF2 $\beta-2$ und alF2 $\gamma$ nachgewiesen werden. Ebenso unter stationären Bedingungen konnte alF2B $\delta$-1 und alF5B als weitere Translationsinitiationsfaktoren identifiziert werden. Bis auf das $50 \mathrm{~S}$ ribosomale Protein rpL10 (HVO_2756) konnten nach der Auswertung der MS-Daten, alle Proteine, die in der exponentiellen Phase identifiziert wurden, auch in der stationären Phase nachgewiesen werden. In der exponentiellen Phase wurde nur ein 30 S und fünf 50 S ribosomale Proteine identifiziert. Dagegen konnten in der exponentiellen Phase sechs 305 und sieben 50 S ribosomale Proteine identifiziert werden.

Im Vergleich von alF2a-exp und -stat konnten weitere Proteine für die Translation und die Transkription in den stationären Kulturen nachgewiesen werden. Unter anderem alF1 (HVO_1946) für die Translation sowie TIFIIB (HVO_1478) und Nob1 (HVO_1965) für die Transkription. Diese drei Proteine konnten mit keinem weiteren Initiationsfaktor co-gereinigt werden.

Tabelle 57: Mitgereinigte Proteine von alF2 $\alpha$ aus exponentieller und stationärer Kultur ( $n=3$ )

\begin{tabular}{|c|c|c|c|c|c|c|}
\hline \multicolumn{2}{|l|}{ Group } & \multirow{2}{*}{$\begin{array}{l}\text { Description } \\
\text { alF2 } \alpha\end{array}$} & \multirow{2}{*}{$\begin{array}{l}\text { Accession } \\
\text { D4GT46 }\end{array}$} & \multirow{2}{*}{$\begin{array}{l}\text { Genloci } \\
\text { HVO_0699 }\end{array}$} & \multirow{2}{*}{$\begin{array}{c}\exp \\
+\end{array}$} & \multirow{2}{*}{$\begin{array}{c}\text { stat } \\
+\end{array}$} \\
\hline Translation & alFs & & & & & \\
\hline & & alF1 & D4GTH5 & HVO_1946 & & + \\
\hline & & alF2 $\beta-2$ & L9VAS4 & HVO_2242 & + & + \\
\hline & & $\mathrm{alF} 2 \gamma$ & D4GTD4 & HVO_1901 & + & + \\
\hline & & alF2Bס-1 & L9USK7 & HVO_0966 & + & + \\
\hline & & alF5B & D4GTJ2 & HVO_1963 & + & + \\
\hline & $\mathrm{aEFs}$ & $\mathrm{aEF} 1 \mathrm{a}$ & L9V6J4 & HVO_2413 & + & + \\
\hline & & aEF1a-like protein & L9V605 & HVO_2575 & + & + \\
\hline & & $\mathrm{aEF} 2$ & L9UK07 & HVO_0356 & + & + \\
\hline & $30 \mathrm{~S} \mathrm{rpS}$ & $30 S$ rpS3 & D4GTZO & HVO_2558 & & + \\
\hline & & $30 \mathrm{~s} r \mathrm{~s} 3 \mathrm{Ae}$ & D4GWA5 & HVO_1145 & & + \\
\hline & & $30 S$ rpS5 & D4GTX6 & HVO_2544 & + & + \\
\hline & & $30 \mathrm{~S}$ rpS8 & D4GTY1 & HVO_2549 & & + \\
\hline & & $30 S$ rpS11 & L9V5R1 & HVO_2782 & & + \\
\hline & & $30 S \mathrm{rpS} 19 \mathrm{P}$ & L9V659 & HVO_2560 & & + \\
\hline & $50 \mathrm{~S} \mathrm{rpL}$ & $50 \mathrm{~S}$ rpL1 & P41199 & HVO_2757 & + & + \\
\hline & & $50 \mathrm{~S}$ rpL2 & D4GTZ3 & HVO_2561 & & + \\
\hline & & $50 \mathrm{~S} r p L 3$ & L9V5K9 & HVO_2564 & & + \\
\hline & & $50 S$ rpL6 & L9V5X7 & HVO_2548 & & + \\
\hline & & $50 \mathrm{~S}$ rpL10 & P41198 & HVO_2756 & + & \\
\hline & & $50 \mathrm{~s}$ rpL10e & D4GS24 & HVO_0484 & + & + \\
\hline & & $50 \mathrm{~S} r p L 15 \mathrm{e}$ & L9UPT6 & HVO_0561 & + & + \\
\hline & & $50 S$ rpL30 & L9V5X1 & HVO_2543 & + & + \\
\hline
\end{tabular}


Ergebnisse

\begin{tabular}{|c|c|c|c|c|c|c|}
\hline Group & & Description & Accession & Genloci & $\exp$ & stat \\
\hline & transferase & tRNA(Met) cytidine acetyltransferase TmcA & D4GW73 & HVO_2736 & + & + \\
\hline \multirow[t]{33}{*}{ Transcription } & RNAP-subunits & RpoA1 & D4GZX6 & HVO_0349 & + & + \\
\hline & & RpoA2 & D4GZX7 & HVO_0350 & + & + \\
\hline & & RpoB2 & L9UK99 & HVO_0347 & + & + \\
\hline & factor & Transcription initiation factor IIB & D4GYB5 & HVO_1478 & & + \\
\hline & endonuclease & rRNA maturation endonuclease Nob1 & D4GTJ4 & HVO_1965 & & + \\
\hline & regulator & ArcR family TR & L9UXN3 & HVO_A0093 & & + \\
\hline & & ArcR family $T R$ & L9V9M0 & HVO_2110 & & + \\
\hline & & ArcR family TR & L9VI32 & HVO_B0101 & & + \\
\hline & & ArcR family $T R$ & L9VI90 & HVO_B0040 & & + \\
\hline & & Cro/C1 family TR & D4GQZ0 & HVO_A0313 & & + \\
\hline & & HTH-10 family TR & D4GQF3 & HVO_A0121 & + & + \\
\hline & & HTH-type TRGIpR & D4GYE7 & HVO_1501 & & + \\
\hline & & IcIR family TR & D4GPB5 & HVO_B0114 & & + \\
\hline & & IcIR family TR & D4GPK2 & HVO_B0201 & & + \\
\hline & & ICIR family TR & D4GQB4 & HVO_A0082 & & + \\
\hline & & IcIR family TR & D4GQV7 & HVO_A0280 & & + \\
\hline & & IcIR family TR & D4GRP3 & HVO_A0583 & & + \\
\hline & & IcIR family TR & D4GUQ5 & HVO_2108 & + & + \\
\hline & & Lrp/AsnC family TR & D4GSB6 & HVO_1792 & + & + \\
\hline & & SirR/DtxR family TRSirR & D4GUE2 & HVO_0819 & & + \\
\hline & & TR & L9VNN6 & HVO_A0465 & & + \\
\hline & & TR & L9UFW5 & HVO_0163 & + & + \\
\hline & & TR & L9UGU5 & HVO_0179 & & + \\
\hline & & TR & L9UK32 & HVO_2928 & + & + \\
\hline & & TR & L9V758 & HVO_2374 & + & + \\
\hline & & $\mathrm{TR}$ & L9V878 & HVO_2636 & & + \\
\hline & & TrmB family TR & D4GXQ1 & HVO_1360 & & + \\
\hline & & PadR family TR & D4GXH6 & HVO_2869 & & + \\
\hline & & RNA-binding protein AU-1 & D4GRU7 & HVO_0406 & & + \\
\hline & & RNA-binding protein Lsm & D4GW47 & HVO_2723 & + & + \\
\hline & & TATA-box-binding protein & D4GQ28 & HVO_B0382 & & + \\
\hline & & TATA-box-binding protein & L9VGC6 & HVO_1727 & + & + \\
\hline & & TATA-box-binding protein 1 & D4GZA2 & HVO_0158 & & + \\
\hline \multirow[t]{3}{*}{ Protein folding } & chaperone & Chaperone protein DnaK & L9VEIO & HVO_1590 & & + \\
\hline & chaperone & Hsp20-type molecular chaperone & D4GRZ1 & HVO_0450 & + & + \\
\hline & factor & Peptide chain release factor subunit 1 & D4GZV0 & HVO_0321 & & + \\
\hline \multirow[t]{3}{*}{ Protein turnover } & thermosome & Thermosome subunit 2 & 030560 & HVO_0455 & + & + \\
\hline & & Thermosome subunit 3 & Q9HHA2 & HVO_0778 & + & + \\
\hline & peptidase & Peptidase S9 family protein & D4GUG3 & HVO_0829 & & + \\
\hline \multirow[t]{9}{*}{$\begin{array}{l}\text { Replication and } \\
\text { Repair }\end{array}$} & repair & $\begin{array}{l}\text { DNA double-strand break repair Rad50 } \\
\text { ATPase }\end{array}$ & D4GUK1 & HVO_0854 & & + \\
\hline & & Putative DNA helicase Rad25 & L9VE99 & HVO_1723 & & + \\
\hline & & DNA mismatch repair protein MutS & D4GSE9 & HVO_0552 & & + \\
\hline & & DNA repair and recombination protein $\operatorname{RadA}$ & Q48328 & HVO_0104 & + & + \\
\hline & & DNA repair and recombination protein $\mathrm{RadB}$ & L9V6G6 & HVO_2383 & + & + \\
\hline & & Helicase domain protein & D4H0D0 & HVO_C0042 & & + \\
\hline & & Repair helicase UvrD & D4GRV6 & HVO_0415 & + & + \\
\hline & replication & ORC1-type DNA replication protein & A0A1U8QPN7 & HVO_C0057 & & + \\
\hline & & Orc1-type DNA replication protein & D4GYI1 & HVO_1537 & & + \\
\hline
\end{tabular}




\begin{tabular}{|c|c|c|c|c|c|}
\hline Group & Description & Accession & Genloci & $\exp$ & stat \\
\hline & ORC1-type DNA replication protein & L9UGW2 & HVO_0194 & & + \\
\hline & Replication factor A & L9UJU8 & HVO_0292 & + & + \\
\hline & Type 2 DNA topoisomerase 6 subunit B & L9VEG4 & HVO_1571 & + & + \\
\hline \multirow[t]{4}{*}{ RNA turnover } & Ribonuclease $\mathrm{HI}$ & L9V6L9 & HVO_2438 & + & + \\
\hline & Ribonuclease J & L9V5P6 & HVO_2724 & & + \\
\hline & Ribonuclease $\mathrm{R}$ & L9UJI9 & HVO_0388 & & + \\
\hline & Ribonuclease Z & L9UHJ9 & HVO_0144 & & + \\
\hline Vorkommen exp und stat & Vorkommen nur in exp & Vorkomm & ur in stat & & \\
\hline
\end{tabular}

\subsection{FPLC von alF2a}

Um die Komplexbildung von alF2 und seinen Untereinheiten genauer zu untersuchen, wurde nach der Aufreinigung der einzelnen His-getaggten Faktoren FPLCs durchgeführt. Hierfür wurde die Affinitätsaufreinigung, wie zuvor beschrieben, durchgeführt. Anschließend wurde jeweils die zweite Elutionsfraktion direkt in der FPLC aufgetrennt. Das Spektrum für alF2 $\alpha$ ist in Abbildung 25A dargestellt. Die gesammelten Fraktionen sind in rot dargestellt.

Die Fraktionen wurden gesammelt, dialysiert und entsprechend auf einem SDS-Gel aufgetragen. Nach der Coomassie-Färbung konnten verschiedene Proteinmuster, der Größe nach absteigend, in den einzelnen Fraktionen identifiziert werden (Abbildung 25B). Für Fraktion 19 konnten keine Proteinbanden im SDS-Gel nachgewiesen werden (Daten nicht gezeigt). Von drei unabhängigen Aufreinigungen, die das gleiche Spektrum aufwiesen, wurden jeweils die Fraktionen zu Beginn der Schulter (F10; I) des Hauptpeaks und nach der Spitze des Hauptpeaks (F15; III) mittels MS analysiert. Vor der Peak-Spitze (F12;II) wurde eine weitere Fraktion, jedoch nur aus zwei Aufreinigungen, untersucht. In der Abbildung 25A entsprechen die verwendeten Fraktionen den Fraktionen, mit den grünen Punkten.

In der Auswertung wurden die identifizierten Proteine mit einem Wert unter 2 Unique Peptides ausgenommen (Abbildung 25C). Anschließend wurde die Menge der Peptide Spectrum Matches (PSM) absteigend sortiert. Die Proteine, die in allen drei FPLCs auftauchten, wurden zusammengefasst. Die MS-Daten des Leerplasmids und der DHFR wurden auch bei diesen MS-Auswertungen als Kontrolle abgezogen. Dieses Vorgehen wurde für die MS-Daten aller Affinitätsaufreinigungen mit gekoppelter FPLC durchgeführt. 
A

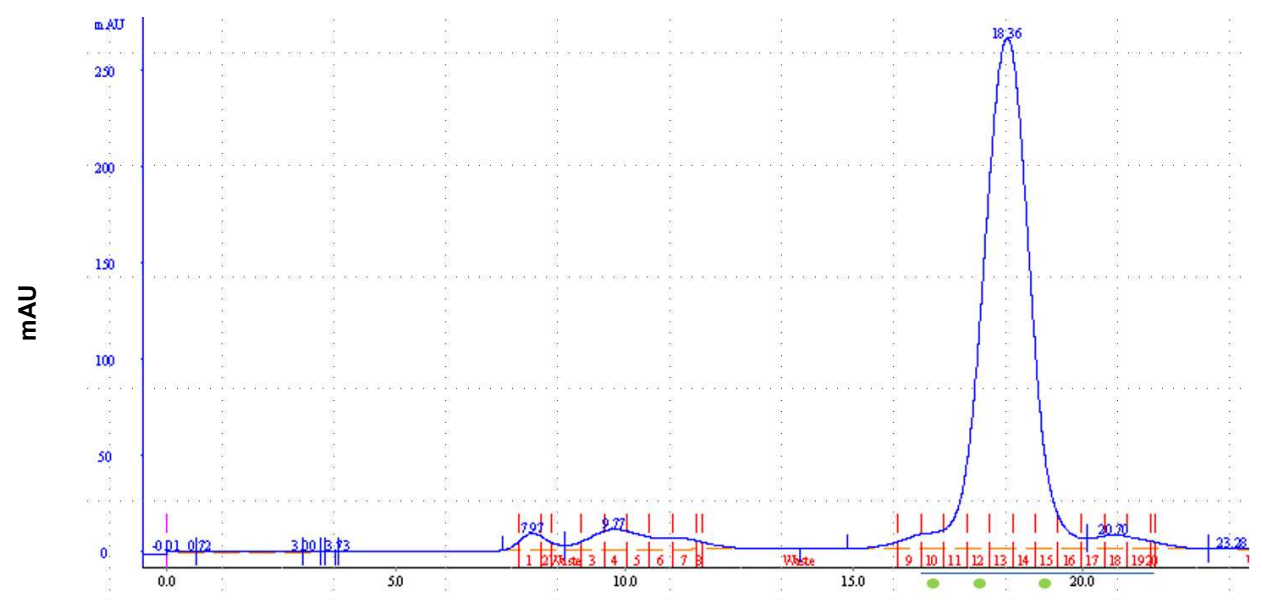

$\mathrm{mL}$

\section{B}

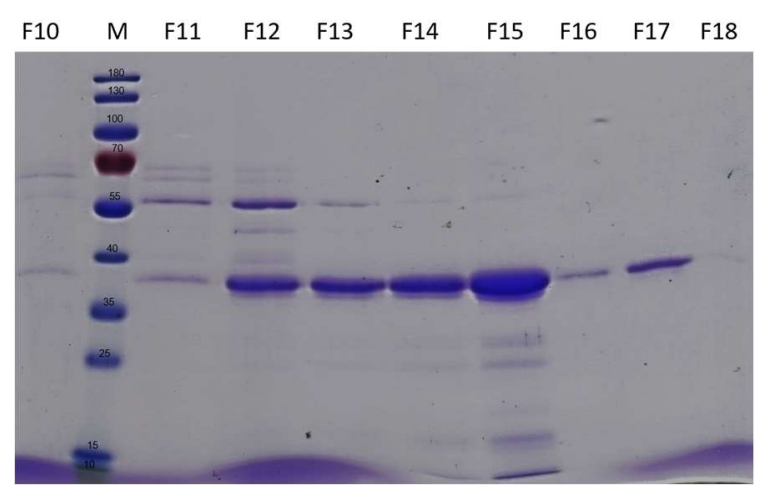

Abbildung 25: FPLC der Elutionsfraktion nach der Affinitätsaufreinigung von alF2 $\alpha$

A. Nach der Affinitätsaufreinigung des alF2 $\alpha$ wurde jeweils die zweite Elutionsfraktion über die FPLC aufgetrennt $(n=3)$. Die grünen Punkte unter der $x$-Achse markieren die Fraktionen, die aus drei FPLCs in der MS analysiert wurden. B. Die gesammelten Fraktionen wurden dialysiert, auf ein SDS-Gel aufgetragen und mittels Coomassie gefärbt. C. Schema des Vorgehens für die Auswertung der MS-Daten bei der Affinitätsaufreinigung mit anschließender FPLC und MSAnalyse der Fraktionen.

\section{C}

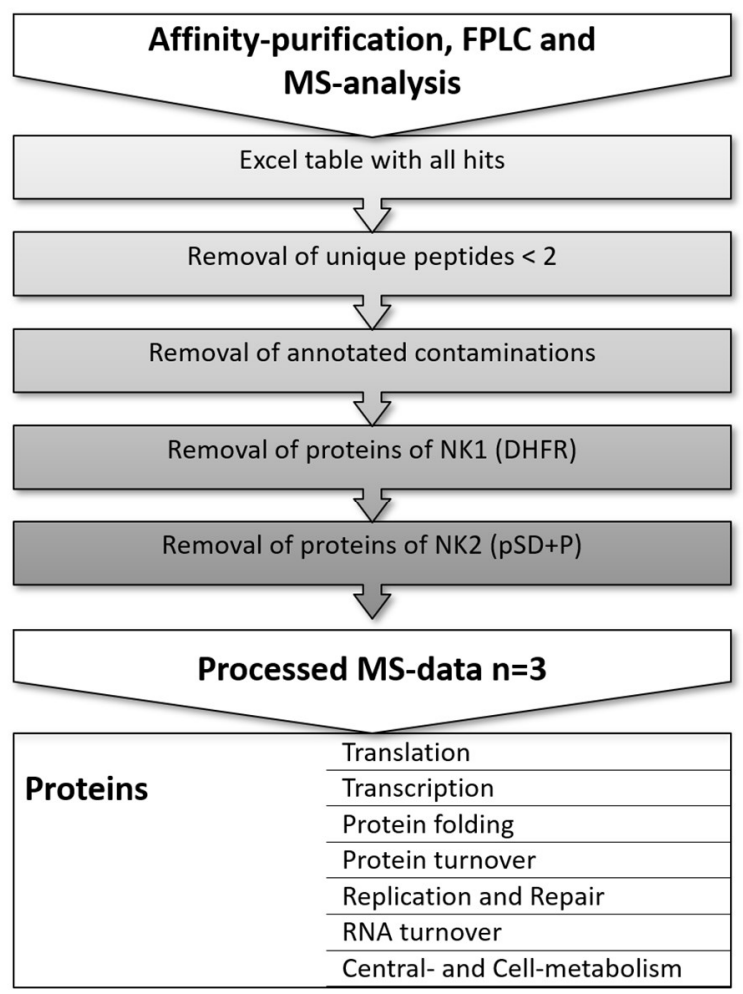


I. Zu Beginn der Schulter: 29 Proteine in drei FPLC-Läufen identifiziert

Die Verteilung der Proteine anhand ihrer PSM-Werte von drei unabhängigen Aufreinigungen und anschließender FPLC ist in Tabelle 58 absteigend dargestellt. Analyse der PSM-Werte von drei unabhängigen Messungen der Fraktionen zu Beginn der Schulter in der FPLC. Die PSM-Werte wurden auf alF2 $\alpha$ normiert.

Tabelle 58: MS-Analyse der Fraktionen zu Beginn der Schulter von alF2 $\alpha(n=3)$

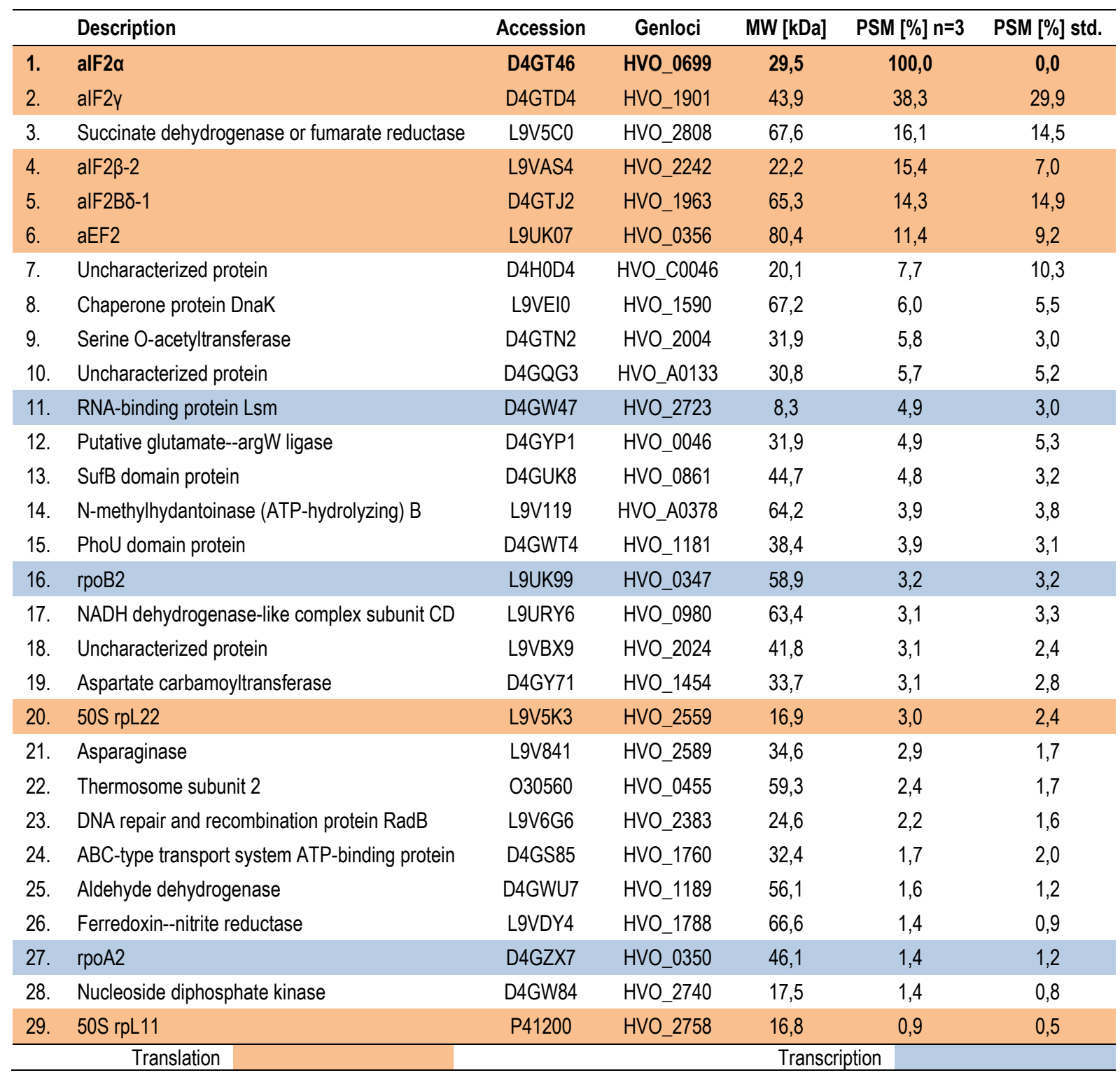

Die Proteine wurden nach dem größten PSM-Wert abwärts sortiert. Der PSM-Wert von Protein 1-6 fiel stark ab. Zu den ersten vier Proteinen mit den höchsten PSM-Werten gehörten alF2 $\alpha$, $-\beta-2$ und $-\gamma$. Als weiterer Initiationsfaktor folgte alF2Bס-1 an fünfter Stelle. Insgesamt konnten 29 Proteine nach der Auswertung identifiziert werden. Davon vier Initiationsfaktoren, zwei 50S ribosomale Proteine, sowie der Elongationsfaktor aEF2. Des Weiteren konnten zwei RNAPUntereinheiten mitgereinigt werden, rpoB2 und rpoA2. 
Ergebnisse

II. Vor der Spitze des Hauptpeaks: 41 Proteine in zwei FPLC-Läufen identifiziert

Die Verteilung der Proteine anhand ihrer PSM-Werte, von zwei unabhängigen Aufreinigungen und anschließender FPLC, ist in Tabelle 59 absteigend dargestellt.

Tabelle 59: MS-Analyse der der Fraktionen vor der Spitze des Hauptpeaks von alF2 $\alpha(n=2)$

\begin{tabular}{|c|c|c|c|c|c|c|}
\hline & Description & Accession & Genloci & MW [kDa] & PSM [\%] n=2 & PSM [\%] std. \\
\hline 1. & alF2a & D4GT46 & HVO_0699 & 29,5 & 100 & 0,0 \\
\hline 2. & alF2ß-2 & L9VAS4 & HVO_2242 & 22,2 & 15,0 & 18,2 \\
\hline 3. & $\mathrm{aEF} 1 \mathrm{a}$ & L9V6J4 & HVO_2413 & 45,6 & 14,0 & 18,5 \\
\hline 4. & Succinate dehydrogenase or fumarate reductase & L9V5C0 & HVO_2808 & 67,6 & 8,8 & 11,8 \\
\hline 5. & alF2y & D4GTD4 & HVO_1901 & 43,9 & 8,6 & 11,2 \\
\hline 6. & tRNA (pseudouridine(54)-N(1))-methyltransferase & L9VBV1 & HVO_1989 & 21,9 & 5,8 & 4,3 \\
\hline 7. & HAD superfamily hydrolase & D4GWL8 & HVO_2370 & 23,4 & 2,0 & 2,2 \\
\hline 8. & Aspartate carbamoyltransferase & D4GY71 & HVO_1454 & 33,7 & 1,9 & 2,2 \\
\hline 9. & Uncharacterized protein & L9V5N6 & HVO_2796 & 12 & 1,9 & 1,9 \\
\hline 10. & Serine 0-acetyltransferase & D4GTN2 & HVO_2004 & 31,9 & 1,7 & 2,0 \\
\hline 11. & HGPRTase-like protein & L9URM2 & HVO_1072 & 20,5 & 1,7 & 0,2 \\
\hline 12. & SufB domain protein & D4GUK8 & HVO_0861 & 44,7 & 1,5 & 1,8 \\
\hline 13. & Lrp/AsnC family transcription regulator & D4GSB6 & HVO_1792 & 18,1 & 1,4 & 0,6 \\
\hline 14. & $50 \mathrm{~S}$ rpL22 & L9V5K3 & HVO_2559 & 16,9 & 1,4 & 1,0 \\
\hline 15. & Putative nickel-responsive regulator & D4GWQ6 & HVO_2409 & 15,2 & 1,3 & 1,2 \\
\hline 16. & Hydantoin racemase & D4GR45 & HVO_A0377 & 28,5 & 1,3 & 1,5 \\
\hline 17. & Uncharacterized protein & D4GQG3 & HVO_A0133 & 30,8 & 1,2 & 1,2 \\
\hline 18. & Uncharacterized protein & L9VDX5 & HVO_2009 & 10,1 & 1,1 & 1,1 \\
\hline 19. & Uncharacterized protein & D4GXF9 & HVO_2861 & 29,1 & 1,0 & 0,9 \\
\hline 20. & Transcriptional regulator & L9UGU5 & HVO_0179 & 28 & 0,9 & 0,9 \\
\hline 21. & Oxidoreductase & L9UQK4 & HVO_0960 & 30,6 & 0,9 & 1,1 \\
\hline 22. & Uncharacterized protein & D4GVI1 & HVO_1004 & 10 & 0,9 & 0,1 \\
\hline 23. & Transcriptional regulator & L9UK32 & HVO_2928 & 27,5 & 0,8 & 0,6 \\
\hline 24. & L-lactate dehydrogenase & D4GZF9 & HVO_0214 & 34,5 & 0,8 & 0,7 \\
\hline 25. & $30 S$ rpS13 & L9V5M6 & HVO_2784 & 18,9 & 0,7 & 0,8 \\
\hline 26. & $30 \mathrm{~s}$ rpS2 & L9V5L7 & HVO_2773 & 28,3 & 0,6 & 0,7 \\
\hline 27. & HTH domain protein & D4GW85 & HVO_1133 & 11,7 & 0,6 & 0,4 \\
\hline 28. & CRISPR-associated protein Cas7 & D4GQN6 & HVO_A0207 & 38,2 & 0,5 & 0,5 \\
\hline 29. & Succinate--CoA ligase [ADP-forming] subunit beta & L9V6P3 & HVO_2465 & 41 & 0,5 & 0,1 \\
\hline 30. & Uncharacterized protein & D4GRR0 & HVO_A0600 & 14,1 & 0,5 & 0,6 \\
\hline 31. & $\mathrm{rpoH}$ & D4GZX3 & HVO_0346 & 8,5 & 0,5 & 0,0 \\
\hline 32. & TrmB family trancscriptional regulator & D4GXQ1 & HVO_1360 & 15,2 & 0,5 & 0,3 \\
\hline 33. & Hsp20-type molecular chaperone & D4GRZ1 & HVO_0450 & 15,2 & 0,4 & 0,2 \\
\hline 34. & Transcriptional regulator & L9ULE5 & HVO_2858 & 17,6 & 0,4 & 0,5 \\
\hline 35. & 5'-nucleotidase SurE & L9V6Z6 & HVO_A0228 & 32 & 0,4 & 0,1 \\
\hline 36. & Uncharacterized protein & L9URL9 & HVO_1077 & 26 & 0,4 & 0,2 \\
\hline 37. & Uncharacterized protein & D4GQG0 & HVO_A0129 & 11,7 & 0,3 & 0,1 \\
\hline 38. & Uncharacterized protein & L9UTQ4 & HVO_1209 & 13,1 & 0,3 & 0,1 \\
\hline 39. & V-type ATP synthase subunit C & Q48330 & HVO_0314 & 38,7 & 0,3 & 0,1 \\
\hline 40. & $50 \mathrm{~S}$ rpL11 & P41200 & HVO_2758 & 16,8 & 0,3 & 0,0 \\
\hline 41. & UCP015877 family protein & D4GS16 & HVO_0476 & 23,8 & 0,2 & 0,1 \\
\hline \multicolumn{7}{|c|}{ Transcription } \\
\hline
\end{tabular}


Analyse der PSM-Werte zweier unabhängiger Messungen der Fraktionen vor der Peak-Spitze in der FPLC. Die PSM-Werte wurden auf alF2 $\alpha$ normiert.

Die Proteine wurden nach dem größten PSM-Wert abwärts sortiert. Es konnten 41 Proteine identifiziert werden. Davon sind drei Proteine Initiationsfaktoren, zwei 30 S ribosomale Proteine und zwei $50 S$ ribosomale Proteine. Unter den ersten fünf Proteinen konnten die drei alF2Untereinheiten nachgewiesen werden, jedoch nicht alF2 $\beta-1$. Auch bei dieser Messung fiel der PSM-Wert von Protein 1-6 stark ab.

Die Translation betreffend konnte eine RNAPU sowie mehrere Transkriptionsregulatoren identifiziert werden.

III. Nach der Spitze des Hauptpeaks: fünf Proteine in drei FPLC-Läufen identifiziert

Die Verteilung der Proteine anhand ihrer PSM-Werte von drei unabhängigen Aufreinigungen und anschließender FPLC ist in Tabelle 60 absteigend dargestellt. Analyse der PSM-Werte dreier unabhängiger Messungen der Fraktionen nach der Peak-Spitze in der FPLC. Die PSMWerte wurden auf alF2 $\alpha$ normiert.

Tabelle 60: MS-Analyse der Fraktionen nach der Spitze des Hauptpeaks von alF2 $\alpha(n=3)$

\begin{tabular}{llccccc}
\hline & Description & Accession & Genloci & MW [kDa] & PSM [\%] n=3 & PSM [\%] std. \\
\hline 1. & alF2 $\alpha$ & D4GT46 & HVO_0699 & 29,5 & 100,0 & $\mathbf{0 , 0}$ \\
2. & aEF1a & L9V6J4 & HVO_2413 & 45,6 & 6,5 & 4,9 \\
3. & alF2y & D4GTD4 & HVO_1901 & 43,9 & 5,6 & 5,5 \\
4. & Uncharacterized protein & D4GXF9 & HVO_2861 & 29,1 & 1,5 & 1,7 \\
5. & HGPRTase-like protein & L9URM2 & HVO_1072 & 20,5 & 1,1 & 1,1 \\
\hline \multicolumn{2}{r}{ Translation } & & & &
\end{tabular}

Ausgehend vom größten PSM-Wert wurden die Proteine abwärts sortiert. In allen drei Fraktionen konnten fünf Proteine nachgewiesen werden. Davon waren zwei alFs (alF2 $\alpha$ und alF2y) sowie ein Elongationsfaktor. Es konnte keine $\beta$-Untereinheit identifiziert werden. Auch in diesen Messungen fielen die PSM-Werte stark ab.

\subsection{Crosslinking von alF2 $\alpha$}

Das Crosslinking wurde als erweiterter Ansatz für die Affinitätsaufreinigung mit Formaldehyd durchgeführt (Kapitel 2.4.4). Unterschiedliche Formaldehyd-Konzentrationen wurden getestet. Anschließend erfolgte die Affinitätsaufreinigung wie oben beschrieben und die jeweils zweite Elutionsfraktion wurde auf ein SDS-Gel aufgetragen (Abbildung 26A).

Beim Crosslinking mit Formaldehyd zeigten die Ansätze mit 0,8 \% und 1,2 \% Formaldehyd für 10 min die meisten Proteine. Um die Proteinbanden in der oberen Hälfte des Gels weiter aufzutrennen, wurden diese Ansätze erneut auf ein $8 \%$ SDS-Gel aufgetragen und die Laufzeit 
verlängert (Abbildung 26B). Von beiden Gelen wurden Banden ausgeschnitten und in der MS analysiert. Bei dem 12\% SDS-Gel handelte es sich um eine Bande (Bande 10), die im Ansatz ohne Crosslinking (x) nicht zu erkennen war (Abbildung 26AB). Von dem 8 \% SDS-Gel wurden Banden des Ansatzes mit $12 \%$ Formaldehyd ausgeschnitten, die in der Affinitätsaufreinigung ohne Crosslinking nicht zu erkennen waren (Banden 11-17). Für die Bestimmung der Proteine wurde bei den MS-Daten die höchsten PSM-Werte sowie die Abundanz als Maßstab herangezogen.

A

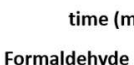

in)

\begin{tabular}{ccccccc} 
& 10 & 30 & 60 & 10 & 10 & \\
\hline$x$ & 0,4 & 0,4 & 0,4 & 0,8 & 1,2 & $M$
\end{tabular}

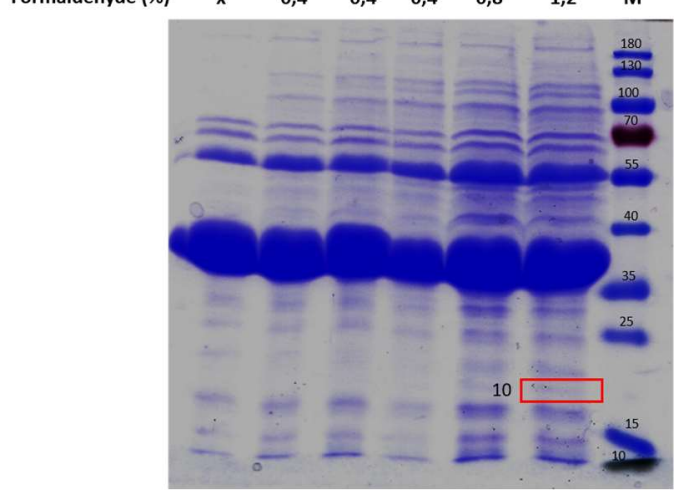

\section{B}

\begin{tabular}{rccccc} 
time $(\min )$ & 10 & & & 10 & \\
\cline { 2 - 6 } Formaldehyde (\%) & 0,8 & $\mathrm{x}$ & 1,2 & $\mathrm{M}$
\end{tabular}

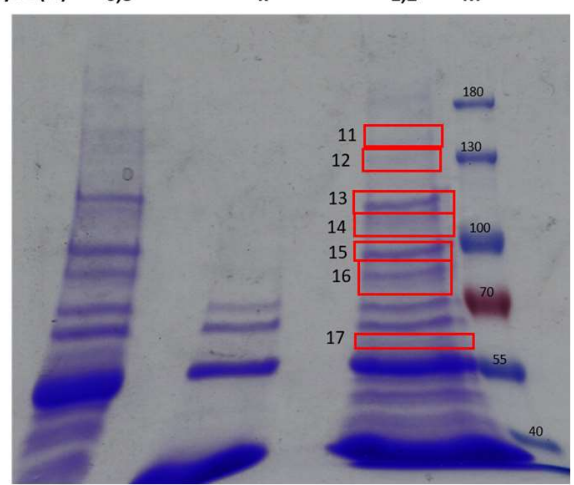

\begin{tabular}{clccccc}
\hline Cut & Description & Accession & Genloci & MW [KDa] & PSM & Abundance \\
\hline 10. & Transcriptional regulator & L9UFW5 & HVO_0163 & 19,8 & Highest & Highest \\
11. & Vitamin B12-dependent ribonucleotide reductase & L9V939 & HVO_2452 & 114,3 & Highest & Highest \\
12. & rpoA1 & D4GZX6 & HVO_0349 & 108,8 & 2. & Highest \\
& Vitamin B12-dependent ribonucleotide reductase & L9V939 & HVO_2452 & 114,3 & Highest & 3. \\
13. & aEF2 & L9UK07 & HVO_0356 & 80,4 & Highest & Highest \\
14. & Aconitate hydratase & L9VCX4 & HVO_1955 & 70,4 & Highest & Highest \\
15. & DNA gyrase subunit B & D4GZ01 & HVO_1572 & 71,2 & Highest & Highest \\
16. & alF5B & D4GTJ2 & HVO_1963 & 65,3 & Highest & 2. \\
& CTP synthase & D4GUG6 & HVO_2624 & 60,8 & $\mathbf{3 .}$ & Highest \\
17. & Succinate dehydrogenase or fumarate reductase & L9V5C0 & HVO_2808 & 67,6 & Highest & 2. \\
& YgfD family GTPase & D4GUG7 & HVO_0831 & 39,6 & $\mathbf{2 .}$ & Highest \\
\hline
\end{tabular}

Abbildung 26: Crosslinking von alF2 $\alpha$

A.-B. Nach Crosslinking und Affinitätsaufreinigung von alF2a mit verschiedenen Formaldehyd-Konzentrationen auf einem 12\% SDS-Gel (A) und einem 8 \% SDS-Gel (B). In der Tabelle sind die in der MS identifizierten Proteine für die einzelnen ausgeschnittenen Gelbanden aufgelistet. Berücksichtigt wurden die Proteine mit dem größten PSMWert und der größten Abundanz.

Für Bande 10 handelte es sich um einen Transkriptionsregulator (HVO_0163), der auch in der MS ohne Crosslinking nachgewiesen werden konnte.

Für Bande 11 wurde eine Vitamin B12-dependent ribonucleotide reductase (HVO_2452) identifiziert, die ebenfalls bereits für alF2a nachgewiesen werden konnte. 
In Bande 12 konnte dieses Protein erneut mit dem höchsten PSM-Wert nachgewiesen werden. Die RNAPU rpoA1 (HVO_0349) zeigte jedoch die höchste Abundanz.

Für Bande 13 konnte der Elongationsfaktor aEF2 (HVO_0356) mit der höchsten Abundanz bestimmt werden. Dieser Elongationsfaktor konnte mit Ausnahme von drei alFs- bzw. Untereinheiten mit allen alFs mitgereinigt werden.

In Bande 14 konnte die Aconitate hydratase (HVO_1955) identifiziert werden und in Bande 15 die DNA-Gyrase B (HVO_1572).

In Bande 16 konnte sowohl alF5B (HVO_1963) mit dem höchsten PSM-Wert, als auch eine CTP synthase (HVO_2624) mit der höchsten Abundanz identifiziert werden.

In Bande 17 konnte Succinate dehydrogenase or fumarate reductase (HVO_2808) mit dem höchsten PSM-Wert nachgewiesen werden. Als Protein mit der höchsten Abundanz wurde die YgfD family GTPase (HVO_0831) in Bande 17 nachgewiesen. Dieses Protein erschien ebenfalls in der Kontrolle 6xHis-DHFR und wurde deshalb als Interaktionspartner ausgeschlossen.

\subsection{Aminosäure-Mimikry für die Untersuchung der Interaktion von alF2a}

In Eukaryonten kann die Affinität von elF2 durch eine reversible Phosphorylierung von elF2 $\alpha$ reguliert werden (Abbildung 27 ).

A

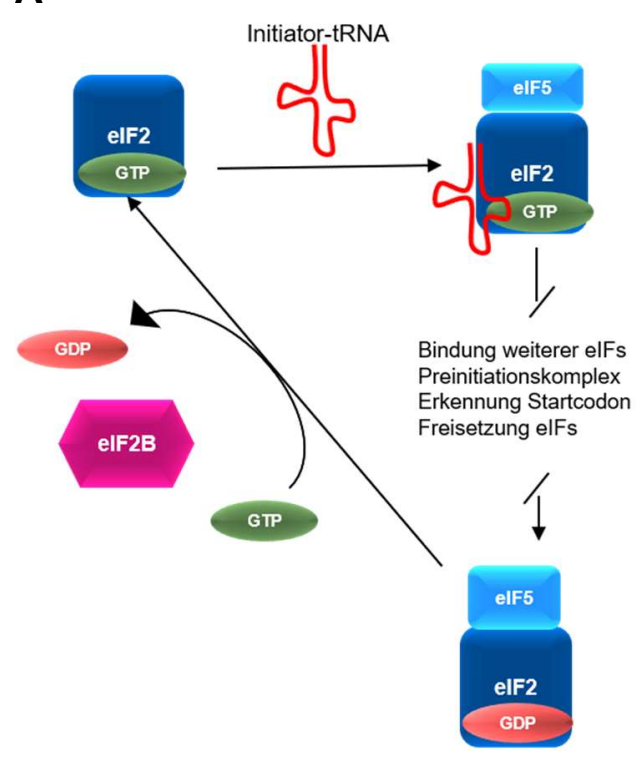

B
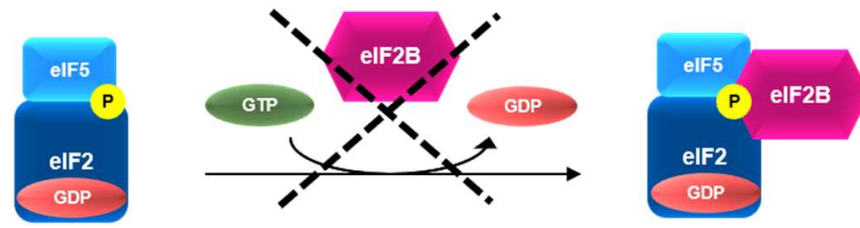

Abbildung 27: Translationsregulation mittels elFs in Eukaryonten

A. Start der Translation erfolgt durch elF2 gebundenes GTP, an das die Initiator-tRNA gebunden wird. Als Nächstes bindet elF5 sowie weitere Translationsinitiationsfaktoren. Es folgen die Bildung des Präinitiationskomplexes, die Erkennung des Startcodons, GTP wird zu GDP und die elFs lösen sich von ihrer Bindungsstelle. elF5 verbleibt gebunden an elF2-GDP. Durch elF2B wird GDP zu GTP ausgetauscht. elF5 kann sich von elF2 lösen. Der Vorgang beginnt von neuem. B. Durch die Phosphorylierung von elF2 kann der Austausch von GDP zu GTP verhindert werden. Es findet eine Inhibierung der Translation statt. Als Komplex verbleiben elF2-GDP, elF2B und elF5 (Jennings et al., 2016).

elF2-GTP besitzt eine starke Affinität für die Initiator-tRNA. Er bringt diese an die kleine ribosomale Untereinheit und ist somit an der Bildung des Präinitiationskomplexes beteiligt (Krishnamoorthy and Pavitt, 2001). Dieser Vorgang kann in Eukaryonten für die Regulation der Translation durch eine reversible Phosphorylierung inhibiert werden. Dabei verbleiben elF2 gebundenes GDP sowie elF5 und elF2B als Komplex. In Eukaryonten wird hierfür das Serin an Position 46 phosphoryliert (Sudhakar et al., 1999; Schmidt, Beilsten-Edmands and 
Robinson, 2016). Dies findet zum Beispiel in S. cerevisiae bei bestimmtem Aminosäuremangel mittels Gcn2-Kinase statt (Dever et al., 1992; Dever and Hinnebusch, 2005).

Trotz des Fehlens eines homologen Faktors für elF5 in Archaeen wurde bereits in Pyrococcus horikoshii (P. horikoshii) an Serin 44 und Serin 48 ein erfolgreicher Aminosäureaustausch für eine in vitro-Phosphorylierung an alF2 $\alpha$ durchgeführt (Tahara et al., 2004).

In dieser Arbeit wurde die Möglichkeit der Phosphorylierung von alF2 $\alpha$ in $H$. volcanii in vitro mittels Aminosäure-Mimikry untersucht. Nach einem Abgleich multipler Aminosäuresequenzen von elF2 $\alpha / a$ IF $2 \alpha$ aus verschiedenen Organismen wurde Serin 46 für den Aminosäureaustausch an alF2 $\alpha$ in $H$. volcanii festgelegt (Abbildung 28).

\section{Multiple Sequenz-Alignment:}

Mmus_eIF2alpha
Hse_eIF2alpha
Ath_eIF2alpha
Cal_eIf2alpha
Sce_Sui2
Nma_aIF2alpha
Hsal_aIF2alpha
Hwa_aIF2alpha
Hvo_aIF2alpha
Hme_aIF2alpha
Sso_aIF2alpha
Pfu_aIF2alpha
Pab_aIF2alpha
Pho_aIF2alpha
Mva_aIF2alpha
Mja_aIF2alpha
Mfe_aIF2alpha
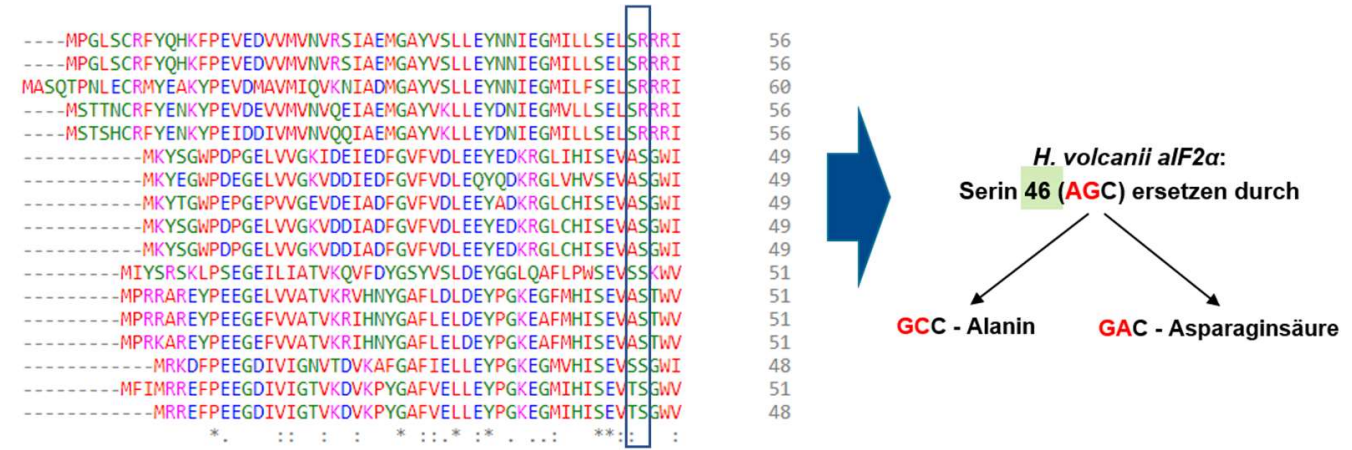

Abbildung 28: Multiple-Sequence-Alignment für die Wahl der Phosphorylierungsstelle in alF2a

Das Sequenz-Alignment wurde mittels Clustal erstellt. In $H$. volcanii wurde in der Aminosäuresequenz von alF2 $\alpha$ das Serin an Position 46 gewählt (blauer Kasten). Je zwei Basen wurden ausgetauscht. Die Änderung der Aminosäure erfolgte für Serin zu Alanin und Serin zu Asparaginsäure. Proteinsequenzen für das Multiple-Sequenz-Alignment von elF2a/alF2a stammen von $H$. volcanii (Hvo; D4GT46), H. mediterranei (Hme; I3R2C2), H. walsbyi (Hwa; Q18KR0), H. salinarum (Hsal; A0A510N505), N. magadii (Nma; D3SY91), M. fervens (Mfe; C7P7V4), M. vannielii (Mva; A6UQZ0), P. abyssi (Pab; Q9V0E4), P. horikoshii (Pho; O58655), S. solfataricus (Sso; Q97Z79), S. cerevisiae (Sce; P20459), C. albicans (Cal; Q5AAU7), H. sapiens (Hsa;P05198), M. musculus (Mmus; Q6ZWX6) und A. thaliana (Ath; Q9SIZ2).

Hierfür wurde das Gen von alF2 $\alpha$ mit N-terminalem His-Tag in den pSK+ kloniert und mittels Site-Directed-Mutagenesis (Kapitel 2.3.5.4) mutiert. Aus AGC für Serin 46 (Ser46) entstand GCC für Alanin und GAC für Asparaginsäure. Hierbei simuliert Alanin den nicht-phosphorylierten Zustand und Asparaginsäure den phosphorylierten Zustand.

Nach der erfolgreichen Mutation wurden beide modifizierte Gene jeweils in den pSD1R16 kloniert und in den $\mathrm{H} 26 \Delta 1279 \Delta 0699$ transformiert. Zur weiteren Untersuchung wurden Wachstumsversuche durchgeführt sowie Aufreinigungen über den His-Tag, wie bisher beschrieben. Anschließend wurden die Elutionsfraktionen auf ein SDS-Gel aufgetragen und zur MS-Analyse geschickt.

Bei den Wachstumsversuchen in Komplexmedium bei $42{ }^{\circ} \mathrm{C}$ zeigte die Mutante mit dem Austausch von Serin zu Alanin (pSDH0699Ala46) ein schlechteres Wachstum als die Kontrolle mit Leerplasmid. Außerdem wuchs die pSDH0699Ala46-Mutante schlechter als die Überexpression von alF2 $\alpha$ (pSDH0699) ohne Mutation an Ser46 (Abbildung 29A). Mittels Aufreinigung über den N-terminalen His-Tag konnte die erfolgreiche Überexpression von alF2 $\alpha-A l a 46$ 
nachgewiesen werden. Wie im Gel zu sehen ist, wurden im Vergleich zur Aufreinigung von alF2 $\alpha$ ohne Mutation (Abbildung 29B) weniger Proteine mitgereinigt. Dies bestätigte auch die MS-Analyse der drei unabhängigen Elutionsfraktionen. Es konnte jedoch gezeigt werden, dass alF2 $\gamma$ und alF2 $\beta-2$ mitgereinigt wurden, allerdings keine weiteren Interaktionspartner (Daten nicht gezeigt).

A

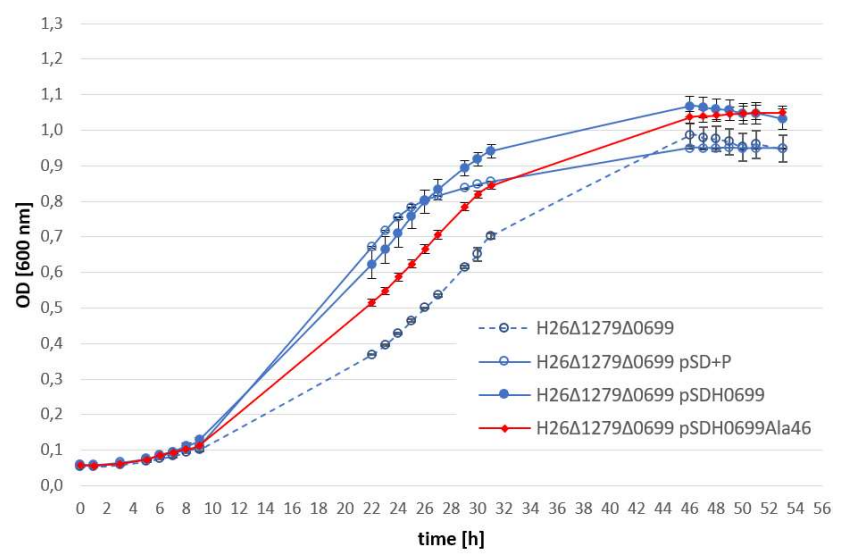

B

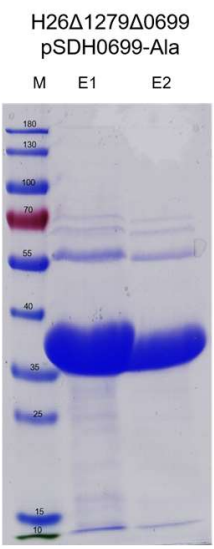

Abbildung 29: Charakterisierung des alF2 $\alpha$ (HVO_0699) mit der Ser46 mutiert zu Ala46

A. Unter optimalen Wachstumsbedingungen bei $42^{\circ} \mathrm{C}$ in Komplexmedium zeigte die Mutante pSDH0699Ala46 ein schlechteres Wachstum im Vergleich zur Überexpression des Gens ohne Mutation (pSDH0699) und dem Leerplasmid $(\triangle 0699 \mathrm{pSD}+\mathrm{P})$. B. Die Elutionsfraktionen der Affinitätsaufreinigung auf einem SDS-Polyacrylamidgel, Coomassie-gefärbt.

Die Mutante mit dem Austausch von Serin zu Asparaginsäure (pSDH0699-Asp46) wuchs ebenfalls schlechter als die Kontrolle mit dem Leerplasmid (Abbildung 30A).

Auch hier konnten im SDS-Gel nach der Affinitätsaufreinigung nur wenige Proteine visualisiert werden (Abbildung 30B). In der MS-Analyse konnte nach der Auswertung von drei unabhängigen Elutionsfraktionen nur alF2 $\alpha$ selbst, jedoch keine weiteren Interaktionspartner nachgewiesen werden (Daten nicht gezeigt). Diese Ergebnisse deuten darauf hin, dass in $H$. volcanii Ser46 in alF2 $\alpha$ nicht an der Regulation von alF2 beteiligt ist.

A

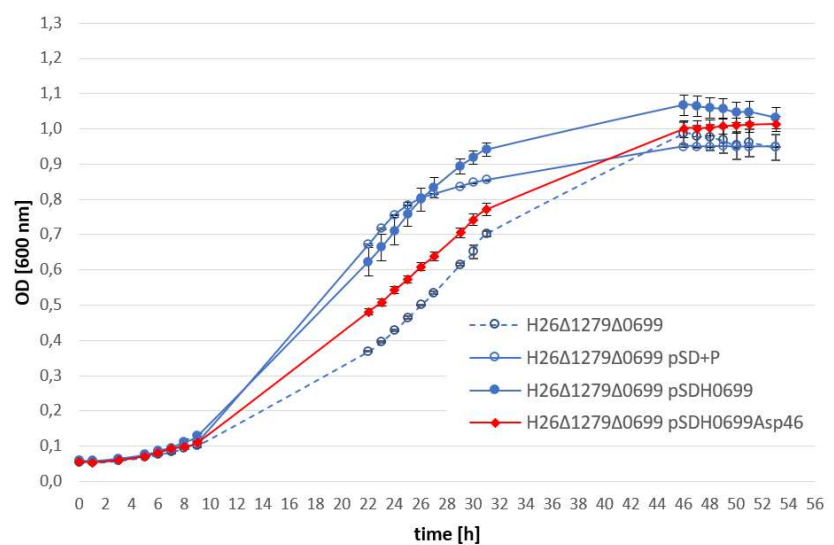

B

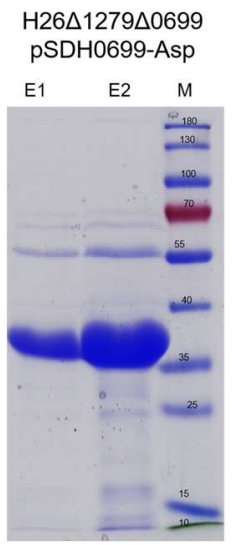

Abbildung 30: Charakterisierung des alF2 $\alpha$ (HVO_0699) mit der Ser46 mutiert zu Asp46

A. Unter optimalen Wachstumsbedingungen bei $42{ }^{\circ} \mathrm{C}$ in Komplexmedium zeigte die Mutante pSDH0699Asp46 ein schlechteres Wachstum im Vergleich zur Überexpression des Gens ohne Mutation (pSDH0699) und dem Leerplasmid $(\triangle 0699 \mathrm{pSD}+\mathrm{P})$. B. Die Elutionsfraktionen der Affinitätsaufreinigung auf einem SDS-Polyacrylamidgel, Coomassie-gefärbt. 


\subsubsection{2 alF2 $2 \beta-1$}

alF2 $\beta$-1 (HVO_1678) ist neben HVO_2242/alF2 $\beta$-2 eines der orthologen Gene, dass für alF2 $\beta$ in $H$. volcanii codiert. alF2 $\beta-1$ konnte deletiert werden und wurde damit als nicht essenziell eingestuft. In der Deletionsmutante von alF2 $\beta-2$ (HVO_2242) konnte gezeigt werden, dass alF2 $\beta$-1 um das zehnfache hochreguliert wird, was für eine Übernahme der Funktion von alF2 $\beta$-2 spricht (Gäbel et al., 2013). Um diesen Umstand weiter zu untersuchen wurde alF2 $\beta$ $1 \mathrm{~N}$-terminal mit einem His-Tag versehen und im neu erstellten Stamm H26 $\Delta 1279 \Delta 1678$ mittels pSDH1678 überexprimiert.

Während den Wachstumsversuchen wuchs die Deletionsmutante mit dem Überexpressionsplasmid (pSDH1678) in Komplexmedium ähnlich der Kontrolle mit dem Leerplasmid (Abbildung $31 \mathrm{~A}$ ). Jedoch zeigte die Überexpressionsmutante in der spätexponentiellen Phase ein besseres Wachstum.

In der Affinitätsaufreinigung konnte alF2 $\beta$-1 bei $15 \mathrm{kDa}$ nachgewiesen werden. Zusätzlich zeigten sich auf dem Coomassie gefärbten SDS-Gel noch weitere Banden (Abbildung 31B). In der MS-Analyse der Elutionsfraktionen konnten 14 Proteine in allen drei Aufreinigungen nachgewiesen werden (Abbildung 31C). Für die alFs konnte zusätzlich zu alF2 $\beta-1$ die beiden weiteren Untereinheiten des alF2 mitgereinigt werden. Diese waren alF2 $\alpha$ und alF2 $\gamma$. Im Bereich der Transkription konnten zwei Transkriptionsregulatoren identifiziert werden.

A

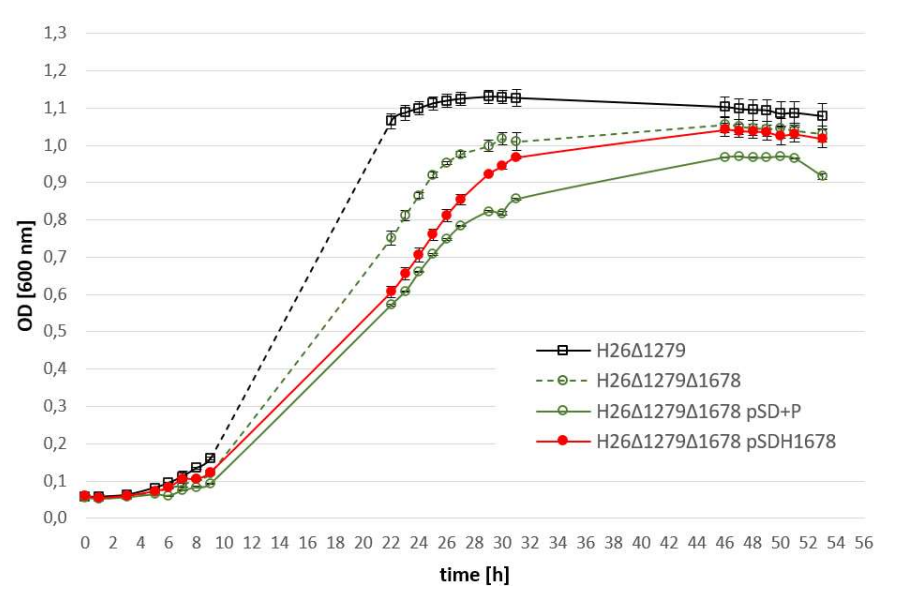

B

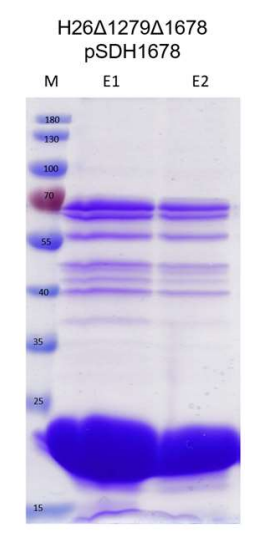

C

\begin{tabular}{lllll}
\hline Group & Specification & Description & Genloci & Accession \\
\hline Translation & alFs & alF2 $\beta$-1 & HVO_1678 & D4GZP2 \\
& & alF2 $\alpha$ & HVO_0699 & D4GT46 \\
& & alF2 $\gamma$ & HVO_1901 & D4GTD4 \\
\hline Transcription & regulator & IcIR family transcription regulator & HVO_2108 & D4GUQ5 \\
& & Transcriptional regulator & HVO_2928 & L9UK32 \\
\hline
\end{tabular}

Abbildung 31: Charakterisierung des alF2 $\beta-1$ (HVO_1678)

A. Im Wachstumsversuch bei $42^{\circ} \mathrm{C}$ in Komplexmedium wuchs die Deletionsmutante $(\mathrm{H} 26(\Delta 1279 \Delta 1678)$ schlechter als der Wildtyp (H26 1279$)$. Im Vergleich dazu wuchs die Überexpressionsmutante (pSDH1678) besser als die Kontrolle mit dem Leerplasmid (pSD+P). B. Elutionsschritte der Überexpression von alF2 $\beta-1$ (15 kDa) nach der Affinitätsaufreinigung auf einem $12 \%$ SDS-Polyacrylamidgel. C. Auflistung der Proteine der MS-Analyse nach der Auswertung. 


\subsection{FPLC von alF2 $\beta-1$}

Für die FPLCs von alF2 $\beta-1$ wurden drei unabhängige exponentielle Kulturen aufgeschlossen und die Affinitätsaufreinigung, wie zuvor beschrieben, durchgeführt. Anschließend wurde jeweils die zweite Elutionsfraktion direkt in der FPLC aufgetrennt. Die Spektren sahen sehr ähnlich aus, weshalb hier eines exemplarisch in Abbildung 32A gezeigt ist. Während des FPLCLaufs wurden die nach Größe aufgetrennten Proteinkomplexe bzw. Proteine in Fraktionen gesammelt und anschließend dialysiert, bevor sie auf ein SDS-Gel aufgetragen wurden. Für die ersten 10 Fraktionen (Daten nicht gezeigt) konnte kein Nachweis von Proteinen im SDS-Gel mittels Coomassie-Färbung erbracht werden, jedoch von Fraktion 11-20 wie in Abbildung 32B gezeigt.

A

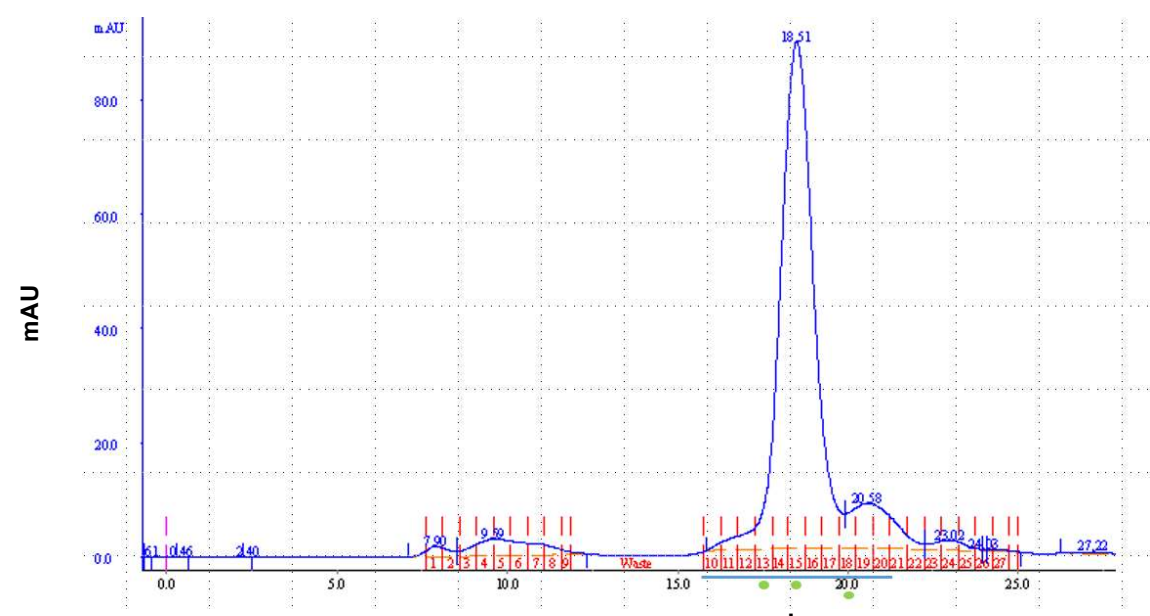

$\mathrm{mL}$

B

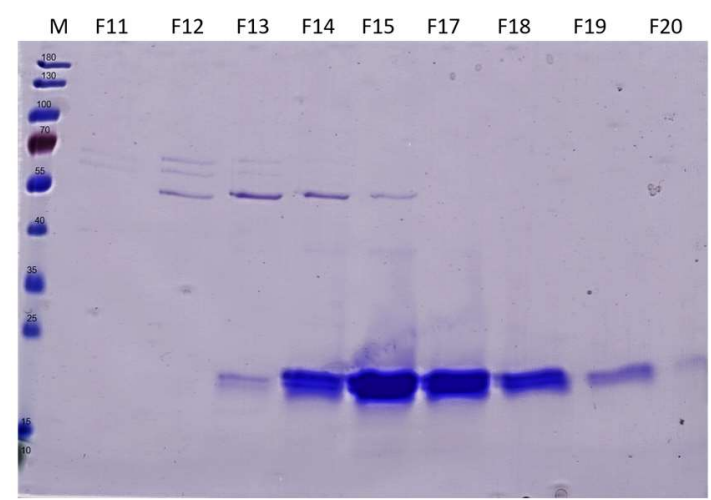

Abbildung 32: FPLC der Elutionsfraktion nach der Affinitätsaufreinigung von alF2 $\beta-1$

A. Nach der Affinitätsaufreinigung des alF2 $\beta-1$ wurde jeweils die zweite Elutionsfraktion über die FPLC aufgetrennt $(n=3)$. Die grünen Punkte unter der $\mathrm{x}$-Achse markieren die Fraktionen, die aus drei FPLCs in der MS analysiert wurden. B. Die gesammelten Fraktionen wurden dialysiert, auf ein SDSGel aufgetragen und Coomassie gefärbt.

Nach der Coomassie-Färbung zeigte sich auf dem SDS-Gel eine Bande auf Höhe des alF2 $\beta$ 1 Proteins zwischen der 15-25 kDa Markerbande (Fraktion F13-20). Des Weiteren waren zwei schwache Banden unterhalb des alF2 $\beta-1$ zwischen 10-15 kDa zu sehen (Fraktion F15, F17). Über alF2 $\beta-1$ tauchten in Fraktion F11-15 vier weitere Banden auf.

Fraktion 13, 15 und 18 wurden mittels MS analysiert. Sie entsprechen den Fraktionen mit den grünen Punkten in Abbildung 32A. Dies erfolgte ebenfalls in den zwei weiteren FPLCLäufen, die ähnlich zu dem hier gezeigten Spektrum verliefen. Die Fraktionen wurden nach der MS-Auswertung zusammengefasst. Die Proben stammten vom Beginn der Schulter des Hauptpeaks (I; F13), von der Spitze des Hauptpeaks (II; F15) sowie vom Abschwung nach 
dem Hauptpeak (III; F18). Die Auswertung der MS-Daten erfolgte wie im Kapitel 3.2.3.1.1 FPLC von alF2 $\alpha$ beschrieben.

\section{Zu Beginn der Schulter: zwei Proteine in drei FPLC-Läufen identifiziert}

Die Verteilung der Proteine anhand ihrer PSM-Werte von drei unabhängigen Aufreinigungen und anschließender FPLC ist in Tabelle 61 absteigend dargestellt. Analyse der PSM-Werte von drei unabhängigen Messungen der Fraktionen zur Beginn der Schulter des Hauptpeaks in der FPLC. Die PSM-Werte wurden auf alF2 $\beta-1$ normiert. Die Proteine wurden nach dem größten PSM-Wert abwärts sortiert. Mit alF2 $\beta-1$ konnte nur alF2 $\alpha$ als weiteres Protein in allen drei Fraktionen nachgewiesen werden.

Tabelle 61: MS-Analyse der Fraktionen zu Beginn der Schulter des Hauptpeaks von alF2 $\beta-1(n=3)$

\begin{tabular}{lccccc}
\hline Description & Accession & Genloci & MW [kDa] & PSM [\%] n=3 & PSM [\%] std. \\
\hline 1.alF2 $\beta-1$ & D4GZP2 & HVO_1678 & 14,9 & 100 & 0,0 \\
2.alF2a & D4GT46 & HVO_0699 & 29,5 & 43,4 & 33,0 \\
\hline \multicolumn{1}{r}{ Translation } & & & & & \\
\hline
\end{tabular}

II. In der Spitze des Hauptpeaks: fünf Proteine in drei FPLC-Läufen identifiziert

Die Verteilung der Proteine anhand ihres PSM-Werts von drei unabhängigen Aufreinigungen und anschließender FPLC ist in Tabelle 62 absteigend dargestellt. Analyse der PSM-Werte dreier unabhängiger Messungen der Fraktionen von der Spitze des Hauptpeaks in der FPLC. Die PSM-Werte wurden auf alF2 $\beta$-1 normiert. Die Proteine wurden nach dem größten PSMWert abwärts sortiert.

Tabelle 62: MS-Analyse der Fraktionen in der Spitze des Hauptpeaks von alF2 $\beta-1(n=3)$

\begin{tabular}{|c|c|c|c|c|c|}
\hline Description & Accession & Genloci & MW [kDa] & PSM [\%] n=3 & PSM [\%] std. \\
\hline 1.alF2 $\beta-1$ & D4GZP2 & HVO_1678 & 14,9 & 100,0 & 0,0 \\
\hline 2.alF2a & D4GT46 & HVO_0699 & 29,5 & 4,8 & 6,5 \\
\hline 3.alF2 $\beta-2$ & L9VAS4 & HVO_2242 & 22,2 & 3,5 & 4,5 \\
\hline 4.Transcriptional regulator & L9UK32 & HVO_2928 & 27,5 & 1,4 & 1,4 \\
\hline 5.UPF0145 protein & L9UT93 & HVO_1377 & 12,8 & 0,5 & 0,7 \\
\hline Translation & & & & Transcription & \\
\hline
\end{tabular}

Mit alF2 $\beta$-1 konnten weitere Untereinheiten des alF2 mitgereinigt werden. Hierbei handelte es sich um alF2 $\alpha$ und die alF $\beta-2$. Die alF2 $\gamma$-Untereinheit konnte nicht mitgereinigt werden. $\mathrm{Zu}$ den weiteren mitgereinigten Proteinen gehörte ein Transkriptionsregulator, der bereits in der Elutionsfraktion nach der Affinitätsaufreinigung nachgewiesen werden konnte (Abbildung 31). 
III. Nach der Spitze des Hauptpeaks: zwei Proteine in drei FPLC-Läufen identifiziert

Die Verteilung der Proteine anhand ihrer PSM-Werte von drei unabhängigen Aufreinigungen und anschließender FPLC ist in Tabelle 63 absteigend dargestellt. Analyse der PSM-Werte der drei unabhängigen Messungen der Fraktionen nach der Spitze des Hauptpeaks in der FPLC. Die PSM-Werte wurden auf alF2 $\beta-1$ normiert.

Tabelle 63: MS-Analyse der Fraktionen nach der Spitze des Hauptpeaks von alF2 $\beta-1$ ( $n=3$ )

\begin{tabular}{lccccc}
\hline Description & Accession & Genloci & MW [kDa] & PSM [\%] n=3 & PSM [\%] std. \\
\hline 1.alF2 $\beta-1$ & D4GZP2 & HVO_1678 & 14,9 & 100,0 & 0,0 \\
2.alF2 $\alpha$ & D4GT46 & HVO_0699 & 29,5 & 14,2 & 12,4 \\
\hline \multicolumn{1}{r}{ Translation } & & & & & \\
\hline
\end{tabular}

Die Proteine wurden nach dem größten PSM-Wert abwärts sortiert. Mit alF2 $\beta-1$ konnte auch hier nur alF2 $\alpha$ als weiteres Protein in allen drei Fraktionen nachgewiesen werden.

\subsubsection{3 alF2 $2 \beta-2$}

Das zweite orthologe Gen von alF2 $\beta$ ist $201 \mathrm{nt}$ länger als alF2 $\beta-1$ und damit $609 \mathrm{nt}$ lang. Die Sequenzidentität zwischen alF2 $\beta-1$ und alF2 $\beta-2$ beläuft sich auf 39,3 \%. Da dieser Faktor deletiert werden konnte, wurde er als nicht essenziell eingestuft. Die Überexpression von alF2 $\beta-2$ fand in der Deletionsmutante H26 $1279 \Delta 2242$ mit dem Plasmid pSDH2242 statt.

Bei den Wachstumsversuchen zeigte sich, dass sich die Deletionsmutante von alF2 $\beta-2$ unter optimalen Wachstumsbedingungen wie der Wildtyp verhielt. Hingegen wuchs die Überexpressionsmutante besser als die Deletionsmutante mit Leerplasmid (Abbildung 33A).

A

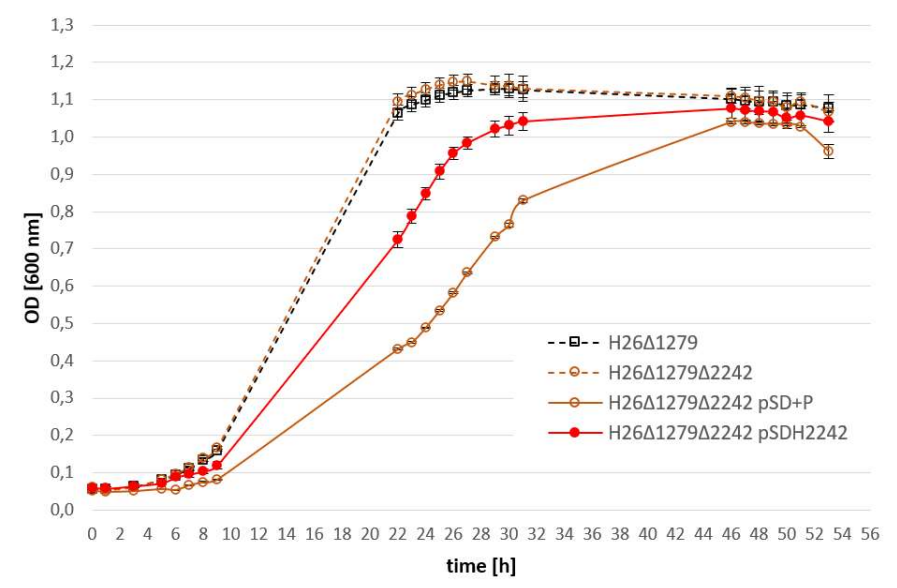

B $H 26 \Delta 1279 \Delta 2242$

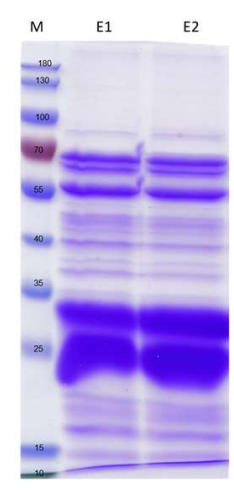

Abbildung 33: Charakterisierung des alF2 $\beta-2$ (HVO_2242)

A. Im Wachstumsversuch bei $42^{\circ} \mathrm{C}$ in Komplexmedium wuchs die Deletionsmutante $(\Delta 2242)$ ähnlich zum Wildtyp $(\Delta 1279)$. Im Vergleich dazu wuchs die Überexpressionsmutante (pSDH2242) besser als die Kontrolle mit dem Leerplasmid $(\triangle 2242$ pSD+P). B. Die Elutionsschritte der Überexpression von alF2 $\beta-2(22,2 \mathrm{kDa})$ nach der Affinitätsaufreinigung auf einem $12 \%$ SDS-Polyacrylamidgel, Coomassie-gefärbt. 
In Abbildung 33B sind die Elutionsschritte der Überexpression von alF2 $\beta$-2 auf einem Polyacrylamdigel, Coomassie-gefärbt, dargestellt. Nach der Aufreinigung der Überexpression von alF2 $\beta$-2 zeigten sich zwei starke Banden zwischen 25 und $30 \mathrm{kDa}$ in den Elutionsfraktionen. Diese Banden wurden aus dem SDS-Gel einzeln ausgeschnitten und in der MS analysiert. Beide Banden wurden als alF2 $\beta$-2 identifiziert (Daten nicht gezeigt). Von drei Affinitätsaufreinigungen wurde jeweils die zweite Elutionsfraktion in der MS analysiert.

In der MS-Analyse von alF2 $\beta-2$ konnten 29 Proteine in drei Elutionsfraktionen nachgewiesen werden (Tabelle 64). Davon waren zwei Proteine nicht charakterisiert und 19 Proteine konnten molekularbiologischen Prozessen zugeordnet werden. Unter anderem war dies die Translation, Transkription und ribosomale Proteine. Bei der Translation konnten mit alF2 $\beta-2$ die beiden anderen Untereinheiten alF2 $\alpha$ und alF2 $\gamma$ des trimeren Faktors alF2 mitgereinigt werden. Zusätzlich konnte alF5B und zwei Elongationsfaktoren mitgereinigt werden.

Für die Transkription konnte ein Transkriptionsregulator identifiziert werden. Zu den mitgereinigten ribosomalen Proteinen gehören zwei Proteine der kleinen 30 S ribosomalen Untereinheit sowie sieben Proteine der großen $50 S$ ribosomalen Untereinheit.

Tabelle 64: Einteilung der mitgereinigten Proteine von alF2 $\beta-2$

\begin{tabular}{|c|c|c|c|c|}
\hline Group & Specification & Description & Genloci & Accession \\
\hline \multirow[t]{15}{*}{ Translation } & alFs & alF2 $\beta-2$ & HVO_2242 & L9VAS4 \\
\hline & & alF2a & HVO_0699 & D4GT46 \\
\hline & & alF2y & HVO_1901 & D4GTD4 \\
\hline & & alF5B & HVO_1963 & D4GTJ2 \\
\hline & aEFs & $\mathrm{aEF} 1 \mathrm{a}$ & HVO_2413 & L9V6J4 \\
\hline & & $\mathrm{aEF} 2$ & HVO_0356 & L9UK07 \\
\hline & $30 \mathrm{~S} \mathrm{rpS}$ & $30 \mathrm{~S}$ rpS3Ae & HVO_1145 & D4GWA5 \\
\hline & & $30 S$ rpS11 & HVO_2782 & L9V5R1 \\
\hline & $50 \mathrm{~S} \mathrm{rpL}$ & $50 \mathrm{~S}$ rpL2 & HVO_2561 & D4GTZ3 \\
\hline & & $50 \mathrm{~S} \mathrm{rpL} 3$ & HVO_2564 & L9V5K9 \\
\hline & & $50 S$ rpL4 & HVO_2563 & D4GTZ5 \\
\hline & & 50S rpL18 & HVO_2545 & P50563 \\
\hline & & $50 \mathrm{~S}$ rpL18e & HVO_2779 & D4GWY3 \\
\hline & & $50 S$ rpL22 & HVO_2559 & L9V5K3 \\
\hline & & $50 S$ rpL30 & HVO_2543 & L9V5X1 \\
\hline Transcription & regulator & ICIR family transcription regulator & HVO_2108 & D4GUQ5 \\
\hline RNA turnover & ribonuclease & Ribonuclease J & HVO_2724 & L9V5P6 \\
\hline \multirow[t]{2}{*}{ Protein turnover } & thermosome & Thermosome subunit 2 & HVO_0455 & 030560 \\
\hline & & Thermosome subunit 3 & HVO_0778 & Q9HHA2 \\
\hline
\end{tabular}




\subsection{FPLC von alF2 $\beta-2$}

Für die FPLCs von alF2 $\beta$-2 wurden drei unabhängige exponentielle Kulturen aufgeschlossen und die Affinitätsaufreinigung, wie zuvor beschrieben, durchgeführt. Anschließend wurde jeweils die zweite Elutionsfraktion direkt in der FPLC aufgetrennt. Die Spektren der FPLC sahen für alF2 $\beta-2$ sehr ähnlich aus, weshalb hier eines exemplarisch (Abbildung $34 \mathrm{~A}$ ) gezeigt wird. Während des FPLC-Laufes wurden die nach Größe aufgetrennten Proteinkomplexe bzw. Proteine in Fraktionen gesammelt und anschließend dialysiert, bevor sie auf ein SDS-Gel aufgetragen wurden. Auch hier ließ sich die Doppelbande anschließend auf dem SDS-Gel nachweisen (Abbildung 34B).

Im Spektrum zeigten sich drei große und drei kleine Peaks (Abbildung 34A). Proteine konnten nur im Hauptpeak nachgewiesen werden (Daten nicht gezeigt).

Die Fraktion 20, 22 und 24 wurden mittels MS analysiert. Dies erfolgte ebenfalls in den zwei weiteren FPLC-Läufen, die ähnlich zu dem hier gezeigten Spektrum verliefen. Die Fraktionen wurden zusammengefasst: MS-Analyse der Proteine in der Schulter des Hauptpeaks (I; F20), die Spitze des Hauptpeaks (II; F22) sowie nach der Spitze des Hauptpeaks (III; F24). Die Auswertung der MS-Daten erfolgte wie im Kapitel 3.2.3.1.1 FPLC von alF2 $\alpha$ beschrieben.

A

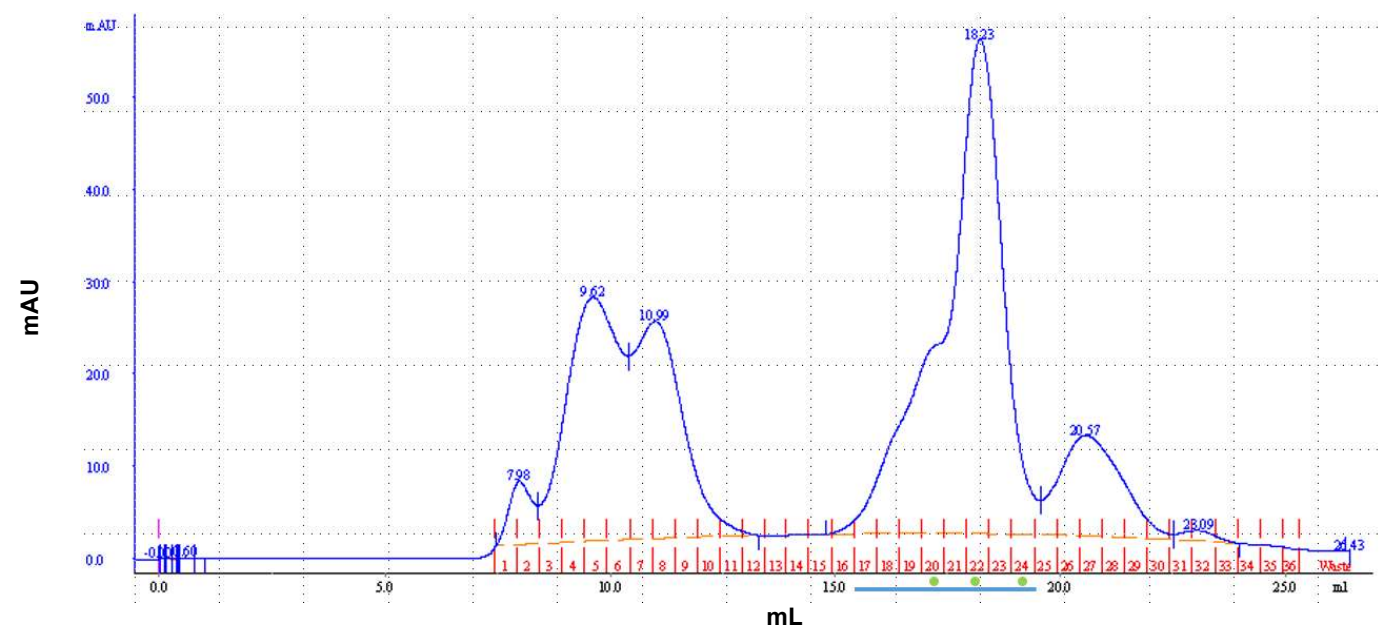

B

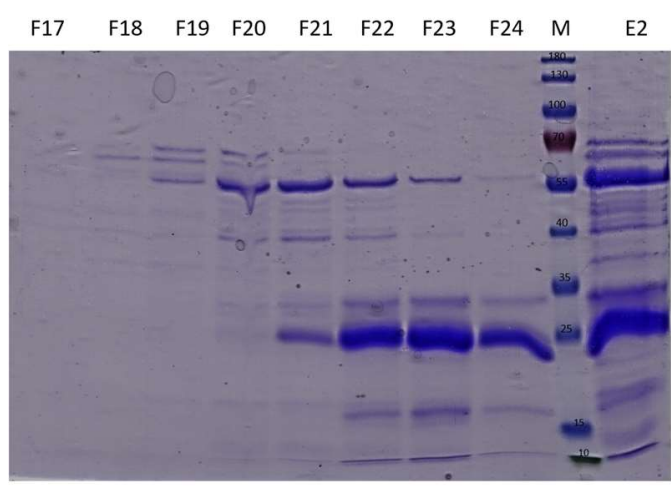

Abbildung 34: FPLC-Analyse des Eluats nach der Affinitätsaufreinigung von alF2 $\beta-2$

A. Das Diagramm der FPLC mit der Auftrennung und den Fraktionen. Die grünen Punkte markieren die Fraktionen, die aus drei FPLCs in der MS analysiert wurden. B. Die Fraktionen 17-24 der nativen FPLC, dialysiert, auf einem 12 \%-SDS-Polyacrylamidgel Coomassie gefärbt, im Vergleich zum Eluat. 
I. In der Schulter des Hauptpeaks: 28 Proteine in drei FPLC-Läufen identifiziert

Die Verteilung der Proteine anhand ihrer PSM-Werte von drei unabhängigen Aufreinigungen und anschließender FPLC ist in Tabelle 65 absteigend dargestellt. Analyse der PSM-Werte dreier unabhängiger Messungen der Fraktionen aus der Schulter des Hauptpeaks in der FPLC. Die PSM-Werte wurden auf alF2 $\beta-2$ normiert. Die Proteine wurden nach dem größten PSM-Wert abwärts sortiert.

Tabelle 65: MS-Analyse der Fraktionen in der Schulter des Hauptpeaks von alF2 $\beta-2$ ( $n=3)$

\begin{tabular}{|c|c|c|c|c|c|c|}
\hline & Description & Accession & Genloci & $\begin{array}{c}\mathrm{MW} \\
{[\mathrm{kDa}]}\end{array}$ & $\begin{array}{c}\text { PSM [\%] } \\
n=3\end{array}$ & $\begin{array}{c}\text { PSM [\%] } \\
\text { std. }\end{array}$ \\
\hline 1. & alF2 $\beta-1$ & D4GZP2 & HVO_1678 & 14,9 & 504,5 & 640,8 \\
\hline 2. & $\mathrm{aEF} 1 \mathrm{a}$ & L9V6J4 & HVO_2413 & 45,6 & 164,1 & 110,5 \\
\hline 3. & Succinate dehydrogenase & L9V5C0 & HVO_2808 & 67,6 & 132,8 & 140,1 \\
\hline 4. & alF2 $\beta-2$ & L9VAS4 & HVO_2242 & 22,2 & 100,0 & 0,0 \\
\hline 5. & alF2a & D4GT46 & HVO_0699 & 29,5 & 71,3 & 5,8 \\
\hline 6. & Putative phosphoribosyltransferase & D4GVU2 & HVO_2226 & 39,6 & 67,8 & 54,4 \\
\hline 7. & alF2y & D4GTD4 & HVO_1901 & 43,9 & 61,0 & 23,4 \\
\hline 8. & Aspartate carbamoyltransferase & D4GY71 & HVO_1454 & 33,7 & 50,9 & 34,1 \\
\hline 9. & PhoU domain protein & D4GWT4 & HVO_1181 & 38,4 & 47,1 & 38,1 \\
\hline 10. & F420H2:NADP oxidoreductase & D4GRX4 & HVO_0433 & 23,3 & 40,3 & 21,0 \\
\hline 11. & $\begin{array}{l}\text { NAD-dependent glucose-6-phosphate dehydro- } \\
\text { genase }\end{array}$ & D4GS48 & HVO_0511 & 29,3 & 40,1 & 30,7 \\
\hline 12. & Serine hydroxymethyltransferase & D4GXG2 & HVO_2862 & 44,3 & 35,7 & 46,5 \\
\hline 13. & Thermosome subunit 3 & Q9HHA2 & HVO_0778 & 55,2 & 33,0 & 35,7 \\
\hline 14. & Thermosome subunit 2 & 030560 & HVO_0455 & 59,3 & 28,4 & 18,8 \\
\hline 15. & RNA-binding protein Lsm & D4GW47 & HVO_2723 & 8,3 & 21,4 & 20,2 \\
\hline 16. & Cobalt-precorrin-5A hydrolase & D4GP61 & HVO_B0059 & 34,5 & 19,7 & 13,1 \\
\hline 17. & Chaperone protein DnaK & L9VEIO & HVO_1590 & 67,2 & 18,9 & 14,0 \\
\hline 18. & Biotin carboxylase & L9V6D6 & HVO_2486 & 65,3 & 18,8 & 9,8 \\
\hline 19. & Siderophore biosynthesis protein lucC & D4GP43 & HVO_B0041 & 70,1 & 17,7 & 15,8 \\
\hline 20. & IcIR family transcription regulator & D4GUQ5 & HVO_2108 & 28 & 17,3 & 8,8 \\
\hline 21. & Thiamine thiazole synthase & D4GSS5 & HVO_0665 & 32,4 & 14,3 & 11,7 \\
\hline 22. & Uncharacterized protein & L9V5N6 & HVO_2796 & 12 & 11,5 & 6,9 \\
\hline 23. & DNA repair and recombination protein RadA & Q48328 & HVO_0104 & 37,3 & 11,1 & 7,6 \\
\hline 24. & DRTGG domain protein & D4GVH6 & HVO_0999 & 39,8 & 10,0 & 6,6 \\
\hline 25. & SufB domain protein & D4GUK8 & HVO_0861 & 44,7 & 9,9 & 6,0 \\
\hline 26. & M20 family amidohydrolase & D4GXW6 & HVO_1395 & 45,4 & 8,0 & 7,7 \\
\hline 27. & Ferredoxin--nitrite reductase & L9VDY4 & HVO_1788 & 66,6 & 5,8 & 4,7 \\
\hline 28. & Aldehyde dehydrogenase & D4GWU7 & HVO_1189 & 56,1 & 5,2 & 5,1 \\
\hline & Translation & \multicolumn{5}{|c|}{ Transcription } \\
\hline
\end{tabular}

Insgesamt konnten 28 Proteine in allen drei Fraktionen identifiziert werden. Darunter vier alFs und der Elongationsfaktor aEF1a.

Unerwartet war alF2 $\beta$-1, das am häufigsten identifizierte Protein, mit dem höchsten PSM-Wert. Der Anteil war im Schnitt um das fünffache höher.

Die alF2 $\beta$-2-Untereinheit sowie die alF2 $\gamma$ - und alF2 $\alpha$-Untereinheit konnten ebenfalls identifiziert werden und lagen unter den sieben Proteinen mit dem höchsten PSM-Wert. 


\section{Ergebnisse}

II. In der Spitze des Hauptpeaks: acht Proteine in drei FPLC-Läufen identifiziert

Die Verteilung der Proteine anhand ihrer PSM-Werte von drei unabhängigen Aufreinigungen und anschließender FPLC ist in Tabelle 66 absteigend dargestellt. Analyse der PSM-Werte dreier unabhängiger Messungen der Fraktionen aus der Spitze des Hauptpeaks in der FPLC. Die PSM-Werte wurden auf alF2 $\beta-2$ normiert. Die Proteine wurden nach dem größten PSMWert abwärts sortiert.

Tabelle 66: MS-Analyse der Spitze des Hauptpeaks von alF2 $\beta-2(n=3)$

\begin{tabular}{|c|c|c|c|c|c|c|}
\hline & Description & Accession & Genloci & MW [kDa] & $\begin{array}{c}\mathrm{PSM}[\%] \\
\mathrm{n}=3\end{array}$ & $\begin{array}{c}\text { PSM [\%] } \\
\text { std. }\end{array}$ \\
\hline 1. & alF2 $\beta-2$ & L9VAS4 & HVO_2242 & 22,2 & 100,0 & 0,0 \\
\hline 2. & alF2 $2 \beta-1$ & D4GZP2 & HVO_1678 & 14,9 & 52,2 & 64,7 \\
\hline 3. & $\mathrm{alF} 2 a$ & D4GT46 & HVO_0699 & 29,5 & 23,0 & 37,3 \\
\hline 4. & HGPRTase-like protein & L9URM2 & HVO_1072 & 20,5 & 7,8 & 8,0 \\
\hline 5. & Aspartate carbamoyltransferase & D4GY71 & HVO_1454 & 33,7 & 6,8 & 2,6 \\
\hline 6. & UPF0058 family protein & D4GYA8 & HVO_1473 & 10,3 & 4,2 & 0,7 \\
\hline 7. & Putative glutamate--argW ligase & D4GYP1 & HVO_0046 & 31,9 & 2,7 & 2,2 \\
\hline 8. & NAD-dependent glucose-6-phosphate dehydrogenase & D4GS48 & HVO_0511 & 29,3 & 2,3 & 0,7 \\
\hline
\end{tabular}

alF2 $\beta$-2 war in diesen Fraktionen das am häufigsten identifizierte Protein mit dem höchsten PSM-Wert. Die alF2 $\beta$-1-Untereinheit sowie die alF2 $\alpha$-Untereinheit konnten ebenfalls identifiziert werden und lagen unter den drei Proteinen mit den höchsten PSM-Wert. Die Untereinheit alF2y konnte nicht nachgewiesen werden.

III. Nach der Spitze des Hauptpeaks: sechs Proteine in drei FPLC-Läufen identifiziert

Die Verteilung der Proteine anhand ihrer PSM-Werte von drei unabhängigen Aufreinigungen und anschließender FPLC ist in Tabelle 67 absteigend dargestellt. Analyse der PSM-Werte dreier unabhängiger Messungen der Fraktionen nach der Spitze des Hauptpeaks in der FPLC. Die PSM-Werte wurden auf alF2 $\beta-2$ normiert. Die Proteine wurden nach dem größten PSMWert abwärts sortiert.

Tabelle 67: MS-Analyse der Fraktionen nach der Spitze des Hauptpeaks alF2 $\beta-2(n=3)$

\begin{tabular}{|c|c|c|c|c|c|c|}
\hline & Description & Accession & Genloci & MW [kDa] & $\begin{array}{c}\mathrm{PSM}[\%] \\
\mathrm{n}=3\end{array}$ & PSM [\%] std. \\
\hline 1. & alF2 $\beta-2$ & L9VAS4 & HVO_2242 & 22,2 & 407,0 & 427,2 \\
\hline 2. & alF2 $\beta-1$ & D4GZP2 & HVO_1678 & 14,9 & 121,0 & 69,5 \\
\hline 3. & alF2a & D4GT46 & HVO_0699 & 29,5 & 25,3 & 9,7 \\
\hline 4. & HGPRTase-like protein & L9URM2 & HVO_1072 & 20,5 & 10,7 & 11,5 \\
\hline 5. & $\mathrm{aEF} 1 \mathrm{a}$ & L9V6J4 & HVO_2413 & 45,6 & 8,7 & 4,2 \\
\hline 6. & 5'-nucleotidase SurE & L9V6Z6 & HVO_A0228 & 32 & 7,0 & 6,9 \\
\hline
\end{tabular}


Der Faktor alF2 $\beta$-2 war in diesen Fraktionen das am häufigsten identifizierte Protein mit dem höchsten PSM-Wert. Die alF2 $\beta$-1-Untereinheit sowie die alF2 $\alpha$-Untereinheit konnten ebenfalls identifiziert werden und lagen unter den vier Proteinen mit dem höchsten PSM-Wert. Die Untereinheit alF2y konnte nach der Spitze des Hauptpeaks nicht nachgewiesen werden.

\subsubsection{4 alF2y}

alF2 $\gamma$ ist die größte Untereinheit des alF2 und sowohl in Archaeen als auch in Eukaryonten essenziell (Gäbel et al., 2013). Der Initiationsfaktor alF2 $\gamma$ wurde im Wildtyp überexprimiert, da eine Deletion nicht möglich war und der Faktor deshalb als essenziell eingestuft wurde. Die Überexpression des $\mathrm{N}$-terminal mit einem His-Tag versehenen alF2 $\gamma$ fand im Stamm H26 1279 mit dem Plasmid pSDH1901 statt. In Komplexmedium unter optimalen Bedingungen zeigte die Überexpressionsmutante ein sehr viel besseres Wachstum als die Kontrolle mit dem Leerplasmid (Abbildung 35A).

Nach der Affinitätsaufreinigung der Überexpression des alF2y konnte auf dem SDS-Gel sowohl alF2y (44 kDa) sowie viele mitgereinigte Proteine visualisiert werden (Abbildung 35B). Zwei breitere Banden erschienen zwischen 55-75 kDa. Von drei Affinitätsaufreinigungen wurde jeweils die zweite Elutionsfraktion in der MS analysiert.

A

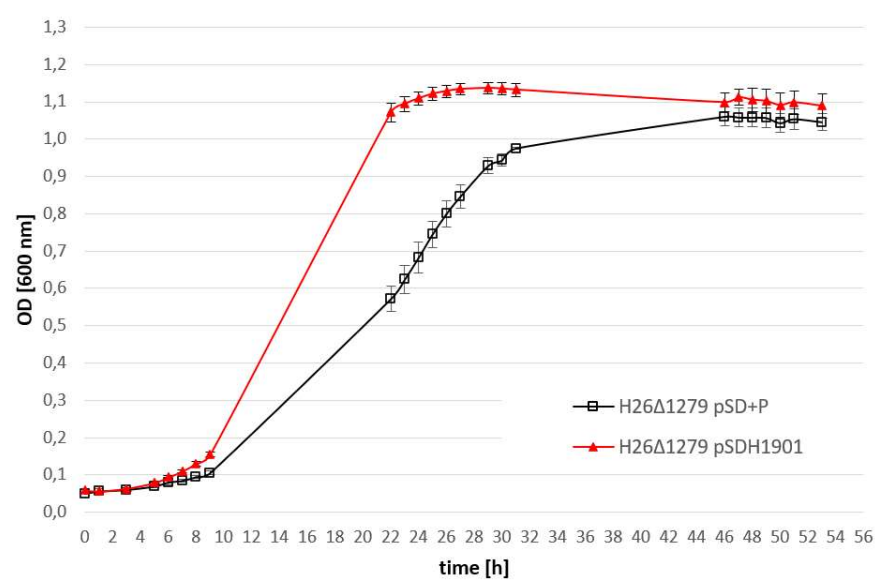

B

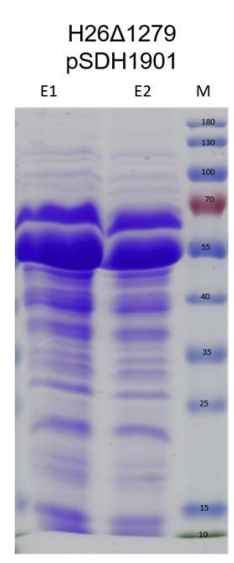

Abbildung 35: Charakterisierung des alF2y (HVO_1901)

A. Im Wachstumsversuch bei $42^{\circ} \mathrm{C}$ in Komplexmedium wuchs die Überexpressionsmutante (pSDH1901) sehr viel besser als die Kontrolle ( $\Delta 1279 \mathrm{pSD}+\mathrm{P})$ mit dem Leerplasmid. B. Die Elutionsschritte der Überexpression von alF2 $\gamma$ (44 kDa) nach der Affinitätsaufreinigung auf einem 12 \% SDS-Polyacrylamidgel, Coomassie-gefärbt.

In drei Messungen konnten in der MS-Analyse 38 Proteine identifiziert werden. Sechs Proteine waren nicht charakterisiert, elf Proteine konnten in die molekularbiologischen Prozesse eingeordnet werden (Tabelle 68 ).

Hierzu zählten in der Translation die beiden weiteren Untereinheiten von alF2, nämlich alF2 $\alpha$ und alF2 $\beta-2$. Zusätzlich konnte alF2Bס-1 sowie alF5B mitgereinigt werden. Für die Transkription konnte unter anderem eine Untereinheit der RNA-Polymerase nachgewiesen werden. Des Weiteren konnte rpL2 als $50 \mathrm{~S}$ ribosomales Protein mitgereinigt werden. 
Tabelle 68: Einteilung der mitgereinigten Proteine von alF2 $\gamma$

\begin{tabular}{lllll}
\hline Group & Specification & Description & Genloci & Accession \\
\hline Translation & alFs & alF2 $y$ & HVO_1901 & D4GTD4 \\
& alFs & alF2a & HVO_0699 & D4GT46 \\
& alFs & alF2 $3-2$ & HVO_2242 & L9VAS4 \\
& alFs & alF2Bס-1 & HVO_0966 & L9USK7 \\
& alFs & alF5B & HVO_1963 & D4GTJ2 \\
\cline { 2 - 5 } & aEFs & aEF1a & HVO_2413 & L9V6J4 \\
& aEFs & aEF2 & HVO_0356 & L9UK07 \\
\cline { 2 - 5 } & 50S rpL & 50S rpL2 & HVO_2561 & D4GTZ3 \\
\hline Transcription & RNAP-subunits & rpoB2 & HVO_0347 & L9UK99 \\
& regulator & HTH domain protein & HVO_1133 & D4GW85 \\
& regulator & Transcriptional regulator & HVO_0179 & L9UGU5 \\
\hline
\end{tabular}

\subsection{FPLC von alF2 $\gamma$}

Für die FPLCs von alF2 $y$ wurden drei unabhängige exponentielle Kulturen aufgeschlossen und die Proteinaufreinigung, wie zuvor beschrieben, durchgeführt. Anschließend wurde jeweils die zweite Elutionsfraktion direkt in der FPLC aufgetrennt. Die Spektren sahen sehr ähnlich aus, weshalb hier eines exemplarisch in Abbildung 36A gezeigt ist.

A

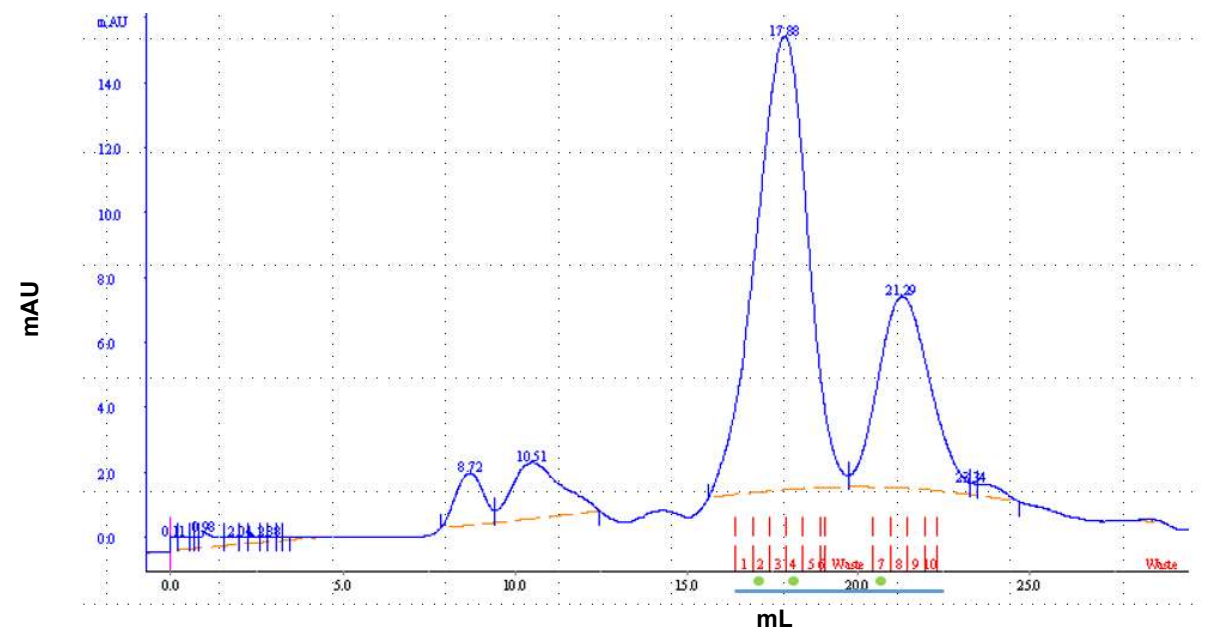

B

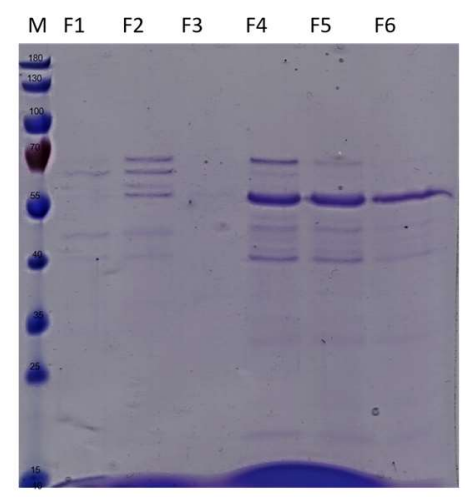

F7 $\quad$ F8 $\quad$ F9 $\quad$ F10

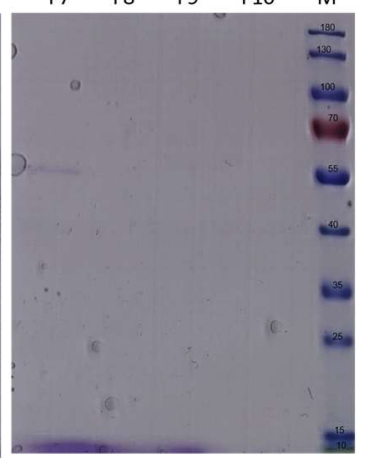

Abbildung 36: FPLC-Analyse des Eluats nach der Affinitätsaufreinigung von alF2y A. Das Diagramm der FPLC mit der Auftrennung der Elutionsfraktion. Die Fraktionen sind als rote Ziffern auf der $x$-Achse markiert. Die grünen Punkte unter der $x$-Achse markieren die Fraktionen, die aus drei FPLCs in der MS analysiert wurden. B. Fraktionen der nativen FPLC, nach der Dialyse, auf einem $12 \%$ SDS-Polyacrylamidgel Coomassie gefärbt. 
Während des FPLC-Laufs wurden die nach Größe aufgetrennten Proteinkomplexe bzw. Proteine in Fraktionen gesammelt und anschließend dialysiert, bevor sie auf ein SDS-Gel aufgetragen wurden. Hierbei konnten für Fraktion 1-8 die Proteine mittels Coomassiefärbung auf dem SDS-Gel sichtbar gemacht werden (Abbildung 36B).

In den Spektren der FPLCs von alF2y zeigten sich zwei kleine Peaks, gefolgt von zwei großen Peaks. In den kleinen Peaks konnten im SDS-Gel keine Proteine nachgewiesen werden (Daten nicht gezeigt). Im letzteren der beiden großen Peaks konnte für die Fraktionen 7-8 mehrere Proteine auf dem SDS-Gel visualisiert werden. Für die Fraktionen 9-10 konnten auf dem SDS-Gel keine Proteine mehr sichtbar gemacht werden (Abbildung 36B).

Jeweils drei dieser gesammelten Fraktionen wurden mittels MS analysiert. Diese befanden sich im Hauptpeak vor der Spitze (I; F2), nach der Spitze des Hauptpeaks (II, F4) und zu Beginn des zweithöchsten Peaks (III; F7). In der Abbildung 36A entsprechen die verwendeten Fraktionen den Fraktionen mit den grünen Punkten. Die Analyse erfolgte für drei FPLC-Läufe. Die Auswertung der MS-Daten erfolgte wie im Kapitel 3.2.3.1.1 FPLC von alF2 $\alpha$ beschrieben.

\section{Zu Beginn des Hauptpeaks: 43 Proteine in drei FPLC-Läufen identifiziert}

Die Verteilung der Proteine anhand ihrer PSM-Werte von drei unabhängigen Aufreinigungen und anschließender FPLC ist in Tabelle 69 absteigend dargestellt. Analyse der PSM-Werte dreier unabhängiger Messungen der Fraktionen zu Beginn des Hauptpeaks in der FPLC. Die PSM-Werte wurden auf alF2y normiert. Die Proteine wurden nach dem größten PSM-Wert abwärts sortiert.

Tabelle 69: MS-Analyse der FPLC-Fraktionen zu Beginn des Hauptpeaks von alF2y ( $n=3$ )

\begin{tabular}{|c|c|c|c|c|c|c|}
\hline & Description & Accession & Genloci & $\begin{array}{c}\mathrm{MW} \\
{[\mathrm{kDa}]}\end{array}$ & $\begin{array}{c}\text { PSM [\%] } \\
n=3\end{array}$ & $\begin{array}{l}\text { PSM [\%] } \\
\text { std. }\end{array}$ \\
\hline 1. & alF2a & D4GT46 & HVO_0699 & 29,5 & 1760,1 & 765,9 \\
\hline 2. & Putative phosphoribosyltransferase & D4GVU2 & HVO_2226 & 39,6 & 649,2 & 675,6 \\
\hline 3. & Succinate dehydrogenase or fumarate reductase & L9V5C0 & HVO_2808 & 67,6 & 585,1 & 235,4 \\
\hline 4. & aEF2 & L9UK07 & HVO_0356 & 80,4 & 481,3 & 724,4 \\
\hline 5. & Uncharacterized protein & D4H0D4 & HVO_C0046 & 20,1 & 478,6 & 172,9 \\
\hline 6. & Serine O-acetyltransferase & D4GTN2 & HVO_2004 & 31,9 & 457,3 & 60,0 \\
\hline 7. & RNA-binding protein Lsm & D4GW47 & HVO_2723 & 8,3 & 243,7 & 85,0 \\
\hline 8. & PhoU domain protein & D4GWT4 & HVO_1181 & 38,4 & 231,4 & 297,9 \\
\hline 9. & alF2Bס-1 & L9USK7 & HVO_0966 & 34,9 & 225,6 & 245,4 \\
\hline 10. & alF5B & D4GTJ2 & HVO_1963 & 65,3 & 210,2 & 281,5 \\
\hline 11. & 3-hydroxy-3-methylglutaryl coenzyme A reductase & L9V660 & HVO_2583 & 41,1 & 202,6 & 265,1 \\
\hline 12. & $\begin{array}{l}\text { NAD-dependent glucose-6-phosphate dehydro- } \\
\text { genase }\end{array}$ & D4GS48 & HVO_0511 & 29,3 & 180,9 & 115,9 \\
\hline 13. & Uncharacterized protein & D4GUI2 & HVO_2629 & 30,3 & 172,5 & 62,8 \\
\hline 14. & Probable urocanate hydratase & L9VJP1 & HVO_A0562 & 67,9 & 172,3 & 156,0 \\
\hline 15. & Putative DNA helicase Rad25 & L9VE99 & HVO_1723 & 76,8 & 171,0 & 184,9 \\
\hline 16. & Aconitate hydratase & L9VCX4 & HVO_1955 & 70,4 & 161,5 & 199,3 \\
\hline 17. & Uridine phosphorylase & L9VEV3 & HVO_1579 & 29 & 158,1 & 167,0 \\
\hline
\end{tabular}


Ergebnisse

\begin{tabular}{|c|c|c|c|c|c|c|}
\hline 18. & AAA-type ATPase (CDC48 subfamily) & D4GWM8 & HVO_2380 & 81,9 & 139,8 & 160,8 \\
\hline 19. & Uncharacterized protein & L9V5N6 & HVO_2796 & 12 & 120,9 & 60,0 \\
\hline 20. & Uncharacterized protein & L9URS0 & HVO_1018 & 69,8 & 116,7 & 125,7 \\
\hline 21. & Siderophore biosynthesis protein lucC & D4GP43 & HVO_B0041 & 70,1 & 110,3 & 64,8 \\
\hline 22. & Putative glutamate--argW ligase & D4GYP1 & HVO_0046 & 31,9 & 109,3 & 83,1 \\
\hline 23. & HGPRTase-like protein & L9URM2 & HVO_1072 & 20,5 & 107,3 & 145,8 \\
\hline 24. & alF2y & D4GTD4 & HVO_1901 & 43,9 & 100,0 & 0,0 \\
\hline 25. & rpoB1 & L9UJM2 & HVO_0348 & 67,7 & 90,2 & 26,8 \\
\hline 26. & Serine hydroxymethyltransferase & D4GXG2 & HVO_2862 & 44,3 & 84,0 & 94,0 \\
\hline 27. & M20 family amidohydrolase & D4GXW6 & HVO_1395 & 45,4 & 81,4 & 23,8 \\
\hline 28. & Putative nickel-responsive regulator & D4GWQ6 & HVO_2409 & 15,2 & 75,6 & 3,1 \\
\hline 29. & NADH dehydrogenase-like complex subunit CD & L9URY6 & HVO_0980 & 63,4 & 75,4 & 40,0 \\
\hline 30. & ABC-type transport system ATP-binding protein & D4GS85 & HVO_1760 & 32,4 & 64,8 & 18,0 \\
\hline 31. & Chaperone protein DnaK & L9VEIO & HVO_1590 & 67,2 & 62,5 & 32,6 \\
\hline 32. & Fructose-bisphosphate aldolase class 2 & D4GYE0 & HVO_1494 & 36,3 & 61,3 & 76,8 \\
\hline 33. & SufB domain protein & D4GUK8 & HVO_0861 & 44,7 & 59,1 & 35,8 \\
\hline 34. & Isocitrate dehydrogenase [NADP] & D4GU92 & HVO_2588 & 45,8 & 55,0 & 31,8 \\
\hline 35. & Ribonuclease Z & L9UHJ9 & HVO_0144 & 34,1 & 48,4 & 16,1 \\
\hline 36. & Acetate--CoA ligase (ADP-forming) & D4GVH7 & HVO_1000 & 74,5 & 44,4 & 34,4 \\
\hline 37. & XerC/D-like integrase & D4GZ49 & HVO_1620 & 39,1 & 43,8 & 9,8 \\
\hline 38. & DNA repair and recombination protein $\mathrm{RadB}$ & L9V6G6 & HVO_2383 & 24,6 & 41,1 & 7,7 \\
\hline 39. & Branched-chain amino acid aminotransferase & L9UK29 & HVO_0329 & 35 & 36,8 & 16,6 \\
\hline 40. & Uncharacterized protein & D4GWI1 & HVO_2332 & 19,4 & 31,8 & 8,6 \\
\hline 41. & tRNA(Met) cytidine acetyltransferase TmcA & D4GW73 & HVO_2736 & 81,2 & 30,2 & 15,3 \\
\hline 42. & Hydantoin racemase & D4GR45 & HVO_A0377 & 28,5 & 27,0 & 17,5 \\
\hline 43. & Uncharacterized protein & L9V6R9 & HVO_2519 & 40,7 & 22,9 & 11,6 \\
\hline & Translation & \multicolumn{5}{|c|}{ Transcription } \\
\hline
\end{tabular}

Insgesamt konnten 43 Proteine in allen drei Fraktionen identifiziert werden. Darunter vier Initiationsfaktoren. Zu Beginn des Hauptpeaks von alF2 $\gamma$ konnte unerwarteterweise alF2 $\alpha$ mit dem höchsten PSM-Wert identifiziert werden. Der Faktor alF2 $y$ folgte erst als 24. Protein. Als weitere Translationsinitiationsfaktoren konnte alF5B sowie alF2Bס-1 identifiziert werden.

\section{In der Spitze des Hauptpeaks: 46 Proteine in drei FPLC-Läufen identifiziert}

Die Verteilung der Proteine anhand ihrer PSM-Werte von drei unabhängigen Aufreinigungen und anschließender FPLC ist in Tabelle 70 absteigend dargestellt. Analyse der PSM-Werte dreier unabhängiger Messungen der Fraktionen aus der Spitze des Hauptpeaks in der FPLC. Die PSM-Werte wurden auf alF2y normiert. Die Proteine wurden nach dem größten PSM-Wert abwärts sortiert.

Tabelle 70: MS-Analyse der FPLC-Fraktionen in der Spitze des Hauptpeaks von alF2y (n=3)

\begin{tabular}{|c|c|c|c|c|c|c|}
\hline & Description & Accession & Genloci & $\begin{array}{c}\text { MW } \\
{[k D a]}\end{array}$ & $\begin{array}{c}\text { PSM [\%] } \\
n=3\end{array}$ & $\begin{array}{c}\text { PSM [\%] } \\
\text { std. }\end{array}$ \\
\hline 1. & $\mathrm{aEF} 1 \mathrm{a}$ & L9V6J4 & HVO_2413 & 45,6 & 3602,3 & 3811,5 \\
\hline 2. & Succinate dehydrogenase or fumarate reductase & L9V5C0 & HVO_2808 & 67,6 & 1592,2 & 1168,4 \\
\hline 3. & alF2a & D4GT46 & HVO_0699 & 29,5 & 1422,8 & 1389,5 \\
\hline
\end{tabular}


Ergebnisse

\begin{tabular}{|c|c|c|c|c|c|c|}
\hline 4. & $\begin{array}{l}\text { NAD-dependent glucose-6-phosphate dehydro- } \\
\text { genase }\end{array}$ & D4GS48 & HVO_0511 & 29,3 & 1291,7 & 1640,3 \\
\hline 5. & PhoU domain protein & D4GWT4 & HVO_1181 & 38,4 & 887,5 & 1379,4 \\
\hline 6. & $\begin{array}{l}\text { Putative phosphoribosyltransferase (Homolog to an- } \\
\text { thranilate phosphoribosyltransferase) }\end{array}$ & D4GVU2 & HVO_2226 & 39,6 & 809,2 & 837,7 \\
\hline 7. & F420H2:NADP oxidoreductase & D4GRX4 & HVO_0433 & 23,3 & 781,8 & 920,3 \\
\hline 8. & $\mathrm{aEF} 2$ & L9UK07 & HVO_0356 & 80,4 & 761,7 & 1245,8 \\
\hline 9. & HGPRTase-like protein & L9URM2 & HVO_1072 & 20,5 & 492,8 & 751,0 \\
\hline 10. & Aspartate carbamoyltransferase & D4GY71 & HVO_1454 & 33,7 & 408,8 & 425,4 \\
\hline 11. & Cobalt-precorrin-5A hydrolase & D4GP61 & HVO_B0059 & 34,5 & 405,5 & 550,0 \\
\hline 12. & Putative glutamate--argW ligase & D4GYP1 & HVO_0046 & 31,9 & 349,7 & 443,0 \\
\hline 13. & Serine 0-acetyltransferase & D4GTN2 & HVO_2004 & 31,9 & 348,0 & 158,3 \\
\hline 14. & tRNA (pseudouridine(54)-N(1))-methyltransferase & L9VBV1 & HVO_1989 & 21,9 & 325,3 & 330,3 \\
\hline 15. & DRTGG domain protein & D4GVH6 & HVO_0999 & 39,8 & 324,3 & 515,9 \\
\hline 16. & ICIR family transcription regulator & D4GUQ5 & HVO_2108 & 28 & 278,7 & 194,3 \\
\hline 17. & AAA-type ATPase (CDC48 subfamily) & D4GWM8 & HVO_2380 & 81,9 & 260,7 & 380,6 \\
\hline 18. & Lrp/AsnC family transcription regulator & D4GSB6 & HVO_1792 & 18,1 & 234,3 & 183,3 \\
\hline 19. & Sensor box protein & D4GPK3 & HVO_B0202 & 33,5 & 221,3 & 149,1 \\
\hline 20. & Transcriptional regulator & L9URY6 & HVO_0980 & 63,4 & 220,8 & 293,9 \\
\hline 21. & ABC-type transport system ATP-binding protein & D4GS85 & HVO_1760 & 32,4 & 214,0 & 182,6 \\
\hline 22. & N-type ATP pyrophosphatase superfamily protein & L9UMR4 & HVO_0580 & 36,1 & 195,8 & 248,4 \\
\hline 23. & Siderophore biosynthesis protein lucC & D4GP43 & HVO_B0041 & 70,1 & 192,7 & 108,1 \\
\hline 24. & Serine hydroxymethyltransferase & D4GXG2 & HVO_2862 & 44,3 & 188,3 & 169,1 \\
\hline 25. & NADH dehydrogenase-like complex subunit CD & L9UGU5 & HVO_0179 & 28 & 181,0 & 189,7 \\
\hline 26. & Putative nickel-responsive regulator & D4GWQ6 & HVO_2409 & 15,2 & 172,2 & 113,5 \\
\hline 27. & aEF1a-like protein & L9V605 & HVO_2575 & 57,8 & 169,5 & 99,3 \\
\hline 28. & DNA repair and recombination protein $\mathrm{RadB}$ & L9V6G6 & HVO_2383 & 24,6 & 147,3 & 166,9 \\
\hline 29. & Transcriptional regulator & L9UK32 & HVO_2928 & 27,5 & 143,3 & 60,3 \\
\hline 30. & Uncharacterized protein & D4GUI2 & HVO_2629 & 30,3 & 136,7 & 158,9 \\
\hline 31. & 5'-nucleotidase SurE & L9V6Z6 & HVO_A0228 & 32 & 117,8 & 158,1 \\
\hline 32. & RNA-binding protein Lsm & D4GW47 & HVO_2723 & 8,3 & 117,2 & 71,8 \\
\hline 33. & Ribonuclease $\mathrm{P}$ protein component 3 & D4GW15 & HVO_1094 & 25,6 & 113,3 & 75,7 \\
\hline 34. & alF2 $\gamma$ & D4GTD4 & HVO_1901 & 43,9 & 100,0 & 0,0 \\
\hline 35. & Thiamine thiazole synthase & D4GSS5 & HVO_0665 & 32,4 & 91,8 & 46,2 \\
\hline 36. & Hydantoin racemase & D4GR45 & HVO_A0377 & 28,5 & 90,7 & 54,6 \\
\hline 37. & Uncharacterized protein & D4GWI1 & HVO_2332 & 19,4 & 82,0 & 67,9 \\
\hline 38. & Dihydroxyacetone kinase subunit DhaK & L9VFD8 & HVO_1546 & 34,8 & 81,5 & 43,3 \\
\hline 39. & Uncharacterized protein & L9V5N6 & HVO_2796 & 12 & 79,7 & 38,2 \\
\hline 40. & Ferredoxin--nitrite reductase & D4GQG0 & HVO_A0129 & 11,7 & 74,0 & 76,9 \\
\hline 41. & Xaa-Pro aminopeptidase, M24 family protein & L9V167 & HVO_A0376 & 39,8 & 64,7 & 49,7 \\
\hline 42. & Uncharacterized protein & L9VDY4 & HVO_1788 & 66,6 & 58,3 & 33,3 \\
\hline 43. & Fructose-bisphosphate aldolase class 2 & D4GYE0 & HVO_1494 & 36,3 & 52,8 & 33,1 \\
\hline 44. & $30 \mathrm{~S} r \mathrm{~s} 2$ & L9V5L7 & HVO_2773 & 28,3 & 49,8 & 45,3 \\
\hline 45. & Ribonuclease Z & L9UHJ9 & HVO_0144 & 34,1 & 49,0 & 22,9 \\
\hline 46. & Uncharacterized protein & L9UTZ7 & HVO_1128 & 32,3 & 48,3 & 44,8 \\
\hline
\end{tabular}

Insgesamt konnten 46. Proteine in drei Fraktionen identifiziert werden, darunter zwei alFs. Die alF2 $\gamma$-Untereinheit konnte nur als 34. Protein identifiziert werden. Der Elongationsfaktor aEF1 $\alpha$ konnte mit dem höchsten PSM-Wert identifiziert werden. Die Untereinheit alF2 $\alpha$ konnte als dritthäufigstes Protein identifiziert werden. 
III. Nach der Spitze des Hauptpeaks: 24 Proteine in drei FPLC-Läufen identifiziert

Die Verteilung der Proteine anhand ihrer PSM-Werte von drei unabhängigen Aufreinigungen und anschließender FPLC ist in Tabelle 71 absteigend dargestellt. Analyse der PSM-Werte dreier unabhängiger Messungen der Fraktionen nach der Spitze des Hauptpeaks in der FPLC. Die PSM-Werte wurden auf alF2 $\alpha$ normiert. Die Proteine wurden nach dem größten PSM-Wert abwärts sortiert.

Tabelle 71: MS-Analyse der FPLC-Fraktionen nach der Spitze des Hauptpeaks von alF2y $(n=3)$

\begin{tabular}{|c|c|c|c|c|c|c|}
\hline & Description & Accession & Genloci & $\begin{array}{c}\text { MW } \\
{[\mathrm{kDa}]}\end{array}$ & $\begin{array}{c}\text { PSM [\%] } \\
n=3\end{array}$ & $\begin{array}{c}\text { PSM [\%] } \\
\text { std. }\end{array}$ \\
\hline 1. & aEF1a & L9V6J4 & HVO_2413 & 45,6 & 141,0 & 192,1 \\
\hline 2. & alF2a & D4GT46 & HVO_0699 & 29,5 & 100,0 & 0,0 \\
\hline 3. & HGPRTase-like protein & L9URM2 & HVO_1072 & 20,5 & 64,5 & 105,5 \\
\hline 4. & Aspartate carbamoyltransferase & D4GY71 & HVO_1454 & 33,7 & 60,0 & 87,5 \\
\hline 5. & Uncharacterized protein & L9UIP5 & HVO_2899 & 9,8 & 55,6 & 74,2 \\
\hline 6. & Succinate dehydrogenase or fumarate reductase & L9V5C0 & HVO_2808 & 67,6 & 43,1 & 64,5 \\
\hline 7. & UPF0058 family protein & D4GYA8 & HVO_1473 & 10,3 & 39,6 & 54,2 \\
\hline 8. & Uncharacterized protein & L9V5N6 & HVO_2796 & 12 & 30,8 & 44,7 \\
\hline 9. & Serine O-acetyltransferase & D4GTN2 & HVO_2004 & 31,9 & 27,7 & 32,4 \\
\hline 10. & F420H2:NADP oxidoreductase & D4GRX4 & HVO_0433 & 23,3 & 25,2 & 35,9 \\
\hline 11. & $\begin{array}{l}\text { NAD-dependent glucose-6-phosphate dehydro- } \\
\text { genase }\end{array}$ & D4GS48 & HVO_0511 & 29,3 & 23,3 & 32,4 \\
\hline 12. & Lrp/AsnC family transcription regulator & D4GSB6 & HVO_1792 & 18,1 & 22,5 & 26,3 \\
\hline 13. & Transcriptional regulator & L9UK32 & HVO_2928 & 27,5 & 18,6 & 20,2 \\
\hline 14. & Transcriptional regulator & L9UGU5 & HVO_0179 & 28 & 17,0 & 22,6 \\
\hline 15. & UCP015877 family protein & D4GS16 & HVO_0476 & 23,8 & 16,4 & 24,9 \\
\hline 16. & DNA repair and recombination protein $\mathrm{RadB}$ & L9V6G6 & HVO_2383 & 24,6 & 11,6 & 15,5 \\
\hline 17. & ABC-type transport system ATP-binding protein & D4GS85 & HVO_1760 & 32,4 & 10,6 & 14,6 \\
\hline 18. & Uncharacterized protein & D4H0D4 & HVO_C0046 & 20,1 & 9,3 & 10,6 \\
\hline 19. & Putative phosphoribosyltransferase & D4GVU2 & HVO_2226 & 39,6 & 7,8 & 10,2 \\
\hline 20. & Aspartate carbamoyltransferase regulatory chain & D4GY73 & HVO_1455 & 16,7 & 7,5 & 8,9 \\
\hline 21. & Ribonuclease Z & L9UHJ9 & HVO_0144 & 34,1 & 5,1 & 5,8 \\
\hline 22. & Nascent polypeptide-associated complex protein & D4GXU3 & HVO_1382 & 13,7 & 4,8 & 6,0 \\
\hline 23. & $50 S$ rpL24 & L9V5Y5 & HVO_2553 & 13,4 & 4,6 & 6,2 \\
\hline 24. & HTH domain protein & D4GW55 & HVO_1116 & 12,6 & 4,6 & 4,6 \\
\hline & Translation & \multicolumn{5}{|c|}{ Transcription } \\
\hline
\end{tabular}

Insgesamt konnten 24. Proteine in drei Fraktionen identifiziert werden. Darunter ein alF, ein aEF sowie ein $50 S$ ribosomales Protein. Der Faktor alF2y konnte nur noch in einer Messung nachgewiesen werden, weshalb die Untereinheit in der Zusammenfassung der drei Fraktionen nicht vertreten ist. Normiert wurde für die Spitze des Hauptpeaks auf alF2a. aEF1 $\alpha$ war in diesen Fraktionen das am häufigsten identifizierte Protein, mit dem höchsten PSM-Wert. alF2 $\alpha$ konnte als zweithäufigstes Protein identifiziert werden. 


\subsection{4 alF2B und seine Untereinheiten}

Der Initiationsfaktor alF2B/elF2B ist sowohl in Archaeen als auch in Eukaryonten vertreten. In Eukaryonten besteht elF2B aus fünf Untereinheiten (Bogorad, Lin and Marintchev, 2017). In Archaeen sind es meist drei Untereinheiten. In $H$. volcanii sind zwei Untereinheiten annotiert. Diese sind alF2Ba (HVO_1934) sowie zwei orthologe $\delta$-Untereinheiten (alF2Bס-1 HVO_0966; alF2Bס-2 HVO_2706). Von diesen drei Untereinheiten konnten alF2Ba und alF2Bס-2 sowohl einzeln als auch gleichzeitig in einer Doppeldeletionsmutante ausgeschaltet werden (Gäbel et al., 2013).

\subsubsection{1 alF2B}

Das Gen des alF2Ba in $H$. volcanii ist $1242 \mathrm{nt}$ lang und das daraus resultierende Protein ist 43,2 kDa schwer. Da das Gen von alF2Ba deletiert werden konnte, wurde die Überexpression in der Deletionsmutante H26 $\mathrm{dhfr} \Delta 1934$ mit dem Plasmid pSDH1934 durchgeführt.

Die Deletionsmutante des alF2Ba wuchs unter optimalen Bedingungen in Komplexmedium wie der Wildtyp (Abbildung 37A). Im Vergleich hierzu wuchs die Überexpression in der Deletionsmutante besser als die Deletionsmutante mit Leerplasmid.

Nach der Affinitätsaufreinigung konnte auf dem SDS-Gel (Abbildung 37B) eine sehr starke Bande auf Höhe von alF2Ba (43,2 kDa), sowie viele weitere Proteinbanden nachgewiesen werden. Von drei Aufreinigungen wurde jeweils die zweite Elutionsfraktion in der MS analysiert.

A

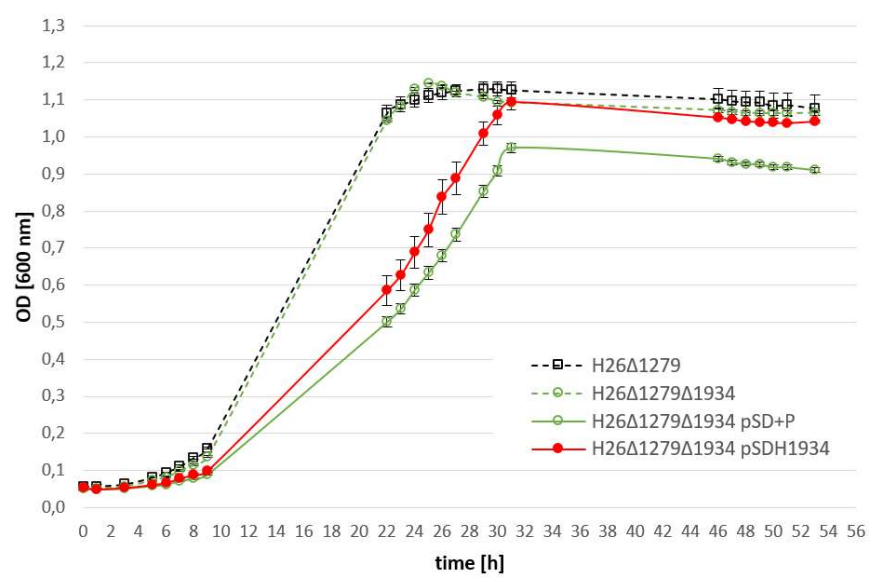

B

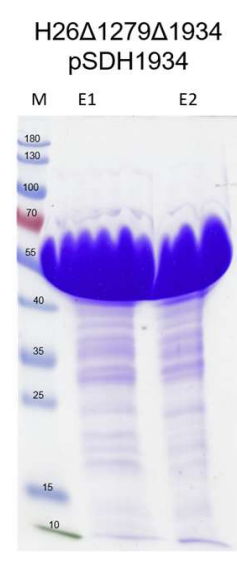

Abbildung 37: Charakterisierung des alF2Ba (HVO_1934)

A. Vergleich des Wachstums der Überexpression von alF2Ba (pSDH1934) mit der Kontrolle ( $\triangle 1934$ pSD+P) unter optimalen Wachstumsbedingungen bei $42{ }^{\circ} \mathrm{C}$ in Komplexmedium. Die Deletionsmutante von alF2Ba $(\Delta 1934)$ wuchs wie der Wildtyp $(\Delta 1279)$. B. Die zwei Elutionsfraktionen von alF2Ba nach der Affinitätsaufreinigung auf einem 12 \% SDS-Polyacrylamidgel, Coomassie-gefärbt. Das Gel zeigt die stärkste Bande für alF2Ba mit 43,2 kDa.

In der MS-Analyse konnten nach der Auswertung 23 Proteine in allen drei Eluaten von alF2Ba identifiziert werden (Tabelle 72 ).

Mit alF2Ba konnten alF2Bס-1 sowie alF5B mitgereinigt werden. Die Untereinheit alF2Bס-2 konnte nicht mitgereinigt werden. Unter anderem konnten vier $50 S$ ribosomale Proteine sowie sechs Transkriptionsregulatoren identifiziert werden. 
Tabelle 72: Einteilung der mitgereinigten Proteine von alF2Ba

\begin{tabular}{|c|c|c|c|c|}
\hline Group & Specification & Description & Genloci & Accession \\
\hline \multirow[t]{10}{*}{ Translation } & alFs & alF2Ba & HVO_1934 & D4GTG3 \\
\hline & & alF2Bס-1 & HVO_0966 & L9USK7 \\
\hline & & alF5B & HVO_1963 & D4GTJ2 \\
\hline & aEFs & $\mathrm{aEF} 1 \mathrm{a}$ & HVO_2413 & L9V6J4 \\
\hline & & aEF1a-like protein & HVO_2575 & L9V605 \\
\hline & & $\mathrm{aEF} 2$ & HVO_0356 & L9UK07 \\
\hline & $50 \mathrm{~S} \mathrm{rpL}$ & $50 \mathrm{~S} \mathrm{rpL1}$ & HVO_2757 & P41199 \\
\hline & & $50 S$ rpL2 & HVO_2561 & D4GTZ3 \\
\hline & & $50 S$ rpL22 & HVO_2559 & L9V5K3 \\
\hline & & $50 \mathrm{~S} \mathrm{rpL30}$ & HVO_2543 & L9V5X1 \\
\hline \multirow[t]{7}{*}{ Transcription } & regulator & HTH domain protein & HVO_1133 & D4GW85 \\
\hline & & ICIR family transcription regulator & HVO_2108 & D4GUQ5 \\
\hline & & Lrp/AsnC family transcription regulator & HVO_1792 & D4GSB6 \\
\hline & & PadR family transcription regulator & HVO_2869 & D4GXH6 \\
\hline & & Transcriptional regulator & HVO_0163 & L9UFW5 \\
\hline & & Transcriptional regulator & HVO_0179 & L9UGU5 \\
\hline & & Transcriptional regulator & HVO_2928 & L9UK32 \\
\hline \multirow[t]{3}{*}{ Replication and Repair } & repair & DNA repair and recombination protein RadA & HVO_0104 & Q48328 \\
\hline & & DNA repair and recombination protein RadB & HVO_2383 & L9V6G6 \\
\hline & replication & ORC1-type DNA replication protein & HVO_0194 & L9UGW2 \\
\hline RNA turnover & ribonuclease & Ribonuclease $\mathrm{R}$ & HVO_0388 & L9UJI9 \\
\hline \multirow[t]{2}{*}{ Protein turnover } & thermosome & Thermosome subunit 2 & HVO_0455 & O30560 \\
\hline & & Thermosome subunit 3 & HVO_0778 & Q9HHA2 \\
\hline
\end{tabular}

\subsubsection{2 alF2B}

In H. volcanii codiert das Gen HVO_0966 für alF2Bס-1 mit einer Länge von 972 nt. Das daraus resultierende Protein für alF2Bס-1 ist 35 kDa schwer. Die vorhandene Deletionsmutante von alF2Bס-1 konnte im Southern Blot nicht bestätigt werden, weshalb alF2B $\delta$-1 im Wildtyp überexprimiert wurde (Abbildung 38).

A

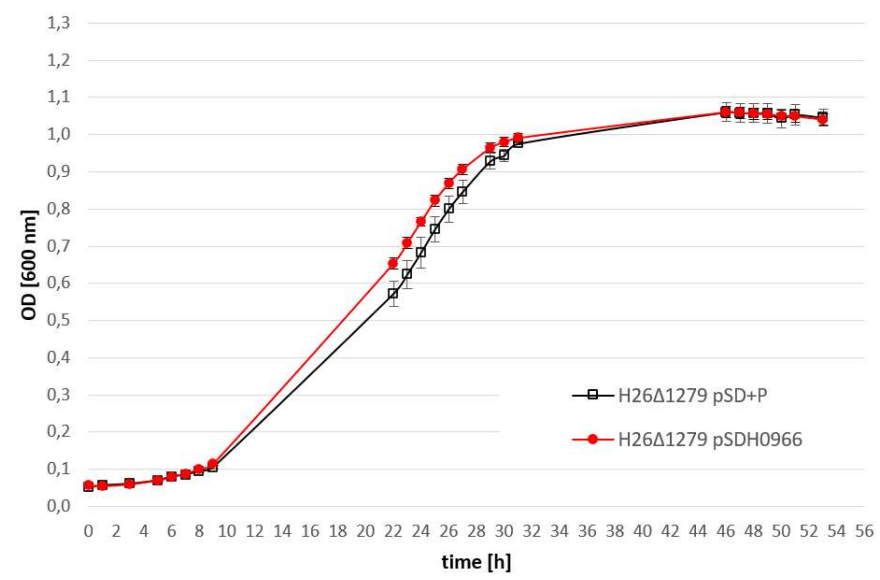

B $\quad H 26 \Delta 1279$

pSDH0966

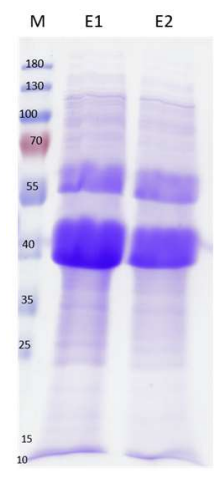

Abbildung 38: Charakterisierung des alF2Bס-1 (HVO_0966)

A. Vergleich des Wachstums der Überexpression von alF2Bס-1 in H26 1279 mit der Kontrolle H26 $\Delta 1279$ pSD+P unter optimalen Wachstumsbedingungen bei $42{ }^{\circ} \mathrm{C}$ in Komplexmedium. B. Affinitätsaufreinigung von alF2B $\delta-1$ auf einem 12 \% SDS-Polyacrylamidgel, Coomassie-gefärbt mit Eluat 1 und 2. 
In den Wachstumsversuchen bei $42{ }^{\circ} \mathrm{C}$ in Komplexmedium wuchs die Mutante mit der Überexpression (pSDH0966) geringfügig besser als H26 1279 mit dem Leerplasmid pSD+P $(\underline{A b-}$ bildung 38A).

Nach der Affinitätsaufreinigung des alF2Bס-1 konnten auf dem SDS-Gel viele mitgereinigte Proteine nachgewiesen werden (Abbildung 38B). Darunter zwei stärkere Banden zwischen 35-70 kDa. Von drei Aufreinigungen wurde jeweils die zweite Elutionsfraktion zur MS geschickt.

Bei der Auswertung der MS-Analyse konnten 79 Proteine identifiziert werden. Mit alF2Bס-1 konnten fünf weitere Translationsinitiationsfaktoren mitgereinigt werden. Darunter alF2 mit den drei Untereinheiten alF2 $\alpha$ alF2 $\beta-2$ alF2 $\gamma$, die zweite alF2Bס-2-Untereinheit sowie alF5B. Für die Transkription konnten sieben RNAPUs mitgereinigt werden (Tabelle 73).

Tabelle 73: Einteilung der mitgereinigten Proteine von alF2Bס-1

\begin{tabular}{|c|c|c|c|c|}
\hline Group & Specification & Description & Genloci & Accession \\
\hline \multirow[t]{29}{*}{ Translation } & alFs & alF2Bס-1 & HVO_0966 & L9USK7 \\
\hline & & $\mathrm{alF} 2 \mathrm{a}$ & HVO_0699 & D4GT46 \\
\hline & & alF2 $\beta-2$ & HVO_2242 & L9VAS4 \\
\hline & & alF2y & HVO_1901 & D4GTD4 \\
\hline & & alF2B $\delta-2$ & HVO_2706 & L9V7F9 \\
\hline & & alF5B & HVO_1963 & D4GTJ2 \\
\hline & aEFs & $\mathrm{aEF} 1 \mathrm{a}$ & HVO_2413 & L9V6J4 \\
\hline & & $\mathrm{aEF} 2$ & HVO_0356 & L9UK07 \\
\hline & $30 S \mathrm{rpS}$ & $30 S$ rpS2 & HVO_2773 & L9V5L7 \\
\hline & & $30 \mathrm{~s}$ rpS3 & HVO_2558 & D4GTZO \\
\hline & & $30 \mathrm{~S} r p S 3 \mathrm{Ae}$ & HVO_1145 & D4GWA5 \\
\hline & & $30 S$ rpS4e & HVO_2552 & L9V7Y2 \\
\hline & & $30 S$ rpS7 & HVO_0354 & L9UJR0 \\
\hline & & 30S rpS11 & HVO_2782 & L9V5R1 \\
\hline & & $30 S$ rpS13 & HVO_2784 & L9V5M6 \\
\hline & & $30 S$ rpS15 & HVO_1148 & L9UVI2 \\
\hline & & $30 S$ rpS17 & HVO_2555 & D4GTY7 \\
\hline & & $30 \mathrm{~S} r p S 19 \mathrm{P}$ & HVO_2560 & L9V659 \\
\hline & $50 \mathrm{~S} \mathrm{rpL}$ & $50 \mathrm{~S}$ rpL1 & HVO_2757 & P41199 \\
\hline & & $50 \mathrm{~S}$ rpL2 & HVO_2561 & D4GTZ3 \\
\hline & & $50 S$ rpL3 & HVO_2564 & L9V5K9 \\
\hline & & $50 S$ rpL4 & HVO_2563 & D4GTZ5 \\
\hline & & 50 S rpL6 & HVO_2548 & L9V5X7 \\
\hline & & $50 S$ rpL10 & HVO_2756 & P41198 \\
\hline & & $50 S$ rpL18 & HVO_2545 & P50563 \\
\hline & & $50 \mathrm{~S}$ rpL18e & HVO_2779 & D4GWY3 \\
\hline & & $50 S$ rpL22 & HVO_2559 & L9V5K3 \\
\hline & & $50 \mathrm{~S}$ rpL30 & HVO_2543 & L9V5X1 \\
\hline & GTP-binding & GTP-binding protein Drg & HVO_0911 & D4GUZ0 \\
\hline \multirow[t]{4}{*}{ Transcription } & RNAP-subunits & rpoA1 & HVO_0349 & D4GZX6 \\
\hline & & rpoA2 & HVO_0350 & D4GZX7 \\
\hline & & rpoB2 & HVO_0347 & L9UK99 \\
\hline & & rpoD & HVO_2781 & L9V5W2 \\
\hline
\end{tabular}


Ergebnisse

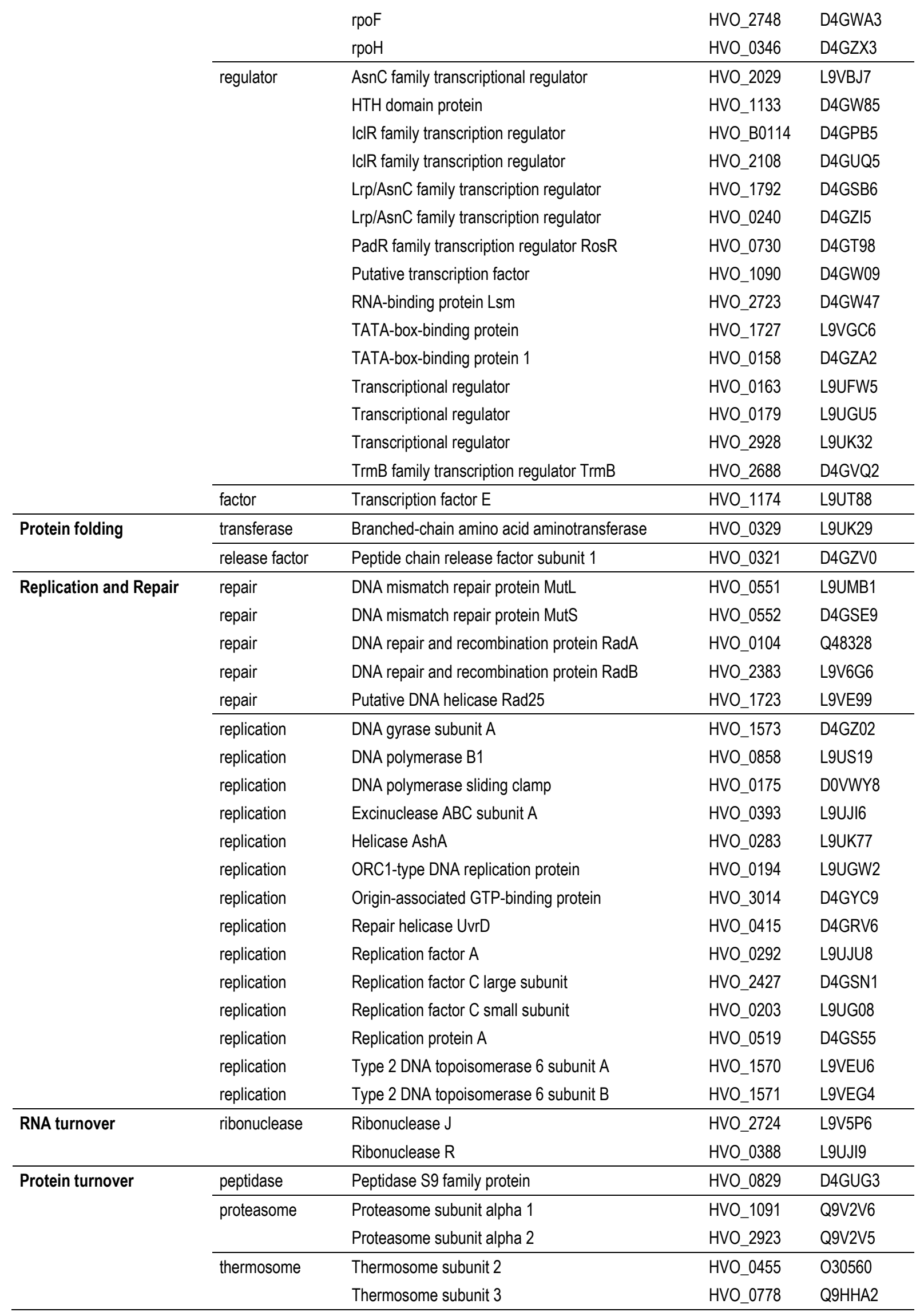




\subsubsection{3 alF2Bס-2}

Das Gen HVO_2706 ist 849 nt lang. Das resultierende Protein alF2Bס-2 ist 30,8 kDa schwer. Das codierende Gen von alF2 $\delta$-2 konnte deletiert werden, weshalb die Überexpression in der Deletionsmutante $\mathrm{H} 26 \Delta \mathrm{dhfr} \Delta 2706$ mit dem Plasmid pSDH2706 stattfand.

In den Wachstumsversuchen wuchs die Deletionsmutante des alF2Bס-2 unter optimalen Bedingungen in Komplexmedium wie der Wildtyp (Abbildung 39A). Im Vergleich hierzu wuchs die Überexpression (pSDH2706) in der Deletionsmutante $\mathrm{H} 26 \Delta \mathrm{dhfr} \Delta 2706$ besser als die Deletionsmutante $\mathrm{H} 26 \Delta$ dhfr $\Delta 2706$ mit Leerplasmid $\mathrm{pSD}+\mathrm{P}$.

Nach der Affinitätsaufreinigung konnte auf dem SDS-Gel in den Elutionsfraktionen eine starke, sowie weitere, schwächere Proteinbanden nachgewiesen werden (Abbildung 39B).

A

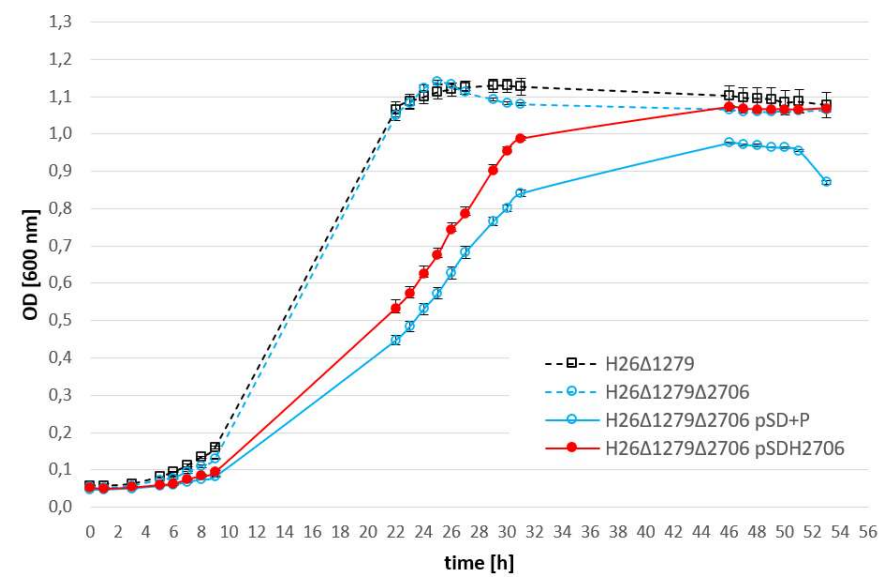

B

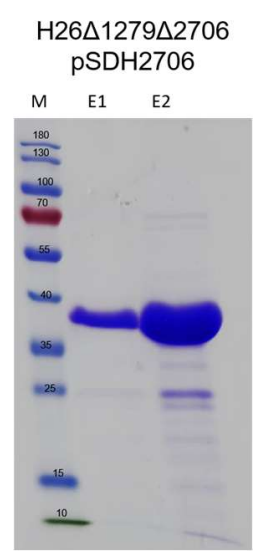

Abbildung 39: Charakterisierung des alF2ס-2 (HVO_2706)

A. Im Wachstumsversuch bei $42^{\circ} \mathrm{C}$ in Komplexmedium wuchs die Deletionsmutante wie der Wildtyp. Im Vergleich dazu wuchs die Überexpressionsmutante besser als die Kontrolle mit dem Leerplasmid. B. Die Elutionsschritte der Überexpression von alF2ঠ-2 ( $30,8 \mathrm{kDa}$ ) nach der Affinitätsaufreinigung auf einem $12 \%$ SDS-Polyacrylamidgel.

Von drei Affinitätsaufreinigungen wurden jeweils die zweite Elutionsfraktion zur MS geschickt. Im Vergleich der beiden alF2 $\delta$-Untereinheiten konnten bei alF2 $\delta$-2 sehr viel weniger Proteine mitgereinigt werden als bei alF2 $\delta$-1. Das war bereits an den SDS-Gelen deutlich ersichtlich und wurde durch die MS-Analyse bestätigt. Mit alF2Bס-2 konnten nach der MS-Datenauswertung sechs Proteine co-gereinigt werden. Darunter fiel das 50S ribosomales Protein L1 und ein Transkriptionsregulator. Es konnten keine weiteren Translationsinitiationsfaktoren bzw. Untereinheiten mitgereinigt werden (Tabelle 74).

Tabelle 74: Einteilung der mitgereinigten Proteine von alF2ס-2

\begin{tabular}{lllll}
\hline Group & Specification & Description & Genloci & Accession \\
\hline Translation & alFs & alF2Bס-2 & HVO_2706 & L9V7F9 \\
\cline { 2 - 5 } & 50S rpL & 50S rpL1 & HVO_2757 & P41199 \\
\hline Transcription & regulator & Transcriptional regulator & HVO_2928 & L9UK32 \\
\hline Protein turnover & proteasome & Proteasome subunit beta & HVO_1562 & L9VFN7 \\
\cline { 2 - 5 } & thermosome & Thermosome subunit 2 & HVO_0455 & O30560 \\
& thermosome & Thermosome subunit 3 & HVO_0778 & Q9HHA2 \\
\hline
\end{tabular}




\subsection{5 elF4A-homolog}

Das Gen HVO_1333 codiert mit 2841 nt für das Protein elF4A-homolog (104,5 kDa). Dieser Initiationsfaktor gehört zu den nicht-essenziellen Initiationsfaktoren, da das Gen in der vorherigen Arbeit deletiert werden konnte (Gäbel et al., 2013). Die Überexpression fand deshalb in der Deletionsmutante $\mathrm{H} 26 \Delta 1279 \Delta 1333$ mit dem Plasmid pSDH1333 statt.

Ein Phänotyp der Deletionsmutante H26 $1279 \Delta 1333$ konnte in Form von sehr viel schlechterem Wachstum im Vergleich zum Wildtyp H26 1279 gezeigt werden (Abbildung 40A).

Die Deletionsmutante H26 $\Delta 1279 \Delta 1333$ mit dem Überexpressionsplasmid pSDH1333 des elF4A-homolog wuchs im Vergleich zur Deletionsmutante $H 26 \Delta 1279 \Delta 1333$ mit Leerplasmid pSD+P sehr viel schlechter.

Mit $104,5 \mathrm{kDa}$ ist elF4A-homolog der größte annotierte Translationsinitiationsfaktor in $H$. volcanii. Dieser konnte auch nach der Affinitätsaufreinigung auf dem SDS-Polyacrylamidgel in den Elutionsfraktionen nachgewiesen werden (Abbildung 40B). Zusätzlich konnten weitere Proteine im Gel visualisiert werden.

A

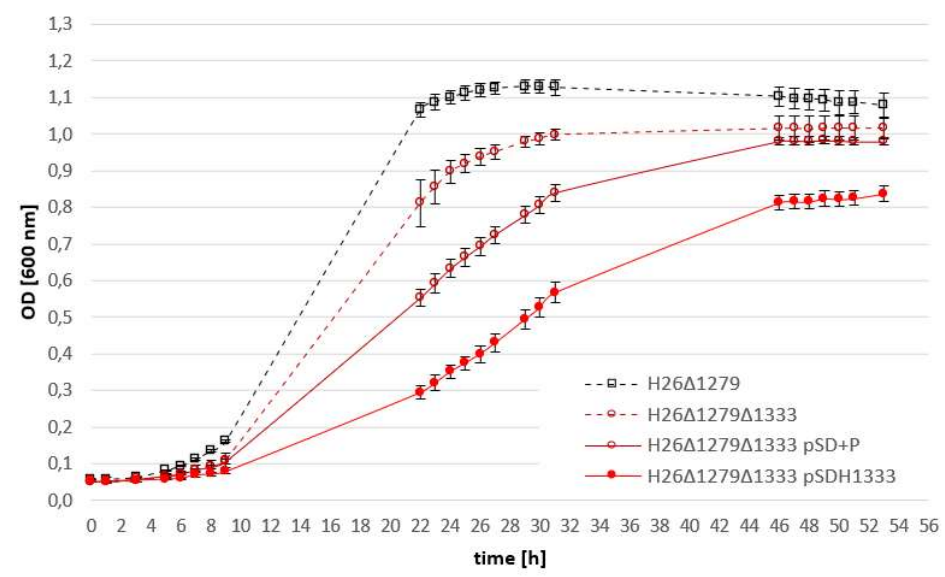

B

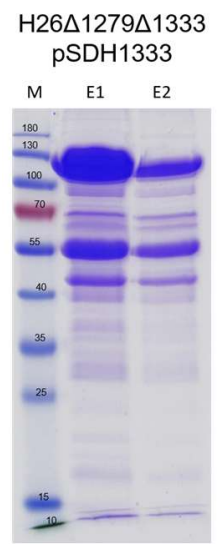

Abbildung 40: Charakterisierung des elF4A-homologes (HVO_1333)

A. Im Wachstumsversuch bei $42{ }^{\circ} \mathrm{C}$ in Komplexmedium wuchs die Deletionsmutante $(\Delta 1333)$ schlechter als der Wildtyp ( $(1279)$. Im Vergleich dazu wuchs die Überexpressionsmutante des elF4A-homologes (pSDH1333) schlechter als die Deletionsmutante mit dem Leerplasmid ( $\triangle 1333$ pSD+P). B. Elutionsschritte der Überexpression des elF4A-homologs (104,5 kDa) nach der Affinitätsaufreinigung auf einem $12 \%$ SDS-Polyacrylamidgel, Coomassie-gefärbt.

Von drei Aufreinigungen wurde jeweils die zweite Elutionsfraktion zur MS-Analyse geschickt. In der MS-Analyse konnten nach der Auswertung 50 Proteine identifiziert werden. alF2 $\delta-1$ sowie alF5B konnten mit dem elF4A-homolog mitgereinigt werden (Tabelle 75).

Tabelle 75: Einteilung der mitgereinigten Proteine von elF4A-homolog

\begin{tabular}{lllll}
\hline Group & Specification & Description & Genloci & Accession \\
\hline Translation & alFs & elF4A-hom. & HVO_1333 & D4GXK1 \\
& & alF2Bס-1 & HVO_0966 & L9USK7 \\
& alF5B & HVO_1963 & D4GTJ2 \\
\cline { 2 - 5 } & aEFs & aEF1a & HVO_2413 & L9V6J4 \\
& aEF1a-like protein & HV_2575 & L9V605 \\
& aEF2 & HVO_0356 & L9UK07 \\
\hline
\end{tabular}


Ergebnisse

\begin{tabular}{|c|c|c|c|c|}
\hline & \multirow[t]{4}{*}{$30 \mathrm{~S} \mathrm{rpS}$} & $30 \mathrm{~S} \mathrm{rpS3}$ & \multirow{2}{*}{$\begin{array}{l}\text { HVO_2558 } \\
\text { HVO_2552 }\end{array}$} & D4GTZO \\
\hline & & $30 \mathrm{~S} \mathrm{rpS4e}$ & & L9V7Y2 \\
\hline & & $30 \mathrm{~S} \mathrm{rpS5}$ & HVO_2544 & D4GTX6 \\
\hline & & $30 \mathrm{~S} \mathrm{rpS7}$ & HVO_0354 & L9UJR0 \\
\hline & \multirow[t]{8}{*}{$50 \mathrm{~S} \mathrm{rpL}$} & $50 \mathrm{~s} \mathrm{rpL} 1$ & HVO_2757 & P41199 \\
\hline & & $50 \mathrm{~S} \mathrm{rpL} 2$ & HVO_2561 & D4GTZ3 \\
\hline & & $50 \mathrm{~S} \mathrm{rpL3}$ & HVO_2564 & L9V5K9 \\
\hline & & $50 \mathrm{~s}$ rpL4 & HVO_2563 & D4GTZ5 \\
\hline & & $50 \mathrm{~S}$ rpL6 & HVO_2548 & L9V5X7 \\
\hline & & $50 S$ rpL10 & HVO_2756 & P41198 \\
\hline & & $50 S$ rpL22 & HVO_2559 & L9V5K3 \\
\hline & & $50 \mathrm{~S}$ rpL30 & HVO_2543 & L9V5X1 \\
\hline & transferase & tRNA(Met) cytidine acetyltransferase TmcA & HVO_2736 & D4GW73 \\
\hline \multirow[t]{16}{*}{ Transcription } & \multirow[t]{3}{*}{ RNAP-subunits } & rpoA1 & HVO_0349 & D4GZX6 \\
\hline & & rpoA2 & HVO_0350 & D4GZX7 \\
\hline & & rpoB2 & HVO_0347 & L9UK99 \\
\hline & \multirow[t]{13}{*}{ regulator } & HTH domain protein & HVO_1133 & D4GW85 \\
\hline & & HTH domain protein & HVO_1695 & D4H040 \\
\hline & & HTH-10 family transcription regulator & HVO_A0121 & D4GQF3 \\
\hline & & ICIR family transcription regulator & HVO_B0114 & D4GPB5 \\
\hline & & ICIR family transcription regulator & HVO_A0583 & D4GRP3 \\
\hline & & ICIR family transcription regulator & HVO_2108 & D4GUQ5 \\
\hline & & Lrp/AsnC family transcription regulator & HVO_1792 & D4GSB6 \\
\hline & & PadR family transcription regulator & HVO_2869 & D4GXH6 \\
\hline & & SirR/DtxR family transcription regulator SirR & HVO_0819 & D4GUE2 \\
\hline & & TATA-box-binding protein & HVO_1727 & L9VGC6 \\
\hline & & Transcriptional regulator & HVO_0163 & L9UFW5 \\
\hline & & Transcriptional regulator & HVO_0179 & L9UGU5 \\
\hline & & Transcriptional regulator & HVO_2928 & L9UK32 \\
\hline \multirow[t]{2}{*}{ Protein folding } & chaperone & Chaperone protein DnaK & HVO_1590 & L9VEI0 \\
\hline & release factor & Peptide chain release factor subunit 1 & HVO_0321 & D4GZVO \\
\hline \multirow[t]{8}{*}{ Replication and Repair } & \multirow[t]{5}{*}{ repair } & DNA double-strand break repair Rad50 ATPase & HVO_0854 & D4GUK1 \\
\hline & & DNA mismatch repair protein MutS & HVO_0552 & D4GSE9 \\
\hline & & DNA repair and recombination protein RadA & HVO_0104 & Q48328 \\
\hline & & DNA repair and recombination protein $\mathrm{RadB}$ & HVO_2383 & L9V6G6 \\
\hline & & Putative DNA helicase Rad25 & HVO_1723 & L9VE99 \\
\hline & \multirow[t]{3}{*}{ replication } & DNA gyrase subunit A & HVO_1573 & D4GZ02 \\
\hline & & ORC1-type DNA replication protein & HVO_0194 & L9UGW2 \\
\hline & & Type 2 DNA topoisomerase 6 subunit B & HVO_1571 & L9VEG4 \\
\hline \multirow[t]{4}{*}{ RNA turnover } & protease & ATP-dependent protease Lon & HVO_0783 & L9UNA4 \\
\hline & \multirow[t]{3}{*}{ ribonuclease } & Ribonuclease $\mathrm{P}$ protein component 3 & HVO_1094 & D4GW15 \\
\hline & & Ribonuclease R & HVO_0388 & L9UJI9 \\
\hline & & Ribonuclease Z & HVO_0144 & L9UHJ9 \\
\hline \multirow[t]{3}{*}{ Protein turnover } & proteasome & Proteasome-activating nucleotidase & & L9UQ37 \\
\hline & \multirow[t]{2}{*}{ thermosome } & Thermosome subunit 2 & HVO_0455 & 030560 \\
\hline & & Thermosome subunit 3 & HVO_0778 & Q9HHA2 \\
\hline
\end{tabular}




\subsection{6 alF5A}

Da der Translationsinitiationsfaktor alF5A in $H$. volcanii nicht deletiert werden konnte, wurde er als essenziell eingestuft (Gäbel et al., 2013). Das Gen HVO_2300 codiert mit einer Länge von 375 nt für alF5A. Das daraus resultierende Protein hat ein Gewicht von 14,2 kDa.

Die Überexpression des HVO_2300 fand im H26 1279 mit dem Plasmid pSDH2300 statt. In den Wachstumsversuchen unter optimalen Bedingungen bei $42{ }^{\circ} \mathrm{C}$ in Komplexmedium wuchs die Überexpression des alF5A schlechter als die Kontrolle mit dem Leerplasmid pSD+P (Abbildung 41A). Nach der Affinitätsaufreinigung konnten auf den SDS-Gelen neben den zwei markanten Banden weitere schwächere Banden nachgewiesen werden (Abbildung 41B). Von drei Aufreinigungen wurde jeweils die zweite Elutionsfraktionen zur MS geschickt.

A

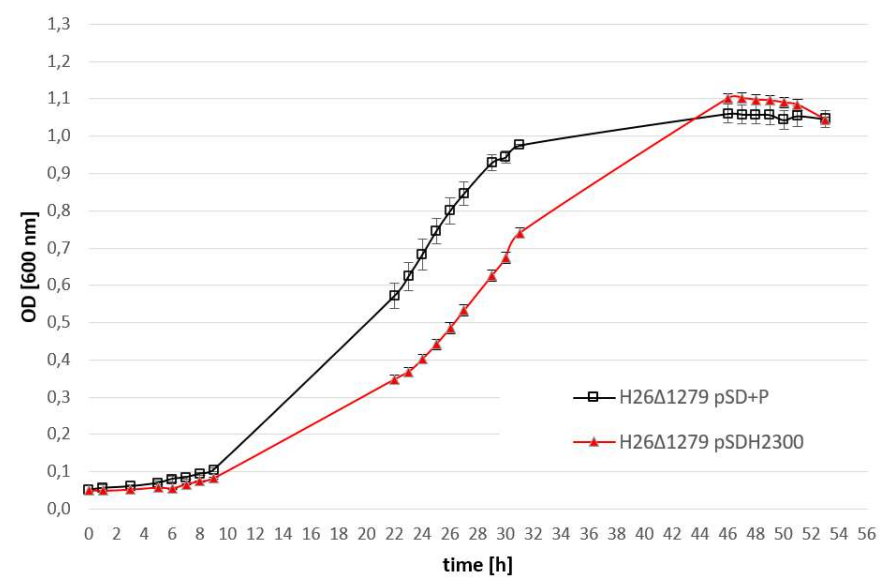

B

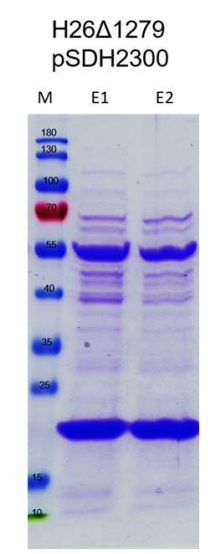

Abbildung 41: Charakterisierung des alF5A (HVO_2300)

A. Vergleich des Wachstums der Überexpression von alF5A (pSDH2300) und der Kontrolle $(\Delta 1279$ pSD+P) mit dem Leerplasmid unter optimalen Wachstumsbedingungen bei $42{ }^{\circ} \mathrm{C}$ in Komplexmedium. B. Affinitätsaufreinigung von alF5A auf einem $12 \%$ SDS-Polyacrylamidgel, Coomassie-gefärbt mit Eluat 1 und 2.

Die MS-Analyse zeigte nach der Auswertung 23 Proteine, die in allen drei Elutionsfraktionen identifiziert werden konnten (Tabelle 76). Mit alF5A konnte alF2 $\alpha$, alF-2Bס-1 und alF-5B mitgereinigt werden. Des Weiteren konnten mit alF5A ein 30S und zwei 50 S ribosomale Proteine sowie zwei RNAPUs co-gereinigt werden.

Tabelle 76: Einteilung der mitgereinigten Proteine von alF5A

\begin{tabular}{lllll}
\hline Group & Specification & Description & Genloci & Accession \\
\hline Translation & alFs & alF5A & HVO_2300 & L9V7A1 \\
& & alF2a & HVO_0699 & D4GT46 \\
& alF2Bס-1 & HV_0966 & L9USK7 \\
& alF5B & HVO_1963 & D4GTJ2 \\
\cline { 2 - 5 } & aEFs & aEF1a & HVO_2413 & L9V6J4 \\
& aEF1a-like protein & HVO_2575 & L9V605 \\
& aEF2 & HVO_0356 & L9UK07 \\
\cline { 2 - 5 } & 30S rpS & 30S rpS4e & HVO_2552 & L9V7Y2 \\
\cline { 2 - 5 } & 50S rpL & 50S rpL1 & HVO_2757 & P41199 \\
& & 50S rpL3 & HVO_2564 & L9V5K9 \\
\hline Transcription & RNAP-subunits & rpoA1 & HVO_0349 & D4GZX6
\end{tabular}




\begin{tabular}{lllll} 
& & rpoB2 & HVO_0347 & L9UK99 \\
\cline { 2 - 5 } & regulator & IcIR family transcription regulator & HVO_2108 & D4GUQ5 \\
& & SirR/DtxR family transcription regulator SirR & HV_0819 & D4GUE2 \\
& & HVanscriptional regulator & HV_0163 & L9UFW5 \\
& & Transcriptional regulator & HV_0179 & L9UGU5 \\
\hline Replication and Repair & repair & DNA double-strand break repair protein Mre11 & HV_0853 & D4GUK0 \\
& & DNA double-strand break repair Rad50 ATPase & HVO_0854 & D4GUK1 \\
& & DNA mismatch repair protein MutS & HVO_0552 & D4GSE9 \\
& & DNA repair and recombination protein RadA & HVO_0104 & Q48328 \\
& & DNA repair and recombination protein RadB & HVO_2383 & L9V6G6 \\
& & Putative DNA helicase Rad25 & HVO_1723 & L9VE99 \\
\hline RNA turnover & & Ribonuclease $R$ & HVO_0388 & L9UJI9
\end{tabular}

\subsection{7 alF5B}

Der Faktor alF5B konnte in $\mathrm{H}$. volcanii nicht deletiert werden und wurde deshalb als essenziell eingestuft (Gäbel et al., 2013). Das Gen HVO_1963 codiert mit einer Länge von 1803 nt für alF5B. Das daraus resultierende Protein hat ein Gewicht von 65,4 kDa. Die Überexpression von alF5B fand im H26 1279 mit dem Plasmid pSDH1963 statt. In den Wachstumsversuchen bei $42{ }^{\circ} \mathrm{C}$ in Komplexmedium wuchs die Überexpressionsmutante sehr viel besser als die Kontrolle $\mathrm{H} 26 \Delta 1279$ mit dem Leerplasmid pSD+P (Abbildung 42A).

In der Affinitätsaufreinigung konnten auf den SDS-Gelen eine markante Bande sowie viele weitere, schwächere Proteinbanden nachgewiesen werden (Abbildung 42B).

A

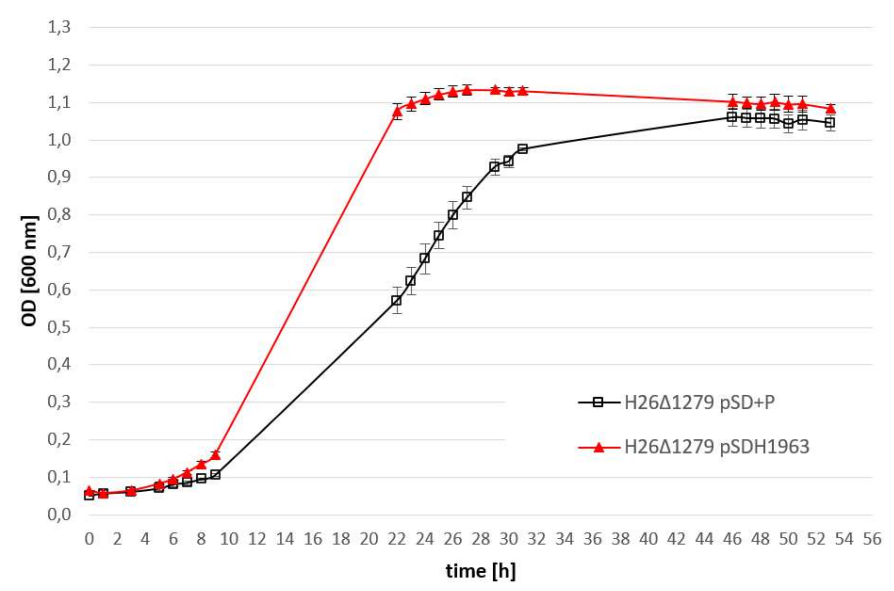

B

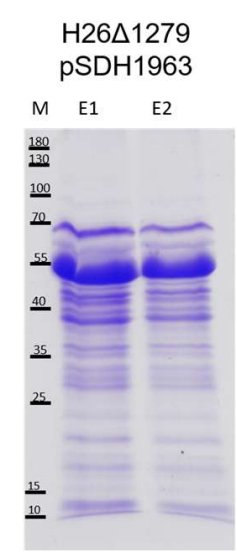

Abbildung 42: Charakterisierung des alF5B (HVO_1963)

A. Vergleich des Wachstums der Überexpression von alF5B (pSDH1963) in H26 1279 mit der Kontrolle $(\mathrm{H} 26 \Delta 1279 \mathrm{pSD}+\mathrm{P})$ unter optimalen Wachstumsbedingungen bei $42{ }^{\circ} \mathrm{C}$ in Komplexmedium. B. Affinitätsaufreinigung von alF5B auf einem 12 \% SDS-Polyacrylamidgel, Coomassie-gefärbt mit Eluat 1 und 2.

Von drei Aufreinigungen wurde jeweils die zweite Elutionsfraktion zur MS geschickt. In der MSAnalyse konnten nach der Auswertung 43 Proteine in allen drei Aufreinigungen identifiziert werden (Tabelle 77). Als Translationsinitiationsfaktor konnte mit alF5B nur alF2Bס-1 
mitgereinigt werden. Auch mit alF5B konnten die beiden RNAPUs rpoA1 und rpoB2 sowie neun Transkriptionsregulatoren co-gereinigt werden.

Tabelle 77: Einteilung der mitgereinigten Proteine von alF5B in molekularbiologische Prozesse

\begin{tabular}{|c|c|c|c|c|}
\hline Group & Specification & Description & Genloci & Accession \\
\hline \multirow[t]{10}{*}{ Translation } & alFs & alF5B & HVO_1963 & D4GTJ2 \\
\hline & & alF2Bס-1 & HVO_0966 & L9USK7 \\
\hline & aEFs & $\mathrm{aEF} 1 \mathrm{a}$ & HVO_2413 & L9V6J4 \\
\hline & & aEF1a-like protein & HVO_2575 & L9V605 \\
\hline & & $\mathrm{aEF} 2$ & HVO_0356 & L9UK07 \\
\hline & $30 \mathrm{sps}$ & $30 S$ rpS10 & HVO_0360 & L9ULL7 \\
\hline & $50 \mathrm{~S} \mathrm{rpL}$ & $50 \mathrm{~S}$ rpL1 & HVO_2757 & P41199 \\
\hline & & $50 \mathrm{~S}$ rpL2 & HVO_2561 & D4GTZ3 \\
\hline & & $50 S$ rpL22 & HVO_2559 & L9V5K3 \\
\hline & & $50 \mathrm{~S} \mathrm{rpL30}$ & HVO_2543 & L9V5X1 \\
\hline \multirow[t]{16}{*}{ Transcription } & RNAP-subunits & rpoA1 & HVO_0349 & D4GZX6 \\
\hline & & rpoB2 & HVO_0347 & L9UK99 \\
\hline & regulator & HTH domain protein & HVO_1695 & $\mathrm{D} 4 \mathrm{H} 040$ \\
\hline & & HTH-10 family transcription regulator & HVO_A0121 & D4GQF3 \\
\hline & & HTH-type transcriptional regulator GlpR & HVO_1501 & D4GYE7 \\
\hline & & ICIR family transcription regulator & HVO_B0114 & D4GPB5 \\
\hline & & ICIR family transcription regulator & HVO_B0201 & D4GPK2 \\
\hline & & ICIR family transcription regulator & HVO_A0583 & D4GRP3 \\
\hline & & ICIR family transcription regulator & HVO_2108 & D4GUQ5 \\
\hline & & Lrp/AsnC family transcription regulator & HVO_B0066 & D4GP68 \\
\hline & & Lrp/AsnC family transcription regulator & HVO_1792 & D4GSB6 \\
\hline & & RNA-binding protein Lsm & HVO_2723 & D4GW47 \\
\hline & & SirR/DtxR family transcription regulator SirR & HVO_0819 & D4GUE2 \\
\hline & & Transcriptional regulator & HVO_0163 & L9UFW5 \\
\hline & & Transcriptional regulator & HVO_0179 & L9UGU5 \\
\hline & & Transcriptional regulator & HVO_2928 & L9UK32 \\
\hline \multirow[t]{8}{*}{ Replication and Repair } & repair & DNA double-strand break repair protein Mre11 & HVO_0853 & D4GUK0 \\
\hline & & DNA double-strand break repair Rad50 ATPase & HVO_0854 & D4GUK1 \\
\hline & & DNA mismatch repair protein MutS & HVO_0552 & D4GSE9 \\
\hline & & DNA repair and recombination protein RadA & HVO_0104 & Q48328 \\
\hline & & DNA repair and recombination protein RadB & HVO_2383 & L9V6G6 \\
\hline & & Putative DNA helicase Rad25 & HVO_1723 & L9VE99 \\
\hline & replication & Orc1-type DNA replication protein & HVO_1537 & D4GYI1 \\
\hline & & ORC1-type DNA replication protein & HVO_0194 & L9UGW2 \\
\hline \multirow[t]{3}{*}{ RNA turnover } & ribonuclease & Ribonuclease $\mathrm{P}$ protein component 3 & HVO_1094 & D4GW15 \\
\hline & & Ribonuclease R & HVO_0388 & L9UJI9 \\
\hline & & Ribonuclease Z & HVO_0144 & L9UHJ9 \\
\hline \multirow[t]{3}{*}{ Protein turnover } & peptidase & Peptidase S9 family protein & HVO_0829 & D4GUG3 \\
\hline & thermosome & Thermosome subunit 2 & HVO_0455 & 030560 \\
\hline & & Thermosome subunit 3 & HVO_0778 & Q9HHA2 \\
\hline
\end{tabular}




\subsection{8 alF6}

In Eukaryonten und Archaeen ist alF6 ein essenzieller Translationsinitiationsfaktor (Benelli et al., 2009). Dieser Fall trifft auch für alF6 in H. volcanii zu. Der Faktor konnte nicht deletiert werden und wurde deshalb als essenziell eingestuft (Gäbel et al., 2013). Das Gen von alF6 ist $666 \mathrm{nt}$ lang. Das daraus resultierende Protein besitzt ein Gewicht von 23 kDa.

Die Überexpression von alF6 fand im H26 1279 mit dem Plasmid pSDH0117 statt. In den Wachstumsversuchen bei $42^{\circ} \mathrm{C}$ in Komplexmedium wuchs die Überexpressionsmutante ähnlich zur Kontrolle H26 1279 mit dem Leerplasmid pSD+P (Abbildung 43A).

A

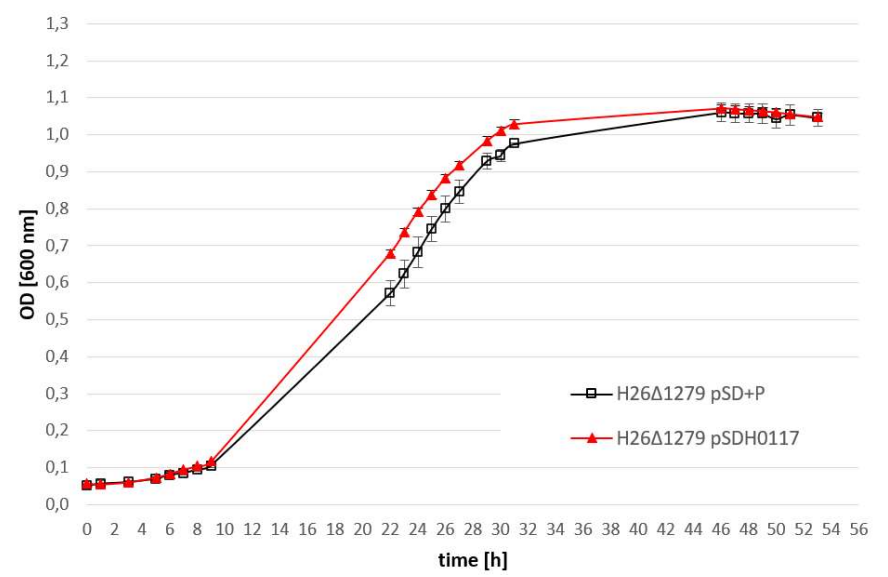

B

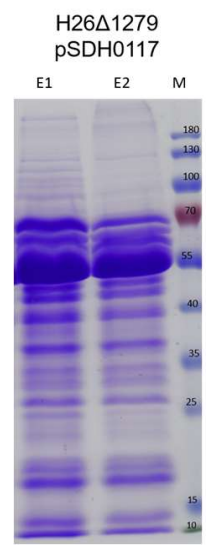

Abbildung 43: Charakterisierung des alF6 (HVO_0117)

A. Vergleich des Wachstums der Überexpression von alF6 (pSDH0117) in H26 1279 mit der Kontrolle H26 1279 pSD+P unter optimalen Wachstumsbedingungen bei $42^{\circ} \mathrm{C}$ in Komplexmedium. B. Affinitätsaufreinigung von alF6 auf einem 12 \% SDS-Polyacrylamidgel, Coomassie-gefärbt mit den beiden Elutionsfraktionen. Der Faktor alF6 hat ein Gewicht von $23 \mathrm{kDa}$.

In den Affinitätsaufreinigungen konnte auf den SDS-Gelen eine markante Bande nachgewiesen werden. Jedoch nicht auf der für alF6 erwarteten Höhe von 23 kDa (Abbildung 43B). Des Weitern konnten viele schwächere Banden sichtbar gemacht werden. Von drei Aufreinigungen wurde jeweils die zweite Elutionsfraktion zur MS geschickt.

Wie erwartet, ließ sich der Initiationsfaktor alF6 bei der Überexpression nur mit geringem PSM-Wert in der MS-Analyse nachweisen. Auch die Anzahl der identifizierten Proteine, die mit alF6 mitgereinigt werden konnten, war gering. Bei einer Aufreinigung lag der Unique Peptides Wert von alF6 unter 1. Bei den anderen beiden Messungen lag der Unique Peptides Wert bei 2-3. Deshalb konnten für die MS-Analyse der Überexpression des alF6 nur zwei Messungen ausgewertet werden.

Insgesamt konnten 19 Proteine in den beiden MS-Analysen nach der Auswertung identifiziert werden (Tabelle 78). Darunter waren drei alFs, vier $50 \mathrm{~S}$ ribosomale Proteine sowie sechs Transkriptionsregulatoren. Mit alF6 konnte sowohl alF2Bס-1 als auch alF5B mitgereinigt werden. 
Ergebnisse

Tabelle 78: Einteilung der mitgereinigten Proteine von alF6 $(n=2)$

\begin{tabular}{|c|c|c|c|c|}
\hline Group & Specification & Description & Genloci & Accession \\
\hline \multirow[t]{9}{*}{ Translation } & alFs & alF6 & HVO_0117 & L9UI67 \\
\hline & & alF2Bס-1 & HVO_0966 & L9USK7 \\
\hline & & alF5B & HVO_1963 & D4GTJ2 \\
\hline & aEFs & $\mathrm{aEF} 1 \mathrm{a}$ & HVO_2413 & L9V6J4 \\
\hline & & $\mathrm{aEF} 2$ & HVO_0356 & L9UK07 \\
\hline & $50 \mathrm{~S} \mathrm{rpL}$ & $50 \mathrm{~S}$ rpL1 & HVO_2757 & P41199 \\
\hline & & $50 \mathrm{~S}$ rpL2 & HVO_2561 & D4GTZ3 \\
\hline & & $50 \mathrm{~S} \mathrm{rpL3}$ & HVO_2564 & L9V5K9 \\
\hline & & $50 \mathrm{~S}$ rpL4 & HVO_2563 & D4GTZ5 \\
\hline \multirow[t]{6}{*}{ Transcription } & regulator & ICIR family transcription regulator & HVO_B0114 & D4GPB5 \\
\hline & & ICIR family transcription regulator & HVO_2108 & D4GUQ5 \\
\hline & & Lrp/AsnC family transcription regulator & HVO_1792 & D4GSB6 \\
\hline & & Transcriptional regulator & HVO_0163 & L9UFW5 \\
\hline & & Transcriptional regulator & HVO_0179 & L9UGU5 \\
\hline & & Transcriptional regulator & HVO_2928 & L9UK32 \\
\hline \multirow[t]{2}{*}{ Replication and Repair } & repair & DNA repair and recombination protein RadA & HVO_0104 & Q48328 \\
\hline & & DNA repair and recombination protein $\mathrm{RadB}$ & HVO_2383 & L9V6G6 \\
\hline RNA turnover & ribonuclease & Ribonuclease Z & HVO_0144 & L9UHJ9 \\
\hline Protein turnover & thermosome & Thermosome subunit 3 & HVO_0778 & Q9HHA2 \\
\hline
\end{tabular}




\subsection{Interaktionsnetzwerk von alFs-alFs}

Um die MS-Daten der einzelnen Initiationsfaktoren besser vergleichen zu können, wurden sie in einer gemeinsamen Tabelle zusammengefasst. Die Tabelle 79 enthält die in dieser Arbeit überproduzierten und in der MS analysierten alFs aus $H$. volcanii, sowie die Initiationsfaktoren, die in der MS identifiziert werden konnten. Bait steht hier für den jeweils überexprimierten Faktor.

Die Affinitätsaufreinigung war, mit der Ausnahme von alF6, für alle His-getaggten alFs erfolgreich. Für alF6 konnte nur eine geringe Überexpression nachgewiesen werden. Des Weiteren konnte lediglich bei zwei Affinitätsaufreinigungen alF6 und dann auch nur mit einem geringen PSM-Wert nachgewiesen werden. Dennoch konnte bei allen getaggten alFs Proteine identifiziert werden. Mit jedem getaggten Faktor konnte mindestens ein weiterer Translationsinitiationsfaktor mitgereinigt werden. Die Ausnahme bildet alF2B $\delta$-2. Hier konnte kein weiterer Initiationsfaktor mitgereinigt werden. Die Faktoren alF6 und alF1A-1 wurden bei keinem weiteren Initiationsfaktor mitgereinigt.

Tabelle 79: Zusammenfassung der MS-Daten für die Interaktion zwischen den alFs

\begin{tabular}{|c|c|c|c|c|c|c|c|c|c|c|c|c|c|c|c|c|c|}
\hline \multirow[b]{2}{*}{$\begin{array}{l}\text { MW } \\
\text { [kDa] }\end{array}$} & \multirow[b]{2}{*}{ Genloci } & \multirow[b]{2}{*}{ Accession } & \multirow[b]{2}{*}{ Description } & \multicolumn{14}{|c|}{ Bait protein } \\
\hline & & & & $\stackrel{\Perp}{\dddot{\Xi}}$ & 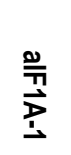 & $\stackrel{\stackrel{0}{\pi}}{\stackrel{\vec{D}}{\mathbf{N}}}$ & $\begin{array}{l}\text { 矛 } \\
\text { 용 }\end{array}$ & $\begin{array}{l}\stackrel{\varrho}{\bar{N}} \\
\stackrel{\Delta}{\dot{\Delta}}\end{array}$ & $\begin{array}{l}\stackrel{0}{\bar{N}} \\
\underset{\mathbf{N}}{\mathbf{N}}\end{array}$ & 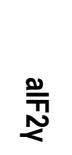 & $\begin{array}{l}\text { М्ग } \\
\text { 芯 }\end{array}$ & 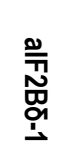 & $\begin{array}{l}\text { 心 } \\
\text { 罢 } \\
\text { N }\end{array}$ & $\begin{array}{l}\frac{D}{7} \\
\stackrel{p}{p} \\
\frac{1}{0} \\
\frac{0}{3}\end{array}$ & 崩 & 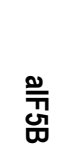 & ஹั \\
\hline 10,8 & HVO_1946 & D4GTH5 & alF1 & bait & & & * & & & & & & & & & & \\
\hline 11,5 & HVO_0136 & D4GZ79 & alF1A-1 & & bait & & & & & & & & & & & & \\
\hline 11,2 & HVO_A0637 & D4GRU5 & alF1A-2 & + & & bait & & & & & & & & & & & \\
\hline 29,5 & HVO_0699 & D4GT46 & alF2a & & & & bait & + & + & + & & + & & & + & & \\
\hline 14,9 & HVO_1678 & D4GZP2 & alF2 $\beta-1$ & & & & & bait & & & & & & & & & \\
\hline 22,2 & HVO_2242 & L9VAS4 & alF2 $\beta-2$ & & & & + & & bait & + & & + & & & & & \\
\hline 43,9 & HVO_1901 & D4GTD4 & alF2y & & & & + & + & + & bait & & + & & & & & \\
\hline 43,2 & HVO_1934 & D4GTG3 & alF2Ba & & & & & & & & bait & & & & & & \\
\hline 34,9 & HVO_0966 & L9USK7 & alF2Bס-1 & + & + & + & + & & & + & + & bait & & + & + & + & + \\
\hline 30,7 & HVO_2706 & L9V7F9 & alF2B $\delta-2$ & & & & & & & & & + & bait & & & & \\
\hline 104,5 & HVO_1333 & D4GXK1 & elF4A-hom. & & & & & & & & & & & bait & & & \\
\hline 14,2 & HVO_2300 & L9V7A1 & alF5A & & & & & & & & & & & & bait & & \\
\hline 65,3 & HVO_1963 & D4GTJ2 & alF5B & + & + & + & + & & + & + & + & + & & + & + & bait & + \\
\hline 22,98 & HVO_0117 & D4GYW3 & alF6 & & & & & & & & & & & & & & bait \\
\hline
\end{tabular}

Der Initiationsfaktor alF1 konnte nur in der stationären Phase von alF2 $\alpha$ identifiziert werden. Der Faktor alF5B hingegen konnte bei elf weiteren Initiationsfaktoren co-gereinigt werden. $\mathrm{Er}$ war somit der am häufigsten identifizierte Initiationsfaktor, dicht gefolgt von alF2B $\delta$-1, der bei zehn Initiationsfaktoren mitgereinigt werden konnte.

Aufgrund der MS-Daten der alFs- bzw. -Untereinheiten konnte ein mögliches Interaktionsnetzwerk der Translationsinitiationsfaktoren erstellt werden (Abbildung 44). Dies verschafft 
einen besseren Überblick über die mitgereinigten Initiationsfaktoren und mögliche Interaktionen zwischen den einzelnen Faktoren und Untereinheiten. Die schwarzen Pfeile stellen dabei die einseitigen Interaktion dar. Dies bedeutet, dass ein Initiationsfaktor einen weiteren Initiationsfaktor mitreinigen konnte.

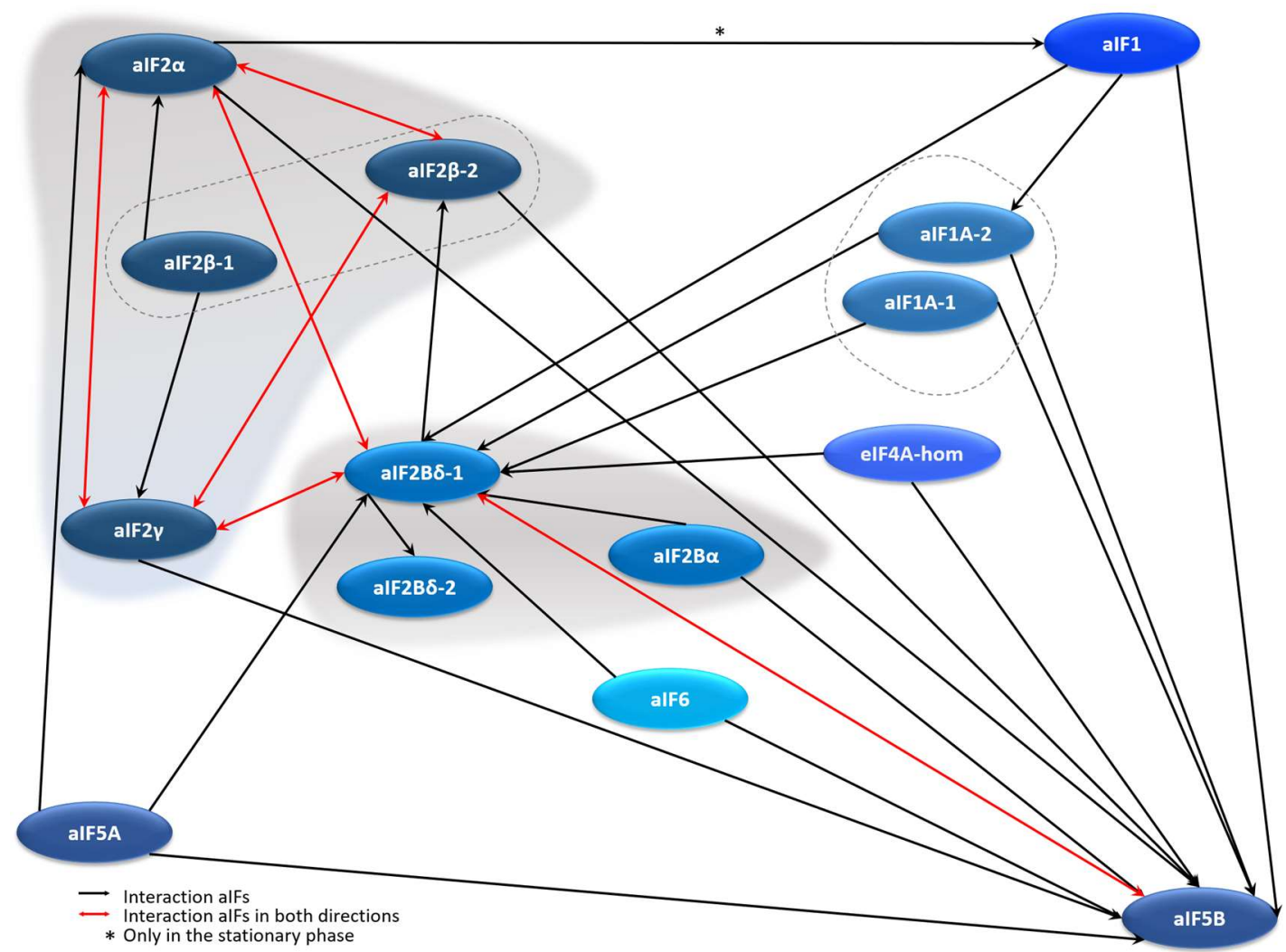

Abbildung 44: Interaktionsnetzwerk der alFs, die weitere alFs mitreinigen konnten

Zusammenfassung der MS-Daten für die alF-alF-Interaktion. Die schwarzen Pfeile stellen die einseitige Interaktion dar. Die roten Pfeile bei der die alFs gegenseitig co-gereinigt werden konnten. Das Sternchen steht für die stationäre Phase, bei der alF1 mit alF2 $\alpha$ mitgereinigt werden konnte.

Bei den roten Doppelpfeilen handelt es sich um gegenseitige Interaktionen zwischen alFs. Jeweils ein getaggter alF konnte einen anderen alF mitreinigen und umgekehrt. Dies traf für die Interaktionen zwischen der alF2 $\alpha$-, alF2 $\beta$-2- als auch für die alF2 $\gamma$-Untereinheit des Initiationsfaktors alF2 zu. Mit alF2 $\gamma$ konnte zusätzlich alF2Bס-1 mitgereinigt werden und umgekehrt. Zusätzlich konnten alF5B und der Faktor alF2Bס-1 gegenseitig co-gereinigt werden.

\subsection{Interaktion alFs mit RNAPUs}

Bei der Affinitätsaufreinigung der einzelnen Initiationsfaktoren konnten nicht nur Proteine mitgereinigt werden, die in die Translation involviert sind, sondern auch die Proteine, die an der Transkription maßgeblich beteiligt sind. Diese sind z.B. Untereinheiten der RNA-Polymerase (RNAPUs). In H. volcanii sind zwölf RNAPUs annotiert. Mit acht alFs- bzw. -Untereinheiten konnten acht der zwölf RNAPUs, mitgereinigt werden. Diese waren rpoA1, rpoA2, rpoB1, rpoB2, rpoD, rpoH, rpoF und rpoL (Tabelle 80). 
Tabelle 80: Zusammenfassung der MS-Daten für die Interaktion zwischen alFs und RNAPUs

\begin{tabular}{|c|c|c|c|c|c|c|c|c|c|c|c|c|c|c|c|c|c|}
\hline \multirow[b]{2}{*}{$\mathrm{kDa}$} & \multirow[b]{2}{*}{ Genloci } & \multirow[b]{2}{*}{ Accession } & \multirow[b]{2}{*}{ Description } & \multicolumn{14}{|c|}{ Bait protein } \\
\hline & & & & 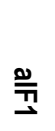 & 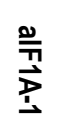 & 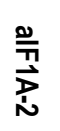 & 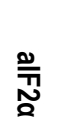 & 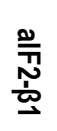 & 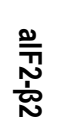 & $\stackrel{\stackrel{N}{N}}{\stackrel{N}{<}}$ & $\begin{array}{l}\stackrel{0}{\pi} \\
\tilde{\tilde{\sigma}}\end{array}$ & 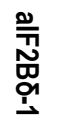 & $\begin{array}{l}\text { 心 } \\
\text { 芯 } \\
\text { N }\end{array}$ & $\begin{array}{l}\frac{D}{7 \pi} \\
\frac{\mathbb{P}}{+} \\
\frac{1}{3}\end{array}$ & 䎡 & 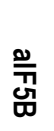 & 쓩 \\
\hline 108,8 & HVO_0349 & D4GZX6 & rpoA1 & + & + & & + & & & & & + & & + & + & + & \\
\hline 46,1 & HVO_0350 & D4GZX7 & rрoA2 & + & & & + & & & & & + & & + & & & \\
\hline 67,7 & HVO_0348 & L9UJM2 & гров1 & + & & & & & & & & + & & & & & \\
\hline 58,9 & HVO_0347 & L9UK99 & rров2 & + & & & + & & & + & & + & & + & + & + & \\
\hline 28,1 & HVO_2781 & L9V5W2 & rpoD & + & & & & & & & & + & & & & & \\
\hline 8,5 & HVO_0346 & D4GZX3 & $\mathrm{rpoH}$ & & & & & & & & & + & & & & & \\
\hline 13,7 & HVO_2748 & D4GWA3 & rpoF & & & & & & & & & + & & & & & \\
\hline 10,3 & HVO_1042 & D4GVL8 & rpoL & + & & & & & & & & & & & & & \\
\hline
\end{tabular}

Aufgrund der MS-Daten der alFs- bzw. -Untereinheiten konnte ein Netzwerk für Translationsinitiationsfaktoren, die RNAPUs mitreinigen konnten, erstellt werden (Abbildung 45).

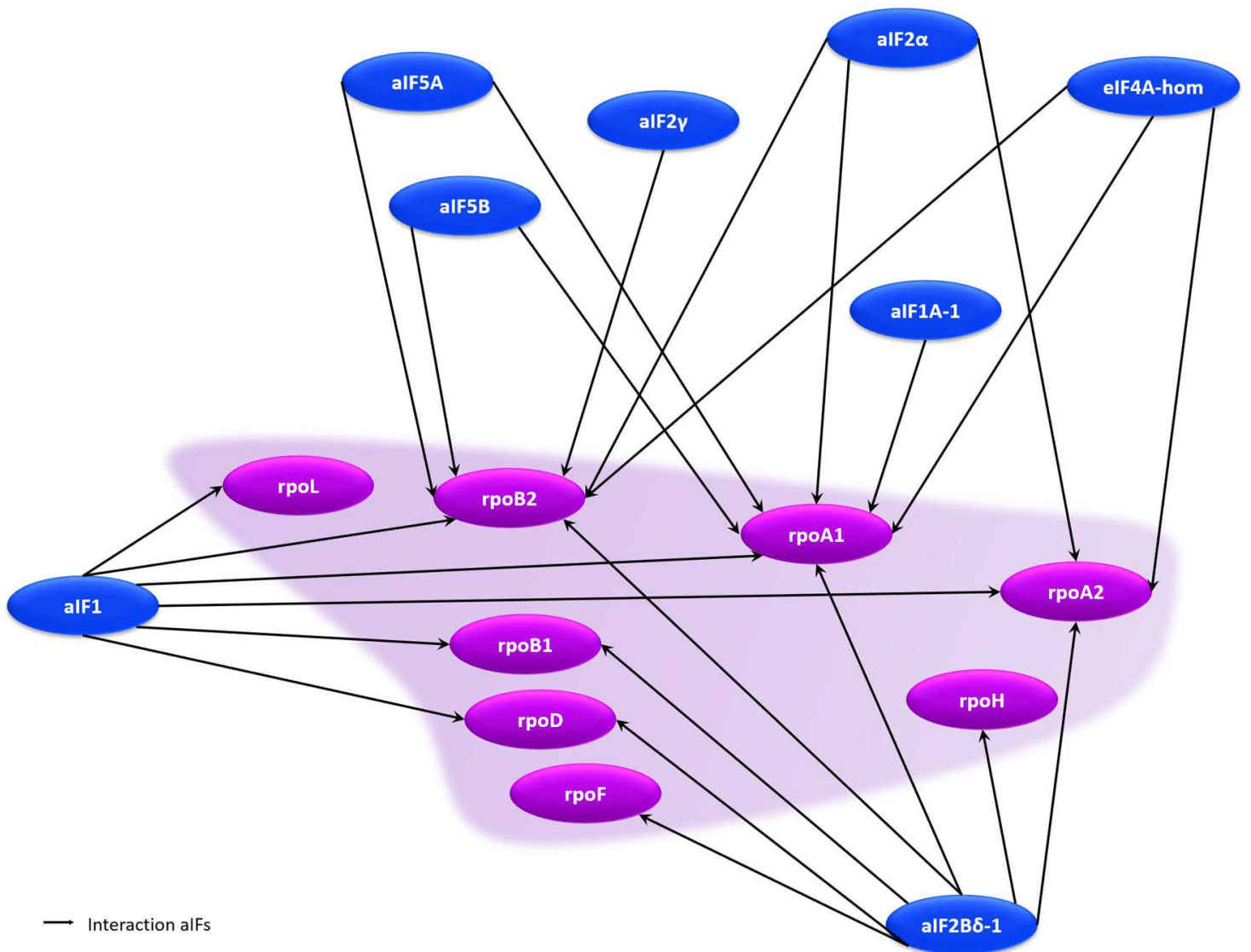

Abbildung 45: Netzwerk der alFs, die RNAPUs mitreinigen konnten

Zusammenfassung der MS-Daten für die alFs, die RNAPUs mitreinigen konnten. Die RNAPUs sind in lila dargestellt, die Initiationsfaktoren in blau. Die schwarzen Pfeile stellen die Interaktion ausgehend von den alFs dar.

Mit alF2B- $\delta 1$ konnten sieben RNPAUs mitgereinigt werden. Mit alF1 konnten sechs der acht RNAPUs mitgereinigt werden. Mit alF2 $\alpha$ und dem elF4A-homolog konnte rpoA1, rpoA2 und rpoB2 co-gereinigt werden. Die am häufigsten co-gereinigten Untereinheiten waren rpoA1 und rpoB2. Mit alF5A und alF5B konnte rpoA1 und rpoA2 mitgereinigt werden. Bei alF2 $\gamma$ konnte nur rpoB2 identifiziert werden und bei alF1A-1 nur rpoA1. 


\subsection{Untersuchung der Interaktion zwischen RNAPUs und alFs}

Die RNA-Polymerase II in $H$. volcanii besteht aus zwölf Untereinheiten. Um die Interaktion zwischen alFs und RNAPUs zu untersuchen wurden sieben RNAPUs, die mit den Initiationsfaktoren mitgereinigt werden konnten, näher betrachtet. Hierfür wurden die Gene dieser RNAPUs ebenfalls mit einem N-terminalen His-Tag versehen, in den pSD1R16 kloniert und im Stamm H26 1279 überexprimiert. Bei den Überexpression handelte es sich um die RNAPUs rpoA1, rpoA2, rpoB1, rpoB2, rpoD, rpoH und rpoL (Tabelle 81). Die Untereinheit rpoF wurde auch mit einem alF co-gereinigt. Aus Zeitgründen war die Überexpression nicht möglich.

Tabelle 81: RNA-Polymerase-Untereinheiten der RNA-Polymerase in $\boldsymbol{H}$. volcanii

\begin{tabular}{|c|c|c|c|c|c|}
\hline Gene & Gene ID & Accession & Overproduction & Strain & $M W$ [kDa] \\
\hline rpoA1 & HVO_0349 & D4GZX6 & + & $\mathrm{H} 26 \Delta 1279$ & 109 \\
\hline rpoA2 & HVO_0350 & D4GZX7 & + & $\mathrm{H} 26 \Delta 1279$ & 46,2 \\
\hline rpoB1 & HVO_0348 & L9UJM2 & + & $\mathrm{H} 26 \Delta 1279$ & 67,8 \\
\hline rpoB2 & HVO_0347 & L9UK99 & + & $\mathrm{H} 26 \Delta 1279$ & 58,9 \\
\hline$r p o D$ & HVO_2781 & L9V5W2 & + & $\mathrm{H} 26 \Delta 1279$ & 28,1 \\
\hline rрoH & HVO_0346 & D4GZX3 & + & $\mathrm{H} 26 \Delta 1279$ & 8,6 \\
\hline rpol & HVO_1042 & D4GVL8 & + & $\mathrm{H} 26 \Delta 1279$ & 10,4 \\
\hline$r p o F$ & HVO_2748 & D4GWA3 & & - & 13,7 \\
\hline$r p o E$ & HVO_1899 & D4GTD2 & & - & 21 \\
\hline rpoK & HVO_2775 & D4GWX4 & & - & 6,6 \\
\hline$r p o N$ & HVO_2776 & D4GWX5 & & - & 7,3 \\
\hline$r p o P$ & HVO_0653 & L9UMK6 & & - & 5,1 \\
\hline
\end{tabular}

\subsection{1 Überexpression der RNAPUs}

Auch mit den Mutanten für die Überexpression der einzelnen RNAPUs wurden Wachstumsversuche bei optimalen Bedingungen von $42^{\circ} \mathrm{C}$ in Komplexmedium durchgeführt. Anhand der Wachstumsversuche wurde der Einfluss der Überexpression der einzelnen RNAPUs im Vergleich zum Wildtyp H26 1279 mit Leerplasmid pSD+P untersucht (Abbildung 46).

Bei der Überexpressionsmutante von rpoD zeigte sich ein sehr viel besseres Wachstum als bei der Kontrolle H26 1279 mit dem Leerplasmid pSD+P. Von allen getaggten RNAPUs zeigte diese Überexpressionsmutante das beste Wachstumsverhalten. Die sechs weiteren Mutanten der RNAPUs wuchsen ähnlich oder schlechter als die Kontrolle mit dem Leerplasmid. Die Untereinheit rpoL zeigte ein ähnliches Wachstum zur Kontrolle. Am schlechtesten wuchs die Mutante mit der Überexpression von rpoB2. 


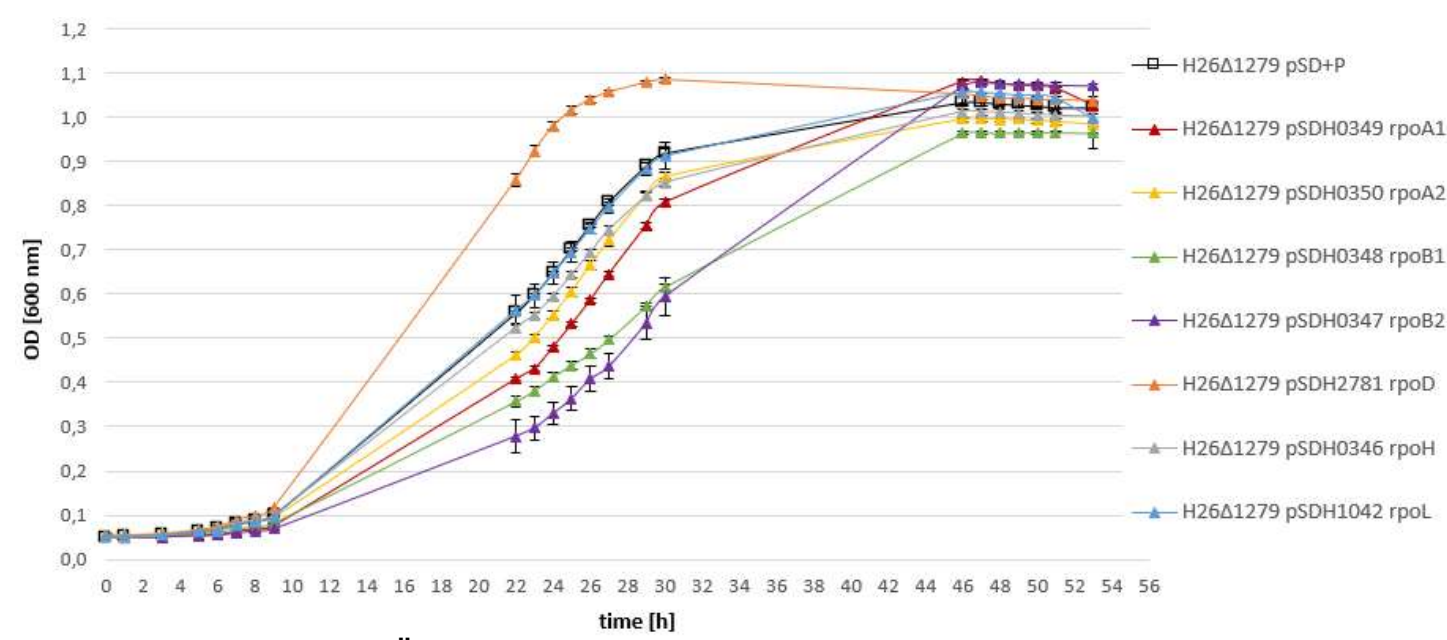

Abbildung 46: Wachstum der Überexpressionsmutanten von RNAPUs

Wachstumsversuche wurden für die sieben RNAPUs in $\mathrm{H} 26 \Delta 1279$ bei optimalen Bedingungen in Komplexmedium bei $42{ }^{\circ} \mathrm{C}$ durchgeführt. $\mathrm{H} 26 \Delta 1279$ mit dem Leerplasmid $\mathrm{pSD}+\mathrm{P}$ diente als Kontrolle.

\subsubsection{Affinitätsaufreinigungen der RNAPUs}

Für die getaggten RNAPUs wurde jeweils dreimal eine Affinitätsaufreinigung durchgeführt. Die Elutionsfraktionen wurden auf ein SDS-Polyacrylamid aufgetragen und verglichen. Für rpoH wurde aufgrund der Größe des Proteins ein Tricin-Gel verwendet. In Abbildung 47 ist jeweils die zweite Elutionsfraktion der RNAPUs rpoA1, rpoA2, rpoB1, rpoB2, rpoD, rpoL bzw. TricinGel für rpoH im Vergleich dargestellt.
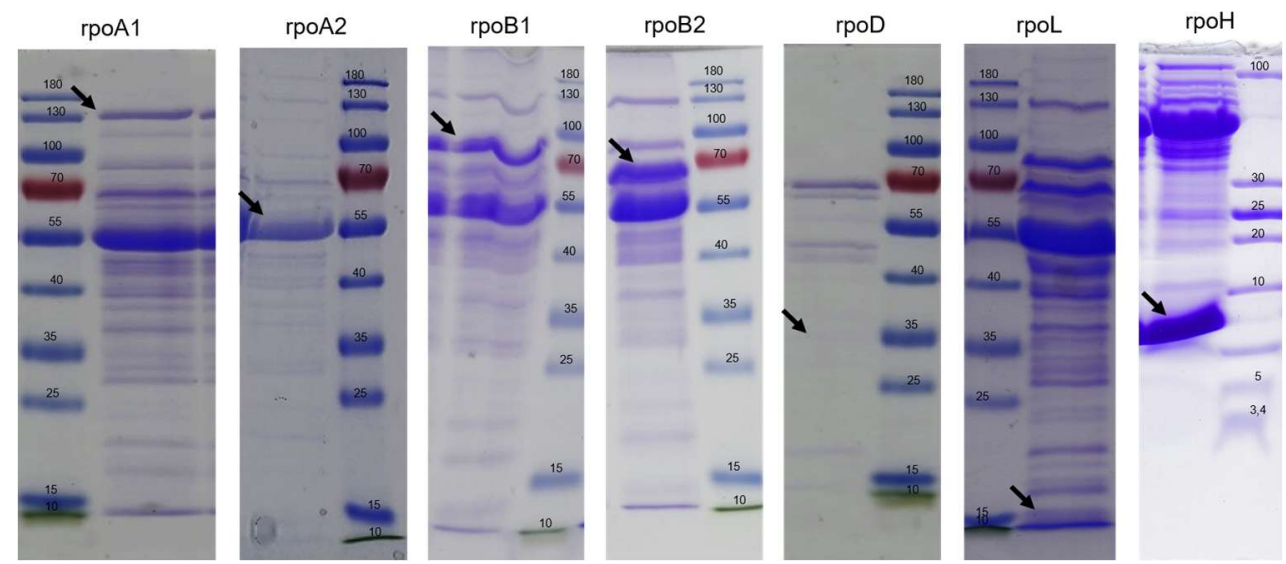

\section{Abbildung 47: Affinitätsaufreinigung der überexprimierten RNAPUs}

Die zweite Elutionsfraktion nach der Affinitätsaufreinigung der sieben RNAPUs. Die Pfeile zeigen zu der jeweiligen überexprimierten Untereinheit auf den SDS-Gelen bzw. für rpoH auf ein Tricin-Gel, die Coomassie-gefärbt wurden.

Für die MS-Analyse der getaggten RNAPUs und der Identifizierung der mitgereinigten Proteine wurde von drei Affinitätsaufreinigungen jeweils die zweite Elutionsfraktion verwendet.

Bereits auf dem SDS-Gel konnte für rpoD nur eine schwache Bande nachgewiesen werden. Im Vergleich mit den anderen getaggten RNAPUs konnte mit rpoD am wenigsten Proteine mitgereinigt werden. Dies spiegelte sich auch in den MS-Daten wider. Bei der Auswertung der MS-Daten konnte nach dem Abgleich der Unique Peptides mit einem Wert von 2 oder größer kein rpoD mehr nachgewiesen werden. 


\subsubsection{MS-Analyse der RNAPUs}

Mit rpoA1 konnte nach der MS-Auswertung 62 Proteine identifiziert werden. Für rpoA2 waren es 19 Proteine, rpoB1 54 Proteine, rpoB2 56 Proteine, rpoD 30 Proteine, rpoL 49 Proteine und rpoH 62 Proteine.

Die für die Transkription identifizierten Proteine, die mit den RNAPUs mitgereinigt werden konnten, sind in Tabelle 82 aufgeführt. Insgesamt konnten zu den getaggten RNAPUs zusätzlich rpoN, rpoP und rpoF mitgereinigt werden.

Tabelle 82: Mit den sieben RNAPUs mitgereinigte RNAPUs

\begin{tabular}{|c|c|c|c|c|c|c|c|c|c|c|}
\hline \multirow[b]{2}{*}{ Specification } & \multirow[b]{2}{*}{ Genloci } & \multirow[b]{2}{*}{ Accession } & \multirow[b]{2}{*}{ Description } & \multicolumn{7}{|c|}{ Bait protein } \\
\hline & & & & $\begin{array}{l}\text { 궁 } \\
\text { 일 }\end{array}$ & $\begin{array}{l}\text { ㅎํㅇ } \\
\text { 足 }\end{array}$ & $\begin{array}{l}\text { 흥 } \\
\text { 㽞 }\end{array}$ & $\begin{array}{l}\text { 긍 } \\
\text { 怘 }\end{array}$ & $\begin{array}{l}\text { 중 } \\
\text { 믐 }\end{array}$ & $\begin{array}{l}\text { 훟 } \\
\text { 오 }\end{array}$ & 궁 \\
\hline \multirow[t]{10}{*}{ RNAP-subunits } & HVO_0349 & D4GZX6 & rpoA1 & bait & + & + & + & + & + & + \\
\hline & HVO_0350 & D4GZX7 & rрoA2 & + & bait & + & + & + & + & + \\
\hline & HVO_0348 & L9UJM2 & rpoB1 & + & + & bait & + & & + & + \\
\hline & HVO_0347 & L9UK99 & гров2 & + & + & + & bait & + & + & + \\
\hline & HVO_2781 & L9V5W2 & rpod & + & + & + & + & (bait) & + & + \\
\hline & HVO_0346 & D4GZX3 & $\mathrm{rpoH}$ & + & + & + & + & & bait & + \\
\hline & HVO_1042 & D4GVL8 & rpol & + & + & + & + & & + & bait \\
\hline & HVO_2776 & D4GWX5 & rpoN & + & + & + & + & & + & + \\
\hline & HVO_0653 & L9UMK6 & rpoP & + & & + & + & & + & + \\
\hline & HVO_2748 & D4GWA3 & rpoF & & & & & & + & \\
\hline \multirow[t]{23}{*}{ regulator } & HVO_2110 & L9V9M0 & ArcR family TR & + & & & & & & \\
\hline & HVO_1116 & D4GW55 & HTH domain protein & & & + & & + & & \\
\hline & HVO_1133 & D4GW85 & HTH domain protein & + & & + & + & + & + & + \\
\hline & HVO_0962 & D4GV69 & HTH domain protein & & & & & & + & \\
\hline & HVO_1695 & D4H040 & HTH domain protein & + & & + & + & & + & + \\
\hline & HVO_A0121 & D4GQF3 & HTH-10 family TR & + & & & & & & \\
\hline & HVO_1501 & D4GYE7 & HTH-type TLR GIpR & + & & & & & + & + \\
\hline & HVO_2108 & D4GUQ5 & ICIR family TR & + & + & + & + & + & + & + \\
\hline & HVO_A0583 & D4GRP3 & IcIR family TR & + & & & & & + & \\
\hline & HVO_B0114 & D4GPB5 & ICIR family TR & + & + & + & + & & + & + \\
\hline & HVO_B0201 & D4GPK2 & ICIR family TR & + & & & + & + & & \\
\hline & HVO_1792 & D4GSB6 & Lrp/AsnC family TR & + & & + & + & + & + & + \\
\hline & HVO_B0066 & D4GP68 & Lrp/AsnC family TR & & & & & & + & \\
\hline & HVO_2869 & D4GXH6 & PadR family TR & + & & & + & & & + \\
\hline & HVO_0819 & D4GUE2 & SirR/DtxR family TR SirR & + & & + & + & & + & + \\
\hline & HVO_0163 & L9UFW5 & TLR & + & & + & + & + & + & + \\
\hline & HVO_0179 & L9UGU5 & TLR & + & & + & + & & + & + \\
\hline & HVO_1360 & D4GXQ1 & TrmB family TR & & & & & & + & \\
\hline & HVO_0568 & L9UN99 & TLR & + & & & & & & \\
\hline & HVO_2928 & L9UK32 & TLR & + & & + & + & + & + & + \\
\hline & HVO_2636 & L9V878 & TLR & & & & & & + & \\
\hline & HVO_2723 & D4GW47 & RNA-binding protein Lsm & + & & & & & + & \\
\hline & HVO_1727 & L9VGC6 & TATA-box-binding protein & & & + & + & + & + & \\
\hline
\end{tabular}

$\mathrm{TR}=$ transcription regulator; $\mathrm{TLR}=$ transcriptional regulator 
Hinzu kamen insgesamt 21 unterschiedliche Transkriptionsregulatoren sowie das RNA-Bindeprotein Lsm und ein TATA-box-Bindeprotein (Tabelle 82).

Mit allen sieben getaggten RNAPUs konnte sowohl rpoA1, rpoA2 als auch rpoB2 mitgereinigt werden. Die fünf Untereinheiten rpoB1, rpoD, rpoH, rpoL und rpoN konnten mit rpoA1, rpoA2, rpoB1, rpoB2, rpoL und rpoH mitgereinigt werden. RpoP konnte mit rpoA1, rpoB1, rpoB2, rpoL und $\mathrm{rpoH}$ mitgereinigt werden. Die Untereinheit rpoF nur mit rpoH. Damit konnte mit den sieben getaggten RNAPUs fast die gesamte RNA-Polymerase, mit Ausnahme von rpoE und rpoK, co-gereinigt werden.

\subsubsection{Interaktionen von RNAPUs-RNAPUs}

Die Interaktion der RNAPUs mit RNAPUs ist in Abbildung 48 als Netzwerk dargestellt und wurde auf Basis der MS-Daten aus Tabelle 82 erstellt. Aus Zeitgründen konnten nur sieben von zwölf RNAPUs überexprimiert werden. Es konnten zehn der zwölf RNAPUs mitgereinigt werden.

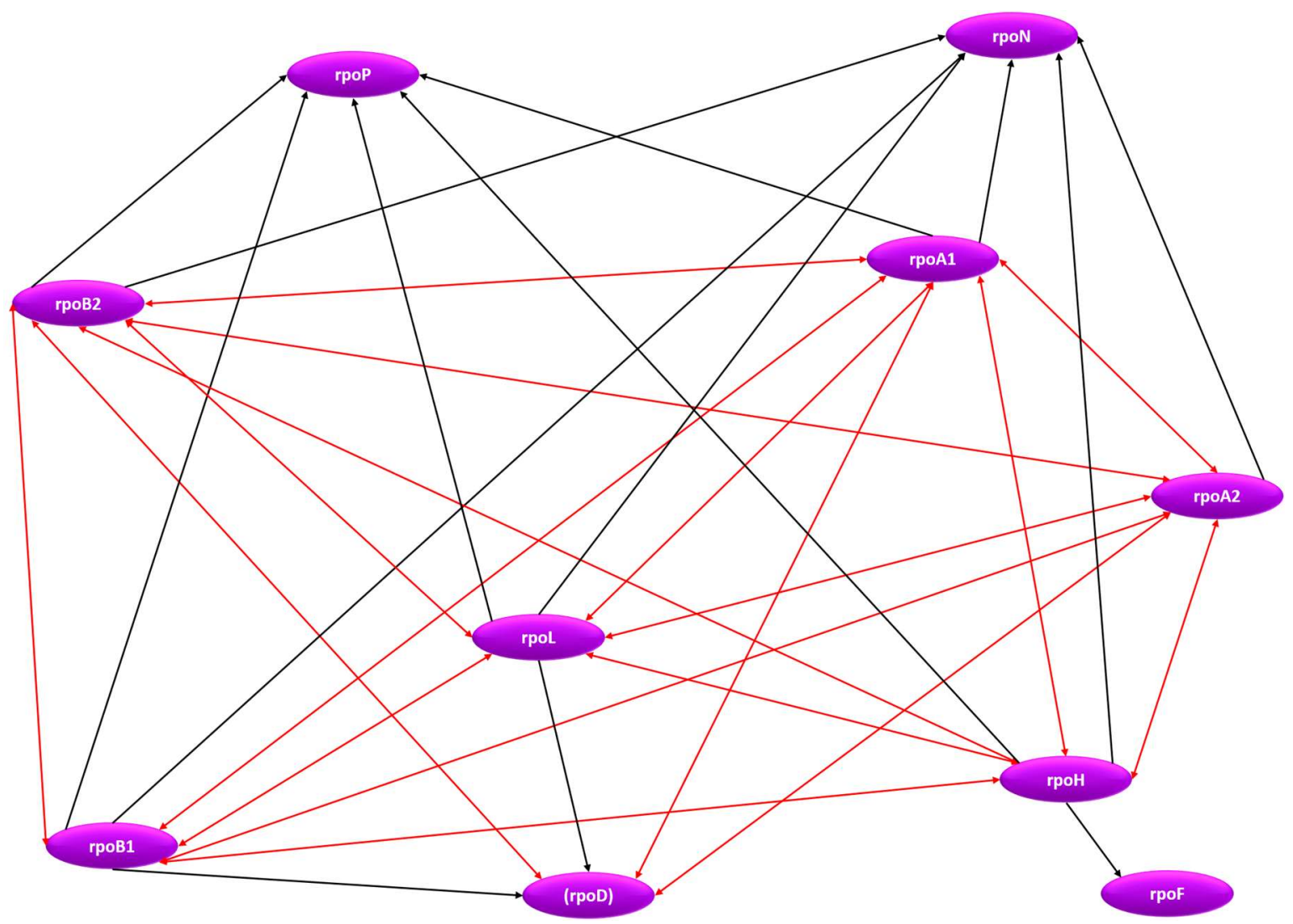

Abbildung 48: Interaktionsnetzwerk der RNAPUs

Die RNAPUs sind in lila dargestellt. Die schwarzen Pfeile stellen die einseitige Co-Reinigung und die roten Pfeile die gegenseitige Co-Reinigung dar. 


\subsubsection{RNAPUS und Proteine der Translation}

Die Proteine der Translation, die mit den RNAPUs mitgereinigt werden konnten, sind in der nachfolgenden Tabelle 83 aufgelistet. Darunter befinden sich Translationsinitiationsfaktoren, Elongationsfaktoren sowie Proteine der kleinen und großen ribosomalen Untereinheit.

Mit den sieben RNAPUs konnte alF2Bס-1 mitgereinigt werden. alF5B konnte mit Ausnahme von rpoD ebenfalls bei allen RNAPUs co-gereinigt werden. alF2Ba konnte nur mit rpoB2 mitgereinigt werden. alF2 $\alpha$ konnte nur bei rpoH identifiziert werden.

Tabelle 83: Mit den sieben RNAPUs mitgereinigte Proteine der Translation

\begin{tabular}{|c|c|c|c|c|c|c|c|c|c|c|}
\hline \multirow[b]{2}{*}{ Specification } & \multirow[b]{2}{*}{ Genloci } & \multirow[b]{2}{*}{ Accession } & \multirow[b]{2}{*}{ Description } & \multicolumn{7}{|c|}{ Bait protein } \\
\hline & & & & $\begin{array}{l}\text { 긍 } \\
\text { 일 }\end{array}$ & $\begin{array}{l}\text { 긍 } \\
\text { 足 }\end{array}$ & $\begin{array}{l}\text { 궁 } \\
\text { 뭄 }\end{array}$ & $\begin{array}{l}\text { 긍 } \\
\text { 怘 }\end{array}$ & $\begin{array}{l}\text { 홍 } \\
\text { 므 }\end{array}$ & $\begin{array}{l}\text { 궁 } \\
\text { 오 }\end{array}$ & 궁 \\
\hline \multirow[t]{4}{*}{ alFs } & HVO_0699 & D4GT46 & alF2a & & & & & & + & \\
\hline & HVO_1934 & D4GTG3 & alF2Ba & & & & + & & & \\
\hline & HVO_0966 & L9USK7 & alF2B $\delta-1$ & + & + & + & + & + & + & + \\
\hline & HVO_1963 & D4GTJ2 & alF5B & + & + & + & + & & + & + \\
\hline \multirow[t]{3}{*}{ aEFs } & HVO_2575 & L9V605 & aEF1a-like protein & + & & + & + & & + & + \\
\hline & HVO_2413 & L9V6J4 & $\mathrm{aEF} 1 \mathrm{a}$ & + & + & + & + & & + & + \\
\hline & HVO_0356 & L9UK07 & $\mathrm{aEF2}$ & + & + & + & + & + & + & + \\
\hline \multirow[t]{8}{*}{$30 \mathrm{~S} \mathrm{rpS}$} & HVO_2558 & D4GTZO & $30 \mathrm{~S}$ rpS3 & & & & & & + & \\
\hline & HVO_2552 & L9V7Y2 & $30 \mathrm{~S}$ rpS4e & + & + & + & + & & + & \\
\hline & HVO_2544 & D4GTX6 & $30 \mathrm{~S}$ rpS5 & & & + & & & & \\
\hline & HVO_2373 & D4GWM1 & $30 \mathrm{~S} \mathrm{rpS8e}$ & & & & & + & & \\
\hline & HVO_0360 & L9ULL7 & $30 S$ rpS10 & + & & + & & & + & \\
\hline & HVO_2784 & L9V5M6 & $30 \mathrm{~S} \mathrm{rpS13}$ & & & & + & & & \\
\hline & HVO_2560 & L9V659 & $30 \mathrm{~S} r p S 19 \mathrm{P}$ & & & + & + & & + & \\
\hline & HVO_1896 & D4GTC9 & $30 \mathrm{~S} r p S 24 \mathrm{e}$ & & & & & + & & \\
\hline \multirow[t]{13}{*}{$50 \mathrm{~S} \mathrm{rpL}$} & HVO_2757 & P41199 & $50 \mathrm{~S}$ rpL1 & + & & + & + & + & + & + \\
\hline & HVO_2561 & D4GTZ3 & 50 S rpL2 & + & & + & + & + & + & + \\
\hline & HVO_2564 & L9V5K9 & $50 \mathrm{~S}$ rpL3 & + & & + & + & + & + & + \\
\hline & HVO_2563 & D4GTZ5 & $50 S$ rpL4 & & & + & + & & & \\
\hline & HVO_2756 & P41198 & $50 \mathrm{~S}$ rpL10 & & & + & + & & + & \\
\hline & HVO_0484 & D4GS24 & $50 \mathrm{~S}$ rpL10e & & & + & & & & \\
\hline & HVO_2758 & P41200 & $50 \mathrm{~S} \mathrm{rpL11}$ & + & & + & + & + & & + \\
\hline & HVO_2542 & L9V7W8 & $50 \mathrm{~S}$ rpL15 & & & + & & & & \\
\hline & HVO_0561 & L9UPT6 & $50 \mathrm{~S} \mathrm{rpL15e}$ & + & & + & + & & + & + \\
\hline & HVO_2559 & L9V5K3 & $50 \mathrm{~S}$ rpL22 & + & + & + & + & & + & + \\
\hline & HVO_2553 & L9V5Y5 & $50 \mathrm{~S} \mathrm{rpL24}$ & & & & & + & & \\
\hline & HVO_2543 & L9V5X1 & $50 \mathrm{~S}$ rpL30 & + & & + & + & & + & + \\
\hline & HVO_2547 & D4GTX9 & $50 \mathrm{~S} \mathrm{rpL32e}$ & & & + & + & + & & \\
\hline
\end{tabular}




\subsubsection{Interaktionen zwischen RNAPUs und alFs kombiniert}

Mit den Daten der RNAPUs wurde das bestehende Netzwerk der Interaktionen zwischen den Translationsinitiationsfaktoren und den RNAPUs erweitert. Zusammengefasst wurden die Daten aus den Aufreinigungen der alFs, die RNAPUs mitreinigen konnten (Tabelle 84) und die Daten aus den Aufreinigungen der RNAPUs, die alFs mitreinigen konnten (Tabelle 85).

Tabelle 84: Mit den 14 alFs und alF-Untereinheiten mitgereinigte RNAPUs

\begin{tabular}{|c|c|c|c|c|c|c|c|c|c|c|c|c|c|c|c|c|c|}
\hline \multirow[b]{2}{*}{$\mathrm{kDa}$} & \multirow[b]{2}{*}{ Genloci } & \multirow[b]{2}{*}{ Accession } & \multirow[b]{2}{*}{ Description } & \multicolumn{14}{|c|}{ Bait protein } \\
\hline & & & & 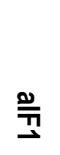 & 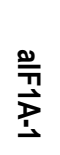 & 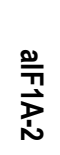 & 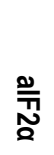 & $\begin{array}{l}\text { 荇 } \\
\text { 岕 }\end{array}$ & $\begin{array}{l}\text { 荇 } \\
\text { 岕 }\end{array}$ & $\stackrel{\text { 矛 }}{\stackrel{2}{<}}$ & $\begin{array}{l}\text { 矛 } \\
\tilde{\tilde{\sigma}}\end{array}$ & 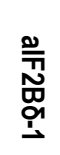 & 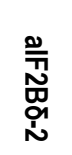 & $\begin{array}{l}\frac{D}{71} \\
\frac{1}{1} \\
\frac{1}{0} \\
\frac{0}{3}\end{array}$ & 雫 & 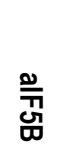 & ๗ \\
\hline 108,8 & HVO_0349 & D4GZX6 & rроA1 & + & + & & + & & & & & + & & + & + & + & \\
\hline 46,1 & HVO_0350 & D4GZX7 & rpoA2 & + & & & + & & & & & + & & + & & & \\
\hline 67,7 & HVO_0348 & L9UJM2 & гров1 & + & & & & & & & & + & & & & & \\
\hline 58,9 & HVO_0347 & L9UK99 & гров2 & + & & & + & & & + & & + & & + & + & + & \\
\hline 28,1 & HVO_2781 & L9V5W2 & rpoD & + & & & & & & & & + & & & & & \\
\hline 8,5 & HVO_0346 & D4GZX3 & rpoH & & & & & & & & & + & & & & & \\
\hline 13,7 & HVO_2748 & D4GWA3 & rpoF & & & & & & & & & + & & & & & \\
\hline 10,3 & HVO_1042 & D4GVL8 & rpol & + & & & & & & & & & & & & & \\
\hline
\end{tabular}

Die meisten RNAPUs konnten mit alF2Bס-1 co-gereinigt werden. Gleichzeitig konnte alF2Bס1 selbst bei allen sieben getaggten RNAPUs mitgereinigt werden. Für rpoF, die siebte RNAPU die mit alF2Bס-1 co-gereinigt werden konnte, konnte die Frage nicht abschließend geklärt werden, da diese RNAPU nicht überexprimiert wurde.

Tabelle 85: Mit den sieben RNAPUs mitgereinigte alFs und alF-Untereinheiten

\begin{tabular}{|c|c|c|c|c|c|c|c|c|c|c|}
\hline \multirow[b]{2}{*}{$\mathrm{kDa}$} & \multirow[b]{2}{*}{ Genloci } & \multirow[b]{2}{*}{ Accession } & \multirow[b]{2}{*}{ Description } & \multicolumn{7}{|c|}{ Bait protein } \\
\hline & & & & 훙 & $\begin{array}{l}\text { 응 } \\
\text { 足 }\end{array}$ & $\begin{array}{l}\text { 긍 } \\
\text { 㽞 }\end{array}$ & 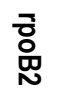 & $\begin{array}{l}\text { 공 } \\
\text { 음 }\end{array}$ & $\begin{array}{l}\text { 훟 } \\
\text { 오 }\end{array}$ & 궁 \\
\hline 10,8 & HVO_1946 & D4GTH5 & alF1 & & & & & & & \\
\hline 11,5 & HVO_0136 & D4GZ79 & alF1A-1 & & & & & & & \\
\hline 11,2 & HVO_A0637 & D4GRU5 & alF1A-2 & & & & & & & \\
\hline 29,5 & HVO_0699 & D4GT46 & alF2 $\alpha$ & & & & & & + & \\
\hline 14,9 & HVO_1678 & D4GZP2 & alF2 $\beta-1$ & & & & & & & \\
\hline 22,2 & HVO_2242 & L9VAS4 & alF2 $\beta-2$ & & & & & & & \\
\hline 43,9 & HVO_1901 & D4GTD4 & alF2y & & & & & & & \\
\hline 43,2 & HVO_1934 & D4GTG3 & alF2Ba & & & & + & & & \\
\hline 34,9 & HVO_0966 & L9USK7 & alF2B $\delta-1$ & + & + & + & + & + & + & + \\
\hline 30,7 & HVO_2706 & L9V7F9 & alF2Bס-2 & & & & & & & \\
\hline 104,5 & HVO_1333 & D4GXK1 & elF4A-hom. & & & & & & & \\
\hline 14,2 & HVO_2300 & L9V7A1 & alF5A & & & & & & & \\
\hline 65,3 & HVO_1963 & D4GTJ2 & alF5B & + & + & + & + & & + & + \\
\hline 22,98 & HVO_0117 & D4GYW3 & alF6 & & & & & & & \\
\hline
\end{tabular}


Der Initiationsfaktor alF5B wurde von sechs RNAPUs mitgereinigt, konnte aber selbst nur zwei RNAPUs co-reinigen. Im Gegensatz zu alF1, hier konnten sechs RNAPUs mitgereinigt werden. alF1 selbst wurde bei keinem RNAPU mitgereinigt.

Der Faktor elF4-homolog konnte 3 RNAPUs mitreinigen, selbst aber bei keinem RNAPU cogereinigt werden. Dies wurde auch für alF1-A1, alF2 $y$ und alF5A festgestellt, die jeweils RNAPUs mitreinigen konnten. Sie selbst konnten bei RNAPUs in der MS nicht identifiziert werden.

Dafür konnte mit alF2Ba keine RNAPU co-gereinigt werden. Hingegen konnte er bei einem RNAPU mitgereinigt werden.

Bei alF2 $\alpha$ verhielt es sich anders. Mit alF2 $\alpha$ konnten drei RNAPUs co-gereinigt werden. alF2 $\alpha$ selbst konnte mit einem RNAPU co-gereinigt werden.

Sowohl in Tabelle 84 als auch in Tabelle 85 wurden die in Wechselbeziehung stehenden RNAPUs und alFs rot markiert.

Die Daten der beiden Tabellen wurden herangezogen, um das Interaktionsnetzwerk der alFs und RNAPUs zu erstellen (Abbildung 49).

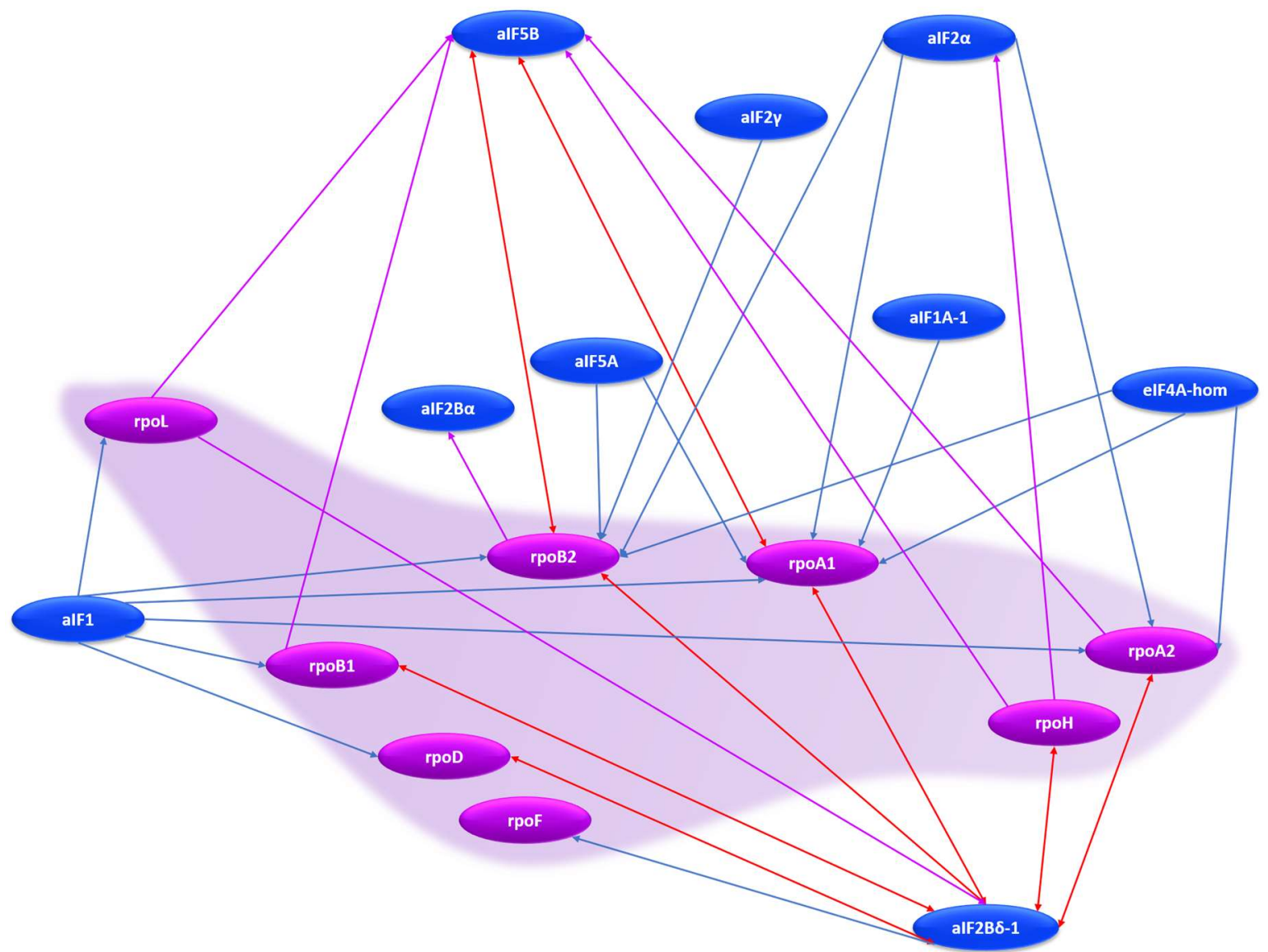

Abbildung 49: Interaktionsnetzwerk zwischen den RNAPUs und alFs

In lila sind die RNAPUs dargestellt, in blau die Translationsinitiationsfaktoren. Die lila Pfeile beschreiben die CoReinigung ausgehend von einer RNAPU. Die blauen Pfeile zeigen die Co-Reinigung ausgehend von einem Translationsinitiationsfaktor. Die roten Doppelpfeile beschreiben die Co-Reinigung in beide Richtungen. 


\section{Diskussion}

Nachdem die Translationsinitiationsfaktoren in allen drei Domänen des Lebens essenziell für die Translation sind, ist die Aufklärung von Protein-Protein-Interaktionen ein wichtiges Verfahren für die Identifizierung von Proteinfunktionen. Die Anwendung von Affinitätsaufreinigung mit anschließender MS ist dabei eine gängige Methode, um solche Protein-Protein-, Protein-RNAund Protein-DNA-Interaktionen aufzuklären. Aufgrund ihrer Vielseitigkeit findet die Methode in allen drei Domänen des Lebens Anwendung (Li et al., 2010; MacNeill, 2011; Lambert, Pawson and Gingras, 2012; Schlesner et al., 2012; Pluchon et al., 2013; Denis et al., 2018). Sie beinhaltet experimentelle Herausforderungen, die zu beachten sind. Das betrifft insbesondere die effiziente Zelllyse, die Wahl des Köderproteins, die Erhaltung der am Köderprotein assoziierten Proteine, das Einfangen von zeitlich begrenzten Interaktionen und die Dynamik innerhalb eines Komplexes (Kaczowka and Maupin-Furlow, 2003; Oeffinger, 2012).

\subsection{Affinitätsaufreinigung und MS-Analyse}

In dieser Arbeit konnte mittels Affinitätsaufreinigung und MS-Analyse ein besserer Überblick über die Funktionen und Interaktionen der in $\mathrm{H}$. volcanii annotierten Translationsinitiationsfaktoren erarbeitet werden.

Interaktionen von Proteinen sind essenziell. Um ihre biologische Aktivität in einer Zelle zu erfüllen interagieren Proteine. Die meisten Proteine funktionieren in Verbindung mit anderen Proteinpartnern oder als Teil einer größeren molekularen Assemblierung. Deshalb ist es für das Verständnis der zellulären Funktion entscheidend, das Interaktionsumfeld eines Proteins zu kennen. Für die Erkennung und Identifizierung solcher Interaktionen gibt es verschiedene Werkzeuge, wie zum Beispiel das "yeast two-hybrid systeme“ und die Affinitätsaufreinigung, gekoppelt mit einer MS-Analyse (Dunham, Mullin and Gingras, 2012; Koh et al., 2012; Yang, Wagner and Beli, 2015).

Dabei geht es nicht nur um direkte, sondern auch um indirekte Interaktionen. So zum Beispiel RNA gekoppelte oder transiente Interaktionen und die Eingrenzung von Funktionsbereichen. Verschiedene Varianten dieser Methoden wurden bereits erfolgreich für die Erstellung von Protein-Protein-Interaktionsnetzwerken in Archaeen angewandt. Das gilt beispielsweise für die Aufklärung von Protein-Protein-Interaktionen der DNA-Replikation. Einer dieser Ansätze umfasste in Archaeoglobus fulgidus das "yeast two-hybrid systeme“ (Motz et al., 2002). In einem weiteren Ansatz wurden stabile Komplexe aus Thermococcus kodakarensis gereinigt und in vivo zusammengesetzt ( $\mathrm{Li}$ et al., 2010). Hier wurde die Affinitätsaufreinigung und MS-Analyse verwendet.

In einer weiteren Studie ging es um die genomischen Erhaltungsprozesse. In $P$. abyssi wurde hierfür mittels Affinitätsaufreinigung in vitro mit anschließender MS-Analyse Proteininteraktionspartner identifiziert und ein Protein-Proteininteraktionsnetzwerk erstellt (Pluchon et al., 
2013). Auch für die Analyse der Chemotaxis in Halobacterium salinarum wurde die Affinitätsaufreinigung mit der MS-Analyse gekoppelt und erfolgreich verwendet (Schlesner et al., 2012).

Die Affinitätsaufreinigung in Verbindung mit der MS-Analyse ist ein hervorragendes Werkzeug, um direkte und indirekte Protein-Protein-Interaktionen sichtbar zu machen. Wie bereits oben beschrieben, wurde es in der Vergangenheit schon mehrfach erfolgreich angewandt. Daher wurde diese Methode in dieser Arbeit auch für die Aufklärung von Protein-Proteininteraktionen während der Translation, im speziellen der Translationsinitiationsfaktoren, verwendet.

In der vorliegenden Arbeit konnten die getaggten Proteine alle erfolgreich überexprimiert und auf einem SDS-Gel sichtbar gemacht werden. Die jeweils zweite Elutionsfraktion von drei unabhängigen Affinitätsaufreinigungen wurde anschließend zur MS-Analyse geschickt. Um falsch positiv identifizierte Proteine auszuschließen wurden mehrere Kontrollschritte verwendet. Nach Erhalt der MS-Daten wurden die markierten Kontaminationen ausgenommen und die Proteine mit Unique Peptides unter 2 ausgeschlossen. Die MS-Daten wurden anschließend mit beiden Kontrollen (DHFR und Leerplasmid) verglichen und die Proteinmatches abgezogen. Danach wurden die drei unabhängigen MS-Daten zusammengefasst.

Im Schnitt konnten 103 Proteine zugeordnet werden. Davon waren im Mittelwert 15 uncharakterisierte- und/ oder DUF-Proteine (domain of unknown function). Hierbei handelt es sich um noch nicht charakterisierte Proteine oder um eine Domäne mit unbekannter Funktion, die bei der Auswertung nicht berücksichtigt wurden. Ebenso wurden die Proteine des Zentral- und Zellstoffwechsels ausgenommen, da dies den Rahmen der Arbeit gesprengt hätte.

Berücksichtigt wurden verschiedene Proteine der Translation, Transkription, Replikation und Reparatur. Hinzu kamen Proteine des Protein- und RNA-Turnovers sowie der Proteinfaltung. Die prozentuale Verteilung der Bereiche in Abhängigkeit der Translation ist in Abbildung 50A für die essenziell eingestuften alFs dargestellt und für die nicht essenziell eingestuften alFs in Abbildung 50B aufgezeigt.

Da der Anteil an co-gereinigten Proteinen, die an der Transkription beteiligt sind, signifikant war, wurden entsprechend Proteine der Transkription ebenfalls mit einem Tag versehen und co-gereinigt. Dabei handelte es sich um sieben RNAPUs und viele Transkriptionsregulatoren. Diese konnten mit mehreren alFs co-gereinigt werden. Somit wurde die Analyse auf die Transkription ausgeweitet.

Um den Zusammenhang zwischen Translation und Transkription in $\mathrm{H}$. volcanii zu Untersuchen wurden die sieben RNAPUs ebenfalls mit einem His-Tag versehen und Affinitätsaufreinigungen mit anschließender MS-Analyse durchgeführt. Die Auswertung erfolgte analog wie für die alFs beschrieben. Berücksichtigt wurden die Proteine der Translation, Transkription, Replikation und Reparatur, Proteine des Protein- und RNA-Turnovers sowie der Proteinfaltung (Abbildung 50C). 
Es ist hervorzuheben, dass dank der in der Arbeit verwendeten Methode nicht nur die gesamte RNAP des $H$. volcanii mit den sieben getaggten RNAPUs co-gereinigt wurden, sondern darüber hinaus auch das Verfahren erfolgreich etabliert werden konnte. Zwei Untereinheiten bildeten dabei die Ausnahme.

Prozentual deckte bei den sieben RNAPUs im Vergleich zu den anderen Gruppen die Transkription den größten Bereich ab. Wobei auch der prozentuale Anteil der zur Translation gehörenden Proteine signifikant hoch war. Hinzu kam, dass mit den sieben RNAPUs vier alFs co-gereinigt werden konnten. Mit den Ergebnissen lässt sich eine enge Verbindung zwischen Transkription und Translation in $H$. volcanii vermuten.

A

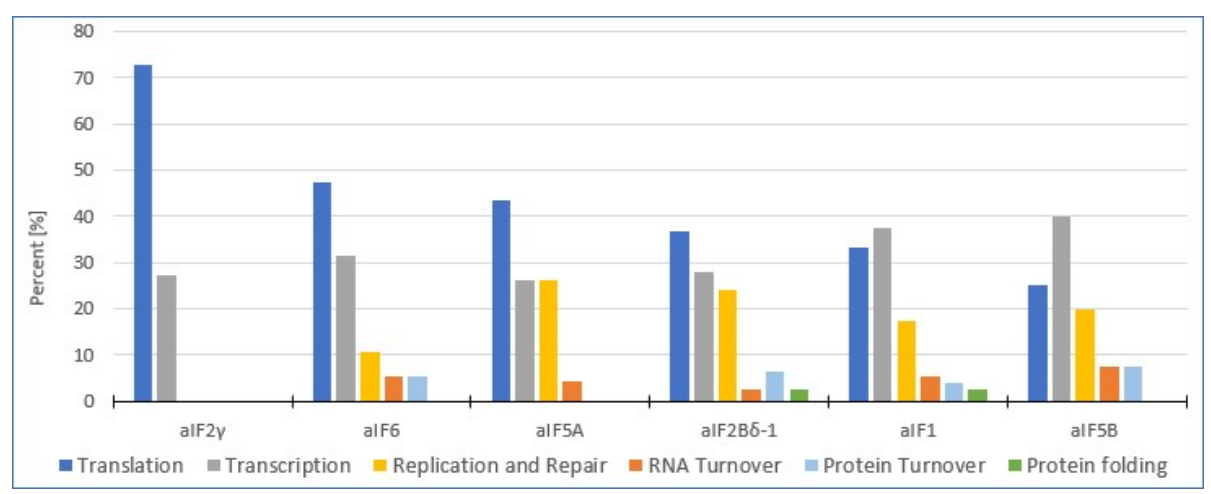

B

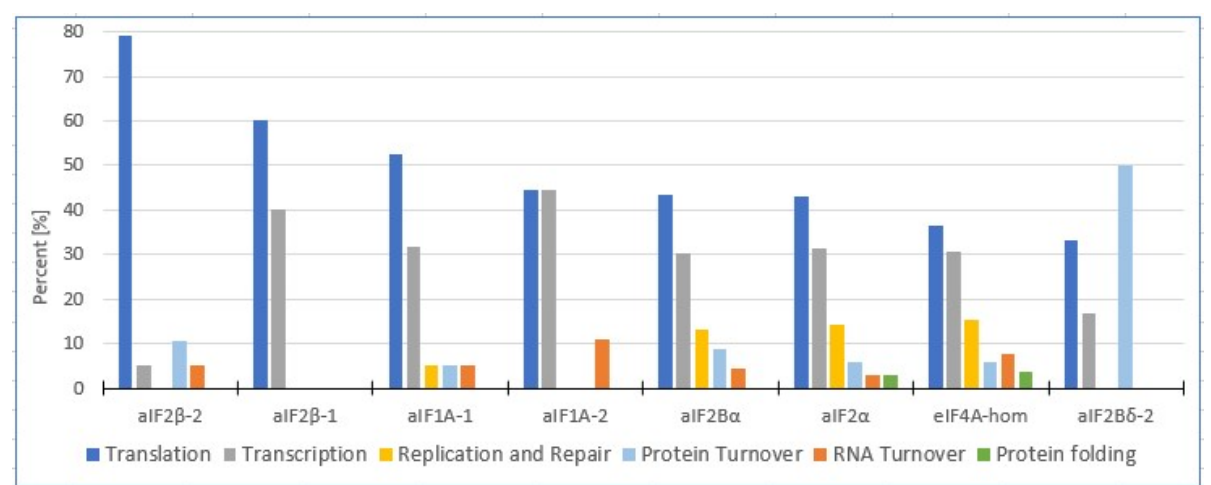

C

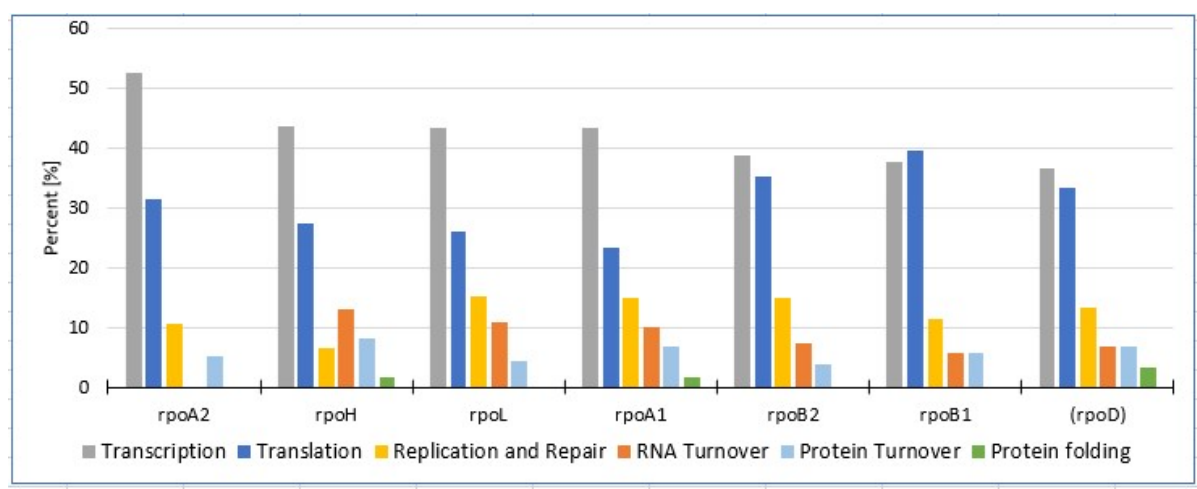

Abbildung 50: Statistische Auswertung der MS-Daten

Prozentuale Verteilung der Proteine in die Bereiche Transcription, Translation, Replication and Repair, RNA-Turnover, Protein-Turnover und Protein folding. A. Statistische Auswertung der essenziell eingestuften alFs, prozentual absteigend, anhand der Translation sortiert. B. Statistische Auswertung der nicht essenziell eingestuften alFs, prozentual absteigend, anhand der Translation sortiert. C. Statistische Auswertung der RNAPUs, prozentual absteigend, anhand der Transcription sortiert. 


\subsection{Auswahl des Tags für die Affinitätsaufreinigung}

Es gibt eine Vielzahl verschiedener Tags, die für die Affinitätsaufreinigung des Köder- bzw. Bait-Proteins verwendet werden können. In dieser Arbeit wurden drei verschiedene Tags ausgewählt, die bereits erfolgreich in Archaeen verwendet wurden. Diese sind die CBD, BBP und der 6xHis (Morag et al., 1995; Allers et al., 2010; Oeffinger, 2012).

Hierfür wurde die CBD, BBP und der 6xHis jeweils N-terminal mit der DHFR unter Kontrolle eines konstitutiven Promotors überproduziert. Für BBP und den His-Tag konnte ein Fusionsprotein im Western Blot nachgewiesen werden. Für die CBD konnte weder im SDS-Gel noch im Western Blot ein Fusionsprotein mit der DHFR nachgewiesen werden. Dies war erstaunlich, da die CBD bereits mehrfach erfolgreich für die Affinitätsaufreinigung in Hochsalz verwendet wurde und hochspezifisch an Cellulose bindet (Irihimovitch et al., 2003; Schlesner et al., 2012; Wang et al., 2014). Ein Grund dafür könnte die Größe des Tags sein, da die CBD allein bereits eine Peptidlänge von 167 AS besitzt und 18,4 kDa schwer ist. Damit ist der CBD-Tag im Vergleich zu den anderen beiden Tags verhältnismäßig groß. Außerdem kann er damit die Faltung des Fusionsproteins beeinflussen.

Auch der BBP-Tag wurde für die Produktion von archaealen Proteinen mehrfach verwendet (Kähler and Antranikian, 2000; Bucher, Evdokimov and Waugh, 2002). Der in dieser Arbeit verwendete BBP-Tag war 14 Aminosäuren lang, aber weniger effizient als der His-Tag mit sechs Aminosäuren. Deshalb wurde der His-Tag für die Aufreinigungen verwendet. Für die Affinitätsaufreinigung in Verbindung mit dem 6xHis-Tag sprach nicht nur die Länge sondern auch die Integrität des Tags. Hinzu kommt die Eigenschaft des His-Tag, der das angehängte Protein meist nur wenig beeinflusst (Carson et al., 2007).

\subsection{Experimentelles Design zur Identifizierung von Bindungspartnern}

Da der 6xHis-Tag anfälliger für die Bindung von nativen Polyhistidinen an das Säulenmaterial ist, wurden verschiedene Kontrollen verwendet. Das bedeutet, das Proteine die in ihrer natürlichen Aminosäuresequenz mehrfach Histidine besitzen und ebenfalls mitgereinigt werden. Wie beispielsweise in H. volcanii pitA (HVO_1871) und cdc48d (HVO_1907) (Allers et al., 2010). Um diese falsch positiven Proteine zu identifizieren wurden sehr stringente Negativkontrollen verwendet. Dazu diente sowohl pSDHDHFR als auch pSD+P in H26 $D$ DHFR. Ferner konnte mit diesen Kontrollen der Einfluss der Überexpression und des Novobiocin überprüft werden. Proteine, die mit den beiden Kontrollen in Dreifachbestimmung in der MS identifiziert wurden, wurden aus den Auswertungen ausgeschlossen. Zu diesen Proteinen gehörten auch cdc48d und PitA. PitA konnte für pSDHDHFR in dreifach-Bestimmung nachgewiesen werden, bei pSD+P konnte er nur in zwei von drei Messungen nachgewiesen werden. Das unterstreicht die Wichtigkeit beider Kontrollen. Bei den mitgereinigten Proteinen gab es zwar Überschneidungen, aber auch Proteine, die nur in einer der beiden Kontrollen identifiziert werden konnten. 
In dieser Arbeit wurde auf eine heterologe Expression in einem Wirt wie zum Beispiel E. coli verzichtet. Durch die Adaption an das Hochsalz und die osmotischen Bedingungen besitzt $H$. volcanii eine hohe Konzentration an Kaliumionen (Danson and Hough, 1997). Zur Anpassung besitzen die Proteine daher einen hohen Anteil an sauren Aminosäuren (Mevarech, Frolow and Gloss, 2000). Unter anderen Bedingungen wie beispielweise in E. coli kann es deshalb zu einer falschen Faltung der Proteine kommen. Durch die geringe lonenstärke können die Proteine aggregieren (Blecher, Goldman and Mevarech, 1993; Connaris et al., 1999). Auch posttranslationale Modifikationen wie Acetylierung und Ubiquitinierung gingen verloren (AltmanPrice and Mevarech, 2009; Humbard et al., 2010).

Durch die stringenten Kontrollen und die Mehrfachbestimmung konnten viele falsch positive Proteine ausgeschlossen werden. Das unterstreicht die Tatsache, dass mit 22 verschiedenen affinitätsgereinigten Proteinen sich die Muster der gereinigten Proteinen unterschieden. Damit wird das hier gewählte experimentelle Design bestätigt.

Um die in der Arbeit verwendeten Methode zur Affinitätsaufreinigung weiter zu modifizieren, könnte man die Proteine anstatt über einen pull-down-Assay auch über eine Säule aufreinigen (Allers, 2010; Stroud, Liddell and Allers, 2012).

\subsection{Vergleich alF-alF-Interaktionen}

\subsection{1 alF1}

Der Translationsinitiationsfaktor IF1/elF1/alF1 ist ein universeller Faktor und ist damit in allen drei Domänen des Lebens vertreten. In Eukaryonten ist er unter anderem als elF1, in Bakterien als YciH und in Archaeen als alF1 benannt. Alle drei Faktoren weisen ähnliche Funktionen auf (Kyrpides and Woese, 1998b).

In H. volcanii sind zwei Gene (HVO_1946 und HVO_B0284) für alF1 codiert. Sie besitzen jedoch nur zu 49 \% eine identische Aminosäuresequenz. Im Gegensatz zu HVO_1946 konnte HVO_B0284 deletiert werden (Gäbel et al., 2013). Dies ist ein weiterer Unterschied der beiden Annotationen.

In Homo sapiens ( $H$. sapiens) codieren ebenfalls zwei Gene für elF1. Diese sind elF1 und elF1B. Die Funktion von elF1 konnte geklärt werden. Für elF1B ist sie noch nicht bekannt (Ivanov et al., 2010).

Zu Beginn dieser Arbeit wurde HVO_B0284 die Funktion als Translationsinitiationsfaktor aberkannt und als falsche Annotation eingestuft. Aus diesem Grund wurde er in dieser Arbeit nicht näher betrachtet (Friedhelm Pfeiffer, Martinsried, persönliche Mitteilung).

Da HVO_1946 essenziell ist, wurde die Überexpression im Wildtyp durchgeführt. Bei der Überexpression von alF1 wurde ein starker Phänotyp der Mutante in Form von sehr viel schlechterem Wachstum nachgewiesen. Dieses Phänomen konnte auch von Ivanov und Kollegen im Jahre 2010 bei der Überexpression von eukaryontischem elF1 aus humanen HEK- 
293T Zellen dokumentiert werden. Dabei findet eine autoregulatorische Repression in Form einer negative Rückkopplung des elF1 statt. Daraus folgt, das aufgrund des Überangebotes an elF1 sich der Translationsinitiationsfaktor selbst hemmt (Ivanov et al., 2010).

In Eukaryonten wird elF1 als „Gatekeeper“ beschrieben. Bei der Erkennung des AUG-Codons als Startcodon, wird elF1 freigesetzt. Dies bewirkt die Hydrolyse von elF2-gebundenem GTP. Es folgt die Freisetzung von Pi von elF2, die von der Dissoziation des elF1 abhängig ist (Algire, Maag and Lorsch, 2005).

Für Archaeen wurde in Pyrococcus abyssi ( $P$. abyssi) mittels Cryo-EM bewiesen, dass alF1 und alF2 ebenfalls Kontakte in ihren Strukturen aufweisen. Einer dieser Bereiche umfasst den Nukleotid-Zustand kontrollierenden Switch. Dabei besitzt die Pi-Bindung von e/alF2 eine stabilisierende Wirkung auf den Kontakt der Switch-Regionen von alF2 $\gamma$ und der N-terminalen Domäne von e/alF1. Bei Verlassen des Komplexes von e/alF1 führt das Freilegen dieses Bereiches zur Destabilisierung des $\mathrm{Pi}$, was in der Freigabe und der Dissoziation von e/alF2-GDP endet (Coureux et al., 2016).

In $H$. volcanii konnte mit alF1 keine alF2-Untereinheit co-gereinigt werden. Allerdings konnte alF1 mit alF2 $\alpha$ unter stationären Bindungen mitgereinigt werden. Sonst konnte alF1 mit keinem weiteren Initiationsfaktor mitgereinigt werden.

Bis jetzt wurde in mehreren Studien gezeigt, dass elF1 und alF1 in ihrer Funktion sehr ähnlich sind. In S. solfataricus ist alF1 für die Bindung des ternären Komplex an das Ribosomen zuständig. Darüber hinaus diskriminiert es nicht-kanonische Startcodons und erhöht die Translationseffizienz. Im Vergleich zu Eukaryonten existiert in Archaeen kein long-range-Scanning. Ein Grund dafür ist, es gibt in Archaeen viele Transkripte ohne bzw. nur mit einer kurzen 5'UTR (Hasenöhrl et al., 2006, 2009; Coureux et al., 2016).

Trotz der ähnlichen Funktionen besitzen aIF1 und eIF1/SUI1 eine geringe Sequenzidentität. Sie sind jedoch in ihrer Struktur sehr ähnlich aufgebaut. Die Aminosäuresequenz von alF1 in $H$. volcanii und $M$. jannaschii ist zu 52,6 \% identisch, wobei der C-terminale Bereich von $H$. volcanii verkürzt ist.

Ein multiples Sequenz-Alignment (Visualisierung in Jalview) und zusätzliche Darstellung der Strukturelemente wurde für den Vergleich der alF1/elF1/SUI1/YciH aus den drei Domänen des Lebens angewandt (Abbildung 51).

In elF1 gibt es sechs basische Reste, die unter anderem für die Interaktion von elF1 mit der 18S rRNA dienen. Diese sind Arg33, Arg36, Lys37, Lys56, Lys59 und Lys60. In alF1 von $H$. volcanii sind Arg33, Lys37 und Lys59 vorhanden. Zusätzlich gibt es Arg34. Die Nummerierung orientiert sich hierbei an der Sequenz von SUI1 in S. cerevisiae. In P. horikoshii ist Lys37, Lys56 und Lys59 von den basischen Resten vertreten. Die für die Interaktion mit der 18S rRNA essenziellen Reste Lys37 und Lys59 sind in allen drei Domänen konserviert. Die anderen drei basischen Reste Arg36, Lys56 und Lys60 sind in H. volcanii durch Gly37, Ser58 und Ser62 ersetzt. Die Aminosäurereste (Asp71, Glu73 und Glu76), die in Eukaryonten wie S. cerevisiae 
den azidischen Loop bilden, sind in alF1 nicht vorhanden. In Eukaryonten ist er für die Bindung an das Ribosom wichtig (Gogoi and Kanaujia, 2018; Monestier et al., 2018). Dennoch konnte in der Cryo-EM in P. abyssi von Monestier und Kollegen 2018 gezeigt werden, dass alF1 ähnlich wie sein eukaryontisches Homolog an das Ribosom bindet. Dabei sind die Aminosäuren Arg34, Tyr35 und Lys37 involviert (Monestier et al., 2018).

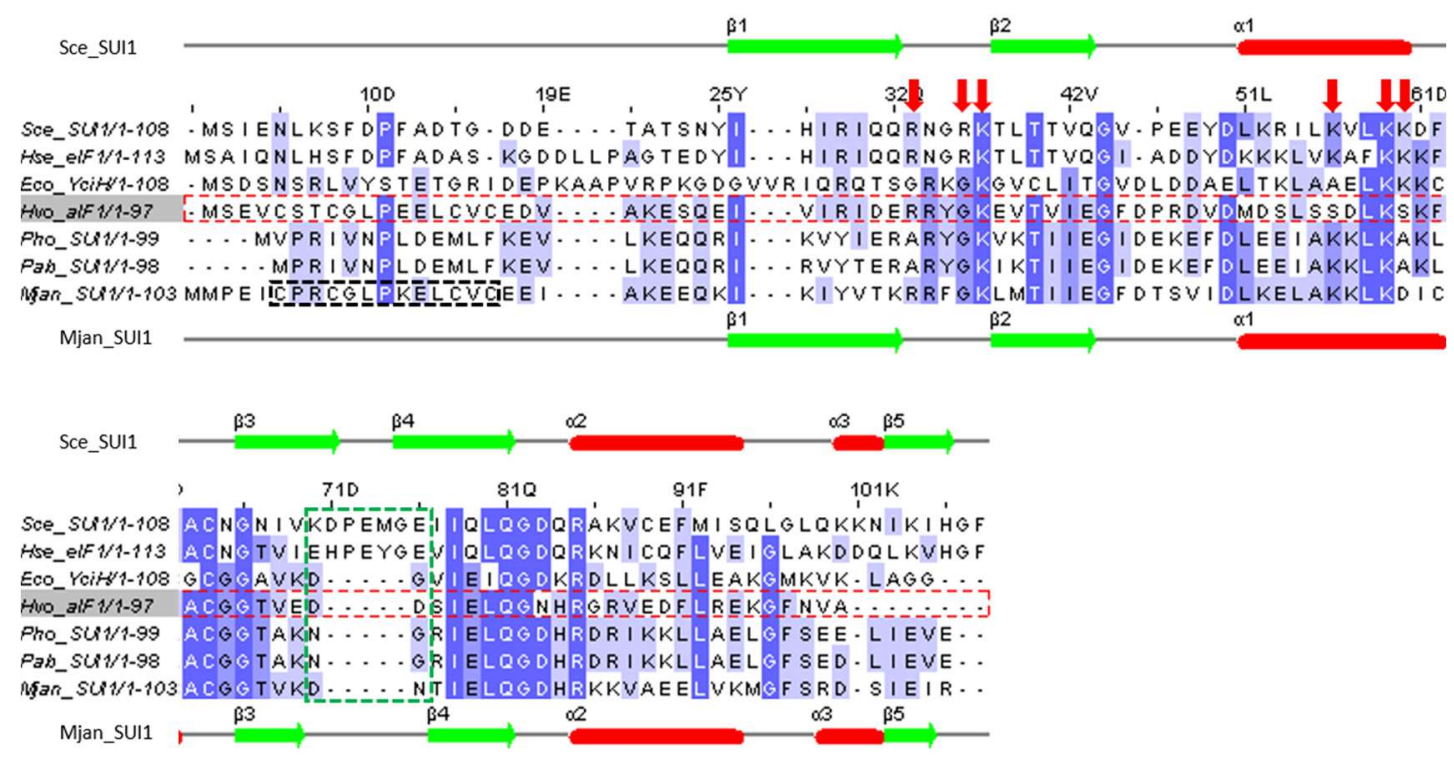

Abbildung 51: Sequenz-Alignment alF1/elF1/SUI1/YciH (modifiziert nach (Gogoi and Kanaujia, 2018))

Ein multiples Sequenz-Alignment mit Visualisierung in Jalview und zusätzliche Darstellung der Strukturelemente von S. cerevisiae (SUI1, P32911), H. sapiens (elF1, P41567), E. coli (YciH, P08245), H. volcanii (alF1, D4GTH5), P. horikoshii (SUI1, P58193), P. abyssi (SUI1, Q9V1U3) und Methanocaldococcus jannaschii (SUI1, Q57902). Die schwarze Box umrahmt das Zinkbinde-Modul. Die roten Pfeile markieren die basischen Reste, die an der Interaktion zwischen elF1 und der 18S rRNA beteiligt sind. Die grüne Box umrahmt die in elF1 konservierten sauren Reste. Die Struktur von SUI1 aus S. cerevisiae und M. jannaschii zeigen die $\beta$-Strands und $\alpha$-Helices.

Monestier und Kollegen konnten 2018 zeigen, dass die alF1-N-terminale Domäne eine Zinkbinde-Modul in 60\% der alF1-Sequenzen in Archaeen besitzen (Abbildung 51). In Eukaryonten ist das Modul nicht vorhanden (Monestier et al., 2018). Dies könnte den Unterschied zwischen dem Scanning in Archaeen und Eukaryonten erklären. In Eukaryonten findet das Scanning über einen großen Bereich und in Archaeen ein lokales Scanning statt.

In $P$. abyssi und $S$. solfataricus konnte für alF1 ein stabilisierender Effekt auf einen 30SmRNA-Komplex nachgewiesen werden (Hasenöhrl et al., 2006; Monestier et al., 2018). Dies könnte eine Erklärung für die mit alF1 co-gereinigten $30 \mathrm{~S}$ ribosomalen Proteine sein. In dieser Arbeit konnte mit alF1 auch alF1A-2 mitgereinigt werden. Hier könnte ein Co-Reinigung durch ribosomale Proteine stattgefunden haben. Beide Faktoren sind in Bakterien, Archaeen und Eukaryonten stark konserviert. Es binden beide Faktoren an die kleine $30 \mathrm{~S}$ ribosomale Untereinheit. Mit dieser 30 S ribosomalen Untereinheit und dem IF2/alF2/elF2 bilden sie den Präinitiationskomplex und sind an der Startcodonwahl beteiligt. 


\subsection{2 alF1A-1 und alF1A-2}

Generell ist der Initiationsfaktor $1 \mathrm{~A}$ in allen drei Domänen des Lebens konserviert. In Bakterien ist er als IF1, in Eukaryonten als elF1A und in Archaeen als alF1A bekannt (Peter Sørensen, Jakob Hedeg, 2001). In H. volcanii gibt es jedoch zwei orthologe Gene, die für alF1A codieren. Dies tritt auch in weiteren Haloferax-Vertretern auf. Beispielsweise in Haloferax larsenii oder Haloferax mucosum (siehe Anhang Abbildung 67).

Die Gene HVO_0136 (alF1A-1) und HVO_A0637 (alF1A-2) in H. volcanii codieren beide für den Initiationsfaktor 1A. Beide Gene konnten einzeln aber nicht gleichzeitig deletiert werden. Dieses Ergebnis spricht dafür, dass sich die beiden Faktoren teilweise in ihrer Funktion ersetzen können (Gäbel et al., 2013). Des Weiteren hat alF1A-1 ein dreifach höheres Expressionslevel als alF1A-2, was unter anderem auf dessen Startcodon GUG zurückzuführen ist (Babski et al., 2016). In der Masterarbeit von Pia Fischer konnte mittels Reportergen-Assay bewiesen werden, dass beide Orthologe eine Rolle bei der Erkennung und Diskriminierung von Transkripten mit dem Startcodon UUG spielen. Dabei wurde das Reportergen DHFR, mit unterschiedlichem Startcodon, sowie mit und ohne $5^{\prime}-\mathrm{UTR}$, in den Deletionsmutanten von alF1A-1 und alF1A-2 verwendet (Pia Fischer, Masterarbeit 2019).

Die beiden Proteine alF1A-1 und alF1A-2 besitzen eine zu $67 \%$ identische Aminosäuresequenz. Ein Sequenz-Alignment des IF1/elF1A/alF1A in den drei Domänen des Lebens sowie alF1A-1 und AIF1A-2 von $\mathrm{H}$. volcanii ist in Abbildung 52 dargestellt. Die für RNA-Bindeproteine typische Oligonukleotid- Bindungsfaltung (OB-Fold) wurde bereits für alle drei Domänen des Lebens in IF1/elF1A/alF1A mittels NMR nachgewiesen (Sette, 1997; Battiste et al., 2000; Li and Hoffmann, 2001).

Die Aminosäure Ala36 ist in M. jannaschii, P. abyssi und E. coli durch Gly36 ersetzt. Jedoch bleiben die Eigenschaften der getauschten Aminosäuren gleich (Abbildung 52, rote Pfeil). Die Nummerierung orientiert sich hierbei an der Sequenz von elF1A von S. cerevisiae. Die grüne Box zeigt die in Eukaryonten konservierte N-terminale Sequenz mit mehreren basischen Resten. Sie werden für die Interaktion von elF1 mit elF5 benötigt. In Archaeen und Bakterien ist die N-terminale Sequenz sowie der Faktor elF5 nicht konserviert (Luna et al., 2013). Dennoch besitzen Archaeen im Vergleich zu Bakterien einen verlängerten N-terminalen Bereich. AuBerdem konkurriert in Eukaryonten elF5 mit elF1A um die Bindung an elF5B (Luna et al., 2013; Lin et al., 2018).

Eukaryonten und Archaeen besitzen N-terminal einen flexiblen Loop und C-terminal eine a-Helix. Beide Strukturbereiche existieren im bakteriellen IF1 nicht (Li and Hoffmann, 2001). Dies trifft auch auf $H$. volcanii zu. Der Vergleich der Strukturen von elF1A/alF1A/IF1 ist in Abbildung $52 \mathrm{C}$ dargestellt. Eine dritte $\alpha$-Helix ist sowohl in elF1A bei $H$. sapiens als auch bei alF1A von $P$. abyssi bekannt.

In Eukaryonten interagiert das C-terminale Ende von elF1A mit elF5B. Ferner beinhaltet die-

ser Bereich saure Reste (Allen and Frank, 2007; Lin et al., 2018). Die beiden schwarz 
umrahmte Kästen zeigen die Helix 1a und den Loop L45. Sie sind sowohl für die Interaktion des C-terminalen Endes von elF1A mit sich selbst, aber auch für die Interaktion von elF1A mit dem Ribosomen zuständig (Yu et al., 2009; Nag et al., 2016).

A

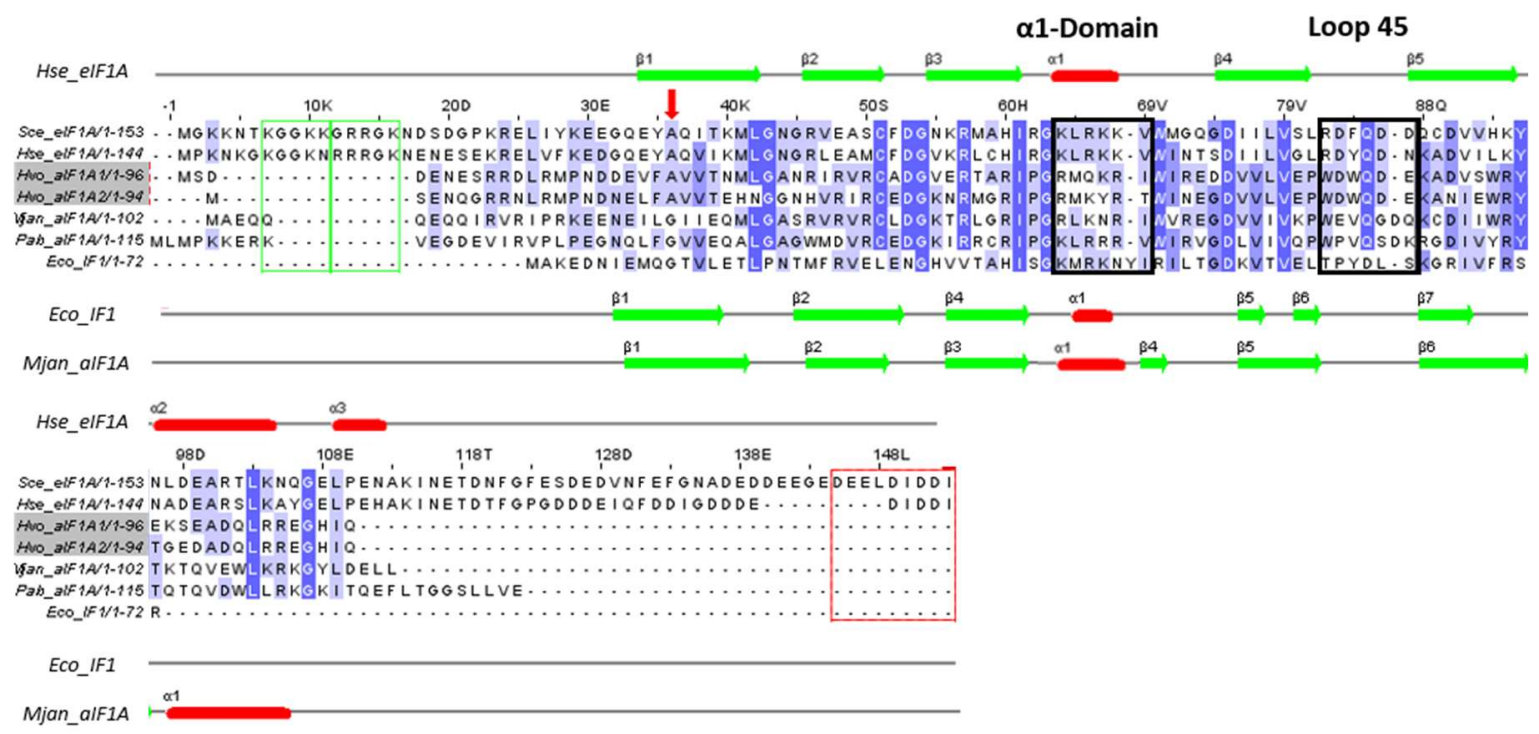

B

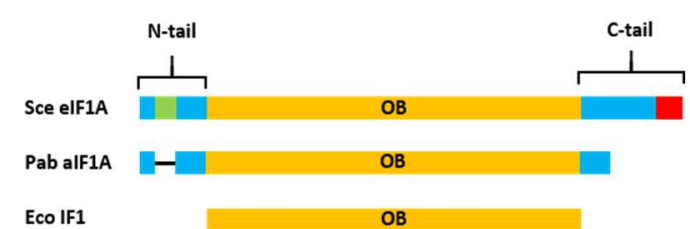

C

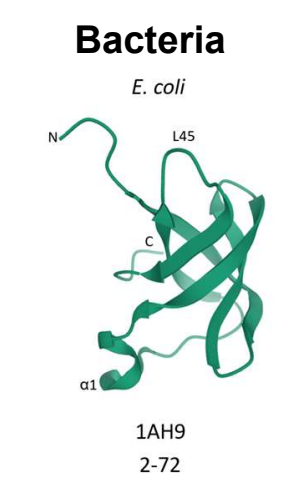

https://www.rcsb.org/3d-view/molstar/1ah9

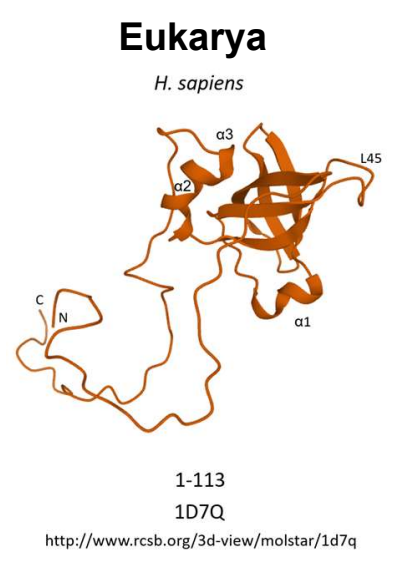

Eukarya

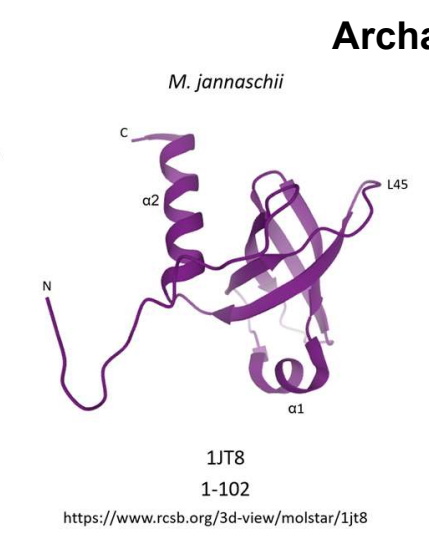

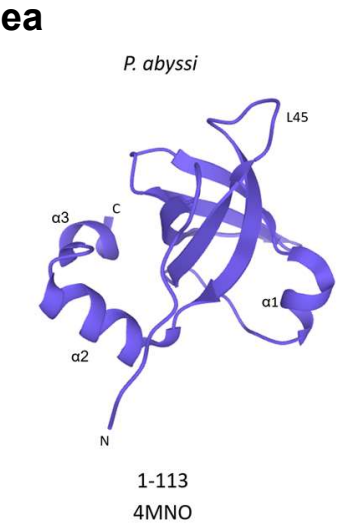

https://www.rcsb.org/3d-view/molstar/4mno

Abbildung 52: Sequenz-Alignment IF1/elF1A/alF1A modifiziert (Li and Hoffmann, 2001; Luna et al., 2013) A. Strukturbasierendes Sequenz-Alignment mittels Clustal Omega visualisiert in Jalview. Dargestellt sind $S$. cerevisiae (elF1A, P38912), H. volcanii (alF1A-1, D4GZ79;alF1A-2, D4GRU5), M. jannaschii (alF1A, Q57887), P. abyssi (alF1A, Q9V138) und E. coli (IF1, P69222). Die Struktur wurde annotiert von E. coli, S. cerevisiae und $M$. jannaschii. Die grüne Box hebt die basischen Reste und die rote Box die azidischen Reste hervor. Beides ist in Eukaryonten konserviert. Die beiden schwarz umrahmten Boxen stehen für die a1 Domäne und den Loop45. Unter anderem interagieren sie mit dem C-Terminus. B. Abgleich des N- und C-Terminus der IF1/elF1A/alF1A. C. Strukturen des IF1/eIF1A/alF1A mit Positionen der $\alpha$-Helices und L45.

Für die weitere Charakterisierung der beiden alF1A codierenden Gene in $\mathrm{H}$. volcanii wurden diese mit einem $\mathrm{N}$-terminalen His-Tag versehen und überexprimiert. Jedoch konnte das 
annotierte Gen für alF1A-1 zunächst weder mit einem N-terminalen noch mit einem C-terminalen His-Tag überexprimiert werden. Nach Überprüfung der RNA-Seq und DNA-Seq-Daten, konnte für alF1A-1 (HVO_0136) ein um 83 nt downstream verlängertes Gen festgestellt werden (Abbildung 21). In dieser Arbeit wurde der Abschnitt als 3'-UTR bezeichnet. Mit dieser Sequenz war es letztendlich möglich alF1A-1 erfolgreich zu exprimieren. Das ist bemerkenswert, da in S. cerevisiae elF1A mit elF5B unter anderem über den OB-Fold interagieren können (Nag et al., 2016). Diese Interaktion wäre mit der 3'-UTR zwischen alF1A und alF5B in H. volcanii ebenfalls möglich.

In Eukaryonten interagiert elF1A mit dem N-terminalen Bereich unter anderem mit elF2 (Olsen et al., 2003; Nag et al., 2016). Jedoch konnte in $H$. volcanii mit alF1A-1 und alF1A-2 keine Untereinheit des alF2 mitgereinigt werden.

Für alF1A-2 konnte die Überexpression ebenfalls durchgeführt werden. Auf dem Coomassiegefärbten SDS-Gel konnte alF1A-2 nur schwach visualisiert werden. Aufgrund dessen und des Gewichts von alF1A-2-Proteins wurde anschließend ein Tricin-Gel angefertigt. Die Bande auf Höhe des alF1A-2-Proteins erschien ebenfalls recht schwach. Dennoch konnte alF1A-2 in der MS-Analyse identifiziert und alF2 $\delta-1$ und alF5B, wie bei alF1A-1, mitgereinigt werden. Zwar konnte in dieser Arbeit mit alF1 der Initiationsfaktor alF1A-1 mitgereinigt werden, dies konnte umgekehrt aber nicht nachgewiesen werden. Weder mit alF1A-1 noch mit alF1A-2 konnte alF1 co-gereinigt werden.

Bei den Wachstumsversuchen unter optimalen Bedingungen in Komplexmedium bei $42{ }^{\circ} \mathrm{C}$ wuchs die Überexpression des alF1A-1 mit 3'-UTR besser als die Kontrolle mit dem Leerplasmid. Bei der Überexpression von alF1A-2 konnte erst in der spätexponentiellen Phase ein besseres Wachstum im Vergleich zur Kontrolle mit Leerplasmid ermittelt werden.

Für alF1A-2 wurde im Rahmen der Auswertung ebenfalls die RNA-Seq- und DNA-Seq-Daten herangezogen. Dabei konnte auch ein verlängertes Transkript in der Transkript-Vorhersage für alF1A-2 (tif1A2) festgestellt werden (Abbildung 53).

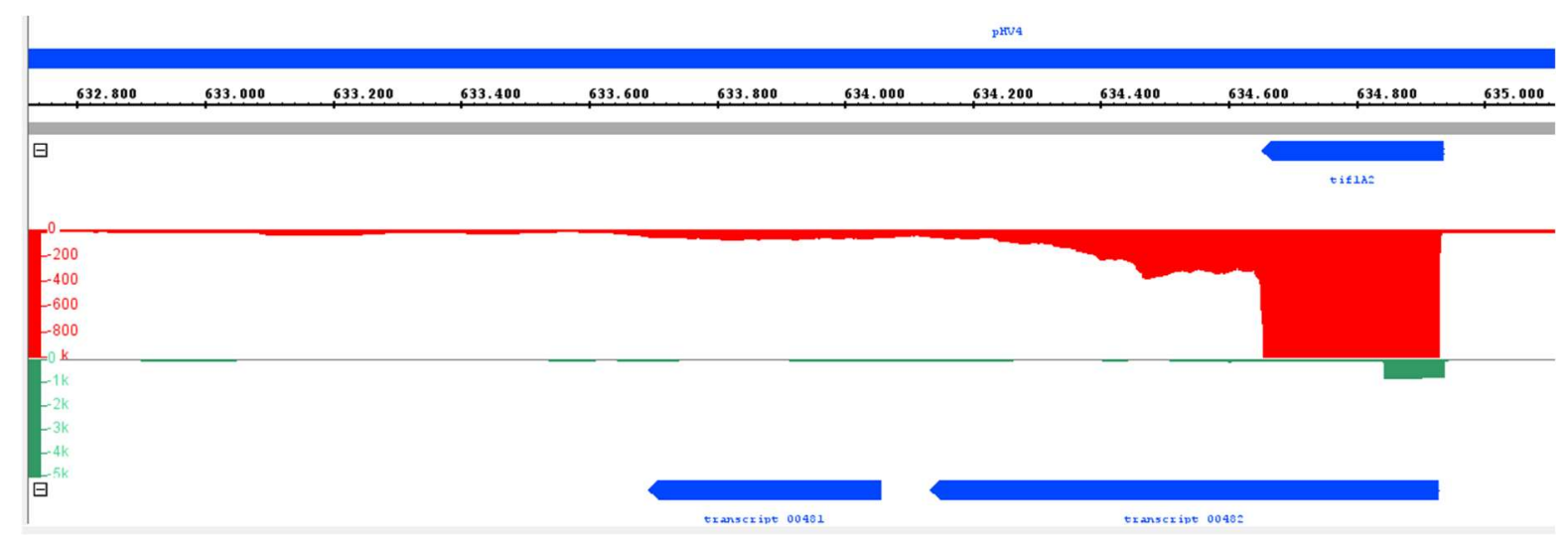

Abbildung 53: DNA- und RNA-Seq-Daten des alF1A-2 (HVO_A0637)

Das Gen alF1A-2 bzw. tif1A2 in blau, das Transkriptionslevel in rot und der Transkriptionsstart in grün auf dem Plasmid pHV4. Transkript 00402 ist das Ergebnis der Transkript-Vorhersage für alF1A-2 (634.651-633.571). 
In Eukaryonten wird angenommen, dass das C-terminale Ende von elF1A an der Rekrutierung und Stabilisierung des ternären Komplexes beteiligt ist. Es wurden Substitutionen in diesem Bereich identifiziert, die die Rate der Bindung des ternären Komplexes an die 405 ribosomale Untereinheit in vitro reduziert, ohne jedoch die 40S-Bindung durch die mutierten Faktoren selbst zu beeinflussen (Fekete et al., 2005, 2007; Saini et al., 2009).

Wie von Hasenöhrl und Kollegen in Archaeen für S. solfataricus beschrieben, könnte auch in $H$. volcanii alF1A-1 bei der Bindung des ternären Komplexes an die kleine ribosomale Untereinheit beteiligt sein (Hasenöhrl et al., 2009).

Um die exakte Länge der Transkripte von HVO_0136 und HVO_A0637 genau zu bestimmen, könnte als nächster Schritt eine 3'-Enden-Bestimmung stattfinden. Des Weiteren könnte ein Northern Blot der mRNA im Wildtyp mit einer Sonde gegen das Transkript verwendet werden, um die genaue Größe zu bestimmen. Eine andere Möglichkeit auf Proteinebene wäre, einen His-Tag N-terminal in die genomische DNA vor den jeweiligen Initiationsfaktor zu klonieren, anschließend über eine Aufreinigung das native Protein mit His-Tag zu gewinnen und die Länge des Proteins in der MS zu bestimmen. 


\subsection{3 alF2}

In Archaeen und Eukaryonten ist der trimere Translationsinitiationsfaktor alF2/elF2 vertreten. Dabei besteht in beiden Domänen des Lebens aus den drei Untereinheiten $\alpha, \beta$ und $\gamma$. In Eukaryonten sind alle drei Untereinheiten unabdingbar, wohingegen in Archaeen einheitlich nur alF2 $\gamma$ essenziell ist (Tabelle 56).

In $H$. volcanii gibt es zwei orthologe Gene (alF2 $\beta-1$ und alF2 $\beta-2)$, die für die $\beta$-Untereinheit codieren. Sie konnten einzeln deletiert. Es konnte aber keine Doppeldeletionsmutante erstellt werden. In der Deletion von alF2 $\beta$-2 wurde alF2 $\beta$-1 um das 10-fache hochreguliert (Gäbel et al., 2013). Des Weiteren besitzt alF2 $\beta-1$ ein siebenfach geringeres Expressionslevel als alF2 $\beta$ 2 (Babski et al., 2016). Im Anhang in Abbildung 68 ist das Sequenz-Alignment der beiden alF2 $\beta$-Untereinheiten dargestellt. Die Sequenzen sind nur zu $39 \%$ identisch.

\subsubsection{1 alF2a}

In $H$. volcanii konnte alF2 $\alpha$ deletiert werden und wurde daher als nicht essenziell eingestuft. Er zeigte jedoch unter allen getesteten Wachstumsbedingungen starke Phänotypen, die sich in sehr viel schlechterem Wachstum äußerten (Gäbel et al., 2013).

In dieser Arbeit zeigte die Überexpressionsmutante von alF2 $\alpha$ zu Beginn ein sehr viel schlechteres Wachstum als die Kontrolle mit dem Leerplasmid. Ab 24 h, in der spätexponentiellen Phase, wuchs die Überexpressionsmutante besser als die Kontrolle mit Leerplasmid.

Im Genom von $H$. voclanii liegt das Gen des alF2 $\alpha$ (tif $2 \alpha$ ) in einem Operon downstream von rpS27e (HVO_0700), rpL42e (HVO_0701) und upstream von nop10 (HVO_0698). Die RNAund DNA-Seqdaten sind hierfür in Abbildung 54 gezeigt. Dieses Cluster enthält Proteine für die Translation und die Ribosomenbiogenese. Es ist sowohl in Archaeen als auch in Eukaryonten konserviert (Berthon, Cortez and Forterre, 2008).

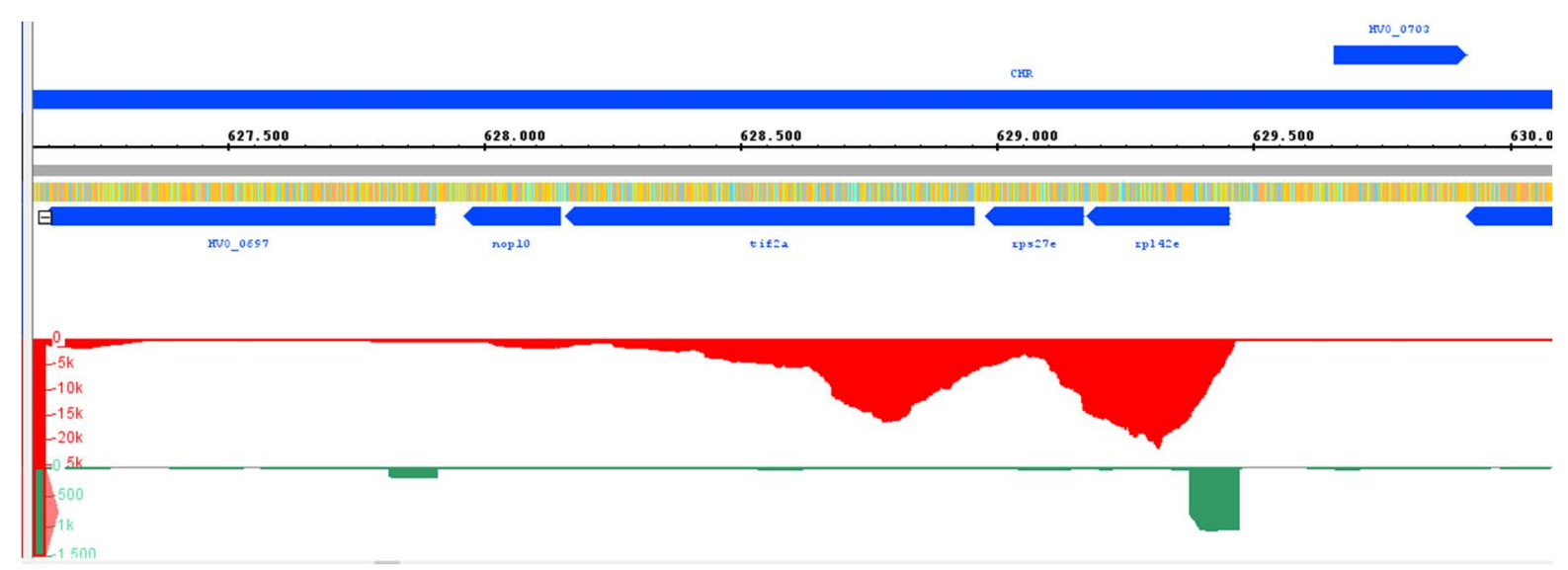

Abbildung 54: DNA- und RNA-Seq-Daten des aIF2a (HVO_0699)

Die Gene sind in blau, das Transkriptionslevel in rot und der Transkriptionsstart in grün dargestellt. Das Gen alF2 $\alpha$ bzw. tif2a liegt als drittes Gen im Operon auf dem Reverse-Strang. 


\section{Diskussion}

\subsection{Vergleich der stationären und exponentiellen Kultur von alF2 $\alpha$}

Bei den Wachstumsuntersuchungen unter optimalen Bedingungen, zeigte die Deletionsmutante des alF2 $\alpha$ ein sehr viel schlechteres Wachstum im Vergleich zum Wildtyp. Die Überexpression im Deletionsstamm hingegen verhielt sich ähnlich zur Deletionsmutante mit Leerplasmid. Jedoch zeigte die Überexpressionsmutante ein besseres spätexponentielles Wachstum. Um diese Beobachtung weiter zu untersuchen, wurden die Affinitätsaufreinigungen des alF2 $\alpha$ nicht nur in der exponentiellen, sondern auch in der stationären Phase untersucht.

Unterschiede zwischen den beiden Ansätzen zeigten sich bereits in den Elutionsfraktionen auf den SDS-Gelen. Zusätzlich zur MS-Analyse der Elutionsfraktionen wurden deshalb einzelne Banden ausgeschnitten (Abbildung 24). Für die Bestimmung der enthaltenen Proteine wurden sie anschließend in der MS analysiert. Anhand des höchsten PSM-Wertes und der Abundanz wurden die identifizierten Proteine für die einzelnen Banden eingeordnet. Es war jedoch schwierig ein eindeutiges Protein zu bestimmen. Bei drei der fünf Banden, die nicht auf der kDa-Höhe von alF2 $\alpha$ lagen, konnte alF2 $\alpha$ mit den höchsten PSM-Werten und der höchsten Abundanz identifiziert werden. Dies ist unter anderem auf das Überladen des SDS-Gels und der Überexpression zurück zu führen. Wegen dieser beiden Gründe wurden für die Banden vier, sechs und sieben zwei Proteine angegeben. Für die beiden letzteren Banden konnte auf gleicher Höhe das gleiche Protein identifiziert werden. Dabei handelt es sich um die Molybdopterin Adenylyltransferase. Dieses Protein wurde allerdings auch bei einer der Kontrollen co-gereinigt (6x-His-DHFR Tabelle 51), weshalb es als unspezifisches Protein ausgeschlossen wurde.

Die in den Banden identifizieren Proteine konnten auch in den MS-Analysen der Elutionsfraktionen für alF2 $\alpha$-exp und alF2 $\alpha$-stat nachgewiesen werden. Es konnten keine Proteine in den Banden identifiziert werden, die nicht in beiden Ansätzen zugegen waren. Unterschiede zwischen den beiden Ansätzen alF2 $\alpha$-exp und alF2 $\alpha$-stat gab es dennoch. Sie zeigten sich anhand der MS-Analysen der Elutionsfraktionen im direkten Vergleich (Tabelle 57). Nach der MS-Auswertung konnten für die exponentielle Kultur alF2 $\alpha$-exp 35 und für die stationäre Kultur alF2 $\alpha$-stat 79 Proteine berücksichtigt werden. Mit Ausnahme von rpL10 (HVO_2756) konnten die in der exponentiellen Phase identifizierten Proteine auch in der stationären Phase nachgewiesen werden.

Das rpL10 wird wegen seiner Homologie in Eukaryonten auch P0 genannt und ist Bestandteil des P-Stiels. Es ist ein universelles ribosomales Protein, das in allen drei Domänen des Lebens vertreten ist (Mitroshin, Garber and Gabdulkhakov, 2016). Dabei ähnelt der archaeale und eukaryontische P-Stiel dem L12-Stiel in Bakterien. Die beteiligten Proteine sind jedoch Homologe zu Eukaryonten (Uchiumi, Wahba and Traut, 1987; Maki et al., 2007).

In Archaeen besteht der P-Stiel aus den ribosomalen Proteinen rpL11, rpL10/P0, sowie rpL12/P1. Er spielt eine wichtige Rolle in der Interaktion des Ribosom mit GTP-gebundenen 
Translationsinitiationsfaktoren. Unter anderem bildet rpL10 mit rpL12 in Archaeen ein starken Komplex und interagiert mit der rRNA (Casiano, Matheson and Traut, 1990).

In $H$. volcanii konnte rpL10/P0 nicht nur mit alF2 $\alpha$-exp, sondern auch mit alF1, alF2Bס und dem elF4A-homolog mitgereinigt werden. Hingegen konnte das Protein rpL12/P1 (HVO_2755) mit keinem Initiationsfaktor mitgereinigt werden. Der rpL11 (HVO_2758) wurde nur in den FPLCs von alF2 $\alpha$ nachgewiesen werden. Dies beschränkte sich auf die Fraktionen in der Schulter und vor der Peak-Spitze.

In H. volcanii scheinen HVO_2755 bis HVO_2757 in einem Operon und rpL11 (HVO_2758) in direkter Nachbarschaft zu liegen. In den meisten Archaeen sind ribosomale Proteine, ähnlich wie in Bakterien, in Operons organisiert. Dies gilt auch für rpL1 (Ramírez et al., 1993). Unter anderem konnte bei Methanococcus vannielii bei der Synthese der ribosomalen Proteine des rpL1-Operon eine regulatorische Funktion von rpL1 nachgewiesen werden (Kraft et al., 1999).

Unter stationären und exponentiellen Kulturbedingungen konnten nach der Affinitätsaufreinigung und MS-Analyse alF2 $\beta-2$ und alF2 $\gamma$ mitgereinigt werden.

Unter stationären Bedingungen konnte als weiterer Translationsinitiationsfaktor, alF1 nachgewiesen werden. Coureux und Kollegen beschrieben 2016 für $P$. abyssi die Interaktion zwischen alF2 und alF1, anhand der Cryo-EM-Struktur des Präinitiationskomplexes. Jedoch findet die Interaktion zwischen der y-Untereinheit von alF2 statt (Coureux et al., 2016). Grund für die Co-Reinigung von alF1 mit alF2 $\alpha$ könnte dem zu Folge an der Interaktion mit alF2y liegen. In S. cerevisiae ist elF1 an der Startcodonwahl beteiligt und besitzt eine autoregulatorische Funktion in der Translationsinitiation (Cheung et al., 2007; Ivanov et al., 2010).

Insgesamt konnten 45 weitere Proteine in der MS-Analyse der stationären Kultur identifiziert werden. Zum Einen für die Translation alF1 (HVO_1946). Zum Anderen für die Transkription TFIIB (Transcription initiation factor IIB; HVO_1478) und Nob1 (HVO_1965). Die Proteine konnten in keiner weiteren Aufreinigung von Initiationsfaktoren nachgewiesen werden.

TFIIB wird in Archaeen und Eukaryonten für die Transkriptionsinitiation mit RNAP-II benötigt. In Archaeen ist TFIIB ferner an der Bindung eines TATA box Bindeproteins (TBP) an die Promotorbox-A (TATA-box) beteiligt. Des Weiteren ist er für die Rekrutierung der RNAP- II und die Bildung des Transkriptions-Präinitiationskomplexes zuständig. Dieser besteht aus DNA, TBP und TFIIB (Thomm, 1996; Perez-Rueda and Janga, 2010). In H. volcanii sind zwölf TFIIB annotiert. Aus dieser TFIIB-Familie konnte nur HVO_1478 ausschließlich in der stationären Phase von alF2 $\alpha$ co-gereinigt werden.

Nob1 ist in Eukaryonten sowie in Archaeen vertreten. Unter anderem ist er in Hefe an der Reifung der kleinen ribosomalen Untereinheit beteiligt. Dabei spaltet Nob1 im pre-rRNA-Processing das Intermediat 20S rRNA an der D-Stelle, um die 18S rRNA zu erhalten (Lamanna and Karbstein, 2009). In P. horikoshii konnte für Nob1 die effiziente und manganabhängige 
Spaltung von RNA-Substraten nachgewiesen werden. Die RNA-Substrate müssen dafür eine

D-Stelle der pre-rRNA enthalten (Veith et al., 2012).

In der Halobacteriaceae liegt Nob1 benachbart zu alF5B. Dabei liegt alF5B auf dem Reverse-Strang. Dies ist auch in H. volcanii (Nob1 HVO_1965; alF5B HVO_1963) der Fall. Das Gen HVO_1964, welches für ein PRC domain protein codiert, liegt zwischen den beiden Genen. Genau wie alF5B konnte das PRC-Domain-Protein ebenfalls im exponentiellen und stationären Ansatz identifiziert werden. Ob hier eine Regulation zwischen den einzelnen Genen vorliegt, konnte in dieser Arbeit nicht geklärt werden.

\subsection{Crosslinking von alF2 $\alpha$}

Das Crosslinking von alF2 $\alpha$ erfolgte mit verschiedenen Formaldehyd-Konzentrationen. Mit einer Konzentration von 0,8 \% und 1,2\% Formaldehyd konnten am meisten Proteine auf dem SDS-Gel mittels Coomassie visualisiert werden. Daher wurden die beiden Ansätze erneut auf ein $8 \%$ SDS-Gel aufgetragen. Dabei sollten die Banden in der oberen Hälfte des Gels besser aufgetrennt werden. Es zeigten sich einzelne Banden, die im optischen Vergleich ohne Formaldehyd nicht auf dem Coomassie-gefärbten SDS-Gel zu erkennen waren. Diese Banden wurden ausgeschnitten und in der MS analysiert.

Der identifizierte Transkriptionsregulator HVO_0163 konnte bereits in der exponentiellen und stationären Aufreinigung nachgewiesen werden. Das Gleiche gilt für die Vitamin B12-dependent ribonucleotide reductase (HVO_2452).

In einer weiteren Bande konnte der Elongationsfaktor aEF2 (HVO_0356) mit der höchsten Abundanz bestimmt werden. Dieser Elongationsfaktor konnte mit der Ausnahme von drei alFsbzw. -Untereinheiten mit allen alFs mitgereinigt werden.

Die YgfD family GTPase (HVO_0831) konnte in Bande 17 als Protein mit der höchsten Abundanz nachgewiesen werden. Dieses Protein erschien ebenfalls in der Kontrolle 6xHisDHFR und wurde deshalb als Interaktionspartner ausgeschlossen.

Mittels Crosslinking und Analyse einzelner Banden aus dem SDS-Gel konnten keine weiteren Interaktionspartner von alF2 $\alpha$ nachgewiesen werden. Zu bemerken ist, dass die gesamten Elutionsfraktionen des Crosslinkings nicht in der MS analysiert wurden. Damit wurde nur ein kleiner Teil der co-gereinigten Proteine beim Crosslinking betrachtet. Dennoch konnte bei der Analyse der Banden auch im Crosslinking alF5B als möglicher Interaktionspartner bestätigt werden. 


\subsection{Aminosäuremimikri in alF2 $\alpha$}

In Eukaryonten stellt die Phosphorylierung von elF2 $\alpha$ an Ser51 eine wichtige Rolle in der Translationsregulation dar. Dabei wird elF2-GDP zu einem kompetitiven Inhibitor für elF2B, der an elF2 bindet und das elF2-gebundene GDP mit GTP austauscht. Bei einer Phosphorylierung von elF2 $\alpha$ wird elF2B $\varepsilon$ blockiert, elF2B bleibt gebunden und es findet kein GDP-GTP Austausch statt. Durch diese Phosphorylierung kann elF2 weder neue Met-tRNAi noch an die $40 S$ ribosomale Untereinheit binden und reguliert somit die Translationsinitiation. Dieser Regulationsmechanismus tritt unter Stress oder bei Mangel an Nährstoffen auf. Dabei wird elF2 $\alpha$ durch spezifische Kinasen phosphoryliert (Ron and Harding, 2007; Donnelly et al., 2013; Wek, 2018).

Um die Interaktion in Archaeen zu untersuchen wurde bereits in $P$. horikoshii von Tahara 2004 eine Phosphorylierung an alF2 $\alpha$ in vitro mittels der elF2 $\alpha$ Kinase PKR nachgewiesen (Tahara et al., 2004). Wobei zu bemerken ist, das die Position Ser51 in Eukaryonten aber nicht in Archaeen konserviert ist (Abbildung 28).

Nach Abgleich der Aminosäuresequenzen wurde in $H$. volcanii Ser46 für die Mutationen im Aminosäuremimikri ausgewählt. Um eine Phosphorylierung an alF2 $\alpha$ zu simulieren wurde diese Aminosäure durch Alanin bzw. Asparaginsäure ausgetauscht. Beide alF2 $\alpha-M u t a n t e n$ wurden mit einem His-Tag versehen und im Deletionsstamm von alF2 $\alpha$ überexprimiert. Die Mutante mit Alanin diente dabei als Kontrolle. Beide Varianten wuchsen schlechter als die Variante ohne Mutation. Nach den Affinitätsaufreinigungen und der folgenden MS-Analyse konnte für beide Mutanten alF2 $\alpha$ nachgewiesen werden. Insgesamt konnten nur wenige Proteine auf dem SDS-Gel visualisiert und in der MS identifiziert werden. Bei keiner der beiden Mutanten wurde eine alF2B-Untereinheit co-gereinigt. Durch die geringe Aussagekraft der Ergebnisse konnte in dieser Arbeit der Austausch von GDP-GTP durch alF2B an alF2 und die Phosphorylierung von alF2 $\alpha$, nicht bestätigt werden (Krishnamoorthy and Pavitt, 2001).

Parallel zur Untersuchung der Phosphorylierung in alF2 $\alpha$ wurde nach einer passenden Kinase in $H$. volcanii gesucht. Hierfür wurde die Sequenz von PH0512 in P. horikoshii verwendet. Dabei konnte die Rio2-Kinase (HVO_0569) in H. volcanii identifiziert werden. Sie ist zu $35,5 \%$ identisch mit der alF2 $\alpha-K i n a s e$ in $P$. horikoshii. Auch dieses Protein wurde mit einem His-Tag versehen und überexprimiert, jedoch konnte kein alF2 $\alpha$ mitgereinigt werden (Daten nicht gezeigt). Daher wurde die Rio2-Kinase als Interaktionspartner für alF2 $\alpha$ in $H$. volcanii ausgeschlossen. Da in Eukaryonten mehrere Kinasen existieren die elF2 $\alpha$ phosphorylieren können, besteht auch in $H$. volcanii die Möglichkeit, dass weitere Kinasen in Frage kommen.

In Eukaryonten besitzt elF2Bס eine wichtige strukturelle Funktion. Er ist unter anderem an der Regulation der Translation bei vorliegendem elF2aP zuständig. 2019 konnten Gordiyenko und Kollegen bei S. pombe in vitro die Interaktion von elF2Bס und elF2aP in Helix 58-63 mittels Cryo-EM nachweisen (Gordiyenko, Llácer and Ramakrishnan, 2019). Dies ist ein interessanter Ansatz für die weitere Untersuchung des alF2 $\alpha$ in $H$. volcanii. 
Wie bereits erwähnt ist Ser51 in Archaeen nicht konserviert. Jedoch konnte in $P$. horikoshii alF2 $\alpha \mathrm{P}$ an Ser48 nachgewiesen werden (Tahara et al., 2004).

Ein Ausschnitt des Sequenz-Alignments von alF2 $\alpha /$ elF2 $\alpha$ ist in Abbildung 55A dargestellt. Der grüner Kasten umfasst den Bereich in dem elF2aP (Ser58-lle63) mit elF2Bס̄ in S. cerevisiae interagiert (Gordiyenko, Llácer and Ramakrishnan, 2019).

Im Strukturvergleich (Abbildung 55B) des N-terminalen Bereichs in elF2 $\alpha / a l F 2 \alpha$ zeigt sich bei $P$. abyssi (1YZ6) eine Helix-Struktur. In H. sapiens (1Q8K) hingegen ist dieser Abschnitt ungefaltet (Ito, Marintchev and Wagner, 2004; Yatime et al., 2005). Bei S. solfataricus (3V11) ist die Struktur in diesem Bereich ebenfalls ungefaltet. Des Weiteren besitzt $S$. solfataricus keine alF2B-Untereinheiten (Schmitt et al., 2012).

A

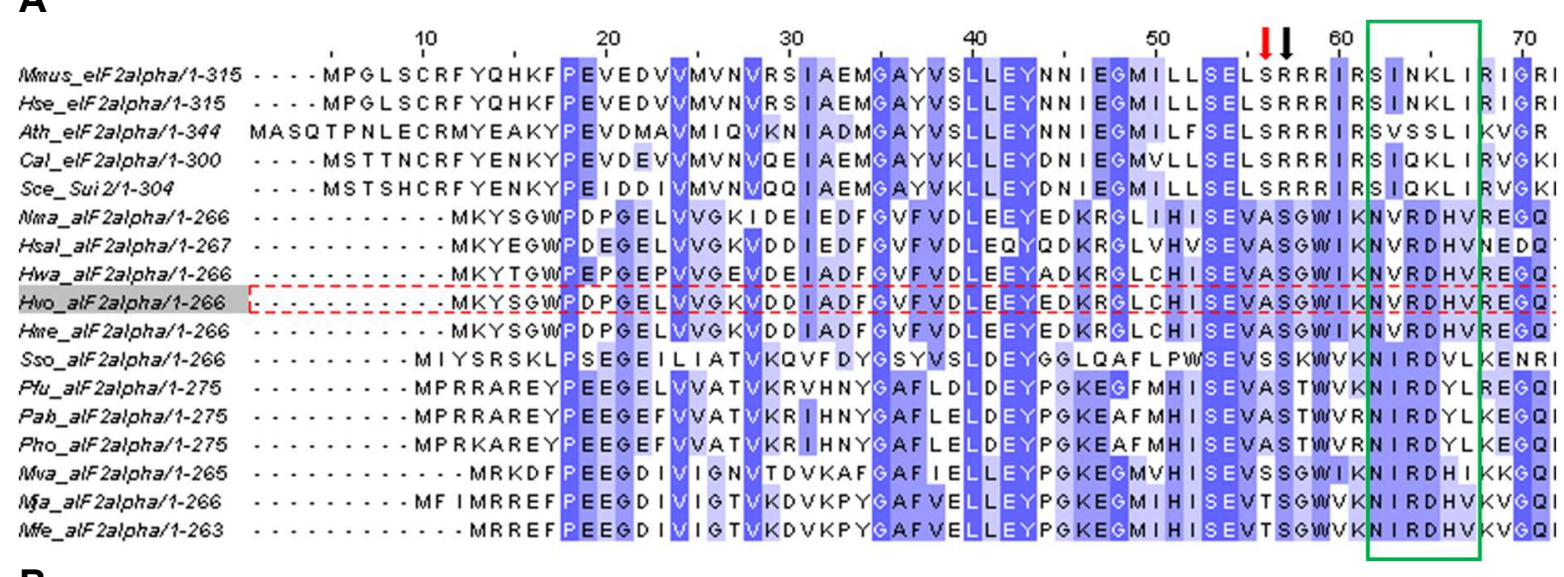

B

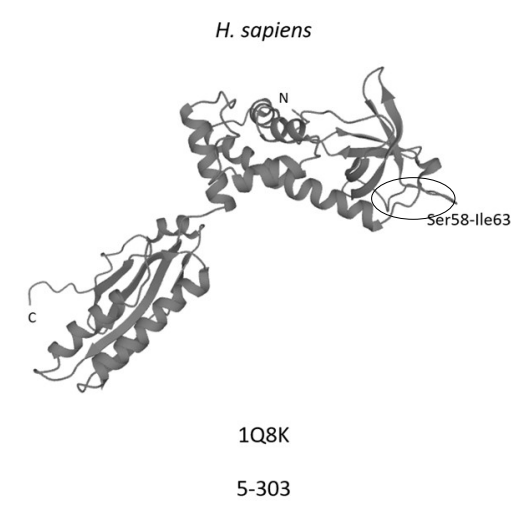

https://www.rcsb.org/3d-view/molstar/1q8k

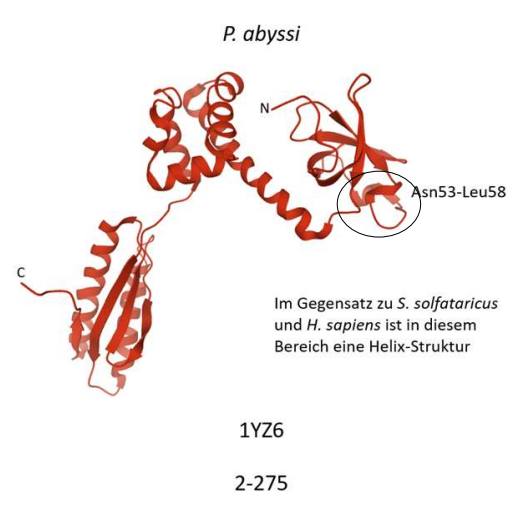

http://www.rcsb.org/3d-view/molstar/1yz6

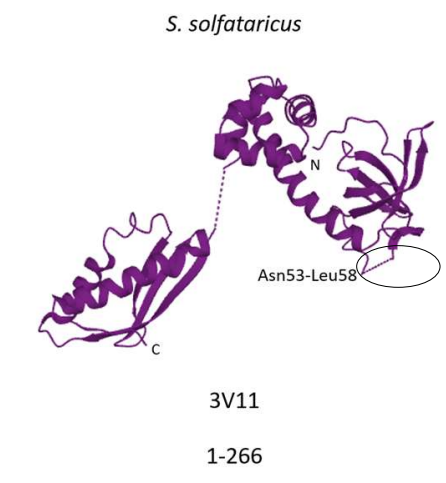

https://www.rcsb.org/3d-view/molstar/3v11

\section{Abbildung 55: Sequenz-Alignment des N-Terminus von alF2 $\alpha /$ elF2 $\alpha$}

A. Im Vergleich wurde in $H$. volcanii in der Aminosäuresequenz von alF2a das Serin an Position 46 gewählt (schwarzer Pfeil). Der rote Pfeil steht für Ser51, das in Eukaryonten phosphoryliert wird. Der Helix 58-63 betreffende Sequenzbereich wurde grün eingerahmt. Das Alignment wurde mittels Clustal erstellt und Jalview visualisiert. Verwendete Aminosäuresequenzen von elF2a/alF2a stammen von $H$. volcanii (Hvo; D4GT46), $H$. mediterranei (Hme; I3R2C2), H. walsbyi (Hwa; Q18KR0), H. salinarum (Hsal; A0A510N505), N. magadii (Nma; D3SY91), M. fervens (Mfe; C7P7V4), M. vannielii (Mva; A6UQZ0), P. abyssi (Pab; Q9V0E4), P. horikoshii (Pho; O58655), S. solfataricus (Sso; Q97Z79), S. cerevisiae (Sce; P20459), C. albicans (Cal; Q5AAU7), H. sapiens (Hsa;P05198), M. musculus (Mmus; Q6ZWX6) und A. thaliana (Ath; Q9SIZ2). B. Strukturen des alF2a/elF2a von H. sapiens, $P$. abyssi und S. solfataricus. Der Helix 58-63-Bereich wurde eingekreist. 


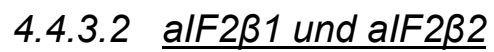

Zwei Gene codieren für alF2 $\beta$ in H. volcanii. Sie besitzen eine Größe von 408 nt (HVO_1678) und 609 nt (HVO_2242). Damit ist das Protein von alF2 $\beta$-2 um 67 Aminosäuren länger als alF2 $\beta$-1. Dies betrifft den C-terminalen Bereich. alF2 $\beta-2$ unterscheidet sich damit auch von vielen anderen Archaeen (Abbildung 56).

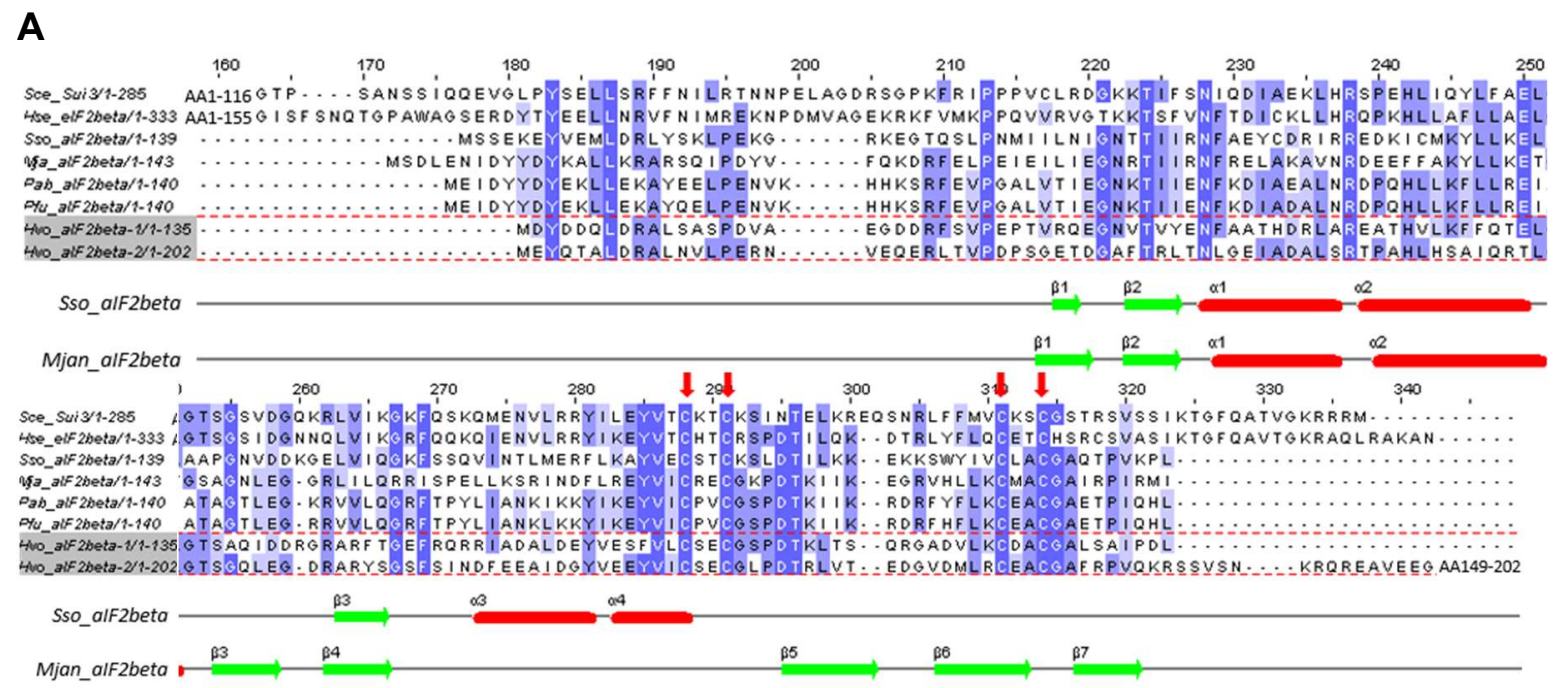

B

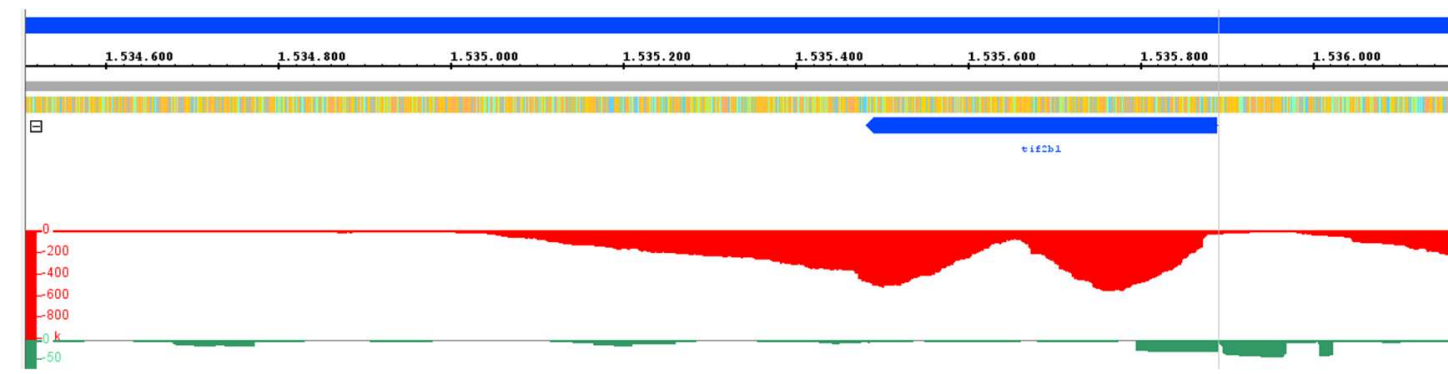

C

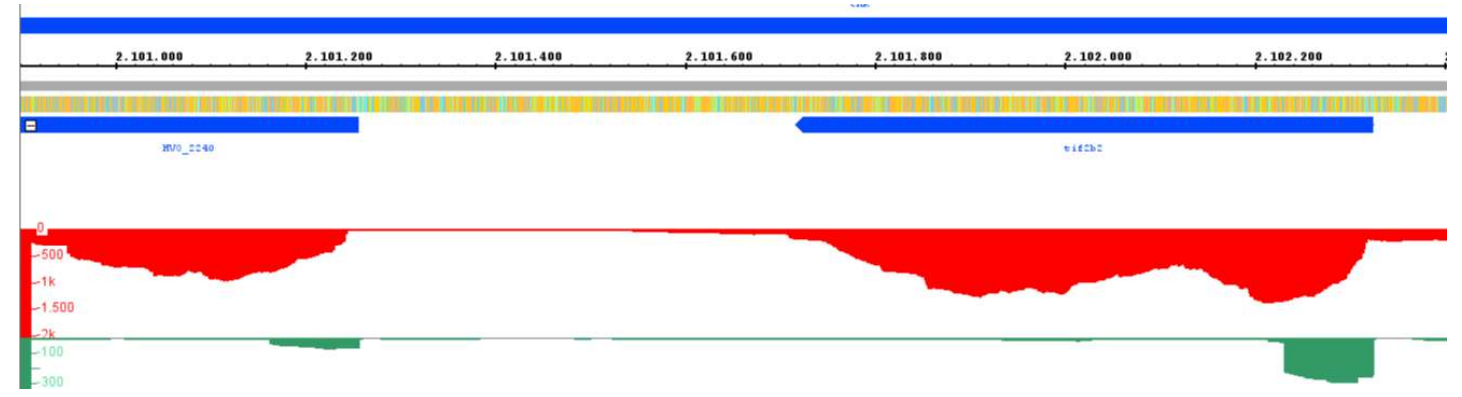

Abbildung 56: Analyse des alF2 $\beta-1$ (HVO_1678) und alF2 $\beta-2$ (HVO_2242)

A. Sequenz-Alignment von S. cerevisiae (P09064), H. sapiens (P20042), S. solfataricus (Q97W59), M. jannaschii (Q57562), P. abyssi (Q9UYR6), P. furiosus (Q8U315) und H. volcanii (D4GZP2, D4GVV8). Die roten Pfeile markieren die Bereiche der Zinkfingerdomäne. Für alF2 $\beta$ von $M$. jannaschii wurde vom $\mathrm{N}$-terminalen und $\mathrm{C}$-terminalen Bereich jeweils eine Struktur analysiert (AA39-89 1k8b; AA 108-143 1k81). B. DNA- und RNA-Seq-Daten von alF2 $\beta$-1 (HVO_1678) und C. alF2 $\beta$-2 (HVO_2242). Die Gene sind in blau, das Transkriptionslevel in rot und der Transkriptionsstart in grün dargestellt. Beide Gene alF2 $\beta-1$ (tif2b1) und alF2 $\beta-2$ bzw. (tif2b2) liegen auf dem Reverse-Strang.

Beim Vergleich der DNA- und RNA-Seq-Daten zeigte sich für alF2 $\beta$-1 eine mögliche 3'-UTR (Abbildung 56B). Sie wurde in dieser Arbeit für die Überexpression nicht berücksichtigt. Jedoch 
könnte sie einen Einfluss auf die Funktion von alF2 $\beta-1$ haben. Deshalb sollte das verlängerte Gen berücksichtigt und bei weiteren Untersuchungen nochmals überexprimiert werden.

In Eukaryonten besitzt das Protein von elF2 $\beta$ einen N-Terminus, mit drei Lysin-reichen Bereichen (Cho and Hoffman, 2002). Dieser existiert in Archaeen nicht. Unter anderem ist der Bereich in Eukaryonten für die Interaktion mit elF5 und elFB2 $\varepsilon$ zuständig. Die beiden Faktoren katalysieren den GDP/GTP-Austausch bzw. die Hydrolyse von GTP (Asano et al., 1999). Beide Faktoren (elF5 und elFB2 $\varepsilon$ ) sind in Archaeen nicht vertreten.

Die eukaryontische IF2 $\beta$-Untereinheit ist sehr viel größer als die archaeale IF2 $\beta$-Untereinheit. Der C-terminale Bereich der elF2 $\beta$-Untereinheit lässt sich annährend mit dem gesamten archaealen Initiationsfaktor alF2 $\beta$ vergleichen. In diesem C-terminalen Bereich ist in Eukaryonten und Archaeen eine 4-C-Zinkfingerdomäne konserviert (Abbildung 56A). Hinzu kommt, dass der $N$-terminale Bereich des archaealen IF2 $\beta$ ebenfalls in beiden Domänen des Lebens konserviert ist (Thompson et al., 2000). In der Strukturanalyse gliedern sich die alF2 $\beta$ in mehrere Bereiche. Diese sind ein ungefalteter N-terminaler Bereich, die Kerndomäne (meist mehrere $\alpha$ - und $\beta$-Domänen) und die C-terminale Zinkfingerdomäne (Gutierrez et al., 2004).

In H. volcanii ist für alF2 $\beta$-2 im C-terminalen Bereich von Aminosäure 145-202 eine TRAMDomäne annotiert. Bei der TRAM-Domäne wird davon ausgegangen, dass sie für die Bindung der tRNA zuständig ist (Anantharaman, Koonin and Aravind, 2001). Unter anderem konnte die Domäne auch in alF2 $\beta$ von Thermoplasma acidophilum nachgewiesen werden. alF2 $\beta$ in $T$. acidophilum ist mit 209 Aminosäuren etwas länger als alF2 $\beta-2$ in $H$. volcanii. Sie besitzen eine zu 33,6 \% identische Aminosäuresequenz (Abbildung 68).

\subsubsection{1 alF2 $\beta-1$}

In $H$. volcanii konnte alF2 $\beta 1$ deletiert werden und wurde deshalb als nicht essenziell eingestuft (Gäbel et al., 2013). Die Deletion in der vorhandenen Mutante konnte mittels Southern Blot nicht mehr nachgewiesen werden. Deshalb wurde die Deletionsmutante neu erstellt. Sie verhielt sich in Komplexmedium wie 2013 von Gäbel und Kollegen beschrieben und wuchs schlechter als der Wildtyp (Gäbel et al., 2013).

Die Überexpressionsmutante wuchs ähnlich wie die Kontrolle in der Deletionsmutante mit dem Leerplasmid. Jedoch zeigte sie im spätexponentiellen Bereich ein besseres Wachstum. Mit alF2 $\beta-1$ konnten nach der Affinitätsaufreinigung nur wenige Proteine auf dem SDS-Gel visualisiert und in der MS-Analyse identifiziert werden. Dennoch konnte mit alF2 $\beta-1$ die alF2 $\alpha-$ sowie die alF2 $y$-Untereinheit mitgereinigt werden.

Auch für alF2 $\beta$-1 konnte anhand der DNA- und RNA-Seq-Daten eine mögliche 3'-UTR identifiziert werden (Abbildung 56B-C). Auch für alF2 $\beta$-1 sollte in diesem Zusammenhang die Überexpression neu durchgeführt werden. 


\subsubsection{2 alF2 $\beta-2$}

Auch alF2 $\beta-2$ konnte deletiert werden. Die Deletion in der vorhandenen Mutante konnte mittels Southern Blot nicht mehr nachgewiesen werden. Deshalb wurde die Deletionsmutante neu erstellt. Sie verhielt sich in Komplexmedium wie 2013 von Gäbel und Kollegen beschrieben (Gäbel et al., 2013).

Die Überexpression wurde anschließend in der Deletionsmutante durchgeführt. Dabei zeigte die Mutante ein sehr viel besseres Wachstum gegenüber der Deletionsmutante mit dem Leerplasmid. Damit unterscheidet sich alF2 $\beta-2$ von alF $2 \beta-1$.

Mit alF2 $\beta$-2 konnten nach der Affinitätsaufreinigung viele mitgereinigte Proteine identifiziert werden. Des Weiteren erschienen zwei sehr starke Banden zwischen 25-30 kDa. Die Banden wurden einzeln ausgeschnitten und in der MS analysiert. Für beide Banden wurde jedoch alF2 $\beta$-2 als Protein identifiziert. Das Erscheinen der Doppelbande ließ sich nicht klären, da für beide Banden alF2 $\beta-2$ als Protein identifiziert wurde. Bei der Denaturierung der Proben wurde im Probenpuffer ß-Mercaptoethanol als Detergens verwendet. Dabei werden die Disulfidbrücken der Proteine aufgebrochen. Da es sich hierbei um eine Gleichgewichtsreaktion handelt, könnte als Alternative ein anderes Detergens, zum Beispiel DTT, verwendet werden.

Mit alF2 $\beta-2$ konnte sowohl alF2 $\alpha$ als auch alF2 $\gamma$ mitgereinigt werden. Als weiterer Initiationsfaktor konnte alF5B mitgereinigt werden. Zusätzlich konnten zwei ribosomale Proteine der kleinen und sieben Proteine der großen ribosomalen Untereinheit zugeordnet werden. Des Weiteren konnte ein IcIR-Transkriptionsregulator (HVO_2108) identifiziert werden. Dieser Transkriptionsregulator konnte jedoch, mit der Ausnahme von alF2 $\gamma$ und alF2Bס-2, auch mit den anderen Initiationsfaktoren mitgereinigt werden.

\subsubsection{3 alF2y}

Die alF2 $\gamma$-Untereinheit bildet den Kern des alF2. Sie enthält die GTP-Bindedomäne und bindet die Met-tRNA. Dubiez und Kollegen konnten 2015 zeigen, dass alF2y GTP hydrolysiert (Dubiez et al., 2015). In seiner Struktur ist elF2y/alF2 $\gamma$ hochkonserviert und eine essenzielle Untereinheit von alF2/elF2. In Archaeen ähnelt alF2 $\gamma$ dem Elongationsfaktor aEF1A bzw. EFTu (Schmitt, Blanquet and Mechulam, 2002). In H. volcanii sind zwei Untereinheiten für aEF1A bzw. aEF1a (aEF1a-1 HVO_0359; aEF1a-2 HVO_2413), sowie ein aEF1a-like Protein (HVO_2575) annotiert. Der Faktor aEF1a-1 konnte mit den Kontrollen DHFR und Leerplasmid mitgereinigt werden. Deshalb wurde er aus allen weiteren Auswertungen ausgeschlossen. Im Sequenzabgleich des alF2 $\gamma$ war die Aminosäuresequenz zu aEF1 $\alpha$-like zu 28,8 \%, mit aEF1 $\alpha-$ 2 zu 25,9 \% und mit aEF1a-1 zu 23,84 \% identisch (Anhang Abbildung 69). Als Razor Peptide werden Proteine bezeichnet die gemeinsame Peptidsequenzen besitzen. Dies kann sich auf die MS-Ergebnisse auswirken. In dieser Arbeit konnten in der MS-Analyse nur aEFs als Razor Peptide untereinander identifiziert werden. alF2 $y$ konnte nicht als Razor Peptid identifiziert 
werden. Somit konnte ein Überschneiden der Aminosäuresequenz der aEFs mit alF2 $\gamma$ ausgeschlossen werden.

In $H$. volcanii ist alF2y eine weitere Untereinheit des alF2, die in einem Operon liegt (Abbildung 57A). Bei den im Operon annotierten Genen handelt es sich um alF2y (HVO_1901), einem putativen RNA-Bindeprotein, das eine PIN-Domäne enthält (HVO_1900), die RNAPU rpoE1 (HVO_1899), den Transkriptionselongationsfaktor spt4/rpoE2 (HVO_1898) sowie einer möglichen GTP-abhängigen Dephospho-CoA-Kinase (HVO_1897). Die unmittelbare Nähe dieser Gene konnte auch bei acht weiteren Vertretern der Halobacteriaceae nachgewiesen werden (Abbildung 57B).

In den meisten Archaeen befindet sich alF2 $y$ in direkter Nachbarschaft zu einem putativen RNA-Bindeproteins, die eine PIN-Domäne enthält. Diese PIN-Domänen gehören zur Überfamilie von Nukleasen. Sie sind sehr vielfältig und spalten Phosphodiesterbindungen von Nukleinsäuren. Dabei können sie RNA oder DNA spalten, aber auch als Endo- oder Exonuklease fungieren (Yang, 2011; Matelska, Steczkiewicz and Ginalski, 2017).

A
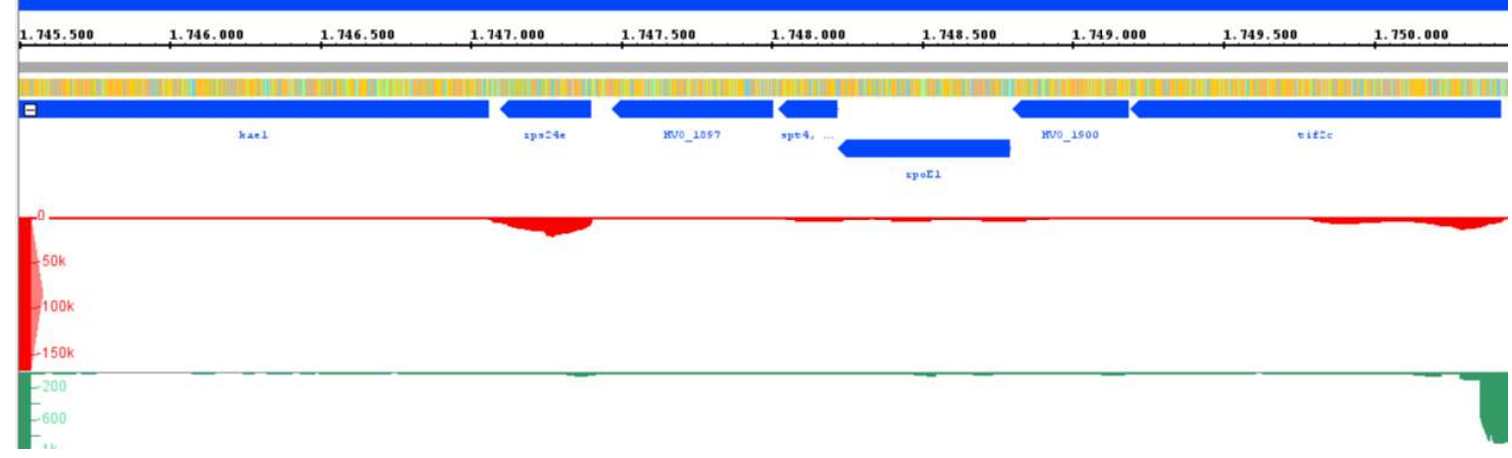

B Halorubrum lacusprofundi

Haloferax volcanii

Haloquadratum walsbyi DSM16790

Halorhabdus utahensis

Natronomonas pharaonis

Natrialba magadii

Haladaptatus paucihalophilus

Halomicrobium mukohataei
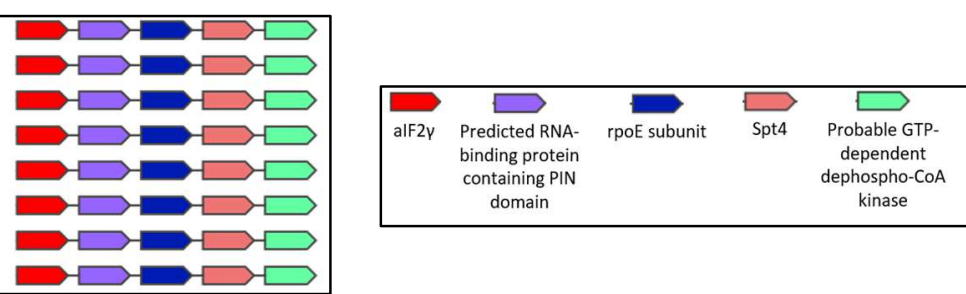

Abbildung 57: DNA- und RNA-Seq-Daten von alF2y (HVO_1901)

A. Die DNA- und RNA-Seq-Daten von alF2y (HVO_1901, tif2c). Er liegt im Operon mit vier weiteren Genen. Die Gene sind in blau, das Transkriptionslevel in rot und der Transkriptionsstart in grün dargestellt. Das Gen für alF2y liegt auf dem Reverse-Strang. B. Die Struktur des Operons konnte auch mittels String bei acht weiteren Vertretern der Halobacteriaceae nachgewiesen werden.

Die Untereinheit alF2 $\gamma /$ elF2 $\gamma$ bildet den Kern des alF2/elF2 und interagiert sowohl mit der $\alpha-$ als auch mit der $\beta$-Untereinheit des alF2/elF2 (Thompson et al., 2000; Schmitt, Blanquet and Mechulam, 2002). Generell besitzt alF2y/elF2y eine GTPase-Aktivität.

Die alF2y-Untereinheit besteht aus drei Domänen (Abbildung 58A). Die erste Domäne enthält sieben $\beta$-Strands und fünf $\alpha$-Helices. In dieser Domäne befindet sich die Nukleotid-Bindetasche. Der Übergang von gebundenem GTP zu GDP und umgekehrt wird von zwei flexiblen Bereichen reguliert. Diese werden Switch1 und Switch2 genannt. Die beiden anderen 
Domänen bestehen aus $\beta$-Barrels (Domäne zwei und drei) und wirken zusammen als starrer Körper (Schmitt, Blanquet and Mechulam, 2002; Roll-Mecak et al., 2004). Bisher wurde von alF2y die Struktur in $P$. abyssi und $S$. solfataricus gelöst. Die Aminosäurensequenz von alF2y in $H$. volcanii und $P$. abyssi sind zu $56 \%$ identisch. Für $H$. volcanii und $S$. solfataricus beträgt die Sequenzidentität von alF2y 48\% (Abbildung 58B).

A
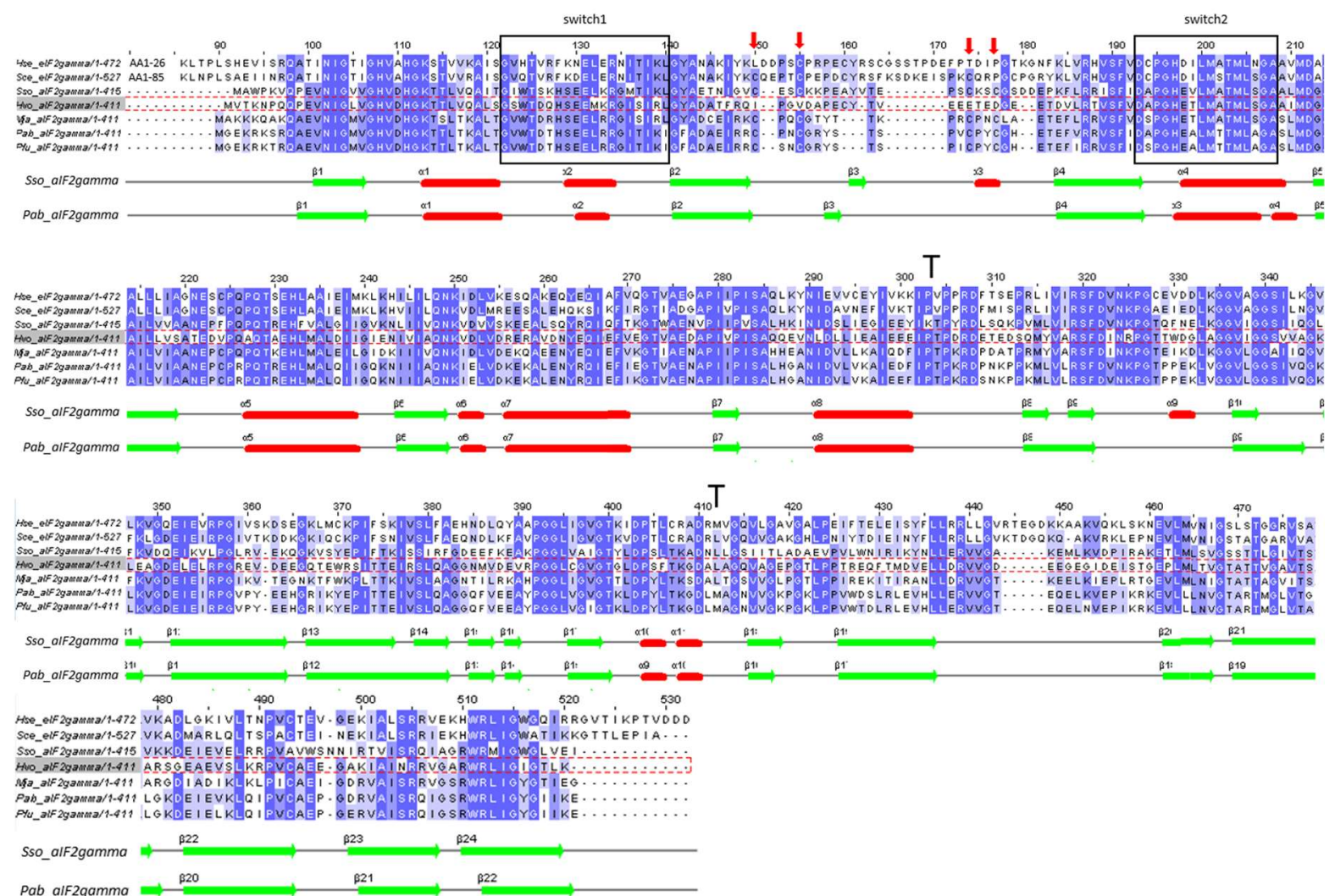

B

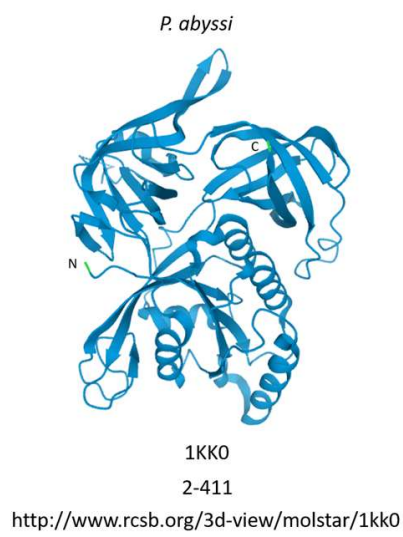

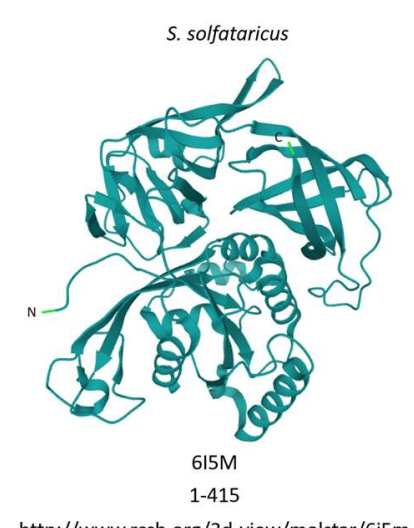

http://www.rcsb.org/3d-view/molstar/6i5m

\begin{abstract}
Abbildung 58: Sequenz-Alignment von alF2y/eIF2y
\end{abstract}

A. Strukturbasierendes Sequenz-Alignment mittels Jalview von alF2y/elF2 $\gamma$ aus S. cerevisiae (P32481), H. sapiens (P41091), S. solfataricus (Q980A5), M. jannaschii (Q58657), P. abyssi (Q9V1G0), P. furiosus (Q8U082) und $H$. volcanii (D4GTD4). Die roten Pfeile markieren die konservierten Cs. Die beiden switch-Boxen sind schwarz umrahmt. B. Die Struktur von alF2y aus $P$. abyssi und S. solfataricus.

In S. solfataricus wurde für alF2 eine Moonlight-Funktion identifiziert. Dabei ist alF2 nicht nur an der Bindung der tRNAi an das Ribosom involviert. Als weitere Funktion kann alF2 an die $5^{\prime}$-Triphosphat-Enden (5'- $\mathrm{P}_{3}$-Enden) von mRNAs binden. Damit werden sie in S. solfataricus vor der Exoribonuklease RNaseJ geschützt. Die Bindung tritt bevorzugt bei einer hohen Konzentration von alF2 $y$ oder bei geringen Konzentration von freien $30 \mathrm{~S}$ ribosomalen Untereinheiten auf (Hasenöhrl et al., 2008; Hasenöhrl, Konrat and Blasi, 2011). Für den trimeren alF2 
und die alF2y-Untereinheit ist in vitro die Affinität höher an das $5^{\prime}-\mathrm{P}_{3}$-Ende anstatt die MettRNAi zu binden. Wenn aber alF1, alF1A und die 30S ribosomale Untereinheiten anwesend sind, besitzt alF2 eine höhere Affinität für Met-tRNAi als für die $5^{\prime}-\mathrm{P}_{3}$-Enden der mRNAs (Hasenöhrl et al., 2009).

Des Weitern konnte im Jahr 2011 von Hasenöhrl und Kollegen nachgewiesen werden, dass die Bindung von alF2 $y$ an das 5'- $\mathrm{P}_{3}$-Ende von mRNA der exoribonukleolytischen Aktivität der RNaseJ in S. solfataricus entgegen wirkt (Hasenöhrl, Konrat and Blasi, 2011).

Die Charakterisierung von essenziellen alFs in $H$. volcanii erfolgte durch Katrin Gäbel mittels Depletionsmutanten, so auch für alF2y. Für alF2y konnte damals die höchste Transkriptstabilität der essenziellen alFs in $H$. volcanii bestimmt werden. Dies deutet darauf hin, dass in $H$. volcanii eine ähnliche Funktion von alF2y vorliegt (Gäbel, 2014).

Bei der Überexpression von alF2 $\gamma$ in $H$. volcanii wuchs die Mutante sehr viel besser als die Kontrolle mit dem Leerplasmid. Dies ist ein weiterer Hinweis, dass alF2 $\gamma$ einen positiven Einfluss auf die Translation ausübt. Hinzu kommt, dass im Gegensatz zu den anderen Faktoren mit alF2y keine Ribonuklease J (HVO_2724) mitgereinigt werden konnte.

Bei der Analyse der MS-Daten von fiel auf, dass er in den Affinitätsaufreinigungen, als auch in den Affinitätsaufreinigungen mit FPLC, alF2y nicht als Protein mit dem höchsten PSM-Wert identifiziert werden konnte. Auch dies deutet auf eine Regulation von alF2y in $\mathrm{H}$. volcanii hin und stellt damit einen interessanten Aspekt für zukünftige Untersuchungen dar.

\subsubsection{FPLC der alF2-Untereinheiten}

Für den alF2 und seine Untereinheiten wurden zusätzlich nach den Affinitätsaufreinigungen FPLCs durchgeführt ( $n=3)$. Anschließend wurden Fraktionen der FPLCs mittels MS analysiert. Ziel war es nicht nur ein Interaktionsfeld, sondern direkte Interaktionspartner zu finden und sich somit auf die direkten Interaktionen der Untereinheiten zu fokussieren.

\subsection{FPLC von alF2 $\alpha$}

Von drei unabhängigen FPLCs wurden die Fraktionen analysiert und zusammengefasst. Diese befanden sich für alF2a zu Beginn der Schulter (I), sowie vor (II) und nach (III) der PeakSpitze.

In Abschnitt (I)-(III) konnte mit alF2 $\alpha$ die alF2 $\gamma$-Untereinheit mitgereinigt werden. Die alF2 $\beta$ 2-Untereinheit (HVO_2242) konnte in (I)-(II) co-gereinigt werden, jedoch nicht in (III). Da alF2Y das Ankerzentrum von alF2 bildet, ist es möglich, dass nur die beiden Untereinheiten alF2 $\alpha$ und alF2y im kleineren Größenverhältnis aneinandergebunden sind.

Zusätzlich konnte alF2Bס-1 mit alF2 $\alpha$ mitgereinigt werden. Dies konnte bereits in den MSDaten der Affinitätsaufreinigungen der exponentiellen und stationären Kulturen gezeigt werden. Für die Affinitätsaufreinigungen der alF2-Untereinheiten war es möglich die Interaktion 
von alF2 $\alpha$, alF2 $\beta-2$ und alF2 $\gamma$ nachzuweisen. Die Untereinheit $\alpha \mathrm{IF} 2 \beta-1$ wurde mit alF2 $\alpha$ nicht co-gereinigt.

In der FPLC von Abschnitt (I)-(II) konnten die ribosomalen Proteine rpL11 (HVO_2758) und rpL22 (HVO_2559) nachgewiesen werden. rpL11 wurde sonst bei keinem weiteren Initiationsfaktor in der MS-Analyse identifiziert. Er konnte jedoch bei fünf RNAPUs mitgereinigt werden. Dafür war es möglich rpL22 mit sechs alFs- bzw. -Untereinheiten (alF1, alF2 $\alpha$ nur FPLC (I)(II), alF2 $\beta-2$, alF2B $\alpha$, alF2Bס-1, elF4-homolog und alF5B) und sechs RNAPUs co-zureinigen.

\subsection{FPLC von alF2 $\beta-1$}

Von drei unabhängigen FPLCs wurden die Fraktionen analysiert und zusammengefasst. Diese befanden sich für alF2 $\beta$-1 sowohl zu Beginn der Schulter (I), im Hauptpeak (II) und nach (III) dem Hauptpeak.

Wie in der Affinitätsaufreinigung konnten auch der FPLC nur wenige Proteine mitgereinigt werden. Anders als in der Affinitätsaufreinigung konnte nach der FPLC zwei starke Banden auf dem SDS-Gel visualisiert werden.

In allen drei Abschnitten konnte mit alF2 $\beta-1$ die alF2 $\alpha$-Untereinheit mitgereinigt werden. In (II) konnte zusätzlich alF2 $\beta-2$ mit alF2 $\beta-1$ co-gereinigt werden. Mit alF2 $\beta-1$ konnten nur wenige Proteine in der MS-Analyse identifiziert werden. Dies deckt sich mit den Daten der Affinitätsaufreinigung und der direkten MS-Analyse. Mit beiden Ansätzen konnte der Transkriptionsregulator HVO_2928 mitgereinigt werden. In welchem Zusammenhang er mit alF2 $\beta$-1 steht, konnte nicht geklärt werden. Er konnte auch mit anderen Initiationsfaktoren bzw. Untereinheiten sowie RNAPUs, mit der Ausnahme von alF2 $\beta-2$, alF2 $\gamma$, alF5A und rpoA2, mitgereinigt werden.

\subsection{FPLC von alF2 $\beta-2$}

Bei der FPLC nach der Affinitätsaufreinigung ist ein deutlicher Unterschied im Verlauf des Chromatogramms zwischen den beiden Untereinheiten zu erkennen. Beide zeigten zwar eine Peakansammlung zwischen 7-12 mL, in der FPLC von alF2 $\beta-2$ war dieser Bereich allerdings um ein Vielfaches höher. Nach dem Auftragen einzelner Fraktionen aus diesem Bereich auf ein SDS-Gel konnten keine Proteine nachgewiesen werden. Erst zu Beginn der Schulter des Hauptpeaks konnten Proteine auf dem SDS-Gel sichtbar gemacht werden.

Bei alF2 $\beta-2$ erschien eine doppelte Bande nach der Affinitätsaufreinigung sowie nach der Affinitätsaufreinigung und FPLC auf dem SDS-Gel.

Die Fraktionen, die für die MS-Analyse nach der FPLC verwendet wurden, lagen in der Schulter des Hauptpeaks (I), in der Spitze (II) und nach der Spitze des Hauptpeaks (III).

Im Vergleich zu alF2 $\beta$-1 konnten mit alF2 $\beta$-2 sehr viel mehr Proteine co-gereinigt und in der MS-Analyse identifiziert werden. Dies traf auch für die FPLCs der Affinitätsaufreinigungen zu. 
Des Weiteren konnten Unterschiede in den co-gereinigten Proteinen festgestellt werden. Nach der Affinitätsaufreinigung und anschließender FPLC konnte mit alF2 $\beta-2$ in allen drei analysierten Fraktionen von (I)-(III) nicht nur alF2 $\alpha$, sondern auch alF2 $\beta-1$ identifiziert werden. Die Untereinheit alF2 $\gamma$ wurde nur in (I) nachgewiesen. In der MS-Analyse direkt nach der Affinitätsaufreinigung von alF2 $\beta-2$ konnte jedoch alF2 $\beta-1$ nicht identifiziert werden.

In (I) konnte alF2 $\beta$-1 sogar mit dem höchsten PSM-Wert identifiziert werden. Es ist bekannt, dass alF2 $\beta-1$ bei der Deletion von alF2 $\beta-2$ um das zehnfache hochreguliert wird. Deshalb wird bei diesen Orthologen davon ausgegangen, dass die Funktionen teilweise gegenseitig übernommen werden können (Gäbel et al., 2013). Wie dieser Vorgang genau abläuft konnte in der vorliegenden Arbeit jedoch nicht geklärt werden.

In (II) und (III) von alF2 $\beta$-2 konnte wie bei alF2 $\beta$-1 ebenfalls kein alF2 $\gamma$ nachgewiesen werden. Dafür wurde alF2 $\alpha$ co-gereinigt. Wie bereits erwähnt ist für alF2 $\alpha$ und alF2 $\beta$ keine direkte Interaktion bekannt.

Es bestätigte sich in der FPLC, dass bei Proteine die stark überproduziert werden ein Überschuss von Monomeren vorhanden ist, da nicht alle einen Interaktionspartner finden.

\subsection{FPLC von alF2 $\gamma$}

In den FPLCs von alF2y zeigten sich auf dem Chromatogramm zwei kleinere Peaks zwischen 7,5-12 mL, dahinter der Hauptpeak und ein weiterer kleinerer Peak. Von alF2 $\gamma$ wurden die Fraktionen im Hauptpeak vor der Peakspitze (I), nach der Peakspitze im Hauptpeak (II) und zu Beginn des zweithöchsten Peaks untersucht (III). In (I) konnte mit alF2 $\gamma$ nur alF2 $\alpha$ des alF2 mitgereinigt werden. Des Weiteren konnte alF2B- $\delta 1$ und alF5B identifiziert werden. Dies war bereits direkt nach der Affinitätsaufreinigung möglich. In (II) konnte nur noch alF2 $\alpha$ mit alF2 $\gamma$ mitgereinigt werden. In (III) konnte alF2 $\gamma$ nichtmehr nachgewiesen werden. Nur noch alF2 $\alpha$ konnte als Initiationsfaktor co-gereinigt werden. Wie bereits bei der Affinitätsaufreinigung beobachtet konnte auch nach den FPLCs alF2 $\gamma$ nicht als Protein mit dem größten PSM-Wert identifiziert werden.

\subsubsection{Interaktionen des alF2 in H. volcanii}

Um die gesammelten MS-Daten der alF2-Untereinheiten besser vergleichen zu können, wurden sie in zwei Tabellen zusammengefasst. Diese umfassen die Interaktion der alF2-Untereinheiten und die Interaktion mit anderen alFs. Dabei enthält Tabelle 86 die Daten für die Affinitätsaufreinigung-MS. Tabelle 87 enthält die Daten für die Affinitätsaufreinigung-FPLC-MS.

Bei den Affinitätsaufreinigungen der alF2-Untereinheiten konnte jeweils ein Set der drei Untereinheiten $(\alpha \beta \gamma)$ co-gereinigt werden. Von den beiden $\beta$-Untereinheiten konnte nur alF2 $\beta-2$ von alF2 $\alpha$ und alF2 $\gamma$ mitgereinigt werden. Damit konnte in allen MS-Analysen von alF2 $\alpha$ die Untereinheit alF2 $\beta-2$ identifiziert werden. 
Bei der Affinitätsaufreinigung-FPLC konnte die alF2 $\alpha$-Untereinheit bei (I)-(III) jeweils ein Set der drei Untereinheiten co-reinigen. Für die $\beta 2$-Untereinheit war dies nur in (I) erfolgreich.

Mit alF2 $\beta-1$ und alF2 $\gamma$ war dies in keiner Affinitätsaufreinigung mit FPLC möglich. Dafür konnte mit alF2 $\beta$-1 in den FPLC-Läufen (I)-(III) die $\beta 2$-Untereinheit mitgereinigt werden. Warum sich diese Ergebnisse, von den Ergebnissen der Affinitätsaufreinigung ohne FPLC unterschieden, konnte in der vorliegenden Arbeit nicht geklärt werden.

Tabelle 86: Interaktion alF2 mit alFs (Affinitätsaufreinigung-MS)

\begin{tabular}{|c|c|c|c|c|c|c|c|c|c|}
\hline alF2 & methode $(n=3)$ & growth phase & alF2 $\alpha$ & alF2 $\beta-1$ & alF2 $\beta-2$ & alF2y & alF2 $\delta-1$ & alF5B & alF1 \\
\hline \multirow[t]{2}{*}{ alF2 $\alpha$} & pull-down & $\exp$ & bait & & + & + & + & + & \\
\hline & pull-down & stat & bait & & + & + & + & + & + \\
\hline alF2 $\beta-1$ & pull-down & $\exp$ & + & bait & & + & & & \\
\hline alF2 $\beta-2$ & pull-down & $\exp$ & + & & bait & + & & + & \\
\hline alF2y & pull-down & $\exp$ & + & & + & bait & + & + & \\
\hline
\end{tabular}

Für die Funktion des alF2 scheint alF2 $\alpha$ eine wichtige Rolle zu spielen. Die $\alpha$-Untereinheit konnte bei allen anderen Überexpressionen von alF2-Untereinheiten mitgereinigt werden. Sowohl bei der Affinitätsaufreinigung als auch bei der Affinitätsaufreinigung gekoppelt mit FPLC. Zusätzlich konnte mit alF2 $\alpha$ und alF2 $\gamma$ der Faktor alF2 $\delta-1$ mitgereinigt werden. Dies gelang nach der Affinitätsaufreinigung und in (I) der FPLCs. Mit alF2 $\alpha$, alF2 $\beta-2$ und alF2 $\gamma$ konnte alF5B nach der Affinitätsaufreinigung mitgereinigt werden. Für alF2y auch in der I der FPLCLäufe.

Tabelle 87: Interaktion alF2 mit alFs (Affinitätsaufreinigung-FPLC-MS)

\begin{tabular}{|c|c|c|c|c|c|c|c|c|}
\hline alF2 & methode $(n=3)$ & fractions & alF2a & alF2 $\beta-1$ & alF2 $\beta-2$ & alF2y & alF2ס-1 & alF5B \\
\hline \multirow{3}{*}{ alF2a } & pull-down-FPLC & I & bait & & + & + & + & \\
\hline & pull-down-FPLC & ॥ & bait & & + & + & & \\
\hline & pull-down-FPLC & III & bait & & + & + & & \\
\hline \multirow[t]{3}{*}{ alF2 $\beta-1$} & pull-down-FPLC & I & + & bait & & & & \\
\hline & pull-down-FPLC & II & + & bait & + & & & \\
\hline & pull-down-FPLC & III & + & bait & & & & \\
\hline \multirow[t]{3}{*}{ alF2 $\beta-2$} & pull-down-FPLC & I & + & + & bait & + & & \\
\hline & pull-down-FPLC & II & + & + & bait & & & \\
\hline & pull-down-FPLC & III & + & + & bait & & & \\
\hline \multirow[t]{3}{*}{ alF2y } & pull-down-FPLC & I & + & & & bait & + & + \\
\hline & pull-down-FPLC & ॥ & + & & & bait & & \\
\hline & pull-down-FPLC & III & + & & & (bait) & & \\
\hline
\end{tabular}

Mit diesen Ergebnissen kann die Hypothese bestärkt werden, dass alF2 $\alpha$ eine wichtige Rolle im alF2 besitzt. Der Platz des Faktor alF2 $\beta-2$ kann von der alF2 $\beta-2$ übernommen werden. Warum alF2 $\beta$-1 in den FPLCs (I)-(III) mit alF2 $\beta$-2 und umgekehrt für alF2 $\beta$-1 (II) co-gereinigt wurde, konnte in dieser Arbeit nicht geklärt werden. 
Da alF2 $\gamma$ den Kern des alF2 bildet und jeweils alF2 $\alpha$ und alF2 $\beta$ bindet, wäre in diesem Zusammenhang eine Version mit einem C-Terminalen His-Tag interessant. Damit kann alF2 und die Interaktion der Untereinheiten weiter zu untersuchen.

\subsection{4 alF2B}

Der eukaryontische elF2B ist ein Heteropentamer, der aus den Untereinheiten $\alpha-\varepsilon$ besteht. Dabei bilden $\alpha, \beta$ und $\delta$ den regulatorischen Subkomplex, während $\gamma$ und $\varepsilon$ das katalytische Zentrum bilden. In Eukaryonten ist elF2B als Guanin-Nukleotid-Austauschfaktor an elF2 zuständig (Bogorad et al., 2014). Für den Austausch von GDP zu GTP bindet elF2B an elF2. Dabei interagieren die Untereinheiten elF2B $\varepsilon$ und elF2 $\beta$ (Asano et al., 1999). Bei der regulatorischen Phosphorylierung von elF2 $\alpha$ (elF2 $\alpha \mathrm{P})$ konnte in $S$. cerevisiae in vitro nachgewiesen werden, dass alF2B zwei Subkomplexe bilden. Bedingt wird dies durch elF2 $\alpha \mathrm{P}$. Beide Subkomplexe können an elF2 binden. Der erste Subkomplex bestehend aus alF2Ba, $-\beta$ und $-\delta$ bindet bevorzugt an die phosphorylierte Form des elF2. Er hat keine GDP-GTP-Austauschaktivität. Der zweite Subkomplex, bestehend aus alF2By und elF2B $\varepsilon$, bindet im gleichen Verhältnis an elF2 und elF2( $\alpha P$ ). Er ist immun gegen die Phosphorylierung und hat eine erhöhte GDPGTP-Austauschaktivität (Pavitt et al., 1998).

Die meisten Archaeen besitzen für alF2B nur die Untereinheiten $\alpha-, \beta$ - und $\delta$. Sie besitzen keine $\gamma$ - und $\varepsilon$-Untereinheit (Kyrpides and Woese, 1998a; Kakuta et al., 2004). In S. cerevisiae besitzt der Subkomplex alF2Baßס wie oben beschrieben, eine regulatorische Funktion, bei der er elF2( $\alpha \mathrm{P})$ in Abhängigkeit der Ser51-Phosphorylierung bindet (Pavitt et al., 1998; Krishnamoorthy and Pavitt, 2001).

Damit fehlen die beiden Untereinheiten des katalytischen Zentrums. Hinzu kommt in Archaeen, das alF2 $\beta$ kleiner ist als das eukaryontische Homolog und nicht die Bindedomäne für alF2B besitzt. Dennoch konnte in mehreren Archaeen in vitro Interaktionen zwischen alF2B und alF2 $\alpha$ nachgewiesen werden (Dev et al., 2009). Dies könnte unter anderem an der Bildung des in S. cerevisiae beschriebenen alF2Baßס-Subkomplexes liegen.

In $H$. volcanii verhält es sich jedoch anders mit den alF2B-Untereinheiten. In diesem Archaeon ist alF2Ba (HVO_1934) und alF2Bס (HVO_2706) als Untereinheiten annotiert. Sowohl alF2Ba (HVO_1934) als auch alF2Bס (HVO_2706) konnten jeweils einzeln und in einer Doppeldeletionsmutante deletiert werden, weshalb sie als nicht essenziell eingestuft wurden (Gäbel et al., 2013). Während der Affinitätsaufreinigungen rückte jedoch ein Protein in den Fokus, das bei vielen Initiationsfaktoren mitgereinigt werden konnte, das bereits als Translationsinitiationsfaktor ausgeschlossen wurde. Dabei handelte es sich um eine weitere alF2BסUntereinheit (HVO_0966; L9USK7; D4GV73), die als „translation initiation factor IF-2B subunit ס“ (L9USK7) aber auch als „ribose-1,5-bisphosphat-isomerase“ (D4GV73) annotiert ist. Zur Vereinfachung wurde in dieser Arbeit HVO_0966 zu alF2Bס-1 und HVO_2706 zu alF2Bס-2 benannt. 


\subsubsection{1 alF2B}

In Eukaryonten besitzt elF2Ba keine katalytische Funktion. In S. cerevisiae hatte die Deletion von elF2Ba bei optimalen Bedingungen keine Auswirkungen. Jedoch konnte unter Nährstoffmangel die Hemmung von elF2B-elF(2aP) nicht mehr nachgewiesen werden (Fabian et al., 1997; Kimball et al., 1998; Pavitt et al., 1998).

In H. volcanii wurde für alF2Ba (HVO_1934) die vorhandene Deletionsmutante im Southern Blot bestätigt. Die Deletionsmutante von alF2Ba verhielt sich wie bereits von Gäbel 2013 beschrieben. Sie zeigte unter optimalen Bedingungen bei $42{ }^{\circ} \mathrm{C}$ in Komplexmedium keinen Phänotypen. Auch bei der damaligen Testung von verschiedenen Wachstumsbedingungen konnte für die Deletionsmutante kein Phänotyp ermittelt werden (Gäbel, 2014).

Die in der vorliegenden Arbeit angewandte Überexpression des alF2Ba aus $H$. volcanii fand in der Deletionsmutante statt. Die Überexpressionsmutante wuchs besser als die Kontrolle mit dem Leerplasmid und näherte sich in der stationären Phase dem Wildtyp an (Abbildung 49).

In den Affinitätsaufreinigungen von alF2Ba konnte auf dem SDS-Gel mittels Coomassie eine sehr starke Bande sichtbar gemacht werden. Es war das Protein, das in dieser Arbeit am stärksten überexprimiert werden konnte. Mit alF2Ba konnten 80 Proteine in allen drei Eluaten von alF2 $\alpha$ identifiziert werden. Davon konnten 23 Proteine in die beschriebenen Prozesse eingeordnet werden. Alle Proteine, die mit alF2Ba mitgereinigt werden konnten, konnten auch mit anderen Faktoren mitgereinigt werden. Es gab kein Protein, welches nur mit alF2Ba mitgereinigt werden konnte.

Als weitere Initiationsfaktoren konnte mit alF2Ba sowohl alF2Bס-1 als auch alF5B mitgereinigt werden. Auch wenn alF2Ba in dieser Arbeit mit keinem anderen Initiationsfaktor mitgereinigt werden konnte, spricht die starke Überexpression und die Co-Reinigung von weiteren Initiationsfaktoren für eine Funktion oder Regulation in der Translation.

Das Protein von alF2Ba ist in H. volcanii 413 Aminosäuren lang und 43,2 kDa schwer. Unter anderem besitzt es eine $\mathrm{N}$-terminale Nudix-Domäne (AS 1-131) und deshalb eine mögliche Hydrolaseaktivität. Nudix steht für „Nukleosiddiphosphat verbunden mit einer weiteren Einheit X“. Proteine mit dieser Domäne besitzen eine Pyrophosphataseaktivität und sind in allen Organismen vertreten (McLennan, 2006). Sie besitzen verschiedene spezifische Substrate mit der allgemeinen Struktur NDP-X (Nukleosiddiphosphat, verbunden mit anderen X Molekülen). Sie hydrolysieren die Substrate um anschließend das Produkt Nukleosidmonophosphat NMP und Phosphat-X zu erhalten. Die Nudix-Domänen-Proteine werden entsprechend der Substrate NDP-X in verschiedene Familien unterteilt (Yoshimura and Shigeoka, 2015). Einige dieser Substrate sind capped-RNA, Nukleotidzucker wie ADP-Ribose, Coenzym A, NAD $(P) H$, $F A D$, Diadenosintetraphosphate und -polyphosphate wie Ap4A, und ApnA $(n>4)$. Diese Substrate sind unter anderem potentiell toxische Moleküle, metabolische Intermediate, Signalmoleküle oder Coenzyme, weshalb Proteine mit Nudix-Domäne als housekeeping-Enzyme eingestuft werden (Bessman, Frick and O'Handley, 1996; Tanaka, Kihara and Sugimoto, 2015). 
Unter anderem agieren diese Proteine in Pflanzen unter abiotischen Einflüssen, wie z.B. bei erhöhten Salzbedingungen, Kälte- und Hitzeschocks (Bessman, Frick and O'Handley, 1996).

Beim Vergleich der Sequenzen der Nudix-Domäne von alF2Ba konnte sowohl in Arabidopsis thaliana (Nudix-Hydrolase 3; Q8L831) als auch in Hordeum vulgare (Putatives Protein; F2CSP9) die Nudix Hydrolase 3 identifiziert werden. Im Sequenz-Alignment der Proteine ist die Nudix-Hydrolase 3 in $A$. thaliana zu 27,5 \% identisch mit alF2Ba und mit 24,5\% zum putativen Protein in $H$. vulgare (Abbildung 70). In beiden Organismen wurde das Enzym als ApnA Pyrophosphohydrolase eingestuft (Ogawa et al., 2005; Tanaka, Kihara and Sugimoto, 2015). Dies könnte auch für alF2Ba in $H$. volcanii zutreffen.

\subsubsection{2 alF2Bס-1 und alF2Bס-2}

In Eukaryonten besitzt elF2Bס eine wichtige strukturelle Funktion. Zusätzlich ist er an der Regulation der Translation bei vorliegendem elF2aP zuständig. Wie bereits erwähnt konnte Gordiyenko und Kollegen 2019 für S. pombe, in vitro mittels Cryo-EM, die Interaktion von elF2B $\alpha \delta$ und elF2 $\alpha \mathrm{P}$ nachweisen.

In $\mathrm{H}$. volcanii sind die Proteine der beiden alF2Bס-Untereinheiten im Sequenz-Alignment zu $30,2 \%$ identisch (Abbildung 71). Im Vergleich zu elF2Bס aus S. pombe ist aus $H$. volcanii alF2Bס-1 zu 22,9 \% und alF2Bס-2 zu 21,2 \% identisch.

Die Interaktion von elF2Bס mit elF2aP wurde von Godiyenko und Kollegen an elF2Bס-E377 beschrieben (Gordiyenko, Llácer and Ramakrishnan, 2019). Dieser Bereich ist jedoch in Archaeen nicht konserviert.

In H. volcanii sind zwei $\delta$-Untereinheiten annotiert, deren Aminosäuresequenz zu 30 \% identisch und zu 65 \% ähnlich sind. Jedoch ist alF2ס-1 mit 323 Aminosäuren um 41 Aminosäuren länger als alF2ס-2.

Wie bereits zuvor beschrieben ist elF2B in Eukaryonten ein wichtiger Guanin-Nukleotid-Austauschfaktor und mit elF2 für die Regulation der Translation wichtig. In Archaeen ist die Funktion von alF2B nicht eindeutig und wird kontrovers diskutiert. Ein Grund dafür ist die Ähnlichkeit von alF2B zu der methylthioribose-1-phosphate isomerases (MTNAs) und der ribose-1,5-bisphosphate isomerases (RBPI). Wobei in H. volcanii keine MTNAs annotiert sind. Dev et al beschrieb 2009 in einem Sequenz-Alignment verschiedene Motive, die zur Unterscheidung von MTNAs, RBPI und alF2B beitragen kann (Dev et al., 2009). Sie sind in Tabelle 88 aufgelistet.

Die von Dev und Kollegen beschriebenen Motive wurden in dieser Arbeit mit den in $H$. volcanii vorhandenen alF2Bס-Untereinheiten abgeglichen. Für alF2Bס-1 (HVO_0966) konnte damit eine größere Ähnlichkeit zu RBPI (Abbildung 59) ermittelt werden. Bei alF2Bס-2 (HVO_2706) besteht hingegen eine größere Ähnlichkeit zu alF2B (Abbildung 60). 
Tabelle 88: MNT-P, RBPI- und alF2B-like Motive nach (Dev et al., 2009)

\begin{tabular}{|c|c|c|c|c|c|}
\hline & Motif I & Motif II & Motif III & Motif IV & Motif V \\
\hline MTNA-like & QXXLP & VRGAPxI & LXXXRPTA & TxCNxGxxATxxxGTA & ETRPXxQGXXLTxxE (x) 12D \\
\hline RBPI-like & - & $x R G A x x I$ & LXXXRPTA & $\begin{array}{l}\mathrm{TxCNX}-------x \times A \\
\operatorname{Tx} \mathrm{CXX}-------x \times A\end{array}$ & 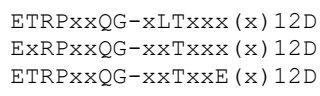 \\
\hline alF2B-like & - & $\begin{array}{l}x \operatorname{RGAXXx} \\
x \times G A x x x \\
x \times G X X x x\end{array}$ & $\begin{array}{l}\text { LXXXX } \\
\text { LXXXXP } \\
\text { LXXXXPT } \\
x \times x x x P\end{array}$ & 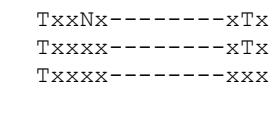 & 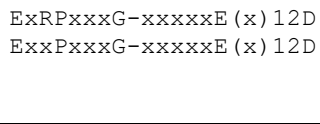 \\
\hline & \multicolumn{3}{|c|}{ Motif VI } & Motif VII & Motif VIII \\
\hline MTNA-like & \multicolumn{3}{|c|}{ GADxxxxxGDxANKxGTxxLA (x) 9F } & GxxIxxExRxxxE (x) 5G & FDxTPxxLIXxxxxxxG \\
\hline RBPI-like & \multicolumn{3}{|c|}{$\begin{array}{l}\text { GADxxxxxGxxxNKxGTxxxA (x) } 9 F \\
\text { GADxxxxxGxxxNKxxxxxxA (x) } 9 F\end{array}$} & 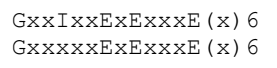 & $\begin{array}{l}\text { FDXTPXXXIXXXXXXxG } \\
\text { FDXTPXXXXXXXXXX }\end{array}$ \\
\hline alF2B-like & \multicolumn{3}{|c|}{ 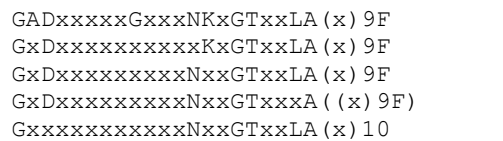 } & 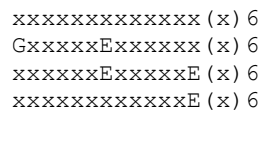 & 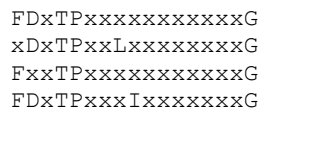 \\
\hline
\end{tabular}

Im direkten Vergleich der Aminosäuresequenzen, konnte für alF2Bס-1 eine höhere Identität zu den RBPI nachgewiesen werden. Zwischen den beiden Untereinheiten zeigte jedoch alF2Bס-1 zu den RBPI als auch zu den alF2B eine höhere Identität als alF2Bס-2 (Abbildung 59-60).

\section{RBPI-like Sequences}
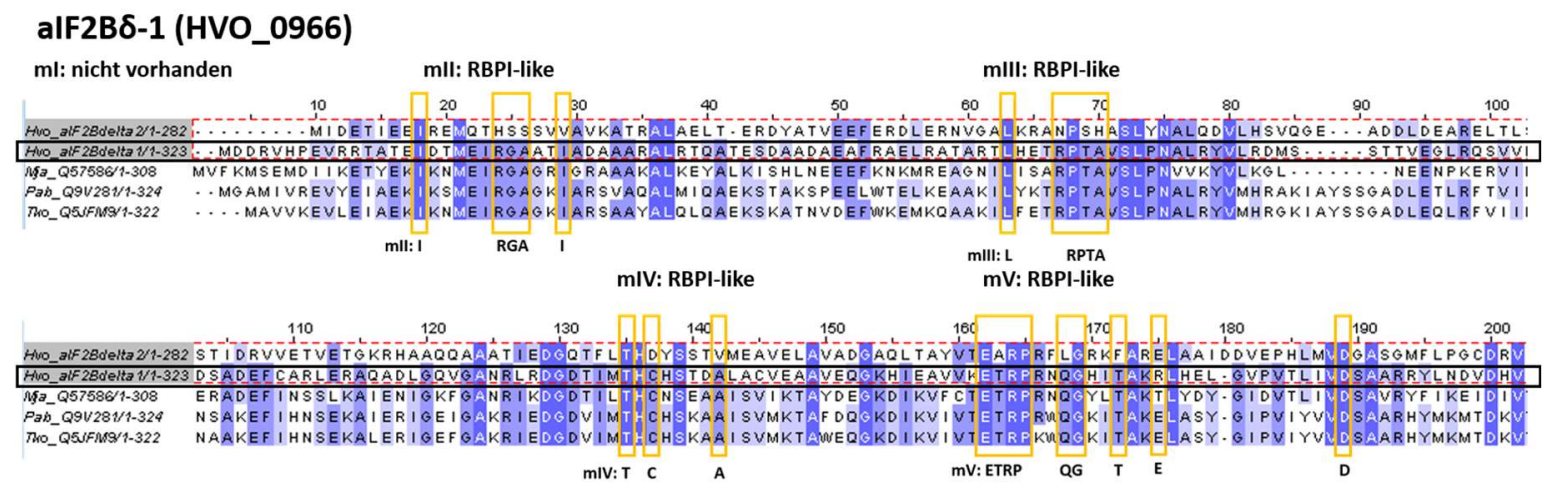

mVI: RBPI-like
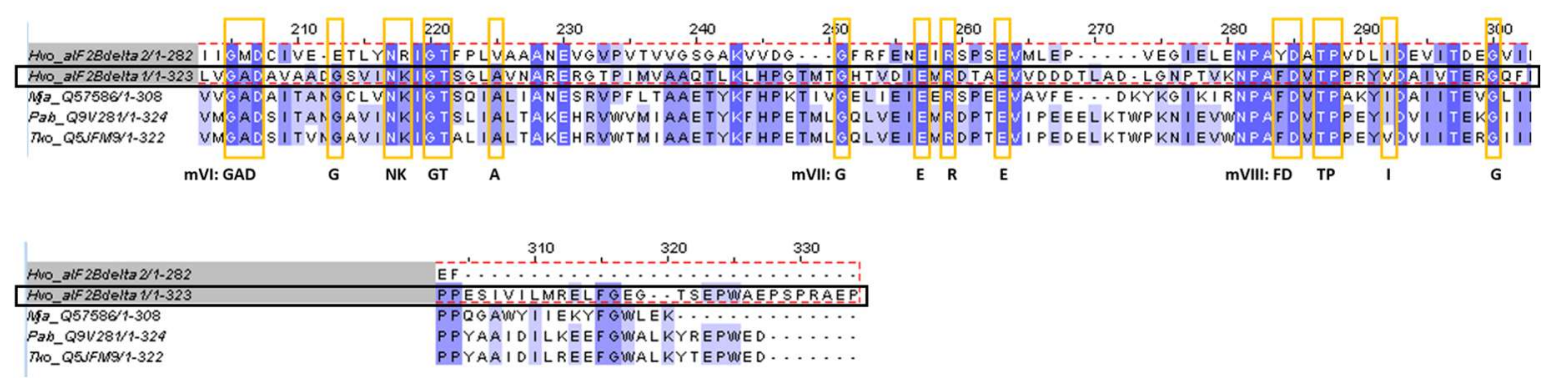

\section{alF2Bס-1 (HVO_0966)}

$30,2 \%$ identisch mit $H$. volcanii (HVO 2706)

$42,1 \%$ identisch mit $M$. jannaschii

$48,2 \%$ identisch mit $P$. abyssi

$48,8 \%$ identisch mit $T$. kodakarensis

\section{alF2Bס-2 (HVO_2706)}

$30,2 \%$ identisch mit $H$. volcanii (HVO_0966)

$29,8 \%$ identisch mit $M$. jannaschii

$28,8 \%$ identisch mit $P$. abyssi

$28,8 \%$ identisch mit $T$. kodakarensis

\section{Abbildung 59: Sequenz-Alignment alF2Bס mit RBPIs}

Das Sequenz-Alignment wurde in Clustal O erstellt und mittels Jalview visualisiert. Die definierten RPBI-like Sequenzen von Dev und Kollegen sind gelb umrahmt (Dev et al., 2009). Verglichen wurden die Sequenzen von alF2Bס-1 und alF2Bס-2 aus H. volcanii. Zusätzlichen wurden die Sequenzen von RBPI aus M. jannaschii (Q57586), P. abyssi (Q9V281) und T. kodakarensis (Q5JFM9) betrachtet. 
Dennoch zeigte sich in dieser Arbeit nach den Affinitätsaufreinigungen und den MS-Analysen ein anderes Ergebnis. Überraschenderweise konnte mit alF2Bס-2 (HVO_2706) kein Initiationsfaktor mitgereinigt werden. Er konnte auch mit keinem weiteren Initiationsfaktor als alF2Bס-1 (HVO_0966) mitgereinigt werden.

\section{alF2B-like Sequences}

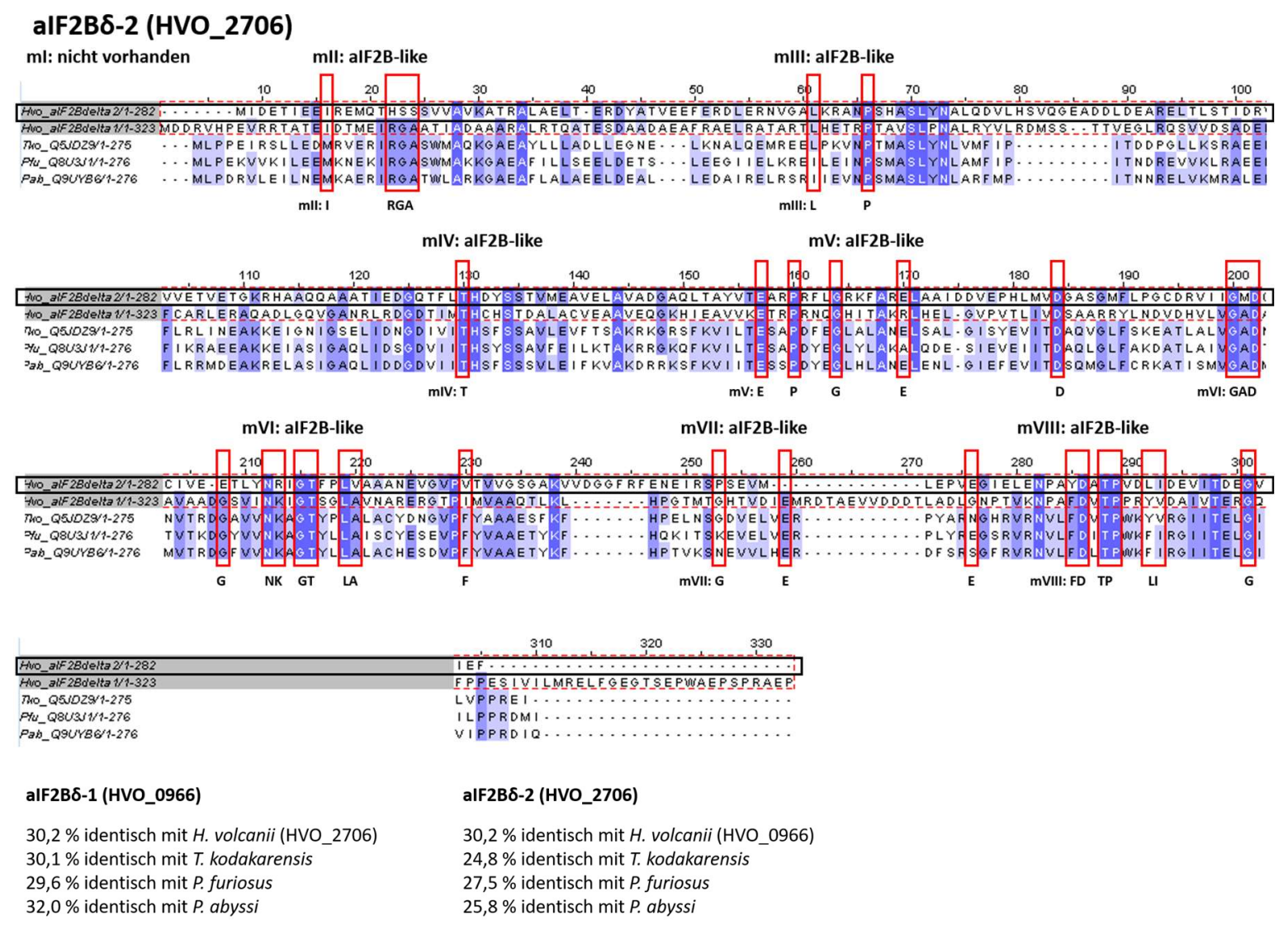

Abbildung 60: Sequenz-Alignment alF2Bס mit alF2Bs

Das Sequenz-Alignment wurde in Clustal $O$ erstellt und mittels Jalview visualisiert. Die definierten alF2B-like Sequenzen von Dev und Kollegen sind rot umrahmt (Dev et al., 2009). Verglichen wurden die Sequenzen von alF2Bס1 und alF2Bס-2 aus $H$. volcanii. Zusätzlichen wurden die Sequenzen von alF2B aus T. kodakarensis (Q5JDZ9), $P$. furiosus (Q8U3J1) und P. abyssi (Q9UYB6) betrachtet.

Anders verhielt es sich mit dem Initiationsfaktor alF2Bס-1 (HVO_0966). Mit inm konnten alF2Bס-2, alF2 $\alpha$, alF2 $\beta-2$ und alF2 $\gamma$ mitgereinigt werden. Des Weiteren konnte er mit der Ausnahme von alF2 $\beta-1$, alF2 $\beta-2$ und alF2Bס-2 (HVO_2706) mit allen anderen alFs mitgereinigt werden.

Für alF2 $\delta$-2 konnten nur sechs Proteine nach der MS-Datenauswertung identifiziert werden. Dies war bereits Anhand der SDS-Gele nach der Affinitätsaufreinigung ersichtlich, da nur wenige Banden auf dem SDS-Gel mittels Coomassie angefärbt werden konnten. Mit keinem anderen Initiationsfaktor als alF2 $\delta$-2 konnte die Proteasom-Untereinheit $\beta$ (HVO_1562) mitgereinigt werden. Dies könnte auch mit der Bande bei $25 \mathrm{kDa}$ auf dem SDS-Gel übereinstimmen.

In den Wachstumsversuchen konnte alF2Bס-1 nur im Wildtyp überexprimiert werden, da die vorhandene Deletionsmutante nicht bestätigt werden konnte. Die Überexpressionsmutante 
von alF2Bס-1 verhielt sich ähnlich zum Wildtyp. Eine Neuerstellung war zeitlich nicht mehr möglich. Es sollte erneut überprüft werden, ob das Gen von alF2Bס-1 deletiert werden kann. Wenn ja, sollte die Überexpression nochmals in der Deletionsmutante wiederholt werden.

Bei alF2Bס-2 konnte die vorhandene Deletionsmutante im Southern Blot bestätigt werden. Sie verhielt sich unter optimalen Wachstumsbedingungen wie der Wildtyp. Dies deckt sich mit den Daten von Gäbel 2014 (Gäbel, 2014). Dennoch wuchs die Überexpressionsmutante besser als die Kontrolle mit Leerplasmid.

Durch die in dieser Arbeit erbrachten Ergebnisse kann davon ausgegangen werden, dass alF2Bס-1 eher als Initiationsfaktor einzustufen ist als alF2Bס-2.

\subsection{5 elF4A-homolog}

Der Translationsinitiationsfaktor elF4A-homolog (HVO_1333) in H. volcanii gehört zur Familie der DEAD-box- bzw. ATP-abhängigen Helikasen. Er konnte deletiert werden (Gäbel et al., 2013). Das elF4A-homolog weist eine zu 23 \% identische Aminosäuresequenz zu elF4A in S. cerevisiae auf. Dabei ist das elF4A-homolog um 551 Aminosäuren länger als elF4A in $S$. cerevisiae. Dieser verlängerte $\mathrm{C}$-terminus könnte regulatorische Domänen enthalten, deren Funktion noch unbekannt sind. Unter anderem wird dieser Bereich auch als DEAD-associated Domäne bezeichnet (Linder and Jankowsky, 2011; Chamieh, Ibrahim and Kozah, 2016).

In Eukaryonten ist elF4A für den Scanning-Mechanismus wichtig und bildet mit elF4E und elF4G einen Komplex, der an die 5'-Cap-Struktur der mRNA bindet. (Schmidt, BeilstenEdmands and Robinson, 2016). Sie rekrutieren damit die 40S ribosomale Untereinheit zur mRNA. elF4A agiert dann als ATP-abhängige Helikase, die für das Aufwinden der sekundären/tertiären RNA zuständig ist. Stimuliert wird die Helikase-Aktivität von elF4B (Fitzgerald and Semler, 2009).

Da Archaeen kein Scanning-Mechanismus für die Translationsinitiation verwenden, sind elF4B, elF4E und elF4G in diesen Organismen nicht vertreten. Anders verhält es sich im Falle des elF4A-homolog, da ATP-abhängige Helikasen in Archaeen vertreten sind. Das Aufwinden nur mit elF4A ist möglich, aber sehr viel ineffizienter im Vergleich zum Komplex mit elF4G und elF4E (Ray et al., 1985; Linder and Fuller-Pace, 2015; Chamieh, Ibrahim and Kozah, 2016).

Im Vergleich der drei Domänen des Lebens können DEAD-box Helikasen an einem oder mehreren Prozessen beteiligt sein. Ihre Vielfalt ist immens und ihre Funktion in Archaeen noch weitestgehend unbekannt (Tieg and Krebber, 2013; Chamieh, Ibrahim and Kozah, 2016).

In der vorliegenden Arbeit konnte die Deletion in der vorhandenen Deletionsmutante von HVO_1333 anhand eines Southern Blots bestätigt werden. Die Deletionsmutante zeigte unter optimalen Wachstumsbedingungen bei $42^{\circ} \mathrm{C}$ in Komplexmedium ein deutlich schlechteres Wachstum im Vergleich zum Wildtyp. Dieses Ergebnis weicht von den bisherigen Daten ab. 
Es wurde von Gäbel 2013 ein ähnlicher Wuchs zum Wildtyp beschrieben und lediglich ein geringerer Wachstumsertrag nachgewiesen(Gäbel et al., 2013).

In dieser Arbeit wurde die Überexpression von HVO_1333 in der Deletionsmutante durchgeführt. Die Überexpressionsmutante zeigte ein sehr viel schlechteres Wachstum als die Deletionsmutante mit Leerplasmid. Dies kann auf die Funktion als Helikase von HVO_1333 zurückgeführt werden. Mit dem elF4A-homolog konnten zwei weitere Translationsinitiationsfaktoren co-gereinigt werden. Dabei handelt es sich um alF5B und alF2B $\delta$-1. Des Weiteren konnte nur für das elF4A-homolog die Protease Lon (HVO_0783) nachgewiesen werden.

Die Deletion als auch die Überexpression von HVO_1333 scheint einen Einfluss auf die Transkription und Translation in $H$. volcanii zu besitzen und damit das Wachstum der Deletions- als auch der Überexpressionsmutante negativ zu beeinflussen.

Inwiefern das elF4A-homolog in $H$. volcanii als Translationsinitiationsfaktor agiert, konnte in dieser Arbeit nicht geklärt werden.

\subsection{6 alF5A}

Der Initiationsfaktor alF5A konnte in $H$. volcanii nicht deletiert werden. Deshalb wurde er als essenziell eingestuft (Gäbel et al., 2013). Er ist sowohl in Archaeen als auch in Eukaryonten (elF5A) hochkonserviert und essenziell. Bei Vertebraten gibt es sogar zwei Isoformen elF5A1 und elF5A2, die in H. sapiens zu 84 \% identisch sind (Caraglia et al., 2013; Dever, Gutierrez and Shin, 2014). Bakterien besitzen den Elongationsfaktor EF-P als homolog zu elF5A, der allerdings nicht essenziell ist (Doerfel et al., 2013; Lassak, Wilson and Jung, 2016).

Die Funktionen von elF5A/alF5A sind vielfältig. Unter anderem ist er in das Zellwachstum, die Translation und in den Zelltod involviert (Jansson, Malandrin and Johansson, 2000; Dever, Gutierrez and Shin, 2014). alF5A aus H. volcanii hat zu 26,6 \% eine identische Aminosäuresequenz zu elF5A aus S. cerevisiae (siehe Anhang Abbildung 72).

In Archaeen ist die Funktion von alF5A noch nicht vollständig aufgeklärt. In S. solfataricus jedoch konnte nachgewiesen werden, dass alF5A nicht nur an der Translationselongation, sondern auch an der Spaltung von RNA beteiligt ist (Bassani et al., 2019).

In dieser Arbeit wurde alF5A aus $H$. volcanii im Wildtyp H26 1279 überexprimiert, da er nicht deletiert werden konnte. Bei den Wachstumsversuchen von alF5A bei $42{ }^{\circ} \mathrm{C}$ in Komplexmedium wuchs die Überexpressionsmutante sehr viel schlechter als die Kontrolle mit dem Leerplasmid. Dies kann sowohl auf seine Aufgaben in der Translation als auch an einer RNAspaltenden Funktion liegen.

In allen drei Domänen des Lebens ist elF5A/alF5A/EF-P wichtig für die effektive Translation von Proteinen mit Polyprolin-Sequenzen, um ein Ribosom-Stalling zu verhindern (Doerfel et al., 2013; Gutierrez et al., 2013; Ude et al., 2013). Hierfür werden in Eukaryonten, Archaeen und Bakterien Proteinmodifikationen benötigt. Diese Modifikationen sind nur in 
elF5A/alF5A/EF-P vorhanden. In Eukaryonten und Archaeen ist die essenzielle, posttranslationale Modifikation die Hypusinierung (Jansson, Malandrin and Johansson, 2000; Bassani et al., 2018). In Bakterien ist es an EF-P die $\beta$-Lysinylierung oder die Rhamnosylierung (Ude et al., 2013; Lassak, Wilson and Jung, 2016).

Die Hypusinierung läuft in Eukaryonten in zwei Schritten ab. Dabei werden die Enzyme Deoxyhypusin-Synthase (DHS), Deoxyhypusin-Hydroxylase (DOHH) und Polyamine benötigt (Michael, 2016). Im ersten Schritt katalysiert die DHS die Übertragung der 4-AminobutylGruppe des Polyamines Spermidin auf den Lysin-Zielrest und bildet so das DeoxyhypusinIntermediat (Wolff et al., 2007). Dieses Zwischenprodukt wird im zweiten Schritt durch DOHH hydroxyliert und bildet die biologisch aktive Form des hypusinylierten Faktors (Park et al., 2010).

In Eukaryonten ist die Deoxyhypusin-/Hypusine-Modifikation essenziell. In Archaeen existieren homologe Enzyme zu DHS. Bisher konnten aber noch keine DOHH auf Genom- oder Proteom-Ebene nachgewiesen werden (Park, 2006; Wolff et al., 2007).

Ein Unterschied zur Verteilung der Aminosäuren Hypusin und Deoxyhypusin zeigt sich in den verschiedenen Arten von Archaeen. In Crenarchaeota, wie zum Beispiel Sulfolobus acidocaldarius, konnte Hypusin nachgewiesen werden. Im Kontrast hierzu wurde für Euryarchaeota, darunter Halobacteriales, Thermokokken, Methanogene und Thermoplasmen hohe Konzentrationen von Deoxyphypusin nachgewiesen, aber keine oder nur geringe Mengen an Hypusin (Bartig, Schümann and Klink, 1990). In H. volcanii liegt alF5A deoxyhypusiniert vor (Prunetti et al., 2016).

Die in $H$. volcanii hauptsächlich vertretenen Polyamine sind Agmatin und Cadaverin. In geringen Mengen kommt Putrescin vor (Hamana, Hamana and Itoh, 1995; Prunetti et al., 2016). Des Weiteren liegt alF5A in einem Operon mit einer Agmatinase (HVO_2299) (Abbildung 61). Sie ist essenziell. Im Allgemeinen sind Agmatinasen in die Bildung von Putrescin aus Agmatin involviert. Ihre Funktion als Agmatinase und die Interaktion mit alF5A konnte in $H$. volcanii jedoch noch nicht belegt werden (Prunetti et al., 2016).

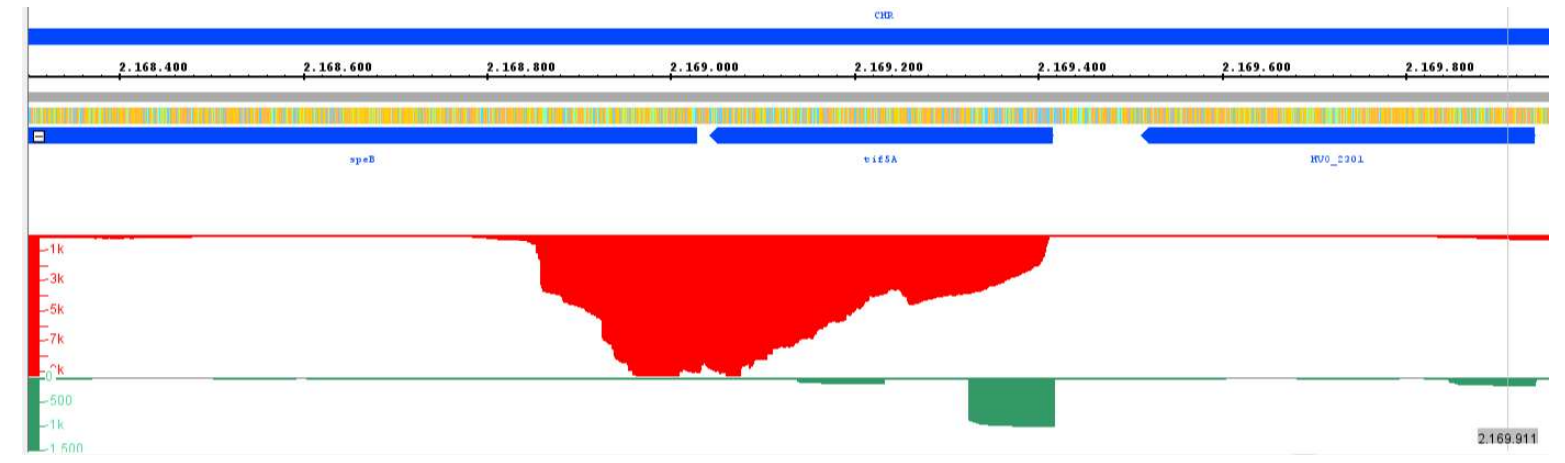

Abbildung 61: DNA- und RNA-Seq-Daten zu alF5A (HVO_2300)

Die Gene sind in blau, das Transkriptionslevel in rot und der Transkriptionsstart in grün dargestellt. Das Gen alF5A bzw. tif5A liegt auf dem Reverse-Strang. 
In S. cerevisiae kann durch die Bindung des Spermidin-Analog GC7 an die DHS, der erste Schritt der Hypusinierung effizient inhibiert werden (Jakus et al., 1993; Lee, Park and Folk, 1995). Eine Inhibierung der Hypusinierung und des Wachstums durch GC7 konnte auch in vier archaealen Organismen nachgewiesen werden (Jansson, Malandrin and Johansson, 2000). Prunetti und Kollegen konnten 2016 in H. volcanii keinen negativen Einfluss von GC7 auf das Wachstum nachweisen (Prunetti et al., 2016).

Wie bereits im Abschnitt zuvor erwähnt ist alF5A in S. solfataricus sowohl an der Translationselongation, als auch an der Spaltung von RNA beteiligt (Bassani et al., 2019).

Bereits 2007 konnte von Wagner und Kollegen für alF5A aus $H$. salinarum die Spaltung von RNA nachgewiesen werden (Wagner and Klug, 2007). Dabei wurden drei Bereiche in der Aminosäuresequenz in $H$. salinarum identifiziert, die für diese Funktion wichtig sind. Zwei Abschnitte befinden sich im N-Terminus und ein Abschnitt im C-Terminus. Mittels Sequenz-Alignment konnte in dieser Arbeit nachgewiesen werden, dass diese Bereiche auch in alF5A von $H$. volcanii konserviert sind (Abbildung 62).
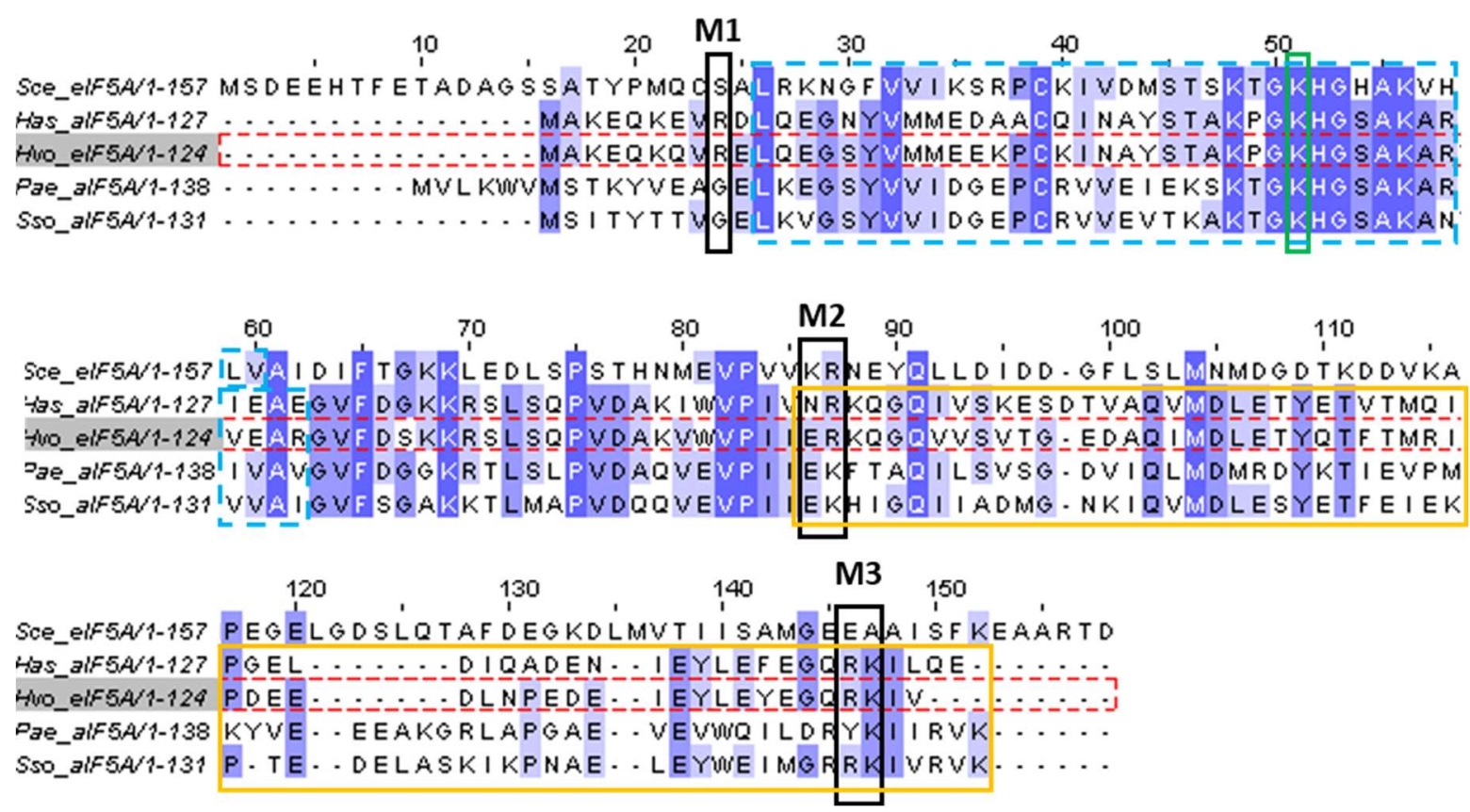

\section{Abbildung 62: Sequenz-Alignment alF5A/elF5A}

Das Sequenz-Alignment wurde mittels Clustal $O$ und Jalview durchgeführt. Die Sequenzen von alF5A/elF5A aus S. cerevisiae (Sce; P23301), H. salinarum (Has; Q9HP78) und H. volcanii (Hvo; D4GWG6), P. aerophilum (Pae; P56635) und S. solfataricus (Sso; Q97ZE8) wurden verglichen. Die schwarzen Kästen umrahmen die Bereiche, die für die Funktion von alF5A in $P$. aerophilum wichtig sind. Das für die Hypusinierung verwendete Lysin wurde grün umrahmt. Die KOW-Domäne wurde blau gestrichelt und die CspA-ähnliche Domäne gelb umrahmt.

In Archaeen besteht alF5A generell aus zwei Domänen. Diese Domänen sind über einen kurzen Link verknüpft. Dabei enthält die N-terminale Domäne den modifizierten Hypusinrest, ein Src-homolog3 Motiv (SH3- $\beta$-Barrel-Motif), sowie ein Kyrpides-Ouzounis-Woese-Motiv (KOWDomain) (Kyrpides, Woese and Ouzounis, 1996). Bei der C-terminalen Domäne im Archaeon Pyrobaculum aerophilum wurde für alF5A von Peat und Kollegen 1998 eine strukturelle Ähnlichkeit zu CspA ermittelt (Peat et al., 1998). Dies konnte auf andere Vertreter der Archaeen 
übertragen werden. Bei CspA handelt es sich um ein Kälteschock-Protein aus E. coli. Es besitzt eine RNA-Bindedomäne und fungiert als RNA-Chaperon (Jiang, Hou and Inouye, 1997). Ähnlich zu CspA weist alF5A auch diese RNA-Bindedomäne auf (Murzin, 1993).

In alF5A aus $H$. volcanii sind im Vergleich der Aminosäuresequenz diese Bereiche ebenfalls konserviert. Deshalb besteht die Wahrscheinlichkeit, dass auch dieser alF5A am RNA-Metabolismus beteiligt ist. Dies ist ein interessanter Aspekt für zukünftige Versuche.

Mit alF5A konnte in dieser Arbeit in drei Affinitätsaufreinigungen nach der MS-Analyse insgesamt 83 Proteine identifiziert werden. Nach Anwendung der Kontrollen konnten 23 Proteine zusammengefasst werden. Mit alF5A konnten alF2 $\alpha$, alF2B $\delta-1$ und alF5B.

Wie bereits erwähnt ist es ein wichtiger Aspekt, dass mit der in dieser Arbeit angewendeten Methode Funktionsbereiche eingegrenzt und direkte und indirekte Interaktionen betrachtet werden können. Dazu zählen auch Interaktionen im weiteren Sinn wie RNA gekoppelt, transient oder im Komplex. Auch im Hinblick darauf, das in Eukaryonten elF5A an der Translationselongation beteiligt ist (Gregio et al., 2009; Patel et al., 2009).

Die Überexpression von alF5A könnte sich auf das Polyamin-Level in $H$. volcanii auswirken. Die Polyamine werden in Säugetierzellen in der Translation sowohl für die Initiation als auch für die Elongation benötigt. Sie sind nicht nur als Vorläufer bei der Hypusinierung von elF5A beteiligt, sondern auch an der Phosphorylierung von elF2 $\alpha$ (Landau et al., 2010). Inwieweit die Überexpression von alF5A in $H$. volcanii auf die Polyamin-Konzentration auswirkt, muss jedoch noch geklärt werden.

Auf dem SDS-Gel konnte alF5A mit einer Größe von 14,2 kDa zwischen 15-25 kDa nachgewiesen werden. Zwei kleinere Banden zwischen 10-15 kDa konnten ebenfalls nachgewiesen werden. In den MS-Daten konnte nach der Auswertung zwei kleinere Proteine zwischen 1015 kDa identifiziert werden. Diese sind eine Peptidyl-tRNA-Hydrolase (HVO_0659; 11,9 kDa) und ein UPF0058 family protein (HVO_1473; 10,3 kDa).

In Eukaryonten interagiert eIF5A mit rpL1 und rpL42/rpL44 der großen ribosomalen Untereinheit (Schmidt et al., 2016). Das rpL1 konnte auch in dieser Arbeit mit alF5A co-gereinigt werden. Dieses ribosomale Protein konnte auch mit acht weiteren alFs- bzw. -Untereinheiten mitgereinigt werden. In $\mathrm{H}$. volcanii liegt rpL1 (HVO_2757) mit zwei weiteren Genen in einem Operon. Diese sind P0/rpL10 (HVO_2756) und rpL11 (HVO_2755).

Unter anderem agiert rpL1 als frühes rRNA-bindendes ribosomales Protein. Es konnte aber auch in $M$. vannielii eine Repressorfunktion von rpL1 nachgewiesen werden. Dabei bindet rpL1 an seine eigene mRNA (Hanner et al., 1994; Tishchenko et al., 2008).

\subsection{7 alF5B}

alF5B ist der dritte Translationsinitiationsfaktor, der in allen drei Domänen des Lebens konserviert ist. Unter anderem als elF5B/IF2/alF5B bzw. alF-2/5B benannt, besitzt er die Funktion 
einer Guanosine-Triphosphatase (GTPase) und ist ein wichtiger Faktor der Translation (Jackson, Hellen and Pestova, 2010).

In Eukaryonten kann elF5B in seinem N-terminalen Bereich sowohl mit sich selbst, als auch mit elF1A interagieren (Nag et al., 2016). Des Weiteren ist er an der Rekrutierung der großen ribosomalen Untereinheit und an der Erkennung der Initiator-tRNA beteiligt. In Eukaryonten bindet elF5B das GTP, dessen Hydrolyse zur Freisetzung des elF5B führt (Pestova et al., 2000). Dabei hydrolysiert elF5B-GTP und die Initiationsfaktoren elF1, elF1A, elF3 und elF2GDP dissoziieren von der kleinen ribosomalen Untereinheit (Fernández et al., 2013).

Im Sequenz-Alignment weist der archaeale alF5B eine größere Ähnlichkeit zum eukaryontischen elF5B als zum bakteriellen IF2 auf (Maone et al., 2007). Dies ist auch bei alF5B aus $H$. volcanii der Fall, wie in Abbildung 63 gezeigt.

Generell teilt sich alF5B/elF5B/IF2 in vier Bereiche. Diese sind die G-Domäne und Domäne II-IV. In der G-Domäne sind unter anderem die für GTP-bindenden Proteine typischen vier Sequenzbereiche (G1/P1-Loop, G2, G3 und G4) sowie die beiden Switch-Regionen konserviert. Die Regionen Switch 1 und Switch 2 unterscheiden sich bei den GTP-Bindeproteinen in ihrer Konformation signifikant im GTP- und GDP-gebundenen Zustand. Dabei ist Switch 1 ein Bestandteil der Effektorregion und Switch 2 enthält zu Beginn das G2-Motiv (Roll-Mecak et al., 2000).

Da alF5B in $H$. volcanii nicht deletiert werden konnte, wurde er als essenziell eingestuft (Gäbel et al., 2013). Dies ist ein entscheidender Unterschied, da in S. cerevisiae elF5B nicht essenziell ist. Aufgrund der beeinträchtigten Translationsinitiation in S. cerevisiae zeigte die Deletionsmutante jedoch ein starkes Wachstumsdefizit (Choi et al., 1998). Durch die Mutation bzw. Deletion von Bereichen, die die Freisetzung von elF5B bei fehlender Hydrolyse ermöglichen und die GTPase-Aktivität blockieren, wurde das Leaky-Scanning erhöht (Shin et al., 2002). Wie ähnlich sich die Homologen der beiden Domänen des Lebens sind, konnte Lee und Kollegen im Jahre 1999 belegen. Sie bewiesen, dass in vitro die Funktion von elF5B aus S. cerevisiae durch alF5B aus Methanocaldococcus jannaschii übernommen werden kann (Lee et al., 1999).

2007 konnte Maone und Kollegen für alF5B aus S. solfataricus in vitro nachweisen, dass der Faktor die Bindung der Initiator-tRNA stimuliert, ohne das vorhanden sein von weiteren Faktoren. Des Weiteren konnte der Faktor in einem zellfreien System sowohl die Translation von leaderloser als auch mRNA mit leader erhöhen (Maone et al., 2007).

Unter anderem konnte in Eukaryonten für elF5B in Kombination mit den HCV-IRES RNA, die Translationsinitiation nachgewiesen werden. Dies konnte bei niedrigen Konzentrationen von elF2-Met-tRNAi-GTP beobachtet werden, bei der der 48S-ähnliche Komplex, die MettRNAi, elF5B und elF3 umfasste (Locker, Easton and Lukavsky, 2007; Fernández et al., 2013; Yamamoto et al., 2014). 
In der hier vorliegenden Arbeit wurde alF5B aufgrund seiner essenziellen Eigenschaft in $H$. volcanii im Wildtyp überexprimiert. Dabei konnte bei der Überexpressionsmutante ein sehr viel besseres Wachstum bei $42{ }^{\circ} \mathrm{C}$ in Komplexmedium gegenüber dem Wildtyp mit dem Leerplasmid nachgewiesen werden.

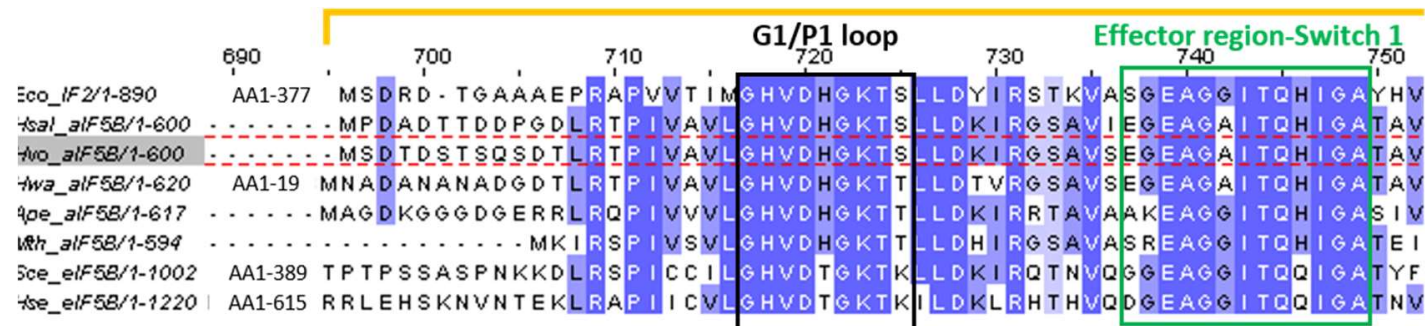

G Domain

Eco_IFL1-890 ETE........................

Eco_IF2/1-890 ETE.........................

Switch 2 HSal_alF58/1-600 PLDTVSEVAGSLVD..PTEFDLPGLLF IDT PG HHSFSTLRSRGGALADIAILVVDVNDGFQPQT

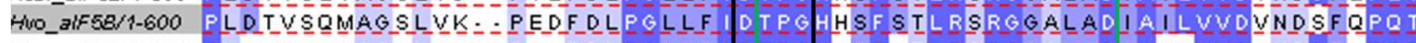
HWa_alF5E/1-620 PLETVSEMAGELVD..PADFDLPGLLF |DTPG HHSF T TLRSRGGALADIAVVVVDVNDGFQPQT ADe_alF58/1-617 PADVIEKIAEPLKKVIPVKLVIPGLLF |DTPG HELFSNLRRRGGSVADFAILVVDIMEGFKPQT MSh_alFSB/1-594 PMDVIEGICGDFLKKFSIRETLPGLFF |DTPGHEAFT TLRKRGGALADLAILIVDINEGF KPQT

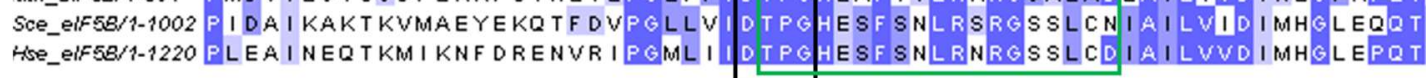

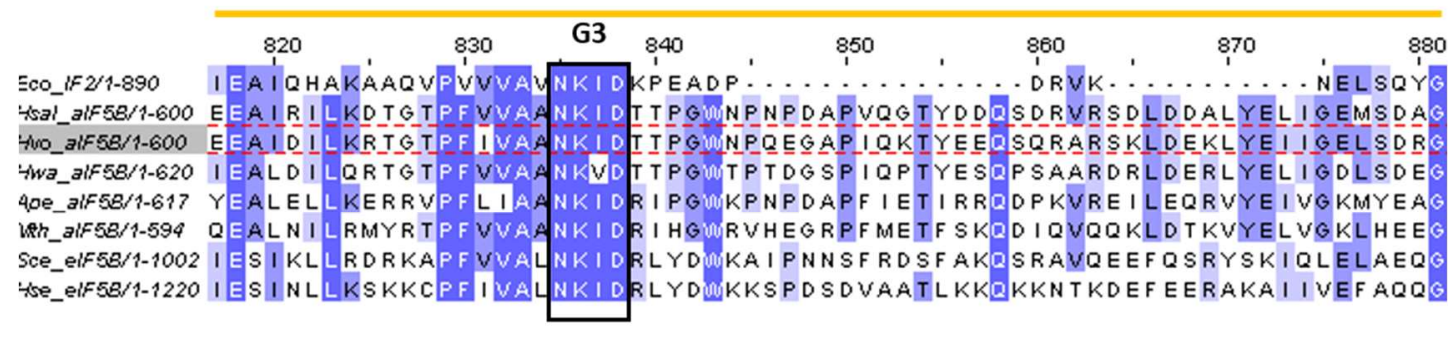

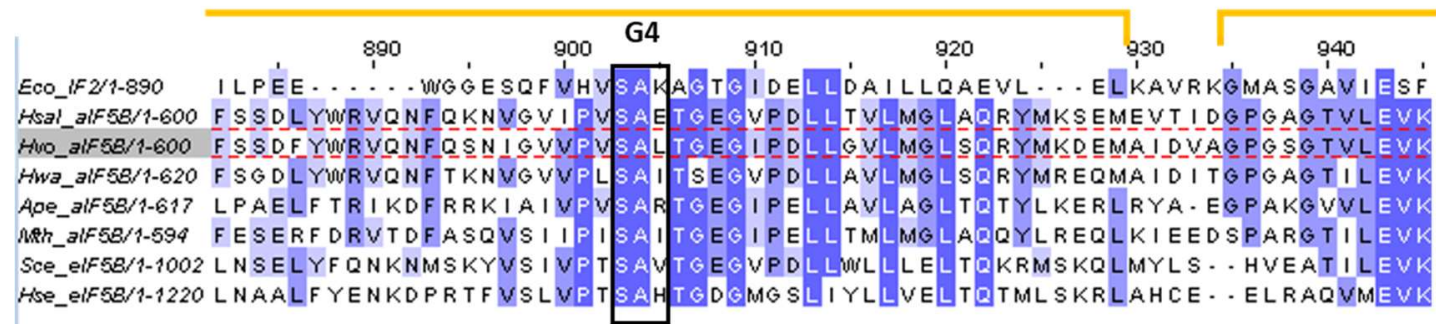

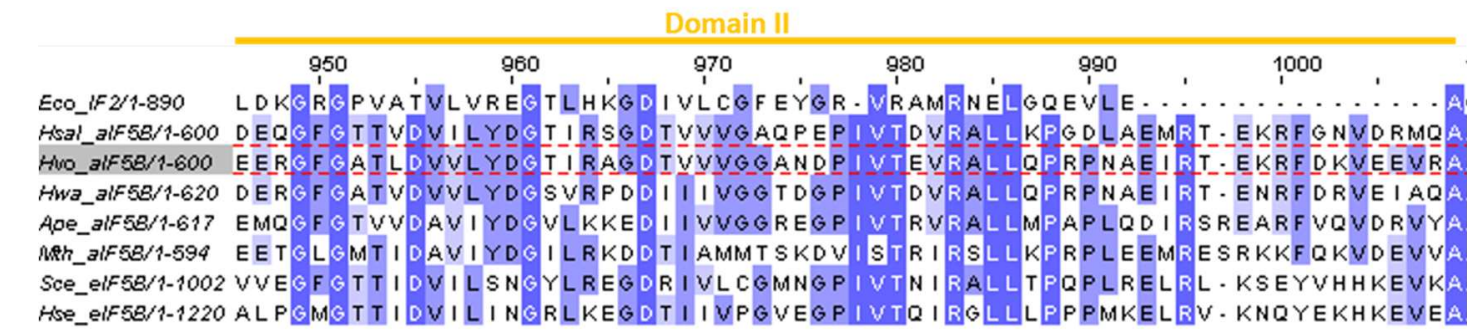

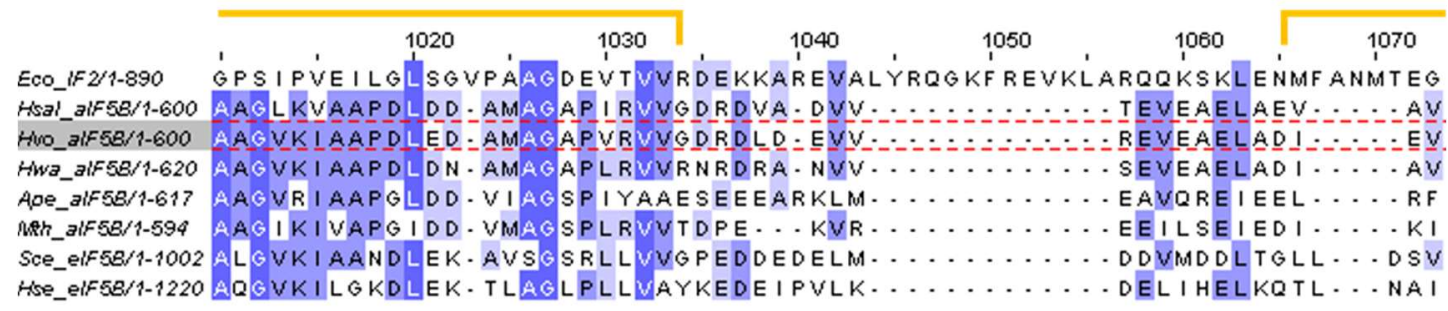




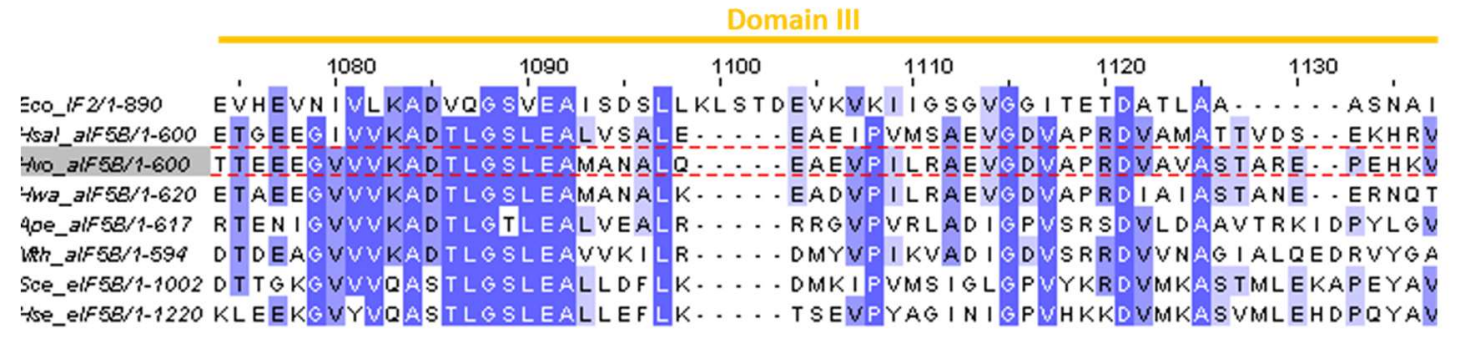

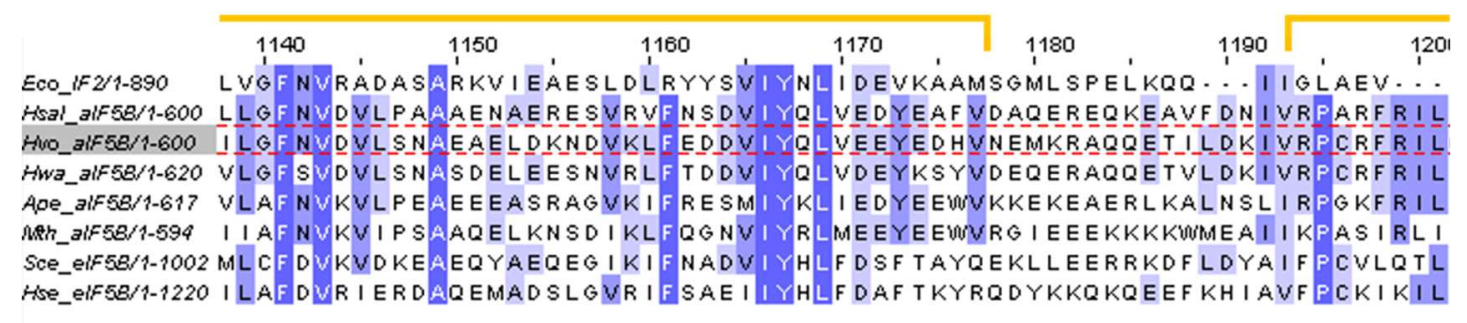

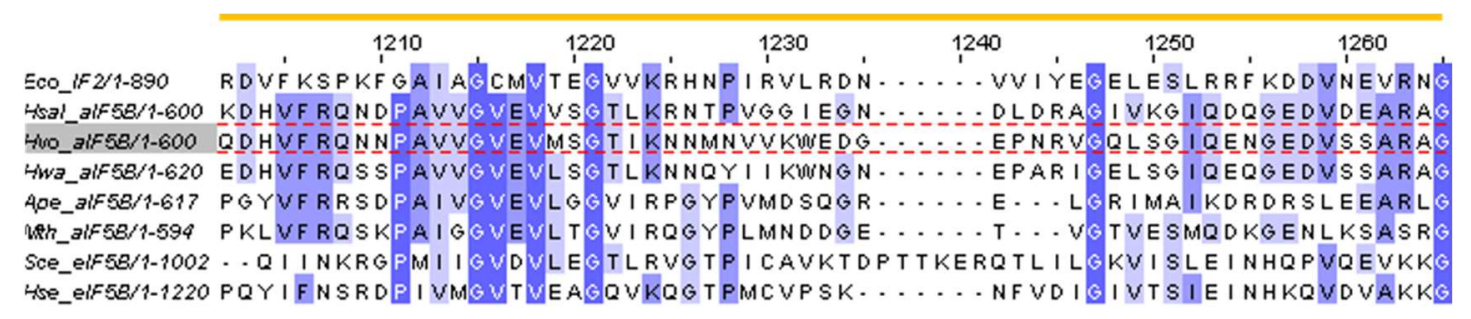

Domain IV

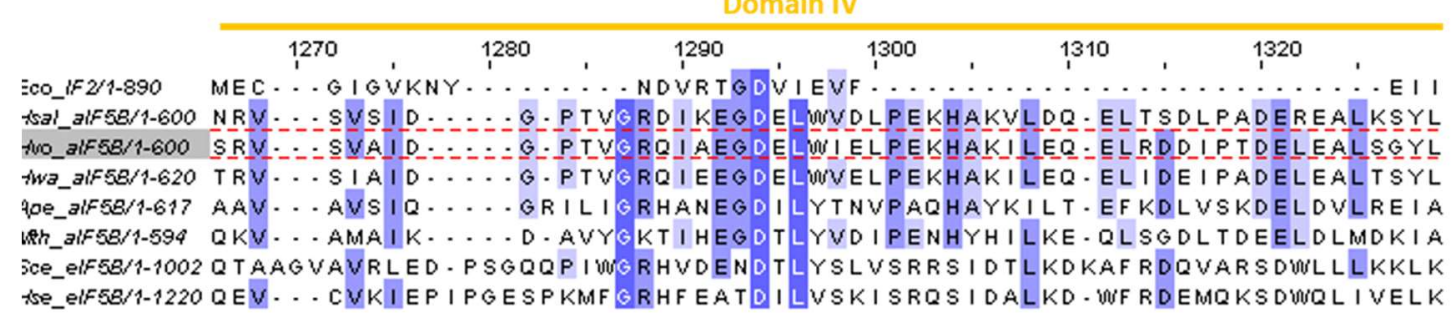

\begin{tabular}{|c|c|c|}
\hline & 1330 & alF5B (HVO_1963) \\
\hline Eco_lF $2 / 1-890$ & EIORTIA.... & $28,3 \%$ identisch mit $E$. coli \\
\hline toal_alFES/1-600 & 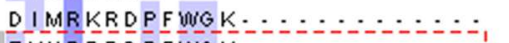 & $71,5 \%$ identisch mit $H$. salinarum \\
\hline tho_alF5B/1-600 I & E K H R R R D P F WU K $=:=$ & $76,0 \%$ identisch mit $H$. walsby \\
\hline 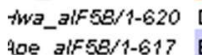 & DSHRKRDPFWGK & $45,4 \%$ identisch mit $A$. pernix \\
\hline 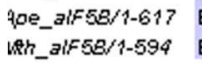 & $\begin{array}{l}\text { E I KRRAADHEYNKVLLRLKIKRUSOI } \\
\text { E I KRKKNPDWGMKAPF }\end{array}$ & $47,6 \%$ identisch mit $M$. thermautotrophicus \\
\hline sce_elf $5 B / 1-1002$ & .............WVGGIE. & $36,9 \%$ identisch mit S. cerevisiae \\
\hline the elF5B/1-1220 & $\cdots \cdots \cdots$ KVFEII & $35,0 \%$ identisch mit $H$. sapiens \\
\hline
\end{tabular}

Abbildung 63: Sequenz-Alignment alF5B/eIF5B/IF2, modifiziert nach (Roll-Mecak et al., 2000)

Das Sequenz-Alignment wurde mittels Clustal O und Jalview durchgeführt. Die Sequenzen von alF5B/elF5B/IF2 aus E. coli (Eco; P0A705), H. salinarum (Has; A0A510N889), H. volcanii (Hvo; D4GTJ2), H. walsbyi (Hwa; GOLMM9), Aeropyrum pernix (Ape; Q9Y9B3) und Methanothermobacter thermautotrophicus (Mth; O26359) S. cerevisiae (Sce; P39730), $H$. sapiens (Hse; O60841) wurden verglichen. Die schwarzen Kästen G1-G4 umrahmen die GTP-Bindemotive. Die Switch1 und Switch2 Regionen sind grün umrahmt. Die vier Domänen sind in gelben Klammern eingefasst. Blau umrahmt ist die C-terminale zusätzliche $\alpha$-Helix15 von alF5B aus A. pernix.

Nach der Affinitätsaufreinigung und MS-Analyse konnte in dieser Arbeit bei der Überexpression von alF5B in $H$. volcanii nur alF2Bס-1 von den Initiationsfaktoren mitgereinigt werden. Jedoch konnte alF5B mit fast allen überexprimierten Initiationsfaktoren mitgereinigt werden.

Die Interaktion zwischen elF1A und elF5B konnte in S. cerevisiae mittels pulldown-Assay gezeigt werden (Choi et al., 2000; Olsen et al., 2003). In Archaeen ist die Interaktion von alF5B und alF1A-1 umstritten. 
Bisher konnten die Struktur von alF5B in Euryarchaeota aus Methanothermobacter thermautotrophicus (Roll-Mecak et al., 2000) und in Crenarchaeota aus Aeropyrum pernix (Murakami et al., 2016) aufgeklärt werden. Im Vergleich sticht vor allem der Unterschied des C-Terminus hervor. Dieser ist in A. pernix verlängert (Abbildung 63, blauer Kasten). Hier konnte von Murakami und Kollegen nachgewiesen werden, dass diese zusätzliche $\alpha$-Helix an die Furche der Domäne IV in alF5B bindet (Murakami et al., 2016). Dieser Bereich wird in Eukaryonten unter anderem für die Interaktion von elF5B mit elF1A1 benötigt (Kuhle and Ficner, 2014b, 2014a; Zheng et al., 2014). Aufgrund der Interaktion der einzelnen Bereiche von alF5B in A. pernix wird angenommen, dass es einen anderen Weg der Interaktion zwischen alF5B und alF1A-1 in Archaeen gibt. Inwiefern dies auf andere Archaeen übertragbar ist, ist anhand der Sequenzen fraglich, da die C-terminalen Enden meist kürzer als die des A. pernix sind (Abbildung 63).

In dieser Arbeit konnte für $H$. volcanii mit alF5B keine der beiden alF1A-Orthologen co-gereinigt werden. Jedoch konnte alF5B mit alF1A-1 und alF1A-2 mitgereinigt werden.

Im direkten Sequenz-Alignment von alF5B aus $H$. volcanii mit $A$. pernix ist keine Übereinstimmung im C-terminalen Bereich vorhanden. Durch das Sequenz-Alignment und die MSDaten kann davon ausgegangen werden, dass alF5B mit alF1A-1 in $H$. volcanii interagieren kann.

Für S. solfataricus konnte gezeigt werden, dass alF5B an das ribosomale Protein L12/P1 bindet und damit eine wichtige Aufgabe in der Assoziation der beiden ribosomalen Untereinheiten besitzt (Nomura et al., 2012; Murakami et al., 2018). In dieser Arbeit konnten bei der Überexpression von alF5B in $H$. volcanii vier ribosomale Proteine der großen $50 S$ ribosomalen Untereinheit mitgereinigt werden, jedoch nicht L12/P1. Bei den vier ribosomalen Proteinen handelte es sich um die 50S ribosomalen Proteine L1 (HVO_2757), L2 (HVO_2561), L22 (HVO_2559) und L30 (HVO_2543).

Wie bereits zuvor beschrieben ist L1 in Archaeen in den tRNA-release-Mechanismus involviert und Teil des L1-stalk (Gabdulkhakov, Nikonov and Garber, 2013). L2 ist ein hochkonserviertes ribosomales Protein, welches für die Verbindung der $30 \mathrm{~S}$ und $50 \mathrm{~S}$ ribosomalen Untereinheit benötigt wird. Des Weiteren ist L2 an der A- und P-Site in die Bindung der tRNA involviert (Ühlein et al., 1998; Diedrich et al., 2000). In E. coli fungiert L2 als Transkriptionsregulator und fördert die Transkription von Genen mit ribosomalem RNA-Promotor (Rippa et al., 2010). L22 ist in Archaeen unter anderem mit der 23S rRNA, L4, L22 und L39e ein Teil des Exit-Tunnels der Polypeptidkette (Nissen et al., 2000; Moore and Steitz, 2002).

Bei L30 oder auch rpL30p/L7E genannt, handelt es ich um ein ribosomales Protein, das bei der Bindung der 5S rRNA an die große ribosomale Untereinheit beteiligt ist (Scholzen and Arndt, 1991; Hansen et al., 2002; Hansen, Moore and Steitz, 2003; Mitroshin, Garber and Gabdulkhakov, 2016).

alF5B konnte in dieser Arbeit bei fast allen Aufreinigungen co-gereinigt werden. Als unspezifisches Protein kann er ausgeschlossen werden, da er nicht in den Kontrollen co-gereinigt 
werden konnte und keine Polyhistidine in seiner Aminosäuresequenz enthält (Abbildung 73). Damit kann von einer wichtigen regulatorischen Funktion von alF5B in $\mathrm{H}$. volcanii ausgegangen werden.

\subsection{8 alF6}

Der Translationsinitiationsfaktor alF6 ist ein monomeres Homolog zu elF6 aus Eukaryonten. In Bakterien ist alF6 nicht vertreten. Sowohl in Eukaryonten als auch in Archaeen ist dieser Translationsinitiationsfaktor essenziell und scheint mehrere Funktion zu besitzen. Hierzu gehören die Ribosomenbiogenese, die Kontrolle der Translation und die Tumorprogression in höheren Eukaryonten (Groft et al., 2000; Benelli et al., 2009; Brina et al., 2015).

Ein Sequenzvergleich von elF6/alF6 aus verschiedenen Eukaryonten und Archaeen ist in Abbildung 64A dargestellt. Die Ähnlichkeit in den Strukturen wird in Abbildung 64B gezeigt.

A
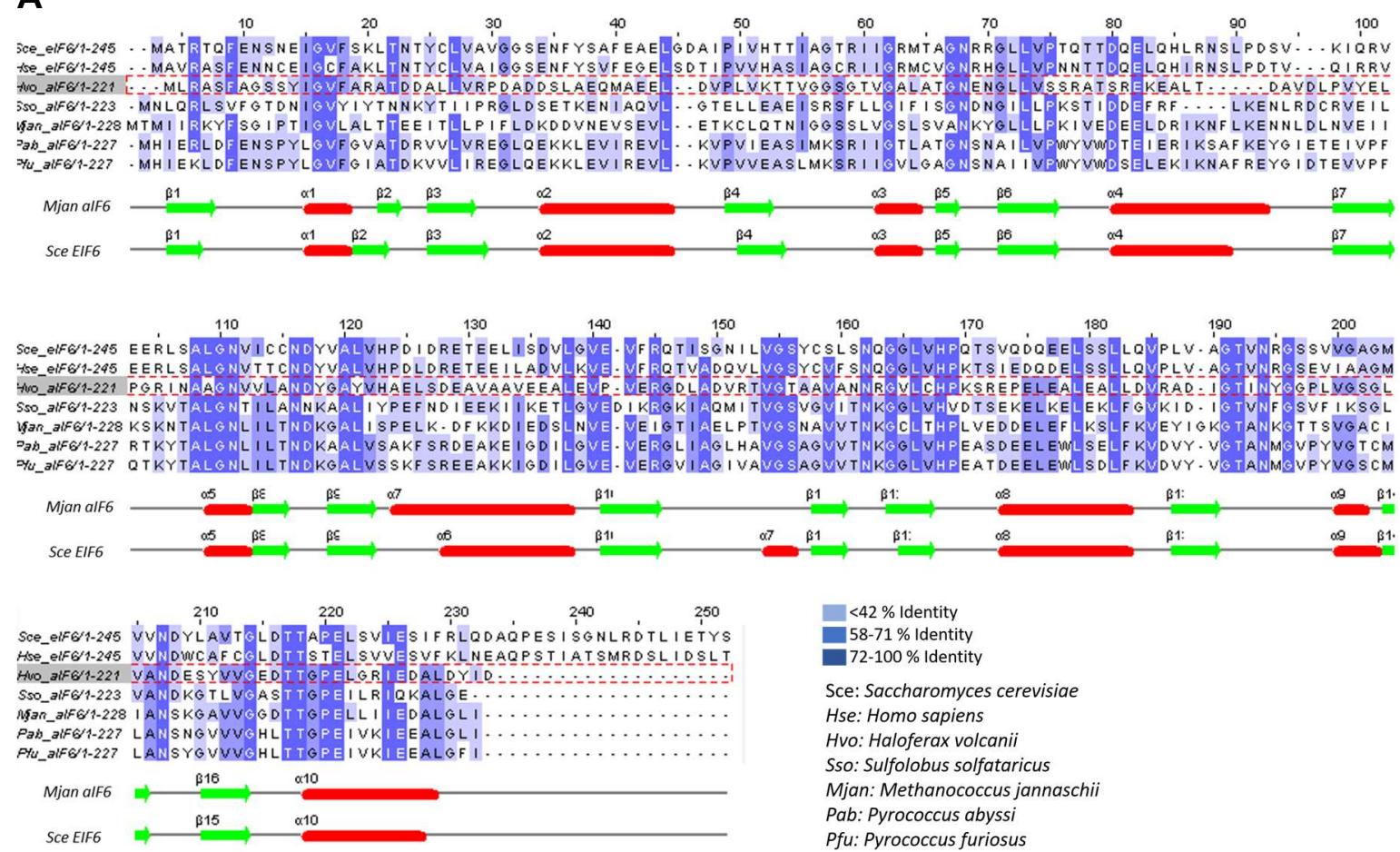

B

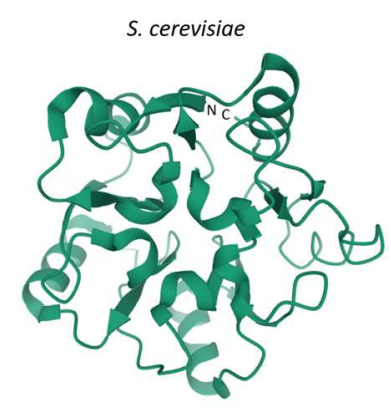

$1 \mathrm{G} 62$

$1-224$

https://www.rcsb.org/3d-view/molstar/1g62

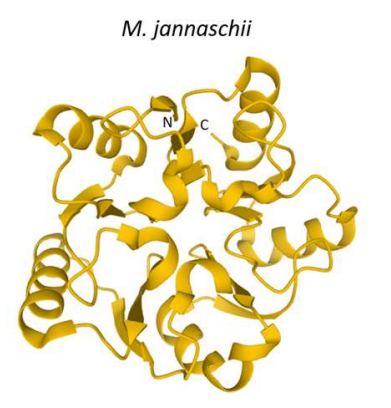

$1 \mathrm{G} 61$

$1-228$

http://www.rcsb.org/3d-view/molstar/1g61
Abbildung 64: Sequenz-Alignment von alF6/elF6

A. Strukturbasierendes Sequenz-Alignment mittels Clustal $O$ erstellt und Jalview visualisiert. Verglichen wurden Sequenzen von alF6/elF6 aus $S$. cerevisiae (Q12522), H. sapiens (P56537), S. solfataricus (Q980G0), M. jannaschii (Q60357), P. abyssi (Q9UYI6), Pyrococcus furiosus (Q8U3S8) und $H$. volcanii (D4GYW3). B. Strukturen von alF6 aus $S$. cerevisiae und $M$. jannaschii zeigen die $\beta$-Strands und $\alpha$-Helices. 
In dieser Arbeit wurde der in $H$. volcanii essenziell eingestufte alF6 im Wildtyp überexprimiert. Die Mutante wuchs geringfügig besser als der Wildtyp mit Leerplasmid. Nach den Affinitätsaufreinigungen konnte nur eine schwache Bande auf der höhe des alF6 mittels Coomassie auf dem SDS-Gel sichtbar gemacht werden. Dies spiegelte sich auch in der MS-Analyse wider. In H. volcanii konnte alF6 nur mit geringen Unique Peptides identifiziert werden. In einer Auswertung lag der Unique Peptides Wert unter zwei, weshalb nur zwei Messungen ausgewertet werden konnten. Unter anderem könnte dies an seiner Funktion in der Kontrolle der Translation liegen. Dabei fungiert er als anti-association-factor zwischen kleiner und großer ribosomaler Untereinheit. Greber und Kollegen konnten 2012 für das Archaeon Methanothermobacter thermautotrophicus nachweisen, dass alF6 an die große 50S ribosomale Untereinheit bindet. Damit verhindert er die vorzeitige Anlagerung an den Präinitiationskomplex bzw. der kleinen ribosomalen Untereinheit (Greber et al., 2012).

Dennoch konnten bei zwei Affinitätsaufreinigungen 57 Proteine identifiziert werden. Mit alF6 konnten nicht nur Translationsinitiationsfaktoren, sondern auch vier ribosomale Proteine der großen 50S ribosomalen Untereinheit co-gereinigt werden. Diese sind L1 (HVO_2757), L2 (HVO_2561), L3 (HVO_2564) und L4 (HVO_2563).

Im Vergleich von S. cerevisiae und M. jannaschii konnte 2000 von Groft und Kollegen gezeigt werden, dass beide Initiationsfaktoren, alF6 und elF6, mit der großen ribosomalen Untereinheit interagieren. In der hier vorliegenden Arbeit konnte die Interaktion von alF6 und L14 nicht gezeigt werden, wie es Benelli und Kollegen 2009 für S. solfataricus beschrieben (Groft et al., 2000; Benelli et al., 2009).

Grebe und Kollegen konnten 2012 für M. thermautotrophicus bei der Cryo-Elektronenmikroskopie die Interaktion von alF6 und der 50 S ribosomalen Untereinheit in Komplex weiter aufklären. Sie konnten dabei auch die Bindung von alF6 und dem ribosomalen Protein L14 (in Eukaryonten L23) bestätigen (Greber et al., 2012). Zusätzlich konnten schwächere Interaktionen mit rpL3, rpL24e und dem Sarcin-Ricin-Loop der 23S rRNA nachgewiesen werden. In der hier vorliegenden Arbeit konnte das ribosomale Protein rpL3 mit alF6 co-gereinigt werden, was auch auf eine Interaktion der beiden Proteine in $H$. volcanii schließen lässt.

In Eukaryonten wurde mehrfach gezeigt, dass elF6 eine Rolle bei der Reifung der 60S ribosomalen Untereinheit spielt (Basu et al., 2001; Brina et al., 2015). In S. cerevisiae scheint elF6 eine geringere Rolle in der Translation zu spielen und eher an der Ribosomenbiogenese beteiligt zu sein (Basu et al., 2001). In Eukaryonten gibt es die elongation factor like 1 GTPase (H. sapiens: EFL1; S. cerevisiae: Efl1) und das Shwachman-Diamond-Syndrom-Protein $(H$. sapiens: SBDS; S. cerevisiae: Sdo1). Beide sind für die Freisetzung des elF6 zuständig. Dies ist einer der letzten Schritte der Reifung der großen ribosomalen Untereinheit und ermöglicht die Bildung reifer Ribosomen (Luviano et al., 2019). In Archaeen gibt es zu Efl1 kein Ortholog. Jedoch existiert ein Ortholog für SBDS/Sdo1 (Pech and Nierhaus, 2012). In H. volcanii konnte SBDS (HVO_1344) in keiner der Affinitätsaufreinigungen identifiziert werden. 
Mit alF6 konnten alF5B als auch alF2Bס-1 mitgereinigt werden. Die Interaktion zu diesen Faktoren wurde bisher in der Literatur nicht beschrieben. alF5B und alF2B $\delta$-1 konnten bei fast allen anderen alFs co-gereinigt werden, was die Funktion der Proteine unterstreicht.

In den RNA- und DNA-Seq-Daten konnte gezeigt werden, dass alF6 ebenfalls in einem Operon liegt. Dabei ist er downstream von zwei ribosomalen Proteinen der $50 \mathrm{~S}$ großen ribosomalen Untereinheit positioniert (Abbildung 65). Diese sind rpl39e (HVO_0115) und rpl31e (HVO_0116), die in dieser Arbeit mit keinem Faktor mitgereinigt werden konnten. Das beschriebene Operon ist in vielen Archaeen konserviert. In direkter Nachbarschaft zu diesem Operon liegen die beiden Gene rpL20e (HVO_0118) und pfdA (HVO_0119). Auch diese Anordnung ist in Archaeen konserviert.

Um die in dieser Arbeit erzielten Ergebnisse zu unterstreichen und einen Einfluss des NTerminalen His-Tags auszuschließen, sollten die Versuche mit einem C-Terminalen His-Tag für alF6 wiederholt werden.

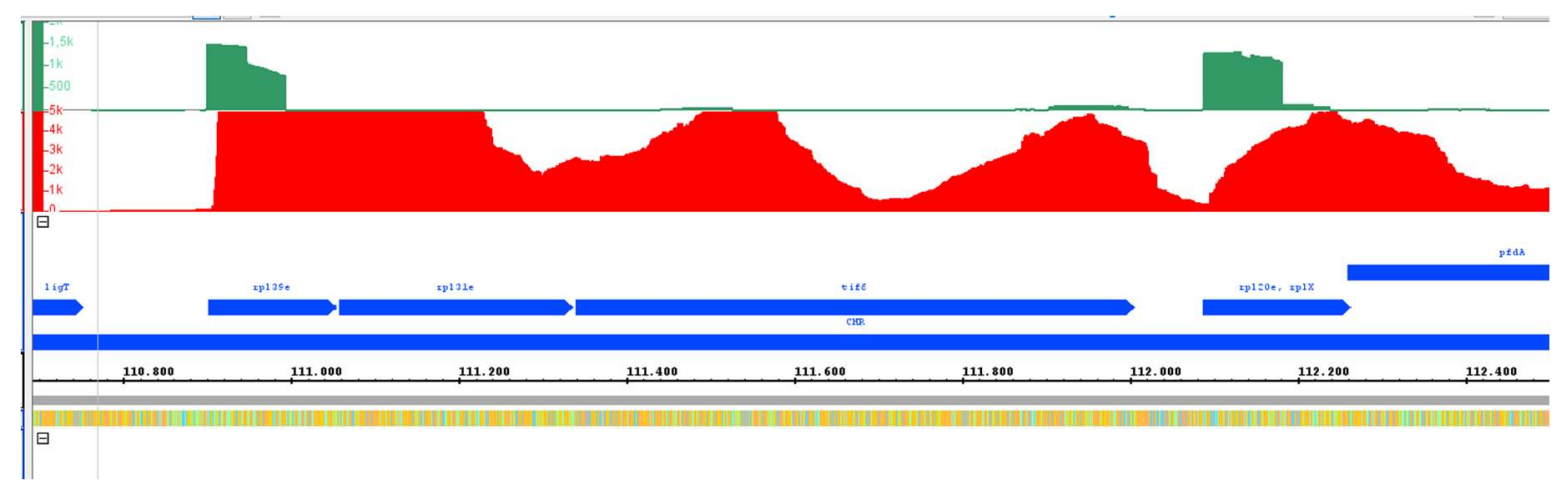

Abbildung 65: DNA- und RNA-Seq-Daten des alF6 (HVO_0117)

Die Gene sind in blau, das Transkriptionslevel in rot und der Transkriptionsstart in grün dargestellt. Das Gen alF6 bzw. tif6 liegt auf dem Forward-Strang.

\subsection{RNAPUs in der MS-Analyse}

Der Mechanismus der Transkription in Archaeen ähnelt der Transkription in Eukaryonten. Unter anderem sind in Archaeen TATA-Box-Promotorsequenzen, TATA-Box-Bindeproteine (TBP), der Transkriptionsfaktor TFIIB (Homolog zu Eukaryonten) und die RNA-Polymerase II vertreten (Goede et al., 2006). Wie bereits in Kapitel 1.1 erwähnt, ähnelt die RNA-Polymerase in Archaeen der eukaryontischen RNA-Polymerase II. Im Gegensatz zu Bakterien mit 6 RNAPUs sind in Eukaryoten und Archaeen 13 Untereinheiten bekannt (Grohmann, Hirtreiter and Werner, 2009).

Die mRNA in Archaeen hingegen ähnelt in ihrer Struktur bakterieller mRNA (Tabelle 2). Die Transkriptionsregulatoren sind bis auf wenige Ausnahmen homolog zu bakteriellen Aktivatoren, Repressoren und Stimulatoren (Krüger et al., 1998; Kyrpides and Woese, 1998b; Bell and Jackson, 2001; Bell, 2005). 
Als Prokaryoten besitzen Archaeen und Bakterien keinen definierten Zellkern. Somit findet die Transkription und Translation im selben Zellraum statt.

Ähnlich zu Bakterien ist auch die Organisation von funktionsverwandten Genen in multicistronischen Operons (Srinivasan, Krebs and RajBhandary, 2006). Bei der Clusterung von Genen kann davon ausgegangen werden, dass ihre Expression co-reguliert ist. Dies ist ein guter Indikator für eine funktionelle oder gar physische Interaktion. Ein Beispiel sind die RNAPUs in Archaeen, die alle in Operons liegen. Das größte Operon bildet rpoA1, rpoA2, rpoB1, rpoB2 und $\mathrm{rpoH}$, dass in vielen Archaeen konserviert ist (Werner, 2007).

Bemerkenswert ist, dass die meisten RNAPUs in Archaeen in Clustern mit ribosomalen Proteinen liegen. Darunter auch nicht-universelle archaeale ribosomale Proteine (Wang, Dasgupta and Fox, 2009). Wie beschrieben ist in einem dieser Cluster auch alF2y enthalten (Kapitel 4.4.3.3).

2008 konnte von Hirata und Kollegen die erste Kristallstruktur der RNA-Polymerase aus S. solfataricus für Archaeen aufgeklärt werden (Hirata, Klein and Murakami, 2008).

Generell lässt sich die RNA-Polymerase mit ihren Untereinheiten in drei Bereiche einteilen. Diese sind die Kerneinheit mit dem katalytischen Zentrum (rpoA1, rpoA2, rpoB1, rpoB2), die Montageplattform (rpoL, rpoN, rpoD, rpoP) und die Hilfseinheit (rpoH, rpoK, rpoF, rpoE) (Grohmann, Hirtreiter and Werner, 2009).

In $H$. volcanii sind 12 RNAPUs annotiert, während rpoG nur in Crenarchaea vertreten ist (Grohmann and Werner, 2010). In dieser Arbeit wurden sieben der zwölf RNAPUs aus $H$. volcanii überexprimiert, aufgereinigt und in der MS analysiert. Damit sollte überprüft werden, ob auch mit den RNAPUs Initiationsfaktoren mitgereinigt werden können. Mit den sieben überexprimierten RNAPUs konnten Proteine der Transkription, Translation, ribosomale Proteine und Proteine der Replikation mitgereinigt werden. Dazu zählen auch Translationsinitiationsfaktoren. Für alF2Bס-1 und alF5B war die Co-Reinigung von RNAPUs erfolgreich. Auch die Co-Reinigung der beiden Faktoren seitens der RNAPUs war möglich (Tabelle 84 und 85).

Insgesamt konnten mit den sieben RNAPUs bis auf rpoK und rpoE alle RNAPUs mitgereinigt werden. Dies spricht für die Validität der in dieser Arbeit etablierten Methode: der His-getaggten Aufreinigung und MS-Analyse in $H$. volcanii, um direkte und indirekte Interaktionspartner von Proteinen zu identifizieren. Dabei konnte ein Funktions- bzw. Interaktionsbereich eingegrenzt werden. Jedoch sind weitere Untersuchungen erforderlich, um diese Bereiche eineindeutig einzugrenzen.

Für die weitere Aufklärung und Vervollständigung des Interaktionsnetzwerks von RNAPUs wäre es hilfreich, die in dieser Arbeit fehlenden RNAPUs (rpoF, rpoE, rpoK, rpoN, rpoP) ebenfalls mittels Überexpression, Affinitätsaufreinigung und MS-Analyse zu untersuchen. 


\subsection{1 rроA1, гроA2, rроB1, rроB2 und $\mathrm{rpoH}$}

Im Genom von $H$. volcanii liegen die fünf RNAPUs rpoA1 (HVO_0349), rpoA2 (HVO_0350), rpoB1 (HVO_0348), rpoB2 (HVO_0347) und rpoH (HVO_0346) in einem Operon mit weiteren Proteinen. Dabei sind die ersten vier genannten RNAPUs ein wichtiger Bestandteil des katalytischen Zentrums der RNAP und in allen drei Domänen des Lebens vertreten (Tabelle 1). In Eukaryonten ist rpb1 die größte Untereinheit. In Archaeen ist diese Untereinheit in zwei Polypeptide und somit in zwei Gene rpoA1 und rpoA2 aufgeteilt. Sie liegen gemeinsam in einem Operon (Langer et al., 1995). Auch rpb2 in Eukaryonten ist in manchen Archaeen in zwei Gene (rpoB1 und rpoB2) und damit in zwei Polypeptidketten geteilt (Langer et al., 1995).

$\mathrm{rpoH}$ ist in Archaeen und Eukaryonten (rpb5) konserviert. In S. shibatae wurde 2009 von Korkhin und Kollegen die Interaktion von rpoH mit rpo13 beschrieben (Korkhin et al., 2009). rpo13 wurde bisher nur in Sulfolobales nachgewiesen (Hirata and Murakami, 2009).

Zu den weiteren annotierten Genen im Operon gehören auch zwei ribosomale Proteine rpS7 (HVO_0354) und rpS12 (HVO_0353). Viele ribosomale Proteine in Archaeen befinden sich in Gen-Clustern (Wang, Dasgupta and Fox, 2009). Das oben genannte Operon ist auch in weiteren Archaeen bekannt und konnte bisher in diesen nachgewiesen werden (Klenk, Schwass and Zillig, 1991).

Bemerkenswert ist dabei, dass das Protein rpS12 sich an der Schnittstelle von 30S und 50S ribosomalen Untereinheit befindet. Zusammen mit rpS4 und rpS5 spielt rpS12 eine wichtige Rolle bei der akkuraten Translation.

In dieser Arbeit konnte rpS12 weder mit den alFs noch mit den RNAPUs co-gereinigt werden. rpS7 konnte ebenfalls nicht mit den RNAPUs mitgereinigt werden. Mit den Initiationsfaktoren alF1, alF2Bס-1 und elF4A-homolog konnte er co-gereinigt werden. Dieses ribosomale Protein ist eines der primären rRNA-Bindeproteine und bindet direkt an die 16S rRNA. Dort ist es am Aufbau der Kopfdomäne der 30 S ribosomalen Untereinheit beteiligt und befindet sich in der Nähe des Dekodierungszentrums an der Schnittstelle der beiden Untereinheiten.

In dieser Arbeit wurden diese fünf RNAPUs unabhängig voneinander überexprimiert, affinitätsgereinigt, in der MS analysiert und ausgewertet. Das Augenmerk lag auf co-gereinigten alFs.

Die RNAPU rpoA1 konnte mit sieben alFs co-gereinigt werden. Er selbst konnte bei der Überexpression zwei alFs mitreinigen. Dabei konnte für rpoA1 und alF2Bס-1 sowie rpoA1 und alF5B eine gegenseitige Co-Reinigung nachgewiesen werden.

rpoA2 konnte mit vier alFs mitgereinigt werden. Er selbst konnte zwei alFs co-reinigen. Auch bei rpoA2 konnte mit alF2Bס-1 eine gegenseitige Co-Reinigung nachgewiesen werden.

rpoB1 konnte mit zwei alFs mitgereinigt werden. Darunter alF1 und alF2Bס-1. rpoB1 selbst konnte zwei alFs mitreinigen, darunter alF2Bס-1.

Die RNAPU rpoB2 konnte mit sieben alFs co-gereinigt werden, unter anderem alF2B $\delta$-1 und alF5B. Mit rpB2 selbst konnten drei alFs mitgereinigt werden, darunter alF2Bס-1 und alF5B. 
Bei rpoH konnte drei alFs darunter alF2 $\alpha$, alF2B $\delta$-1 und alF5B co-gereinigt werden. Aber auch mit alF2Bס-1 konnte rpoH mitgereinigt werden.

Auffallend ist dabei das rpoA1, rpoA2, rpoB1, rpoB2 und rpoH jeweils alF2Bס-1 co-reinigen und auch diese fünf RNAPUs in den MS-Daten von alF2Bס-1 identifiziert werden konnten.

Auch alF5B sticht hervor, da er die beiden RNAPUs rpoA1 und rpoB2 co-reinigen konnte. Umgekehrt konnte alF5B auch bei rpoA2, rpoB1 mitgereinigt werden. Zusätzlich konnte rpoH auch alF5B co-reinigen. Umgekehrt war dies nicht möglich.

\subsection{2 rpoL}

rpoL ist in allen drei Domänen des Lebens vertreten (Bacteria: all; Eukarya: rpb11). In $H$. volcanii liegt rpoL (HVO_1042) mit einem Beta-lactamase domain protein (HVO_1041) in direkter Nachbarschaft. rpoL und rpoD bilden gemeinsam einen stabiles Heterodimer bzw. einen Unterkomplex. Sie stellen gemeinsam mit rpoN und rpoP eine Plattform für die Assemblierung des aktiven Zentrums dar, welches aus den Untereinheiten rpoA1, rpoA2 und rpoB bzw. rpoB1 und rpoB2 besteht (Werner, Eloranta and Weinzierl, 2000; Goede et al., 2006).

In dieser Arbeit konnte rpoL mit alF1 co-gereinigt werden. Bei rpoL selbst konnten nach der Überexpression zwei alFs, alF2Bס-1 und alF5B identifiziert werden. Auffallend war bei rpoL, dass bei inm als einzige RNAPU die in dieser Arbeit untersucht wurde, keine 30 s ribosomale Proteine co-gereinigt werden konnten.

\subsection{3 rpoD}

rpoD ist in allein drei Domänen des Lebens konserviert (Bacteria: $\alpha$; : Eukarya: rpb3). rpoD (HVO_2781) liegt in einem Operon. Das Operon umfasst fünf Gene auf dem Reverse-Strang. Diese sind rpS13 (HVO_2784) rpS4 (HVO_2783) rpS11 (HVO_2782) und rpoD (HVO_2781). Des Weiteren befindet sich N-terminal eine tR30-LeuCAG-tRNA (HVO_2785).

In vielen Archaeen ist die Nachbarschaft der drei ribosomalen Proteine zu rpoD konserviert. Das gilt für viele Bakterien, allerdings nicht für Eukaryonten. Dennoch ist im Sequenzabgleich rpoD aus H. volcanii (D4GWY4) mit RPB3 aus S. cerevisiae (P16370) zu 24 \% identisch, während es zu rpoD aus E. coli (P00579) nur zu 17 \% identisch ist (Abbildung 74).

Wie im vorhergehenden Kapitel beschrieben, bildet rpoD mit rpoL ein Heterodimer bzw. Unterkomplex und mit rpoN und rpoP eine Plattform für die Assemblierung des aktiven Zentrums der RNA-Polymerase (Werner, Eloranta and Weinzierl, 2000; Goede et al., 2006). Zu erwähnen ist, dass rpoD (HVO_2781), rpoK (HVO_2775) und rpoN (HVO_2776) im Genom nahe beieinander liegen.

In dieser Arbeit wurde rpoD überexprimiert. Er konnte jedoch selbst nur mit einem Unique Peptides Wert von eins identifiziert werden. Dennoch konnte mit rpoD der Faktor alF2Bס-1 und umgekehrt co-gereinigt werden. Des Weiteren konnte rpoD mit alF1 mitgereinigt werden. 
Für die Bestätigung der MS-Daten sollte in diesem Fall rpoD mit einem C-terminalen His-Tag erneut überexprimiert und analysiert werden.

\subsection{4 rpoN und rpoK}

rpoN ist in Archaeen und Eukaryonten (rpb10) konserviert. rpoK ist sowohl in Archaeen, Eukaryonten (rpb6) und Bakterien $(\omega)$ vorhanden. Gemeinsam besitzen sie eine hochkonservierte Faltung im Kern.

rpoL, rpoD, rpoP und rpoN bilden die Montageplattform für das aktive Zentrum der RNAPolymerase in Archaeen (Werner, Eloranta and Weinzierl, 2000).

Bei Archaeen ist rpoK und rpoE am Schutz des C-Terminus des rpoA1 beteiligt. Diese Anordnung der Untereinheiten ist auch in der eukaryontischen RNAPII konserviert (Hirata, Klein and Murakami, 2008). Zusätzlich ist rpoK ein wichtiger Ankerpunkt für rpoE und rpoF (Ouhammouch et al., 2004).

In H. marismortui wurde bereits 1994 die Organisation bestimmter RNAPUs in Operons beschrieben (McKune and Woychik, 1994). Dabei handelte es sich unter anderem um rpoN und rpoK. Dies ist auch für $H$. volcanii der Fall. Die beiden RNAPUs rpoN (HVO_2776) und rpoK (HVO_2775) liegen mit mehreren Proteinen, darunter vier ribosomalen Proteine, in einem Operon. Diese sind zwei Proteine der kleinen und zwei Proteine der großen ribosomalen Untereinheit: rpL18e (HVO_2779), rpL13 (HVO_2778), rpS9 (HVO_2777) und rpS2 (HVO_2773). Des Weiteren ist eine Enolase (HVO_2774) im Operon enthalten.

In dieser Arbeit konnte rpoN und rpoK aus zeitlichen Gründen nicht überexprimiert werden. rpoN konnte nicht mit alFs, aber bei sechs RNAPUs (rpoA1, rpoA2, rpoB1, rpoB2, rpoH und $\mathrm{rpoL}$ ) mitgereinigt werden. rpoK konnte dagegen weder bei den alFs noch bei den RNAPUs co-gereinigt werden.

\subsection{5 rpoF und rpoE}

rpoE bzw. rpoE1 (HVO_1899) liegt in einem größeren Operon. Bei den im Operon annotierten Genen handelt es sich um alF2y (HVO_1901), einem putativen RNA-Bindeprotein, das eine PIN-Domäne enthält (HVO_1900), die RNAPU rpoE1 (HVO_1899), den Transkriptionselongationsfaktor spt4/rpoE2 (HVO_1898) sowie einer möglichen GTP-abhängigen Dephospho-CoAKinase (HVO_1897). Die unmittelbare Nähe dieser Gene konnte auch bei acht weiteren Vertretern der Halobacteriaceae nachgewiesen werden (Abbildung 57B). In diesem Cluster ist unter anderem auch das ribosomale Protein rpS24e vertreten (Wang, Dasgupta and Fox, 2009).

rpoF (HVO_2748) liegt mit rpL21e (HVO_2749) in einem Operon. Beide RNAPUs sind sowohl in Archaeen, als auch in Eukaryonten konserviert (Hirata, Klein and Murakami, 2008). 
In der RNA-Polymerase bilden rpoF und rpoE eine stielartige Struktur, die aus dem Kern der RNA-Polymerase hervorragt (Abbildung 2). Dieser Bereich ist an vielen Funktionen beteiligt. Unter anderem stabilisiert er den Initiationskomplex und bindet die naszierende RNA, was sich positiv auf die Elongations- und Terminationseffizienz der RNAP auswirkt.

Als Interaktionspartner dient die stielartige Struktur dem Transkriptionsfaktor E (Naji, Grünberg and Thomm, 2007; Werner, 2007; Griesenbeck, Tschochner and Grohmann, 2017).

Die RNAPUs rpoE und rpoF konnten aus zeitlichen Gründen in dieser Arbeit nicht überexprimiert werden. rpoF konnte aber in dieser Arbeit mit rpoL und alF2Bס-1 co-gereinigt werden. rpoE konnte weder bei alFs noch bei RNAPUs mitgereinigt werden.

Der Transkriptionsfaktor E (TFE, HVO_1174) konnte mit den RNAPUs nicht mitgereinigt werden, aber bei alF1 und alF2Bס-1. TFE ist in Archaeen nicht essenziell, wirkt sich aber positiv auf die Initiationsrate bei manchen, schwach exprimierten Promotoren aus (Hanzelka, Darcy and Reeve, 2001). Zudem konnte mit TFE eine höhere Effizienz bei der Wiederaufnahme von blockierten Elongationskomplexen gezeigt werden, was auf eine Stabilisierung des Elongationskomplexes während der Transkription hindeutet (Grünberg et al., 2007).

\subsection{6 rpoP}

rpoP (HVO_0653) ist in Archaeen und Eukaryonten (rpb12) konserviert. In H. volcanii liegt das Gen des rpoP auf dem Genom in einem Cluster mit dem 50 S ribosomalen Protein L37ae (HVO_0654). Dieses Cluster ist in vielen Archaeen vertreten. Bei L37ae handelt es sich um ein ribosomales Protein, das nur in Archaeen vorkommt (Wang, Dasgupta and Fox, 2009). rpoP ist die kleinste RNAPU in H. volcanii, dessen Protein ein Gewicht von 5,1 kDa besitzt. In dieser Arbeit konnte aus zeitlichen Gründen rpoP nicht überexprimiert werden. Die RNAPU selbst konnte nicht mit Initiationsfaktoren mitgereinigt werden. Bei der Überexpression der RNAPUs rpoA1, rpoB1, rpoB2, rpoH und rpoL konnte rpoP aber co-gereinigt werden.

Für die Assemblierung der RNAPU in Archaeen wurde 2002 von Werner und Weinzierl rpoP als essenziell beschrieben (Werner and Weinzierl, 2002). Dies könnte ein Grund für die CoReinigung von rpoP sein. Des Weiteren wurde von Jun und Kollegen 2011 in S. solfataricus beschrieben, dass rpoP mit seinem C-Terminalen Ende, zwischen rpoD und rpoB positioniert ist (Jun et al., 2011).

Aufgrund der Funktion von rpoP und der erfolgreichen Co-Reinigung mit fünf weiteren RNAPUs wäre eine Untersuchung mittels Überexpression, Aufreinigung und MS-Analyse des rpoP für den Ausbau des bestehenden Interaktionsnetzwerks hilfreich. 


\subsection{Vergleich elF-alF und mögliche Funktion in Archaeen}

Eukaryonten und Archaeen weisen in der Translationsinitiation einen gemeinsamen strukturellen Komplex, den Präinitiationskomplex, auf. Hierfür sind e/alF1, e/alF1A, der ternäre Komplex bestehend aus e/alF2 beladen mit GTP und der Met-tRNAi sowie die mRNA gebunden an die kleine ribosomale Untereinheit zuständig (Hasenöhrl et al., 2009; Coureux et al., 2016). Am Präinitiationskomplex sind unter anderem alF1, alF1A und alF2 in Archaeen beteiligt. Diese weisen Homologien zu ihren eukaryontischen Gegenstücken auf, was zu der Annahme führt, dass sie ähnliche Funktionen besitzen.

Im Jahr 2016 konnte von Coureux mittels Kryoelektronenmikroskopie zwei Konformationen des archaealen 30S-Initiationskomplexes von $P$. abyssi identifiziert werden. In der ersten Konformation ist die tRNA nicht in der Peptidyl-Seite, sondern nach außen orientiert. Dabei befindet sie sich in einer Art Standby-Position. alF2 interagiert währenddessen mit alF1 und der $30 S$ ribosomalen Untereinheit. In der zweiten Konformation ist die tRNA in der Peptidyl-Seite und führt zur Interaktion mit alF2. Die Standby-Position geht in die Dekodier-Position über (Coureux et al., 2016). Es ist jedoch fraglich, inwiefern dieser Vorgang aufgrund der Homologie auf $H$. volcanii übertragbar ist. Das kann zutreffen, da es in $P$. abyssi kaum leaderlose Transkripte gibt und dieser Vorgang einen Scanning-Mechanismus von kurzen 5 '-UTRs voraussetzt (Toffano-Nioche et al., 2013). In H. volcanii sind jedoch $72 \%$ der Transkripte leaderlos (Babski et al., 2016).

In S. solfataricus hingegen sind ähnlich wie in $H$. volcanii $69 \%$ der Transkripte leaderlos. Die Anzahl der Transkripte mit $5^{\prime}$-UTR ist sehr gering und beschränkt sich meist auf den Beginn eines Operons (Wurtzel et al., 2010). Es gibt auch zwischen S. solfataricus und $H$. volcanii gravierende Unterschiede. alF2 $\alpha$ ist in S. solfataricus essenziell und für die Bindung der tRNA zuständig, wohingegen in $H$. volcanii alF2 $\alpha$ nicht essenziell ist. Wie bereits erwähnt existieren keine alF2B-Untereinheit in S. solfataricus (Dev et al., 2009). Hinzu kommt, dass alF2 in S. solfataricus zuerst an die $30 \mathrm{~S}$ ribosomale Untereinheit bindet, bevor die Met-tRNAi rekrutiert wird (La Teana et al., 2013).

\subsection{Elongationsfaktoren und alFs}

In $H$. volcanii sind vier Elongationsfaktoren (aEFs) annotiert, die alle vier co-gereinigt werden konnten. Zu erwähnen ist, dass aEF1a1 (HVO_0359) in der Affinitätsaufreinigung der DHFR nachgewiesen werden konnte. Die Affinitätsaufreinigungen der DHFR dienten als Kontrolle. Die in den MS-Daten der DHFR identifizierten Proteine wurden als unspezifische Proteine in den MS-Analysen abgezogen.

In Eukaryonten ist eEF1a sowohl an der Translationselongation, der Termination, als auch der Qualitätskontrolle der Proteinsynthese beteiligt (Saito et al., 2010). Kobayashi und Kollegen beschrieben 2012 die Struktur des aEF1a mit dem archaeal release factor (aRF1) in 
Aeropyrum pernix. In Verbindung mit aPelota kann hier die Translation beendet werden. aEF1 $\alpha$ ist eine GTPase und transportiert die tRNA zur kleinen ribosomalen Untereinheit. Er ist letztendlich auch am Translationsstopp beteiligt (Kobayashi et al., 2012).

Unter anderem agieren die Elongationsfaktoren mit dem Sarcin-Ricin Loop der 23 S rRNA, welcher eines der aktiven Zentren des Ribosom bildet (Imai et al., 2015).

\subsection{Kopplung von Transkription und Translation}

In Archaeen und Bakterien gibt es keine physikalische Barriere wie in Eukaryonten, die die Transkription von der Translation abtrennt. Dies ermöglicht den Start der Translation während die DNA noch transkribiert wird (French et al., 2007; McGary and Nudler, 2013). Sowohl in vivo als auch in vitro konnte dies bereits für Bakterien nachgewiesen werden (Proshkin et al., 2010; Castro-Roa and Zenkin, 2012).

Bereits 1964 wurde von Byrne und Kollegen vorausgesagt, dass die Transkription und Translation in Prokaryonten gekoppelt ist (Byrne et al., 1964). Mittels Elektronenmikroskopie konnte 1970 die Nähe von transkribierender RNAP zu Ribosomen in E. coli nachgewiesen werden (O. L. Miller, Hamkalo and C. A. Thomas, 1970). Bei der Transkription von DNA zu mRNA, die eine Ribosomen-bindende Sequenz enthält, kann die Translation die Transkriptions-Termination initiieren und verhindern (Adhya and Gottesman, 1978). Die kinetische Kopplung der Transkription und Translation zeigt sich unter anderem bei der Inhibierung der Translation und führt zu einem erhöhten Stocken der RNAP (Landick, Carey and Yanofsky, 1985; Proshkin et al., 2010). So fördert ein an die naszierende mRNA gebundenes Ribosom die Transkription und reguliert die Rate der Genexpression. Es wird angenommen, dass eine Art physikalische Brücke zwischen RNAP und Ribosomen unter anderem von NusG, ribosomalen Proteinen und weiteren Proteinen wie das Paralog RfaH gebildet wird (Burmann et al., 2010, 2012).

In E. coli konnte von Kohler und Kollegen 2017 gezeigt werden, dass E. coli ein transkribierendes und translatierendes Expressom bilden kann (Abbildung 66).

Mittels Kryoelektronenmikroskopie konnten sie ein Expressom nachweisen, bei dem die RNAP mit dem Ribosom über die mRNA verbunden ist. Zwischen dem aktiven Zentrum der RNAP und dem Ribosom-Dekodierungs-Zentrum zeigte sich ein kontinuierlich geschützter Abschnitt der mRNA von 30 Nukleotiden. Hierbei dockt die RNA-Ausgangsregion der RNAP an die Eingangsseite der ribosomalen RNA-Bindungskanal zwischen S3, S4, und S5 an. Des Weiteren sind die ribosomalen Proteine S2, S9 und S10 involviert (Kohler et al., 2017). 


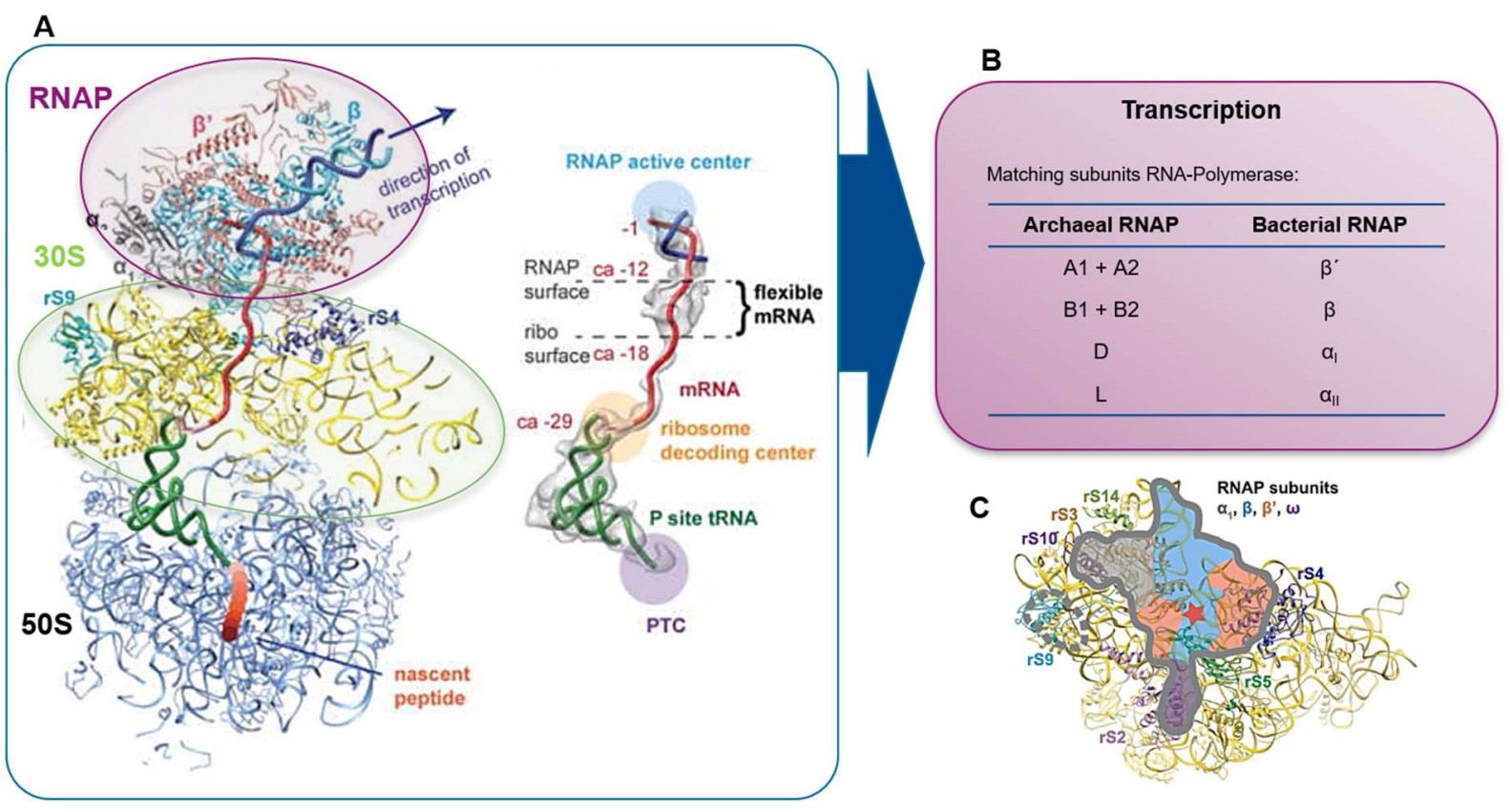

Abbildung 66: Transkriptions-Translations-Expressom modifiziert nach (Kohler et al., 2017)

A. Kryoelektronische Struktur des Expressoms in E. coli. Übergang der RNA vom aktiven Zentrum der RNAP in das Ribosomen-Dekodierungs-Zentrum. B. Homologe zu den RNAP-Untereinheiten zwischen Archaeen und Bakterien, die an der Interaktion mit der kleinen ribosomalen Untereinheit beteiligt sind. C. Die Interaktionsstelle zwischen RNAP und 30S ribosomaler Untereinheit. Der rote Stern markiert den Eingang zum mRNA-Tunnel.

Teilweise konnten diese ribosomalen Proteine in der vorliegenden Arbeit nach den Affinitätsaufreinigungen in der MS-Analyse der alFs und den RNAPUs identifiziert werden (Tabelle 89). Die Zusammenfassung der MS-Daten der 14 alFs und sieben RNAPUs sind in Tabelle 90-101 im Anhang aufgelistet.

Tabelle 89: Identifikation von rpS2, rpS3, rpS5, rpS10 in den MS-Daten von alFs und RNAPUs

\begin{tabular}{|c|c|c|c|c|c|c|c|c|c|c|c|}
\hline \multicolumn{12}{|l|}{ alFs $->$ Bait } \\
\hline Genloci & Accession & Description & $\stackrel{\Perp}{\dddot{\prod}}$ & 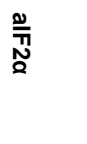 & $\begin{array}{l}\stackrel{N}{\bar{N}} \\
\text { No } \\
\text { ஸे }\end{array}$ & & 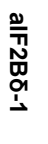 & $\begin{array}{l}\frac{D}{7} \\
\stackrel{1}{\$} \\
\frac{1}{1} \\
\frac{1}{0} \\
0\end{array}$ & 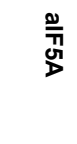 & 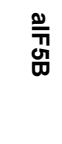 & 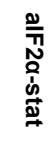 \\
\hline HVO_2773 & L9V5L7 & $30 S$ rps2 & & & & & + & & & & \\
\hline HVO_2558 & D4GTZ0 & $30 S$ rps3 & + & & & & + & + & & & + \\
\hline HVO_1145 & D4GWA5 & $30 \mathrm{~S}$ rpS3Ae & & & + & & + & & & & + \\
\hline HVO_2552 & L9V7Y2 & $30 \mathrm{spS} 4 \mathrm{e}$ & + & & & & + & + & + & & \\
\hline HVO_2544 & D4GTX6 & $30 S$ rpS5 & & + & & & & + & & & + \\
\hline HVO_0360 & L9ULL7 & $30 S$ rpS10 & + & & & & & & & + & \\
\hline \multicolumn{12}{|c|}{ RNAPUs -> Bait } \\
\hline Genloci & Accession & Description & $\begin{array}{l}7 \\
\text { 훙 } \\
\stackrel{2}{2}\end{array}$ & 궁 & & $\begin{array}{l}\text { 긍 } \\
\text { 뭄 }\end{array}$ & & $\begin{array}{l}\text { 긍 } \\
\text { 몀 } \\
\text { N }\end{array}$ & $\begin{array}{l}\text { 궁 } \\
\text { 믐 }\end{array}$ & $\begin{array}{l}\text { 궁 } \\
\text { 음 }\end{array}$ & $\begin{array}{l}\text { 궁 } \\
\text { 우 }\end{array}$ \\
\hline HVO_2558 & D4GTZ0 & $30 S$ rpS3 & & & & & & & & & + \\
\hline HVO_2552 & L9V7Y2 & $30 \mathrm{spS} 4 \mathrm{e}$ & + & + & & + & & + & & & + \\
\hline HVO_2544 & D4GTX6 & $30 \mathrm{~s}$ rpS5 & & & & + & & & & & \\
\hline HVO_0360 & L9ULL7 & $30 S$ rps 10 & + & & & + & & & & & + \\
\hline
\end{tabular}


Ribosomale Proteine spielen nicht nur eine entscheidende Rolle bei der Translation, sondern interagieren auch mit der RNAP und/ oder sind in der Nähe des Transkriptionsstarts lokalisiert. Sie sind dabei Teil des Ribosoms oder können auch als Monomer vorliegen. Dieser Umstand wurde bereits in der Vergangenheit schon mehrfach beschrieben (Warner and McIntosh, 2009; Bhavsar, Makley and Tsonis, 2010; De and Brogna, 2010; Rippa et al., 2010).

Unter anderem beschrieben Fan und Kollegen 2017 in E. coli durch chemisches Crosslinking und LC-MS/MS eine Kopplung der RNAP mit dem Ribosom, der 305 und 50 S ribosomalen Untereinheit (Fan et al., 2017). Hierbei konnten zum Beispiel für RNAP-70S die Proteine $\beta, \beta^{\prime}$, S6, S9 und L7/L12 identifiziert werden. Bei RNAP-30S waren es $\beta^{\prime}$ S1, S2, S6, S9, S11 und S7. Mit RNAP-50S konnten die Proteine $\beta, \beta^{\prime}, L 1, L 9, L 7 / L 12$ und L19 identifiziert werden. Beim Abgleich der in der MS identifizierten Proteine zu den in dieser Arbeit mit RNAPUs cogereinigten Proteinen konnte nur L1 bestätigt werden. Dennoch konnten mit den sieben RNAPUs acht 30 S ribosomale Proteine und 13 50S ribosomalen Proteine co-gereinigt werden.

Wichtig in diesem Zusammenhang ist, dass ribosomale Proteine auch als Transkriptionsregulatoren fungieren können. So zum Beispiel das 50 S ribosomale Protein L2. Wie bereits im vorherigen Kapitel beschrieben fördert dieses Protein die Transkription von Genen mit ribosomalem Promotor (Rippa et al., 2010).

Beim Modell von Kohler und Kollegen ist zu bedenken, dass es eventuell nur einen Komplex zwischen RNAP und dem Ribosom mit einer kurzen naszierenden RNA widerspiegelt. Mögliche Gründe sind, dass ein Crosslinking mittels Glutaraldehyd verwendet wurde, um die physikalischen Interaktionen zwischen der RNAP und dem Ribosomen zu stabilisieren (Kohler et al., 2017). Ferner wurde durch die Translation der gesamten entstehenden RNA eines vorgeformten, stabilen RNAP-Komplexes ein Expressom-Komplex hergestellt (Conn et al., 2019).

Eine weitere Untersuchung mittels Cryo-EM erfolgte von Demo und Kollegen ebenfalls 2017 anhand der RNAP und der 30S ribosomalen Untereinheit in E. coli (Demo et al., 2017). Hier wurde unter anderem beschrieben, dass die RNAP in E. coli mittels rpS1 eine Wand zwischen der RNAP und der kleinen ribosomalen Untereinheit bildet. Im Vergleich zu $H$. volcanii gibt es in diesem Archaeon jedoch kein Homolog zum ribosomalen Protein S1 aus E. coli.

Im Vergleich unterscheiden sich die beiden Cryo-EM-Aufnahmen von Kohler und Demo, da sie für die RNAP unterschiedliche Positionen aufweisen. Conn und Kollegen (2019) stellten die Theorie auf, dass beide Modelle einzelne Schritte eines Zyklus darstellen, bei dem die RNAP und das Ribosomen ihre Positionen ändern (Conn et al., 2019).

Für polycistronische Operons wurde in Bakterien bereits mehrfach die Interaktion zwischen RNA Polymerasen und dem Ribosom beschrieben. Jedoch handelt es sich hierbei um die Attenuation, bei der die Transkription vorzeitig abgebrochen wird (Yanofsky and Ito, 1966; Landick, Carey and Yanofsky, 1985; Yanofsky, 2000).

Bisher ist über die Transkriptions- und Translationskopplung in Archaeen nur wenig bekannt. Bereits 2007 konnte von French und Kollegen in T. kodakarensis mittels 
Elektronenmikroskopie Polysomen nachgewiesen werden. Sie waren direkt an die genomische DNA gebunden (French et al., 2007). Damit konnte in T. kodakarensis nachgewiesen werden, dass die Translation am Transkript bereits startet, bevor die Transkription abgeschlossen ist und eine Kopplung besteht.

Conn und Kollegen beschrieben 2019 beim Vergleich der aktuellen Modelle für das Transkriptions-Translationsexpressom, dass ein dynamisches System bestehen könnte. Dies wird durch die Möglichkeit des wiederholten bilden und brechen der Interaktionen zwischen RNAP und Ribosomen vermutet und durch die geringe Affinität von RNAP zum Ribosomen begründet (Demo et al., 2017; Fan et al., 2017; Kohler et al., 2017; Conn et al., 2019).

Von Burmann und Kollegen wurde beschrieben, dass die Kopplung der Transkription und Translation auch faktorabhängig über das Protein NusG bzw. das Paralog, RfaH begünstigt wird (Burmann et al., 2010, 2012). NusG ist in Bakterien sowohl in die Transkription als auch in die Translation involviert.

Er interagiert unter anderem N-terminal mit der RNAP und C-terminal mit rpS10/NusE oder dem Faktor Roh, der an der Termination der Transkription beteiligt ist (Kyrpides, Woese and Ouzounis, 1996; Mooney et al., 2009; Burmann et al., 2010). NusG/Spt5 ist der einzige Transkriptionsfaktor, der in allen drei Domänen des Lebens vertreten ist (Werner, 2012). Sowohl Spt5 in Archaeen als auch NusG in Bakterien besitzen eine NusG N-terminale Domäne (NGN) sowie eine KOW-Domäne am C-terminalen Ende (Knowlton et al., 2003; Mooney et al., 2009). Bisher ist nicht belegt, dass dieser Faktor auch an einer Transkriptions-Translationskopplung in Archaeen beteiligt ist.

Bemerkenswert ist, dass in den beiden Strukturen, von Kohler und Kollegen (2017) sowie von Demo und Kollegen (2017), die jeweilige NusG-Bindestelle auf dem Ribosom und der RNAP räumlich zu weit voneinander entfernt lagen. Da davon ausgegangen wird, dass es sich um eine hochdynamische Struktur handelt, wird hier von weiteren Strukturen bzw. Konformationen ausgegangen, die bisher nicht aufgeklärt wurden (Conn et al., 2019).

In dieser Arbeit konnte Spt5/NusG (HVO_0719) von $H$. volcanii bei den MS-Auswertungen identifiziert werden. Dies war in der FPLC für alF2 $\alpha$ und alF2 $\beta-2$ und in den Affinitätsaufreinigungen für alF2 $\alpha$-stat und rpoD der Fall. Spt5 konnte jeweils nur in 1-2 Messungen identifiziert werden und lag bei einem PSM von 1-2 sowie einem Unique Peptide Wert von 1-2. Deshalb wurde er aus den MS-Ergebnissen herausgenommen. Als nächster Schritt könnte eine Überexpression, Affinitätsaufreinigung und MS-Analyse von Spt5 in $\mathrm{H}$. volcanii einen Aufschluss über die Interaktionspartner von Spt5 geben. Da dieses Protein in anderen Organismen sowohl an der Transkription als auch der Translation beteiligt ist. Das ribosomale Protein rpS10, das in E. coli NusG als Bindungspartner zwischen dem Ribosom und der RNAP dient, konnte in dieser Arbeit sowohl bei zwei Initiationsfaktoren als auch bei drei RNAPUs mitgereinigt werden. 
In der vorliegenden Arbeit konnten bei alFs und RNAPUs Transkriptionsregulatoren mitgereinigt werden. Bei den alFs waren es 37 und bei den RNAPUs 22 Proteine. Dazu zählen unter anderem HTH domain proteins, IcIR family transcription regulators, Lrp/AsnC family transcription regulators, PadR family transcription regulators, SirR/DtxR family transcription regulators und TrmB (Tabelle 91,96).

In H. volcanii sind $13 \mathrm{TrmB}$ (transcriptional regulator of mal operon) family transcription regulators annotiert. Im Allgemeinen gehört TrmB zur Familie der Transkriptionsregulatoren, die sowohl als Aktivator als auch als Repressor agieren (Perez-Rueda and Janga, 2010; Gindner, Hausner and Thomm, 2014). Aus der Familie der TrmB konnten in H. volcanii zwei TrmBs cogereinigt werden. TrmB HVO_1360 konnte mit rpoH, mit alF1 und in alF2 $\alpha$-stat nachgewiesen werden. Des Weiteren konnte mit alF2Bס-1 der TrmB HVO_2688 mitgereinigt werden.

In Archaeen sind TrmB hauptsächlich in Euryarchaeota vertreten. Bei Crenarchaeota kommen sie nur selten vor. In Bakterien sind sie nicht vertreten (Gindner, Hausner and Thomm, 2014). Die bisher in Archaeen untersuchten TrmBs können über ein Helix-Turn-Helix-Motiv (HTHMotif) an die DNA binden und weisen eine Effektor-Bindedomäne auf (Maruyama et al., 2011; Gindner, Hausner and Thomm, 2014). Die Effektor-Bindedomäne hat unterschiedliche Funktionen wie z.B. Enzymaktivität, Ligandenbindung und Protein-Protein-Wechselwirkungen (Perez-Rueda et al., 2018). TrmBs sind an unterschiedlichen Genregulationen beteiligt, unter anderem den Zucker-Metabolismus betreffend. Interessant ist, dass sie auch an der Regulation von spezifischen Transkriptionsfaktoren beteiligt sind. Für ihre Funktion erkennen TrmB unterschiedliche DNA-Bindemotive, die upstream (Aktivierung Promotor) oder downstream (Repression Promotor) der TATA-Box liegen (Gindner, Hausner and Thomm, 2014).

Festzuhalten ist, dass die Transkription und die Translation jeweils einen eigenen Prozess darstellen, der dynamisch ist. Sie können sich gegenseitig beeinflussen und sind mit weiteren wichtigen zellulären Prozessen gekoppelt. Für die Transkription ist dies in Bakterien und Archaeen unter anderem die DNA-Reparatur (Spivak, 2016; Stantial et al., 2016). Für die Translation betrifft es unter anderem die Translocation und die Proteinfaltung (Fulle and Gohlke, 2009; Elvekrog and Walter, 2015; Thommen, Holtkamp and Rodnina, 2017). Außerdem wurden die Untersuchungen mittels eines Ansatzes der Überexpression durchgeführt, was ebenfalls eine Auswirkung auf die Genregulation haben kann.

Generell scheint eine Kopplung der Transkription und Translation in H. volcanii möglich. Die in dieser Arbeit erbrachten Ergebnisse weisen darauf hin. Ob es einen Translations-Transkriptionsexpressom in $H$. volcanii gibt, sollte in weiteren Untersuchungen geklärt werden. 


\subsection{Kopplung von Translation und Replikation}

Bei der Untersuchung der Translationsinitiationsfaktoren konnten zusätzlich zu den Proteinen der Translation auch Proteine für die Replikation und DNA-Reparatur mitgereinigt werden. Berthon und Kollegen beschrieben 2008 für Archaeen und Eukaryonten die räumliche Nähe zweier Operons, die auf eine Kopplung der Translation und Replikation hindeuteten. Eines der Operons codiert für Proteine der Ribosomenbiogenese und der Translation (rpS27e, rpL42e/rpL44e, alF2 $\alpha$, Nop10). Das andere Operon codiert für Gene, die an der DNA-Replikation beteiligt sind (PcnA, PriS, Gins15). In H. volcanii sind priL (HVO_0173), pcnA (HVO_0175), priS (HVO_2697) und ginS (HVO_2698) co-lokalisiert. Dies konnte auch für andere archaeale Genome nachgewiesen werden (Berthon, Fujikane and Forterre, 2009). In H. volcanii verhält sich die Anordnung jedoch anders. Beide Cluster sind vom Operon, das alF2 $\alpha$ enthält, weiter entfernt. Diese Gene sind mit keinem weiteren annotierten Translationsinitiationsfaktor co-lokalisiert. In dieser Arbeit konnte dennoch in $H$. volcanii, mit alF2Bס-1 das pcnA (HVO_0175) mitgereinigt werden (siehe Anhang, Tabelle 93).

Die meisten Proteine der Replikation konnten mit alF1 und alF2Bס-1 mitgereinigt werden. Inwieweit die Co-Reinigung von Replikationsfaktoren mit dem Überschneiden bzw. der Kopplung von Translation und Replikation zusammenhängen, konnte nicht geklärt werden.

Wichtig ist, dass die Überexpression und damit die Hochregulation von einzelnen alFs sich auf die Expression anderer Gene auswirken kann. Hinzu kommt, das auch bei der Co-Affinitätsaufreinigung der RNAPUs Proteine der Replikation mitgereinigt werden konnten (siehe Anhang, Tabelle 99). 


\subsection{Fazit und Ausblick}

Das in dieser Arbeit angewandte Verfahren zur Charakterisierung der Translationsinitiationsfaktoren in $H$. volcanii vertieft das bisherige Verständnis der Translation in Archaeen und zeigt Tendenzen für mögliche Interaktionsfelder auf. Für die Initiationsfaktoren konnte anhand der MS-Analyse gezeigt werden, in welche Richtung die Funktion der einzelnen Initiationsfaktoren einzuordnen ist. Potentielle Interaktionspartner konnten beschrieben werden. Sie müssen aber weiter untersucht werden.

13 der insgesamt 14 untersuchten Initiationsfaktoren konnten andere Initiationsfaktoren coreinigen. Sechs Initiationsfaktoren konnten in der Affinitätsaufreinigung mit anschließender MS-Analyse bei keinem weiteren Initiationsfaktor mitgereinigt werden. Einer dieser Faktoren war alF2 $\beta$-1. Dieser konnte in den Affinitätsaufreinigungen mit nachfolgender FPLC von alF2 $\beta$-2 identifiziert werden. Der Faktor alF1 konnte in der stationären Phase von alF2 $\alpha$ mitgereinigt werden.

Die am häufigsten co-gereinigten Proteine waren überraschenderweise alF2Bס-1, der bereits als Translationsinitiationsfaktor ausgeschlossen wurde, sowie der universelle und in $H$. volcanii essenzielle alF5B. Mit alF2Bס-1 selbst konnten fünf alFs co-gereinigt werden.

Mit den alFs war es auch möglich, Proteine co-zureinigen, die für die Transkription wesentlich sind. Darunter auch RNAPUs. Diese wurden ebenfalls überexprimiert und in der MS analysiert.

Auch bei der Überexpression der mit alFs co-gereinigten RNAPUs konnte alF2Bס-1 und alF5B am häufigsten co-gereinigt werden.

Auf Basis der Affinitätsaufreinigung und MS-Daten besteht die Möglichkeit einer stärkeren Regulation zwischen Transkription und Translation in $H$. volcanii. Hierbei konnten mit den Initiationsfaktoren die RNAPUs co-gereinigt und bei der Überexpression von RNAPUs die alFs mitgereinigt werden.

Um die Funktionen der Initiationsfaktoren in H. volcanii detaillierter aufklären zu können, sind weitere Untersuchungen erforderlich. 


\section{Literatur}

Adam, P. S. et al. (2017) 'The growing tree of Archaea: New perspectives on their diversity, evolution and ecology', ISME Journal. Nature Publishing Group, pp. 2407-2425. doi: 10.1038/ismej.2017.122.

Adhya, S. and Gottesman, M. (1978) 'Control of Transcription Termination', Annual Review of Biochemistry, 47(1), pp. 967996. doi: 10.1146/annurev.bi.47.070178.004535.

Akulich, K. A. et al. (2016) 'Four translation initiation pathways employed by the leaderless mRNA in eukaryotes', Scientific Reports. Nature Publishing Group, 6(June), pp. 1-9. doi: 10.1038/srep37905.

Algire, M. A., Maag, D. and Lorsch, J. R. (2005) 'Pi Release from elF2, Not GTP Hydrolysis, Is the Step Controlled by StartSite Selection during Eukaryotic Translation Initiation', Molecular Cell, 20(2), pp. 251-262. doi: 10.1016/j.molcel.2005.09.008.

Allen, G. S. and Frank, J. (2007) 'Structural insights on the translation initiation complex: ghosts of a universal initiation complex', Molecular Microbiology, 63(4), pp. 941-950. doi: 10.1111/j.1365-2958.2006.05574.x.

Allers, T. et al. (2010) 'Improved strains and plasmid vectors for conditional overexpression of His-tagged proteins in Haloferax volcanii', Applied and Environmental Microbiology, 76(6), pp. 1759-1769. doi: 10.1128/AEM.02670-09.

Allers, T. (2010) 'Overexpression and purification of halophilic proteins in Haloferax volcanii.', Bioengineered bugs, 1(4), pp. 288-290. doi: 10.4161/bbug.1.4.11794.

Allers, T. and Ngo, H.-P. (2003) 'Genetic analysis of homologous recombination in Archaea: Haloferax volcanii as a model organism', Biochemical Society Transactions, 31(3), pp. 706-710. doi: 10.1042/bst0310706.

Altman-Price, N. and Mevarech, M. (2009) 'Genetic evidence for the importance of protein acetylation and protein deacetylation in the halophilic archaeon Haloferax volcanii', Journal of Bacteriology, 191(5), pp. 1610-1617. doi: 10.1128/JB.01252-08.

Anantharaman, V., Koonin, E. V and Aravind, L. (2001) 'TRAM, a predicted RNA-binding domain, common to tRNA uracil methylation and adenine thiolation enzymes', FEMS Microbiology Letters, 197(2), pp. 215-221. doi: 10.1016/S03781097(01)00112-4.

Andreev, D. E. et al. (2006) 'A Leaderless mRNA Can Bind to Mammalian 80S Ribosomes and Direct Polypeptide Synthesis in the Absence of Translation Initiation Factors', Molecular and Cellular Biology, 26(8), pp. 3164-3169. doi: 10.1128/mcb.26.8.31643169.2006 .

Andreou, A. Z. and Klostermeier, D. (2014) 'elF4B and elF4G Jointly Stimulate elF4A ATPase and Unwinding Activities by Modulation of the elF4A Conformational Cycle', Journal of Molecular Biology. Elsevier Ltd, 426(1), pp. 51-61. doi: 10.1016/j.jmb.2013.09.027.

Antoun, A. et al. (2003) 'The roles of initiation factor 2 and guanosine triphosphate in initiation of protein synthesis', EMBO Journal, 22(20), pp. 5593-5601. doi: 10.1093/emboj/cdg525.

Aoki, H. et al. (1997) 'The gene encoding the elongation factor $\mathrm{P}$ protein is essential for viability and is required for protein synthesis', Journal of Biological Chemistry, 272(51), pp. 32254-32259. doi: 10.1074/jbc.272.51.32254.

Arkhipova, V. et al. (2015) 'Binding of the 5'-Triphosphate End of mRNA to the $\mathrm{Y}$-Subunit of Translation Initiation Factor 2 of the Crenarchaeon Sulfolobus solfataricus', Journal of Molecular Biology. Elsevier B.V., 427(19), pp. 3086-3095. doi: 10.1016/j.jmb.2015.07.020.

Armache, J. P. et al. (2013) 'Promiscuous behaviour of archaeal ribosomal proteins: Implications for eukaryotic ribosome evolution', Nucleic Acids Research, 41(2), pp. 1284-1293. doi: 10.1093/nar/gks1259.

Asano, K. et al. (1999) 'Conserved bipartite motifs in yeast elF5 and elF2Bepsilon , GTPase-activating and GDP-GTP exchange factors in translation initiation, mediate binding to their common substrate elF2', The EMBO Journal, 18(6), pp. 1673-1688. doi: 10.1093/emboj/18.6.1673.

Asano, K. et al. (2000) 'A multifactor complex of eukaryotic initiation factors, elF1, elF2, elF3, elF5, and initiator tRNAMet is an important translation initiation intermediate in vivo', Genes \& Development, 14(19), pp. 2534-2546. doi: 10.1101/gad.831800.

Babski, J. et al. (2016) 'Genome-wide identification of transcriptional start sites in the haloarchaeon Haloferax volcanii based on differential RNA-Seq (dRNA-Seq)', BMC Genomics. BMC Genomics, 17(1), p. 629. doi: 10.1186/s12864-016-2920-y.

Barry, E. R. and Bell, S. D. (2006) 'DNA Replication in the Archaea', Microbiology and Molecular Biology Reviews, 70(4), pp. 876-887. doi: 10.1128/mmbr.00029-06.

Bartig, D., Schümann, H. and Klink, F. (1990) 'The Unique Posttranslational Modification Leading to Deoxyhypusine or Hypusine is a General Feature of the Archaebacterial Kingdom', Systematic and Applied Microbiology, 13(2), pp. 112-116. doi: 10.1016/S0723-2020(11)80156-6.

Bassani, F. et al. (2018) 'Modification of translation factor alF5A from Sulfolobus solfataricus', Extremophiles. Springer Japan, 22(5), pp. 769-780. doi: 10.1007/s00792-018-1037-4.

Bassani, F. et al. (2019) 'Indications for a moonlighting function of translation factor alF5A in the crenarchaeum Sulfolobus solfataricus', RNA Biology. Taylor \& Francis, 16(5), pp. 675-685. doi: 10.1080/15476286.2019.1582953. 
Basu, U. et al. (2001) 'The Saccharomyces cerevisiae TIF6 Gene Encoding Translation Initiation Factor 6 Is Required for 605 Ribosomal Subunit Biogenesis', Molecular and Cellular Biology, 21(5), pp. 1453-1462. doi: 10.1128/MCB.21.5.1453-1462.2001.

Battiste, J. L. et al. (2000) 'The elF1A Solution Structure Reveals a Large RNA-Binding Surface Important for Scanning Function', Molecular Cell, 5(1), pp. 109-119. doi: 10.1016/S1097-2765(00)80407-4.

Bayley, S. T., Morton, R. A. and Lanyi, J. K. (1978) 'Recent Developments in the Molecular Biology of Extremely Halophilic Bacteria', CRC Critical Reviews in Microbiology, 6(2), pp. 151-206. doi: 10.3109/10408417809090622.

Bell, S. D. (2005) 'Archaeal transcriptional regulation - variation on a bacterial theme?', Trends in Microbiology, 13(6), pp. 262265. doi: 10.1016/j.tim.2005.03.015.

Bell, S. D. and Jackson, S. P. (2001) 'Mechanism and regulation of transcription in archaea', Microbiology, 4(2), pp. $208-213$. Available at: http://www.ncbi.nlm.nih.gov/entrez/query.fcgi?cmd=Retrieve\&db=PubMed\&dopt=Citation\&list_uids=11282478.

Ben-Shem, A. et al. (2010) 'Crystal Structure of the Eukaryotic Ribosome', Science, 330(6008), pp. 1203-1209. doi: 10.1126/science.1194294.

Benelli, D. et al. (2009) 'Function and ribosomal localization of alF6, a translational regulator shared by Archaea and Eukarya', Nucleic Acids Research, 37(1), pp. 256-267. doi: 10.1093/nar/gkn959.

Benelli, D. and Londei, P. (2009) 'Begin at the beginning: evolution of translational initiation', Research in Microbiology. Elsevier Masson SAS, 160(7), pp. 493-501. doi: 10.1016/j.resmic.2009.06.003.

Benelli, D. and Londei, P. (2011) 'Translation initiation in Archaea: conserved and domain-specific features.', Biochemical Society transactions, 39(1), pp. 89-93. doi: 10.1042/BST0390089.

Benelli, D., Maone, E. and Londei, P. (2003) 'Two different mechanisms for ribosome/mRNA interaction in archaeal translation initiation', Molecular Microbiology, 50(2), pp. 635-643. doi: 10.1046/j.1365-2958.2003.03721.x.

Berthon, J., Cortez, D. and Forterre, P. (2008) 'Genomic context analysis in Archaea suggests previously unrecognized links between DNA replication and translation', Genome Biology, 9(4), pp. 1-16. doi: 10.1186/gb-2008-9-4-r71.

Berthon, J., Fujikane, R. and Forterre, P. (2009) 'When DNA replication and protein synthesis come together', Trends in Biochemical Sciences, 34(9), pp. 429-434. doi: 10.1016/j.tibs.2009.05.004.

Bessman, M. J., Frick, D. N. and O'Handley, S. F. (1996) 'The MutT Proteins or "Nudix" Hydrolases, a Family of Versatile, Widely Distributed, "Housecleaning" Enzymes', Journal of Biological Chemistry, 271(41), pp. 25059-25062. doi: 10.1074/jbc.271.41.25059.

Bhavsar, R. B., Makley, L. N. and Tsonis, P. A. (2010) 'The other lives of ribosomal proteins', Human Genomics, 4(5), p. 327. doi: 10.1186/1479-7364-4-5-327.

Blecher, O., Goldman, S. and Mevarech, M. (1993) 'High expression in Escherichia coli of the gene coding for dihydrofolate reductase of the extremely halophilic archaebacterium Haloferax volcanii Reconstitution of the active enzyme and mutation studies', European Journal of Biochemistry, 216(1), pp. 199-203. doi: 10.1111/j.1432-1033.1993.tb18133.x.

Blum H., Beier H., G. H. J. (1987) 'Improved silver staining of plant protein, RNA \& DNA in PAA gels', Electrophoresis, 8(2), pp. 93-99.

Bogorad, A. M. et al. (2014) 'Insights into the architecture of the elF2Ba/ $/ / \delta$ regulatory subcomplex', Biochemistry. doi: 10.1021/bi500346u.

Bogorad, A. M., Lin, K. Y. and Marintchev, A. (2017) 'Novel mechanisms of elF2B action and regulation by elF2 phosphorylation', Nucleic Acids Research. Oxford University Press, 45(20), pp. 11962-11979. doi: 10.1093/nar/gkx845.

Brenneis, M. et al. (2007) 'Experimental Characterization of Cis-Acting Elements Important for Translation and Transcription in Halophilic Archaea', PLoS Genetics, 3(12), p. e229. doi: 10.1371/journal.pgen.0030229.

Brina, D. et al. (2015) 'elF6 anti-association activity is required for ribosome biogenesis, translational control and tumor progression', Biochimica et Biophysica Acta (BBA) - Gene Regulatory Mechanisms. Elsevier B.V., 1849(7), pp. 830-835. doi: 10.1016/j.bbagrm.2014.09.010.

Brininger, C. et al. (2018) 'The more adaptive to change, the more likely you are to survive: Protein adaptation in extremophiles', Seminars in Cell \& Developmental Biology. Elsevier Ltd, 84, pp. 158-169. doi: 10.1016/j.semcdb.2017.12.016.

Brown, E. D. (2005) 'Conserved P-loop GTPases of unknown function in bacteria: an emerging and vital ensemble in bacterial physiology', Biochemistry and Cell Biology, 83(6), pp. 738-746. doi: 10.1139/o05-162.

Bucher, M. H., Evdokimov, A. G. and Waugh, D. S. (2002) 'Differential effects of short affinity tags on the crystallization of Pyrococcus furiosus maltodextrin-binding protein', Acta Crystallographica Section D: Biological Crystallography. International Union of Crystallography, 58(3), pp. 392-397. doi: 10.1107/S0907444901021187.

Burmann, B. M. et al. (2010) 'A NusE:NusG Complex Links Transcription and Translation', Science, 328(5977), pp. 501-504. doi: 10.1126/science.1184953

Burmann, B. M. et al. (2012) 'An a Helix to $\beta$ Barrel Domain Switch Transforms the Transcription Factor RfaH into a Translation 
Factor', Cell, 150(2), pp. 291-303. doi: 10.1016/j.cell.2012.05.042.

Byrne, R. et al. (1964) 'THE IN VITRO FORMATION OF A DNA-RIBOSOME COMPLEX', Proceedings of the National Academy of Sciences, 52(1), pp. 140-148. doi: 10.1073/pnas.52.1.140.

Caraglia, M. et al. (2013) 'elF5A isoforms and cancer: two brothers for two functions?', Amino Acids, 44(1), pp. 103-109. doi: 10.1007/s00726-011-1182-x.

Carson, M. et al. (2007) 'His-tag impact on structure', Acta Crystallographica Section D Biological Crystallography, 63(3), pp. 295-301. doi: 10.1107/S0907444906052024.

Caserta, E. et al. (2006) 'Translation Initiation Factor IF2 Interacts with the 30 S Ribosomal Subunit via Two Separate Binding Sites', Journal of Molecular Biology, 362(4), pp. 787-799. doi: 10.1016/j.jmb.2006.07.043.

Casiano, C., Matheson, A. T. and Traut, R. R. (1990) 'Occurrence in the archaebacterium Sulfolobus solfataricus of a ribosomal protein complex corresponding to Escherichia coli (L7/L12)4..L10 and eukaryotic (P1)2/(P2)2.P0*', The Journal of biological chemistry, 265(31), pp. 18757-61. Available at: http://www.jbc.org/content/265/31/18757.

Castro-Roa, D. and Zenkin, N. (2012) 'In vitro experimental system for analysis of transcription-translation coupling', Nucleic Acids Research, 40(6), pp. e45-e45. doi: 10.1093/nar/gkr1262.

Chamieh, H., Ibrahim, H. and Kozah, J. (2016) 'Genome-wide identification of SF1 and SF2 helicases from archaea', Gene. Elsevier B.V., 576(1), pp. 214-228. doi: 10.1016/j.gene.2015.10.007.

Cheung, Y.-N. et al. (2007) 'Dissociation of elF1 from the 40S ribosomal subunit is a key step in start codon selection in vivo', Genes \& Development, 21(10), pp. 1217-1230. doi: 10.1101/gad.1528307.

Cho, S. and Hoffman, D. W. (2002) 'Structure of the beta subunit of translation initiation factor 2 from the Archaeon Methanococcus jannaschii: A representative of the elF2 beta/elF5 family of proteins', Biochemistry, 41(18), pp. 5730-5742. doi: 10.1021/bi011984n.

Choi, S. K. et al. (1998) 'Promotion of Met-tRNA(i)/(Met) binding to ribosomes by ylF2, a bacterial IF2 homolog in yeast', Science, 280(5370), pp. 1757-1760. doi: 10.1126/science.280.5370.1757.

Choi, S. K. et al. (2000) 'Physical and Functional Interaction between the Eukaryotic Orthologs of Prokaryotic Translation Initiation Factors IF1 and IF2', Molecular and Cellular Biology, 20(19), pp. 7183-7191. doi: 10.1128/MCB.20.19.7183-7191.2000.

Christian, J. H. B. and Waltho, J. A. (1962) 'Solute concentrations within cells of halophilic and non-halophilic bacteria', Biochimica et Biophysica Acta, 65(3), pp. 506-508. doi: 10.1016/0006-3002(62)90453-5.

Conn, A. B. et al. (2019) 'Two Old Dogs, One New Trick: A Review of RNA Polymerase and Ribosome Interactions during Transcription-Translation Coupling', International Journal of Molecular Sciences, 20(10), p. 2595. doi: 10.3390/ijms20102595.

Connaris, H. et al. (1999) 'Expression, reactivation, and purification of enzymes from Haloferax volcanii in Escherichia coli', Biotechnology and Bioengineering, 64(1), pp. 38-45. doi: 10.1002/(SICI)1097-0290(19990705)64:1<38::AID-BIT4>3.0.CO;2-7.

Coureux, P.-D. et al. (2016) 'Cryo-EM study of start codon selection during archaeal translation initiation', Nature Communications, $7(1)$, p. 13366. doi: 10.1038/ncomms13366.

Dallas, A. and Noller, H. F. (2001) 'Interaction of translation initiation factor 3 with the 30 S ribosomal subunit', Molecular Cell, 8(4), pp. 855-864. doi: 10.1016/S1097-2765(01)00356-2.

Danson, M. J. and Hough, D. W. (1997) 'The structural basis of protein halophilicity', Comparative Biochemistry and Physiology - A Physiology, 117(3), pp. 307-312. doi: 10.1016/S0300-9629(96)00268-X.

De, S. and Brogna, S. (2010) 'Are ribosomal proteins present at transcription sites on or off ribosomal subunits?', Biochemical Society Transactions, 38(6), pp. 1543-1547. doi: 10.1042/BST0381543.

Demo, G. et al. (2017) 'Structure of RNA polymerase bound to ribosomal 30S subunit.', eLife, 6(October), pp. 1-17. doi: 10.7554/eLife.28560.

Denis, A. et al. (2018) 'Dissecting the Repertoire of DNA-Binding Transcription Factors of the Archaeon Pyrococcus furiosus DSM 3638', Life, 8(4), p. 40. doi: 10.3390/life8040040.

Dev, K. et al. (2009) 'Archaeal alF2B Interacts with Eukaryotic Translation Initiation Factors elF2 $\alpha$ and elF2Ba: Implications for alF2B Function and elF2B Regulation', Journal of Molecular Biology. Elsevier B.V., 392(3), pp. 701-722. doi: 10.1016/j.jmb.2009.07.030.

Dever, T. E. et al. (1992) 'Phosphorylation of initiation factor 2a by protein kinase GCN2 mediates gen-specific translational control of GCN4 in yeast', Cell, 68, pp. 585-596.

Dever, T. E., Gutierrez, E. and Shin, B.-S. (2014) 'The hypusine-containing translation factor elF5A', Critical Reviews in Biochemistry and Molecular Biology, 49(5), pp. 413-425. doi: 10.3109/10409238.2014.939608.

Dever, T. E. and Hinnebusch, A. G. (2005) 'GCN2 whets the appetite for amino acids', Molecular Cell, 18(2), pp. 141-142. doi: 10.1016/j.molcel.2005.03.023 
Dever, T. E., Kinzy, T. G. and Pavitt, G. D. (2016) 'Mechanism and regulation of protein synthesis in Saccharomyces cerevisiae', Genetics, 203(1), pp. 65-107. doi: 10.1534/genetics.115.186221.

Dias, C. A. O. et al. (2012) 'elF5A interacts functionally with eEF2', Amino Acids, 42(2-3), pp. 697-702. doi: 10.1007/s00726011-0985-0.

Diedrich, G. et al. (2000) 'Ribosomal protein L2 is involved in the association of the ribosomal subunits, tRNA binding to A and P sites and peptidyl transfer', EMBO Journal, 19(19), pp. 5241-5250. doi: 10.1093/emboj/19.19.5241.

Dmitriev, S. E. et al. (2010) 'GTP-independent tRNA delivery to the ribosomal P-site by a novel eukaryotic translation factor', Journal of Biological Chemistry, 285(35), pp. 26779-26787. doi: 10.1074/jbc.M110.119693.

Dmitriev, S. E. et al. (2011) 'Archaeal translation initiation factor alF2 can substitute for eukaryotic elF2 in ribosomal scanning during mammalian 48s complex formation', Journal of Molecular Biology. Elsevier Ltd, 413(1), pp. 106-114. doi: 10.1016/j.jmb.2011.08.026.

Doerfel, L. K. et al. (2013) 'EF-P Is Essential for Rapid Synthesis of Proteins Containing Consecutive Proline Residues', Science, 339(6115), pp. 85-88. doi: 10.1126/science.1229017.

Donnelly, N. et al. (2013) 'The elF2 $\alpha$ kinases: their structures and functions', Cellular and Molecular Life Sciences, 70(19), pp. 3493-3511. doi: 10.1007/s00018-012-1252-6.

Drozdetskiy, A. et al. (2015) 'JPred4: a protein secondary structure prediction server', Nucleic Acids Research, 43(W1), pp. W389-W394. doi: 10.1093/nar/gkv332.

Dubiez, E. et al. (2015) 'Identification of a second GTP-bound magnesium ion in archaeal initiation factor 2', Nucleic Acids Research, 43(5), pp. 2946-2957. doi: 10.1093/nar/gkv053.

Duncker, B. P., Chesnokov, I. N. and McConkey, B. J. (2009) 'The origin recognition complex protein family', Genome Biology, 10(3), p. 214. doi: 10.1186/gb-2009-10-3-214.

Dunham, W. H., Mullin, M. and Gingras, A. C. (2012) 'Affinity-purification coupled to mass spectrometry: Basic principles and strategies', Proteomics, 12(10), pp. 1576-1590. doi: 10.1002/pmic.201100523.

Elvekrog, M. M. and Walter, P. (2015) 'Dynamics of co-translational protein targeting', Current Opinion in Chemical Biology, 29, pp. 79-86. doi: 10.1016/j.cbpa.2015.09.016.

Eme, L. et al. (2017) 'Archaea and the origin of eukaryotes', Nature Reviews Microbiology, 15(12), pp. 711-723. doi: 10.1038/nrmicro.2017.133.

Eme, L. and Doolittle, W. F. (2015) 'Archaea', Current Biology, 25(19), pp. R851-R855. doi: 10.1016/j.cub.2015.05.025

Fabbretti, A. et al. (2012) 'Translation initiation without IF2-dependent GTP hydrolysis', Nucleic Acids Research, 40(16), pp. 7946-7955. doi: 10.1093/nar/gks569.

Fabian, J. R. et al. (1997) 'Subunit Assembly and Guanine Nucleotide Exchange Activity of Eukaryotic Initiation Factor-2B Expressed in Sf9 Cells', Journal of Biological Chemistry, 272(19), pp. 12359-12365. doi: 10.1074/jbc.272.19.12359.

Fan, H. et al. (2017) 'Transcription-translation coupling: direct interactions of RNA polymerase with ribosomes and ribosomal subunits', Nucleic Acids Research, 45(19), pp. 11043-11055. doi: 10.1093/nar/gkx719.

Fekete, C. A. et al. (2005) 'The elF1A C-terminal domain promotes initiation complex assembly, scanning and AUG selection in vivo', EMBO Journal, 24(20), pp. 3588-3601. doi: 10.1038/sj.emboj.7600821.

Fekete, C. A. et al. (2007) ' $\mathrm{N}$ - and C-terminal residues of elF1A have opposing effects on the fidelity of start codon selection', EMBO Journal, 26(6), pp. 1602-1614. doi: 10.1038/sj.emboj.7601613.

Fernández, I. S. et al. (2013) 'Molecular Architecture of a Eukaryotic Translational Initiation Complex', Science, 342(6160), pp. 1240585-1240585. doi: 10.1126/science.1240585.

Fitzgerald, K. D. and Semler, B. L. (2009) 'Bridging IRES elements in mRNAs to the eukaryotic translation apparatus', Biochimica et Biophysica Acta - Gene Regulatory Mechanisms, pp. 518-528. doi: 10.1016/j.bbagrm.2009.07.004.

Forterre, P. (2015) 'The universal tree of life: An update', Frontiers in Microbiology, 6(JUN), pp. 1-18. doi: 10.3389/fmicb.2015.00717.

French, S. L. et al. (2007) 'Transcription and Translation are Coupled in Archaea', Molecular Biology and Evolution, 24(4), pp. 893-895. doi: 10.1093/molbev/msm007.

Fulle, S. and Gohlke, H. (2009) 'Statics of the Ribosomal Exit Tunnel: Implications for Cotranslational Peptide Folding, Elongation Regulation, and Antibiotics Binding', Journal of Molecular Biology. Elsevier Ltd, 387(2), pp. 502-517. doi: 10.1016/j.jmb.2009.01.037.

Furuichi, Y. and Shatkin, A. J. (2000) 'Viral and cellular mRNA capping: Past and prospects', Advances in Virus Research, 55, pp. 135-184. doi: 10.1016/s0065-3527(00)55003-9.

Gabdulkhakov, A., Nikonov, S. and Garber, M. (2013) 'Revisiting the Haloarcula marismortui 50 S ribosomal subunit model', 
Gäbel, K. et al. (2013) 'A Comprehensive Analysis of the Importance of Translation Initiation Factors for Haloferax volcanii Applying Deletion and Conditional Depletion Mutants', PLOS ONE. Edited by T. Preiss, 8(11), p. e77188. doi: 10.1371/journal.pone.0077188.

Gäbel, K. (2014) Molekulare Analyse der Translationsinitiation in halophilen Archaea, Dissertation.

Gandin, V. et al. (2008) 'Eukaryotic initiation factor 6 is rate-limiting in translation, growth and transformation', Nature, 455(7213), pp. 684-688. doi: 10.1038/nature07267.

Gartmann, M. et al. (2010) 'Mechanism of elF6-mediated inhibition of ribosomal subunit joining', Journal of Biological Chemistry, 285(20), pp. 14848-14851. doi: 10.1074/jbc.C109.096057.

Gehring, A. M., Walker, J. E. and Santangelo, T. J. (2016) 'Transcription regulation in archaea’, Journal of Bacteriology, 198(14), pp. 1906-1917. doi: 10.1128/JB.00255-16.

Gilbert, W. V. (2010) 'Alternative ways to think about cellular internal ribosome entry', Journal of Biological Chemistry, 285(38), pp. 29033-29038. doi: 10.1074/jbc.R110.150532.

Gindner, A., Hausner, W. and Thomm, M. (2014) 'The TrmB family: a versatile group of transcriptional regulators in Archaea', Extremophiles, 18(5), pp. 925-936. doi: 10.1007/s00792-014-0677-2.

Godefroy-Colburn, T. et al. (1975) 'Light-scattering studies showing the effect of initiation factors on the reversible dissociation of Escherichia coli ribosomes', Journal of Molecular Biology, 94(3), pp. 461-478. doi: 10.1016/0022-2836(75)90215-6.

Goede, B. et al. (2006) 'Protein-protein interactions in the archaeal transcriptional machinery: Binding studies of isolated RNA polymerase subunits and transcription factors', Journal of Biological Chemistry, 281(41), pp. 30581-30592. doi: 10.1074/jbc.M605209200.

Gogoi, P. and Kanaujia, S. P. (2018) 'Archaeal and eukaryal translation initiation factor 1 differ in their RNA interacting loops', FEBS Letters, 592(9), pp. 1602-1610. doi: 10.1002/1873-3468.13044.

Gordiyenko, Y. et al. (2014) 'elF2B is a decameric guanine nucleotide exchange factor with a $ү 2 \varepsilon 2$ tetrameric core.', Nature communications. Nature Publishing Group, 5(May), p. 3902. doi: 10.1038/ncomms4902.

Gordiyenko, Y., Llácer, J. L. and Ramakrishnan, V. (2019) 'Structural basis for the inhibition of translation through elF2a phosphorylation', Nature Communications. Springer US, 10(1), pp. 1-11. doi: 10.1038/s41467-019-10606-1.

Graindorge, J. S. et al. (2005) 'Deletion of EFL1 results in heterogeneity of the 60 S GTPase-associated rRNA conformation', Journal of Molecular Biology, 352(2), pp. 355-369. doi: 10.1016/j.jmb.2005.07.037.

Greber, B. J. et al. (2012) 'Cryo-EM structure of the archaeal 50 S ribosomal subunit in complex with initiation factor 6 and implications for ribosome evolution', Journal of Molecular Biology. Elsevier Ltd, 418(3-4), pp. 145-160. doi: 10.1016/j.jmb.2012.01.018.

Gregio, A. P. B. et al. (2009) 'elF5A has a function in the elongation step of translation in yeast', Biochemical and Biophysical Research Communications. Elsevier Inc., 380(4), pp. 785-790. doi: 10.1016/j.bbrc.2009.01.148.

Griesenbeck, J., Tschochner, H. and Grohmann, D. (2017) 'Structure and Function of RNA Polymerases and the Transcription Machineries', in, pp. 225-270. doi: 10.1007/978-3-319-46503-6_9.

Grigoriadou, C. et al. (2007) 'The Translational Fidelity Function of IF3 During Transition from the 30 S Initiation Complex to the 70 S Initiation Complex', Journal of Molecular Biology, 373(3), pp. 551-561. doi: 10.1016/j.jmb.2007.07.031.

Grill, S. et al. (2000) 'Selective stimulation of translation of leaderless mRNA by initiation factor 2: Evolutionary implications for translation', EMBO Journal, 19(15), pp. 4101-4110. doi: 10.1093/emboj/19.15.4101.

Grill, S. et al. (2001) 'Modulation of ribosomal recruitment to 5'-terminal start codons by translation initiation factors IF2 and IF3', FEBS Letters, 495(3), pp. 167-171. doi: 10.1016/S0014-5793(01)02378-X.

Groft, C. M. et al. (2000) 'Crystal structures of ribosome anti- association factor IF6', Nature Structural Biology, 7(December), pp. 1156-1164. doi: https://doi.org/10.1038/82017.

Grohmann, D., Hirtreiter, A. and Werner, F. (2009) 'Molecular mechanisms of archaeal RNA polymerase', Biochemical Society Transactions, 37(1), pp. 12-17. doi: 10.1042/BST0370012.

Grohmann, D. and Werner, F. (2010) 'Hold on! RNA polymerase interactions with the nascent RNA modulate transcription elongation and termination', RNA Biology, 7(3). doi: 10.4161/rna.7.3.11912.

Grünberg, S. et al. (2007) 'Transcription factor E is a part of transcription elongation complexes', Journal of Biological Chemistry, 282(49), pp. 35482-35490. doi: 10.1074/jbc.M707371200.

Gualerzi, C. O. et al. (2001) 'Initiation factors in the early events of mRNA translation in bacteria', in Cold Spring Harbor Symposia on Quantitative Biology, pp. 363-376. doi: 10.1101/sqb.2001.66.363.

Gualerzi, C. O. and Pon, C. L. (2015) 'Initiation of mRNA translation in bacteria: Structural and dynamic aspects', Cellular and 
Molecular Life Sciences. Springer Basel, pp. 4341-4367. doi: 10.1007/s00018-015-2010-3.

Guillon, L. et al. (2005) 'Initiator tRNA Binding by e/alF5B, the Eukaryotic/Archaeal Homologue of Bacterial Initiation Factor IF2', Biochemistry, 44(47), pp. 15594-15601. doi: 10.1021/bi051514j.

Gutierrez, E. et al. (2013) 'elF5A Promotes Translation of Polyproline Motifs', Molecular Cell. Elsevier Inc., 51(1), pp. 35-45. doi: 10.1016/j.molcel.2013.04.021.

Gutierrez, P. et al. (2004) 'Structure of the archaeal translation initiation factor alF2beta from Methanobacterium thermoautotrophicum: Implications for translation initiation', Protein Science, 13(3), pp. 659-667. doi: 10.1110/ps.03506604.

Guy, L. and Ettema, T. J. G. (2011) 'The archaeal "TACK" superphylum and the origin of eukaryotes', Trends in Microbiology. Elsevier Ltd, 19(12), pp. 580-587. doi: 10.1016/j.tim.2011.09.002.

Hamana, K., Hamana, H. and Itoh, T. (1995) 'Ubiquitous occurrence of agmatine as the major polyamine within extremely halophilic archaebacteria.', The Journal of General and Applied Microbiology, 41(2), pp. 153-158. doi: 10.2323/jgam.41.153.

Hammelmann, M. and Soppa, J. (2008) 'Optimized generation of vectors for the construction of Haloferax volcanii deletion mutants', Journal of Microbiological Methods, 75(2), pp. 201-204. doi: 10.1016/j.mimet.2008.05.029.

Hanner, M. et al. (1994) 'Autogenous translational regulation of the ribosomal MvaL1 operon in the archaebacterium Methanococcus vannielii.', Journal of Bacteriology, 176(2), pp. 409-418. doi: 10.1128/JB.176.2.409-418.1994.

Hansen, J. L. et al. (2002) 'The structures of four macrolide antibiotics bound to the large ribosomal subunit', Molecular Cell, 10(1), pp. 117-128. doi: 10.1016/S1097-2765(02)00570-1.

Hansen, J. L., Moore, P. B. and Steitz, T. A. (2003) 'Structures of five antibiotics bound at the peptidyl transferase center of the large ribosomal subunit', Journal of Molecular Biology, 330(5), pp. 1061-1075. doi: 10.1016/S0022-2836(03)00668-5.

Hanzelka, B. L., Darcy, T. J. and Reeve, J. N. (2001) 'TFE, an Archaeal Transcription Factor in Methanobacterium thermoautotrophicum Related to Eucaryal Transcription Factor TFIIEa', Journal of Bacteriology, 183(5), pp. 1813-1818. doi: 10.1128/JB.183.5.1813-1818.2001.

Hartman, A. L. et al. (2010) 'The complete genome sequence of Haloferax volcanii DS2, a model archaeon', PLoS ONE, 5(3). doi: 10.1371/journal.pone.0009605.

Hartz, D., McPheeters, D. S. and Gold, L. (1989) 'Selection of the initiator tRNA by Escherichia coli initiation factors.', Genes \& Development, 3(12a), pp. 1899-1912. doi: 10.1101/gad.3.12a.1899.

Hasenöhrl, D. et al. (2006) 'Sulfolobus solfataricus translation initiation factor 1 stimulates translation initiation complex formation', RNA, 12(4), pp. 674-682. doi: 10.1261/rna.2289306.

Hasenöhrl, D. et al. (2008) 'Translation initiation factor a/elF2(gamma) counteracts 5' to 3' mRNA decay in the archaeon Sulfolobus solfataricus', Proceedings of the National Academy of Sciences, 105(6), pp. 2146-2150. doi: 10.1073/pnas.0708894105.

Hasenöhrl, D. et al. (2009) 'Translation initiation complex formation in the crenarchaeon Sulfolobus solfataricus', RNA, 15(12), pp. 2288-2298. doi: 10.1261/rna.1662609.

Hasenöhrl, D., Konrat, R. and Blasi, U. (2011) 'Identification of an RNase J ortholog in Sulfolobus solfataricus: Implications for 5'-to-3' directional decay and 5'-end protection of mRNA in Crenarchaeota', RNA, 17(1), pp. 99-107. doi: 10.1261/rna.2418211.

Hellen, C. U. T. and Sarnow, P. (2001) 'Internal ribosome entry sites in eukaryotic mRNA molecules', Genes and Development, 15(13), pp. 1593-1612. doi: 10.1101/gad.891101.

Hering, O. et al. (2009) 'A novel mechanism for translation initiation operates in haloarchaea', Molecular Microbiology, 71(6), pp. 1451-1463. doi: 10.1111/j.1365-2958.2009.06615.x.

Hinnebusch, A. G. (2011) 'Molecular Mechanism of Scanning and Start Codon Selection in Eukaryotes', Microbiology and Molecular Biology Reviews, 75(3), pp. 434-467. doi: 10.1128/mmbr.00008-11.

Hinnebusch, A. G. (2014) 'The Scanning Mechanism of Eukaryotic Translation Initiation', Annual Review of Biochemistry, 83(1), pp. 779-812. doi: 10.1146/annurev-biochem-060713-035802.

Hirata, A., Klein, B. J. and Murakami, K. S. (2008) 'The X-ray crystal structure of RNA polymerase from Archaea.', Nature, 451(7180), pp. 851-4. doi: 10.1038/nature06530.

Hirata, A. and Murakami, K. S. (2009) 'Archaeal RNA polymerase', Current Opinion in Structural Biology, 19(6), pp. 724-731. doi: 10.1016/j.sbi.2009.10.006.

Hoffman, E. A. et al. (2015) 'Formaldehyde crosslinking: A tool for the study of chromatin complexes', Journal of Biological Chemistry, 290(44), pp. 26404-26411. doi: 10.1074/jbc.R115.651679.

Humbard, M. A. et al. (2010) 'Phosphorylation and methylation of proteasomal proteins of the haloarcheon haloferax volcanii', Archaea, 2010, pp. 1-10. doi: 10.1155/2010/481725.

Hussain, T. et al. (2016) 'Large-Scale Movements of IF3 and tRNA during Bacterial Translation Initiation', Cell, 167(1), pp. 133- 
144.e13. doi: 10.1016/j.cell.2016.08.074.

Imai, H. et al. (2015) 'Functional role of the C-terminal tail of the archaeal ribosomal stalk in recruitment of two elongation factors to the sarcin/ricin loop of 23S rRNA', Genes to Cells, 20(7), pp. 613-624. doi: 10.1111/gtc.12256.

Irihimovitch, V. et al. (2003) 'Isolation of fusion proteins containing SecY and SecE, components of the protein translocation complex from the halophilic archaeon Haloferax volcanii', Extremophiles, 7(1), pp. 71-77. doi: 10.1007/s00792-002-0297-0.

Ito, T., Marintchev, A. and Wagner, G. (2004) 'Solution Structure of Human Initiation Factor elF2 $\alpha$ Reveals Homology to the Elongation Factor eEF1B', Structure, 12(9), pp. 1693-1704. doi: 10.1016/j.str.2004.07.010.

Ivanov, I. P. et al. (2010) 'Initiation context modulates autoregulation of eukaryotic translation initiation factor 1 (elF1)', Proceedings of the National Academy of Sciences of the United States of America, 107(42), pp. 18056-18060. doi: 10.1073/pnas.1009269107.

Jackson, R. J., Hellen, C. U. T. and Pestova, T. V. (2010) 'The mechanism of eukaryotic translation initiation and principles of its regulation', Nature Reviews Molecular Cell Biology. Nature Publishing Group, 11(2), pp. 113-127. doi: 10.1038/nrm2838.

Jaenicke, R. (1991) 'Protein stability and molecular adaptation to extreme conditons', European Journal of Biochemistry, 202(3), pp. 715-728. doi: 10.1111/j.1432-1033.1991.tb16426.x.

Jäger, D. et al. (2009) 'Deep sequencing analysis of the Methanosarcina mazei Gö 1 transcriptome in response to nitrogen availability', Proceedings of the National Academy of Sciences of the United States of America, 106(51), pp. 21878-21882. doi: 10.1073/pnas.0909051106.

Jäger, D. et al. (2014) 'Primary transcriptome map of the hyperthermophilic archaeon Thermococcus kodakarensis', BMC Genomics, 15(1), pp. 1-15. doi: 10.1186/1471-2164-15-684.

Jakus, J. et al. (1993) 'Features of the spermidine-binding site of deoxyhypusine synthase as derived from inhibition studies. Effective inhibition by bis- and mono- guanylated diamines and polyamines', Journal of Biological Chemistry, 268(18), pp. 1315113159. doi: 10.1016/S0021-9258(19)38631-4.

Jan, E. (2006) 'Divergent IRES elements in invertebrates', Virus Research, 119(1), pp. 16-28. doi: 10.1016/j.virusres.2005.10.011.

Jan, E. and Sarnow, P. (2002) 'Factorless Ribosome Assembly on the Internal Ribosome Entry Site of Cricket Paralysis Virus', Journal of Molecular Biology, 324(5), pp. 889-902. doi: 10.1016/S0022-2836(02)01099-9.

Jansson, B. P. M., Malandrin, L. and Johansson, H. E. (2000) 'Cell Cycle Arrest in Archaea by the Hypusination Inhibitor N 1Guanyl-1,7-Diaminoheptane', Journal of Bacteriology, 182(4), pp. 1158-1161. doi: 10.1128/JB.182.4.1158-1161.2000.

Jantzer, K. and Zerulla, K. (2011) 'Phenotyping in the archaea: optimization of growth parameters and'. doi: 10.1111/j.15746968.2011.02341.x.

Jeffery, C. J. (2016) 'What is Protein Moonlighting and Why is it Important?', Moonlighting Proteins: Novel Virulence Factors in Bacterial Infections, (figure 1), pp. 1-19. doi: 10.1002/9781118951149.ch1.

Jennings, M. D. et al. (2016) 'elF2 $\beta$ is critical for elF5-mediated GDP-dissociation inhibitor activity and translational control.', Nucleic acids research, 44(20), pp. 9698-9709. doi: 10.1093/nar/gkw657.

Jia, B., Cheong, G. W. and Zhang, S. (2013) 'Multifunctional enzymes in archaea: Promiscuity and moonlight', Extremophiles, 17(2), pp. 193-203. doi: 10.1007/s00792-012-0509-1.

Jiang, S. et al. (2016) 'Developing Protocols of Tricine-SDS-PAGE for Separation of Polypeptides in the Mass Range 1-30 kDa with Minigel Electrophoresis System', International Journal of Electrochemical Science, 11, pp. 640-649. doi: 10.1016/S0165022X(99)00041-X.

Jiang, W., Hou, Y. and Inouye, M. (1997) 'CspA, the major cold-shock protein of Escherichia coli, is an RNA chaperone', Journal of Biological Chemistry, 272(1), pp. 196-202. doi: 10.1074/jbc.272.1.196.

Johnson, A. G. et al. (2017) 'Dynamics of IRES-mediated translation', Philosophical Transactions of the Royal Society B: Biological Sciences, 372(1716), p. 20160177. doi: 10.1098/rstb.2016.0177.

Jun, S. H. et al. (2011) 'Archaeal RNA polymerase and transcription regulation', Critical Reviews in Biochemistry and Molecular Biology, 46(1), pp. 27-40. doi: 10.3109/10409238.2010.538662.

Kaczowka, S. J. and Maupin-Furlow, J. A. (2003) 'Subunit Topology of Two 20 S Proteasomes from Haloferax volcanii', Journal of Bacteriology, 185(1), pp. 165-174. doi: 10.1128/JB.185.1.165-174.2003.

Kähler, M. and Antranikian, G. (2000) 'Cloning and characterization of a family B DNA polymerase from the hyperthermophilic crenarchaeon Pyrobaculum islandicum', Journal of Bacteriology, 182(3), pp. 655-663. doi: 10.1128/JB.182.3.655-663.2000.

Kakuta, Y. et al. (2004) 'Crystal structure of the regulatory subunit of archaeal initiation factor 2B (alF2B) from hyperthermophilic archaeon Pyrococcus horikoshii OT3: A proposed structure of the regulatory subcomplex of eukaryotic IF2B', Biochemical and Biophysical Research Communications, 319(3), pp. 725-732. doi: 10.1016/j.bbrc.2004.05.045.

Kimball, S. R. et al. (1998) 'Regulation of Guanine Nucleotide Exchange through Phosphorylation of Eukaryotic Initiation Factor 
elF2a', Journal of Biological Chemistry, 273(21), pp. 12841-12845. doi: 10.1074/jbc.273.21.12841.

Kimball, S. R. (1999) 'Eukaryotic initiation factor elF2', The International Journal of Biochemistry \& Cell Biology, 31(1), pp. 2529. doi: $10.1016 / \mathrm{S} 1357-2725(98) 00128-9$.

Klenk, H.-P., Schwass, V. and Zillig, W. (1991) 'Nucleotide sequence of the genes encoding the L30, S12 and S7 equivalent ribosomal proteins from the archaeum Thermococcus celer', Nucleic Acids Research, 19(21), pp. 6047-6047. doi: 10.1093/nar/19.21.6047.

Knowlton, J. R. et al. (2003) 'A spring-loaded state of NusG in its functional cycle is suggested by X-ray crystallography and supported by site-directed mutants', Biochemistry, 42(8), pp. 2275-2281. doi: 10.1021/bi0272508.

Kobayashi, K. et al. (2012) 'Structural basis for translation termination by archaeal RF1 and GTP-bound EF1a complex', Nucleic Acids Research, 40(18), pp. 9319-9328. doi: 10.1093/nar/gks660.

Koh, G. C. K. W. et al. (2012) 'Analyzing protein-protein interaction networks', Journal of Proteome Research, 11(4), pp. 20142031. doi: $10.1021 / \mathrm{pr} 201211 \mathrm{w}$.

Kohler, R. et al. (2017) 'Architecture of a transcribing-translating expressome', Science, 356(6334), pp. 194-197. doi: 10.1126/science.aal3059.

Komar, A. A., Mazumder, B. and Merrick, W. C. (2012) 'A new framework for understanding IRES-mediated translation', Gene. Elsevier B.V., 502(2), pp. 75-86. doi: 10.1016/j.gene.2012.04.039.

Korkhin, Y. et al. (2009) 'Evolution of complex RNA polymerases: The complete archaeal RNA polymerase structure', PLoS Biology, 7(5). doi: 10.1371/journal.pbio.1000102.

Korobeinikova, A. V, Garber, M. B. and Gongadze, G. M. (2012) 'Ribosomal Proteins: Structure, Function, and Evolution', Biochemistry (Moscow), 77(6), pp. 562-574. doi: 10.1134/S0006297912060028 Key.

Korostelev, A. A. (2014) 'A deeper look into translation initiation', Cell. Elsevier Inc., 159(3), pp. 475-476. doi: 10.1016/j.cell.2014.10.005.

Kozak, M. (1999) 'Initiation of translation in prokaryotes and eukaryotes', Gene, 234(2), pp. 187-208. doi: S0378111999002103 [pii].

Kozak, M. (2002) 'Pushing the limits of the scanning mechanism for initiation of translation', Gene, pp. 1-34. doi: 10.1016/S0378-1119(02)01056-9.

Kozak, M. (2005a) 'A second look at cellular mRNA sequences said to function as internal ribosome entry sites', Nucleic Acids Research, 33(20), pp. 6593-6602. doi: 10.1093/nar/gki958.

Kozak, M. (2005b) 'Regulation of translation via mRNA structure in prokaryotes and eukaryotes', Gene, 361(1-2), pp. $13-37$. doi: 10.1016/j.gene.2005.06.037.

Kraft, A. et al. (1999) 'Control of ribosomal protein L1 synthesis in mesophilic and thermophilic archaea.', Genetics, 152(4), pp. 1363-72. Available at: http://www.ncbi.nlm.nih.gov/pubmed/10430567.

Kramer, P. et al. (2014) 'Haloferax volcanii, a Prokaryotic Species that Does Not Use the Shine Dalgarno Mechanism for Translation Initiation at 5'-UTRs', PLoS ONE. Edited by V. de Crécy-Lagard, 9(4), p. e94979. doi: 10.1371/journal.pone.0094979.

Krishnamoorthy, T. and Pavitt, G. (2001) 'Tight binding of the phosphorylated $\alpha$ subunit of initiation factor 2 (elF2 $\alpha$ ) to the regulatory subunits of guanine nucleotide exchange factor eIF2B is required for inhibition of translation', Molecular \& Cellular Biology, 21(15), pp. 5018-5030. doi: 10.1128/MCB.21.15.5018.

Krüger, K. et al. (1998) 'The transcriptional activator GvpE for the halobacterial gas vesicle genes resembles a basic region leucine-zipper regulatory protein', Journal of Molecular Biology, 279(4), pp. 761-771. doi: 10.1006/jmbi.1998.1795.

Kuhle, B. and Ficner, R. (2014a) 'elF5B employs a novel domain release mechanism to catalyze ribosomal subunit joining', The EMBO Journal, 33(10), pp. 1177-1191. doi: 10.1002/embj.201387344.

Kuhle, B. and Ficner, R. (2014b) 'Structural insight into the recognition of amino-acylated initiator tRNA by elF5B in the 80 S initiation complex', BMC Structural Biology, 14(1), p. 20. doi: 10.1186/s12900-014-0020-2.

Kuzminov, A. (2014) 'The precarious prokaryotic chromosome', Journal of Bacteriology, 196(10), pp. 1793-1806. doi: 10.1128/JB.00022-14

Kyrpides, N. C. and Woese, C. R. (1998a) 'Archaeal translation initiation revisited: The initiation factor 2 and eukaryotic initiation factor 2B - - subunit families', Proceedings of the National Academy of Sciences, 95(7), pp. 3726-3730. doi: 10.1073/pnas.95.7.3726.

Kyrpides, N. C. and Woese, C. R. (1998b) 'Universally conserved translation initiation factors', Proceedings of the National Academy of Sciences, 95(1), pp. 224-228. doi: 10.1073/pnas.95.1.224.

Kyrpides, N. C., Woese, C. R. and Ouzounis, C. A. (1996) 'KOW: A novel motif linking a bacterial transcription factor with ribosomal proteins', Trends in Biochemical Sciences, 21(11), pp. 425-426. doi: 10.1016/S0968-0004(96)30036-4. 
Lamanna, A. C. and Karbstein, K. (2009) 'Nob1 binds the single-stranded cleavage site D at the 3'-end of 18S rRNA with its PIN domain', Proceedings of the National Academy of Sciences, 106(34), pp. 14259-14264. doi: 10.1073/pnas.0905403106.

Lambert, J. P., Pawson, T. and Gingras, A. C. (2012) 'Mapping physical interactions within chromatin by proteomic approaches', Proteomics, 12(10), pp. 1609-1622. doi: 10.1002/pmic.201100547.

Landau, G. et al. (2010) 'The role of polyamines in supporting growth of mammalian cells is mediated through their requirement for translation initiation and elongation', Journal of Biological Chemistry, 285(17), pp. 12474-12481. doi: 10.1074/jbc.M110.106419.

Landick, R., Carey, J. and Yanofsky, C. (1985) 'Translation activates the paused transcription complex and restores transcription of the trp operon leader region.', Proceedings of the National Academy of Sciences, 82(14), pp. 4663-4667. doi: 10.1073/pnas.82.14.4663.

Langer, D. et al. (1995) 'Transcription in archaea: Similarity to that in eucarya', Proceedings of the National Academy of Sciences of the United States of America, 92(13), pp. 5768-5772. doi: 10.1073/pnas.92.13.5768.

Lassak, J., Wilson, D. N. and Jung, K. (2016) 'Stall no more at polyproline stretches with the translation elongation factors EF$\mathrm{P}$ and IF-5A', Molecular Microbiology, 99(2), pp. 219-235. doi: 10.1111/mmi.13233.

Lecompte, O. et al. (2002) 'Comparative analysis of ribosomal proteins in complete genomes: An example of reductive evolution at the domain scale', Nucleic Acids Research, 30(24), pp. 5382-5390. doi: 10.1093/nar/gkf693.

Lee, J. H. et al. (1999) 'Universal conservation in translation initiation revealed by human and archaeal homologs of bacterial translation initiation factor IF2', Proceedings of the National Academy of Sciences of the United States of America, 96(8), pp. 4342-4347. doi: 10.1073/pnas.96.8.4342.

Lee, Y. B., Park, M. H. and Folk, J. E. (1995) 'Diamine and Triamine Analogs and Derivatives as Inhibitors of Deoxyhypusine Synthase: Synthesis and Biological Activity', Journal of Medicinal Chemistry, 38(16), pp. 3053-3061. doi: 10.1021/jm00016a008.

Legault, L., Jeantet, C. and Gros, F. (1972) 'Inhibition of in vitro protein synthesis by ppGpp', FEBS Letters, 27(1), pp. 71-75. doi: 10.1016/0014-5793(72)80412-5.

Li, W. and Hoffmann, D. W. (2001) 'Structure and dynamics of translation initiation factor alF-1A from the archaeon Methanococcus jannaschii determined by NMR spectroscopy', pp. 2426-2438. doi: 10.1101/ps.18201.AUG.

Li, Z. et al. (2010) 'Affinity Purification of an Archaeal DNA Replication Protein Network', mBio. Edited by S. Adhya, 1(5), pp. 110. doi: $10.1128 / \mathrm{mBio} .00221-10$.

Lin, K. Y. et al. (2018) 'Human elF5 and elF1A Compete for Binding to elF5B', Biochemistry. American Chemical Society, 57(40), pp. 5910-5920. doi: 10.1021/acs.biochem.8b00839.

Linder, P. and Fuller-Pace, F. (2015) 'Happy Birthday: 25 Years of DEAD-Box Proteins', in RNA Remodeling Proteins: Methods and Protocols, pp. 17-33. doi: 10.1007/978-1-4939-2214-7_2.

Linder, P. and Jankowsky, E. (2011) 'From unwinding to clamping - the DEAD box RNA helicase family', Nature Reviews Molecular Cell Biology. Nature Publishing Group, 12(8), pp. 505-516. doi: 10.1038/nrm3154.

Locker, N., Easton, L. E. and Lukavsky, P. J. (2007) 'HCV and CSFV IRES domain II mediate elF2 release during 80S ribosome assembly', EMBO Journal, 26(3), pp. 795-805. doi: 10.1038/sj.emboj.7601549.

Lomakin, I. B. et al. (2003) 'Position of eukaryotic initiation factor elF1 on the 40S ribosomal subunit determined by directed hydroxyl radical probing', Genes \& Development, 17(22), pp. 2786-2797. doi: 10.1101/gad.1141803.

Londei, P. (2005) 'Evolution of translational initiation: New insights from the archaea', FEMS Microbiology Reviews, 29(2), pp. 185-200. doi: 10.1016/j.femsre.2004.10.002.

Ludt, K. and Soppa, J. (2018) 'Influence of origin recognition complex proteins on the copy numbers of three chromosomes in Haloferax volcanii', Journal of Bacteriology, 200(17), pp. 1-13. doi: 10.1128/JB.00161-18.

Luna, R. E. et al. (2013) 'The interaction between eukaryotic initiation factor $1 \mathrm{~A}$ and elF5 retains eif1 within scanning preinitiation complexes', Biochemistry, 52(52), pp. 9510-9518. doi: 10.1021/bi4009775.

Luviano, A. et al. (2019) 'Cooperative energetic effects elicited by the yeast Shwachman-Diamond syndrome protein (Sdo1) and guanine nucleotides modulate the complex conformational landscape of the elongation factor-like 1 (Efl1) GTPase', Biophysical Chemistry. Elsevier, 247(January), pp. 13-24. doi: 10.1016/j.bpc.2019.02.003.

MacNeill, S. A. (2011) 'Protein-protein interactions in the archaeal core replisome', Biochemical Society Transactions, 39(1), pp. 163-168. doi: 10.1042/bst0390163.

Maki, Y. et al. (2007) 'Three Binding Sites for Stalk Protein Dimers Are Generally Present in Ribosomes from Archaeal Organism', Journal of Biological Chemistry, 282(45), pp. 32827-32833. doi: 10.1074/jbc.M705412200.

Maone, E. et al. (2007) 'Functional analysis of the translation factor alF2/5B in the thermophilic archaeon Sulfolobus solfataricus', Molecular Microbiology, 65(3), pp. 700-713. doi: 10.1111/j.1365-2958.2007.05820.x.

Martinez-Salas, E. et al. (2018) 'Insights into structural and mechanistic features of viral IRES elements', Frontiers in 
Microbiology, 8(JAN), pp. 1-15. doi: 10.3389/fmicb.2017.02629.

Maruyama, $\mathrm{H}$. et al. (2011) 'Histone and TK0471/TrmBL2 form a novel heterogeneous genome architecture in the hyperthermophilic archaeon Thermococcus kodakarensis', Molecular Biology of the Cell. Edited by W. P. Tansey, 22(3), pp. 386398. doi: 10.1091/mbc.e10-08-0668.

Matelska, D., Steczkiewicz, K. and Ginalski, K. (2017) 'Comprehensive classification of the PIN domain-like superfamily', Nucleic Acids Research, 45(12), pp. 6995-7020. doi: 10.1093/nar/gkx494.

McGary, K. and Nudler, E. (2013) 'RNA polymerase and the ribosome: The close relationship', Current Opinion in Microbiology. Elsevier Ltd, 16(2), pp. 112-117. doi: 10.1016/j.mib.2013.01.010.

McKune, K. and Woychik, N. A. (1994) 'Halobacterial S9 operon contains two genes encoding proteins homologous to subunits shared by eukaryotic RNA polymerases I, II, and III.', Journal of bacteriology, 176(15), pp. 4754-6. doi: 10.1128/jb.176.15.47544756.1994.

McLennan, A. G. (2006) 'The Nudix hydrolase superfamily', Cellular and Molecular Life Sciences, 63(2), pp. 123-143. doi: $10.1007 / \mathrm{s} 00018-005-5386-7$.

Melnikov, S., Manakongtreecheep, K. and Söll, D. (2018) 'Revising the structural diversity of ribosomal proteins across the three domains of life', Molecular Biology and Evolution, 35(7), pp. 1588-1598. doi: 10.1093/molbev/msy021.

Mevarech, M., Frolow, F. and Gloss, L. M. (2000) 'Halophilic enzymes: Proteins with a grain of salt', Biophysical Chemistry, 86(2-3), pp. 155-164. doi: 10.1016/S0301-4622(00)00126-5.

Michael, A. J. (2016) 'Polyamines in eukaryotes, bacteria, and archaea', Journal of Biological Chemistry, 291(29), pp. 1489614903. doi: 10.1074/jbc.R116.734780.

Milon, P. et al. (2006) 'The nucleotide-binding site of bacterial translation initiation factor 2 (IF2) as a metabolic sensor', Proceedings of the National Academy of Sciences of the United States of America, 103(38), pp. 13962-13967. doi: 10.1073/pnas.0606384103.

Miluzio, A. et al. (2009) 'Eukaryotic initiation factor 6 mediates a continuum between $60 \mathrm{~S}$ ribosome biogenesis and translation', EMBO Reports, 10(5), pp. 459-465. doi: 10.1038/embor.2009.70.

Mitroshin, I. V., Garber, M. B. and Gabdulkhakov, A. G. (2016) 'Investigation of structure of the ribosomal L12/P stalk', Biochemistry (Moscow), 81(13), pp. 1589-1601. doi: 10.1134/S0006297916130022.

Moazed, D. et al. (1995) 'Specific protection of 16 S rRNA by translationalinitiation factors', Journal of Molecular Biology, 248(2), pp. 207-210. doi: 10.1016/S0022-2836(95)80042-5.

Mojica, F. J. M. et al. (1997) 'Osmotically induced response in representatives of halophilic prokaryotes: The bacterium Halomonas elongata and the archaeon Haloferax volcanii', Journal of Bacteriology, 179(17), pp. 5471-5481. doi: 10.1128/jb.179.17.5471-5481.1997.

Moll, I. et al. (2002) 'Leaderless mRNAs in bacteria: Surprises in ribosomal recruitment and translational control', Molecular Microbiology, 43(1), pp. 239-246. doi: 10.1046/j.1365-2958.2002.02739.x.

Moll, I. et al. (2004) 'Translation initiation with 70S ribosomes: An alternative pathway for leaderless mRNAs', Nucleic Acids Research, 32(11), pp. 3354-3363. doi: 10.1093/nar/gkh663.

Monestier, A. et al. (2018) 'Role of alF1 in Pyrococcus abyssi translation initiation', Nucleic acids research, 46(20), pp. 1106111074. doi: $10.1093 /$ nar/gky850.

Mooney, R. A. et al. (2009) 'Two Structurally Independent Domains of E. coli NusG Create Regulatory Plasticity via Distinct Interactions with RNA Polymerase and Regulators', Journal of Molecular Biology. Elsevier Ltd, 391(2), pp. 341-358. doi: 10.1016/j.jmb.2009.05.078.

Moore, P. B. and Steitz, T. A. (2002) 'The Structural Basis of Large Ribosomal Subunit Function', Annual Review of Biochemistry, pp. 813-850. doi: 10.1146/annurev.biochem.71.110601.135450.

Morag, E. et al. (1995) 'Expression, Purification , and Characterization of the Cellulose- Binding Domain of the Scaffoldin Subunit from the Cellulosome of Clostridium thermocellum', Applied and environmental microbiology, 61(5), pp. 1980-1986.

Motz, M. et al. (2002) 'Elucidation of an archaeal replication protein network to generate enhanced PCR enzymes', Journal of Biological Chemistry, 277(18), pp. 16179-16188. doi: 10.1074/jbc.M107793200.

Mullakhanbhai, M. F. and Larsen, H. (1975) 'Halobacterium volcanii spec. nov., a Dead Sea halobacterium with a moderate salt requirement', Archives of Microbiology, 104(1), pp. 207-214. doi: 10.1007/BF00447326.

Murakami, R. et al. (2016) 'Crystal structure of translation initiation factor 5B from the crenarchaeon Aeropyrum pernix', Proteins: Structure, Function and Bioinformatics, 84(5), pp. 712-717. doi: 10.1002/prot.25009.

Murakami, R. et al. (2018) 'The Interaction between the Ribosomal Stalk Proteins and Translation Initiation Factor 5B Promotes Translation Initiation', Molecular and Cellular Biology, 38(16), p. MCB.00067-18. doi: 10.1128/MCB.00067-18.

Murzin, A. G. (1993) 'OB(oligonucleotide/oligosaccharide binding)-fold: common structural and functional solution for non- 
homologous sequences.', The EMBO Journal, 12(3), pp. 861-867. doi: 10.1002/j.1460-2075.1993.tb05726.x.

Nag, N. et al. (2016) 'EIF1A/elF5B interaction network and its functions in translation initiation complex assembly and remodeling', Nucleic Acids Research, 44(15), pp. 7441-7456. doi: 10.1093/nar/gkw552.

Naji, S., Grünberg, S. and Thomm, M. (2007) 'The RPB7 Orthologue E' Is Required for Transcriptional Activity of a Reconstituted Archaeal Core Enzyme at Low Temperatures and Stimulates Open Complex Formation', Journal of Biological Chemistry, 282(15), pp. 11047-11057. doi: 10.1074/jbc.M611674200.

Nanda, J. S. et al. (2013) 'Coordinated movements of eukaryotic translation initiation Factors elF1, elF1A, and elF5 trigger phosphate release from elF2 in response to start codon recognition by the ribosomal preinitiation complex', Journal of Biological Chemistry, 288(8), pp. 5316-5329. doi: 10.1074/jbc.M112.440693.

Naveau, M. et al. (2013) 'Roles of yeast elF2 $\alpha$ and elF2 $\beta$ subunits in the binding of the initiator methionyl-tRNA', Nucleic Acids Research, 41(2), pp. 1047-1057. doi: 10.1093/nar/gks1180.

Nissen, P. et al. (2000) 'The Structural Basis of Ribosome Activity in Peptide Bond Synthesis', Science, 289(5481), pp. 920930. doi: 10.1126/science.289.5481.920.

Nomura, N. et al. (2012) 'Archaeal ribosomal stalk protein interacts with translation factors in a nucleotide-independent manner via its conserved C terminus', Proceedings of the National Academy of Sciences of the United States of America, 109(10), pp. 3748-53. doi: 10.1073/pnas.1112934109.

Nunoura, T. et al. (2011) 'Insights into the evolution of Archaea and eukaryotic protein modifier systems revealed by the genome of a novel archaeal group', Nucleic Acids Research, 39(8), pp. 3204-3223. doi: 10.1093/nar/gkq1228.

O. L. Miller, J., Hamkalo, B. A. and C. A. Thomas, J. (1970) 'Visualization of Bacterial Genes in Action', Science, 169(3943), pp. 392-395. Available at: https://www.jstor.org/stable/1729589?seq=1\&cid=pdf-reference/analyze.

O'Donnell, S. M. and Janssen, G. R. (2002) 'Leaderless mRNAs Bind 70S Ribosomes More Strongly than 30S Ribosomal Subunits in Escherichia coli Leaderless mRNAs Bind 70S Ribosomes More Strongly than 30 S Ribosomal Subunits in Escherichia coli', Journal of bacteriology, 184(23), pp. 1-5. doi: 10.1128/JB.184.23.6730-6733.2002.

O'Leary, S. E. et al. (2013) 'Dynamic Recognition of the mRNA Cap by Saccharomyces cerevisiae elF4E', Structure, 21(12), pp. 2197-2207. doi: 10.1016/j.str.2013.09.016.

Oeffinger, M. (2012) 'Two steps forward-one step back: Advances in affinity purification mass spectrometry of macromolecular complexes', Proteomics, 12(10), pp. 1591-1608. doi: 10.1002/pmic.201100509.

Ogawa, T. et al. (2005) 'Comprehensive Analysis of Cytosolic Nudix Hydrolases in Arabidopsis thaliana', Journal of Biological Chemistry, 280(26), pp. 25277-25283. doi: 10.1074/jbc.M503536200.

Olsen, D. S. et al. (2003) 'Domains of elF1A that mediate binding to elF2, elF3 and elF5B and promote ternary complex recruitment in vivo', EMBO Journal, 22(2), pp. 193-204. doi: 10.1093/emboj/cdg030.

Oren, A. and Ventosa, A. (1999) 'Benjamin Elazari Volcani Dead Sea studies of the microbiology of the (1915-1999): Sixtythree years of Correspondence', Internatl Microbiol, (June), pp. 195-198. doi: https://www.researchgate.net/publication/41953283 Benjamin.

Ortega, G., Diercks, T. and Millet, O. (2015) 'Halophilic Protein Adaptation Results from Synergistic Residue-lon Interactions in the Folded and Unfolded States', Chemistry and Biology. Elsevier Ltd, 22(12), pp. 1597-1607. doi: 10.1016/j.chembiol.2015.10.010.

Osada, Y., Saito, R. and Tomita, M. (1999) 'Analysis of base-pairing potentials between 16S rRNA and 5' UTR for translation initiation in various prokaryotes', Bioinformatics, 15(7), pp. 578-581. doi: 10.1093/bioinformatics/15.7.578.

Osterman, I. A. et al. (2015) 'A bacterial homolog YciH of eukaryotic translation initiation factor elF1 regulates stress-related gene expression and is unlikely to be involved in translation initiation fidelity', RNA Biology, 12(9), pp. 966-971. doi: 10.1080/15476286.2015.1069464

Ouhammouch, M. et al. (2004) 'A fully recombinant system for activator-dependent archaeal transcription', Journal of Biological Chemistry, 279(50), pp. 51719-51721. doi: 10.1074/jbc.C400446200.

Palacios Moreno, J. M. et al. (2000) 'Macromolecular mimicry in translation initiation: A model for the initiation factor IF2 on the ribosome', IUBMB Life, 50(6), pp. 347-354. doi: 10.1080/152165400300089330.

Park, M. H. (2006) 'The Post-Translational Synthesis of a Polyamine-Derived Amino Acid, Hypusine, in the Eukaryotic Translation Initiation Factor 5A (elF5A)', The Journal of Biochemistry, 139(2), pp. 161-169. doi: 10.1093/jb/mvj034.

Park, M. H. et al. (2010) 'Functional significance of elF5A and its hypusine modification in eukaryotes', Amino Acids, 38(2), pp. 491-500. doi: 10.1007/s00726-009-0408-7.

Passmore, L. A. et al. (2007) 'The Eukaryotic Translation Initiation Factors elF1 and elF1A Induce an Open Conformation of the 40S Ribosome', Molecular Cell, 26(1), pp. 41-50. doi: 10.1016/j.molcel.2007.03.018.

Patel, P. H. et al. (2009) 'The Drosophila deoxyhypusine hydroxylase homologue nero and its target elF5A are required for cell growth and the regulation of autophagy', Journal of Cell Biology, 185(7), pp. 1181-1194. doi: 10.1083/jcb.200904161. 
Pavitt, G. D. et al. (1998) 'elF2 independently binds two distinct elF2b subcomplexes that catalyze and regulate guaninenucleotide exchange', Genes and Development, 12(4), pp. 514-526. doi: 10.1101/gad.12.4.514.

Peat, T. S. et al. (1998) 'Structure of translation initiation factor 5 A from Pyrobaculum aerophilum at 1.75 å resolution', Structure, 6(9), pp. 1207-1214. doi: 10.1016/S0969-2126(98)00120-8.

Pech, M. and Nierhaus, K. H. (2012) 'Identical Binding Sites-Nonidentical Functions in Eukarya and Archaea: The Complex of aelF6 with the Large Ribosomal Subunit', Journal of Molecular Biology, 418(3-4), pp. 131-133. doi: 10.1016/j.jmb.2012.02.033.

Pedullà, N. et al. (2005) 'The archaeal elF2 homologue: functional properties of an ancient translation initiation factor.', Nucleic acids research, 33(6), pp. 1804-12. doi: 10.1093/nar/gki321.

Pelletier, J. and Sonenberg, N. (1988) 'Internal initiation of translation of eukaryotic mRNA directed by a sequence derived from poliovirus RNA', Nature, 334(6180), pp. 320-325. doi: 10.1038/334320a0.

Perez-Rueda, E. et al. (2018) 'Abundance, diversity and domain architecture variability in prokaryotic DNA-binding transcription factors', PLoS ONE, 13(4), pp. 1-16. doi: 10.1371/journal.pone.0195332.

Perez-Rueda, E. and Janga, S. C. (2010) 'Identification and Genomic Analysis of Transcription Factors in Archaeal Genomes Exemplifies Their Functional Architecture and Evolutionary Origin', Molecular Biology and Evolution, 27(6), pp. 1449-1459. doi: 10.1093/molbev/msq033.

Pestova, T. V. et al. (2000) 'The joining of ribosomal subunits in eukaryotes requires elF5B', Nature, 403(6767), pp. 332-335. doi: $10.1038 / 35002118$.

Pestova, T. V. et al. (2008) 'elF2-dependent and elF2-independent modes of initiation on the CSFV IRES: A common role of domain II', EMBO Journal, 27(7), pp. 1060-1072. doi: 10.1038/emboj.2008.49.

Peter Sørensen, Jakob Hedeg, H. (2001) 'Remarkable Conservation of Translation Initiation Factors: IF1/elF1A and IF2/elF5B are Universally Distributed Phylogenetic Markers', IUBMB Life (International Union of Biochemistry and Molecular Biology: Life), 51(5), pp. 321-327. doi: 10.1080/152165401317190842.

Pisarev, A. V. et al. (2008) 'Ribosomal position and contacts of mRNA in eukaryotic translation initiation complexes', EMBO Journal, 27(11), pp. 1609-1621. doi: 10.1038/emboj.2008.90.

Plavner, N. and Eichler, J. (2008) 'Defining the topology of the N-glycosylation pathway in the halophilic archaeon Haloferax volcanii', Journal of Bacteriology, 190(24), pp. 8045-8052. doi: 10.1128/JB.01200-08.

Pluchon, P. F. et al. (2013) 'An extended network of genomic maintenance in the archaeon Pyrococcus abyssi highlights unexpected associations between eucaryotic homologs', PLOS ONE, 8(11), pp. 1-15. doi: 10.1371/journal.pone.0079707.

Pohlschroder, M. and Schulze, S. (2019) 'Haloferax volcanii', Trends in Microbiology. Elsevier Ltd, 27(1), pp. 86-87. doi: 10.1016/j.tim.2018.10.004.

Proshkin, S. et al. (2010) 'Cooperation Between Translating Ribosomes and RNA Polymerase in Transcription Elongation', Science, 328(5977), pp. 504-508. doi: 10.1126/science.1184939.

Prunetti, L. et al. (2016) 'Deciphering the Translation Initiation Factor 5A Modification Pathway in Halophilic Archaea', Archaea, 2016, pp. 1-14. doi: 10.1155/2016/7316725.

Qureshi, S. A. et al. (1995) 'Molecular cloning of the transcription factor TFIIB homolog from Sulfolobus shibatae', Proceedings of the National Academy of Sciences of the United States of America, 92(13), pp. 6077-6081. doi: 10.1073/pnas.92.13.6077.

Rajkovic, A. and Ibba, M. (2017) 'Elongation Factor P and the Control of Translation Elongation', Annual Review of Microbiology, 71(1), pp. 117-131. doi: 10.1146/annurev-micro-090816-093629.

Ramanathan, A., Robb, G. B. and Chan, S. H. (2016) 'mRNA capping: Biological functions and applications', Nucleic Acids Research, 44(16), pp. 7511-7526. doi: 10.1093/nar/gkw551.

Ramírez, C. et al. (1993) 'The structure, function and evolution of archaeal ribosomes', New Comprehensive Biochemistry, 26(C), pp. 439-466. doi: 10.1016/S0167-7306(08)60263-X.

Ray, B. K. et al. (1985) 'ATP-dependent unwinding of messenger RNA structure by eukaryotic initiation factors', Journal of Biological Chemistry, 260(12), pp. 7651-7658.

Reibarkh, M. et al. (2008) 'Eukaryotic initiation factor (elF) 1 carries two distinct elF5-binding faces important for multifactor assembly and AUG selection', Journal of Biological Chemistry, 283(2), pp. 1094-1103. doi: 10.1074/jbc.M708155200.

Richard, D. J., Bell, S. D. and White, M. F. (2004) 'Physical and functional interaction of the archaeal single-stranded DNAbinding protein SSB with RNA polymerase', Nucleic Acids Research, 32(3), pp. 1065-1074. doi: 10.1093/nar/gkh259.

Richter, D. and Lipmann, F. (1970) 'Formation of a Ternary Complex between Formylatable Yeast Met-tRNA, GTP and Binding Factor T of Yeast and of E.coli', Nature, 228(October 17th), pp. 227-231.

Rippa, V. et al. (2010) 'The ribosomal protein L2 interacts with the RNA polymerase a subunit and acts as a transcription modulator in Escherichia coli', Journal of Bacteriology, 192(7), pp. 1882-1889. doi: 10.1128/JB.01503-09. 
Rogers, G. W. et al. (2001) 'Modulation of the Helicase Activity of elF4A by elF4B, elF4H, and elF4F', Journal of Biological Chemistry, 276(33), pp. 30914-30922. doi: 10.1074/jbc.M100157200.

Roll-Mecak, A. et al. (2000) 'X-Ray Structures of the Universal Translation Initiation Factor IF2/elF5B', Cell, 103(5), pp. 781792. doi: 10.1016/S0092-8674(00)00181-1.

Roll-Mecak, A. et al. (2004) 'X-ray Structure of Translation Initiation Factor elF2y: Implications for tRNA and elF2 $\alpha$ binding', Journal of Biological Chemistry, 279(11), pp. 10634-10642. doi: 10.1074/jbc.M310418200.

Ron, D. and Harding, H. (2007) 'elF2 Phosphorylation in Cellular Stress Responses and Disease', Translational Control in Biology and Medicine, pp. 349-372. doi: 10.1101/087969767.48.345.

Saini, A. K. et al. (2009) 'Regulatory elements in elF1A control the fidelity of start codon selection Met binding by modulating tRNA $\mathrm{i}$ to the ribosome', Genes \& Development, (24), pp. 97-110. doi: 10.1101/gad.1871910.triplets.

Saini, A. K. et al. (2014) 'Eukaryotic translation initiation factor elF5 promotes the accuracy of start codon recognition by regulating Pi release and conformational transitions of the preinitiation complex', Nucleic Acids Research, 42(15), pp. 9623-9640. doi: $10.1093 /$ nar/gku653.

Saito, K. et al. (2010) 'Omnipotent role of archaeal elongation factor 1 alpha (EF1) in translational elongation and termination, and quality control of protein synthesis', Proceedings of the National Academy of Sciences, 107(45), pp. 19242-19247. doi: 10.1073/pnas.1009599107.

Samson, R. Y., Abeyrathne, P. D. and Bell, S. D. (2016) 'Mechanism of Archaeal MCM Helicase Recruitment to DNA Replication Origins', Molecular Cell, 61(2), pp. 287-296. doi: 10.1016/j.molcel.2015.12.005.

Samson, R. Y. and Bell, S. D. (2014) 'Archaeal Chromosome Biology', J Mol Microbiol Biotechnol., 46(5), p. 795. doi: 10.6009/jjrt.KJ00003532530.

Santos, H. and da Costa, M. S. (2002) 'Compatible solutes of organisms that live in hot saline environments', Environmental Microbiology, 4(9), pp. 501-509. doi: 10.1046/j.1462-2920.2002.00335.x.

Schlesner, M. et al. (2012) 'The protein interaction network of a taxis signal transduction system in a halophilic archaeon', BMC Microbiology, 12, pp. 1-20. doi: 10.1186/1471-2180-12-272.

Schmidt, C. et al. (2016) 'Structure of the hypusinylated eukaryotic translation factor elF-5A bound to the ribosome', Nucleic Acids Research, 44(4), pp. 1944-1951. doi: 10.1093/nar/gkv1517.

Schmidt, C., Beilsten-Edmands, V. and Robinson, C. V. (2016) 'Insights into Eukaryotic Translation Initiation from Mass Spectrometry of Macromolecular Protein Assemblies', Journal of Molecular Biology. The Authors, 428(2), pp. 344-356. doi: 10.1016/j.jmb.2015.10.011.

Schmitt, E. et al. (1998) 'Crystal structure of methionyl-tRNA(f)(Met) transformylase complexed with the initiator formylmethionyl-tRNA(f)(Met)', EMBO Journal, 17(23), pp. 6819-6826. doi: 10.1093/emboj/17.23.6819.

Schmitt, E. et al. (2012) 'Structure of the ternary initiation complex alF2-GDPNP-methionylated initiator tRNA', Nature Structural \& Molecular Biology. Nature Publishing Group, 19(4), pp. 450-454. doi: 10.1038/nsmb.2259.

Schmitt, E. et al. (2019) 'Start codon recognition in eukaryotic and archaeal translation initiation: A common structural core', International Journal of Molecular Sciences, 20(4). doi: 10.3390/ijms20040939.

Schmitt, E., Blanquet, S. and Mechulam, Y. (2002) 'The large subunit of initiation factor alF2 is a close structural homologue of elongation factors', Embo Journal, 21(7), pp. 1821-1832.

Schmitt, E., Naveau, M. and Mechulam, Y. (2010) 'Eukaryotic and archaeal translation initiation factor 2: A heterotrimeric tRNA carrier', FEBS Letters. Federation of European Biochemical Societies, 584(2), pp. 405-412. doi: 10.1016/j.febslet.2009.11.002.

Scholzen, T. and Arndt, E. (1991) 'Organization and nucleotide sequence of ten ribosomal protein genes from the region equivalent to the spectinomycin operon in the archaebacterium Halobacterium marismortui', MGG Molecular \& General Genetics, 228(1-2), pp. 70-80. doi: 10.1007/BF00282450.

Seino, A. et al. (2005) 'Translational control by internal ribosome entry site in Saccharomyces cerevisiae', Biochimica et Biophysica Acta - Gene Structure and Expression, 1681(2-3), pp. 166-174. doi: 10.1016/j.bbaexp.2004.11.009.

Sette, M. (1997) 'The structure of the translational initiation factor IF1 from E.coli contains an oligomer-binding motif', The EMBO Journal, 16(6), pp. 1436-1443. doi: 10.1093/emboj/16.6.1436.

Shatsky, I. N. et al. (2010) 'Cap- and IRES-independent scanning mechanism of translation initiation as an alternative to the concept of cellular IRESs', Molecules and Cells, 30(4), pp. 285-293. doi: 10.1007/s10059-010-0149-1.

Shin, B. S. et al. (2002) 'Uncoupling of initiation factor elF5B/IF2 GTPase and translational activities by mutations that lower ribosome affinity', Cell, 111(7), pp. 1015-1025. doi: 10.1016/S0092-8674(02)01171-6.

Shine, J. and Dalgarno, L. (1974) 'The 3'-Terminal Sequence of Escherichia coli 16S Ribosomal RNA: Complementarity to Nonsense Triplets and Ribosome Binding Sites', Proceedings of the National Academy of Sciences, 71(4), pp. 1342-1346. doi: 10.1073/pnas.71.4.1342. 
Simonetti, A. et al. (2009) 'A structural view of translation initiation in bacteria', Cellular and Molecular Life Sciences, 66(3), pp. 423-436. doi: 10.1007/s00018-008-8416-4.

Simonson, T. and Satpati, P. (2012) 'Nucleotide recognition by the initiation factor alF5B: Free energy simulations of a neoclassical GTPase', Proteins: Structure, Function and Bioinformatics, 80(12), pp. 2742-2757. doi: 10.1002/prot.24158.

Soppa, J. (2011) 'Functional genomic and advanced genetic studies reveal novel insights into the metabolism, regulation, and biology of Haloferax volcanii', Archaea, 2011, pp. 1-14. doi: 10.1155/2011/602408.

Spivak, G. (2016) 'Transcription-coupled repair: an update', Archives of Toxicology, 90(11), pp. 2583-2594. doi: 10.1007/s00204-016-1820-x.

Srinivasan, G., Krebs, M. P. and RajBhandary, U. L. (2006) 'Translation initiation with GUC codon in the archaeon Halobacterium salinarum: Implications for translation of leaderless mRNA and strict correlation between translation initiation and presence of mRNA', Molecular Microbiology, 59(3), pp. 1013-1024. doi: 10.1111/j.1365-2958.2005.04992.x.

Stantial, N. et al. (2016) 'Transcription-coupled repair of UV damage in the halophilic archaea', DNA Repair. Elsevier B.V., 41, pp. 63-68. doi: 10.1016/j.dnarep.2016.03.007.

Steinchen, W. and Bange, G. (2016) 'The magic dance of the alarmones (p)ppGpp', Molecular Microbiology, 101(4), pp. 531544. doi: $10.1111 / \mathrm{mmi} .13412$.

Stolboushkina, E. et al. (2013) 'Crystal Structure of the Archaeal Translation Initiation Factor 2 in Complex with a GTP Analogue and Met-tRNAfMet', Journal of Molecular Biology. Elsevier Ltd, 425(6), pp. 989-998. doi: 10.1016/j.jmb.2012.12.023.

Stroud, A., Liddell, S. and Allers, T. (2012) 'Genetic and biochemical identification of a novel single-stranded DNA-binding complex in Haloferax volcanii', Frontiers in Microbiology, 3(JUN), pp. 1-14. doi: 10.3389/fmicb.2012.00224.

Sudhakar, A. et al. (1999) 'Serine 48 in initiation factor $2 \alpha($ elF2 $\alpha)$ is required for high-affinity interaction between elF2 alpha(P) and elF2B.', Biochemistry, 38(46), pp. 15398-15405. doi: 10.1021/bi991211n.

Tahara, M. et al. (2004) 'In Vitro Phosphorylation of Initiation Factor 2alpha (alF2alpha) from Hyperthermophilic Archaeon Pyrococcus horikoshii OT3', Journal of Biochemistry, 135, pp. 479-485. doi: 10.1093/jb/mvh055vh055.

Tanaka, S., Kihara, M. and Sugimoto, M. (2015) 'Structure and molecular characterization of barley nudix hydrolase genes', Bioscience, Biotechnology, and Biochemistry. Taylor \& Francis, 79(3), pp. 394-401. doi: 10.1080/09168451.2014.978259.

La Teana, A. et al. (2013) 'Translation initiation in the crenarchaeon Sulfolobus solfataricus: eukaryotic features but bacterial route.', Biochemical Society transactions, 41(1), pp. 350-5. doi: 10.1042/BST20120300.

La Teana, A., Gualerzi, C. O. and Dahlberg, A. E. (2001) 'Initiation factor IF 2 binds to the $\alpha$-sarcin loop and helix 89 of Escherichia coli $23 \mathrm{~S}$ ribosomal RNA', Rna, 7(8), pp. 1173-1179. doi: 10.1017/S1355838201010366.

Tedin, K. et al. (1999) 'Translation initiation factor 3 antagonizes authentic start codon selection on leaderless mRNAs', Molecular Microbiology, 31(1), pp. 67-77. doi: 10.1046/j.1365-2958.1999.01147.x.

Terenin, I. M. et al. (2008) 'Eukaryotic translation initiation machinery can operate in a bacterial-like mode without elF2', Nature Structural and Molecular Biology, 15(8), pp. 836-841. doi: 10.1038/nsmb.1445.

Thakur, A., Marler, L. and Hinnebusch, A. G. (2019) 'A network of elF2 interactions with elF1 and Met-tRNAi promotes accurate start codon selection by the translation preinitiation complex', Nucleic Acids Research. Oxford University Press, 47(5), pp. 25742593. doi: $10.1093 /$ nar/gky1274.

Thomm, M. (1996) 'Archaeal transcription factors and their role in transcription initiation', FEMS Microbiology Reviews, 18(23), pp. 159-171. doi: 10.1016/0168-6445(96)00009-5.

Thommen, M., Holtkamp, W. and Rodnina, M. V. (2017) 'Co-translational protein folding: progress and methods', Current Opinion in Structural Biology. Elsevier Ltd, 42, pp. 83-89. doi: 10.1016/j.sbi.2016.11.020.

Thompson, G. M. et al. (2000) 'Conserved sequences in the $\beta$ subunit of archaeal and eukaryal translation initiation factor 2 (elF2), absent from elF5, mediate interaction with elF2y', Biochemical Journal, 347(3), p. 703. doi: 10.1042/0264-6021:3470703.

Tieg, B. and Krebber, H. (2013) 'Dbp5 - From nuclear export to translation', Biochimica et Biophysica Acta (BBA) - Gene Regulatory Mechanisms. Elsevier B.V., 1829(8), pp. 791-798. doi: 10.1016/j.bbagrm.2012.10.010.

Tishchenko, S. et al. (2008) 'Domain II of Thermus thermophilus Ribosomal Protein L1 Hinders Recognition of Its mRNA', Journal of Molecular Biology, 383(2), pp. 301-305. doi: 10.1016/j.jmb.2008.08.058.

Toffano-Nioche, C. et al. (2013) 'RNA at $92^{\circ} \mathrm{C}$ : The non-coding transcriptome of the hyperthermophilic archaeon Pyrococcus abyssi', RNA Biology, 10(7), pp. 1211-1220. doi: 10.4161/rna.25567.

Uchiumi, T., Wahba, A. J. and Traut, R. R. (1987) 'Topography and stoichiometry of acidic proteins in large ribosomal subunits from Artemia salina as determined by crosslinking.', Proceedings of the National Academy of Sciences, 84(16), pp. 5580-5584. doi: $10.1073 /$ pnas.84.16.5580

Ude, S. et al. (2013) 'Translation Elongation Factor EF-P Alleviates Ribosome Stalling at Polyproline Stretches', Science, 339(6115), pp. 82-85. doi: 10.1126/science.1228985. 
Ühlein, M. et al. (1998) 'Functional implications of ribosomal protein L2 in protein biosynthesis as shown by in vivo replacement studies', Biochemical Journal, 331(2), pp. 423-430. doi: 10.1042/bj3310423.

Unbehaun, A. et al. (2004) 'The $40 \mathrm{~S}$ subunit in $48 \mathrm{~S}$ complexes formed at the initiation codon of mRNA is bound to eukaryotic initiation factor (elF) 3, elF1, elF1A, and an elF2/GTP/Met-tRNA', Genes \& Development, pp. 3078-3093. doi: 10.1101/gad.1255704.elF1.

Valášek, L. et al. (2003) 'The yeast elF3 subunits TIF32/a, NIP1/c, and elF5 make critical connections with the 40S ribosome in vivo', Genes \& Development, 17(6), pp. 786-799. doi: 10.1101/gad.1065403.

Veith, T. et al. (2012) 'Structural and functional analysis of the archaeal endonuclease Nob1', Nucleic Acids Research, 40(7), pp. 3259-3274. doi: 10.1093/nar/gkr1186.

Wagner, S. and Klug, G. (2007) 'An Archaeal Protein with Homology to the Eukaryotic Translation Initiation Factor 5A Shows Ribonucleolytic Activity', Journal of Biological Chemistry, 282(19), pp. 13966-13976. doi: 10.1074/jbc.M701166200.

Wang, J. et al. (2014) 'CBD binding domain fused $y$-lactamase from Sulfolobus solfataricus is an efficient catalyst for (-) $\mathrm{Y}$ lactam production', BMC Biotechnology, 14(1), p. 40. doi: 10.1186/1472-6750-14-40.

Wang, J., Dasgupta, I. and Fox, G. E. (2009) 'Many nonuniversal archaeal ribosomal proteins are found in conserved gene clusters', Archaea, 2(4), pp. 241-251. doi: 10.1155/2009/971494.

Warner, J. R. and McIntosh, K. B. (2009) 'How Common Are Extraribosomal Functions of Ribosomal Proteins?', Molecular Cell. Elsevier Inc., 34(1), pp. 3-11. doi: 10.1016/j.molcel.2009.03.006.

Wek, R. C. (2018) 'Role of elF2 $\alpha$ Kinases in Translational Control and Adaptation to Cellular Stress', Cold Spring Harbor Perspectives in Biology, 10(7), p. a032870. doi: 10.1101/cshperspect.a032870.

Werner, F. (2007) 'Structure and function of archaeal RNA polymerases', Molecular Microbiology, 65(6), pp. 1395-1404. doi: 10.1111/j.1365-2958.2007.05876.x.

Werner, F. (2012) 'A nexus for gene expression-molecular mechanisms of Spt5 and NusG in the three domains of life', Journal of Molecular Biology. Elsevier Ltd, 417(1-2), pp. 13-27. doi: 10.1016/j.jmb.2012.01.031.

Werner, F., Eloranta, J. J. and Weinzierl, R. O. . J. (2000) 'Archaeal RNA polymerase subunits F and P are bona fide homologs of eukaryotic RPB4 and RPB12', Nucleic Acids Research, 28(21), pp. 4299-4305. doi: 10.1093/nar/28.21.4299.

Werner, F. and Weinzierl, R. O. J. (2002) 'A Recombinant RNA Polymerase Il-like Enzyme Capable of Promoter-Specific Transcription', Molecular Cell, 10(3), pp. 635-646. doi: 10.1016/S1097-2765(02)00629-9.

Wintermeyer, W. and Gualerzi, C. (1983) 'Effect of Escherichia coli initiation factors on the kinetics of N-AcPhe-tRNAPhe binding to 30 S ribosomal subunits. A fluorescence stopped-flow study', Biochemistry, 22(3), pp. 690-694. doi: 10.1021/bi00272a025.

Woese, C. R. and Fox, G. E. (1977) 'Phylogenetic structure of the prokaryotic domain: The primary kingdoms', Proceedings of the National Academy of Sciences, 74(11), pp. 5088-5090. doi: 10.1073/pnas.74.11.5088.

Woese, C. R., Kandler, O. and Wheelis, M. L. (1990) 'Towards a natural system of organisms: proposal for the domains Archaea, Bacteria, and Eucarya.', Proceedings of the National Academy of Sciences, 87(12), pp. 4576-4579. doi: 10.1073/pnas.87.12.4576.

Wolff, E. C. et al. (2007) 'Posttranslational synthesis of hypusine: evolutionary progression and specificity of the hypusine modification', Amino Acids, 33(2), pp. 341-350. doi: 10.1007/s00726-007-0525-0.

Wool, I. G., Chan, Y. L. and Glück, A. (1995) 'Structure and evolution of mammalian ribosomal proteins.', Biochemistry and cell biology = Biochimie et biologie cellulaire, 73(11-12), pp. 933-947. doi: 10.1139/o95-101.

Wurtzel, O. et al. (2010) 'A single-base resolution map of an archaeal transcriptome', Genome Research, 20(1), pp. $133-141$. doi: $10.1101 / \mathrm{gr} .100396 .109$.

Yamamoto, H. et al. (2014) 'Structure of the mammalian 80 S initiation complex with initiation factor 5B on HCV-IRES RNA', Nature Structural \& Molecular Biology, 21(8), pp. 721-727. doi: 10.1038/nsmb.2859.

Yang, J., Wagner, S. A. and Beli, P. (2015) 'llluminating spatial and temporal organization of protein interaction networks by mass spectrometry-based proteomics', Frontiers in Genetics, 6(DEC), pp. 1-7. doi: 10.3389/fgene.2015.00344.

Yang, W. (2011) 'Nucleases: diversity of structure, function and mechanism', Quarterly Reviews of Biophysics, 44(1), pp. 1-93. doi: $10.1017 /$ S0033583510000181.

Yanofsky, C. (2000) 'Transcription attenuation: Once viewed as a novel regulatory strategy', Journal of Bacteriology, 182(1), pp. 1-8. doi: 10.1128/JB.182.1.1-8.2000.

Yanofsky, C. and Ito, J. (1966) 'Nonsense codons and polarity in the tryptophan operon', Journal of Molecular Biology, 21(2), pp. 313-334. doi: 10.1016/0022-2836(66)90102-1.

Yatime, L. et al. (2005) 'Structure - Function relationships of the intact alF2a subunit from the archaeon Pyrococcus abyssi', Biochemistry, 44(24), pp. 8749-8756. doi: 10.1021/bi050373i. 


\section{Literatur}

Yatime, L. et al. (2007) 'Structure of an archaeal heterotrimeric initiation factor 2 reveals a nucleotide state between the GTP and the GDP states', Proceedings of the National Academy of Sciences of the United States of America, 104(47), pp. 1844518450. doi: $10.1073 /$ pnas.0706784104.

Yoshimura, K. and Shigeoka, S. (2015) 'Versatile physiological functions of the Nudix hydrolase family in Arabidopsis', Bioscience, Biotechnology and Biochemistry. Taylor \& Francis, 79(3), pp. 354-366. doi: 10.1080/09168451.2014.987207.

Yu, Y. et al. (2009) 'Position of eukaryotic translation initiation factor elF1A on the 40S ribosomal subunit mapped by directed hydroxyl radical probing', Nucleic Acids Research, 37(15), pp. 5167-5182. doi: 10.1093/nar/gkp519.

Zeman, J. et al. (2019) 'Binding of elF3 in complex with elF5 and elF1 to the $40 \mathrm{~S}$ ribosomal subunit is accompanied by dramatic structural changes', Nucleic Acids Research, 47(15), pp. 8282-8300. doi: 10.1093/nar/gkz570.

Zheng, A. et al. (2014) 'X-ray structures of elF5B and the elF5B-elF1A complex: The conformational flexibility of elF5B is restricted on the ribosome by interaction with elF1A', Acta Crystallographica Section D: Biological Crystallography, 70(12), pp. 3090-3098. doi: 10.1107/S1399004714021476.

Zheng, X. et al. (2011) 'Leaderless genes in bacteria: Clue to the evolution of translation initiation mechanisms in prokaryotes', BMC Genomics. BioMed Central Ltd, 12(1), p. 361. doi: 10.1186/1471-2164-12-361. 


\section{Anhang}

\subsection{Abkürzungsverzeichnis}

\begin{tabular}{|c|c|}
\hline Abkürzung & Ausgeschrieben \\
\hline alF & Archaealer Translationsinitiationsfaktor \\
\hline AK & Antikörper \\
\hline A & Aminoacyl-tRNA \\
\hline Amp & Ampicillin \\
\hline APS & Ammoniumperoxodisulfat \\
\hline $\mathrm{BCA}$ & Bicinchoninic acid \\
\hline bidest. & bidestilliert \\
\hline $\mathrm{bp}$ & Basenpaar \\
\hline BSA & Bovines Serumalbumin \\
\hline bzw. & beziehungsweise \\
\hline${ }^{\circ} \mathrm{C}$ & Grad Celsius \\
\hline CAS & Casaminosäuren \\
\hline ca. & circa \\
\hline cDNA & complementary DNA \\
\hline dATP & Desoxyadenosintriphosphat \\
\hline dCTP & Desoxycytosintriphosphat \\
\hline dGTP & Desoxyguanosintriphosphat \\
\hline dTTP & Desoxythymidintriphosphat \\
\hline dNTP & Desoxynukleotidtriphosphat \\
\hline dUTP & Desoxyuridintriphosphat \\
\hline DHFR & Dihydrofolatreduktase \\
\hline DMSO & Dimethylsulfoxid \\
\hline DNA & Deoxyribonucleic acid (Desoxyribonukleinsäure) \\
\hline DNase & Desoxyribonuklease \\
\hline EDTA & Ethylendiamintetraacetat \\
\hline ECL & Enhanced chemoluminescence \\
\hline E & Exite \\
\hline elF & Eukaryotischer Translationsinitiationsfaktor \\
\hline $\mathrm{EtOH}$ & Ethanol \\
\hline $\mathrm{h}$ & hour/s (Stunde/n) \\
\hline HRP & horse raddish peroxidase (Meerrettichperoxidase) \\
\hline IF & Translationsinitiationsfaktor \\
\hline g & Gramm \\
\hline GAP & GTPase aktivierende Proteine \\
\hline GEF & Guanin-Nukleotid-Austausch-Faktoren \\
\hline $\lg G$ & Immunglobulin G \\
\hline GTPase & Enzym das Guanosintriphosphat hydrolysiert (gehört zur großen Familie der Hydrolaseenzyme) \\
\hline IRES & Internal ribosome entry site \\
\hline GTP & Guanosintriphosphat \\
\hline GDP & Guanosindiphosphat \\
\hline ITAF & IRES transacting factors \\
\hline $\mathrm{Kb}$ & Kilobasen \\
\hline $\mathrm{H}+$ & Wasserstoffionen \\
\hline $\mathrm{HCl}$ & Salzsäure \\
\hline$\mu \mathrm{L}$ & Mikroliter \\
\hline$\mu \mathrm{m}$ & Mikrometer \\
\hline$\mu \mathrm{M}$ & Mikromol \\
\hline $\mathrm{mA}$ & Milliampere \\
\hline $\mathrm{mAU}$ & milli absorption units \\
\hline L & Liter \\
\hline M & Mol \\
\hline
\end{tabular}




\section{Anhang}

\begin{tabular}{|c|c|}
\hline $\mathrm{mg}$ & Milligramm \\
\hline $\min$ & Minute/n \\
\hline $\mathrm{mL}$ & Milliliter \\
\hline $\mathrm{mm}$ & Millimeter \\
\hline $\mathrm{mM}$ & Millimol \\
\hline MOPS & Morpholinopropansulfonsäure \\
\hline mRNA & Messenger RNA \\
\hline MTP & Mikrotiterplatte \\
\hline Novo & Novobiocin \\
\hline $\mathrm{ng}$ & Nanogramm \\
\hline $\mathrm{nm}$ & Nanometer \\
\hline $\mathrm{nt}$ & Nukleotid \\
\hline OD & Optische Dichte \\
\hline ORF & open reading frame(offener Leserahmen) \\
\hline Ori & origin of replication (Replikationsursprung) \\
\hline RNAPU & RNA-Polymerase-Untereinheit \\
\hline $\mathrm{rpL}$ & 50 S ribosomal subunit protein \\
\hline rpS & 30 s ribosomal subunit protein \\
\hline PCR & polymerase chain reaction (Polymerasekettenreaktion) \\
\hline PBS & phosphate buffered saline (phosphatgepufferte Salzlösung) \\
\hline PEG & Polyethylenglycol \\
\hline$P$ & Peptidyl-tRNA \\
\hline P0 & $50 S$ ribosomal protein $L 10$ \\
\hline P1 & 50 S ribosomal protein $L 12$ \\
\hline P-stalk & L12-stalk \\
\hline pmol & Picomol \\
\hline RBS & Ribosomenbindestelle \\
\hline $\mathrm{pH}$ & Potentia Hydrogenii \\
\hline RNA & Ribonukleinsäure \\
\hline RNAPUs & RNA-polymerase subunits \\
\hline RNase & Ribonuklease \\
\hline rRNA & Ribosomale RNA \\
\hline RT & Raumtemperatur \\
\hline sec & Sekunde/n \\
\hline SD & Shine-Dalgarno \\
\hline SDS & Sodiumdodecylsulfat \\
\hline sRNA & Small RNA \\
\hline SSC & Saline sodium citrate \\
\hline TBE & Tris-Borat-EDTA \\
\hline TE & Tris-EDTA \\
\hline TEMED & Tetramethylethylendiamin \\
\hline TMAO & Trimethylaminoxid \\
\hline TR & transcriptional/transcription regulator \\
\hline Tris & Tris-(hydroxymethyl)-aminomethan \\
\hline tRNA & Transfer-RNA \\
\hline UE & Untereinheit \\
\hline upm & Umdrehungen pro Minute \\
\hline UTR & Untranslatierte Region \\
\hline UV & Ultraviolet \\
\hline $\mathrm{v} / \mathrm{v}$ & Volumen pro Volumen \\
\hline$w / v$ & Gewicht pro Volumen \\
\hline VE & Vollentsalzt \\
\hline WT & Wildtyp \\
\hline z.B. & Zum Beispiel \\
\hline
\end{tabular}




\subsection{Sequenz-Alignment}

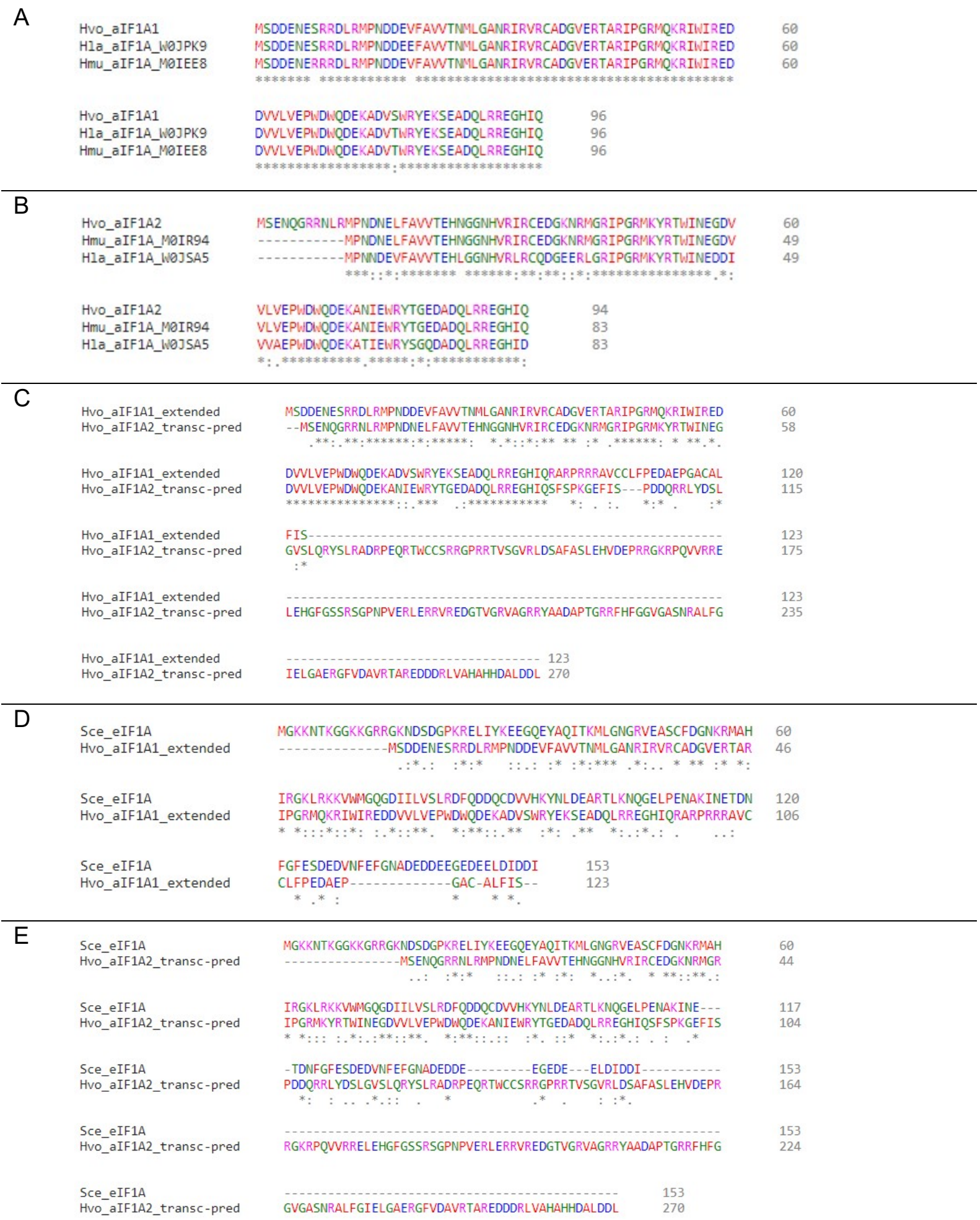

Abbildung 67: Sequenz-Alignment von alF1A-1 und alF1A-2 im Haloferax-Genus

Sequenz-Alignment von $H$. mucosum und $H$. volcanii sowie $H$. larsenii. Für alF1A-1 (HVO_0136) aus $H$. volcanii konnte mit alF1A (WOJPK9) von $H$. larsenii und für alF1A (MIOEE8) von $H$. mucosum $98 \%$ İdentität nachgewiesen werden (A). Bei alF1A-2 (HVO_A0637) ) aus $H$. volcanii konnte sowohl für alF1A (MOIR94) von $H$. mucosum eine Identität von $100 \%$ und für alF1A (WOJSA5) von $H$. larsenii eine Identität von $78 \%$ nachgewiesen werden (B). alF1A-1 und alF1A-2 aus $H$. volcanii im Sequenz-Alignment mit verlängerter Aminosäuresequenz (C). SequenzAlignment von elF1A (P38912) aus S. cerevisiae mit alF1A-1 verlängert, aus $H$. volcanii (D) und mit alF1A-2 mit der AS-Verlängerung durch die Transkript-Vorhersage aus $H$. volcanii (E). 


\section{Anhang}

A

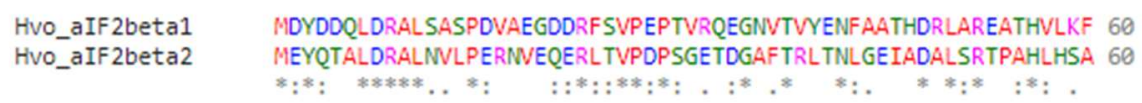

Hvo_aIF2beta1 FQTELGTSAQIDDRGRARFTGEFRQRRIADALDEVVESFVLCSECGSPDTKLTSQRGADV 120 Hvo_aIF2beta2 IORTLGTSGQLEG-DRARYSGSFSINDFEEAIDGWEEWICSECGLPDTRLVTEDGVDI 119

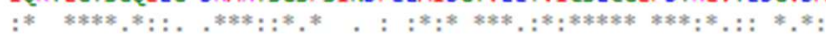

Hvo_aIF2beta1

LKCDACGALSAIPDL 135

Hvo_aIF2beta2 LRCEACGAFRPVQKRSSVSNKRQREAVEEGRTYEVEITGTGRKGDGVAQRGKYTIFVPGA 179 $*: *: * * * *$ : : .

Hvo_aIF2beta1 135

Hvo_aIF2beta2

QEGQTVRIYIKNTSGSLAFARLA 202

$\mathrm{B}$

Tac_aIF2beta
Hvo_aIF2 beta2
Tac_aIf2 beta
Hvo_aIF2 beta2
Tac_aIF2beta
Hvo_aIF2 beta2
Tac_aIF2 beta
Hvo_aIF2 beta2

MTDDYEKLLEKAKMVLSSTKNIDRLKIPDPEIIREGKATIIRNFODIVDIINRDPEHII 60 --MEYQTALDRALLNLPERNVEQERLTVPDPSGETDGAFTRLTNLGEIADALSRTPAHLH 58

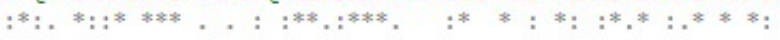

KFLTREFGTNIVONGRRLIINRKLTLEELLDKMNEYINTYVRCYECGSLDTEIOKSGRIS 120 SAIQRTLGTSGQLEGDRARYSGSFSINDFEEAIDGYVEEYVICSECGLPDTRLVTEDGVD 118

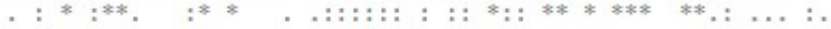

LLVCKACGAQHPIHS---VREAKDDETIEEGKEYVEITEVGSSGEGRTNYKGYTIFVPG 177 MLRCEACGAFRPVQKRSSVSNKRQREAVEEGRTYEVEITGTGRKGDGVAQRGKYTIFVPG 178

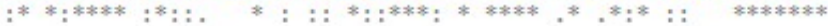

AKRGETVKVRIKKVKNDVAIGEIIERSKQEKK 209 AOEGOTVRIYIKNTSGSLAFARLA-....- 202 *: :*:**:: **:....:**..;

Abbildung 68: Sequenz-Alignment von alF2 $\beta-1$ (D4GZP2) und alF2 $\beta-2$ (D4GVV8) aus $\boldsymbol{H}$. volcanii Das Sequenz-Alignment wurde mittels Clustal Omega erstellt. Die Aminosäuresequenzen von alF2 $\beta-1$ und alF2 $\beta-$ 2 sind zu $39,3 \%$ identisch (A). Alignment von alF2 $\beta-2$ von $H$. volcanii und alF2 $\beta$ von Thermoplasma acidophilum (Q9HKJ3) und sind zu 33,6\% identisch.

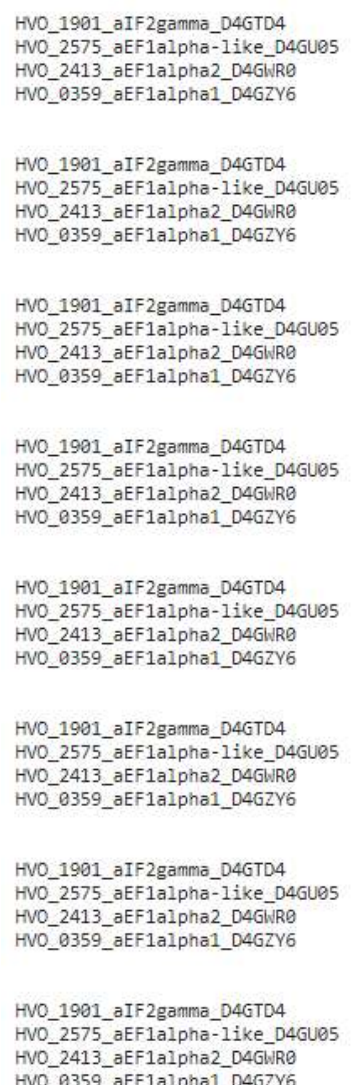

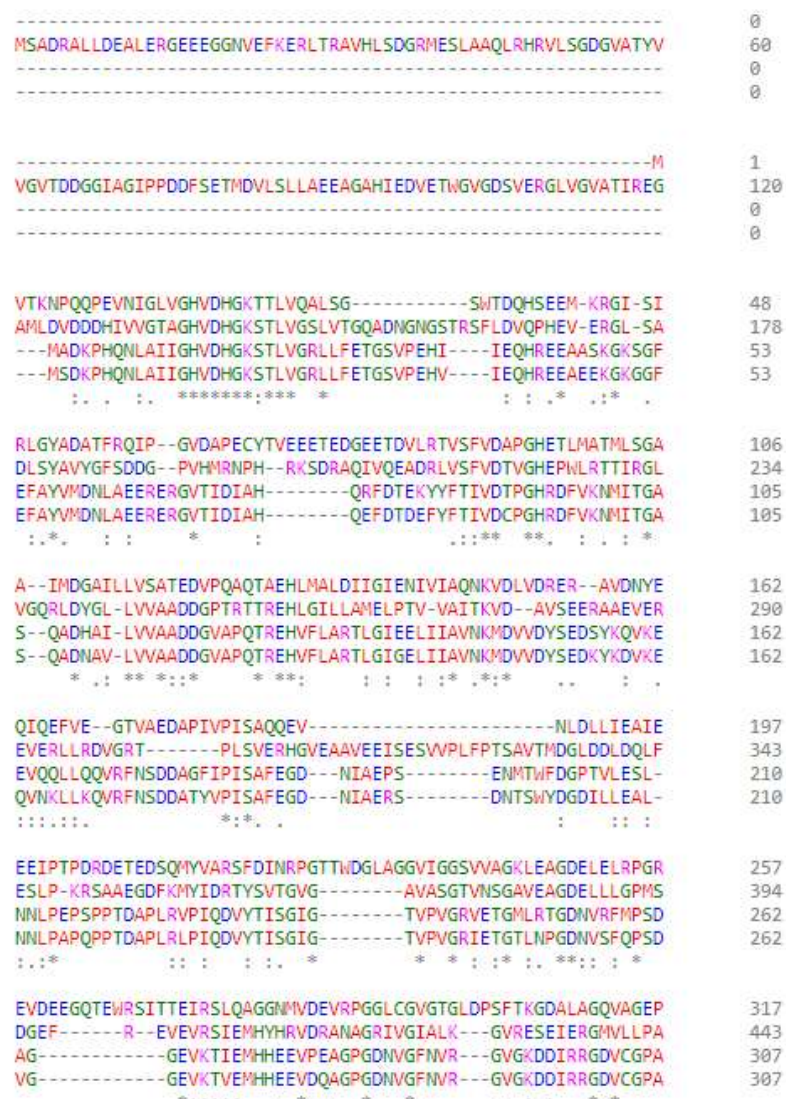




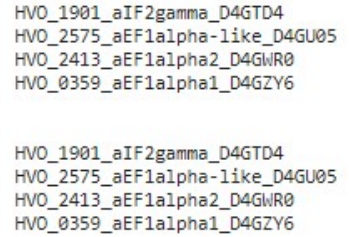

GTLPPTREQFTMDVELLDRWGDEEGEGIDEISTGEPLMLTVGTATTVGAVTSA-..... DAEPTSVREFEADVIVLNHPTRIOEGY--EPWHLETISEAAVFHPDGGRLLPGDTGTTR DDPPSVAKTFTAOIWMOHPSVITAGY--TPVIHAHTAQVACTFESLDOKLDPASGEVAE DDPPKVAETFKAQVMMOHPSVITAGY--TPVFHAHTAQVACTIESIDQKLDPASGEVAE

-...-...-RSGEAEVSL---KRPVCAEEGAKIAINRR--VGARWRLIGIGTLK-..- 411 VEFKFRSYFVEEGQRFVF--.-. EEP-.-DFIKAGDAAVILRPOKPLSIEPSSEIAELGSFAIRDNGOTIAAGKVLEVNE 420

EEP---DFIKAGDAAVVTLRPQKPLSIEPSSEIAELGSFAIRDMGQTIAAGKVLEVNE 420
ENP---DFIKSGDAAIVTVRPQKPLSIEPSSEIPELGSFAVRDMGTIAAGKVLEVNE 420

\section{Abbildung 69: Sequenz-Alignment von alF2y (D4GTD4) aus $\boldsymbol{H}$. volcanii}

Das Sequenz-Alignment wurde mittels Clustal Omega erstellt. Die Aminosäuresequenzen von alF2 $\gamma$ wurde mit den drei Proteinen, die für aEF1 $\alpha$ in $H$. volcanii codiert sind, abgeglichen.

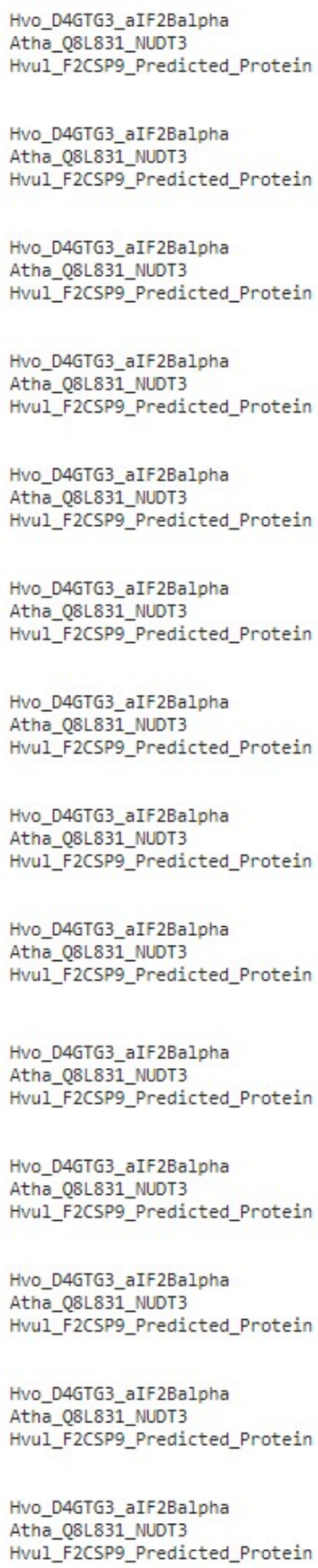

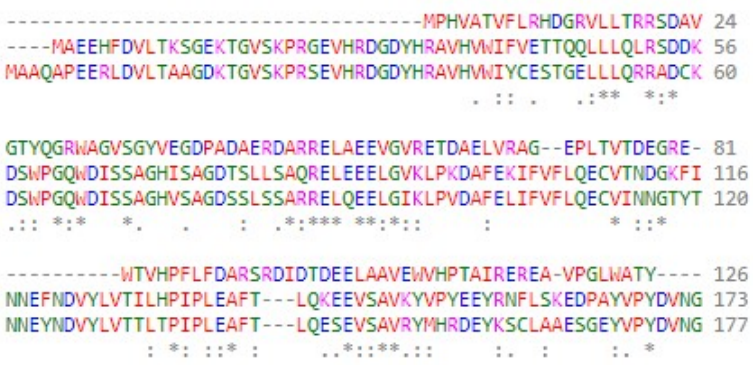

--RRVAPAVETVADDETHGSTWISLRALEVLRDAAAEADSLEAVASVARRLRDARPNMAA 184

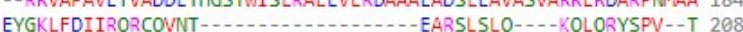
QYGQLFSIIEERYKDNT--$\therefore \quad: .:^{*} \quad *: * *$ : : *

VENRVNRVMAESDSDPESVRRRAEAAIDAAAEADDAAAARAAELIRER-----GVDRLAT 239 LEAKLTE-LSEADQKALGLIVKAAKIMDDIFYEQ---VWWSNPALRDWLKDHANASKLDK 264 LEPELTT-LSEGDREALGYILKASMVIDEIFYEQ---WWNSNTMLRDWLKAHADSSSLDT 268

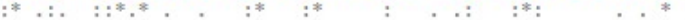

LS - . - - RSGTVLAALEA - . - - - AEAAAVVAVLVSESRP - GGEGVGVAERLARD -.--GR 283 LKWDYFTINKSPWSSLDENEAFLSTADSAVKLLPGATKAIAGWKGLEYRAAFPVTKPPGA 324 LKWAYYSINKSPWISCLDENKAFLSTADSAVKLLTDATKPISGWIKGLEYRAAFPLDKPRGA 328

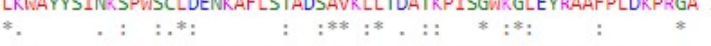

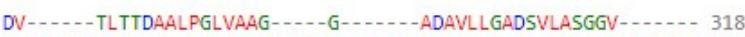
NFYPPDMDKMEFTLWLNGLTEEQKHAATGFFSVIKRRSEANLDASDHLASSTKKLPDSNS 384 NFYPADMDKMEFDLWKSGLTDKEQKDATGFFTVIKRPDALLTTS--VAQSDGPNQTNTSD 386 $\therefore$ :

DLYSIPYSEIYRPFLKKASEFLOKAGDLVSSPSLKKLLHSKAEAFLSNEYYESDIAWMIL 444 DLFIVPYSKEYKTSLEKAAELLLKASDCSDCPSLKNLLKTKANAFLSNDYYESDIAWMEL 446 $* * *$

- AARADVPVFAVCARDKVRGDDRFAGEDAGALYDGEAAIGTE 371 DSKLDITIGPYETYEDEIFGYKATFETFIGIRDDKATADLKLFGDNLK--.--LLEDN 497 DSNIDITIGPYETYEDGLFSYKATFEAFVGVRDEVATSOVKLFGDOLE-.-.---DLEKN 499

$$
\text { . :*. .* : . : : : : : : : : }
$$

NPLFEVVPADSLSGV--VTESGVLNAGDIGAVAD -................... 403 LPLESVYKSTDVSAAPIRVIOLIYNSGDVKGPQTVAYNLPNDEKIVKDRGTSMMILKNVQ 557 LPLDNIYKSDNVSAAPIRVMNLLYNSGDVKGPQTIAFNLPNDERIVNERGTSIMMLKNVS 559 ** : : : : *

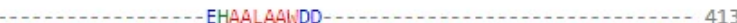
EAKFEHILKPIAEITISKEQRGLVDFDSFFTHTICHECCHGIGPHTITLPGGQTSTVRKE 617 EAKFKHILKPIANACIREEQKEYNDFPYYTHIVCHECCHGIGPHSITLPGGKKSTVRME 619 $*:$ : : : LOEVHSAMEEAKADIVGLWALKFLITKGLLSKSMVESMYVSFLAGCFRSIRFGLTEAHGK 677 LQECHSALEEAKADIVGLWALNFLINKGLLPKSLSKSMYVSFLAGCFRSIRFGLEEAHGK 679 GQALQFNYLYEKGAFVFHEDSTFSVDFAKIEGAVESLSHEILTIQGKGDKNAATLLLNKY 737 GQALQFNULYDKGAFILHSDGKFSIDFTKVEEAVESLGREIMTIQAKGDKPAAQSLLQSR 739

FVKVPVISPTFPLAEALMN-

413

\section{Abbildung 70: Sequenz-Alignment von alF2Ba und Abgleich Nudix-Domäne}

Das Sequenz-Alignment wurde mittels Clustal Omega mit den Sequenzen aus H. volcanii (D4GTG3), Arabidopsis thaliana (Q8L831) und Hordeum vulgare (F2CSP9) erstellt. 


\begin{tabular}{|c|c|}
\hline Hvo_aIf2Bdelta1 & MDDRVHPEVRRTATEIDTMEIRGAATIADAAARALRTQATESDAADAEAFRAELRATART \\
\hline HVO_aIF2Bdelta2 & 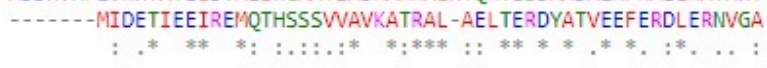 \\
\hline Hvo_aIF2Bdelta1 & LHETRPTAVSLPNALRWLRDMSSTT--VEGLRQSWVSSADEFCARLERAQADLGQVGAN \\
\hline HVO_aIF2Bdelta2 & 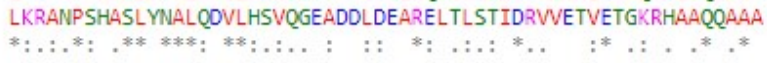 \\
\hline Hvo_aIF2Bdelta1 & RLRDGDTIMTHCHSTDALACVEAAVEQGKHIEAVVKETRPRNQGHITAKRLHELG-VPVT \\
\hline HVO_aIF2Bdelta2 & 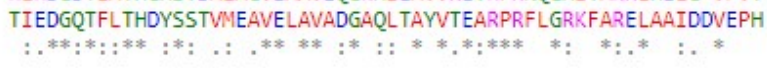 \\
\hline Hvo_aIf2Bdelta1 & LIVDSAARRYLNDVDHVLVGADAVAADGSVINKIGTSGLAVNARERGTPIMVAAQTLKLH \\
\hline HVO_aIF2Bdelta2 & 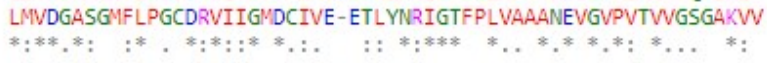 \\
\hline Hvo_aIF2Bdelta1 & PGTMTGHTVDIEMRDTAEWDDDTLADLGNPTVKNPAFDVTPPRYVDAIVTERGQFPPES \\
\hline HVO_aIF2Bdelta2 & 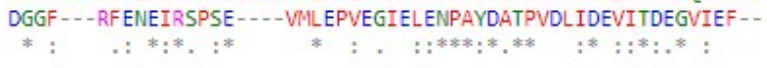 \\
\hline Hvo_aIF2Bdelta1 & IVILMRELFGEGTSEPNAEPSPRAEP 323 \\
\hline
\end{tabular}

Abbildung 71: Sequenz-Alignment von alF2Bס-1 und alF2Bס-2

Das Sequenz-Alignment wurde mittels Clustal Omega mit den Sequenzen alF2Bס-1 (HVO_0966; L9USK7) und alF2Bס-2 (HVO_2706; D4GW08) durchgeführt. Die beiden Proteine sind zu 30,2 \% identisch.
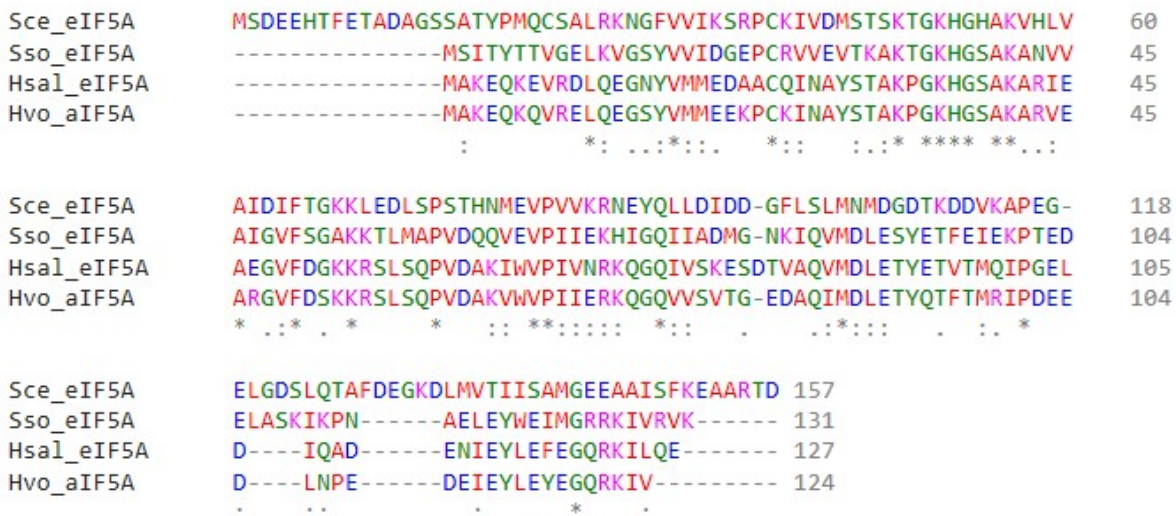

Abbildung 72: Sequenz-Alignment von alF5A aus $\boldsymbol{H}$. volcanii

Das Sequenz-Alignment wurde für S. cerevisiae (elF5A, P23301), S. solfataricus (elF5A, Q97ZE8), $H$. salinarum (elF5A, Q9HP78) und $H$. volcanii (alF5A, D4GWG6) durchgeführt. Für alF5A aus $H$. volcanii konnte mit elF5A aus $S$. cerevisiae eine zu $26 \%$ identische Aminosäurensequenz gezeigt werden. Für S. solfataricus konnte die Sequenzidentität mit $46,9 \%$ und für $H$. salinarum mit $72,8 \%$ bestimmt werden.

\begin{abstract}
$>$ Hvo_D4GTJ2_aIF5B
MSDTDSTSQSDTLRTPIVAVLGHDHGKTSLLDKIRGSAVSEGEAGAITQHIGATAVPLD TVSQMAGSLVKPEDFDLPGLLFIDTPGHHSFSTLRSRGGALADIAILVVDVNDSFQPQTE EAIDILKRTGTPFIVAANKIDTTPGWNPQEGAPIQKTYEEQSQRARSKLDEKLYEIIGEL SDRGFSSDFYWRVQNFQSNIGVVPVSALTGEGIPDLLGVLMGLSQRYMKDEMAIDVAGPG SGTVLEVKEERGFGATLDVVLYDGTIRAGDTVVVGGANDPIVTEVRALLQPRPNAEIRTE KRFDKVEEVRAAAGVKIAAPDLEDAMAGAPVRVVGDRDLDEVVREVEAELADIEVTTEEE GVVVKADTLGSLEAMANALQEAEVPILRAEVGDVAPRDVAVASTAREPE KVILGFNVDV LSNAEAELDKNDVKLFEDDVIYQLVEEYEDHVNEMKRAQQETILDKIVRPCRFRILQDHV FRQNNPAVVGVEVMSGTIKNNMNVVKWEDGEPNRVGQLSGIQENGEDVSSARAGSRVSVA IDGPTVGRQIAEGDELWIELPEK AKILEQELRDDIPTDELEALSGYLEK RRRDPFWGK
\end{abstract}

\title{
Abbildung 73: Sequenz-Alignment von alF5B aus $H$. volcanii
}

Das Sequenz-Alignment wurde für alF5B/elF5B aus S. cerevisiae (P39730), $H$. sapiens (O60841), $H$. volcanii (G0LMM9), H. walsbyi (G0LMM9) und H. salinarum (A0A510N889) durchgeführt (A). Alle Histidine die in der natürlichen Aminosäure-Sequenz von alF5B in $H$. voclanii enthalten sind wurden rot markiert $(B)$. 


\section{Anhang}

A Hvo_rpoD Sce_rpb3

Hvo_rpoD

Sce_rpb3

Hvo rpoD

Sce_rpb3

Hvo_rpod

Sce_rpb3

Hvo_rpoD

Sce_rpb3

Hvo_rpoD

Sce_rpb3
-MVNDFQVEFIEREDRRARFVARGLTPALANGIRRAMVADVPTFSIDTVRFVENTSVMFD MSEEGPQVKIREASKDNVDFILSNVDLAMANSLRRVMIAEIPTLAIDSVEVETNTTVLAD :. ${ }^{* *}::^{*} \ldots \ldots{ }^{*}: \quad .:{ }^{*}:^{* *},:^{* *} .^{*}:^{*}::^{* *}::^{* *}:^{*} . . \quad *^{*}:^{*}:{ }^{*}$

EMIGLRLGLVPLTTPLD-DFEPG-...-..---DTVTVAL--EV----DGPATAYSGDIES EFIAHRLGLIPLQSMDIEQLEYSRDCFCEDHCDKCSWLTLQAFGESESTTNVYSKDLVI

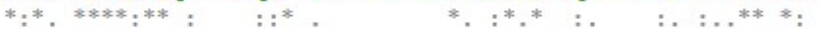

ADDIVV -........ PADENIPIIELKEGORLEF EADAVLGHGKDHAKNOGGVAVGYRVSNL/4GRNI GHPIIODKEGNGVLICKLRKGOELKLTCVAKKGIAKEHAKWGPAAAIEFEY

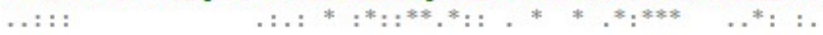

-HLORVEVVGDAGEFDEQEPNI LRGVIEEAAAEHAEGDAEDGDLVATETFGNDLTERYPG

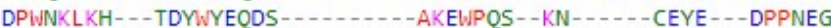
$::: \quad: \therefore: * * ;$ * *

KEVEVHDVPGAFVFSVETDGSFDVDELVTRAVASLGDRAAELEEKVAL............ DPFDYKAQADTFYMNVESVGSIPVDOWVRGIDTLQKKVASILLALTQMDQDKVNFASGD . : : $\quad:^{*}:$ : $^{* *}:{ }^{* *}: *^{* *}::^{*} *^{*} .::^{*}$. . $^{*} .: \quad:$ :

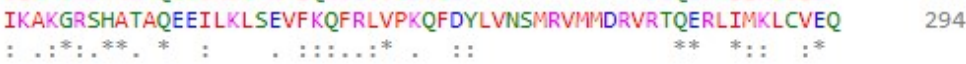

\section{Abbildung 74: Sequenz-Alignment von rpoD aus $H$. volcanii}

Ein Sequenz-Alignment wurde für rpoD aus H. volcanii (D4GWY4) und S. cerevisiae (rpb3, P16370) durchgeführt. Die Sequenzen sind zu $24 \%$ identisch (A). Das andere Sequenz-Alignment wurde für rpoD aus $\mathrm{H}$. volcanii (D4GWY4) und E. coli (rpoD, P00579) durchgeführt. Die Sequenzen sind zu 17 \% identisch (B). 


\subsection{Zusammenfassung MS-Daten alFs}

Tabelle 90: alFs-MS-Daten Translation

\begin{tabular}{|c|c|c|c|c|c|c|c|c|c|c|c|c|c|c|c|c|}
\hline & & 14 alFs $\rightarrow$ Translation & & & & & & & & & & & & & & \\
\hline Genloci & Accession & Description & $\stackrel{\Perp}{\dddot{\longrightarrow}}$ & 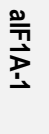 & 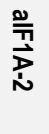 & 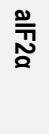 & 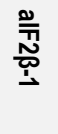 & 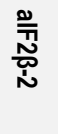 & $\stackrel{\cong}{\stackrel{N}{ }}$ & 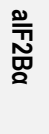 & 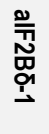 & 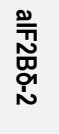 & $\begin{array}{l}\frac{D}{7 \pi} \\
\frac{1}{>} \\
\frac{1}{5} \\
\frac{0}{3}\end{array}$ & ฏ & ஹ & 뀽 \\
\hline HVO_1946 & D4GTH5 & alF1 & B & & & * & & & & & & & & & & \\
\hline HVO_0136 & D4GZ79 & alF1A-1 & & B & & & & & & & & & & & & \\
\hline HVO_A0637 & D4GRU5 & alF1A-2 & + & & B & & & & & & & & & & & \\
\hline HVO_0699 & D4GT46 & alF2a & & & & B & + & + & + & & + & & & + & & \\
\hline HVO_1678 & D4GZP2 & alF2 $\beta-1$ & & & & & B & & & & & & & & & \\
\hline HVO_2242 & L9VAS4 & alF2 $\beta-2$ & & & & + & & B & + & & + & & & & & \\
\hline HVO_1901 & D4GTD4 & alF2y & & & & + & + & + & B & & + & & & & & \\
\hline HVO_1934 & D4GTG3 & $\mathrm{alF} 2 \mathrm{Ba}$ & & & & & & & & B & & & & & & \\
\hline HVO_0966 & L9USK7 & alF2B $\delta-1$ & + & + & + & + & & & + & + & B & & + & + & + & + \\
\hline HVO_2706 & L9V7F9 & alF2Bס-2 & & & & & & & & & + & B & & & & \\
\hline HVO_1333 & D4GXK1 & elF4A-hom. & & & & & & & & & & & B & & & \\
\hline HVO_2300 & L9V7A1 & alF5A & & & & & & & & & & & & B & & \\
\hline HVO_1963 & D4GTJ2 & alF5B & + & + & + & + & & + & + & + & + & & + & + & B & + \\
\hline HVO_0117 & L9U167 & alF6 & & & & & & & & & & & & & & B \\
\hline HVO_2413 & L9V6J4 & $a E F 1 a$ & + & + & + & + & & + & + & + & + & & + & + & + & + \\
\hline HVO_2575 & L9V605 & aEF1a-like protein & + & & & + & & & & + & & & + & + & + & \\
\hline HVO_0356 & L9UK07 & $\mathrm{aEF} 2$ & + & + & & + & & + & + & + & + & & + & + & + & + \\
\hline HVO_2773 & L9V5L7 & $30 \mathrm{~s}$ rpS2 & & & & & & & & & + & & & & & \\
\hline HVO_2558 & D4GTZ0 & $30 \mathrm{~s}$ rpS3 & + & & & & & & & & + & & + & & & \\
\hline HVO_1145 & D4GWA5 & $30 \mathrm{~S}$ rpS3Ae & & & & & & + & & & + & & & & & \\
\hline HVO_2552 & L9V7Y2 & $30 \mathrm{~S}$ rpS4e & + & & & & & & & & + & & + & + & & \\
\hline HVO_2544 & D4GTX6 & $30 \mathrm{~S}$ rpS5 & & & & + & & & & & & & + & & & \\
\hline HVO_0354 & L9UJR0 & $30 \mathrm{~S} \mathrm{rpS7}$ & + & & & & & & & & + & & + & & & \\
\hline HVO_0360 & L9ULL7 & $30 S$ rpS10 & + & & & & & & & & & & & & + & \\
\hline HVO_2782 & L9V5R1 & $30 S$ rpS11 & & & & & & + & & & + & & & & & \\
\hline HVO_2784 & L9V5M6 & $30 \mathrm{~s}$ rpS13 & + & & & & & & & & + & & & & & \\
\hline HVO_1148 & L9UVI2 & $30 S$ rpS15 & & & & & & & & & + & & & & & \\
\hline HVO_2555 & D4GTY7 & $30 S$ rpS17 & & & & & & & & & + & & & & & \\
\hline HVO_2560 & L9V659 & $30 \mathrm{~S} r \mathrm{~s} 19 \mathrm{P}$ & + & + & & & & & & & + & & & & & \\
\hline HVO_1896 & D4GTC9 & $30 \mathrm{~S} r \mathrm{rp} 24 \mathrm{e}$ & + & & & & & & & & & & & & & \\
\hline HVO_2757 & P41199 & $50 \mathrm{~S}$ rpL1 & + & & & + & & & & + & + & + & + & + & + & + \\
\hline HVO_2561 & D4GTZ3 & $50 \mathrm{~S}$ rpL2 & + & + & & & & + & + & + & + & & + & & + & + \\
\hline HVO_2564 & L9V5K9 & $50 \mathrm{~S}$ rpL3 & + & & & & & + & & & + & & + & + & & + \\
\hline HVO_2563 & D4GTZ5 & $50 S$ rpL4 & + & + & & & & + & & & + & & + & & & + \\
\hline HVO_2548 & L9V5X7 & $50 \mathrm{~S}$ rpL6 & & & & & & & & & + & & + & & & \\
\hline HVO_2756 & P41198 & $50 \mathrm{~S} \mathrm{rpL} 10$ & + & & & + & & & & & + & & + & & & \\
\hline HVO_0484 & D4GS24 & $50 \mathrm{~S} r \mathrm{rL} 10 \mathrm{e}$ & & & & + & & & & & & & & & & \\
\hline HVO_2778 & D4GWY1 & 50S rpL13 & + & & & & & & & & & & & & & \\
\hline HVO_0561 & L9UPT6 & $50 \mathrm{~S} r p L 15 e$ & & & & + & & & & & & & & & & \\
\hline HVO_2545 & P50563 & $50 S$ rpL18 & & & & & & + & & & + & & & & & \\
\hline HVO_2779 & D4GWY3 & $50 \mathrm{~S} \mathrm{rpL} 18 \mathrm{e}$ & + & & & & & + & & & + & & & & & \\
\hline HVO_2559 & L9V5K3 & $50 \mathrm{~S}$ rpL22 & + & & & & & + & & + & + & & + & & + & \\
\hline HVO_2553 & L9V5Y5 & $50 S$ rpL24 & & + & & & & & & & & & & & & \\
\hline HVO_2543 & L9V5X1 & $50 \mathrm{~S}$ rpL30 & + & + & & + & & + & & + & + & & + & & + & \\
\hline HVO_2547 & D4GTX9 & $50 \mathrm{~S}$ rpL32e & + & & & & & & & & & & & & & \\
\hline HVO_2736 & D4GW73 & tRNA(Met) cytidine acetyl. TmcA & + & & & + & & & & & & & + & & & \\
\hline HVO_0911 & D4GUZ0 & GTP-binding protein Drg & & & & & & & & & + & & & & & \\
\hline
\end{tabular}


Tabelle 91: alFs-MS-Daten Transcription

\begin{tabular}{|c|c|c|c|c|c|c|c|c|c|c|c|c|c|c|c|c|}
\hline & & 14 alFs $\rightarrow$ Transcription & & & & & & & & & & & & & & \\
\hline Genloci & Accession & Description & $\stackrel{\Perp}{\rightrightarrows}$ & 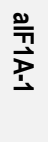 & 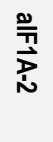 & 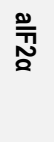 & 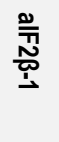 & $\begin{array}{l}\cong \\
\text { N } \\
\text { N }\end{array}$ & $\stackrel{\Perp}{\stackrel{\aleph}{\gtrless}}$ & $\begin{array}{l}\text { ஹु్ } \\
\text { 罟 }\end{array}$ & 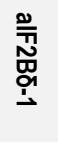 & 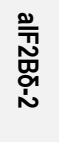 & $\begin{array}{l}\frac{D}{T} \\
\frac{1}{3} \\
\frac{1}{5} \\
\frac{0}{3}\end{array}$ & 变 & 留 & 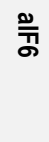 \\
\hline HVO_0349 & D4GZX6 & rpoA1 & + & + & & + & & & & & + & & + & + & + & \\
\hline HVO_0350 & D4GZX7 & rpoA2 & + & & & + & & & & & + & & + & & & \\
\hline HVO_0348 & L9UJM2 & rpoB1 & + & & & & & & & & & & & & & \\
\hline HVO_0347 & L9UK99 & rpoB2 & + & & & + & & & + & & + & & + & + & + & \\
\hline HVO_2781 & L9V5W2 & rpoD & + & & & & & & & & + & & & & & \\
\hline HVO_2748 & D4GWA3 & rpoF & & & & & & & & & + & & & & & \\
\hline HVO_0346 & D4GZX3 & $\mathrm{rpoH}$ & & & & & & & & & + & & & & & \\
\hline HVO_1042 & D4GVL8 & rpol & + & & & & & & & & & & & & & \\
\hline HVO_2029 & L9VBJ7 & $\begin{array}{l}\text { AsnC family transcriptional regula- } \\
\text { tor }\end{array}$ & & + & & & & & & & + & & & & & \\
\hline HVO_A0135 & D4GQG4 & HTH domain protein & + & & & & & & & & & & & & & \\
\hline HVO_1133 & D4GW85 & HTH domain protein & + & + & & & & & + & + & + & & + & & & \\
\hline HVO_1695 & $\mathrm{D} 4 \mathrm{H} 040$ & HTH domain protein & + & + & & & & & & & & & + & & + & \\
\hline HVO_A0121 & D4GQF3 & $\begin{array}{l}\text { HTH-10 family transcription regula- } \\
\text { tor }\end{array}$ & + & & & + & & & & & & & + & & + & \\
\hline HVO_1501 & D4GYE7 & $\begin{array}{l}\text { HTH-type transcriptional regulator } \\
\text { GlpR }\end{array}$ & + & & & & & & & & & & & & + & \\
\hline HVO_B0114 & D4GPB5 & ICIR family transcription regulator & + & & & & & & & & + & & + & & + & + \\
\hline HVO_B0201 & D4GPK2 & ICIR family transcription regulator & & & & & & & & & & & & & + & \\
\hline HVO_A0583 & D4GRP3 & ICIR family transcription regulator & + & & & & & & & & & & + & & + & \\
\hline HVO_2108 & D4GUQ5 & ICIR family transcription regulator & + & + & + & + & + & + & & + & + & & + & + & + & + \\
\hline HVO_B0066 & D4GP68 & $\begin{array}{l}\text { Lrp/AsnC family transcription regu- } \\
\text { lator }\end{array}$ & + & & & & & & & & & & & & + & \\
\hline HVO_1792 & D4GSB6 & $\begin{array}{l}\text { Lrp/AsnC family transcription regu- } \\
\text { lator }\end{array}$ & + & & + & + & & & & + & + & & + & & + & + \\
\hline HVO_0240 & D4GZI5 & $\begin{array}{l}\text { Lrp/AsnC family transcription regu- } \\
\text { lator }\end{array}$ & & & & & & & & & + & & & & & \\
\hline HVO_2869 & D4GXH6 & PadR family transcription regulator & + & & & & & & & + & & & + & & & \\
\hline HVO_0730 & D4GT98 & $\begin{array}{l}\text { PadR family transcription regulator } \\
\text { RosR }\end{array}$ & & & & & & & & & + & & & & & \\
\hline HVO_1090 & D4GW09 & Putative transcription factor & & & & & & & & & + & & & & & \\
\hline HVO_0406 & D4GRU7 & RNA-binding protein AU-1 & & & & & & & & & & & & & & \\
\hline HVO_2723 & D4GW47 & RNA-binding protein Lsm & + & & & + & & & & & + & & & & + & \\
\hline HVO_0819 & D4GUE2 & $\begin{array}{l}\text { SirR/DtxR family transcription reg- } \\
\text { ulator SirR }\end{array}$ & + & & & & & & & & & & + & + & + & \\
\hline HVO_1727 & L9VGC6 & TATA-box-binding protein & + & & & + & & & & & + & & + & & & \\
\hline HVO_B0382 & D4GQ28 & TATA-box-binding protein & & & & & & & & & & & & & & \\
\hline HVO_0158 & D4GZA2 & TATA-box-binding protein 1 & & & & & & & & & + & & & & & \\
\hline HVO_2067 & D4GU80 & TetR family transcription regulator & + & & & & & & & & & & & & & \\
\hline HVO_A0161 & L9V4Z6 & $\begin{array}{l}\text { TetR family transcriptional regula- } \\
\text { tor }\end{array}$ & + & & & & & & & & & & & & & \\
\hline HVO_0163 & L9UFW5 & Transcriptional regulator & + & & + & + & & & & + & + & & + & + & + & + \\
\hline HVO_0179 & L9UGU5 & Transcriptional regulator & + & & & & & & + & + & + & & + & + & + & + \\
\hline HVO_2928 & L9UK32 & Transcriptional regulator & + & + & + & + & + & & & + & + & + & + & & + & + \\
\hline HVO_0568 & L9UN99 & Transcriptional regulator & + & & & & & & & & & & & & & \\
\hline HVO_2636 & L9V878 & Transcriptional regulator & & & & + & & & & & & & & & & \\
\hline HVO_1360 & D4GXQ1 & TrmB family transcription regulator & + & & & & & & & & & & & & & \\
\hline HVO_2688 & D4GVQ2 & $\begin{array}{l}\text { TrmB family transcription regulator } \\
\text { TrmB }\end{array}$ & & & & & & & & & + & & & & & \\
\hline HVO_1174 & L9UT88 & Transcription factor $\mathrm{E}$ & + & & & & & & & & + & & & & & \\
\hline
\end{tabular}


Tabelle 92: alFs-MS-Daten Protein folding

\begin{tabular}{|c|c|c|c|c|c|c|c|c|c|c|c|c|c|c|c|c|}
\hline & & 14 alFs $\rightarrow$ Protein folding & & & & & & & & & & & & & & \\
\hline Genloci & Accession & Description & $\stackrel{\Perp}{\dddot{7}}$ & 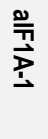 & 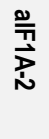 & 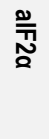 & 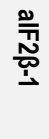 & $\begin{array}{l}\cong \\
\text { N̦ } \\
\text { ஸे }\end{array}$ & 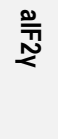 & 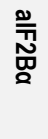 & 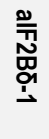 & 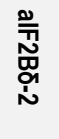 & $\begin{array}{l}\frac{0}{7 \pi} \\
\text { 苦 } \\
\frac{1}{\overline{0}} \\
\frac{0}{3}\end{array}$ & 罗 & 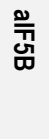 & ๗ั๊ \\
\hline HVO_0329 & L9UK29 & $\begin{array}{l}\text { Branched-chain amino acid ami- } \\
\text { notransferase }\end{array}$ & & & & & & & & & + & & & & & \\
\hline HVO_1590 & L9VEI0 & Chaperone protein DnaK & + & & & & & & & & & & + & & & \\
\hline HVO_0450 & D4GRZ1 & Hsp20-type molecular chaperone & & & & + & & & & & & & & & & \\
\hline HVO_0321 & D4GZV0 & $\begin{array}{l}\text { Peptide chain release factor subu- } \\
\text { nit } 1\end{array}$ & + & & & & & & & & + & & + & & & \\
\hline
\end{tabular}

Tabelle 93: alFs-MS-Daten Replication and Repair

\begin{tabular}{|c|c|c|c|c|c|c|c|c|c|c|c|c|c|c|c|c|}
\hline & & $\begin{array}{l}14 \text { alFs } \rightarrow \text { Replication and Re- } \\
\text { pair }\end{array}$ & & & & & & & & & & & & & & \\
\hline Genloci & Accession & Description & $\stackrel{\Perp}{\Pi}$ & 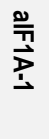 & $\underset{⿱ 亠 䒑}{\stackrel{D}{\Delta}}$ & $\stackrel{๗}{\stackrel{\pi}{\circledR}}$ & 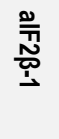 & $\begin{array}{l}\cong \\
\text { N̦ } \\
\text { N }\end{array}$ & $\stackrel{\cong}{\stackrel{7}{\sim}}$ & 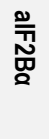 & 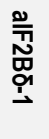 & 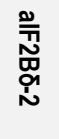 & $\begin{array}{l}\frac{0}{71} \\
\frac{1}{5} \\
\frac{1}{3} \\
\frac{0}{3}\end{array}$ & 芦 & 节 & 离 \\
\hline HVO_0853 & D4GUK0 & $\begin{array}{l}\text { DNA double-strand break repair } \\
\text { protein Mre11 }\end{array}$ & + & & & & & & & & & & & + & + & \\
\hline HVO_0854 & D4GUK1 & $\begin{array}{l}\text { DNA double-strand break repair } \\
\text { Rad50 ATPase }\end{array}$ & + & & & & & & & & & & + & + & + & \\
\hline HVO_0551 & L9UMB1 & DNA mismatch repair protein MutL & + & & & & & & & & + & & & & & \\
\hline HVO_0552 & D4GSE9 & DNA mismatch repair protein MutS & + & & & & & & & & + & & + & + & + & \\
\hline HVO_0104 & Q48328 & $\begin{array}{l}\text { DNA repair and recombination pro- } \\
\text { tein RadA }\end{array}$ & + & & & + & & & & + & + & & + & + & + & + \\
\hline HVO_2383 & L9V6G6 & $\begin{array}{l}\text { DNA repair and recombination pro- } \\
\text { tein RadB }\end{array}$ & + & + & & + & & & & + & + & & + & + & + & + \\
\hline HVO_1723 & L9VE99 & Putative DNA helicase Rad25 & + & & & & & & & & + & & + & + & + & \\
\hline HVO_1573 & D4GZO2 & DNA gyrase subunit $A$ & + & & & & & & & & + & & + & & & \\
\hline HVO_0858 & L9US19 & DNA polymerase B1 & + & & & & & & & & + & & & & & \\
\hline HVO_0175 & DOVWY8 & DNA polymerase sliding clamp & & & & & & & & & + & & & & & \\
\hline HVO_0393 & L9UJI6 & Excinuclease $A B C$ subunit $A$ & & & & & & & & & + & & & & & \\
\hline HVO_0283 & L9UK77 & Helicase AshA & & & & & & & & & + & & & & & \\
\hline HVO_1537 & D4GYI1 & Orc1-type DNA replication protein & + & & & & & & & & & & & & + & \\
\hline HVO_0194 & L9UGW2 & ORC1-type DNA replication protein & + & & & & & & & + & + & & + & & + & \\
\hline HVO_3014 & D4GYC9 & $\begin{array}{l}\text { Origin-associated GTP-binding } \\
\text { protein }\end{array}$ & + & & & & & & & & + & & & & & \\
\hline HVO_0415 & D4GRV6 & Repair helicase UvrD & & & & + & & & & & + & & & & & \\
\hline HVO_0292 & L9UJU8 & Replication factor A & & & & + & & & & & + & & & & & \\
\hline HVO_2427 & D4GSN1 & Replication factor $\mathrm{C}$ large subunit & & & & & & & & & + & & & & & \\
\hline HVO_0203 & L9UG08 & Replication factor $\mathrm{C}$ small subunit & & & & & & & & & + & & & & & \\
\hline HVO_0519 & D4GS55 & Replication protein A & & & & & & & & & + & & & & & \\
\hline HVO_1570 & L9VEU6 & $\begin{array}{l}\text { Type } 2 \text { DNA topoisomerase } 6 \text { sub- } \\
\text { unit } A\end{array}$ & + & & & & & & & & + & & & & & \\
\hline HVO_1571 & L9VEG4 & $\begin{array}{l}\text { Type } 2 \text { DNA topoisomerase } 6 \text { sub- } \\
\text { unit B }\end{array}$ & & & & + & & & & & + & & + & & & \\
\hline
\end{tabular}


Tabelle 94 alFs-MS-Daten RNA turnover

\begin{tabular}{|c|c|c|c|c|c|c|c|c|c|c|c|c|c|c|c|c|}
\hline & & 14 alFs $\rightarrow$ RNA turnover & & & & & & & & & & & & & & \\
\hline Genloci & Accession & Description & $\stackrel{\Perp}{\dddot{T}}$ & 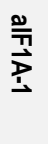 & 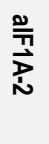 & 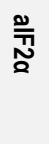 & 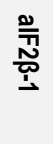 & 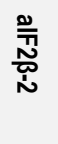 & $\stackrel{\Perp}{\stackrel{\aleph}{\aleph}}$ & 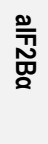 & 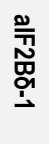 & 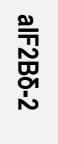 & $\begin{array}{l}\frac{D}{T} \\
\frac{1}{3} \\
\frac{1}{1} \\
\frac{0}{3}\end{array}$ & 界 & 哥 & 芩 \\
\hline HVO_0783 & L9UNA4 & ATP-dependent protease Lon & & & & & & & & & & & + & & & \\
\hline HVO_2438 & L9V6L9 & Ribonuclease H I & & & & + & & & & & & & & & & \\
\hline HVO_2724 & L9V5P6 & Ribonuclease J & + & + & & & & + & & & + & & & & & \\
\hline HVO_1094 & D4GW15 & $\begin{array}{l}\text { Ribonuclease P protein compo- } \\
\text { nent } 3\end{array}$ & + & & & & & & & & & & + & & + & \\
\hline HVO_0388 & L9UJI9 & Ribonuclease $\mathrm{R}$ & + & & & & & & & + & + & & + & + & + & \\
\hline HVO_0144 & L9UHJ9 & Ribonuclease Z & + & & + & & & & & & & & + & & + & + \\
\hline
\end{tabular}

Tabelle 95: alFs-MS-Daten Protein turnover

\begin{tabular}{|c|c|c|c|c|c|c|c|c|c|c|c|c|c|c|c|c|}
\hline & & 14 alFs $\rightarrow$ Protein turnover & & & & & & & & & & & & & & \\
\hline Genloci & Accession & Description & $\stackrel{\Perp}{\dddot{T}}$ & 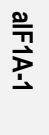 & 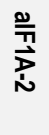 & 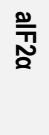 & 忍 & 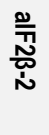 & 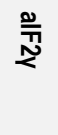 & $\begin{array}{l}\stackrel{๗}{\bar{T}} \\
\text { 怘 }\end{array}$ & 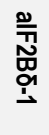 & 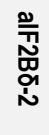 & $\begin{array}{l}\frac{D}{T} \\
\frac{1}{1} \\
\frac{1}{3} \\
\frac{0}{3}\end{array}$ & ฏ & 节 & 뀽 \\
\hline HVO_0829 & D4GUG3 & Peptidase S9 family protein & + & & & & & & & & + & & & & + & \\
\hline HVO_1091 & Q9V2V6 & Proteasome subunit alpha 1 & & & & & & & & & + & & & & & \\
\hline HVO_2923 & Q9V2V5 & Proteasome subunit alpha 2 & & & & & & & & & + & & & & & \\
\hline \multirow[t]{2}{*}{ HVO_1562 } & L9VFN7 & Proteasome subunit beta & & & & & & & & & & + & & & & \\
\hline & L9UQ37 & Proteasome-activating nucleotid. & & & & & & & & & & & + & & & \\
\hline HVO_0455 & 030560 & Thermosome subunit 2 & + & + & & + & & + & & + & + & + & + & & + & \\
\hline HVO_0778 & Q9HHA2 & Thermosome subunit 3 & + & & & + & & + & & + & + & + & + & & + & + \\
\hline
\end{tabular}




\subsection{Zusammenfassung MS-Daten RNAPUs}

Tabelle 96: RNAPU-MS-Daten Transcription

\begin{tabular}{|c|c|c|c|c|c|c|c|c|c|}
\hline & & 7 RNAPUs $\rightarrow$ Transcription & & & & & & & \\
\hline Genloci & Accession & Description & $\begin{array}{l}\text { 궁 } \\
\stackrel{0}{\geq}\end{array}$ & $\begin{array}{l}\text { 궁 } \\
\text { 엉 }\end{array}$ & $\begin{array}{l}\text { 궁 } \\
\text { 모 }\end{array}$ & $\begin{array}{l}\text { 궇 } \\
\text { 毘 }\end{array}$ & 좋 & $\begin{array}{l}\text { 궁 } \\
\text { 옴 }\end{array}$ & 궁 \\
\hline HVO_0349 & D4GZX6 & rpoA1 & bait & + & + & + & + & + & + \\
\hline HVO_0350 & D4GZX7 & rроA2 & + & bait & + & + & + & + & + \\
\hline HVO_0348 & L9UJM2 & rpoB1 & + & + & bait & + & & + & + \\
\hline HVO_0347 & L9UK99 & rрoB2 & + & + & + & bait & + & + & + \\
\hline HVO_2781 & L9V5W2 & rpoD & + & + & + & + & (bait) & + & + \\
\hline HVO_0346 & D4GZX3 & rpoH & + & + & + & + & & bait & + \\
\hline HVO_1042 & D4GVL8 & rpol & + & + & + & + & & + & bait \\
\hline HVO_2776 & D4GWX5 & rpoN & + & + & + & + & & + & + \\
\hline HVO_0653 & L9UMK6 & rроP & + & & + & + & & + & + \\
\hline HVO_2748 & D4GWA3 & rpoF & & & & & & + & \\
\hline HVO_2110 & L9V9M0 & ArcR family transcription regulator & + & & & & & & \\
\hline HVO_1116 & D4GW55 & HTH domain protein & & & + & & + & & \\
\hline HVO_1133 & D4GW85 & HTH domain protein & + & & + & + & + & + & + \\
\hline HVO_0962 & D4GV69 & HTH domain protein & & & & & & + & \\
\hline HVO_1695 & $\mathrm{D} 4 \mathrm{H} 040$ & HTH domain protein & + & & + & + & & + & + \\
\hline HVO_A0121 & D4GQF3 & HTH-10 family transcription regulator & + & & & & & & \\
\hline HVO_1501 & D4GYE7 & HTH-type transcriptional regulator GlpR & + & & & & & + & + \\
\hline HVO_2108 & D4GUQ5 & IcIR family transcription regulator & + & + & + & + & + & + & + \\
\hline HVO_A0583 & D4GRP3 & IcIR family transcription regulator & + & & & & & + & \\
\hline HVO_B0114 & D4GPB5 & IcIR family transcription regulator & + & + & + & + & & + & + \\
\hline HVO_B0201 & D4GPK2 & ICIR family transcription regulator & + & & & + & + & & \\
\hline HVO_1792 & D4GSB6 & Lrp/AsnC family transcription regulator & + & & + & + & + & + & + \\
\hline HVO_B0066 & D4GP68 & Lrp/AsnC family transcription regulator & & & & & & + & \\
\hline HVO_2869 & D4GXH6 & PadR family transcription regulator & + & & & + & & & + \\
\hline HVO_0819 & D4GUE2 & SirR/DtxR family transcription regulator SirR & + & & + & + & & + & + \\
\hline HVO_0163 & L9UFW5 & Transcriptional regulator & + & & + & + & + & + & + \\
\hline HVO_0179 & L9UGU5 & Transcriptional regulator & + & & + & + & & + & + \\
\hline HVO_1360 & D4GXQ1 & TrmB family transcription regulator & & & & & & + & \\
\hline HVO_0568 & L9UN99 & Transcriptional regulator & + & & & & & & \\
\hline HVO_2928 & L9UK32 & Transcriptional regulator & + & & + & + & + & + & + \\
\hline HVO_2636 & L9V878 & Transcriptional regulator & & & & & & + & \\
\hline HVO_2723 & D4GW47 & RNA-binding protein Lsm & + & & & & & + & \\
\hline HVO_1727 & L9VGC6 & TATA-box-binding protein & & & + & + & + & + & \\
\hline
\end{tabular}


Tabelle 97: RNAPU-MS-Daten Translation

\begin{tabular}{|c|c|c|c|c|c|c|c|c|c|}
\hline & & 7 RNAPUs $\rightarrow$ Translation & & & & & & & \\
\hline Genloci & Accession & Description & $\begin{array}{l}\text { 궁 } \\
\stackrel{2}{2}\end{array}$ & $\begin{array}{l}\text { 귱 } \\
\text { 足 }\end{array}$ & $\begin{array}{l}\text { 긍 } \\
\text { 뭄 }\end{array}$ & $\begin{array}{l}\text { 긍 } \\
\text { 怘 }\end{array}$ & $\begin{array}{l}\widehat{\bar{y}} \\
\text { 믐 }\end{array}$ & $\begin{array}{l}\text { 긍 } \\
\text { 오 }\end{array}$ & 궁 \\
\hline HVO_0699 & D4GT46 & alF2a & & & & & & + & \\
\hline HVO_1934 & D4GTG3 & $\mathrm{alF} 2 \mathrm{Ba}$ & & & & + & & & \\
\hline HVO_0966 & L9USK7 & alF2B $\delta-1$ & + & + & + & + & + & + & + \\
\hline HVO_1963 & D4GTJ2 & alF5B & + & + & + & + & & + & + \\
\hline HVO_2575 & L9V605 & aEF1a-like protein & + & & + & + & & + & + \\
\hline HVO_2413 & L9V6J4 & $\mathrm{aEF} 1 \mathrm{a}$ & + & + & + & + & & + & + \\
\hline HVO_0356 & L9UK07 & $\mathrm{aEF} 2$ & + & + & + & + & + & + & + \\
\hline HVO_2558 & D4GTZ0 & 30 S ribosomal protein S3 & & & & & & + & \\
\hline HVO_2552 & L9V7Y2 & $30 S$ ribosomal protein $\mathrm{S} 4 \mathrm{e}$ & + & + & + & + & & + & \\
\hline HVO_2544 & D4GTX6 & 30 S ribosomal protein S5 & & & + & & & & \\
\hline HVO_2373 & D4GWM1 & $30 S$ ribosomal protein S8e & & & & & + & & \\
\hline HVO_0360 & L9ULL7 & $30 S$ ribosomal protein $\mathrm{S} 10$ & + & & + & & & + & \\
\hline HVO_2784 & L9V5M6 & 30 S ribosomal protein $\mathrm{S} 13$ & & & & + & & & \\
\hline HVO_2560 & L9V659 & 30 S ribosomal protein S19P & & & + & + & & + & \\
\hline HVO_1896 & D4GTC9 & $30 \mathrm{~S}$ ribosomal protein $\mathrm{S} 24 \mathrm{e}$ & & & & & + & & \\
\hline HVO_2757 & P41199 & 50 S ribosomal protein L1 & + & & + & + & + & + & + \\
\hline HVO_2561 & D4GTZ3 & 50 S ribosomal protein $\mathrm{L} 2$ & + & & + & + & + & + & + \\
\hline HVO_2564 & L9V5K9 & $50 S$ ribosomal protein $\mathrm{L} 3$ & + & & + & + & + & + & + \\
\hline HVO_2563 & D4GTZ5 & $50 S$ ribosomal protein $\mathrm{L} 4$ & & & + & + & & & \\
\hline HVO_2756 & P41198 & 50 S ribosomal protein L10 & & & + & + & & + & \\
\hline HVO_0484 & D4GS24 & $50 \mathrm{~S}$ ribosomal protein $\mathrm{L} 10 \mathrm{e}$ & & & + & & & & \\
\hline HVO_2758 & P41200 & 50 S ribosomal protein $\mathrm{L} 11$ & + & & + & + & + & & + \\
\hline HVO_2542 & L9V7W8 & 50 S ribosomal protein L15 & & & + & & & & \\
\hline HVO_0561 & L9UPT6 & $50 S$ ribosomal protein $\mathrm{L} 15 \mathrm{e}$ & + & & + & + & & + & + \\
\hline HVO_2559 & L9V5K3 & 50 S ribosomal protein L22 & + & + & + & + & & + & + \\
\hline HVO_2553 & L9V5Y5 & 50 S ribosomal protein L24 & & & & & + & & \\
\hline HVO_2543 & L9V5X1 & $50 \mathrm{~S}$ ribosomal protein $\mathrm{L} 30$ & + & & + & + & & + & + \\
\hline HVO_2547 & D4GTX9 & $50 \mathrm{~S}$ ribosomal protein $\mathrm{L} 32 \mathrm{e}$ & & & + & + & + & & \\
\hline
\end{tabular}

Tabelle 98: RNAPU-MS-Daten RNA turnover

\begin{tabular}{|c|c|c|c|c|c|c|c|c|c|}
\hline & & 7 RNAPUs $\rightarrow$ RNA turnover & & & & & & & \\
\hline Genloci & Accession & Description & $\begin{array}{l}\text { 궁 } \\
\text { 옴 }\end{array}$ & $\begin{array}{l}\text { 궁 } \\
\text { 언 }\end{array}$ & $\begin{array}{l}\text { 궁 } \\
\text { 뭄 }\end{array}$ & $\begin{array}{l}\text { 긍 } \\
\text { 멍 }\end{array}$ & $\begin{array}{l}\widehat{\bar{z}} \\
\text { 믐 }\end{array}$ & $\begin{array}{l}\text { 궁 } \\
\text { 오 }\end{array}$ & 궁 \\
\hline HVO_1703 & $\mathrm{D} 4 \mathrm{H} 048$ & Putative DEAD/DEAH box helicase & + & & & & & & \\
\hline HVO_2438 & L9V6L9 & Ribonuclease H I & + & & & + & + & + & + \\
\hline HVO_2724 & L9V5P6 & Ribonuclease J & + & & + & & & & + \\
\hline HVO_1094 & D4GW15 & Ribonuclease $\mathrm{P}$ protein component 3 & + & & & + & + & + & + \\
\hline HVO_0388 & L9UJI9 & Ribonuclease $\mathrm{R}$ & + & & + & + & & + & + \\
\hline HVO_0144 & L9UHJ9 & Ribonuclease Z & + & & + & + & & + & + \\
\hline
\end{tabular}


Tabelle 99: RNAPU-MS-Daten Replication and Repair

\begin{tabular}{|c|c|c|c|c|c|c|c|c|c|}
\hline & & 7 RNAPUs $\rightarrow$ Replication and Repair & & & & & & & \\
\hline Genloci & Accession & Description & $\begin{array}{l}\text { 궁 } \\
\text { 임 }\end{array}$ & $\begin{array}{l}\text { 귱 } \\
\text { 足 } \\
\text { N }\end{array}$ & $\begin{array}{l}\text { 궁 } \\
\text { 㽞 }\end{array}$ & $\begin{array}{l}\text { 긍 } \\
\text { 囬 }\end{array}$ & $\begin{array}{l}\text { 증 } \\
\text { 믐 }\end{array}$ & $\begin{array}{l}\text { 궁 } \\
\text { 오 }\end{array}$ & 궁 \\
\hline HVO_1573 & D4GZ02 & DNA gyrase subunit $A$ & & & & & & + & + \\
\hline HVO_0853 & D4GUK0 & DNA double-strand break repair protein Mre11 & + & & & + & & + & \\
\hline HVO_0854 & D4GUK1 & DNA double-strand break repair Rad50 ATPase & + & & + & + & + & + & + \\
\hline HVO_0552 & D4GSE9 & DNA mismatch repair protein MutS & + & & + & + & & + & + \\
\hline HVO_0858 & L9US19 & DNA polymerase B1 & + & & & & & & \\
\hline HVO_0104 & Q48328 & DNA repair and recombination protein RadA & + & + & + & + & + & + & + \\
\hline HVO_2383 & L9V6G6 & DNA repair and recombination protein $\operatorname{RadB}$ & + & + & + & + & + & + & + \\
\hline HVO_A0441 & L9VPT6 & DNA repair helicase Rad25 & + & & & & & & \\
\hline HVO_1723 & L9VE99 & Putative DNA helicase Rad25 & + & & + & + & + & & + \\
\hline HVO_3013 & D4GYC7 & Origin-associated protein & & & & & & + & \\
\hline HVO_0194 & L9UGW2 & ORC1-type DNA replication protein & + & & + & + & & + & + \\
\hline HVO_1537 & D4GYI1 & Orc1-type DNA replication protein & & & & + & & & \\
\hline
\end{tabular}

Tabelle 100: RNAPU-MS-Daten Protein folding

\begin{tabular}{|c|c|c|c|c|c|c|c|c|c|}
\hline & & 7 RNAPUs $\rightarrow$ Protein folding & & & & & & & \\
\hline Genloci & Accession & Description & $\begin{array}{l}\text { 궁 } \\
\text { 일 }\end{array}$ & 긍 & $\begin{array}{l}\text { 긍 } \\
\text { 㽞 }\end{array}$ & $\begin{array}{l}\text { 긍 } \\
\text { 怘 }\end{array}$ & $\begin{array}{l}\widehat{\bar{z}} \\
\text { 므 }\end{array}$ & $\begin{array}{l}\text { 긍 } \\
\text { 오 }\end{array}$ & 궁 \\
\hline HVO_1590 & L9VEI0 & Chaperone protein DnaK & & & & & + & & \\
\hline HVO_0766 & L9UNS7 & Hsp20-type molecular chaperone & + & & & & & & \\
\hline HVO_0450 & D4GRZ1 & Hsp20-type molecular chaperone & & & & & & + & \\
\hline
\end{tabular}

Tabelle 101: RNAPU-MS-Daten Protein turnover

\begin{tabular}{|c|c|c|c|c|c|c|c|c|c|}
\hline & & 7 RNAPUs $\rightarrow$ Protein turnover & & & & & & & \\
\hline Genloci & Accession & Description & 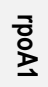 & 귱 & $\begin{array}{l}\text { 귱 } \\
\text { 몸 }\end{array}$ & $\begin{array}{l}\text { 귱 } \\
\text { 怘 }\end{array}$ & $\begin{array}{l}\text { 흠 } \\
\text { 믐 }\end{array}$ & $\begin{array}{l}\text { 긍 } \\
\text { 오 }\end{array}$ & 궁 \\
\hline \multirow[t]{2}{*}{ HVO_0829 } & D4GUG3 & Peptidase S9 family protein & + & & & & & + & \\
\hline & L9UQ37 & Proteasome-activating nucleotidase & & & & & & + & \\
\hline HVO_0321 & D4GZV0 & Peptide chain release factor subunit 1 & + & & + & & & + & + \\
\hline HVO_0455 & 030560 & Thermosome subunit 2 & + & + & + & + & + & + & + \\
\hline HVO 0778 & Q9HHA2 & Thermosome subunit 3 & + & & + & + & + & + & \\
\hline
\end{tabular}

